\title{
SEDIMENTOLOGÍA E ICNOLOGÍA DE LA FORMACIÓN RÍO MAYER, CUENCA AUSTRAL, PROVINCIA DE SANTA CRUZ, ARGENTINA.
}

Lic. Sebastián Miguel Richiano

\author{
Director: Dr. Daniel Gustavo Poiré
}




\section{SEDIMENTOLOGÍA E ICNOLOGÍA DE LA FORMACIÓN RÍO MAYER, CUENCA AUSTRAL, PROVINCIA DE SANTA CRUZ, ARGENTINA.}

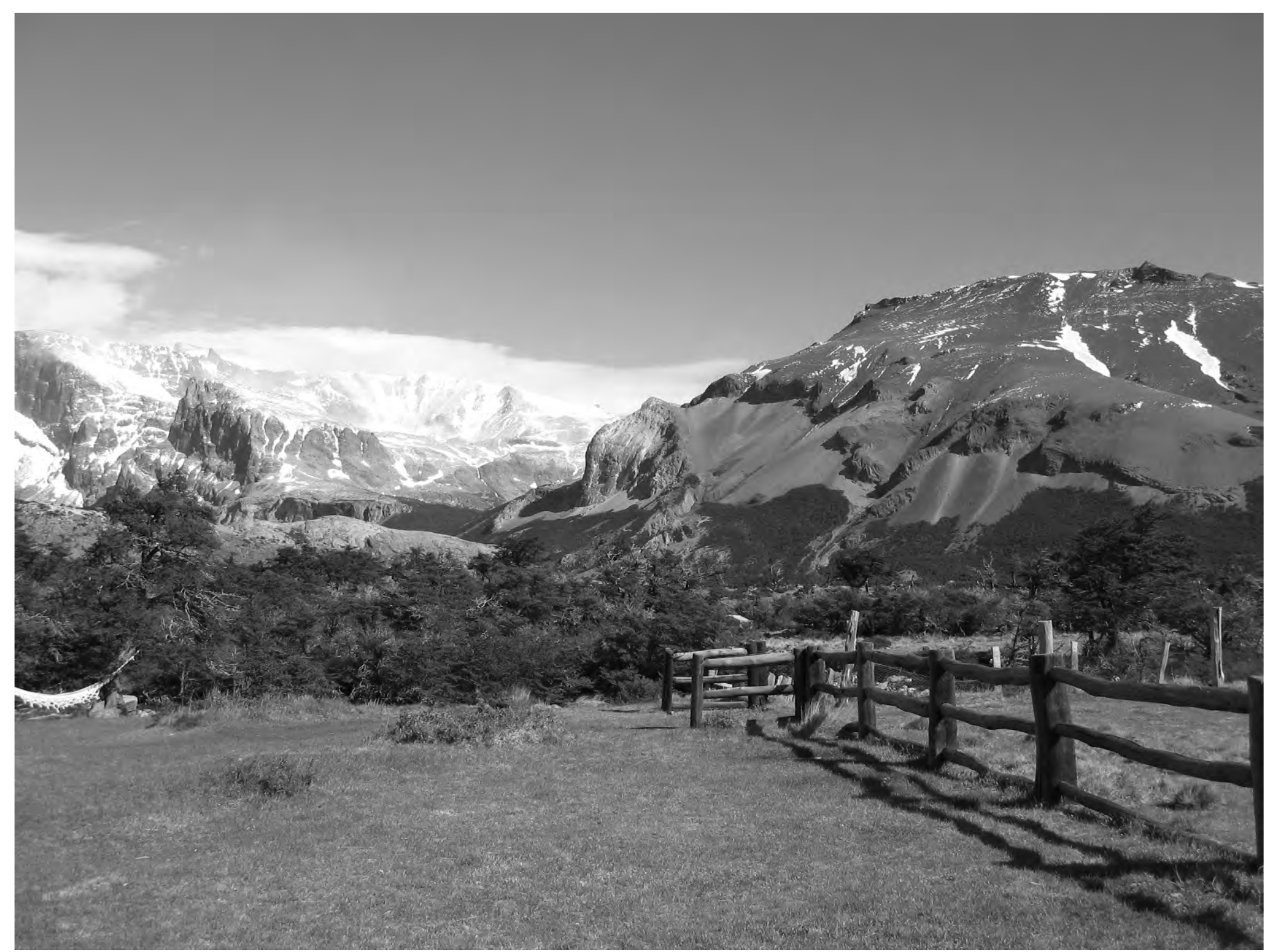

Lic. Sebastián Miguel Richiano

Director: Dr. Daniel Gustavo Poiré

Facultad de Ciencias Naturales y Museo, Universidad Nacional de La Plata 2012 
Índice sintético

Índice ..ii

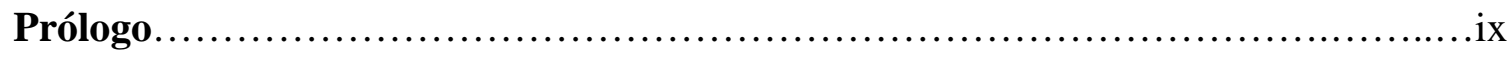

Resumen........................................................................

Abstract..............................................................................

Primer Parte

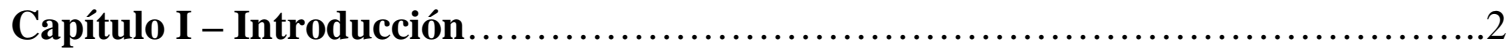

Capítulo II - Antecedentes................................................ 13

Capítulo III - Descripción de las Secciones Relevadas........................28

Segunda Parte

Capítulo IV - Análisis de las Facies Sedimentarias..............................59

Capítulo V - Análisis por Difracción de Rayos X..............................91

Capítulo VI - Estudio Petrográfico.......................................113

Capítulo VII - Análisis Geoquímico.....................................149

Capítulo VIII - Estudio de las Estructuras Sedimentarias Orgánicas..............196

\section{Tercer Parte}

Capítulo IX - Discusión..................................................232

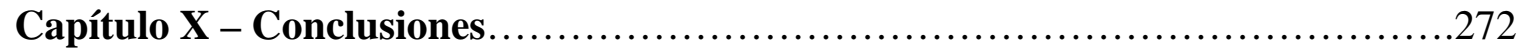

Agradecimientos

Bibliografía

Anexo 1- Mapa de localidades + perfiles en miniatura

Anexo 2- Perfiles relevados 


\section{Índice}

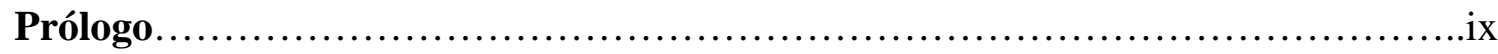

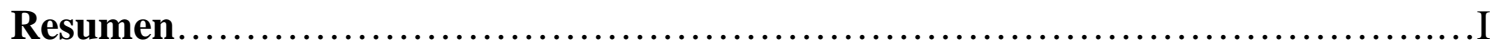

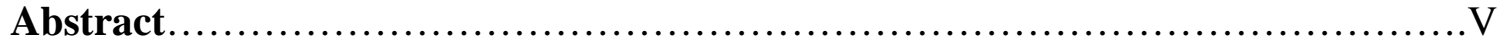

\section{Capítulo I - Introducción}

I. 1 - Área de estudio.................................................................

I. 2 - Objetivos................................................................

I. 3 - Hipótesis............................................................... 5

I. 4 - Metodología

I.4.1- Trabajo de recopilación bibliográfica..................................5

I.4.2- Trabajo de campo................................................ 6

I.4. 3- Trabajo de gabinete y laboratorio

I.4.3.1- Representación de las secciones columnares.........................7

I.4.3.2- Análisis de las facies sedimentarias...................................

I.4.3.3- Tratamiento del material fósil....................................

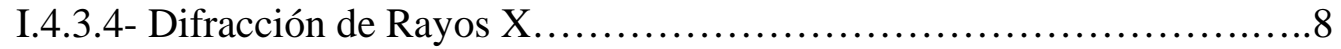

I.4.3.5- Petrografía..................................................... 10

I.4.3.6- Análisis geoquímicos.............................................11

I.4.3.7- Análisis de las estructuras sedimentarias orgánicas....................11

I.4.3.8- Análisis intelectual de los datos...................................11

I.4.3.9- Presentación de los resultados en un manuscrito de tesis................12

\section{Capítulo II - Antecedentes}

II. 1 - Cuenca Austral.......................................................... 13

II.1.1- Etapas tectónicas de la Cuenca Austral..................................16

II.1.2- Ciclos sedimentarios de la Cuenca Austral..............................16

II. 2 - Formación Río Mayer

II.2.1- Denominación......................................................17

II.2.2- Relación con las formaciones supra e infrayacentes......................18 
II.2.3- Características generales..........................................20

II.2.4- Generalidades de las regiones seleccionadas para su estudio

II.2.4.1- Región del Lago San Martín....................................21

II.2.4.2- Región de las Nacientes del Río Guanaco......................23

II.2.4.3- Región de la margen norte del Lago Argentino....................24

II.2.5- Generalidades de los depósitos de la República de Chile................25

\section{Capítulo III - Descripción de las Secciones Relevadas}

III.1 - Introducción......................................................28

III. 2 - Localidad Tipo...................................................28

III. 3 - Sector entre Lagos San Martín y Viedma................................29

III.3.1- Bahía de la Lancha - Lago San Martín.................................29

III.3.1.1- Perfil Estancia La Lila -PELL-.............................30

III.3.1.2- Perfil Estancia La Federica -PEF-..........................31

III.3.1.3- Perfil Estancia Kachaike -PEKA-.............................32

III.3.2- Entre Lagos San Martín y Viedma.................................32

III.3.3- Consideraciones preliminares de la Región entre los lagos

San Martín y Viedma...............................................38

III.4- Sector Seccional Río Guanaco......................................39

III.4.1- Perfil Inicio del Graben -PIG-...............................40

III.4.2- Perfil Pliegue Guanaco -PPG-..................................40

III.4.3- Perfil Este de Cerro Pintado -PECP-...............................41

III.4.4- Perfil Oeste de Vega de Pérez -PWVP-...........................45

III.4.5- Perfiles Este de Vega de Pérez 1 y 2 -PEVP1 y 2-....................45

III.4.6- Perfil Cerro Establo -PCE-.....................................46

III.4.7- Síntesis de la región de las Nacientes del Río Guanaco.................51

III. 5 - Margen Norte de Lago Argentino..................................53

III.5.1- Perfil Cerro Hobler -PCH-.....................................53

III.5.2- Perfil Este de Cerro Horqueta -PECH-............................54

III.5.3- Observaciones al Norte del Cerro Horqueta..........................54

III.5.4- Consideraciones preliminares de la Región del Lago Argentino.........57 


\section{Capítulo IV - Análisis de las Facies Sedimentarias}

IV. 1 - Facies Sedimentarias. 59

IV.1.1- Pelitas

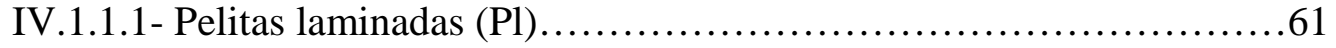

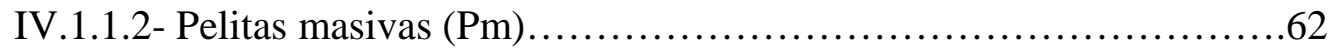

IV.1.1.3- Pelitas con concreciones y/o nódulos (Pn)........................62

IV.1.2- Margas

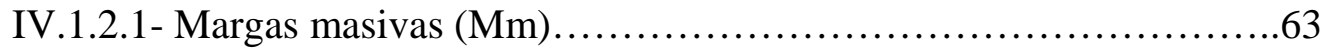

IV.1.2.2- Margas bioturbadas (Mb)......................................64

IV.1.3- Heterolíticas

IV.1.3.1- Heterolítica pelítica con estratificación mixta lentiforme (Htpw)...65

IV.1.3.2- Heterolítica con estratificación mixta ondulosa (Hto)................65

IV.1.3.3- Heterolítica arenosa con estratificación mixta flaser (Htaf).........66 IV.1.4- Psamitas

IV.1.4.1- Areniscas masivas (Am) ......................................67

IV.1.4.2- Areniscas laminadas (Al).....................................68

IV.1.4.3- Areniscas con estratificación entrecruzada planar (Ap).............68

IV.1.4.4- Areniscas con estratificación entrecruzada en artesa (Aa)...........69

IV.1.4.5- Areniscas con deformación sin-sedimentaria (As)..................70

IV.1.4.6- Areniscas con intraclastos (Ai) ..................................70

IV.1.4.7- Areniscas sabulíticas gradada (AGc).............................71

IV.1.4.8- Areniscas glauconítica (Ag) ..................................72

IV.1.5- Psefitas

IV.1.5.1- Paraconglomerado masivo con intraclastos (Fmi)..................73 IV.1.6- Caliza

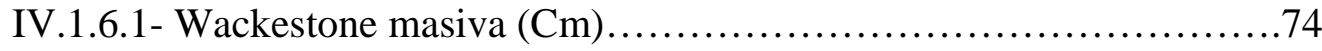

IV. 2 - Interpretación de Facies...............................................75

IV. 3 - Asociaciones de Facies............................................. 77

IV.4 - Interpretación de los Procesos sedimentarios en la Formación Río Mayer

IV4.1- Características de los depósitos autigénicos.............................82 
IV.4.2- Características de los depósitos hemipelágicos.........................84

IV.4.3- Características de los depósitos de sedimentación episódica..............86

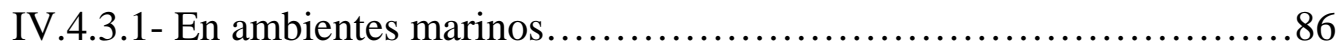

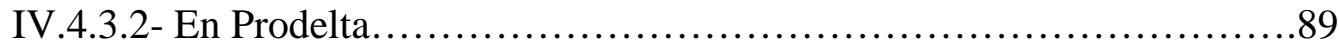

IV.5- Consideraciones Preliminares..........................................90

\section{Capítulo V - Análisis por Difracción de Rayos X}

V.1 - Introducción...........................................................

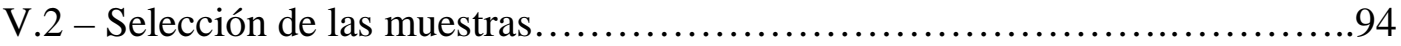

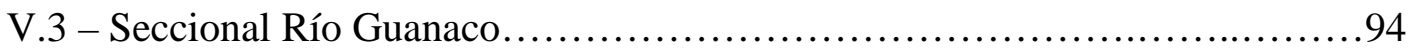

V.3.1- Análisis de la roca total y la fracción fina

V.3.2- Índice de cristalinidad de Illita e Índice de Esquevin.....................102

V.3.3- Interestratificados Illita/Esmectita (IS)..............................104

V.3.4- Consideraciones preliminares para la difracción de rayos X en la Seccional Río Guanaco...............................................105

V.4- Lago San Martín....................................................... 108

V.4.1- Análisis de la roca total y la fracción arcilla

V.4.2- Índice de cristalinidad de Illita e Índice de Esquevin.....................110

V.4.3- - Interestratificados Illita/Esmectita (IS).............................110

V.4.4- Consideraciones preliminares para la difracción de rayos X en el Lago San Martín...................................................111

V.5- Consideraciones para la Formación Río Mayer a partir de la DRX..........112

\section{Capítulo VI - Estudio Petrográfico}

VI.1 - Introducción........................................................113

VI. 2 -Petrografía de areniscas.............................................113

VI. 2.1 - Componentes detríticos............................................114

VI. 2.1.1 - Cuarzo monocristalino......................................114

VI. 2.1.2 - Cuarzo policristalino....................................... 115

VI. 2.1.3 - Plagioclasa................................................116

VI. 2.1.4 - Feldespato potásico.......................................117 
VI. 2.1.5 - Biotita.....................................................117

VI. 2.1.6 - Opacos............................................... 118

VI. 2.1.7 - Otros componentes detríticos...................................119

VI. 2.2 - Cementos.........................................................

VI. 2.3 - Clasificación de Psamitas...........................................124

VI. 2.3.1 - Areniscas de la Formación Río Mayer...........................126

VI. 2.4 - Procedencia de Psamitas..............................................126

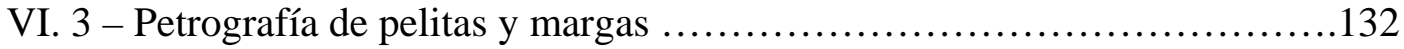

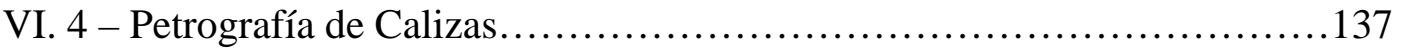

VI. 5 - Petrografía de Glauconitas............................................141

VI. 6 - Petrografía de trazas fósiles.........................................143

VI. 7 - Consideraciones preliminares sobre los aspectos petrográficos............146

\section{Capítulo VII - Análisis Geoquímico}

VII.1 - Introducción.......................................................149

VII.1.1- Selección de las muestras...............................................151

VII. 2 - Roca Total......................................................... 152

VII. 2.1 - Elementos mayoritarios y minoritarios..............................152

VII. 2.2- Elementos traza y tierras raras......................................160

VII. 2.3 - Clasificación geoquímica de las muestras.............................164

VII. 2.4 - Meteorización de las muestras analizadas.............................165

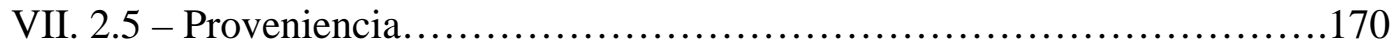

VII. 2.6 - Ambiente tectónico..............................................174

VII. 2.7- Tierras Raras..................................................... 178

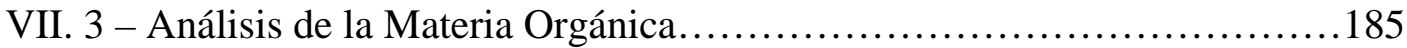

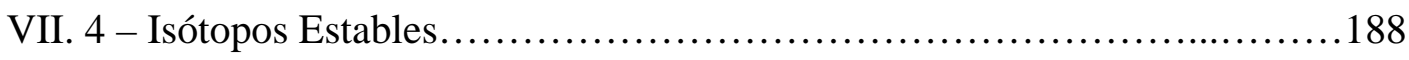

VII. 5 - Consideraciones finales sobre los aspectos geoquímicos.................194

\section{Capítulo VIII - Estudio de las Estructuras Sedimentarias Orgánicas}

VIII.1 - Introducción...................................................196

VIII. 2 - Icnogéneros reconocidos.........................................197 
Icnogénero Bergaueria

Icnogénero Chondrites

Icnogénero Gyrolithes

Icnogénero Ophiomorpha

Icnogénero Paleophycus

Icnogénero Teredolites

Icnogénero Thalassinoides

Icnogénero Zoophycos

VIII. 3 - Icnofacies e Icnoasociaciones..................................215

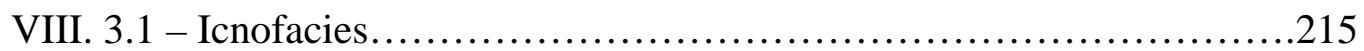

VIII. 3.1.1- Icnofacies de Zoophycos................................215

VIII. 3.1.2- Icnofacies transportadas.................................216

VIII. 3.2 - Icnoasociaciones........................................217

VIII. 4 -Paleoniveles de oxigenación en la Formación Río Mayer..............223

VIII. 5 - Modelo Icnológico de la Formación Río Mayer

VIII. 5.1 - Modelo Icnológico Valanginiano...............................226

VIII. 5.2 - Modelo Icnológico Albiano...................................228

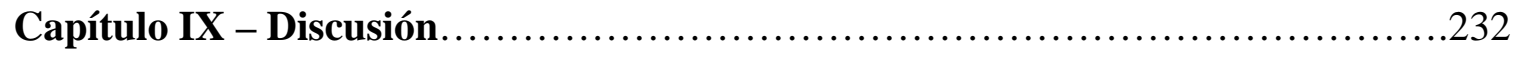

IX. 1 - Límites temporales y físicos de la Formación Río Mayer en el

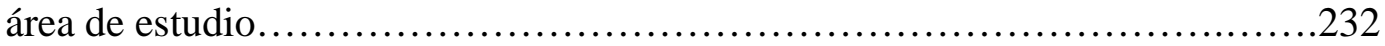

IX. 2 - Aspectos Composicionales de la Formación Río Mayer................236

IX. 2.1 -Procedencia y Ambiente tectónico ............................238

IX. 3 - Paleoambientes de sedimentación.................................241

IX. 3.1 -Modelo sedimentario/icnológico................................241

IX. 3.2 -Estratigrafía Secuencial en la Formación Río Mayer.................249

IX. 3.2.1 -Superficies reconocidas...................................252

IX. 3.2.1.1- Titoniano -Superficie Transgresiva 1 (ST1).................253

IX. 3.2.1.2 - Superficies neocomianas...............................255

IX. 3.2.1.3 - Aptiano-Albiano inferior- Superficie Regresiva b (SRb).....259

IX. 3.2.1.4 -Albiano superior-Cenomaniano inferior-Superficie ST3-.....260 
IX. 3.2.2- Modelo estratigráfico-secuencial para la depositación de la Formación Río Mayer..................................................262

IX. 4 -Correlación de la Formación Río Mayer con las unidades de la Cuenca de Rocas Verdes................................................268 IX. 5 -La Formación Río Mayer como roca generadora de Hidrocarburos: su importancia en la Cuenca Austral y las perspectivas a futuro....

Capítulo X - Conclusiones.

\section{Agradecimientos}

\section{Bibliografía}

\section{Anexo 1- Mapa de localidades + perfiles en miniatura}

\section{Anexo 2- Perfiles relevados}




\section{Prologo}

El presente trabajo de tesis doctoral titulado "Sedimentología e Icnología de la Formación Río Mayer, Cuenca Austral, Patagonia, Argentina” se divide en tres partes principales, cada una de las cuales se compone a su vez de capítulos.

La primer parte dispone de tres capítulos que dan forma al universo de información previa y a los datos que el lector necesitará para el desarrollo posterior del trabajo. El capítulo I (Introducción), expresa los objetivos planteados y la metodología desarrollada para cumplirlos. En el segundo capítulo se analizan los antecedentes tanto de la Cuenca como de la Formación estudiada. Por último, se detallan los resultados del trabajo de campo incluyendo localidades estudiadas, perfiles analizados, vistas generales de los afloramientos, las rocas y el material fósil entre otros. La finalidad de esta primer parte es que el lector disponga de todas las herramientas necesarias para seguir de una manera ordenada el resto de los capítulos.

La segunda parte encierra todos los enfoques realizados sobre los datos y muestras relevadas en el capítulo 3. Esto incluye el análisis de facies sedimentarias (Capítulo IV), el análisis por difracción de Rayos X (Capítulo V), el análisis petrográfico (Capítulo VI), el análisis geoquímico (Capítulo VII) y el estudio de las Estructuras Sedimentarias Orgánicas (Capítulo VIII).

En último lugar, la tercer parte se compone de las discusiones y conclusiones que se desprenden del desarrollo de las dos primeras partes.

Como complemento se adjunta como anexo un mapa desplegable con todos los perfiles relevados, de modo tal que el lector pueda disponer de esta información en cualquier punto de la lectura sin necesidad de volver a la primera parte. Además se adjunta otro anexo con una lámina que contiene todos los perfiles realizados en un mayor tamaño para verlos con mayor detalle. 


\section{Resumen}

El presente trabajo de tesis doctoral se centró en el estudio sedimentológico e icnológico de las sedimentitas marinas de la Formación Río Mayer, depositada en el Cretácico inferior de la Cuenca Austral. Dicha cuenca se ubica en el extremo suroccidental de la Patagonia abarcando un sector de Sudamérica que incluye el sur de Argentina y Chile, y representa una de las más importantes cuencas productoras de hidrocarburos de Argentina. El área de estudio contempla la región entre los lagos San Martín y Argentino en la Provincia de Santa Cruz.

Se seleccionaron tres regiones dentro del área de estudio para concentrar las tareas realizadas, que consistieron en el relevamiento de 13 secciones sedimentológicas de detalle (escala 1:100) identificándose las litologías participantes, las estructuras sedimentarias primarias, el contenido paleontológico, la geometría de los cuerpos de rocas, su orientación, y los contactos con la unidades infra y suprayacentes. A su vez, se efectuó un muestreo sistemático a fin de realizar estudios composicionales mediante difracción de rayos $\mathrm{X}$, petrografía y geoquímica. Un tratamiento especial se le dio a las trazas fósiles, las que se fotografiaron y describieron detalladamente en el campo, para la posterior identificación taxonómica y análisis paleoambiental. Una de las localidades, la Seccional Río Guanaco, posee los mejores y más completos afloramientos de la unidad, razón por la cual allí se concentraron los análisis de laboratorio. A partir del trabajo de campo en la Seccional Río Guanaco se dividió a la Formación Río Mayer en 3 secciones, la sección inferior se compone casi exclusivamente de pelitas negras con intercalaciones de margas, la sección media es de composición margosa y la sección superior está formada por pelitas negras con frecuentes intercalaciones de areniscas.

El análisis de facies sedimentarias permitió discriminar 18 facies sedimentarias que se agruparon en tres asociaciones de facies. La primera asociación de facies corresponde a los depósitos tradicionalmente atribuidos a la Formación Río Mayer, o sea, sedimentos depositados en un paleoambiente de plataforma externa dominado por los procesos hemipelágicos. La segunda asociación de facies corresponde a una plataforma externa influenciada por un sistema deltaico, el cual genera la intercalación de areniscas depositadas a partir de flujos turbidíticos distales. Finalmente, la tercera asociación está caracterizada por depósitos de prodelta. 
El empleo de difractometría de rayos X permitió caracterizar mineralógicamente los depósitos de esta unidad. Se analizaron 119 muestras, las cuales se componen de proporciones variables de cuarzo (dominante), calcita, plagioclasas y arcillas. La fracción fina se compone de illita, interestratificados de illita y esmectita (I/S), clorita y caolinita. Hay dos arreglos principales, la sección inferior de la unidad está dominada por illita y la sección superior por clorita. Sólo se registró esmectita en las muestras provenientes del prodelta en la región del Lago San Martín. Se determinó el grado diagenético de la unidad a partir del empleo de los interestratificados IS, y en general todas las muestras se encuentran mayoritariamente en la mesodiagénesis.

Se realizó el análisis petrográfico de 51 cortes delgados de areniscas, pelitas, margas, glauconitas, calizas y trazas fósiles de la Formación Río Mayer. A partir de las modas detríticas las muestras son vaques líticos ó feldespáticos, a excepción de una arenisca subarcósica. En cuanto a la procedencia de las areniscas se definieron 4 poblaciones, que se separan por edad y paleoambiente, dos poblaciones tienen afinidad con los campos de orógeno reciclado y arco volcánico y dos poblaciones con el bloque continental. En las margas y pelitas es notoria la participación de materia orgánica y de microfósiles.

Los análisis geoquímicos de roca total permitieron determinar que el grado de meteorización en general es moderado, y no se aleja del comportamiento esperado para rocas pelíticas. Se observó que la concentración de algunos elementos mayoritarios está ligada a la abundancia de algunos grupos de arcillas. Desde el punto de vista de la proveniencia hay una tendencia evolutiva desde composiciones ácidas en la sección inferior a ácida-intermedia en las secciones media y superior. Sobre la base de los diagramas de discriminación tectónica, el ambiente en el cual se depositaron las muestras estaría representado entre el margen continental activo y arco volcánico. Se cuantificó el Carbono Orgánico Total, y se observó que la sección inferior y el inicio de la sección superior poseen los valores más elevados, comparables con los necesarios para ser considerados roca madre de hidrocarburos. El análisis de los isótopos estables de O y C reveló que las rocas de esta formación están en mayor o menor medida alteradas diagenéticamente. Sin embargo se pudo registrar una tendencia positiva en la sección media de la unidad que 
podría correlacionarse con el evento generalizado de anoxia oceánica denominado Weissert (Valanginiano).

Si se comparan los resultados geoquímicos de las pelitas de esta unidad con los valores de las vulcanitas de la Provincia volcánica del Chon-Aike (rocas volcánicas jurásico-cretácicas de Patagonia), queda muy clara la afinidad de las rocas aquí analizadas con las provenientes del sin-rift de la Cuenca Austral. En definitiva, las distintas fuentes de información utilizadas (principalmente petrografía, geoquímica y difracción de rayos X), sugieren que la depositación de la Formación Río Mayer fue coetánea con el desarrollo de un arco volcánico al menos desde el Valanginiano. Dicho arco volcánico tuvo mayor influencia sobre la unidad en la región norte del área de estudio.

Se identificó en la Formación Río Mayer una importante icnofauna, sobre la cual muy poco se conocía, y se describieron un total de 8 icnogéneros para esta unidad: Bergaueria, Chondrites, Gyrolithes, Ophiomorpha, Palaeophycus, Teredolites, Thalassinoides y Zoophycos. Se reconoció una icnofacies de Zoophycos, que se presenta de dos maneras diferentes, la primera se ubica en la sección media y está muy desarrollada, la segunda se encuentra en la parte final de la unidad, donde la frecuencia de flujos turbidíticos interrumpe el normal desarrollo de la icnofacies. La distribución de icnogéneros permite reconocer tres asociaciones de icnofósiles. La icnoasociación I incluye a los icnogéneros de Zoophycos, Chondrites y Bergaueria. La icnoasociación II se compone de los icnogéneros Chondrites, Ophiomorpha, Palaeophycus y Zoophycos, y la icnoasociación III incluye a solo dos icnogéneros, Teredolites y Gyrolithes. Utilizando correlaciones temporales se generaron dos modelos: el Modelo Icnológico Valanginiano, que incluye la icnofacies de Zoophycos en la zona sur del área de estudio y la icnofacies de Cruziana en el norte, y el Modelo Icnológico Albiano, que se compone de la icnoasociación II en el sur y la icnoasociación III del norte.

Se utilizó diversas fuentes de información (icnología y geoquímica principalmente) para reconstruir la curva relativa de paleo-oxigenación a partir de la cual se reconocieron 4 sectores bien diferenciados en la Formación Río Mayer que varían entre anóxicos y disóxicos. 
A partir de la utilización del modelo estratigráfico secuencial y el reconocimiento de superficies claves se generó un modelo estratigráfico-secuencial para el Cretácico inferior de la Cuenca Austral, en el cual se identificaron 3 secuencias de tercer orden compuestas por cortejos Transgresivo y de Mar Alto desarrolladas entre el Titoniano y el Aptiano. Posteriormente, desde el Aptiano hasta el Cenomaniano inferior se registran condiciones regresivas asociadas al sistema deltaico de la Formación Piedra Clavada. Este esquema fue cotejado con otros previamente referidos para el Cretácico inferior de la Cuenca Austral.

Los afloramientos de la Formación Río Mayer son equivalentes a los de la Formación Zapata de la Cuenca de Rocas Verdes (Chile), pero se diferencian en la ubicación paleogeográfica, ya que la Formación Río Mayer representa la sedimentación en plataforma externa mientras que la Formación Zapata corresponde a los ambientes de cuenca profunda.

Por último, cabe destacar que la Formación Río Mayer posee todos los atributos necesarios para incorporarse al nuevo horizonte exploratorio: Yacimientos de Hidrocarburos no Convencionales (Shale oil- Shale gas). Los contenidos moderados a altos de COT, el estadio de diagénesis alcanzado, los importantes espesores y la gran distribución areal hacen que esta unidad sea muy propicia para la búsqueda de nuevas reservas hidrocarburíferas en la Cuenca Austral. 


\begin{abstract}
In this work the sedimentological and ichnological analysis of the marine deposits of the Río Mayer Formation (Lower Cretaceous) was carried out. This unit is part of the initial filling of the Austral Basin, which is developed in the southwestern of Patagonia (Santa Cruz and Tierra del Fuego Provinces) along an area of South America including the south of Argentina and Chile. The study area is located between the San Martín and Argentino lakes in the Santa Cruz Province.

Three main regions were selected along the study area to concentrate the research activities, which comprise the description of 13 detailed sedimentological sections of the unit (scale 1:100) taking into account the lithology, the primary sedimentary structures, the palaeontological content, rock bodies geometry, their orientation and the hierarchy as well as the contacts with underlying and overlying units. A detailed systematic sampling was performed in each section for compositional analyses (X-Ray diffraction, petrography, geochemistry). A differential treatment was given to the trace fossils, which were photographed in situ and described in detail in the field for later taxonomic identification and palaeoenvironmental analysis in the laboratory. The best and most complete exposures of the unit were observed in the Río Guanaco locality, where the laboratory analyses were concentrated and the Río Mayer Formation was divided into 3 sections: the lower section is composed almost exclusively of black shales with intercalations of marl, the middle section is marly composition and the upper section is formed by black shales with frequent intercalations of sandstone.

In the deposits studied 18 sedimentary facies were identified, which were grouped into three facies associations. The first association corresponds to the deposits traditionally assigned to the Río Mayer Formation according to the available bibliography, sediments deposited in a distal platform palaeoenvironment dominated by hemipelagic processes. The second association is also developed in a distal platform environment, but influenced by a deltaic system which generates the deposition of sandy levels in the outer platform. Finally, the third section is characterized by the prodeltaic deposits.

The X-Ray Diffraction of 119 samples allows to characterize the mineralogical composition of the Río Mayer Formation. All the samples are composed of different proportions of quartz, calcite, plagioclase and clay minerals. The fine fraction is composed
\end{abstract}


of illite, I/S interestratified, chlorite and caolinite. In general, two groups were distinguished; in the lower section the illite is predominant, while in the upper section the chlorite is dominant. The smectite was only registered recorded in the samples from the prodelta in the Lago San Martín region. The degree of diagenesis was also determined using the interstratified IS, and in general all samples are mostly in the mesodiagenesis.

The petrographic analysis of 51 thin sections was performed in sandstones, shales, marls, glauconite, limestone and trace fossils from the Rio Mayer Formation. From the analyses of detrital modes, all the samples are lithic or feldspathic wackes, except for a subarcosic sandstone. As for the provenance of the sandstones 4 populations were identified, which are separated by age and palaeoenvironment. Firstly, two populations show affinity with the recycled orogen and volcanic arc fields, and secondly two populations have an affinity with the continental block. Organic matter and microfossils are highly abundant in marls and shales. On the other hand, some microscopic features of three ichnogenus were observed.

The whole rock geochemical analysis allows to determine that the degree of weathering is generally moderate and is not far from expected behavior for mudrocks. It was observed that the concentration of some major elements is linked to the abundance of some groups of clays. Regarding their provenance, there is a trend from acid compositions in the lower section to acid-intermediate in the middle and upper sections of the unit. The tectonic environment in which the samples were deposited would be represented between the active continental margin and/or a volcanic arc.

The total organic carbon was quantified, and it can be concluded that the lower section and the beginning of the upper section have the higher values, comparable to those required to be considered the source rock for hydrocarbons. The analysis of stable isotopes of $\mathrm{O}$ and $\mathrm{C}$ revealed that the rocks of this formation show different grades of diagenetic alteration. However, it failed to record a positive trend in the middle section of the unit that could be correlated with the ocean anoxic event called Weissert (Valanginian).

If we compare the geochemical results from shales of this unit with the values of the volcanic rocks from the Chon-Aike volcanic Province (jurassic to cretacic volcanic rocks from Patagonia), it is clear that the affinity of the rocks here analyzed are mainly with those from the syn-rift of the Austral Basin. In short, the various sources of information (mainly 
petrography and geochemistry, to a lesser extent X-ray diffraction), suggest that the deposition of the Rio Mayer Formation was coeval with the development of a volcanic arc at least since the Valanginian. This volcanic arc was more influential on this unit in the north of the study area.

In the Río Mayer Formation a significant ichnofauna was identified, about which very little was known. A total of 8 ichnogenus were described for this unit: Bergaueria, Chondrites, Gyrolithes, Ophiomorpha, Palaeophycus, Teredolites, Thalassinoides and Zoophycos. The Zoophycos ichnofacies was recognized, which is present in two different ways, the first is located in the middle section and is highly developed, the second one is at the end of the unit, where the frequency of turbidite flows interrupts the normal development of ichnofacies.

From the ichnogenus distribution three associations of trace fossils can be recognized. The ichnoasociation I includes the ichnogenus Zoophycos, Chondrites and Bergaueria. The ichnoasociation II consists of the ichnogenus Chondrites, Ophiomorpha, Palaeophycus and Zoophycos, and the ichnoasociation III includes only two ichnogenus, Gyrolithes and Teredolites. Using temporal correlations with other units two models were established: The Valanginian Ichnological Model, including Zoophycos ichnofacies in the south and Cruziana ichnofacies in the north, and the Albian Ichnological Model, which consists of ichnoassociation II in the south and the ichnoassociation III in the north.

A paleo-oxygenation relative curve was reconstructed, on the basis of which 4 distinct areas could be recognized in the Rio Mayer Formation, ranging from anoxic to disoxic palaeoenvieronments.

A sequence-stratigraphic model for the Lower Cretaceous of the Austral Basin was created. In this model three third order sequences have been identified between the Tithonian and Aptian times. Each sequence consists of a couple of Transgressive and Highstand Systems Tracts. Subsequently, since the Aptian to the Lower Cenomanian, regressive conditions are recorded associated with the deltaic system of Piedra Clavada Formation. This model was matched against others previously referred to the Early Cretaceous of the Austral Basin.

The Rio Mayer Formation deposits are equivalent to the Zapata Formation of the Rocas Verdes Basin (Chile), but differ in the palaeogeographic location. Since the Río 
Mayer Formation represents the deposition in the outer shelf, the Zapata Formation corresponds to deep basin environments.

Finally, it is outstanding that the Rio Mayer Formation has all the attributes needed to join the new exploration horizon: Unconventional Hydrocarbon Reservoirs (Shale oilShale gas). Moderate to high contents of TOC, the stage of diagenesis reached, the important thickness and high areal distribution of this unit make it very appropriate to search for new hydrocarbon reserves in the Austral Basin. 


\section{PRIMERA PARTE}




\section{Capítulo I - Introducción}

Las rocas pelíticas representan el grupo más abundante y distribuido dentro de las rocas sedimentarias (Scasso y Limarino, 1997; Potter et al., 2005). Aportan valiosa información acerca de las condiciones del medio en el cuál fueron depositadas (oxigenación y $\mathrm{pH}$, entre otros). Ayudan a identificar movimientos relativos del nivel del mar, característica que acompañada por el contenido de faunas, posibilitan correlaciones tanto locales como regionales que constituyen una información de primer orden en todo proyecto de investigación. Pero su importancia no sólo radica en el aspecto netamente científico, ya que son las pelitas un muy importante componente dentro de los sistemas petroleros, participando de los mismos como roca madre y roca sello de trampas. Por tal razón el estudio de este tipo de depósitos es fundamental para el entendimiento del desarrollo histórico temporal de una cuenca sedimentaria (Potter et al., 2005).

La icnología estudia las perturbaciones dejadas por los organismos animales durante su interacción con el sustrato en el que viven. Son las condiciones del paleoambiente (sustrato, energía, oxigenación entre otros) las que restringen el contenido cuali-cuantitativo de trazas fósiles en un cuerpo de roca. Durante las últimas décadas la icnología tuvo y tiene un crecimiento significativo. La razón es que esta disciplina aporta información muy útil para comprender las condiciones de depositación de los sedimentos, desde un enfoque diferente al de un análisis sedimentológico tradicional.

La cuenca Austral se encuentra ubicada en el extremo suroccidental de la Patagonia incluyendo territorio tanto argentino como chileno. Dentro de Argentina, posee su mayor desarrollo en la provincia de Santa Cruz, y en menor proporción en el Territorio Nacional de Tierra del Fuego. Sus afloramientos se encuentran en la Cordillera Surpatagónica, con una extensión mayor a los $1000 \mathrm{~km}$ de longitud entre los $47^{\circ} \mathrm{LS}$ y los $55^{\circ} \mathrm{LS}$ (Riccardi, 1988).

El inicio de la cuenca se relaciona a la extensión generada por el impacto de una pluma mantélica sobre la Patagonia (Pankhurst et al., 2000). Los primeros depósitos corresponden al Complejo el Quemado (Feruglio en Fossa Mancini et al., 1938) que se compone principalmente de rocas volcánicas y volcaniclásticas acompañadas por rocas carbonáticas y pelíticas (Poiré et al., 2002; 2007) depositadas durante la etapa de sinrift. 
Sobre el mencionado complejo se acumularon sedimentos de carácter continental y marino somero incluidos dentro de la Formación Springhill (Thomas, 1949a, b) y marinos correspondientes a la Formación Río Mayer (Hatcher, 1897). Estas dos formaciones se depositaron de manera diacrónica, siendo sus edades cada vez más jóvenes hacia el norte. La Fm. Springhill tiene edades desde el Titoniano hasta el Berriasiano (Riccardi, 1988), mientras que la Fm. Río Mayer ocupa el lapso Berriasiano - Aptiano/Albiano (Riccardi, 1988). Luego la Fm. Río Mayer es cubierta de norte a sur por las formaciones Kachaike, Piedra Clavada, Lago Viedma y Cerro Toro. Las dos primeras corresponderían a ambientes deltaicos, la Fm. Lago Viedma a ambiente marino somero y la Fm. Cerro Toro a ambiente marino profundo (Arbe, 2002).

Desde el punto de vista aplicado, la cuenca provee importantes volúmenes de recursos hidrocarburíferos tanto onshore como offshore (Rodríguez y Miller, 2005).

La Formación Río Mayer se depositó de manera aproximada durante la totalidad del Cretácico inferior, sus depósitos se componen mayoritariamente de rocas pelíticas de tonalidades oscuras y posee además una diversa fauna de invertebrados marinos y en menor proporción vertebrados marinos, plantas y trazas fósiles.

La finalidad del presente trabajo es caracterizar, desde el punto de vista sedimentológico e icnológico a la Formación Río Mayer en la región comprendida entre los lagos San Martín y Argentino en la provincia de Santa Cruz, Argentina.

Este trabajo es un aporte al conocimiento de los inicios de la Cuenca Austral, de la cual poco se conoce de los depósitos finos del Cretácico inferior, desde el punto de vista sedimentológico e icnológico. A su vez, provee información para la correlación con los depósitos descriptos en el subsuelo y hacia el sur en la República de Chile.

\section{1 - Área de estudio}

El área de estudio se encuentra en el sector suroccidental de la Provincia de Santa Cruz, dentro del Departamento de Lago Argentino, más específicamente entre los lagos San Martín y Argentino (figura 1.1).

Los afloramientos de la Formación Río Mayer dentro de la región mencionada poseen una distribución elongada $\mathrm{N}-\mathrm{S}$, teniendo un desarrollo en sentido E-O siempre menor a 1 km. La Principal ciudad dentro del área de estudio es El Calafate, desde la cual 
se hizo base para gran parte del trabajo. Las localidades de El Chalten y Tres Lagos también fueron importantes desde el punto de vista logístico, ya que las grandes distancias a recorrer las hicieron necesarias. Gran parte de la superficie del área de estudio está comprendida por el Parque Nacional Los Glaciares. Fuera de los límites de dicho parque los afloramientos de la unidad en cuestión se encuentran en campos de estancias privadas, con lo cual el acceso a dichas rocas requirió el permiso especial de los dueños o encargados de estas tierras (Figura 1.2).

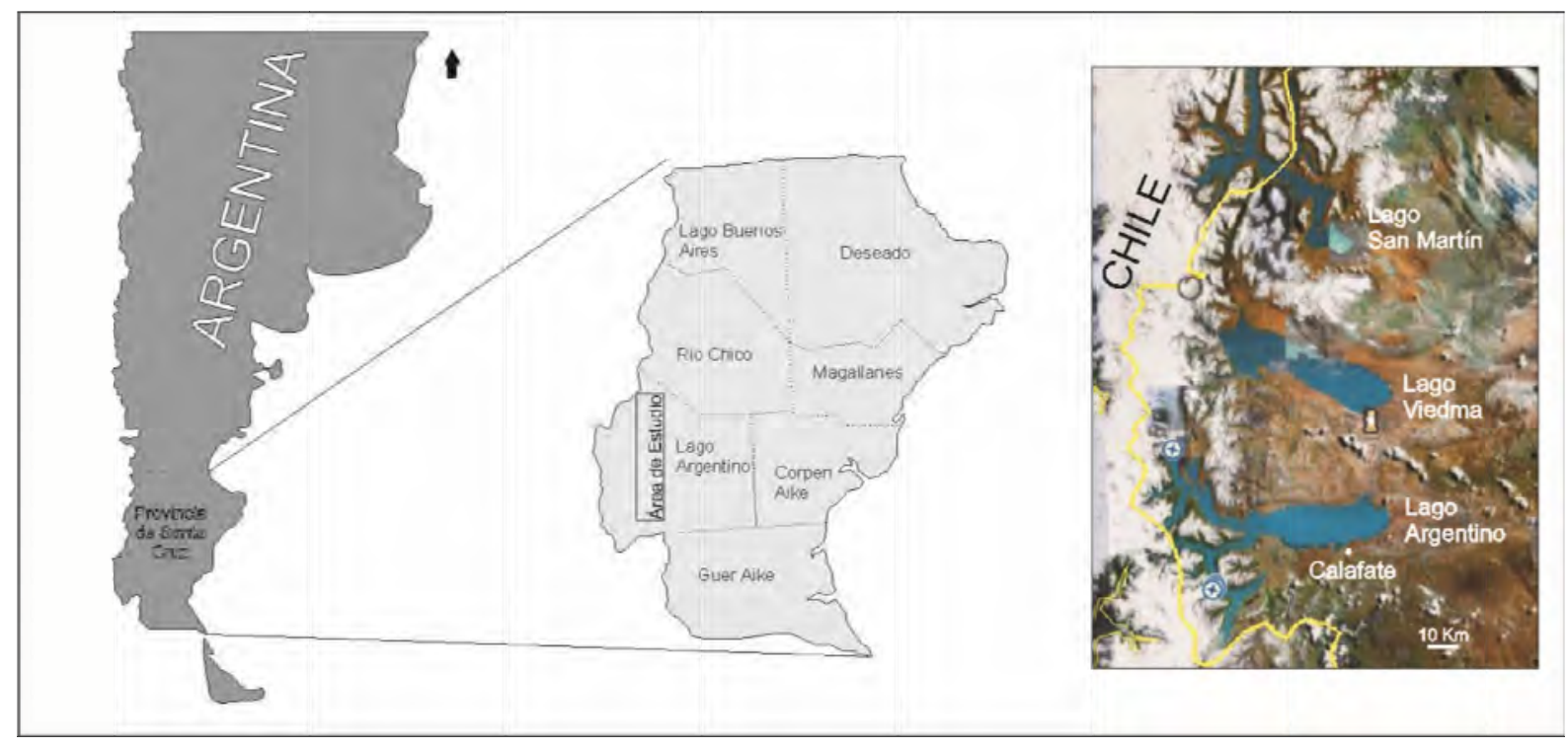

Figura 1.1- Ubicación del área de estudio.

\section{2 - Objetivos}

El presente proyecto se plantea caracterizar, con el mayor detalle posible, las sedimentitas de la Formación Río Mayer en el ámbito de la Cuenca Austral, en la región comprendida entre los lagos San Martín y Argentino en la provincia de Santa Cruz.

Dentro de este planteamiento general hay varios objetivos específicos a tener en cuenta, a fin de reconstruir los paleoambientes sedimentarios reinantes durante la depositación de la Formación Río Mayer. Entre ellos, el análisis de facies sedimentarias, con sus arreglos y cambios en el espacio, junto con el reconocimiento de todas las estructuras sedimentarias mecánicas y orgánicas, llevan a la determinación de los procesos sedimentarios y su relación con los organismos. 
Analizar detalladamente las trazas fósiles reconocibles para esta unidad, a los fines de llegar a un modelo icnológico.

Analizar las arcillas y su distribución, a fin de tener otro elemento de consideración en cuanto a paleoclimas y zonas de aporte.

Caracterizar la signatura geoquímica de los depósitos finos con el fin de determinar procedencia y ambiente tectónico de los materiales estudiados.

Dar límites temporales y físicos (relación con las formaciones supra e infrayacente) en la zona de estudio.

\section{3- Hipótesis}

Dentro del marco general a estudiar se plantean las siguientes hipótesis iniciales de trabajo:

$>\quad$ El contacto de la Formación Río Mayer tanto con el Complejo El Quemado como con la Formación Springhill sería neto, mientras que el límite superior sería transicional.

$>\quad$ La depositación de la Formación Río Mayer no fue uniforme durante el Cretácico inferior, sino que debió verse afectada por cambios eustáticos.

$>\quad$ La Formación Río Mayer sería portadora de una rica icnofauna que podría brindar valiosa información para el análisis paleoambiental.

$>\quad$ Las áreas de aporte podrían haber variado en el tiempo de la depositación. Esto se vería reflejado en aspectos composicionales dentro de la unidad.

\section{4 - Metodología}

\section{4.1 - Trabajo de recopilación bibliográfica}

Se ha analizado de manera crítica la bibliografía existente tanto para la Cuenca Austral como para la Fm. Río Mayer. Se puso especial énfasis en los trabajos que comprenden a la sedimentología e icnología de la unidad antes mencionada. De esta tarea surgió un acabado marco conceptual del conocimiento a la fecha de la Cuenca Austral para el área de estudio.

Por otra parte, en lo concerniente a la Fm. Río Mayer, cabe destacar que se carece de trabajos sedimentológicos e icnológicos de detalle, con lo cual surge del análisis 
bibliográfico el importante aporte del presente trabajo al conocimiento de los inicios de la sedimentación de la Cuenca Austral luego de desarrollado el complejo El Quemado.

\section{I.4.2 - Trabajo de campo}

A través de las 4 campañas realizadas se totalizaron unos 90 días de trabajo de campo. Durante la primera campaña se recorrió toda el área de tesis y se seleccionaron tres lugares principales de trabajo, que a prima facies eran aquellos que poseían mejores y más completos afloramientos acompañados por una mínima deformación tectónica. A su vez, se recorrió la localidad tipo de la unidad a modo de punto de control, pero sin realizar tareas de detalle. Las tres localidades (figura 1.2) en que se concentraron los trabajos de las campañas siguientes son:

I) Alrededores de Bahía de la Lancha - Lago San Martín-

II) Río Guanaco - Dentro del ámbito del Parque Nacional Los Glaciares-

III) Margen Norte de Lago Argentino.

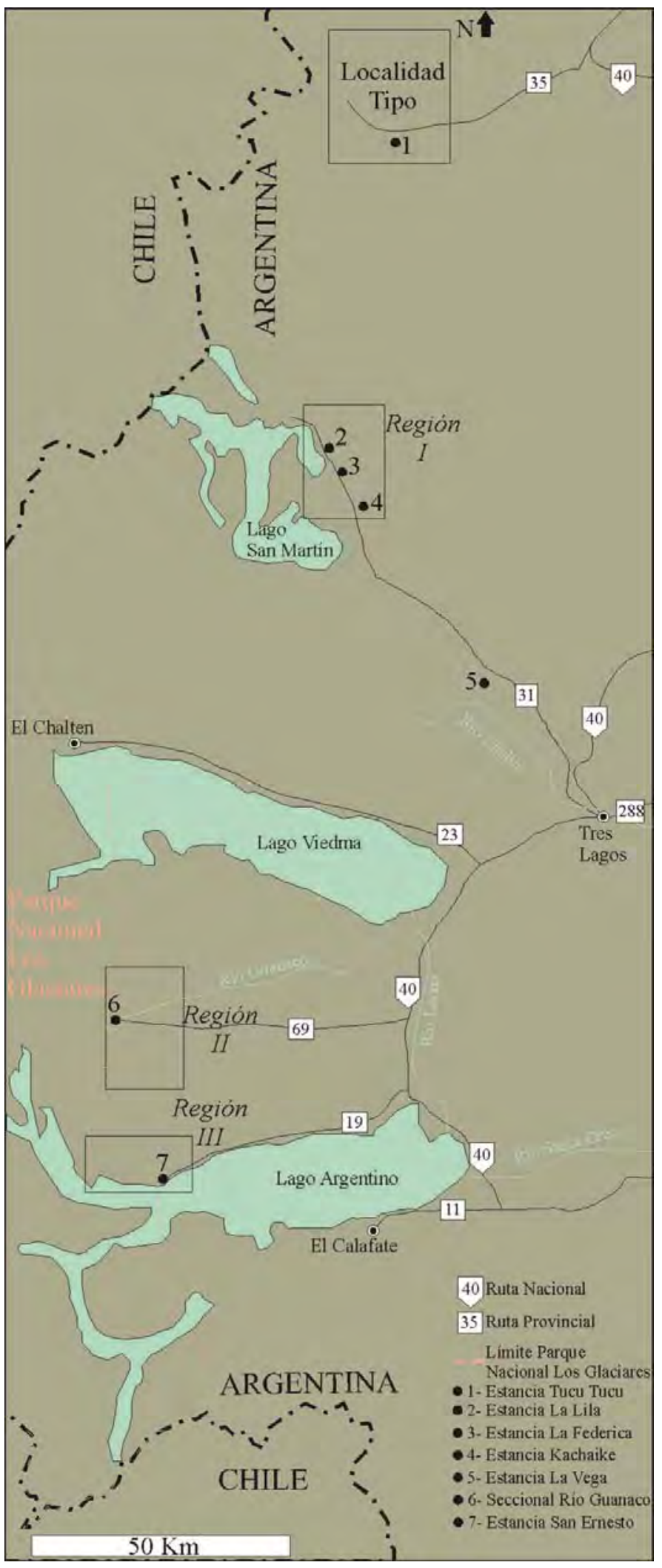

Figura 1.2- Mapa de ubicación 
En todas las áreas seleccionadas se realizaron perfiles sedimentológicos de detalle a escala 1:100, se utilizó un GPS para ubicar espacialmente el inicio de cada perfil. En cada sección se tomaron muestras de rocas sedimentarias y material fósil, a la vez que se documentó por medio de fotografía digital las estructuras sedimentarias orgánicas para su posterior tratamiento en gabinete.

En el área comprendida entre las regiones seleccionadas se realizaron observaciones generales, pero no se desarrollaron tareas de detalle.

\section{4.3 - Trabajo de gabinete y laboratorio}

\section{4.3.1- Representación de las secciones columnares}

Las secciones columnares relevadas durante las tareas de campo fueron representadas de manera gráfica mediante el uso de programas convencionales de dibujo. Esto permitió una rápida visualización de los datos, no sólo de campo, sino también de los posteriormente obtenidos en laboratorio.

\section{4.3.2-Análisis de las facies sedimentarias}

A partir de las características observadas en afloramiento (litología y estructura primaria) en cada cuerpo de roca se definieron litofacies sedimentarias, las cuales fueron descriptas e interpretadas. Para ello se procedió a la confección de un código de facies para las rocas de la Formación Río Mayer, el cual se compone de una letra mayúscula correspondiente a la litología y una letra minúscula que se relaciona con la característica saliente de la roca (en general estructura sedimentaria primaria).

\section{4.3.3- Tratamiento del material fósil}

El abundante material fósil recolectado en la Formación Río Mayer fue descripto por la Dra. Beatriz Aguirre Urreta (Amonoideos) y el Dr. Juan Pablo Pérez Panera (microfósiles). Dada la gran cantidad de trabajos concernientes a este tópico, en la presente tesis sólo se tuvieron en cuenta aquellos fósiles que aportan datos temporales.

Una mención aparte corresponde para las trazas fósiles, las cuales son una parte fundamental del presente trabajo (véase I.4.3.7; Capítulo VIII). 


\section{4.3.4 - Difracción de rayos $x$}

Se realizó un análisis de difractometría de rayos x a las muestras seleccionadas de los perfiles sedimentológicos. Este análisis consiste en la identificación de la composición mineral de la roca a partir de la lectura de un difractograma.

El primer paso es moler unos fragmentos pequeños de muestra inalterada en mortero de porcelana hasta obtener un polvo impalpable (figura 1.3), el cual se coloca en porta muestra para ser luego colocado en el difractómetro de rayos x. El Centro de Investigaciones Geológicas cuenta con un equipo de rayos x Philips con lámpara de $\mathrm{Cu}$ $(K \alpha=1,5403)$. Se hace correr la muestra desde los 3 grados hasta los 37 grados y esto da como resultado la primera lectura, que corresponde a la muestra “total”.

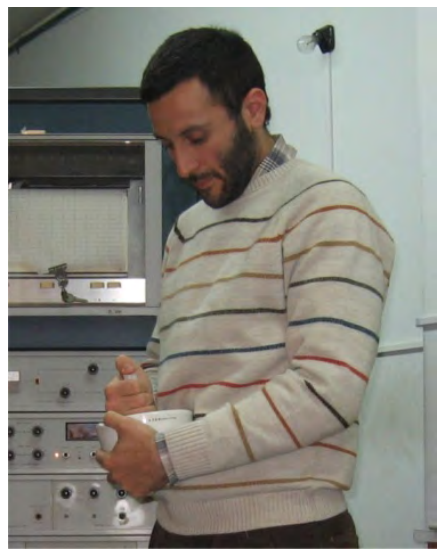

Figura 1.3- Proceso de molienda en mortero de porcelana.

Posteriormente se coloca el polvo de la muestra en un vaso correctamente rotulado, y se lo completa con agua destilada. La mezcla de sedimento y agua se agita bien y se la deja reposar 20 minutos para que decante la fracción más gruesa y concentrar la fracción menor a 40 micrones. Pasado este tiempo con una pipeta se toman unos mililitros de la mezcla y se coloca en dos portaobjetos de vidrio en los que luego se deja secar la fina película de sedimento (figura 1.4a).

Una de las muestras preparadas se la pasa por el difractómetro de rayos x desde los 2 grados hasta los 32 grados, siendo esta la denominada lectura “normal”. Esta misma muestra se coloca en un glicolador y se la deja expuesta a los vapores de etilenglicol durante al menos 24 horas para la hidratación de arcillas expansivas (figura 1.4b). De esa muestra "glicolada” se extrae la tercera lectura. 


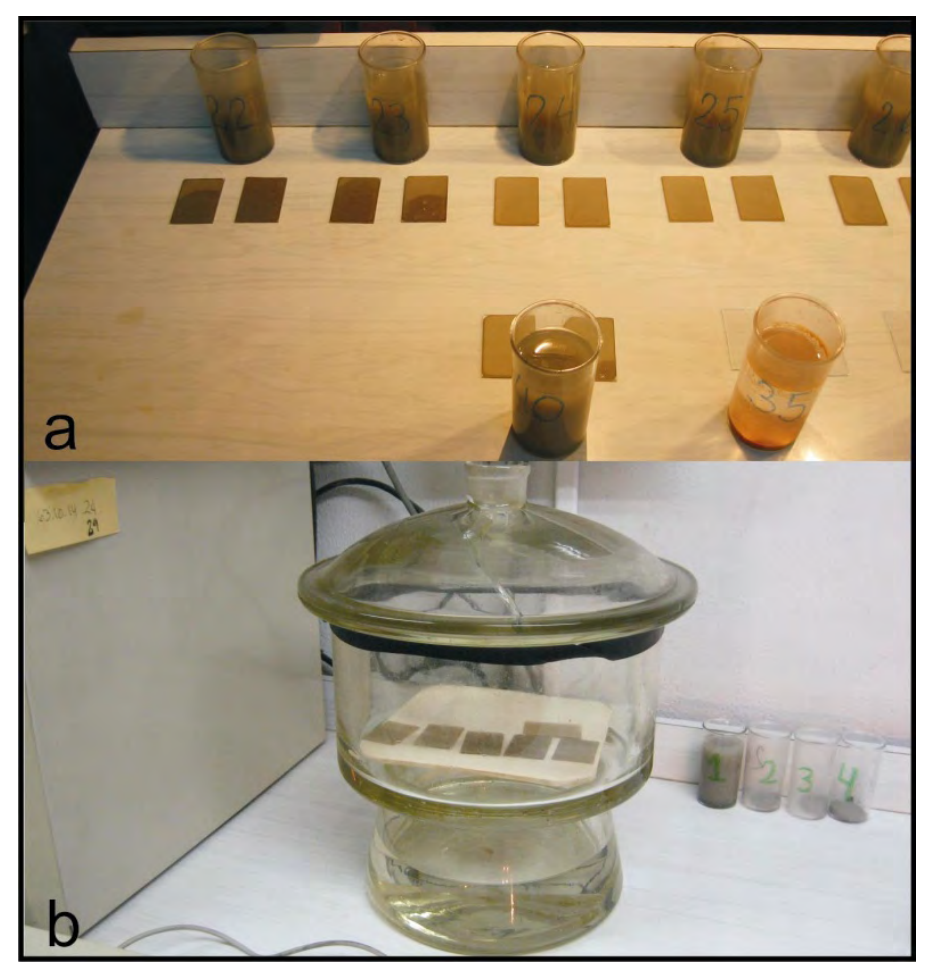

Figura 1.4- a. muestras

recientemente pipeteadas

dispuestas en porta-muestras

secándose; b. muestras en el

glicolador.

La cuarta y última lectura se realiza sobre la segunda muestra montada a partir de la mezcla de sedimento con agua destilada, y se efectúa después de pasar la muestra por una mufla a $550^{\circ} \mathrm{C}$ durante 2 horas para generar el colapso de la estructura cristalina de las arcillas expansivas y de la caolinita. Esta es la denomina muestra calcinada.

Luego se procede a graficar los resultados, tarea para la cual se utilizó el programa $\operatorname{Origin}{ }^{\circledR}$, realizando por separado un diagrama para la muestra total y otro para la fracción arcilla. El siguiente paso es la cuantificación de los minerales a partir de los gráficos. Para las muestras totales se tuvieron en cuenta 6 categorías: Traza ( $\mathrm{Tr})$ : minerales presentes en cantidades menores al 1\%. Muy escaso (ME): minerales presentes con cantidades entre 1 y 5\%.

Escaso (E): minerales presentes con cantidades entre 5 y 15\%.

Moderado (M): minerales presentes con cantidades entre 15 y 25\%.

Abundante (A): minerales presentes con cantidades entre 25 y 50\%.

Muy abundante (MA): minerales presentes con cantidades mayores al 50\%.

Sobre la base a esta categorización se cuantificaron las cantidades de cuarzo, calcita, feldespatos y arcillas, ya que entre éstos conforman más del 95\% de los componentes de las 
muestras. Para graficar los contenidos arriba mencionados se utilizó un valor fijo arbitrario para cada una de las 6 categorías, así los valores asignados fueron los siguientes:

Traza (Tr): $1 \%$.

Muy escaso (ME): 4\%.

Escaso (E): 10\%.

Moderado (M): 20\%.

Abundante (A):35\%.

Muy abundante (MA): 60\%.

Utilizando éstos últimos valores se generaron diagramas con el programa Excel para los perfiles seleccionados.

Para la fracción arcilla también se realizaron gráficos con el programa Origin ${ }^{\circledR}$ y la cuantificación se realizó utilizando el método establecido en el Laboratorio de Difracción de Rayos X del Centro de Investigaciones Geológicas (más detalles en capítulo 5). Entre las arcillas se identificaron illita, clorita, caolinita e interestratificados illita/esmectita. Del mismo modo que para las muestras totales, mediante el empleo del programa Excel se graficaron los resultados para los perfiles correspondientes.

\section{4.3.5 - Petrografía}

Se analizó la petrografía de las muestras de rocas sedimentarias tamaño arena, a fin de determinar la composición mineralógica, los tipos de cementos y las relaciones entre sus componentes. Con el mismo fin se trataron las secciones delgadas de facies finas. Para llevar a cabo esta tarea se utilizó un microscopio binocular NIKON modelo Eclipse E200POL.

También se efectuó el análisis modal de areniscas. Para esta tarea se utilizó un microscopio petrográfico conectado a un contador Swift ${ }^{\circledR}$.

Los resultados fueron ploteados en los diagramas de clasificación (Folk et al., 1970; Dott, 1964, modificado por Pettijohn et al., 1972) y en los diagramas de procedencia (Dickinson et al., 1983). (Más detalles en capítulo 6). 


\section{4.3.6-Análisis geoquímicos}

Se realizaron análisis geoquímicos de muestras seleccionadas de la Fm. Río Mayer. Para tal fin se molieron unos 20 g de muestra y se lo tamizó en malla 200 (75 micrones). Los análisis fueron llevados a cabo por la empresa ALS Laboratory Group, con laboratorios en Canadá.

Otro tipo de análisis desarrollado fue la cuantificación del contenido de Carbono Orgánico Total (COT). Estos análisis fueron realizados por la Empresa Geolab Sur SRL, bajo la dirección del Lic. Héctor Villar.

Finalmente, se realizaron estudios isotópicos de $\mathrm{O} 18$ y $\mathrm{C} 13$ en facies con porcentajes de carbonato intermedio a alto (20-60\%). Dichos análisis fueron realizados en la Universidad de Recife, dirigidos por el Dr. Alcides Sial.

Todos los resultados fueron representados a modo de tablas y de logs junto al perfil correspondiente, además de gráficos discriminados con finalidades específicas. (Más detalles en capítulo 7).

\section{4.3.7 - Análisis de las estructuras sedimentarias orgánicas}

Se llevó a cabo el reconocimiento de las trazas fósiles presentes en los perfiles sedimentológicos. Las tareas se concentraron en la digitalización in situ de las trazas y su descripción detallada en el campo. La posterior identificación taxonómica y análisis paleoambiental se realizó en gabinete.

Teniendo en cuenta la distribución de los icnogéneros en cada perfil se definieron icnofacies e icnoasociaciones. (Más detalles en capítulo 8).

\section{4.3.8- Análisis intelectual de los datos}

A partir de la información recopilada en los perfiles sedimentológicos, el análisis litofacial y las interpretaciones de las asociaciones de facies, el estudio mineralógico por difracción de rayos $\mathrm{X}$, la petrografía y la geoquímica, sumados al estudio minucioso de las trazas fósiles (capítulos 3 a 8) se llegó a un modelo paleoambiental integrado para la Formación Río Mayer. 


\section{4.3.9 -Presentación de los resultados en un Manuscrito de Tesis}

Finalmente, toda la información recopilada y procesada, junto con las interpretaciones realizadas durante el presente trabajo de tesis doctoral fue dispuesta y ordenada en un manuscrito de tesis para su presentación. 


\section{Capítulo II - Antecedentes}

\section{1 - Cuenca Austral}

El conocimiento de la Cuenca Austral es pobre en comparación con otras cuencas sedimentarias de la República Argentina. Si se tiene en cuenta la cantidad de trabajos publicados para las unidades que conforman dicha cuenca y se los coteja, por ejemplo, con los dedicados a las Cuencas Neuquina y Cuyana, se notará la falta de investigaciones detalladas para esta región del país.

Los afloramientos de la Cuenca Austral están presentes en las provincias geológicas de la Cordillera Patagónica Austral, la Patagonia Austral Extraandina y la Cordillera Fueguina (Russo y Flores, 1972; Caminos, 1980; Riccardi y Rolleri, 1980; Russo et al., 1980). La cuenca de subsuelo, posee una superficie aproximada de $230.000 \mathrm{~km} 2$ y está limitada por la Cordillera Patagónica al oeste y por el Macizo del Deseado - Dorsal de Río Chico al noreste y este (Rodríguez y Miller, 2005) (Figura 2.1).

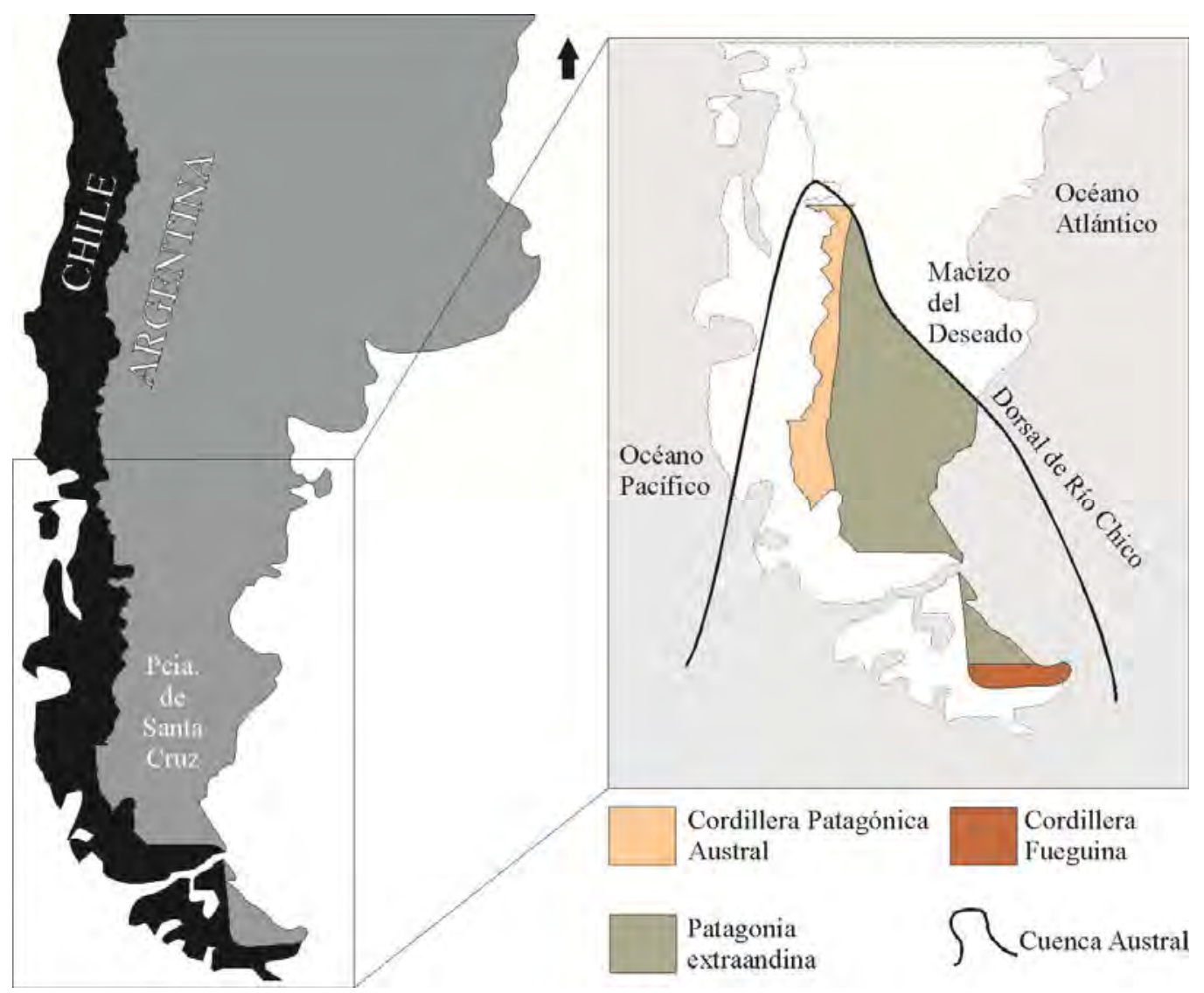

Figura 2.1 - Ubicación y límites de los depósitos de la Cuenca Austral. 
La historia del estudio principalmente de la Cordillera Patagónica Austral puede dividirse en cuatro períodos (Riccardi, 1986). El primero abarca desde el siglo XVI hasta el siglo XVIII, dejando como legado la base geográfica de la región (Fernando de Magallanes año 1520-, Nicolás Mascardi -1670-1672-, José Cardiel -1745-, Tomás Falkner -1774Antonio Viedma -1783- ).

Una segunda etapa en el conocimiento de esta zona del país se desarrolla entre el siglo XIX y el inicio del siglo XX. Es durante este período que se realizaron las primeras observaciones de índole geológica. Entre los primeros están Charles Darwin $(1842,1846)$, Alcides d’Orbigny (1842), Francisco Moreno (1879), Ramón Lista (1880), Carlos Moyano (1888) y Gustav Steinmann (1883). Esta etapa continúa con una importante exploración por parte del Museo de La Plata, el cual a partir de 1886 envió varios investigadores a desarrollar tareas científicas a la Patagonia. Los investigadores que participaron de estas campañas son: Carlos Ameghino, Santiago Pozzi, Clemente Onelli, Juan Ivovich, Antonio Steinfeld, Eduardo Botello, Emilio Beaufils y Federico Berry. Entre 1891 y 1892, Carlos Burmeister (también perteneciente al Museo de La Plata), realizó dos expediciones recolectando abundante material fósil, en el sector suroeste de la Provincia de Santa Cruz. La estratigrafía de la región fue estudiada en la época por Alcide Mercerat (1896-1897). En 1905, Otto Nordenskjöld, publicó sus investigaciones realizadas durante una expedición sueca en la Provincia de Tierra del Fuego y parte sur de Santa Cruz entre los años 1895 y 1897. En esta publicación los fósiles de plantas fueron descriptos por Dusen (1899) y los invertebrados por Steinmann y Wilckens (1908). Al norte de la zona estudiada por Nordenskjöld y sus colaboradores, trabajó entre los años 1898 y 1900 el geólogo adscripto al Museo de La Plata, R. Hauthal. La carta realizada por éste fue publicada en 1907 por Wilckens, quien además trabajó con los fósiles invertebrados del Cretácico (excepto amonites) y terciarios. Los cefalópodos fueron estudiados por W. Paulcke (1907) y F. Favre (1908), mientras que la flora fósil la estudió F. F. Kurtz (1902). Una de las más importantes contribuciones al conocimiento científico de la Patagonia austral es, sin duda alguna, la realizada por la expedición de la Universidad de Princeton, EEUU, bajo la dirección de J. B. Hatcher. Este trabajo se publicó en ocho tomos bajo la dirección de W. B. Scott. Como resultado de una expedición sueca entre 1907 y 1909, al mando de C. Skottsberg, se publicó el mapa geológico de Los Andes Australes, en ella las rocas ígneas fueron estudiadas por P. D. Quensel (1911, 1913), las plantas fósiles por T. G. 
Halle (1913) y los invertebrados cretácicos por E. Stolley (1912). Finalmente, durante esta etapa, entre 1910 y 1916, varias expediciones de la Sociedad Científica Alemana de Buenos Aires dio como uno de sus resultados el primer bosquejo de la geología de la región del Lago Viedma (Witte, 1917).

La etapa tercera en el desarrollo del estudio del sector suroccidental de la Patagonia tiene una marcada influencia económica, ya que la mayor parte de los estudios fueron llevados a cabo por organismos oficiales (Dirección Nacional de Geología y Minería, Yacimientos Petrolíferos Fiscales y Yacimientos Carboníferos Fiscales). En 1921 G. Bonarelli y J. J. Nágera publican un informe estratigráfico y paleontológico de la zona del Lago San Martín. En 1932, Carl Caldenius publicó sus estudios sobre los glaciares cuaternarios de la región cordillerana patagónica. En ese mismo año inicia sus trabajos en la Patagonia quien será un referente obligado de todos los trabajos posteriores en esta región, incluso aún en nuestros días, el Dr. Egidio Feruglio. Una serie de trabajos realizados en esta época (Huene, 1929; Frenguelli, 1930, 1935, 1941a, 1941b, 1953 a-b; Kraglievich,1930; Feruglio, 1936, 1938,1944; Conci, 1935; d’Erasmo, 1935; Berry, 1937; Roll, 1937; Fossa Mancini et al., 1938; Piatnitzky, 1938; Simpson, 1940; Zuffardi, 1944; Brandmayr, 1945) llevan a la confección por parte de E. Feruglio la “Descripción Geológica de la Patagonia” en 1950, en ella recopila todo lo publicado al momento más información inédita. Este trabajo se convertirá en la base de la geología de gran parte de la Patagonia, y hasta hoy varias de sus conclusiones permanecen invariadas. Borrelo en 1956 publicó una síntesis de la información recopilada para Yacimientos Carboníferos Fiscales por V. G. Galante (1953-1954), P. Fernández (1957) y F. Bergmann (1956- 1957- 1959). Durante esos años se iniciaron algunas tesis doctorales auspiciadas por los organismos oficiales, así B. Quartino (1952) trabajó en Lago Fontana, M. Hünicken (1955) en el río Turbio y J. Riggi (1957) en los lagos Pueyrredón y Posadas.

La última etapa en el estudio de la Patagonia suroccidental se extiende hasta el presente. Riccardi (1986) consideró como el inicio de esta nueva era la publicación de la “Geología Regional Argentina” primera edición en 1972 (Leanza, A., editor), sin olvidar los trabajos realizados por J. Bianchi (1967), M. Turic (1967, 1971), H. Di Benedetto (1972, 1973), M. Flores y J. Perrot (1961), que son contemporáneos a esta publicación. Los trabajos realizados en esta etapa son de índole diversa, abarcando todas las áreas del conocimiento 
científico. La lista de investigadores que en esta última etapa aportaron al conocimiento de la Cuenca Austral es amplia, razón por la cual no cabe en estos párrafos.

\section{II.1.1- Etapas tectónicas de la Cuenca Austral}

La evolución tectónica de la cuenca puede ser dividida en 3 etapas (Biddle et al., 1986; Kraemer et al., 2002; Rodríguez y Miller, 2005):

Etapa de Rift: Se desarrolla durante en Jurásico superior como producto de la extensión generada por el impacto de una pluma mantélica sobre la litósfera patagónica (Pankhrust et al., 2000). Los depósitos de esta etapa corresponden a las rocas volcánicas y volcaniclásticas del Complejo El Quemado. Dicho complejo presenta edades de 187Ma a 144Ma (Féraud et al., 1999). En la continuidad de la cuenca hacia el sur, en la República de Chile, esta etapa generó el desarrollo de la cuenca marginal de Rocas Verdes (Dalziel et al., 1974), que se asocia a la apertura del Mar de Wedell.

Etapa de Sag: la etapa de subsidencia térmica se desarrolló durante el Cretácico inferior y en ella se registra la mayor transgresión marina en la cuenca. Los depósitos son muy variados, desde continentales a marinos profundos.

Etapa de Antepaís: Se desarrolla en el Cretácico superior, relacionándose con el cierre de la cuenca marginal y el levantamiento de la Cordillera de Los Andes.

II.1.2- Ciclos sedimentarios cretácicos de la Cuenca Austral Arbe (2002), divide al Cretácico de la Cuenca Austral en 3 ciclos transgresivoregresivos, que del más antiguo al más joven son los Ciclos Río Mayer, Lago San Martín y Lago Viedma.

Ciclo Río Mayer: se compone de dos subciclos, el subciclo transgresivo Springhill (ST1) que se habría desarrollado entre el Berriasiano y el Hauteriviano superior, y el subciclo regresivo Río Tarde (SR1) desde el Hauteriviano superior hasta el Aptiano inferior. 
Ciclo Lago San Martín: está integrado por los subciclos Arroyo Potrancas (transgresivo; ST2) del Aptiano y Kachaike (regresivo; SR2) desde el Aptiano superior hasta Turoniano inferior.

Ciclo Lago Viedma: se inicia con el subciclo transgresivo Mata Amarilla (ST3) que va desde el Turoniano inferior hasta Santoniano inferior, luego el subciclo regresivo Anita (SR3) que ocupó el lapso Santoniano superiorMaastrichtiano.

\section{2 - Formación Río Mayer}

\section{2. 1- Denominación}

En lo que concierne a la Formación Río Mayer, ésta es una unidad que ha recibido diferentes nombres en su historia, desde su primera descripción en 1897 por Hatcher, que denominó “Mayer River Beds” a unos sedimentos duros, muy fragmentados y ricos en amonites, en la cuenca del río homónimo. Luego Ameghino (1898), estableció el Mayerense para esta unidad. En 1912 Stolley usó el término “Meseta Schiefer" para las mismas sedimentitas, pero en el Lago San Martín. La sinonimia fue discutida por Frenguelli (1935) y Fossa Mancini et al. (1938), dando la prioridad al nombre utilizado por Hatcher. En 1950 E. Feruglio confirmó el nombre dado por Hatcher por sobre todos los propuestos a la fecha, aunque aclara que no estaba seguro de la edad de las Capas del Río Mayer. Dicho autor agrupó en lo que él denominó “Complejo Arcillítico- Areniscoso del Infracretáceo” a las actuales formaciones Springhill y Río Mayer, ambas situadas en ese orden sobre el "Complejo Porfírico” (actualmente Complejo El Quemado). En 1967, Bianchi en un informe inédito utilizó el nombre de Formación San Martín para esta unidad en las inmediaciones del Lago San Martín, pero este término fue empleado por primera vez en la literatura publicada en Zambrano y Urien (1970) y Leanza (1970) (Riccardi, 1986; Riccardi y Rolleri, 1980).

Más recientes son los aportes de Nullo y otros (1978, 1981, 1999), Riccardi y Rolleri (1980), Arbe (1989, 2002), Kraemer y Riccardi (1997), entre otros. Estos autores han sido quienes contribuyeron, en mayor o menor medida, a formular consideraciones sedimentológicas y paleoambientales de esta unidad. 
Es extensa la lista de nombres dados a esta unidad en otras zonas de la Patagonia, como la región del lago Pueyrredón, lago Fontana y lago Argentino por diversos autores, a la vez que posee denominación propia para los depósitos del subsuelo. Situación similar a la planteada en esta región se da en la Provincia de Tierra del Fuego (Riccardi y Rolleri, 1980).

II. 2. 2- Relación con las Formaciones supra e infrayacente

La Formación Río Mayer apoya en paraconcordancia sobre El Complejo El Quemado y en concordancia o paraconcordancia sobre la Formación Springhill (Kraemer y Riccardi, 1997).

Con respecto al límite superior cabe aclarar que en el área de estudio esta unidad se encuentra cubierta por cuatro formaciones, y con todas ellas, el paso desde la Formación Río Mayer es transicional. De norte a sur esas formaciones son: Kachaike, Piedra Clavada, Lago Viedma y Cerro Toro (Riccardi 1968, 1971; Riccardi y Rolleri 1980; Arbe y Hechem, 1984; Kraemer y Riccardi, 1997; Marinelli, 1998; Canessa et al., 2006).

En el siguiente cuadro puede apreciarse la estratigrafía de la región estudiada y su comparación con los depósitos del subsuelo y de la República de Chile. 


\begin{tabular}{|c|c|c|c|c|c|c|c|}
\hline & & LAGOSAN MARTIN & LAGO VIEDMA & RIOO GUANACO & LAGO ARGENTINO & CHLE & SUBSUELO \\
\hline \multirow{4}{*}{ 喜 } & \multirow{2}{*}{$\frac{\text { Masstrictiano }}{\text { Campatiano }}$ 80.6t0. } & & & & & Formación Tres pasos & $\begin{array}{l}\text { Magallanes } \\
\text { (inferior) }\end{array}$ \\
\hline & & & & Formación Alta Vista & Formación Alta Vista & \multirow{2}{*}{ Formación Cerro Toro } & \multirow{5}{*}{$\begin{array}{l}\text { Palermo Aike } \\
\text { (superior) }\end{array}$} \\
\hline & Santoniano & & & \multirow{5}{*}{ Formación Cerro Toro } & \begin{tabular}{|l} 
Conglomerado Lago Sofia \\
\end{tabular} & & \\
\hline & Conaciano & \multirow{3}{*}{ Formación Mata Amarilla } & & & \multirow{2}{*}{ Formación Cerro Toro } & \multirow[t]{2}{*}{ Formación Punta Barrosa } & \\
\hline \multirow{4}{*}{$\begin{array}{l}0 \\
0 \\
0 \\
\frac{0}{0} \\
0 \\
0\end{array}$} & Turovizano & & Formación Puesto el Alamo & & & & \\
\hline & Cenomenisno & & Formación Lago Viedma & & & & \\
\hline & Albino & $\begin{array}{c}\text { Formación Piedra Clavada } \\
(=\text { Kachaike }) \\
\end{array}$ & -------------0 & & & & Palermo Aike \\
\hline & Aptiano & \multirow{2}{*}{ Formación Rio Mayer } & \multirow{3}{*}{ Formación Rio Mayer } & \multirow{4}{*}{ Formación Río Mayer } & \multirow{4}{*}{ Formación Río Mayer } & \multirow{4}{*}{ Formación Zapata } & \\
\hline \multirow[t]{3}{*}{ 言 } & $\begin{array}{l}\text { Barreniano } \\
\text { Haterviano }\end{array}$ & & & & & & $\begin{array}{l}\text { Palermo Aike } \\
\text { (inferior) }\end{array}$ \\
\hline & Valanginiano & \multirow{2}{*}{ Formación Springhill } & & & & & \\
\hline & Butriasiano & & Formaciön Springhill & & & & Formación Springhill \\
\hline & & & & Formación Springhill & & Formación Tobifera & Formación Tobifera \\
\hline
\end{tabular}

Figura 2.2-Cuadro estratigráfico del Cretácico de la Cuenca Austral (superficie y subsuelo) y de la Cuenca de Rocas Verdes (Chile).

Modificado de Arbe, 2002; Canessa et al., 2006; Fildani et al., 2003; Fildani y Hessler, 2005; Kraemer y Riccardi, 1997; Riecardi 1971; Rodriguez y Miller, 2005; Varela, 2011. 


\section{2. 3- Características generales}

La caracterización más frecuente de la Formación Río Mayer en la bibliografía es la de “pelitas negras laminadas con abundante fauna de invertebrados”. Estas palabras fueron las empleadas por Hatcher (1897), y con posterioridad los trabajos sedimentológicos dedicados a esta unidad son escasos. La mayor parte de estos son de neto carácter paleontológico, en especial con respecto a los moluscos, casi sin hacer mención al resto del material fósil contenido por esta unidad. Algunos autores citan como frecuente la presencia de niveles de margas, en general de poco espesor (hasta 1 m máximo), y en menor proporción areniscas finas en estratos poco potentes (Canessa et al., 2005).

En el marco sedimentológico regional empleado por Arbe la formación Río Mayer representa dentro del Ciclo Río Mayer parte del subciclo transgresivo Springhill (ST1) y la parte más austral del subciclo regresivo Río Tarde (SR1). Dentro del Ciclo Lago San Martín forma parte del subciclo transgresivo Arroyo Potrancas (ST2). En la Figura 2.3 se puede observar la distribución de las Formaciones Springhill y Río Mayer para el Cretácico inferior (modificado de Arbe, 2002).

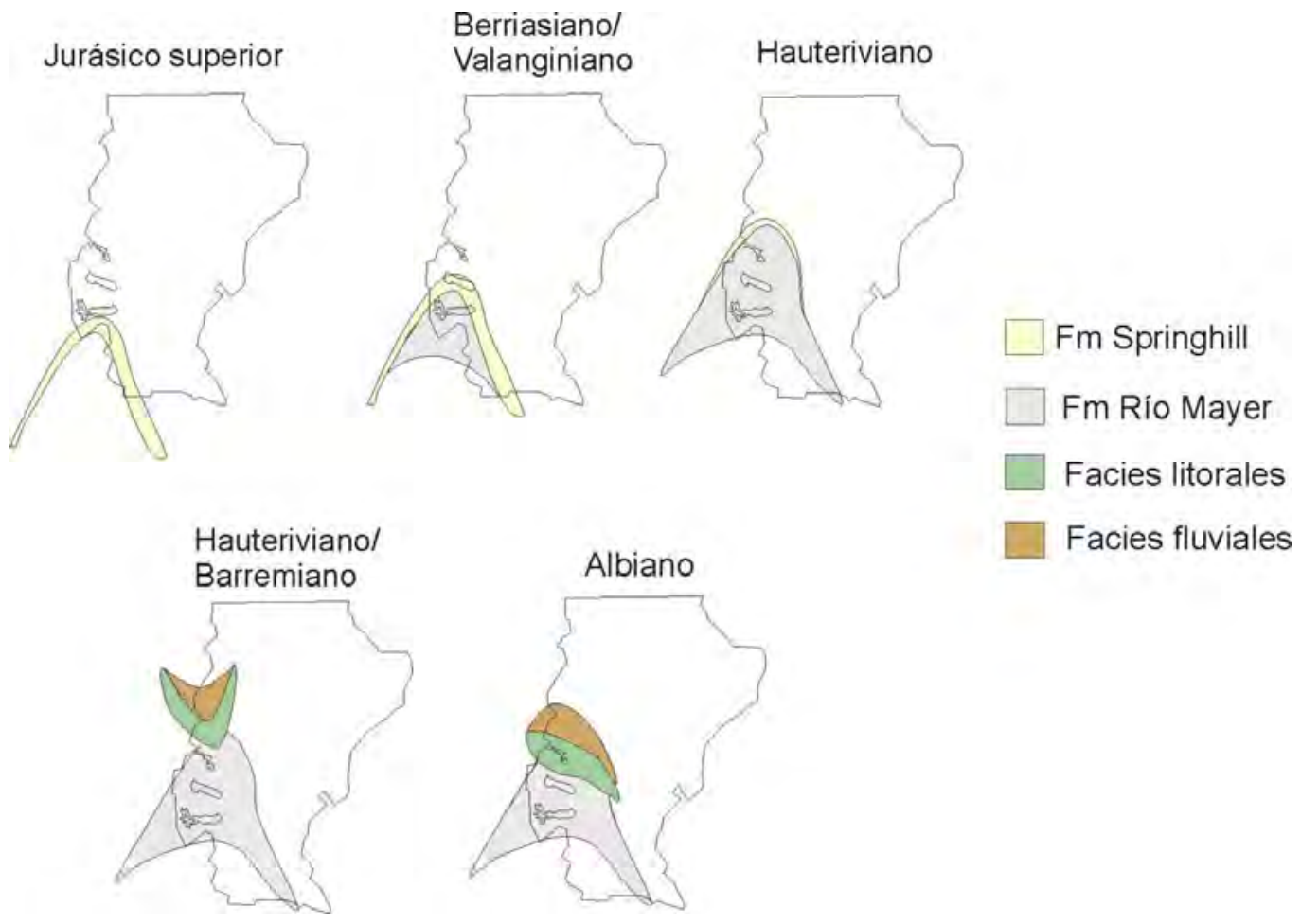

Figura 2.3- Distribución de las formaciones Río Mayer y Springhill durante el Jurásico superior y el Cretácico inferior. Modificado de Arbe, 2002. 
En cuanto al contenido paleontológico de esta formación, el mismo está bien documentado por importantes investigadores, entre ellos Stanton (1901), Favre (1908), Stolley (1912, 1928), Halle (1913), Bonarelli y Nágera (1921), Cabrera (1927), Huene (1927), D’Erasmo (1935), Frenguelli (1935), Piatnitzky (1938), Leanza (1967b, 1968, 1970), Waterhouse y Riccardi (1970), Riccardi (1970, 1971, 1979), Riccardi et al. (1987), Aguirre Urreta (1987), Aguirre Urreta y Doyle (1989), Aguirre Urreta y Riccardi (1989), Cichowolski (2003), Kellner et al. (2003), Medina y Riccardi (2005), entre otros. De estos trabajos cabe destacar, desde el punto de vista icnológico, los de Aguirre Urreta (1987) y el de Medina et al. (2008).

II. 2. 4- Generalidades de las regiones seleccionadas para su estudio

\section{2.4.1 - Región del Lago San Martín}

Los estudios geológicos y paleontológicos para esta región se remontan a principios de siglo XX, con gran desarrollo durante la primera mitad del mencionado siglo. Entre estas investigaciones se destacan las realizadas por Halle (1913), Bonarelli y Nágera (1921), Frenguelli (1935 y 1941), Piatnitzky (1938) y Feruglio (en Fossa Mancini et al., 1938; y 1950), entre otros. Más reciente es el trabajo Riccardi (1968 y 1971), que describe la estratigrafía del oriente de la Bahía de La Lancha. El mapa geológico realizado por Riccardi (1971) se presenta en la figura 2.4. Dicho mapa fue utilizado de guía durante las tareas de campo, resultando muy fidedigno de los afloramientos.

La estratigrafía comienza con la Formación Bahía de la Lancha (Borrello, 1967), la cual se compone de rocas meta-sedimentarias de edad paleozoica. Continúan unos 70 metros de rocas psefíticas agrupadas en el Conglomerado Arroyo de la Mina (Bianchi, 1967), asignadas por relaciones estratigráficas al Jurásico (Riccardi, 1971). Por arriba están los depósitos del Complejo El Quemado (Feruglio en Fossa Mancini et al., 1938), con un espesor aproximado de 200 metros y compuesto principalmente por rocas volcánicas y volcaniclásticas de edad jurásica. La Formación Springhill se encuentra bien expuesta en la Bahía de la Lancha, con un espesor de 70 metros que se inician con psamitas medias a finas con niveles de pelitas carbonosas y finalizan con psamitas con fósiles marinos y un nivel de caliza (Riccardi, 1971). La edad asignada a esta formación es Berriasiano - Valanginiano 
inferior (Pirrie et al., 2004). La Formación Río Mayer posee 700 metros de espesor y se compone pelitas negras con niveles o concreciones calcáreas y abundantes invertebrados fósiles de edad Valanginiano superior - Albiano inferior (Riccardi, 1971; Pirrie et al., 2004). Por arriba, y de manera transicional se encuentra la Formación Kachaike, con 110 a 170 metros de espesor compuesto principalmente por psamitas finas a gruesas de color amarillento depositadas durante el Albiano medio (Riccardi, 1971; Pirrie et al., 2004). Intruyendo la Formación Río Mayer se encuentra la Andesita Puesto Nuevo fechada aproximadamente en 81 Ma (Santoniano; Riccardi, 1971). La estratigrafía se completa con rocas intrusivas y eruptivas terciarias y sedimentos de origen glacial cuaternarios.

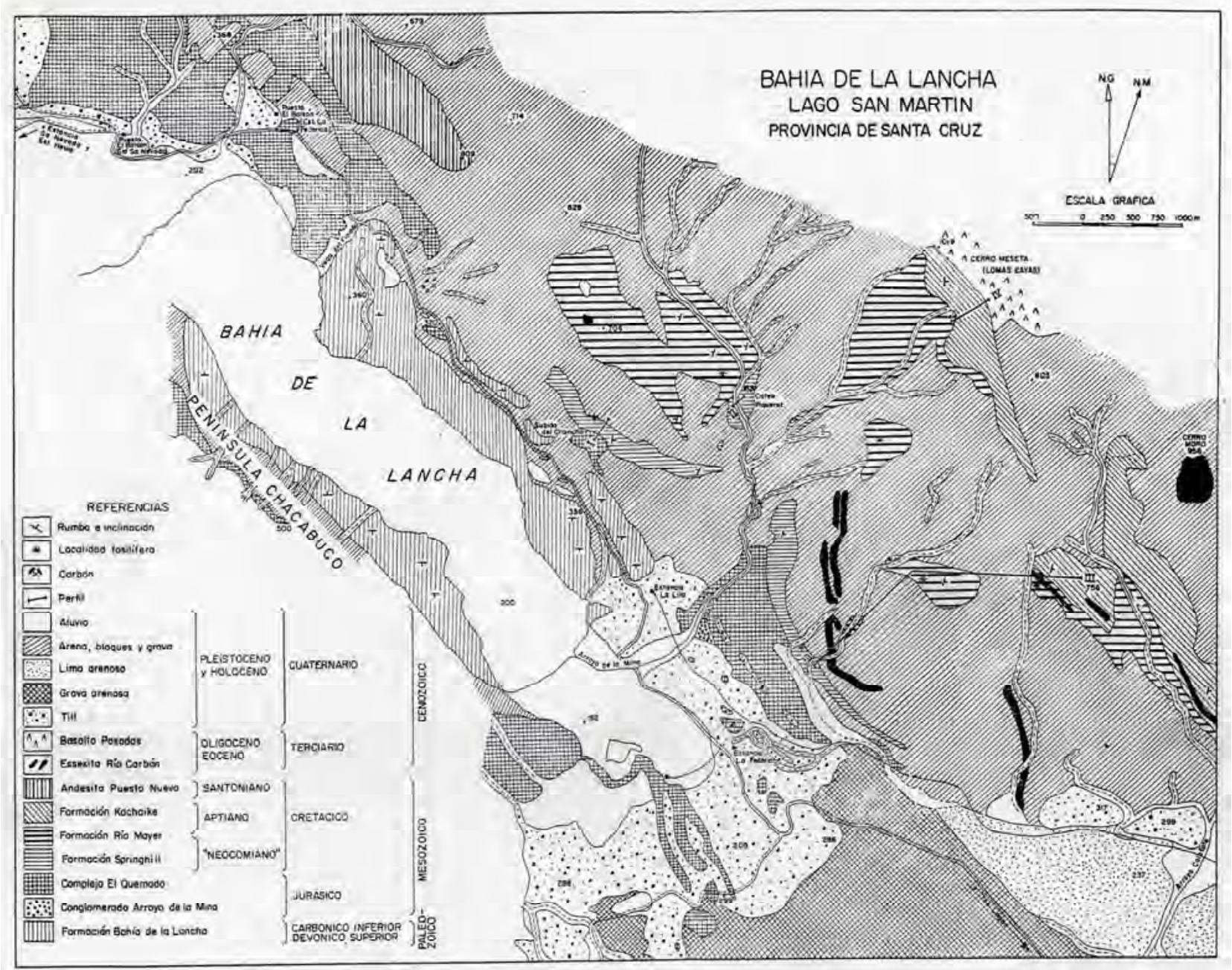

Figura 2.4- Mapa geológico de la Bahía de la Lancha (Tomado de Riccardi, 1971). 


\section{2.4.2 - Región de las Nacientes del Río Guanaco}

En la región de las nacientes del Río Guanaco las referencias en la bibliografía son escasas, destacándose el trabajo realizado por Kraemer y Riccardi (1997), en el que describen la estratigrafía del área. En comparación con la región del Lago San Martín, aquí no se registra el Conglomerado Arroyo de la Mina, quedando comprendidos los depósitos del inicio de la cuenca por el Complejo El Quemado y las formaciones Springhill y Río Mayer. Por encima de estas unidades se deposita en concordancia la Formación Cerro Toro, que se compone de pelitas negras y areniscas, interpretadas como depósitos marinos profundos (Cecioni, 1955; Katz, 1963, Arbe y Hechem, 1984). Kraemer y Riccardi (1997), sitúan el inicio de la Formación Cerro Toro por el incremento en la relación arenisca / pelita, ubicando en los niveles basales la presencia de Birostrina? cf. concentrica de edad Albiano medio - Cenomaniano temprano, y por encima, varios niveles con Inoceramus sp.

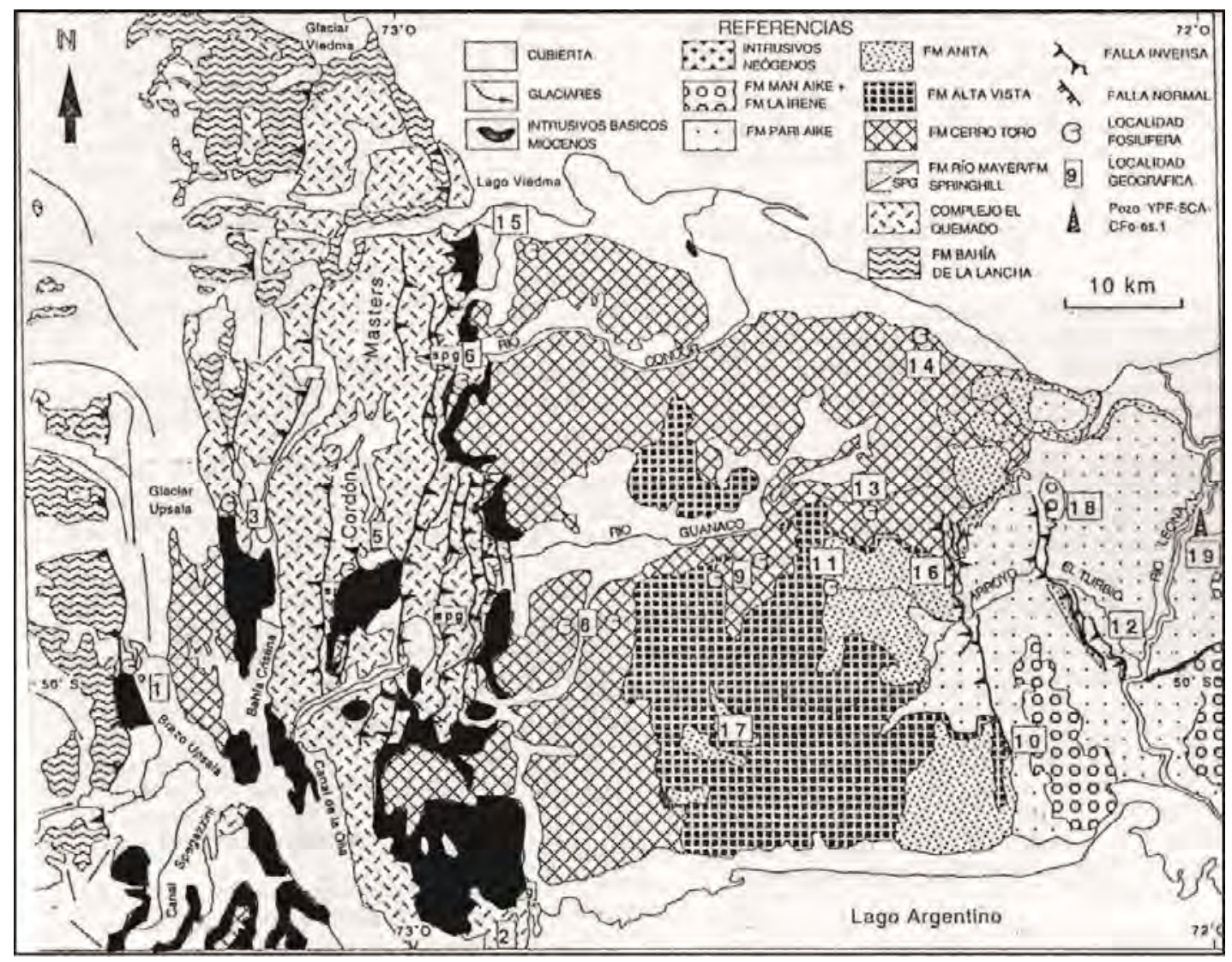

Figura 2.5 - Mapa Geológico de la región de las Nacientes del Río Guanaco. Tomado de Kraemer y Riccardi (1997), en negro se resaltan los depósitos de las formaciones Springhill y Río Mayer. 
II. 2.4.3 - Región de la margen norte del Lago Argentino

Feruglio en 1950 describe para esta región la presencia del Complejo El Quemado y por arriba un complejo sedimentario muy potente (más de 1000 metros) compuesto por “rocas arcillíticas, ftaníticas y finamente areniscosas, por lo general duras, de fractura astillosa y de color negruzco a gris oscuro...”. Describe además varias asociaciones de amonites que aportan edades del Cretácico inferior. Esta descripción corresponde a depósitos de la Formación Río Mayer.

En 1973, Furque realizó la hoja geológica Lago Argentino con escala 1:200.000. En ese trabajo la estratigrafía utilizada por el autor difiere con lo utilizado y conocido hasta esa fecha. Las equivalencias son las siguientes:

\begin{tabular}{|c|l|}
\hline Estratigrafía empleada en este trabajo & Estratigrafía de Furque (1973) \\
\hline Complejo El Quemado & Formación Barragán \\
\hline Formación Río Mayer & Formación El Quemado; \\
& Formación La Unión \\
\hline Formación Cerro Toro & \multicolumn{2}{|c|}{ Miembro Horqueta de Formación Las } \\
& Hayas \\
\hline
\end{tabular}

Arbe y Hechem (1984), analizaron los depósitos marinos profundos del Cretácico superior, evidentemente no incluyen a la Formación Río Mayer, pero su trabajo es importante por la coincidencia en el área de estudio. En la figura 2.6 se observa el mapa geológico realizado por Arbe y Hechem (1984) y en sombreado verde al área estudiada en este trabajo. 


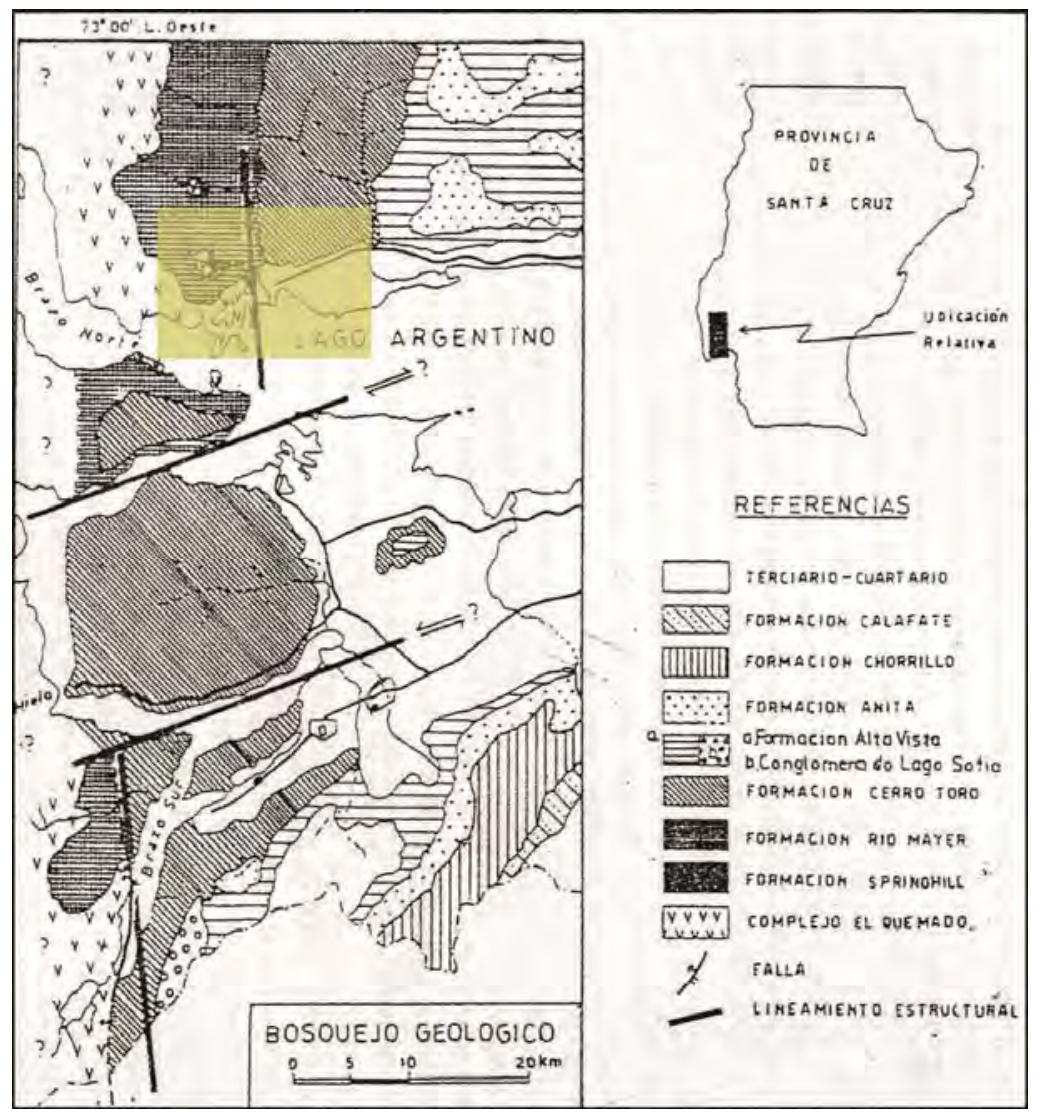

Figura 2.6 - Mapa geológico del Lago Argentino (Tomado de Arbe y Hechem, 1984). El sombreado verde es el área estudiada en el presente trabajo.

\section{2. 5- Generalidades de los depósitos de la República de Chile}

La región de la Cordillera de Última Esperanza, en la Provincia de Magallanes, República de Chile, representa la continuación austral del área de estudio de este trabajo (Figura 2.7). Entre las contribuciones publicadas para esta región, uno de los más importantes desde el punto de vista estratigráfico es el realizado por Katz (1963). Las unidades descriptas por este autor, que se correlacionan con las aquí utilizadas son:

Formación Quemado: Toma el nombre propuesto por Feruglio (en Fossa Mancini et al., 1938) y lo correlaciona con la Formación Tobífera del subsuelo del este patagónico y Tierra del Fuego. Se compone de rocas volcánicas y volcaniclásticas con intercalaciones esporádicas de areniscas y pelitas negras laminadas. La presencia de diques 
porfíricos cortando los depósitos del Cretácico inferior demuestran que la actividad volcánica estuvo activa en esta región después de la transgresión marina.

Formación Zapata: es una sucesión monótona de pelitas y margas negras con un espesor de 1000 a 1200 metros, con un pronunciado adelgazamiento desde la cordillera hacia el este. La edad abarca el intervalo Titoniano - Cenomaniano (Fildani et al., 2003). Katz la correlaciona con las “Mayer River Beds” de Hatcher (1897).

$>\quad$ Formación Punta Barrosa: Se compone de pelitas de color gris a verde oliva con intercalaciones de areniscas de finas a gruesas, incluso conglomerados, con espesores entre 0,20 a 1,5 metros. Este nuevo tipo de sedimentación continuará predominando en la cuenca durante el resto del Cretácico, razón por la cual Katz menciona la posible inclusión de esta unidad como el miembro inferior de la Formación Cerro Toro, pero prefiere mantenerla con rango formacional por su fácil distinción en el campo. La edad de esta unidad es Turoniano - Santoniano (Shultz y Hubbard, 2005).

Formación Cerro Toro: Se compone de más de 2000 metros de pelitas gris oscuras con frecuentes intercalaciones delgadas de areniscas muy finas. Katz enfatiza que esta unidad está esencialmente constituida por depósitos pelíticos de "flysch" con intercalaciones psamíticas y conglomerádicas locales. Esta unidad incluye el Miembro Lago Sofía, que está formado por grandes canales rellenos de conglomerados, e interpretados como un sistema de drenaje axial que interrumpe el dominio de las pelitas en la sucesión (Fildani et al., 2008). La edad es Santoniano - Campaniano. 


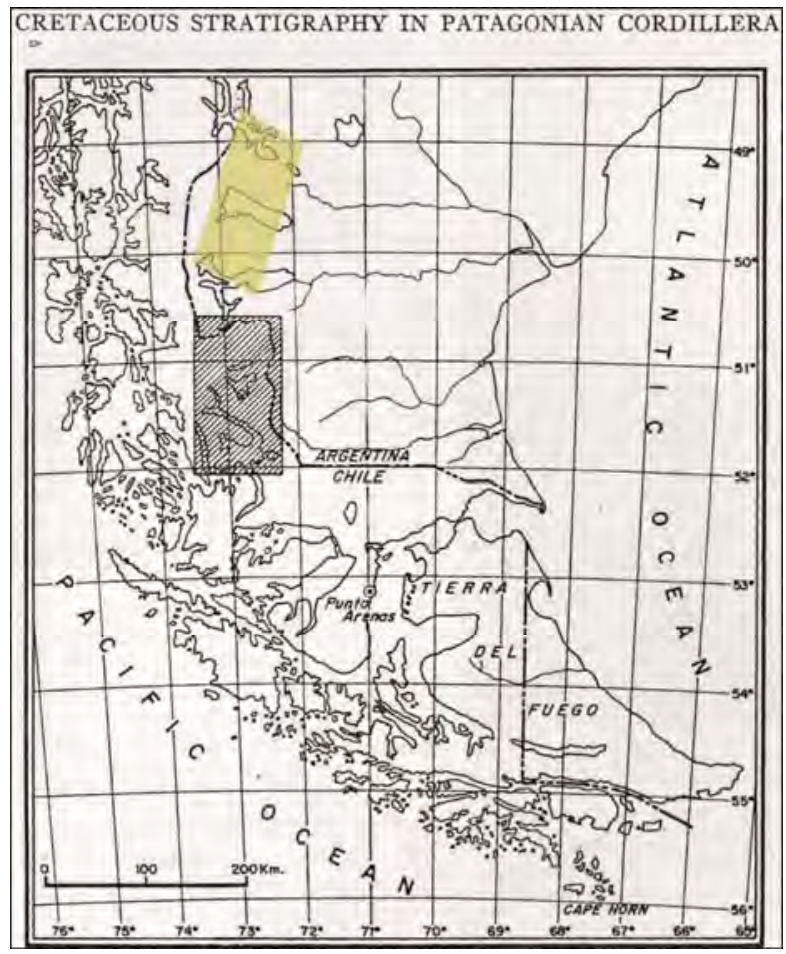

Figura 2.7 - Mapa de la región limítrofe Argentina - Chile en la Patagonia sur (Tomado de Katz, 1963). Con sombreado verde se marca el área de estudio del presente trabajo y con sombreado a rayas diagonales la región de Última Esperanza. 


\section{Capítulo III - Descripción de las Secciones Relevadas}

\section{III.1 - Introducción}

Se relevaron un total de trece secciones columnares de detalle de la Formación Río Mayer en el área de estudio (ver Figura 1.2), las cuales se distribuyen de la siguiente manera:

$>\quad 4$ en la región comprendida entre los lagos San Martín y Viedma

> $\quad 7$ en la Seccional Río Guanaco

$>\quad 2$ en la margen norte del Lago Argentino

Asimismo, se recorrió las inmediaciones de la localidad tipo (figura 1.2), se realizaron observaciones generales, por lo cual no se hicieron tareas de detalle y fue utilizada como punto de control para el posterior desarrollo de las áreas seleccionadas.

\section{2 - Localidad Tipo}

La localidad donde esta unidad fue definida se encuentra en las nacientes del Río Mayer, donde Hatcher (1897) caracterizó las Mayer River Beds por primera vez (figura 1.2). La información que el autor brindó en referencia a estas rocas en ese punto geográfico es verdaderamente escasa. Sin embargo, en el mismo artículo expresó que los afloramientos de mejor calidad y más completos son los que se encuentran en la Loma Pelada (Bald Mountain sensu Hatcher, 1897). En estos afloramientos (figura 3.1), se divisan 3 secciones, una inferior de relieve fuerte con ángulos marcados, una media de relieve suave y colores oscuros y una superior en la cual es evidente la participación de areniscas con una mayor frecuencia hacia el techo. Hatcher no hace referencia a la sección inferior y asigna la sección media a las Mayer River Beds. La última parte correspondería a las Areniscas Abigarradas de Ameghino (1890).

La estratigrafía que hoy se conoce para la región (figura 3.1) se compone del Complejo El Quemado, La Formación Río Mayer y la Formación Arroyo Potrancas (Arbe, 1989; 2002). 


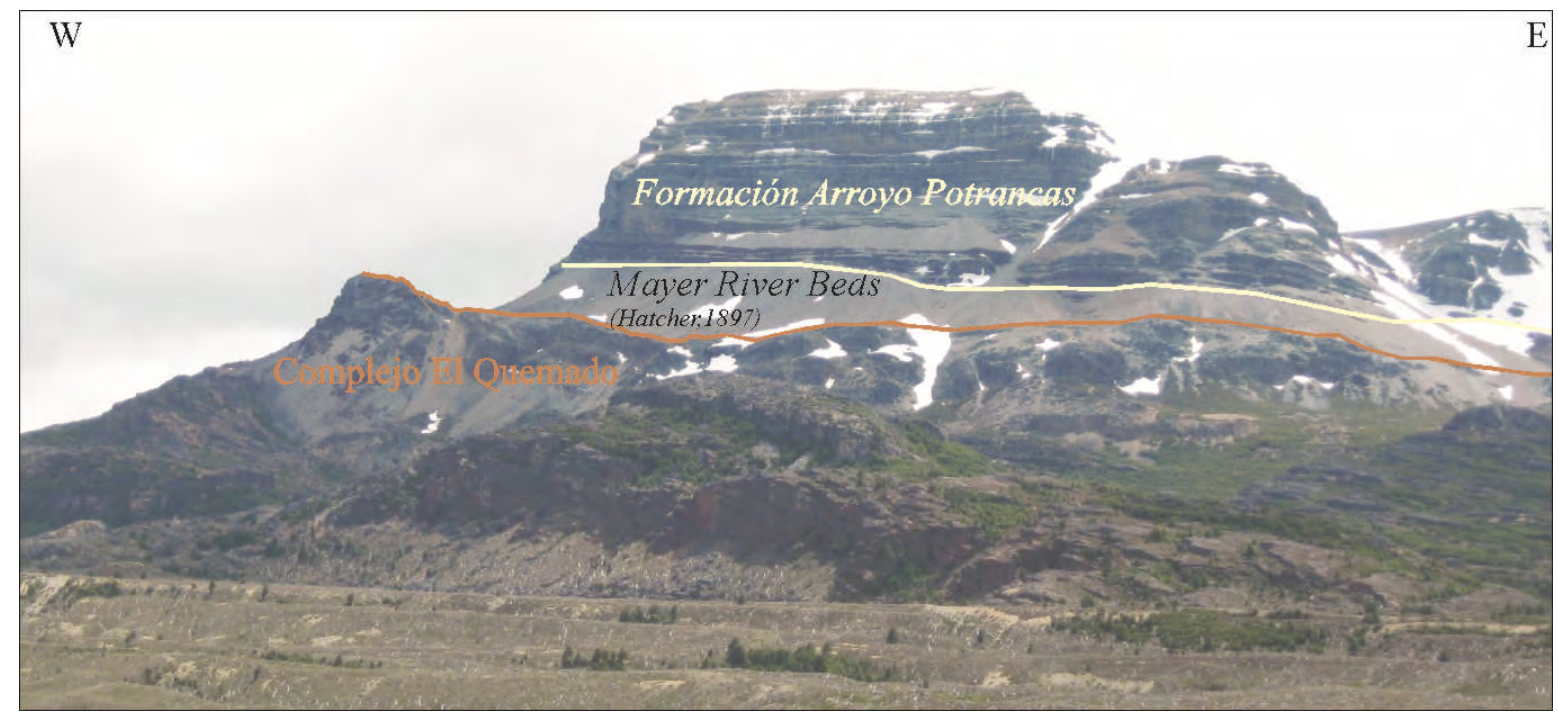

Figura 3.1- Foto de la Loma Pelada. La parte inferior corresponde al Complejo El Quemado. La parte central es la Formación Río Mayer y la superior es la Formación Arroyo Potrancas.

\section{3 - Sector entre los lagos San Martín y Viedma}

En la región más septentrional del área de estudio (figura 1.2) se llevaron a cabo tareas de perfilaje sedimentológico de detalle que dieron como resultado la confección de 4 secciones, tres de las cuales se encuentran en la Bahía de la Lancha y una en la Ea. La Vega (Figuras 3.2; 3.3; 3.4).

\section{3.1 - Bahía de la Lancha - Lago San Martín}

Se realizó el levantamiento de tres perfiles a escala 1:100 en cercanías de las estancias La Lila, La Federica y Kachaike en los alrededores de la Bahía de La Lancha (Figura 3.2). Dichos perfiles se encuentran aflorando en una estructura homoclinal que inclina hacia el sudeste. Esta característica de la estructura permitió el análisis de la estratigrafía comprendida entre el basamento de la Formación Bahía de La Lancha y la Formación Kachaike. 


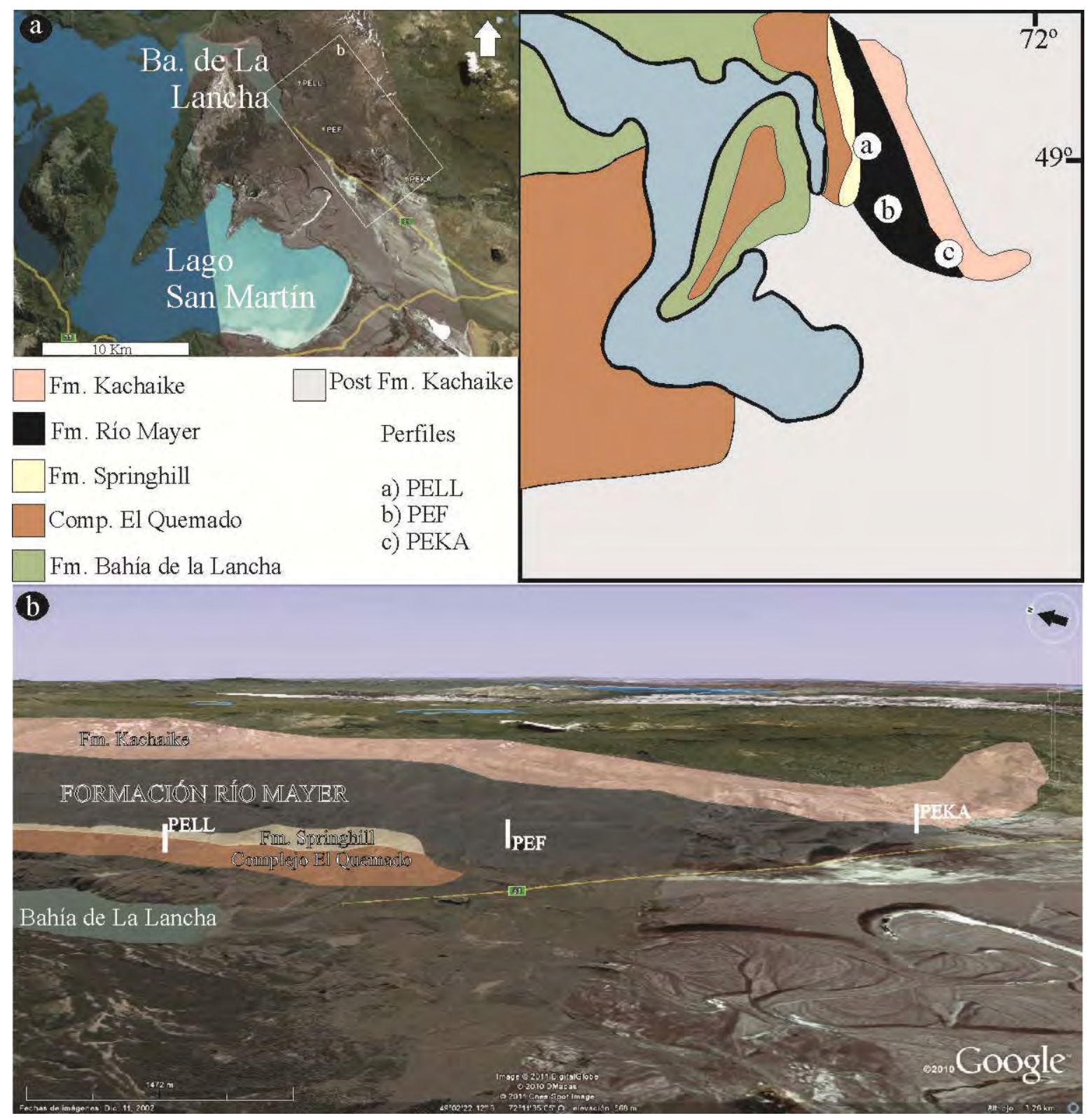

Figura 3.2- a) Mapas de ubicación y geológico de las secciones en la Bahía de La Lancha. b) Imagen Google de la región de la Bahía de La Lancha. Se puede observar la ubicación de los perfiles con respecto a la distribución de las unidades.

III. 3.1.1 - Perfil Estancia La Lila -PELL- (Figuras 3.2; 3.3; 3.5; 3.7)

El perfil se inicia con rocas metamórficas correspondientes a la Formación Bahía de la Lancha, sigue con el Conglomerado Arroyo de la Mina y posteriormente el Complejo El Quemado. Sobre estas tres unidades se deposita una alternancia de areniscas y pelitas, ricas 
en briznas vegetales, madera petrificada y material carbonoso. Estos depósitos corresponderían al inicio de la Formación Springhill (comúnmente conocido como Springhill continental). Arriba se encuentran unos 10 metros de areniscas medianas a gruesas que en la base poseen una rica icnofauna compuesta por los icnogéneros Arenicolites, Cylindrichnus, Ophiomorpha, Planolites, Rosselia y Skolitos (Poiré y Franzese, 2008). Hacia el final de este paquete arenoso es evidente la impregnación con hidrocarburos. Estos depósitos corresponderían al informalmente denominado Springhill marino. Continúan pelitas negras laminadas en las que alternan 2 niveles de areniscas y una caliza muy fosilíferos, conteniendo belemnites y bivalvos principalmente, junto a posibles fragmentos de amonites. Estos últimos depósitos, comenzando en las pelitas negras, corresponderían a la Formación Río Mayer. En la muestra PELL 8 se determinó la presencia de Olcostephanus sp. de edad Valanginiana.

\section{3.1.2 - Perfil Estancia La Federica -PEF- (Figuras 3.2; 3.3; 3.5; 3.7)}

El perfil no posee base expuesta. Se inicia con unos 10 metros de pelitas negras, en general masivas, con un nivel de marga y uno de areniscas finas de espesores entre 0,30 y 0,50 metros. Se encontraron restos de amonites y belemnites. La sección se ve interrumpida por un filón capa de la Essexita Río Carbón (Eoceno-Oligoceno; Riccardi, 1987) de unos 10 a 20 metros de espesor. Continúan unos 130 metros de pelitas negras bien laminadas con intercalaciones de margas a modo de niveles de unos decímetros como máximo o bien como concreciones. Los primeros 20 metros son muy fosilíferos, recuperándose gran cantidad de amonites. Luego hay unos 45 metros que carecen de material fósil, nuevamente unos 20 metros con abundante material y los 45 metros finales sin fósiles. Todo el perfil corresponde a la Formación Río Mayer. En la muestra PEF 9 se hallaron Favrella americana (Favre) y Belemnopsis sp. ambos indicativos del Hauteriviano inferior. En la muestra PEF 18 se recuperaron Pseudohatchericeras argentinense (Stanton) y Hatchericeras semilaeve (Leanza) ambos de edad Barremiana temprana. Finalmente en el último tramo del perfil se halló Emericiceras sp. (Barremiano). 
III. 3.1.3 - Perfil Estancia Kachaike -PEKA- (Figuras 3.2; 3.4; 3.5; 3.7)

El perfil no posee base expuesta. Se compone principalmente de unos 75 metros de sedimentitas finas en donde alternan pelitas negras laminadas, pelitas grises a verdes en general masivas, heterolíticas pelíticas y arenosas de tonalidades variables y areniscas de finas a gruesas de espesores siempre menores al metro de potencia. Domina la alternancia muy fina de pelitas y areniscas en proporciones variables (ver facies heterolíticas -capítulo IV-). Pese a que todo el perfil se desarrolla en ambiente marino, el contenido fósil es exclusivamente vegetal, compuesto por briznas, madera petrificada y material carbonoso.

Por arriba se evidencia un cambio en las coloraciones y se pasa de areniscas con tonalidades grises a areniscas amarillentas. Esta última litología se vuelve dominante y forma estratos de espesores mayores a 10 metros.

La primer parte en la descripción del perfil correspondería a la transición entre las formaciones Río Mayer y Kachaike, mientras que la parte superior es con seguridad la Formación Kachaike.

\section{3.2 - Entre Lagos San Martín y Viedma}

Para esta región se realizó el levantamiento de un perfil sedimentológico de detalle en la Estancia La Vega -PELV- (S 49²2’21,5’’; W 71² 47’34,9’’; Figuras 1.2; 3.4; 3.6; 3.7).

El perfil no posee base expuesta, se compone principalmente de pelitas negras laminadas en las que intercalan niveles de pelitas y areniscas margosas, calizas y areniscas de unos 0,30 a 1 metro de espesor. La Fm. Río Mayer pasa en transición a la suprayacente Fm. Piedra Clavada.

El contenido fósil se compone de gasterópodos y bivalvos principalmente. Además hay abundantes briznas vegetales y madera petrificada. Se reconocieron trazas fósiles, habiendo Teredolites isp. en los troncos y Gyrolithes isp. 


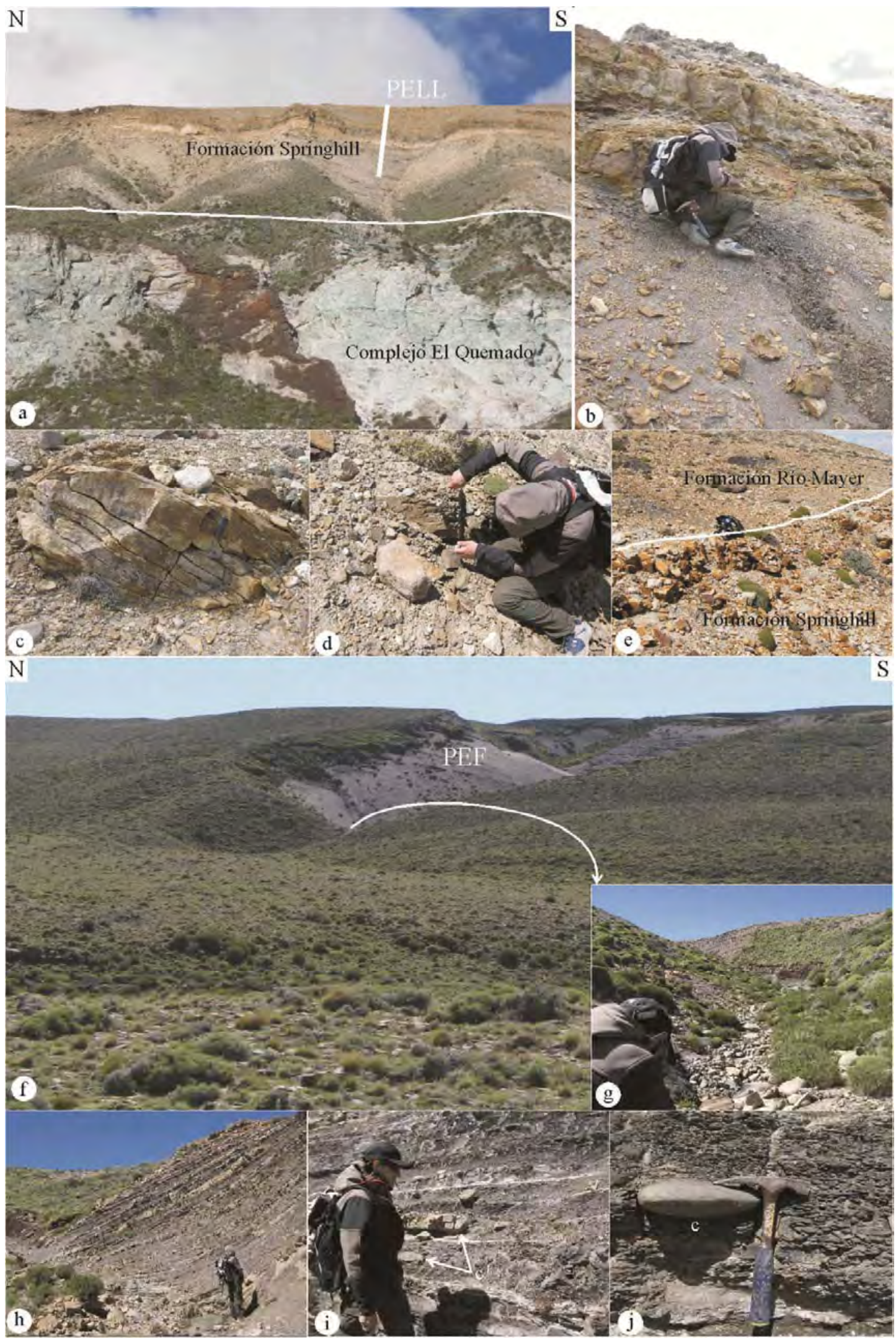

Figura 3.3- a)Vista panorámica del perfil en Ea. La Lila. b) Pelitas negras y areniscas de la Fm. Springhill. c) Areniscas entrecruzadas con impregnación de hidrocarburos y d) Arenisca masiva, Fm. Springhill. e) Limite entre las formaciones Springhill y Rio Mayer.

f-g) Vista panorámica del perfil en Ea. La Federica. h) Intercalación de pelitas negras y margas en la Fm. Río Mayer. i-j) Detalle de las concreciones margosas. 


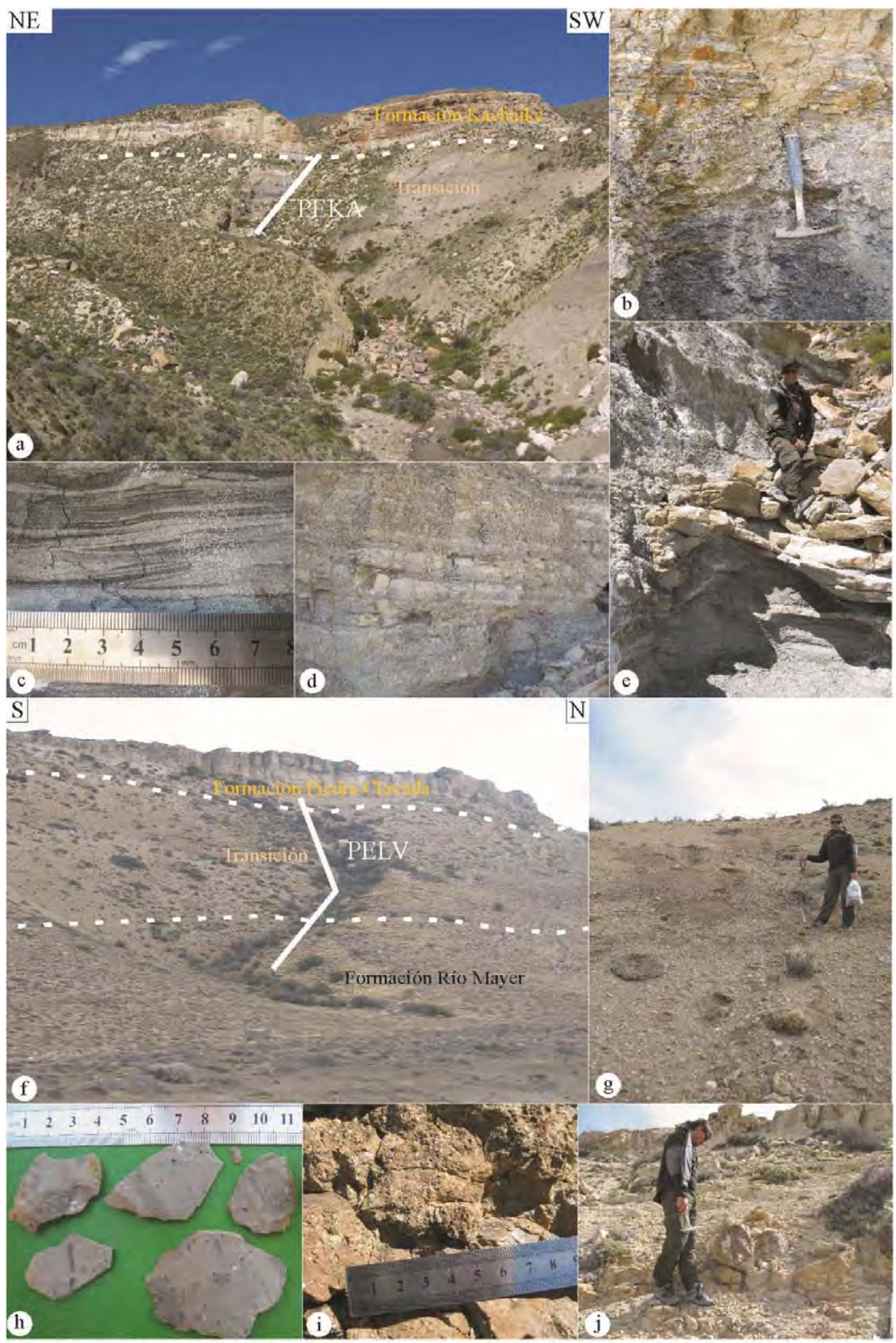

Figura 3.4- Vista panorámica del perfil en Ea. Kachaike. b-c-d) Intercalación de pelitas negras y areniscas, transición entre Fm. Río Mayer y Fm. Kachaike. e) Primer nivel de areniscas amarillentas de Fm. Kachaike. $\mathrm{f}$ - g) Vistas panorámicas del perfil en Ea. La Vega. h) Pelitas grises con briznas vegetales, transición entre Fm. Río Mayer y Fm. Piedra Clavada. i) Arenisca sabulítica con bivalvos, transición. j) Arenisca con troncos fósiles, Fm. Piedra Clavada. 


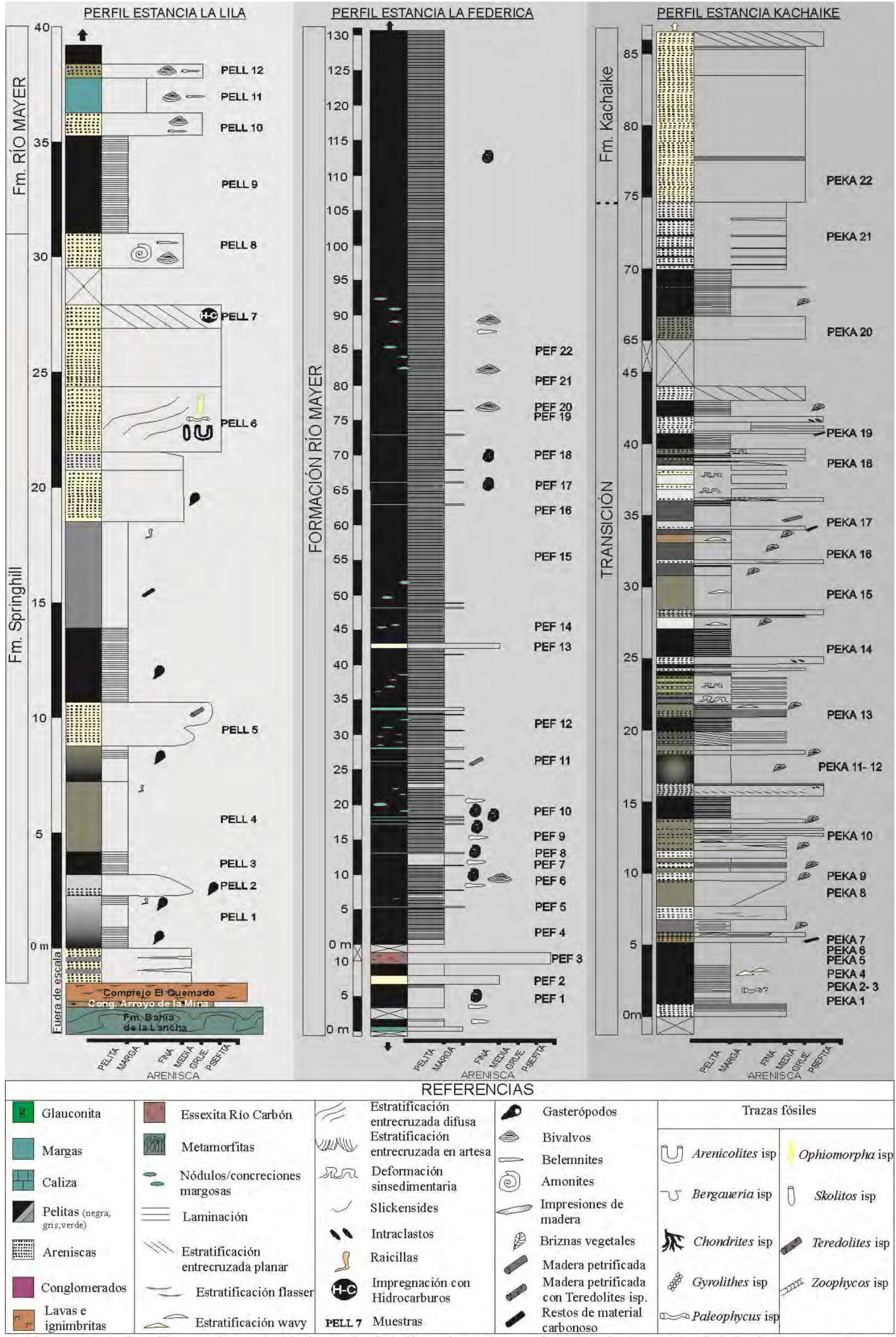

Figura 3.5- Perfiles sedimentológicos de detalle relevados en los alrededores de Bahía de La Lancha, 


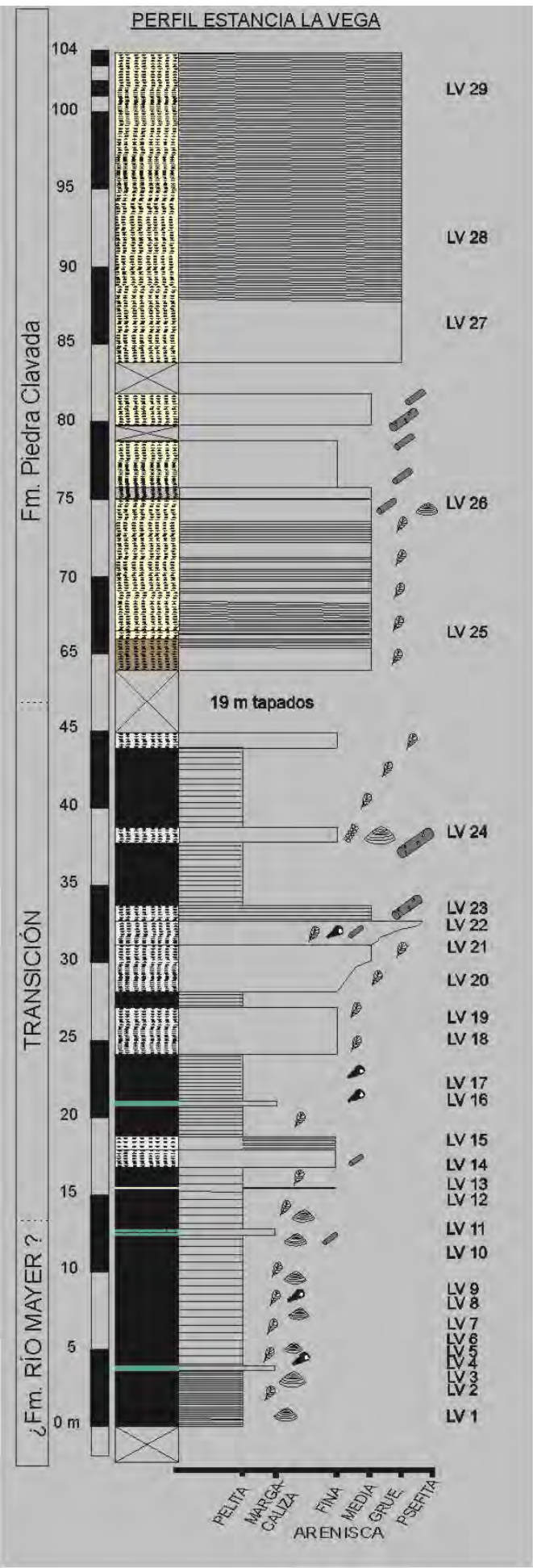

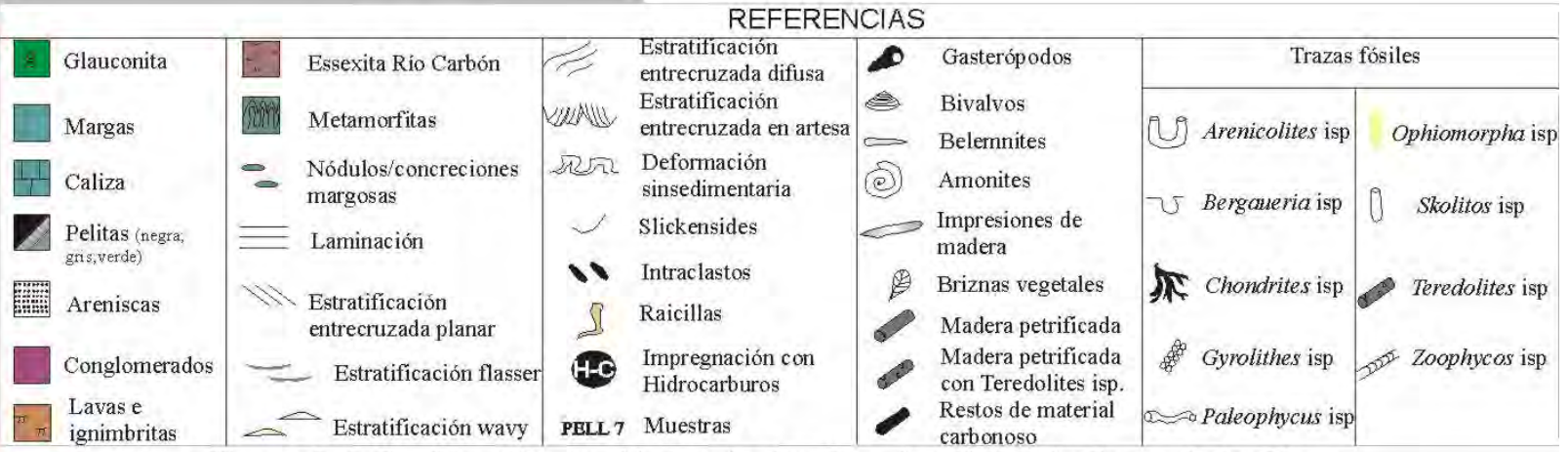

Figura 3.6- Perfíl sedimentológico de detalle relevado en la Estancia La Vega. 


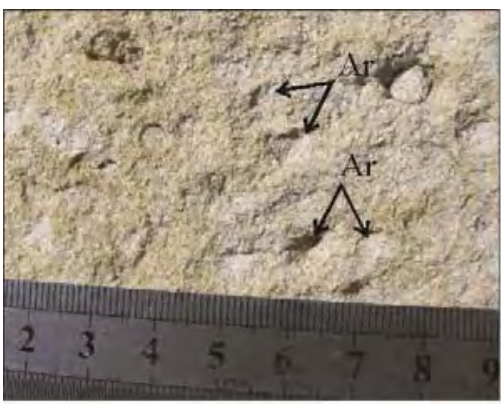

Icnogénero Arenicolites. Perfil ELL

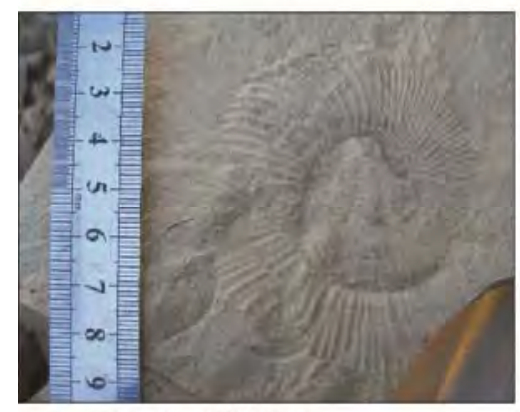

Amonite. Perfil ELF

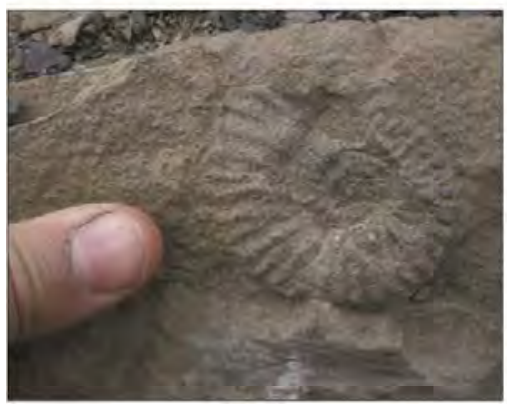

Amonite. Perfil ELF

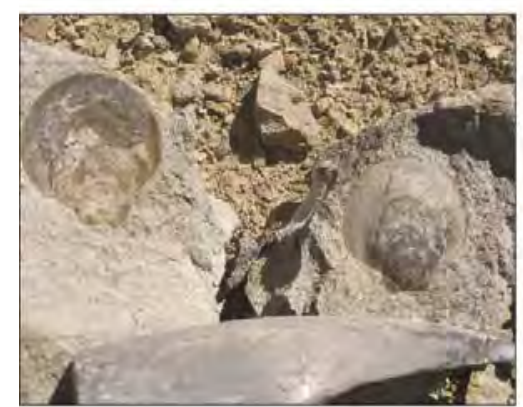

Bivalvos pectínidos. Perfil ELV

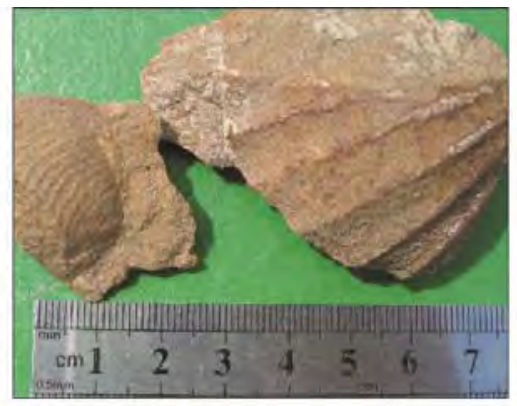

Bivalvos trigónidos. Perfil ELL

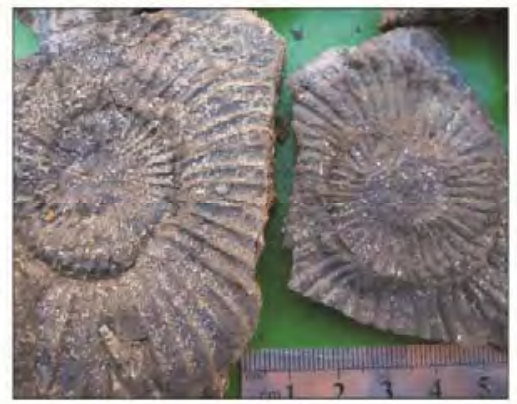

Amonite. Perfil ELF

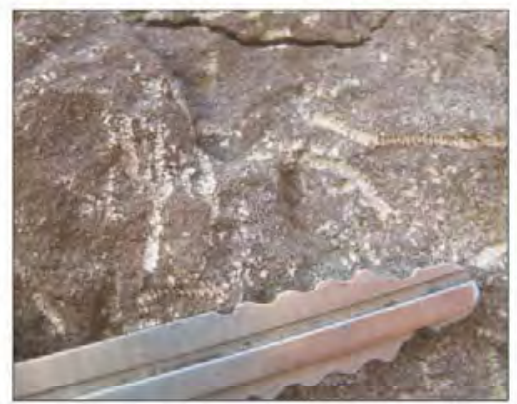

Icnogénero Gyrolithes. Perfil ELV

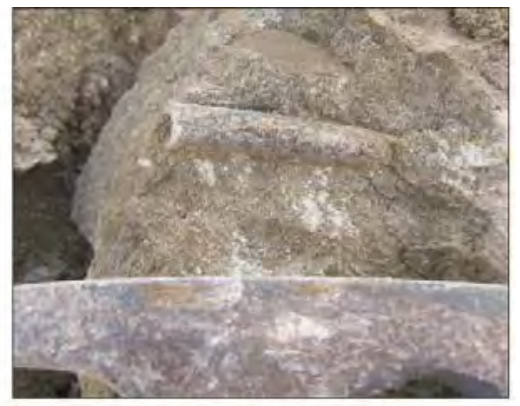

Belemnite. Perfil ELL

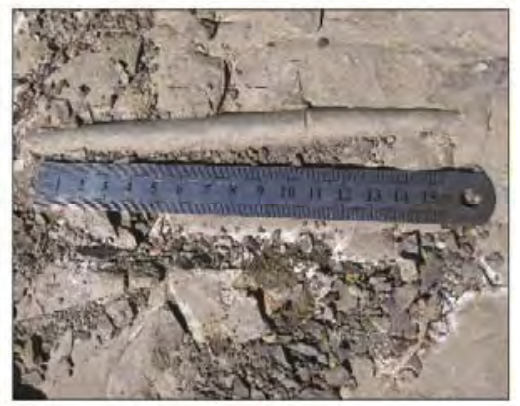

Belemnite. Perfil ELF

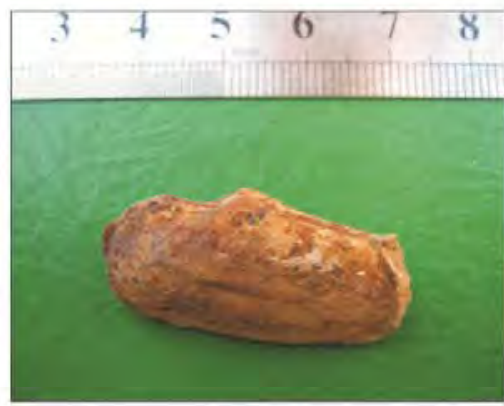

Molde interno de un bivalvo. Perfil ELV

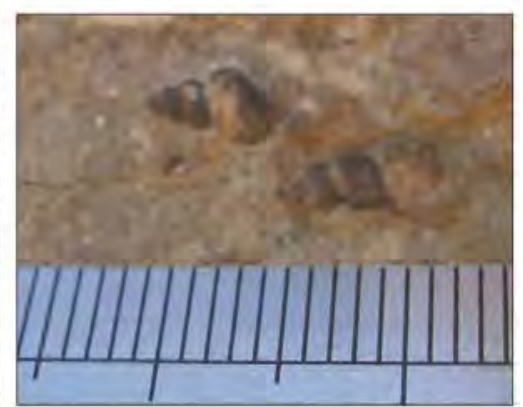

Madera petrificada con Teredolites Gasterópodos. Perfil ELV isp. Perfil ELV

Figura 3.7- Material fósil reconocido en los perfiles de la región entre los lagos San Martín y Viedma. 
III. 3.3 - Síntesis de la Región entre los lagos San Martín y Viedma

Para esta región se relevaron cuatro perfiles de detalle, ninguno posee la base y el techo de la unidad estudiada en un mismo perfil. Pese a esto, algunas observaciones preliminares pueden ser realizadas:

$>\quad$ La Formación Río Mayer se apoya en concordancia sobre la Formación Springhill, quedando marcado por la aparición de las primeras pelitas negras marinas.

$>\quad$ El desarrollo principal de la Formación Río Mayer se encuentra en el perfil de Ea. La Federica (PEF), correspondiéndose estos depósitos con los tradicionalmente citados para esta unidad.

$>\quad$ El paso de la Formación Río Mayer hacia las formaciones Kachaike y Piedra Clavada es transicional, estando caracterizado por la alternancia de areniscas y pelitas, ricas en materiales fósiles de origen vegetal. 


\section{4 - Sector Seccional Río Guanaco}

En la zona de los alrededores de las nacientes del Río Guanaco se confeccionaron siete perfiles sedimentológicos de detalle a escala 1:100 (Figuras 1.2; 3.8).

Los perfiles son:

1- Perfil Inicio del Graben (IG), S 49 54’ 29.8'’; W 72 51’ 47’’

2- Perfil Pliegue Guanaco (PG), S 4954' 29.8'’; W 72 51' 47’’

3- Perfil Este de Vega de Pérez 1 (EVP 1), S 49 58' 36.5'”; W 72 49’ 45.1',

4- Perfil Este de Vega de Pérez 2 (EVP 2), S 49 57’ 16.7’’; W 72º 49’ 48.3’’

5- Perfil Oeste de Vega de Pérez (WVP), S 49 57’ 11.1’’; W 72 51’ 59’’

6- Perfil Este de Cerro Pintado (ECP), S 49 54' 20’'; W 72 50’ 40’,

7- Perfil del Cerro Establo (CE), S 49 55’ 39’’; W 72 50’ 02’’
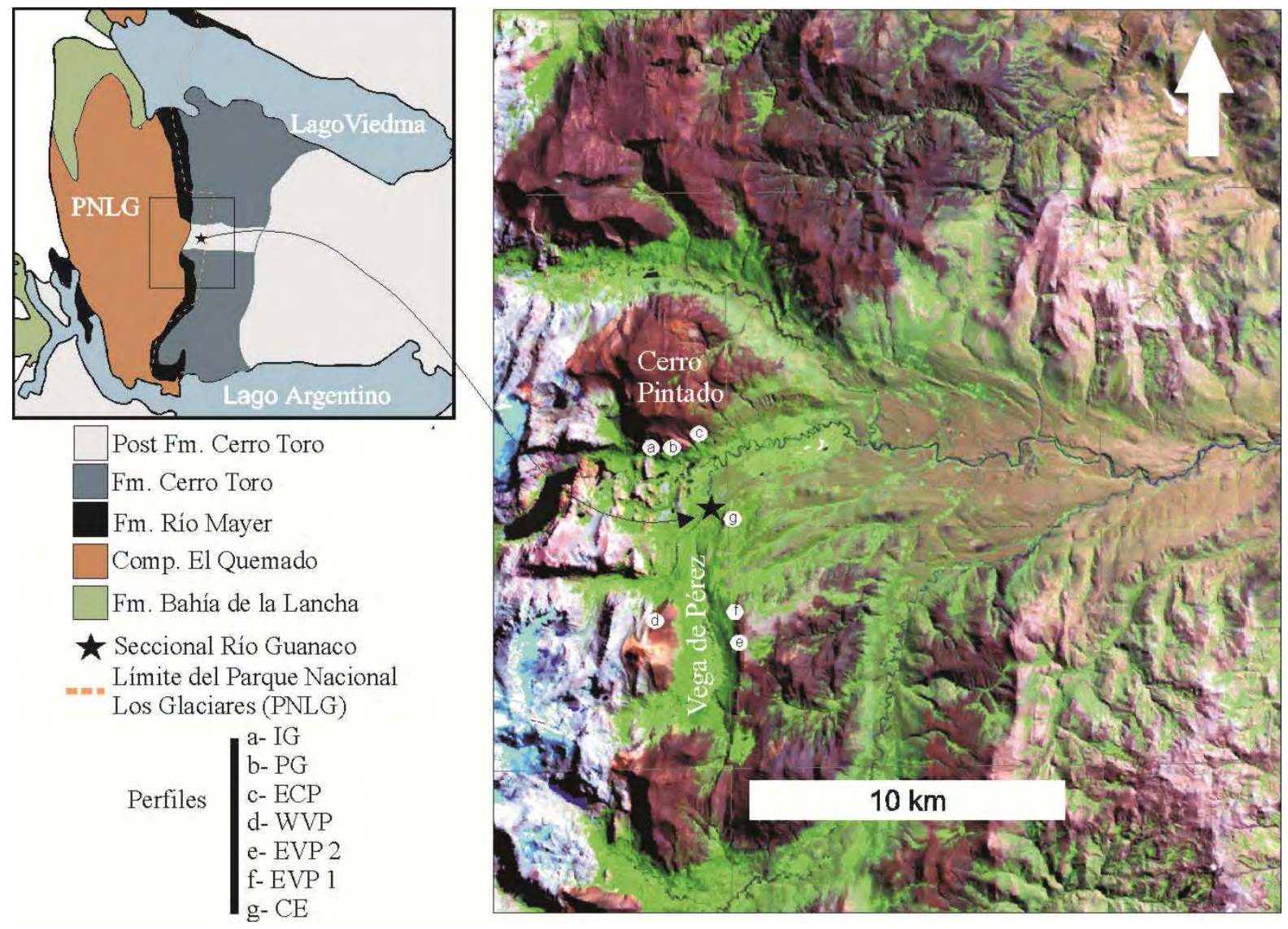

Figura 3.8- Mapa de distribución de los afloramientos de la Formación Río Mayer en el área de las Nacientes del Río Guanaco. Ubicación de los perfiles. 
III. 4.1 - Perfil Inicio del Graben -PIG- (Figuras 3.8; 3.9; 3.10; 3.11)

Este perfil se encuentra en un hemigraben desarrollado en el Complejo el Quemado. El relleno inicial de la estructura extensional tiene unos 15 metros, constituido por areniscas y areniscas sabulíticas que finalizan con un nivel carbonático de 0,30 m. Luego de manera concordante continua la Fm. Río Mayer con unos 67 metros de pelitas negras bien laminadas o en bancos masivos de 0,20 a 0,40 m. Alternan niveles de margas en bancos o concreciones.

El contenido fósil es abundante constituido principalmente belemnites, los cuales están acompañados por bivalvos y en ocasiones impresiones de amonites mal conservados. No se registraron trazas fósiles. Entre las muestras IG 34 e IG 43 se reconoció una fauna de Belemnopsis sp. de edad Valanginiano - Hauteriviano.

III. 4.2 - Perfil Pliegue Guanaco -PPG- (Figuras 3.8; 3.9; 3.10; 3.11)

El perfil se encuentra en una posición estratigráfica superior al perfil IG. La base no se encuentra expuesta, y se inicia con unos 8 metros de pelitas negras laminadas en las que intercala un nivel de arenisca fina de geometría lenticular. Luego de manera neta aparecen unos 35 metros de margas que poseen abundantes trazas fósiles. Antes de la finalización de la sedimentación mixta se desarrolla un nivel de erosión y retrabajo. Luego se encuentra un estrato de $1 \mathrm{~m}$ de arenisca fina a media internamente masivo, a partir del cual cambia el desarrollo del perfil. Cinco metros arriba de la finalización de las trazas fósiles hay un nivel de glauconita. El perfil termina con 40 metros de pelitas negras laminadas con frecuentes intercalaciones de areniscas finas masivas y facies heterolíticas de poco espesor (hasta 0,30 $\mathrm{m})$.

El contenido fósil es abundante incluyendo principalmente los icnogéneros Bergaueria, Chondrites y Zoophycos, en menor medida Thalassinoides, además de belemnites, bivalvos e impresiones de amonites. Todo el perfil corresponde a la Formación Río Mayer. En la muestra PG5 se halló el microfósil Watznaueria británica de edad Valanginiano superior - Hauteriviano inferior. 
III. 4.3 - Perfil Este de Cerro Pintado -PECP- (Figuras 3.8; 3.9; 3.10; 3.11)

Este perfil posee 70 metros y se compone exclusivamente de pelitas negras laminadas. No hay base ni techo expuesto.

El contenido fósil no es abundante. Hay escasas trazas fósiles, pocos belemnites, bivalvos e impresiones de amonites. Todo el perfil corresponde a la Formación Río Mayer. 


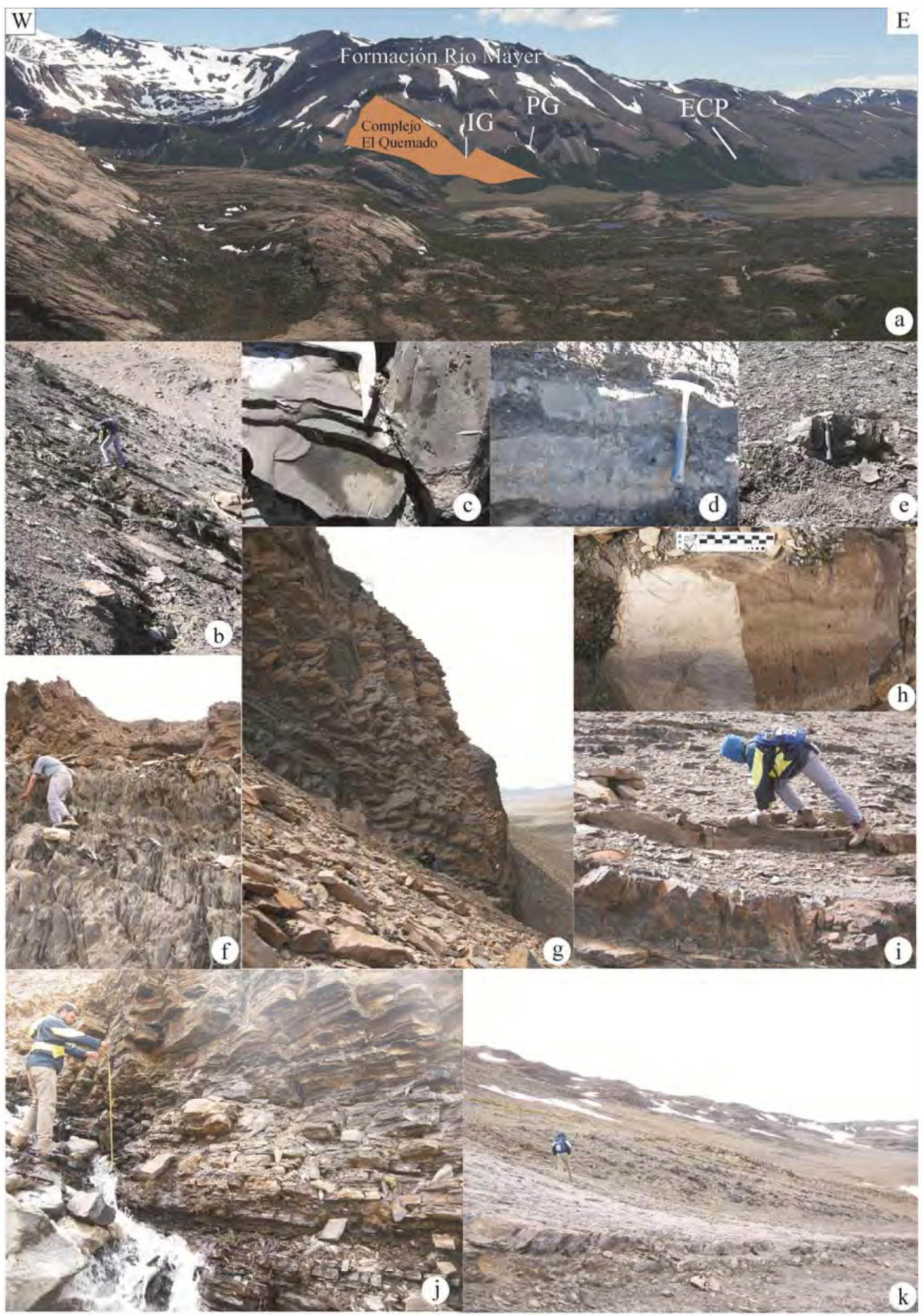

Figura 3.9- a) Vista panorámica de los perfiles en el Cerro Pintado. b - c) Pelitas negras en el perfil IG. d - e) Margas en el perfil IG en bancos y concreciones respectivamente.

f) Pelitas negras en el perfil PG. g) Niveles de margas en el perfil PG (35 metros aprox.). h) detalle de las margas muy bioturbadas. i) Nivel de arenisca en el perfil PG.

$\mathrm{j}-\mathrm{k}$ ) Vistas de las pelitas negras laminadas en el perfil ECP. 


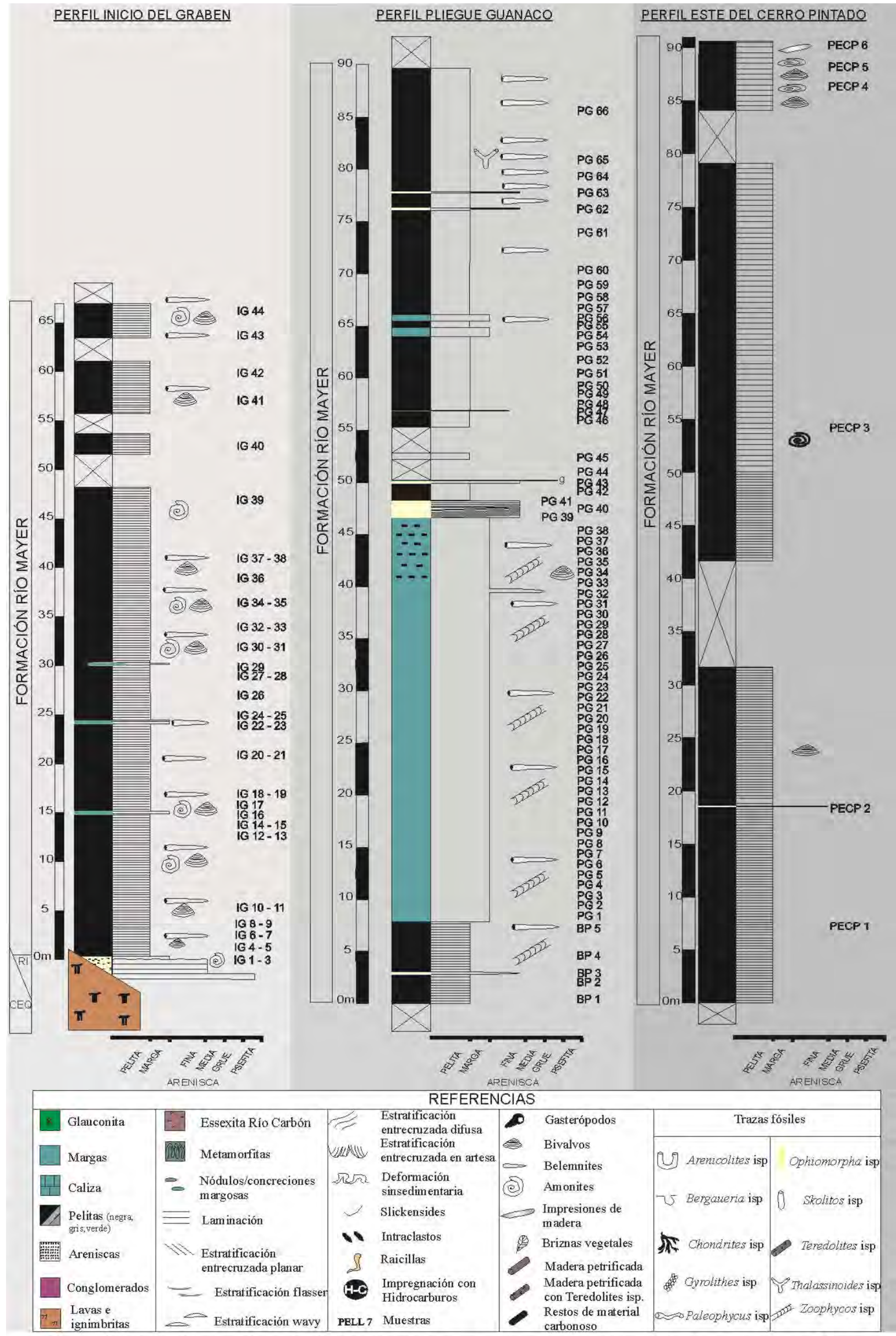

Figura 3.10- Perfiles sedimentológicos de detalle relevados en el Cerro Pintado, alrededores de la 


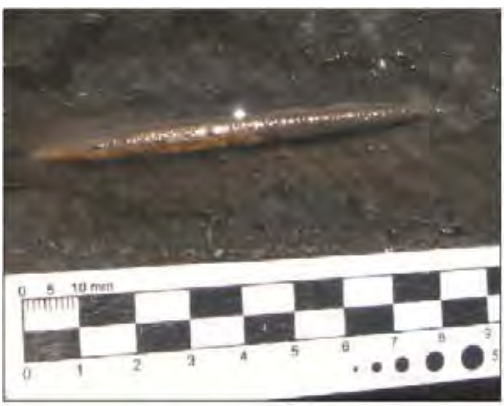

Belemnite. Perfil IG

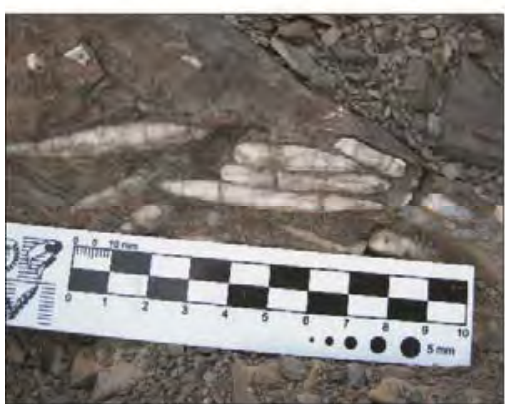

Concentración de belemnites. Perfil PG

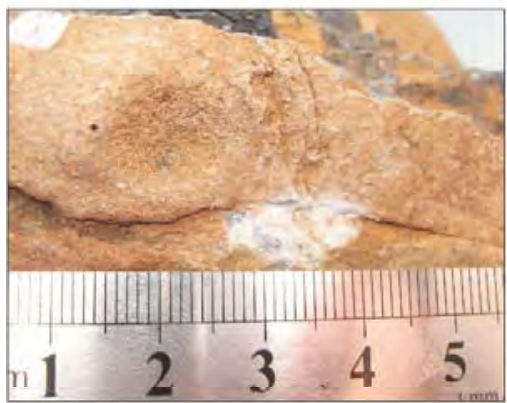

Icnogénero Bergaueria. Perfil PG

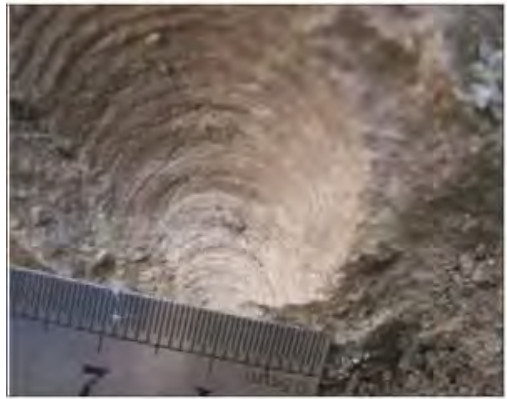

Impresión de bivalvo indet. Perfil ECP

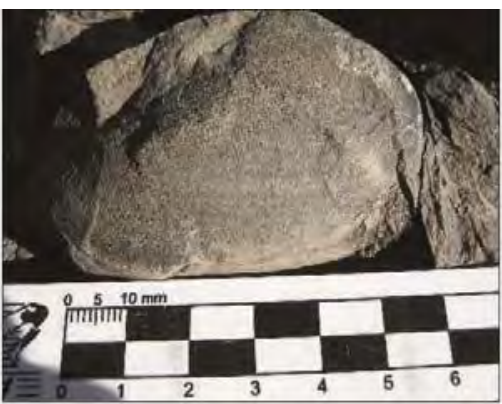

Bivalvo, se observa en la superficie externa la presencia de briozoos. Perfil IG

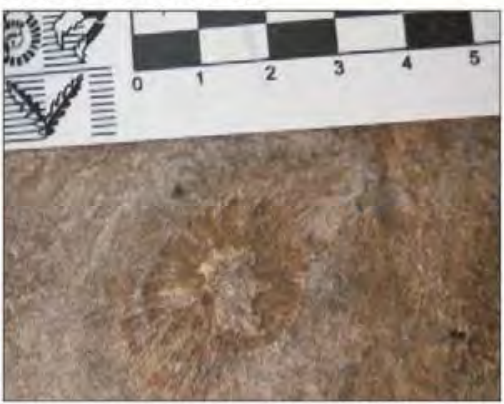

Impresión de amonite. Perfil PG

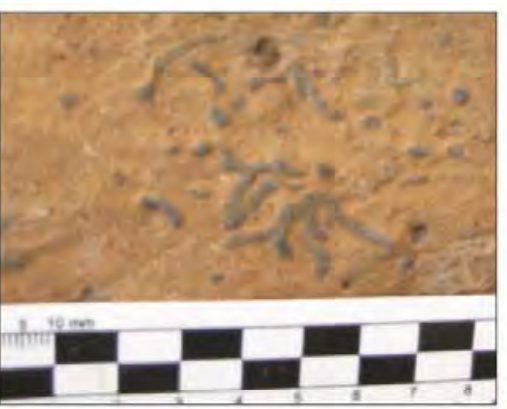

Icnogénero Chondrites. Perfil PG

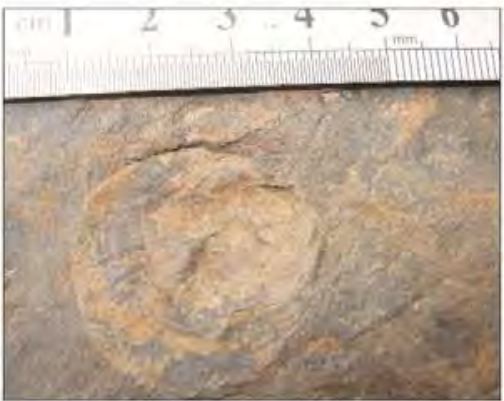

Impresión de bivalvo indet. Perfil ECP

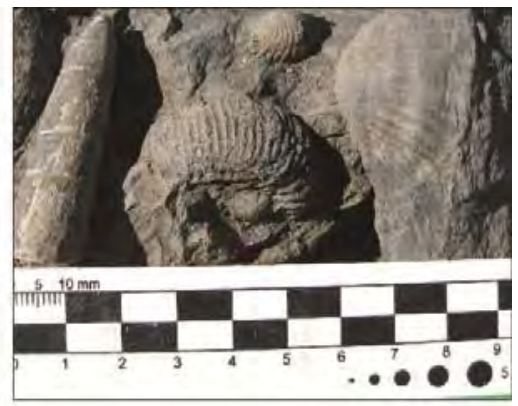

Contenido fósil general del Perfil IG. Belemnites, amonites y bivalvos.

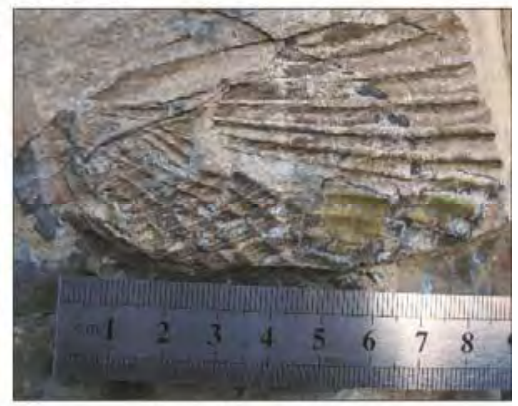

Bivalvo trigónido. Perfil PG

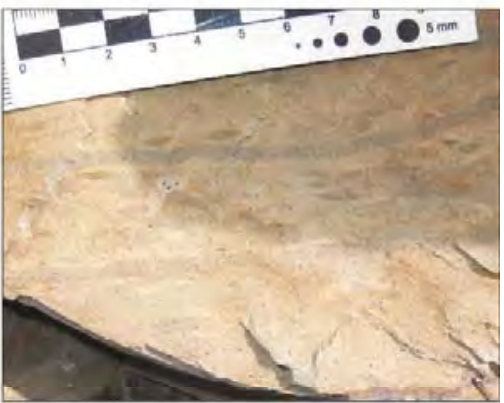

Icnogénero Zoophycos. Perfil PG

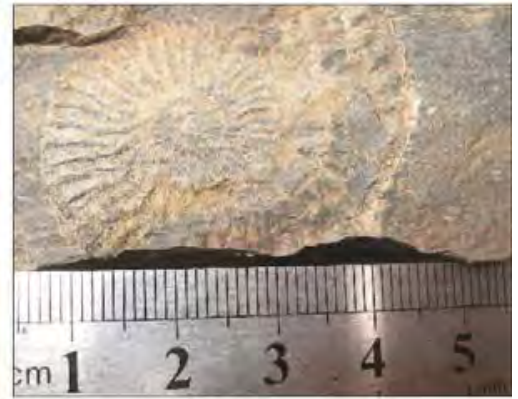

Impresión de amonite. Perfil ECP

Figura 3.11- Material fósil reconocido en los perfiles del Cerro Pintado en la Seccional Río Guanaco. 
III. 4.4 - Perfil Oeste de Vega de Pérez -PWVP- (Figuras 3.8; 3.12; 3.13; 3.15)

En la sección que aflora al oeste de la Vega de Pérez se encuentra el Complejo el Quemado y por encima unos 40 metros de areniscas y areniscas sabulíticas que rellenan un hemigraben. La primera parte de la Fm. Río Mayer está cubierta, se compone al menos de 70 metros de pelitas muy mal afloradas sobre las cuales es imposible hacer estudios de detalle. Los primeros afloramientos bien conservados consisten en 20 metros de pelitas negras margosas en bancos de 0,15 a 0,50 m con abundantes trazas fósiles. Luego siguen pelitas negras sin trazas fósiles que a los 5 metros aproximadamente están cortadas por un conglomerado con intraclastos de hasta 0,05 m. En la base del conglomerado hay glauconita. El perfil continúa con unos 60 metros de pelitas negras con escasas intercalaciones de niveles arenosos de hasta $1 \mathrm{~m}$ de espesor.

El contenido fósil es abundante en trazas del icnogénero Zoophycos, con menor participación de belemnites, bivalvos e impresiones de amonites. En los últimos metros del relleno inicial de los hemigrábenes (Formación Springhill) se encontraron amonites cerca del contacto con la Formación Río Mayer los cuales se asemejan a los descriptos por Kraemer y Riccardi (1997) para la misma localidad asignados a la Formación Springhill de edad Titoniano.

III. 4.5 -Perfiles Este de Vega de Pérez 1 y 2 -PEVP 1 y 2- (Figuras 3.8; 3.12; 3.13; 3.15)

Ambos perfiles afloran al este de la Vega de Pérez, y se encuentran próximos el uno del otro. En general se componen de pelitas negras a verde oliva masivas en bancos de 0,3 a $1 \mathrm{~m}$ de espesor. La característica principal es la abundante cantidad de niveles de areniscas, los cuales poseen de 0,01 a 0,5 m de espesor, en general masivos pero pueden también presentar estructura entrecruzada de pequeña escala. La frecuencia de estos bancos se incrementa hacia el tope del perfil, de modo tal que en la parte superior se pueden reconocer hasta 2 o 3 niveles por metro.

El contenido fósil es abundante en inocerámidos, con menor participación de belemnites, otros bivalvos e impresiones de amonites. Las trazas fósiles son escasas. En estos perfiles además se han encontrado troncos pequeños que incluso presentan Teredolites isp. 
Estos dos perfiles representarían la transición desde la Formación Río Mayer hacia la Formación Cerro Toro. Se recolectó en el perfil EVP1 un ejemplar de Birostrina sp. aff. concentrica de edad Albiano- Cenomaniano.

\section{4.6 - Perfil Cerro Establo -PCE- (Figuras 3.8; 3.14; 3.15)}

A unos 300 metros al este desde la seccional Río Guanaco de Parques Nacionales se encuentra un pequeño cerro con afloramientos de la Formación Río Mayer, el cual no posee denominación en la carta topográfica del IGM y que por la cercanía al establo de dicha seccional hemos decidido nombrarlo de esa manera.

Los afloramientos se aproximan a 80 metros, aunque no poseen base ni techo expuesto. Se componen de pelitas negras, en ocasiones verde oliva oscuro, que afloran en bancos masivos de 0,3 a 0,6 m, con alternancia de areniscas finas masivas de 0,03 a 0,1 m. La característica más importante observada en este cerro es el contenido icnofosilífero. El relevamiento de un perfil de unos 10 metros evidenció la presencia de galerías, en bancos de pelitas, atribuidas al icnogénero Ophiomorpha por debajo de niveles de areniscas. Este hallazgo es importante debido a que muestra un ordenamiento de las trazas fósiles no evidenciado en otros perfiles, ya que unos metros por debajo de las galerías se identificaron niveles con Zoophycos isp y Chondrites isp.

Otros componentes encontrados en este cerro son bivalvos e impresiones de madera, las cuales en ocasiones presentan trazas de Teredolites isp. 

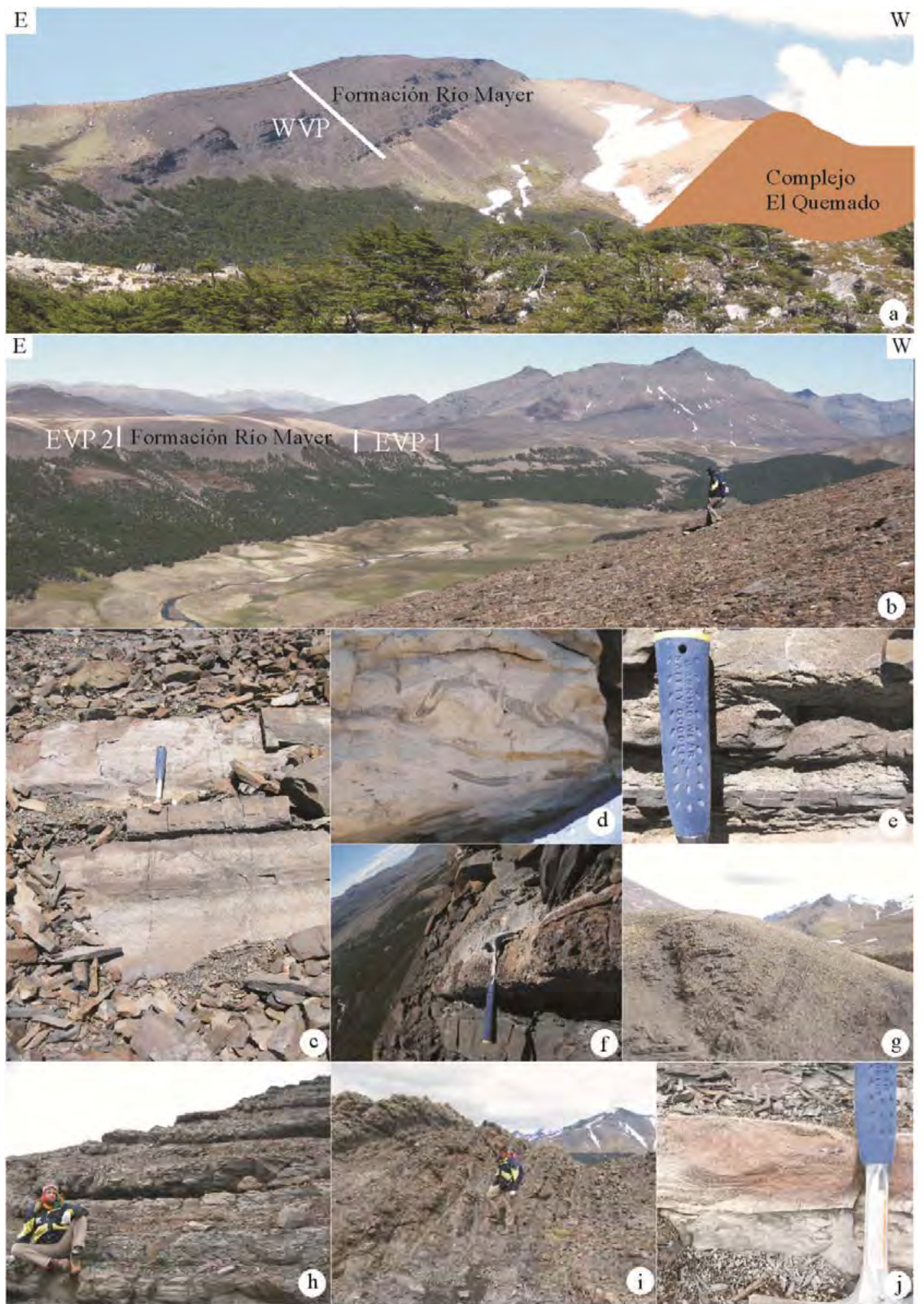

Figura 3.12- a - b) Vistas panorámicas de los perfiles en la Vega de Pérez. c) Niveles de areniscas en el perfil WVP. d) Pelitas margosas con trazas fósiles, perfil WVP. e) Intercalaciones de areniscas y pelitas negras, perfil WVP. f) Nivel de conglomerado en el perfil WVP. $\mathrm{g}-\mathrm{h}$-i) Vistas de los perfiles al este de la Vega de Pérez. j) Nivel de areniscaen el perfil EVP 1. 


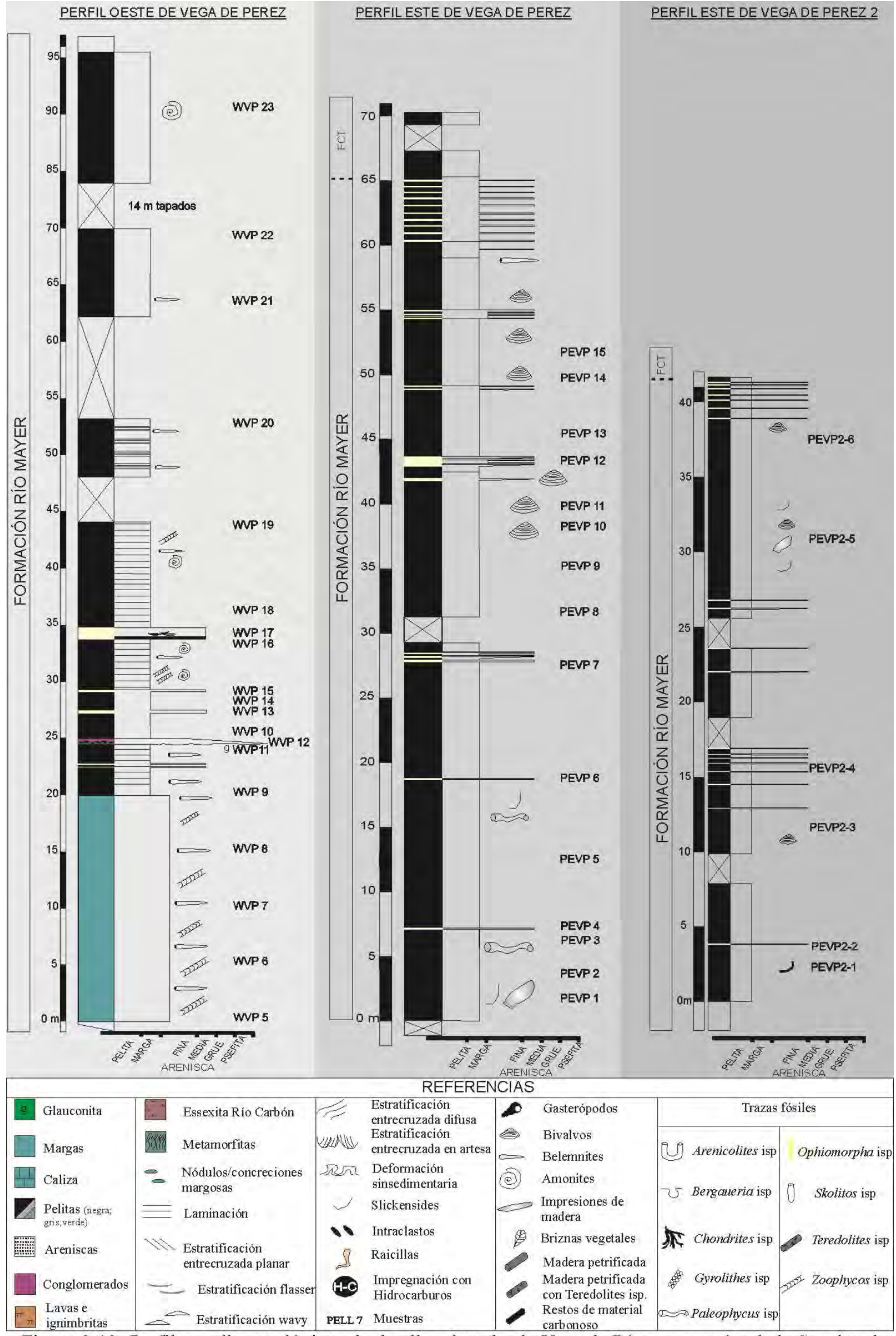

Figura 3.13- Perfiles sedimentológicos de detalle relevados la Vega de Pérez, cercanías de la Seccional Río Guanaco. 


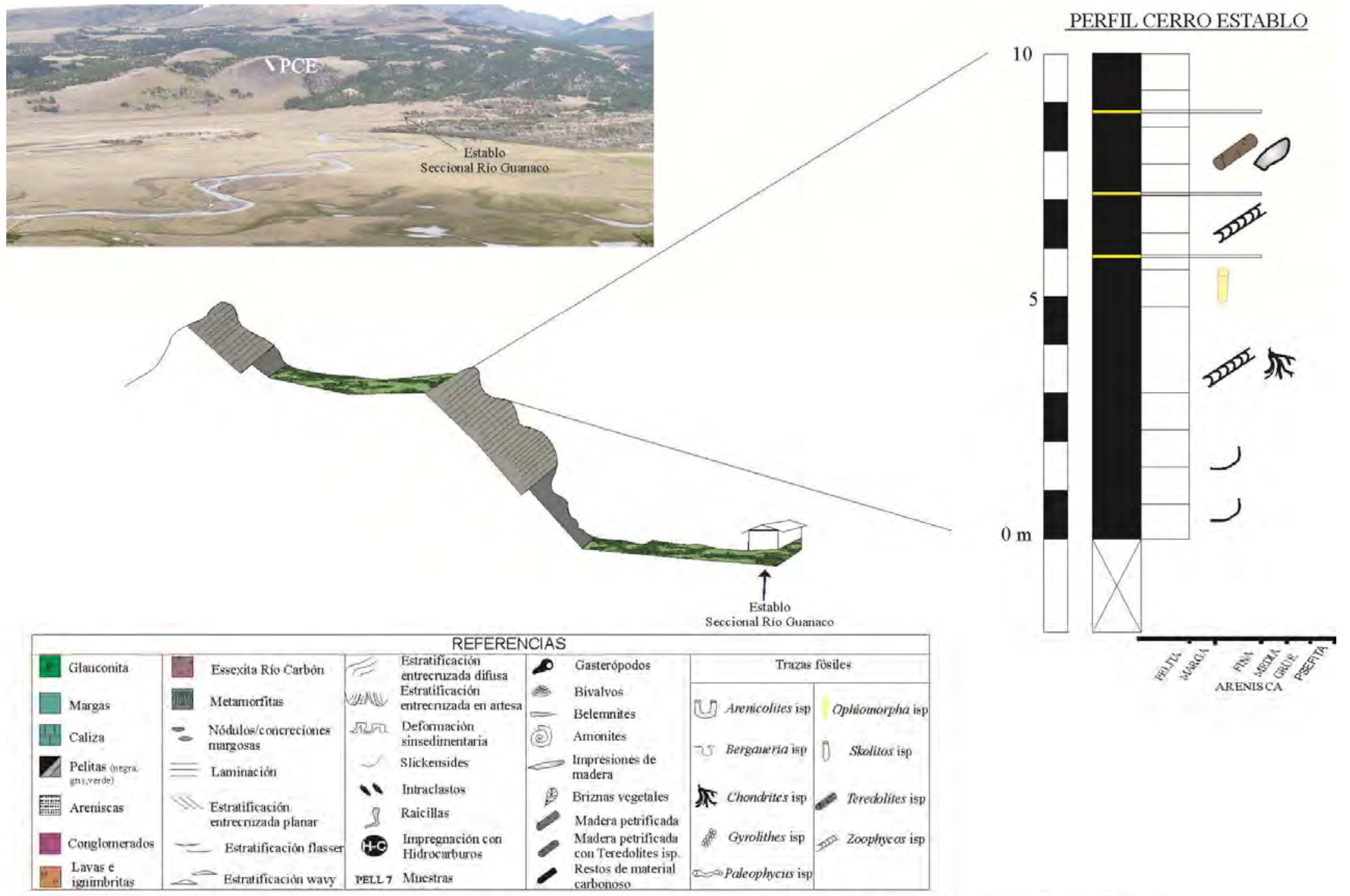

Figura 3.14- Perfil sedimentológico de detalle relevados en el Cerro Establo, alrededores de la Seccional Río Guanaco. 


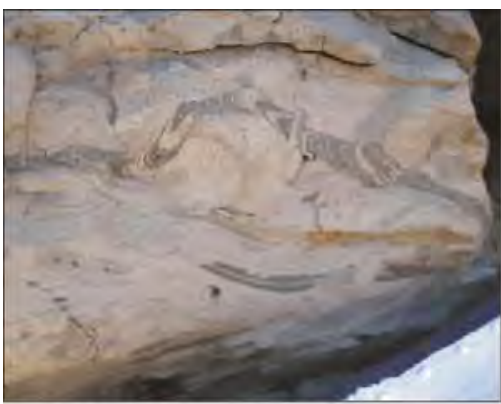

Icnogénero Zoophycos. Perfil WVP

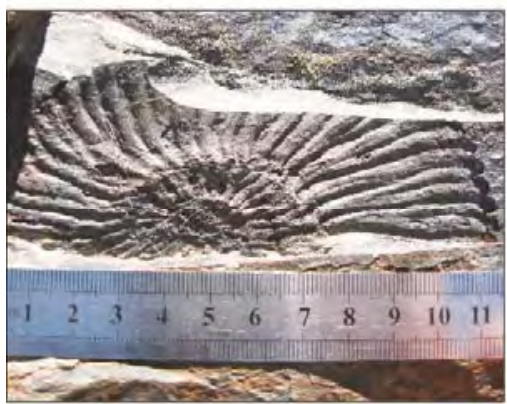

Impresión de amonite. Perfil WVP

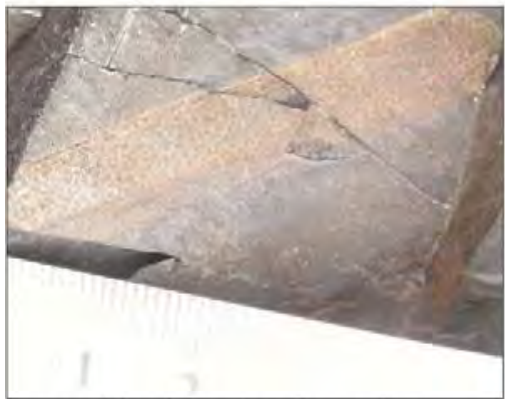

Impresión de restos de madera. Perfil EVP 1

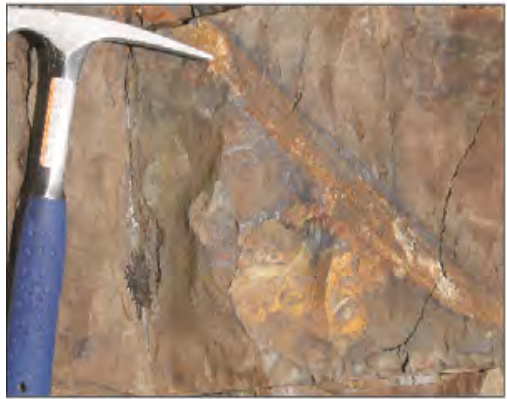

Impresión de restos de madera. Perfil CE

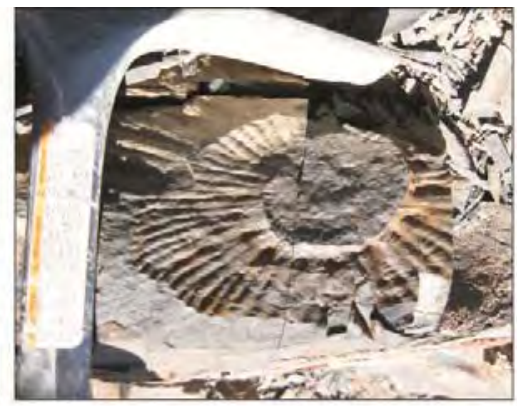

Amonite. Perfil WVP

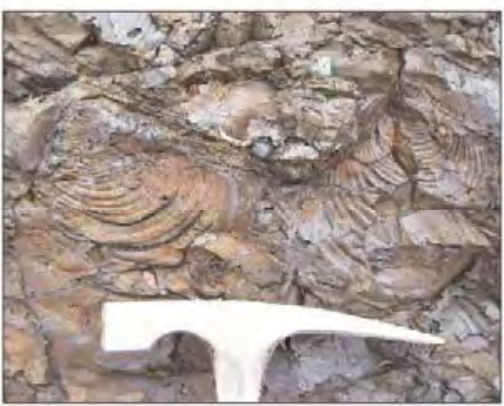

Bivalvos inocerámidos. Perfil EVP 1

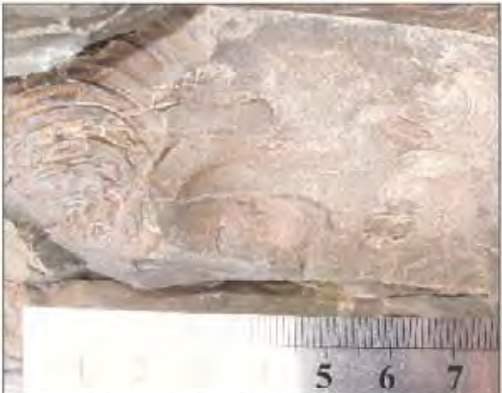

Impresiones de bivalvos varios. Perfil EVP 1

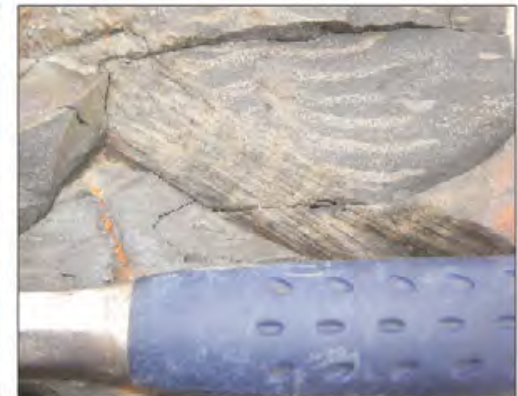

Icnogénero Zoophycos. Perfil CE

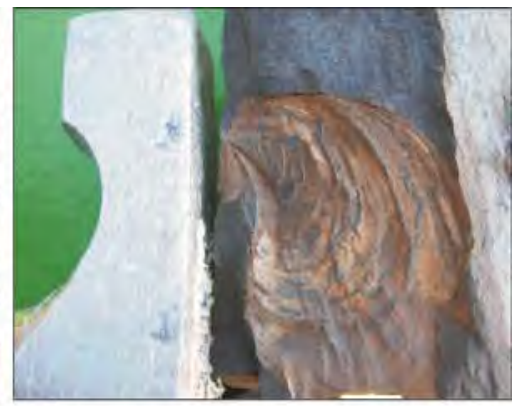

Bivalvo inocerámido. Perfil WVP

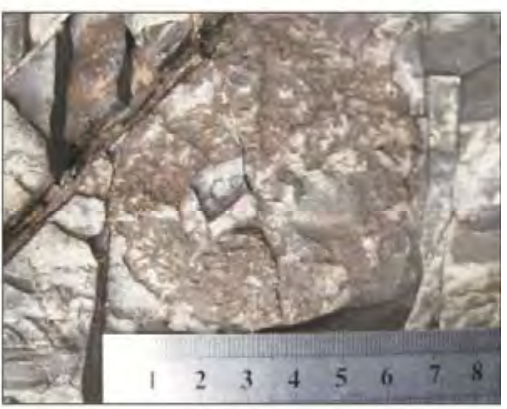

Preservación de la sutura de un amonite. Perfil EVP 1

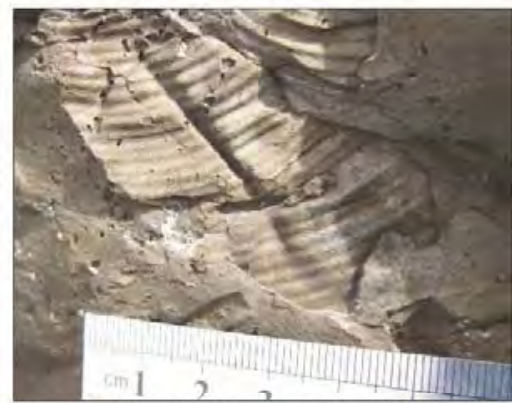

Impresión de bivalvo. Perfil EVP1

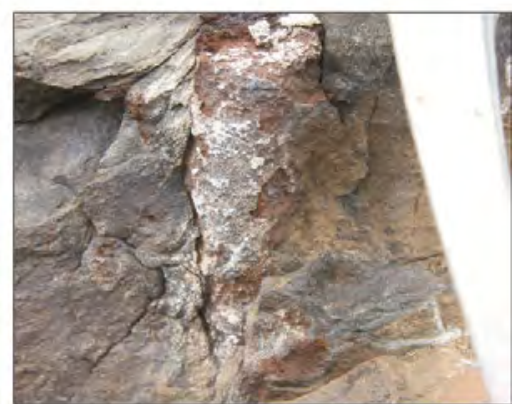

Icnogénero Ophiomorpha. Perfil $\mathrm{CE}$

Figura 3.15- Material fósil reconocido en los perfiles de la Vega de Perez y el Cerro Establo en la Seccional Río Guanaco. 
III. 4.7 - Síntesis de la Región de las Nacientes del Río Guanaco

En el área de estudio no se halló un perfil que contenga tanto la base como el techo de la Fm. Río Mayer, razón por la cual, la información brindada por cada perfil desde el punto de vista de las sedimentológico e icnológico permitió la posterior correlación de las secciones para formar un solo perfil de carácter ideal. Dicho perfil se compone de tres secciones (Figura 3.16).

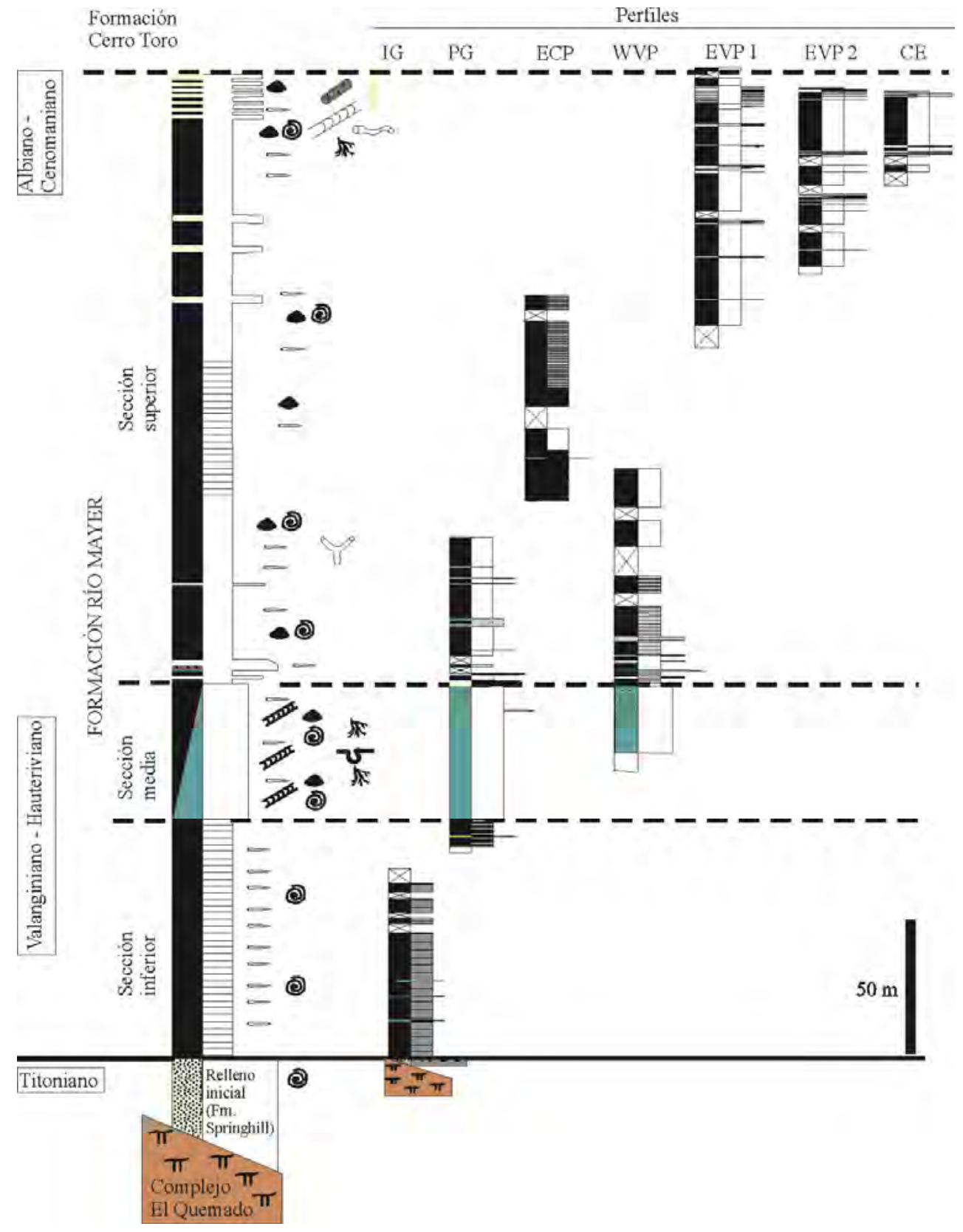

Figura 3.16- Correlación entre los perfiles de la región de las nacientes del Río Guanaco. 
Sección Inferior: Se caracteriza por estar compuesta casi exclusivamente de pelitas negras, en general bien laminadas y en ocasiones en bancos masivos de 0,15 a 0,30 m de espesor. Alternan niveles de margas en bancos continuos o a modo de concreciones. Se inicia de forma neta, apoyando sobre niveles de areniscas que rellenan parte de los hemigrábenes del Complejo el Quemado. El espesor estimado es de 70 a 100 metros, en los primeros metros de esta sección rellenan espacios libres de los hemigrábenes, una vez colmatados los mismos, abarca toda el área de estudio.

Desde el punto de vista del contenido fósil es abundante la presencia de belemnites, acompañados por impresiones de amonoideos y bivalvos y no presenta desarrollo de estructuras sedimentarias orgánicas.

Sección Media: De esta sección se destaca en los afloramientos su relieve positivo, dado por la dureza de sus bancos. Posee de 20 a 40 metros de espesor y se compone de margas negras en bancos de 0,30 a 0,50 m con menor o mayor presencia carbonática.

Desde el punto de vista del contenido fósil es abundante la presencia trazas fósiles, reconociéndose los icnogéneros Bergaueria, Chondrites y Zoophycos. Además posee belemnites, acompañados por impresiones de amonoideos y bivalvos.

Sección Superior: Esta sección posee entre 250 y 300 metros, se destaca por la abundancia de bancos de arenisca intercalados en pelitas negras a verde oliva oscuras. Las areniscas en general de 0,05 a 0,5 m de espesor, masivas o con laminación fina, en pocas ocasiones con laminación entrecruzada. Al inicio de esta sección (4m por arriba de la sección 2) hay un nivel de arenisca glauconítica sobre la cual se encuentra un conglomerado de 0,4 m en el Oeste de la Vega de Pérez que no aparece en el Cerro Pintado (Perfil PG).

El contenido fósil es similar a las dos secciones anteriores, posee poco desarrollo de trazas fósiles, siendo éstas eventuales. En este sentido son importantes las observaciones realizadas en el denominado Cerro Establo, donde se recuperaron los icnogéneros Chondrites, Ophiomorpha, Teredolites y Zoophycos. Presenta belemnites acompañados por impresiones de amonoideos y bivalvos. También en esta sección se hallaron restos de madera petrificada. 


\section{5 -Margen Norte del Lago Argentino}

En esta región del área de estudio se realizaron 2 perfiles de detalle. Cabe aclarar que las secciones halladas no son de la calidad esperada, ya que poseen una gran alteración tanto tectónica como meteórica, encontrándose casi en estado metamórfico. Las secciones fueron realizadas en los Cerros Hobler y Horqueta (Figuras 1.2; 3.17). Además se recorrió el sector norte del Cerro Horqueta, sobre la margen este del Río de las Hayas.

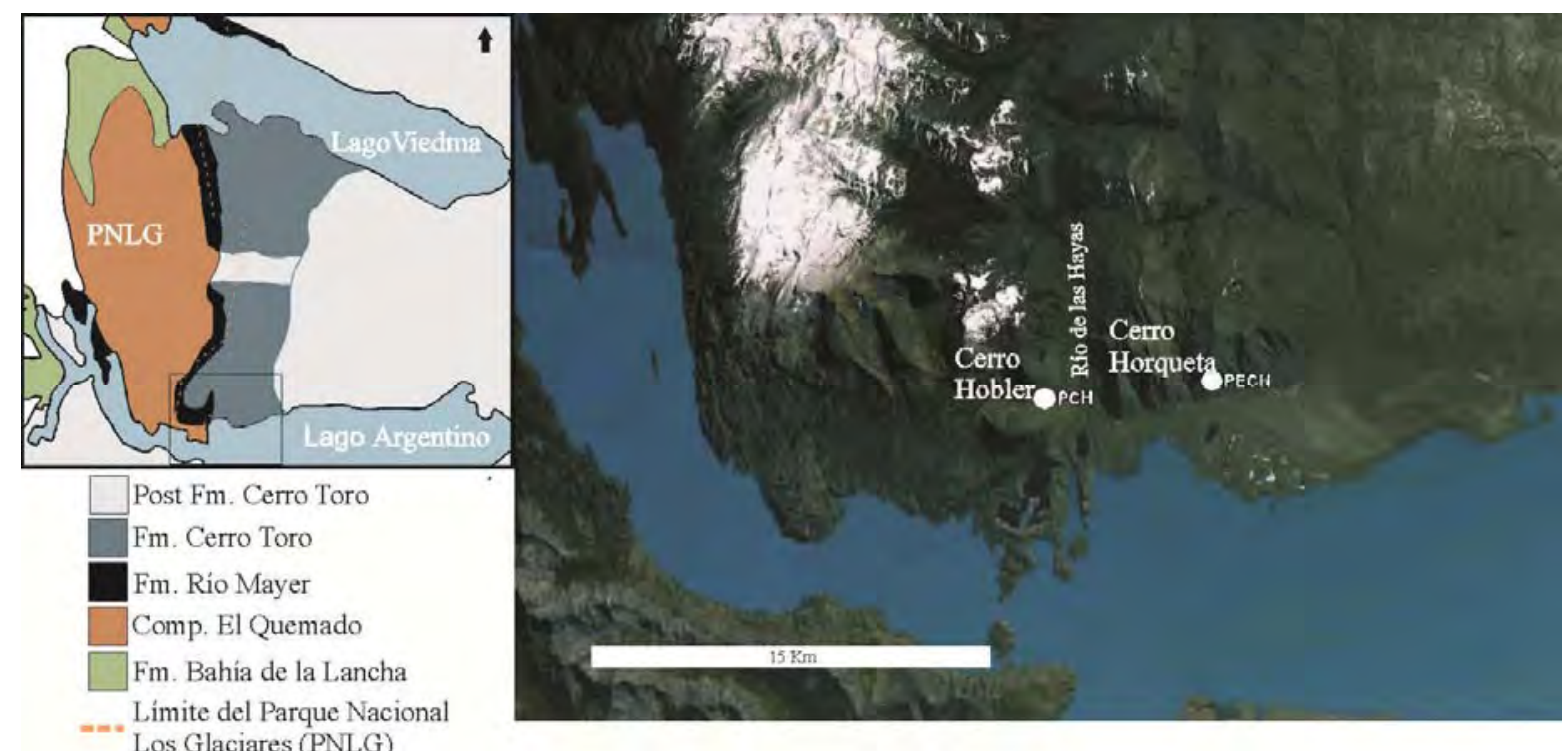

Figura 3.17- Mapa de ubicación de los perfiles en la margen norte del Lago Argentino.

III. 5.1- Perfil Cerro Hobler -PCH- (Figuras 3.17; 3.18; 3.19; 3.20)

Los afloramientos en este cerro están en su mayor parte cubiertos, siendo apreciable el dominio de rocas principalmente pelíticas. Por esta razón se utilizó la altura barométrica registrada con el GPS en la base de cada uno de los tres perfiles parciales realizados. El perfil general se inicia con el Complejo El Quemado.Luego de unos 20 metros cubiertos siguen 18 metros de pelitas negras masivas en bancos de 0,30 a 0,70 m con belemnites y trazas fósiles (icnogénero Zoophycos).

El segundo de los perfiles posee 17 metros dominados por pelitas negras masivas, en ocasiones laminadas, con tres intercalaciones de margas de entre 0,15 y 0,50 m. Intercala también un nivel de arenisca de 0,50 m el cual comienza con tamaño de grano medio y 
estructura masiva y finaliza en arenisca fina laminada. Desde el punto de vista del contenido fósil se registró la presencia de belemnites y amonites.

Finalmente el último perfil tiene unos 37 metros en donde dominan las pelitas negras, cuyos primeros 5 metros son laminados y luego masivos. Intercalan en los primeros 20 metros margas a modo de concreciones. Sólo se registró un nivel de arenisca fina de geometría lenticular de 0,20 m de espesor. El perfil contiene belemnites, amonites, bivalvos y Chondrites isp.

Los tres perfiles pertenecen a la Formación Río Mayer.

III. 5.2- Perfil E Cerro Horqueta -PECH- (Figuras 3.17; 3.18; 3.19; 3.20)

El perfil no posee base expuesta, se compone de 83 metros en los cuales el rasgo más significativo es la abundante cantidad de arenisca presente. En los primeros 15 metros dominan las rocas heterolíticas (tanto pelíticas como arenosas), las que se componen de areniscas finas amarillentas y pelitas negras. Hacia el tope del perfil, los sedimentos psamíticos se presentan principalmente a modo de bancos de 0,01 a 0,15 m con estructura masiva, y en general se amalgaman dando espesores de 0,5 a 1,5 metros.

Este perfil realizado en el sector este del Cerro Horqueta corresponde enteramente a la Formación Cerro Toro.

\section{5.3- Observaciones al N del Cerro Horqueta (Figuras 3.17; 3.20)}

En los alrededores de la margen este del Río de las Hayas se realizaron observaciones generales en el Cerro Horqueta. Las labores tuvieron como objeto caracterizar de modo superficial las rocas encontradas. En general son pelitas negras masivas o laminadas, muy fracturadas, las cuales poseen en ocasiones belemnites y trazas fósiles (Figura 3.20).

Los depósitos corresponden a la Formación Río Mayer. Lamentablemente no pudieron hallarse las rocas que evidencien el paso hacia la Formación Cerro Toro, aunque es en este sector donde la transición podría haberse encontrado. 

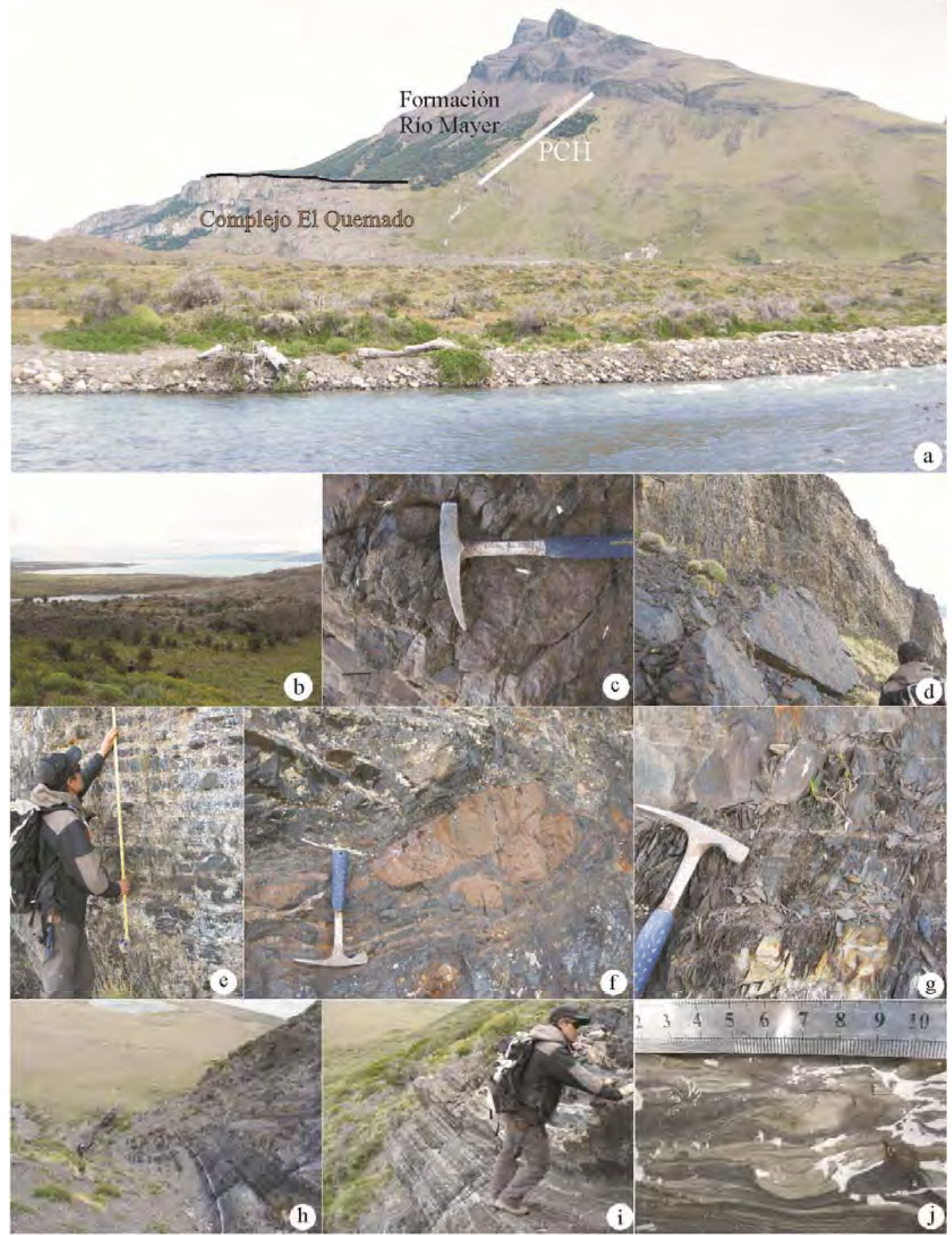

Figura 3.18- a) Vista panorámica del perfil en el Cerro Hobler. b)vista de los afloramientos del Complejo El Quemado en la margen norte del Lago Argentino. c) Pelitas negras con belemnites en la Fm. Río Mayer. d - e) Vistas de las pelitas negras. f - g) Efectos de la deformación Andina sobre la Fm. Rio Mayer en esta región; en f) se observa que las pelitas que rodean las concreciones absorben la deformación. En g) clivaje pizarreño perpendicular a la estratificación original. h) Vista panorámica del perfil al este del Cerro Horqueta. i) Intercalaciones de areniscas y pelitas negras; Fm. Cerro Toro. j) deformación sinsedimentaria; Fm. Cerro Toro. 


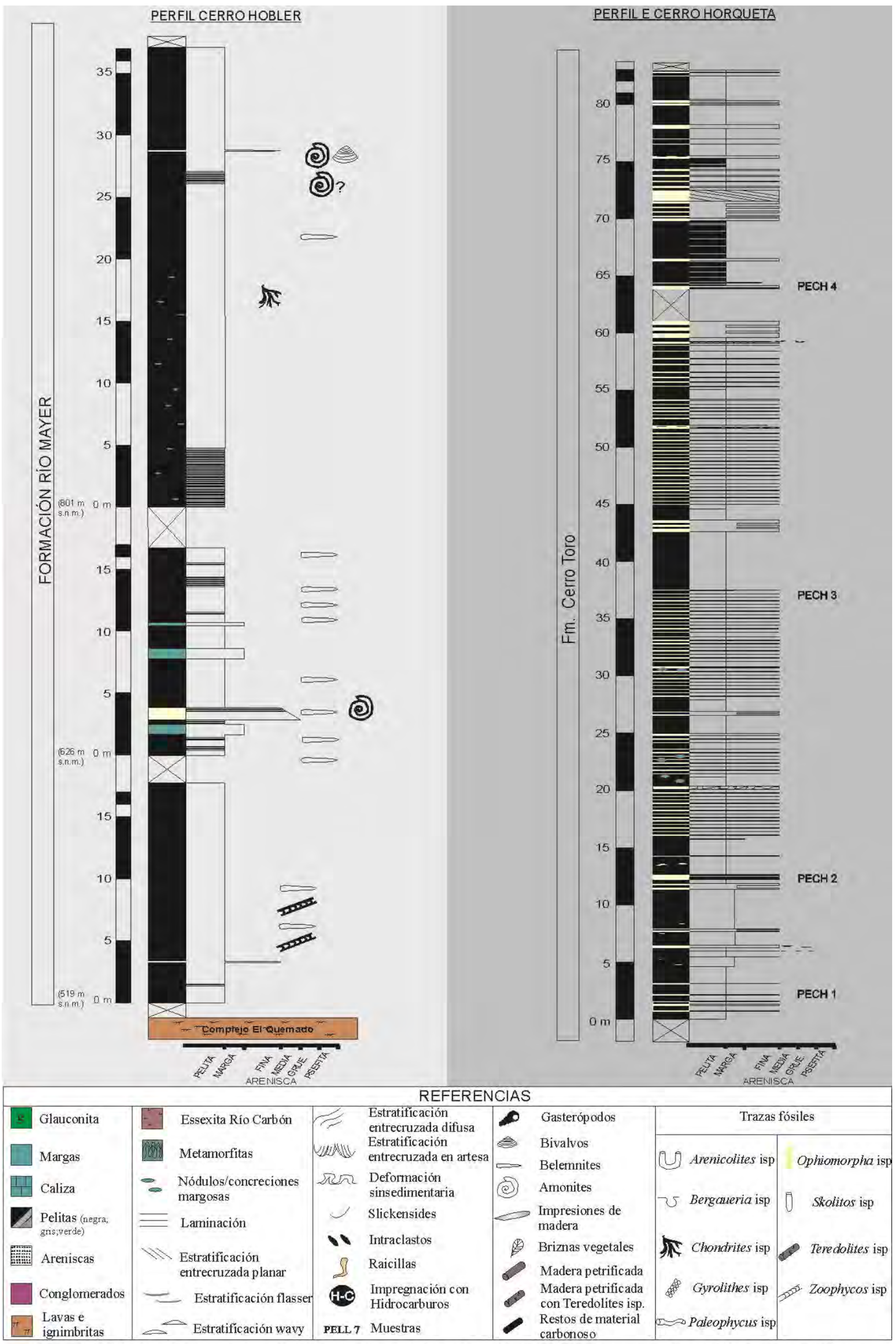

Figura 3.19- Perfiles sedimentológicos de detalle relevados en la margen norte del Lago Argentino. 


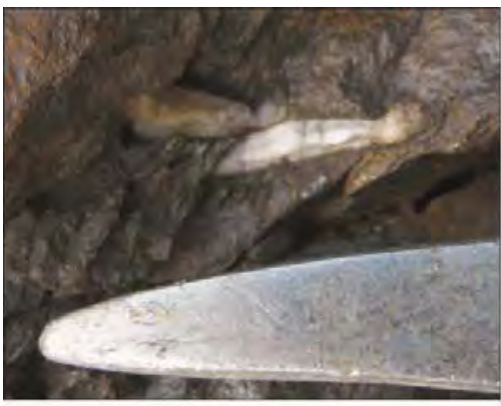

Belemnite. Perfil CH

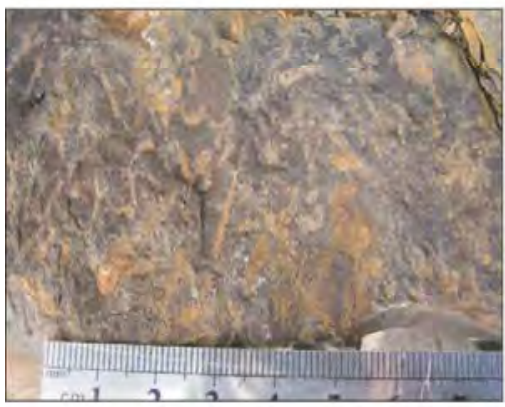

Icnogénero Chondrites. Perfil $\mathrm{CH}$

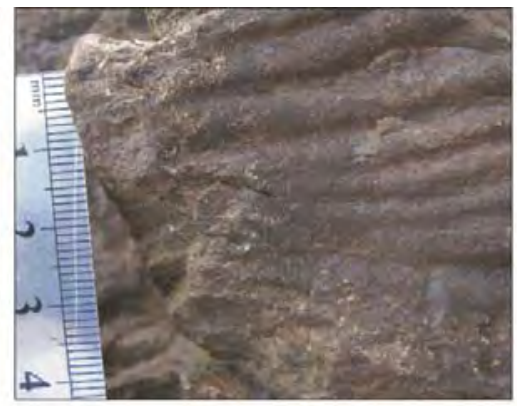

Impresión de amonite. Perfil $\mathrm{CH}$

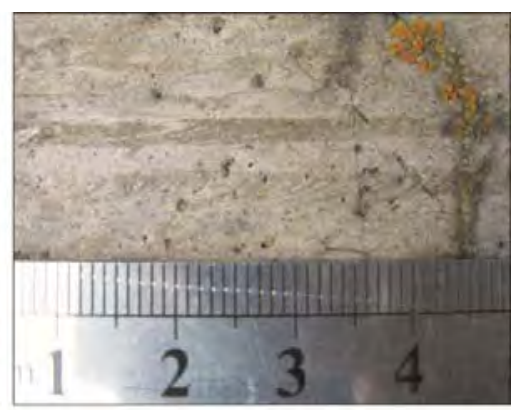

Icnogénero Zoophycos. Perfil CH

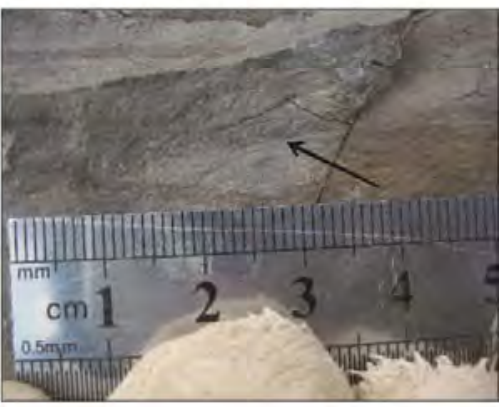

Icnogénero Zoophycos. $\mathrm{N} \mathrm{C}^{\circ}$ Horqueta

Figura 3.20- Material fósil reconocido en los perfiles de la margen norte del Lago Argentino.

III. 5.4 - Síntesis de la Región del Lago Argentino

De los trabajos realizados en los depósitos de la Formación Río Mayer en la margen norte del Lago Argentino una conclusión puede desprenderse:

El grado de alteración tectónica y meteórica que poseen las rocas de la Formación Río Mayer es alto, razón por la cual casi no se efectuó muestreo y los perfiles relevados aquí aportan poca información al desarrollo del presente trabajo. 


\section{SEGUNDA PARTE}




\section{Capítulo IV -Análisis de las Facies Sedimentarias}

El término facies, en su actual concepción, fue introducido por Gressly en 1838 para expresar la suma de las características litológicas y paleontológicas de una unidad de roca (Walker, 2006). Las facies sedimentarias pueden nombrarse con designaciones informales (facies A) o breves caracterizaciones (“facies de pelitas laminadas”), pero siempre su definición debe ser objetiva y estar fundada en las observaciones de campo. Es esencial al momento de efectuar interpretaciones, la comparación con casos bien documentados tanto del registro estratigráfico como ejemplos modernos (Walker, 2006).

A partir de los datos relevados durante el trabajo de campo se realizó un análisis de facies sedimentarias en la Formación Río Mayer fundamentado en las características observacionales en los cuerpos de roca (litología y estructura). Luego de la definición de las facies se procedió a la interpretación de cada una de ellas para posteriormente agruparlas en asociaciones de facies sedimentarias.

Por último, una vez puntualizadas las asociaciones de facies presentes se prosiguió con el análisis de los procesos formadores de dichas asociaciones en un contexto ambiental mediante la comparación con modelos preestablecidos.

\section{1 - Facies Sedimentarias}

Se caracterizó cada cuerpo de roca y se le asignó una facies sedimentaria, para lo cual se utilizó el siguiente código de facies:

\begin{tabular}{|l|l|l|l|}
\hline & Litología & & Característica distintiva \\
\hline P & Pelita & $\mathbf{m}$ & Masiva \\
\hline A & Arenisca & $\mathbf{l}$ & Laminación \\
\hline M & Marga & $\mathbf{n}$ & Nódulos y/o concreciones \\
\hline C & Caliza & $\mathbf{i}$ & Intraclastos \\
\hline Ht & Heterolítica & $\mathbf{s}$ & Deformación sin-sedimentaria \\
\hline Htp & Heterolítica pelítica & $\mathbf{p}$ & Estratificación entrecruzada planar \\
\hline Hta & Heterolítica arenosa & $\mathbf{a}$ & Estratificación entrecruzada en artesa \\
\hline
\end{tabular}




\begin{tabular}{|l|l|l|l|}
\hline F & Conglomerado & w & Estratificación mixta lentiforme \\
\hline G & Sábulo & $\mathbf{o}$ & Estratificación mixta ondulosa \\
\hline & & $\mathbf{f}$ & Estratificación mixta flaser \\
\hline & & $\mathbf{c}$ & Gradación \\
\hline & & $\mathbf{g}$ & Glauconita \\
\hline & & $\mathbf{b}$ & bioturbación \\
\hline
\end{tabular}

Se identificaron en la Formación Río Mayer un total de 18 facies sedimentarias, las cuales son las siguientes:

$>\quad$ Facies pelíticas: Pelitas masivas (Pm); Pelitas laminadas (Pl); Pelitas con nódulos y/o concreciones (Pn).

$>\quad$ Facies de margas: Margas masivas (Mm); Margas bioturbadas (Mb).

> Facies heterolíticas: Heterolítica pelítica con estratificación mixta lentiforme (Htpw); Heterolítica con estratificación mixta ondulosa (Hto); Heterolítica arenosa con estratificación flaser (Htaf).

$>$ Facies de areniscas: Arenisca masiva (Am); Arenisca laminada (Al); Arenisca con estratificación entrecruzada planar (Ap); Arenisca con estratificación entrecruzada en artesa (Aa); Arenisca con deformación sinsedimentaria (As); Arenisca con intraclastos (Ai); Arenisca sabulítica con gradación (AGc); Arenisca glauconítica (Ag).

$>\quad$ Facies Psefíticas: Paraconglomerado masivo con intraclastos (Fmi).

$>$ Facies de calizas: Wackestone masivo $(\mathrm{Cm})$. 


\section{1.1 - Facies de Pelitas}

Las pelitas son las rocas sedimentarias más abundantes en la Formación Río Mayer, constituyendo la mayor parte del espesor aflorante (82,3\%). En la región del Lago San Martín (incluyendo Ea. La Vega) estas rocas representan el 77,51 \% de los afloramientos, en la Seccional Río Guanaco 82,84 \% y en el Lago Argentino 96 \%.

A continuación se describirán las 3 facies sedimentarias pelíticas.

\section{1.1.1- Facies de pelitas laminadas (PI)}

Son fangolitas y arcilitas en general de colores que varían desde negro a gris oscuro (figura 4.1). La laminación es de escala variable, desde muy fina a media (1 a 3 mm, Potter et al., 2005). No presentan reacción al ácido clorhídrico. Presentan pirita diseminada en forma de “chips”, no se encontraron formas de este mineral bien cristalizadas.

El contenido fósil es variable, en general portan belemnites, impresiones de amonites y en menor proporción bivalvos, sin evidencias de trazas fósiles.

Esta facies es dominante en los perfiles IG (95\%) y ECP (52\%) de la Seccional Río Guanaco y el perfil ELF (71\%) del Lago San Martín. Se encuentra en menor proporción en el resto de los perfiles.

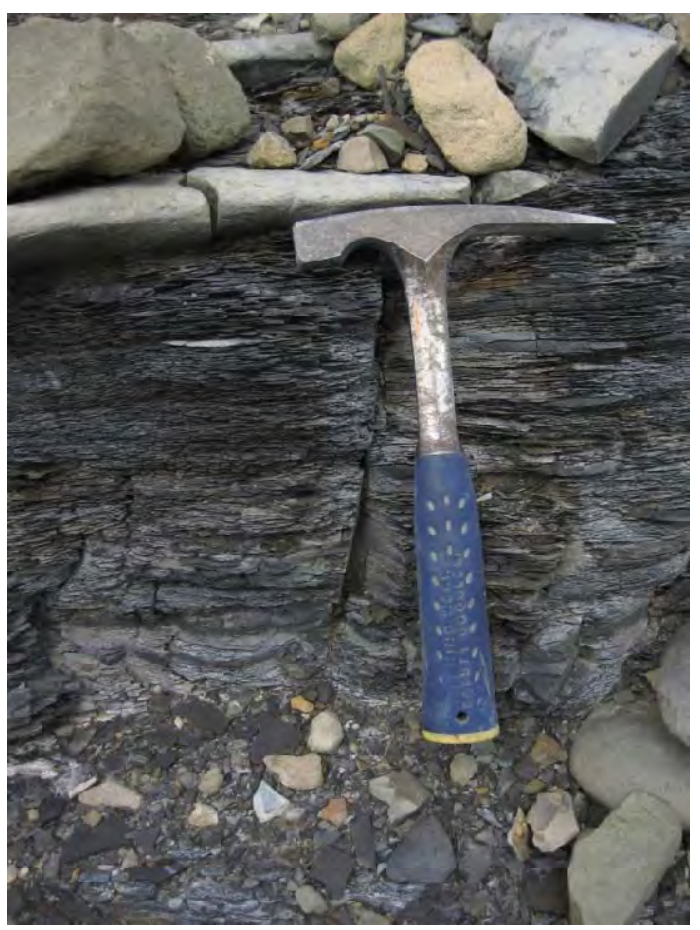

Figura 4.1- Pelitas laminadas. Foto perfil ELF, Lago San Martín. 


\section{1.1.2- Facies de pelitas masivas (Pm)}

En general son fangolitas negras a verde oliva oscuro, que afloran en bancos de poco espesor, entre 0,20 y 0,40 m, con pirita diseminada (figura 4.2).

El contenido fósil es variable, poseen belemnites, impresiones de amonites y en menor proporción bivalvos, como así también impresiones y restos de madera petrificada. En ocasiones presentan trazas fósiles, aunque éstas no son del todo claras dada la mala preservación de estas estructuras en los niveles pelíticos.

Esta facies es dominante en los perfiles EVP 1 (97,45\%); EVP 2 (97,5\%) y CE (98\%) en Río Guanaco y en el perfil CH (77,8 \%) del Lago Argentino. Se encuentra en el resto de los perfiles en forma subordinada.

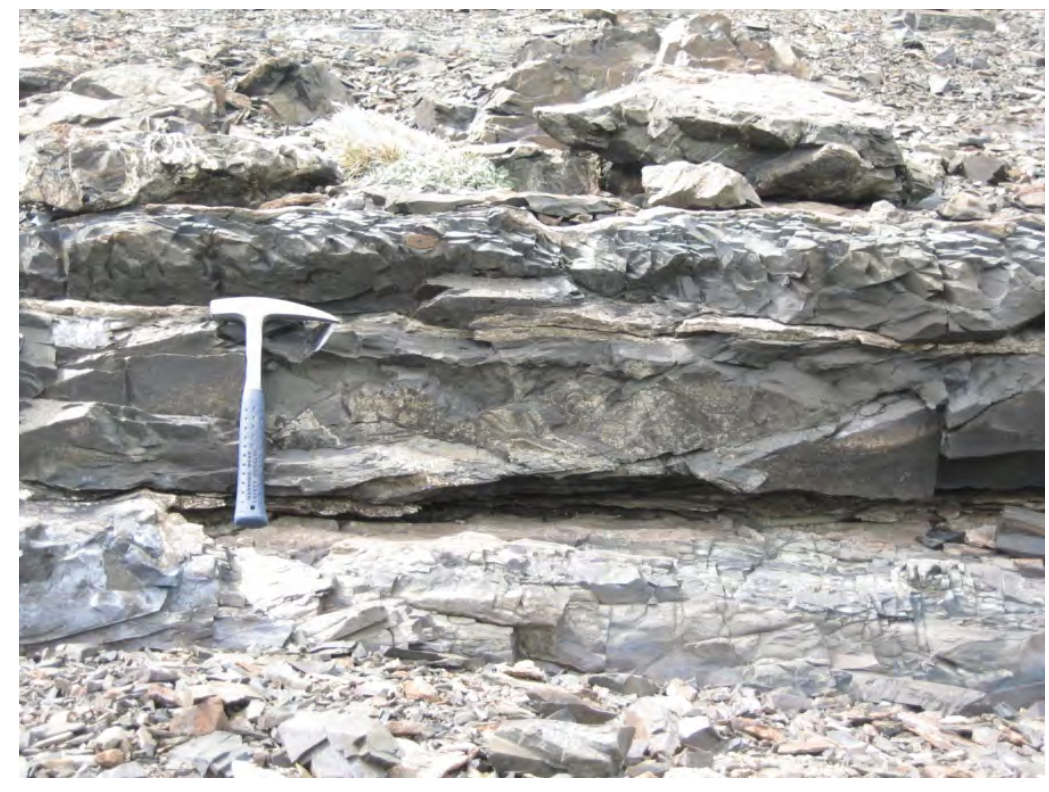

Figura 4.2- Pelitas masivas. Foto perfil EVP 1, Seccional Río Guanaco.

\section{1.1.3- Facies de pelitas con concreciones y/o nódulos (Pn)}

Esta facies se compone tanto de pelitas masivas como laminadas, en general negras aunque también pueden ser verdes oliva oscuras. La característica principal es la presencia de nódulos y/o concreciones margosas de forma ovalada y tamaño variable, entre 1 y $50 \mathrm{~cm}$ de longitud en su eje mayor (figura 4.3).

El material fósil es similar a las otras facies pelíticas e incluye belemnites, amonites y bivalvos, además de trazas fósiles que son eventuales. 
Esta facies es importante en el perfil PEF (19\%) de Lago San Martín y en el perfil CH (8\%) de Lago Argentino, tiene poca presencia en el perfil IG de Río Guanaco, y está ausente en los perfiles restantes.

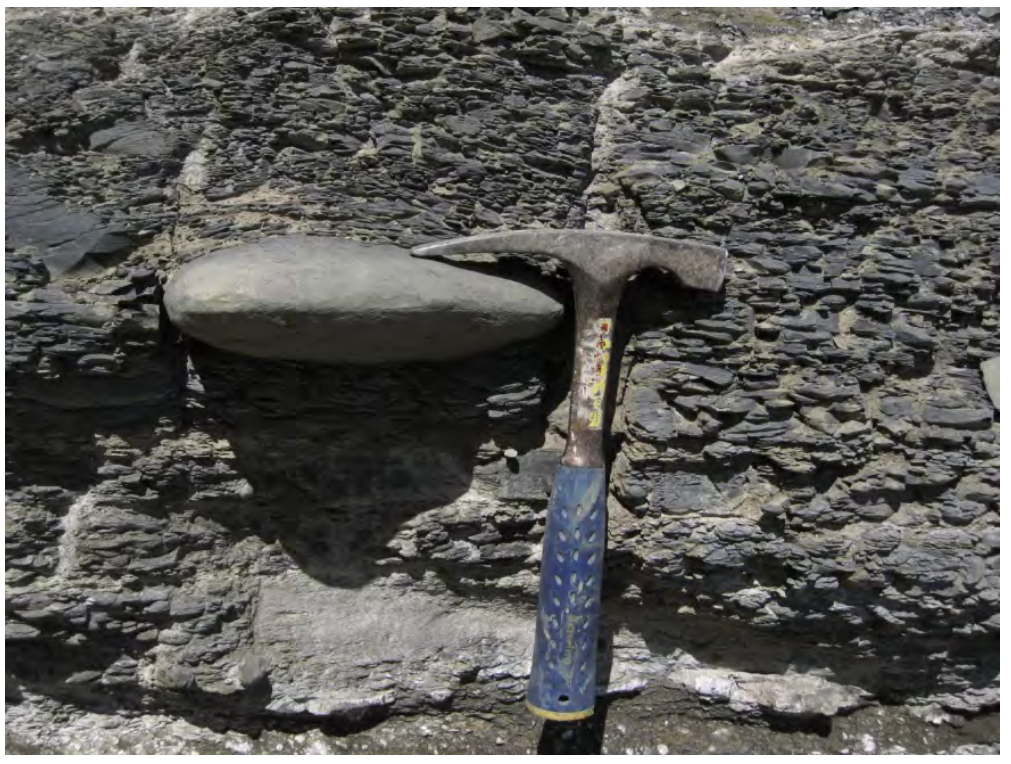

Figura 4.3- Pelitas con concreciones y/o nódulos. Foto perfil ELF, Lago San Martín.

\section{1.2- Facies de Margas}

Las rocas margosas constituyen el segundo grupo más abundante en la Formación Río Mayer con casi un 10 \% de los afloramientos. El porcentaje de carbonato varía entre un 20 y un 60\% (ver capítulo V). Se definieron 2 facies para estas rocas y se las describe en detalle a continuación.

\section{1.2.1 - Facies de margas masivas (Mm)}

Margas de color negro a gris oscuro que suelen por meteorización tomar un tono castaño exteriormente. Aparecen en bancos masivos de entre 0,15 y 0,50 m (figura 4.4).

En esta facies sólo se encontraron belemnites y no se registraron trazas fósiles.

Está presente con poca participación (menos de 2\%) en los perfiles IG y PG en la Seccional Río Guanaco y en los perfiles PEF (3,2\%) y PELV (0,7\%) de la región comprendida entre los lagos Viedma y San Martín. 


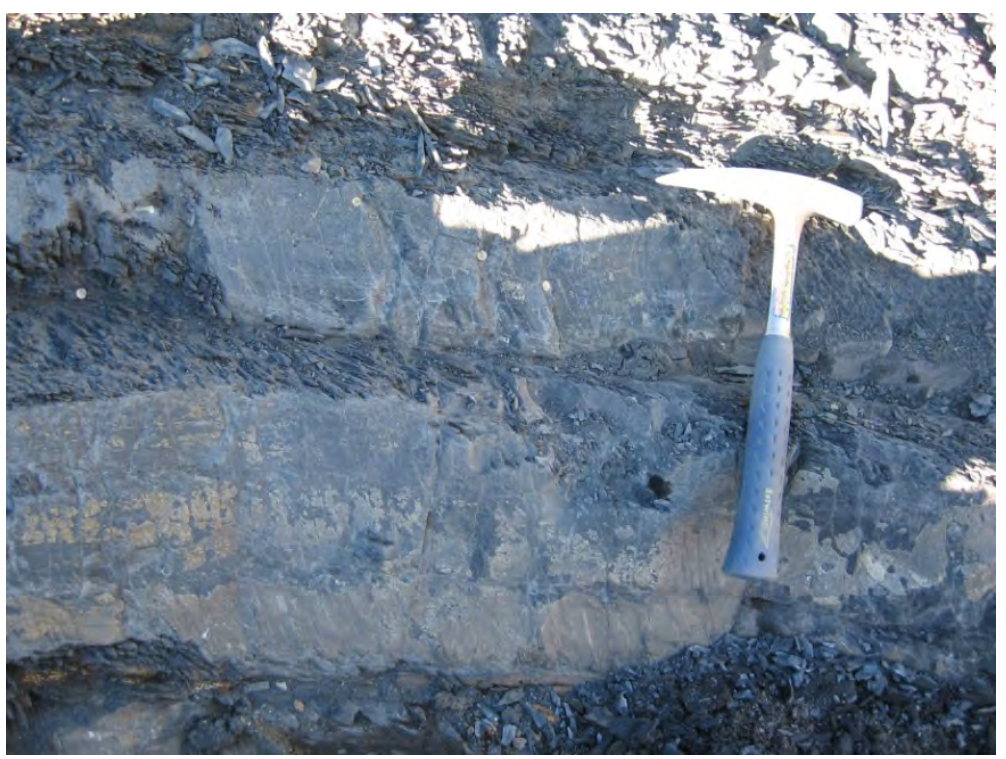

Figura 4.4- Facies de margas masivas en el Perfil IG de la Seccional Río Guanaco.

\section{1.2.2 - Facies de margas bioturbadas (Mb)}

Margas de color negro a gris oscuro que suelen por meteorización tomar un tono castaño exteriormente. Aparecen como bancos tabulares de espesores entre 0,40 y 0,80 m (figura 4.5).

En esta facies se encuentran amonites, belemnites y bivalvos como material fósil. A su vez están asociadas a un gran desarrollo de trazas fósiles que se presentan con distinto grado de abundancia.

Es exclusiva de los perfiles PG (43\%) y WVP (29\%) en la Seccional Río Guanaco, donde posee un espesor de 20 a 35 metros.

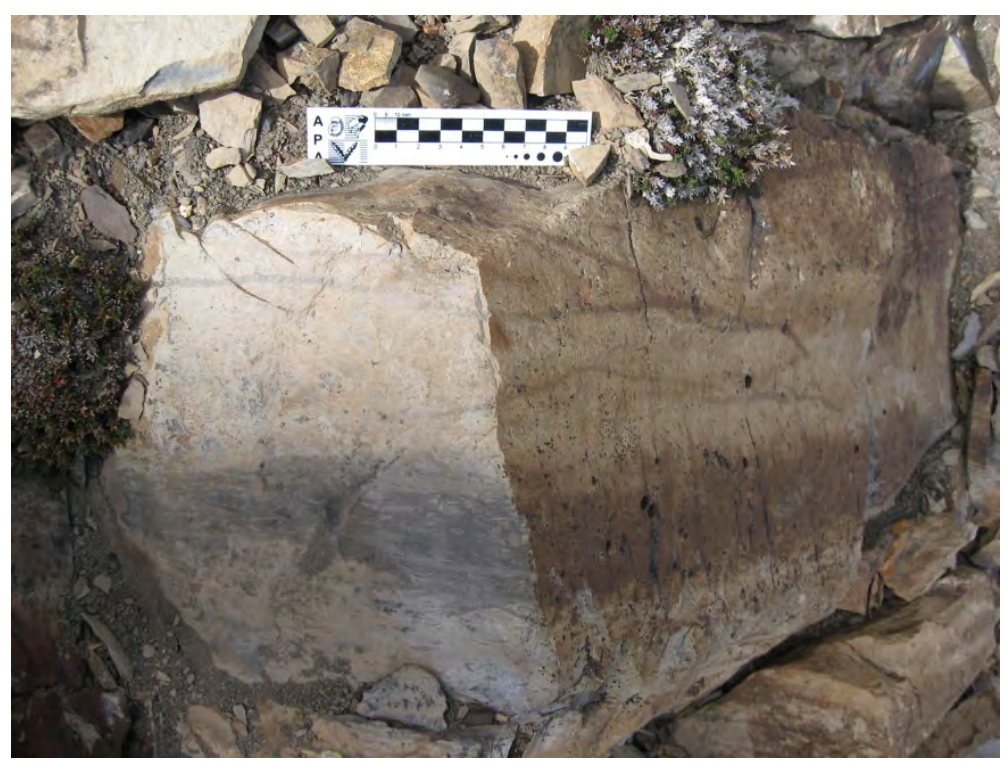

Figura 4.5- Margas bioturbadas. Foto perfil PG, Seccional Río Guanaco. 


\section{1.3- Facies Heterolíticas}

Las facies heterolíticas sólo representan el 2\% de los afloramientos de la Formación Río Mayer y se encuentran en el perfil de Estancia Kachaike de la región del Lago San Martín.

\section{1.3.1- Facies de Heterolítica pelítica con estratificación mixta lentiforme} (Htpw)

Esta facies se compone de heterolíticas ricas en pelitas masivas de tonalidades oscuras (negro a gris) con areniscas finas en forma de pequeñas lentes milimétricas muy subordinadas (figura 4.6).

En cuanto al contenido fósil sólo se recuperaron briznas vegetales de esta facies.

Se encuentra en el perfil EKA con un 15\% y está ausente en el resto de las regiones, a excepción del perfil ECH en el Lago Argentino, aunque en depósitos de la Formación Cerro Toro.

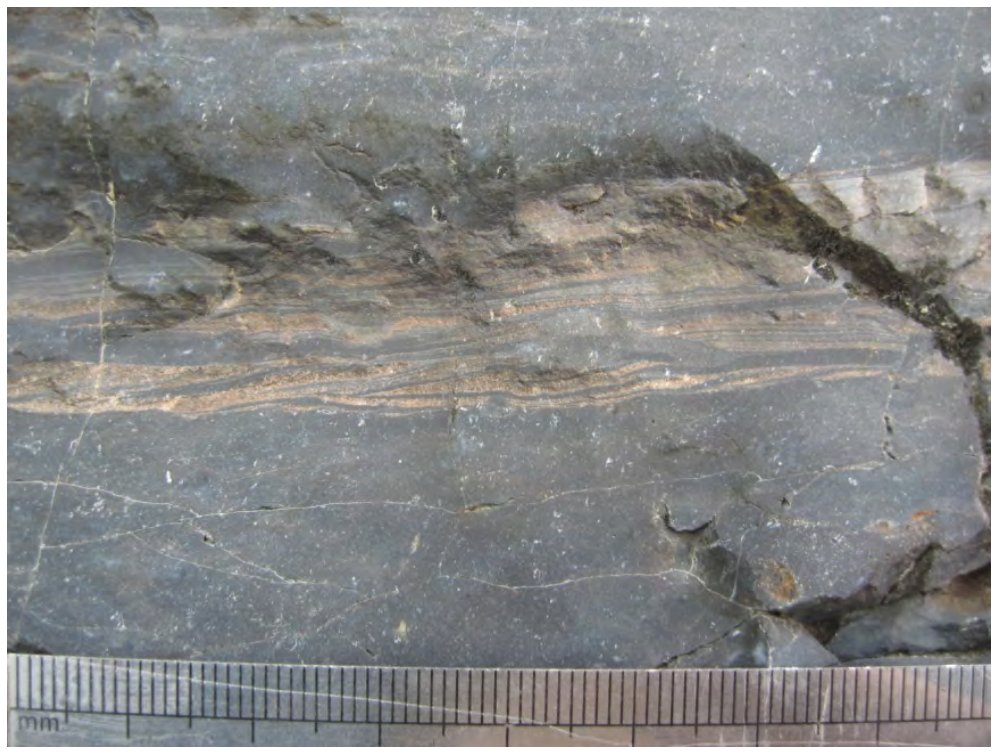

Figura 4.6- Heterolítica pelítica con estratificación mixta lentiforme. Foto perfil ECH, Lago Argentino.

\section{1.3.2 - Facies de Heterolítica con estratificación mixta ondulosa (Hto)}

Intercalaciones de pelitas de tonalidades oscuras y areniscas finas blanquecinas, en aproximadamente la misma proporción. Las pelitas son masivas mientras que las areniscas suelen presentar laminación entrecruzada (figura 4.7).

$\mathrm{Al}$ igual que en la anterior facies sólo se recuperaron briznas vegetales. 
Esta facies está presente en el perfil EKA del Lago San Martín (6,83\%) y ausente en el resto de los perfiles.

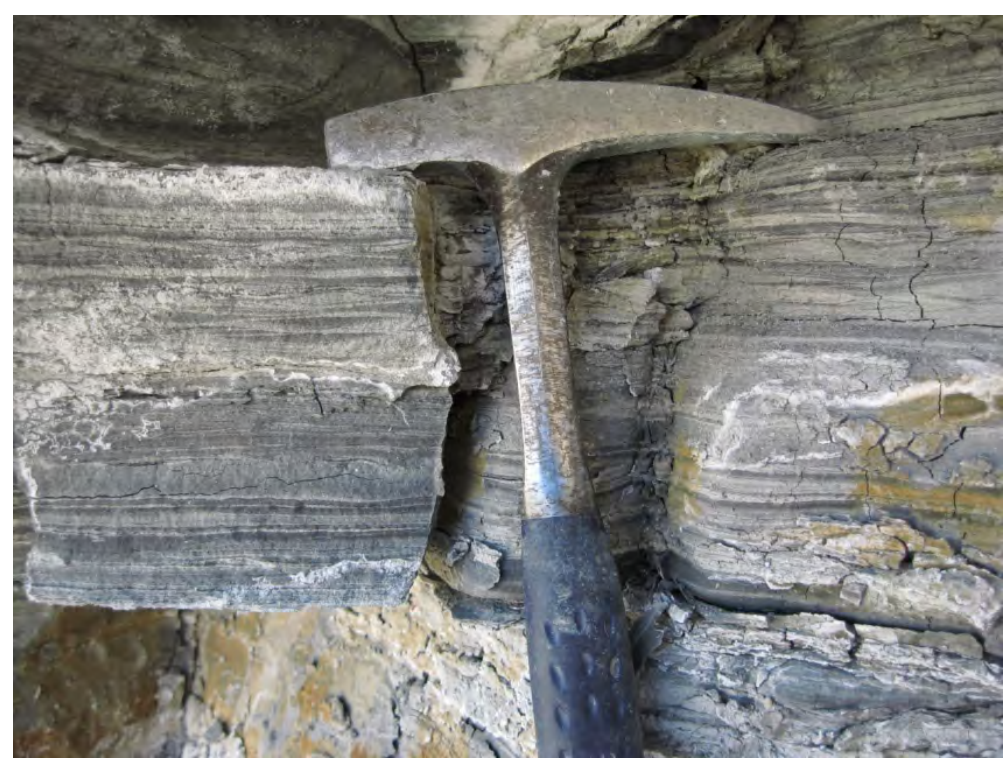

Figura 4.7- Heterolíticas con estructura mixta ondulosa. Foto perfil ELF, Lago San Martín.

\section{1.3.3 - Facies de Heterolítica arenosa con estratificación mixta flaser (Htaf)}

En esta facies mixta predominan las areniscas finas blanquecinas por sobre las pelitas oscuras (figura 4.8). Presenta laminación entrecruzada en la cual con frecuencia intercala una lámina de arenisca y una de pelita.

Sólo se recuperaron briznas vegetales de esta facies.

Esta facies está presente en el perfil EKA del Lago San Martín (5,79\%) y ausente en el resto de los perfiles.

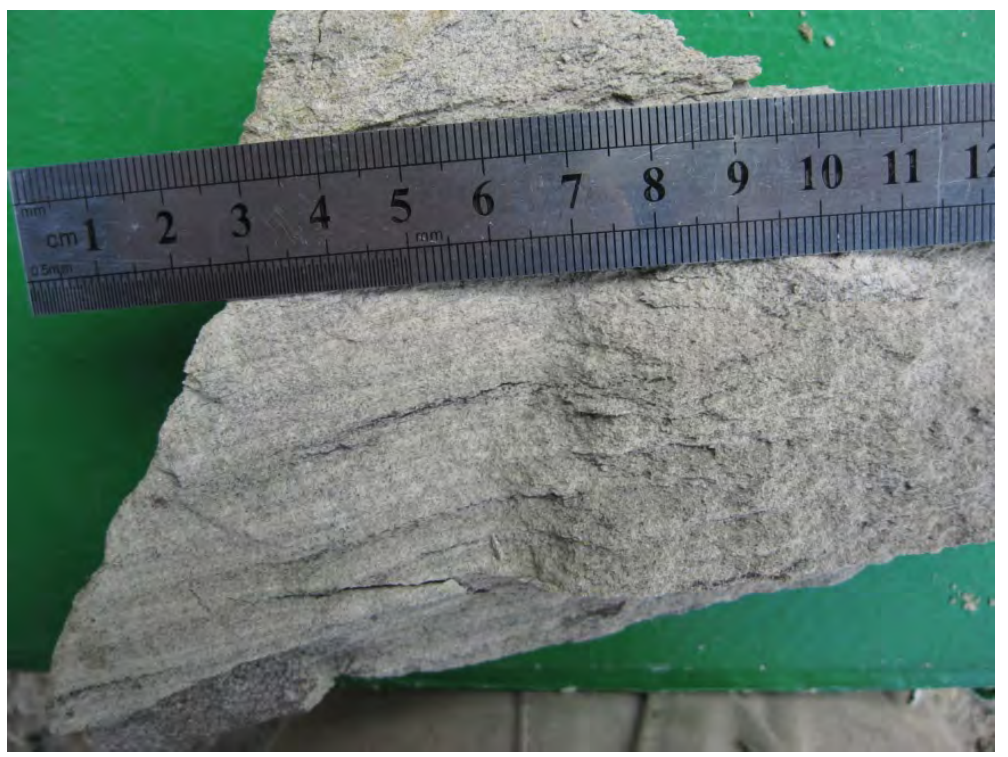

Figura 4.8- Heterolítica arenosa con estructura mixta flaser. Foto perfil ELF, Lago San Martín. 


\section{1.4- Facies Psamíticas}

Las areniscas son una facies subordinada en la Formación Río Mayer y representan el 5,81\% de los afloramientos. Están presentes en todas las localidades con diferentes porcentajes de participación, en la región del Lago San Martín (más Ea. La Vega) alcanzan un 13,88\%, en Seccional Río Guanaco 1,62\% y en Lago Argentino 1,54\%.

\section{1.4.1- Facies de Areniscas masivas (Am)}

Arenisca de tamaño de grano fino a grueso con moderada selección, en general con matriz pelítica en proporciones variables y estructura masiva. Se encuentra formando estratos de 0,05 a 0,8 m con coloraciones variables, las más frecuentes son las blanquecinas y grises. En muestra de mano el componente que domina es el cuarzo con cantidades menores de feldespatos y micas (figura 4.9).

El contenido fósil se compone de bivalvos, gasterópodos, briznas vegetales y madera petrificada en los perfiles EKA y ELV de la región del Lago San Martín. También belemnites y bivalvos en el perfil ELL de la misma región. Asociadas a esta facies suelen registrarse trazas fósiles.

Esta facies se encuentra en todos los perfiles del área de estudio a excepción del perfil IG de la Seccional Río Guanaco. La abundancia va desde 23 \% (PELV, Ea. La Vega) hasta menos de 1 \% (perfiles ECP y PG de Río Guanaco)

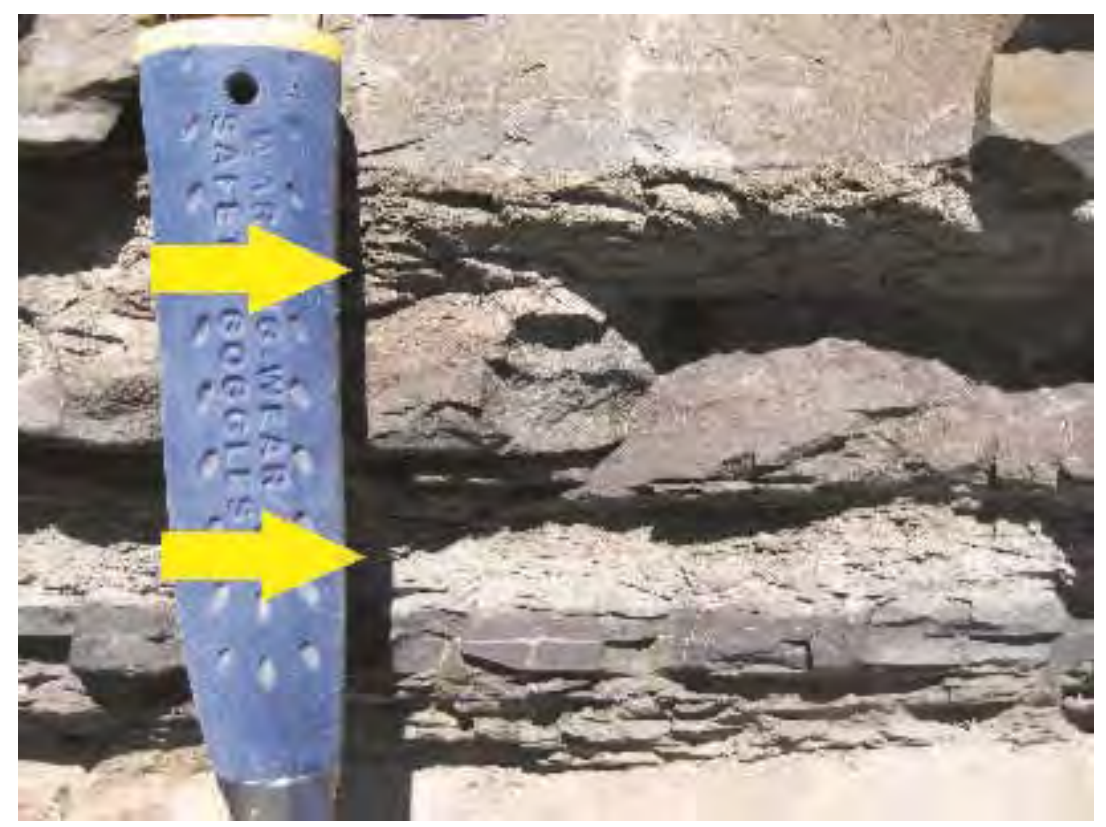

Figura 4.9- Areniscas masivas. Foto perfil EVP 1, Seccional Río Guanaco. 


\section{1.4.2- Facies de Areniscas laminadas (Al)}

Areniscas finas a medianas en estratos que van desde 0,1 a 0,3 metros con laminación gruesa (1 a 3 cm, Potter et al., 2005), la cual en ocasiones se encuentra difusa. Los colores son variados e incluyen tonos de grises, verdes y marrones, además de los blanquecinos (figura 4.10).

Asociados a esta facies se encontraron restos de amonites, belemnites, bivalvos y briznas vegetales. No se registraron trazas fósiles.

Se presenta en los perfiles EKA (3,3\%) y ELV (2,28\%) de la región del Lago San Martín, los perfiles PG (1,74\%) y muy subordinada en los perfiles EVP 1 de la Seccional Río Guanaco y CH del Lago Argentino (menos del 1\% en ambos).

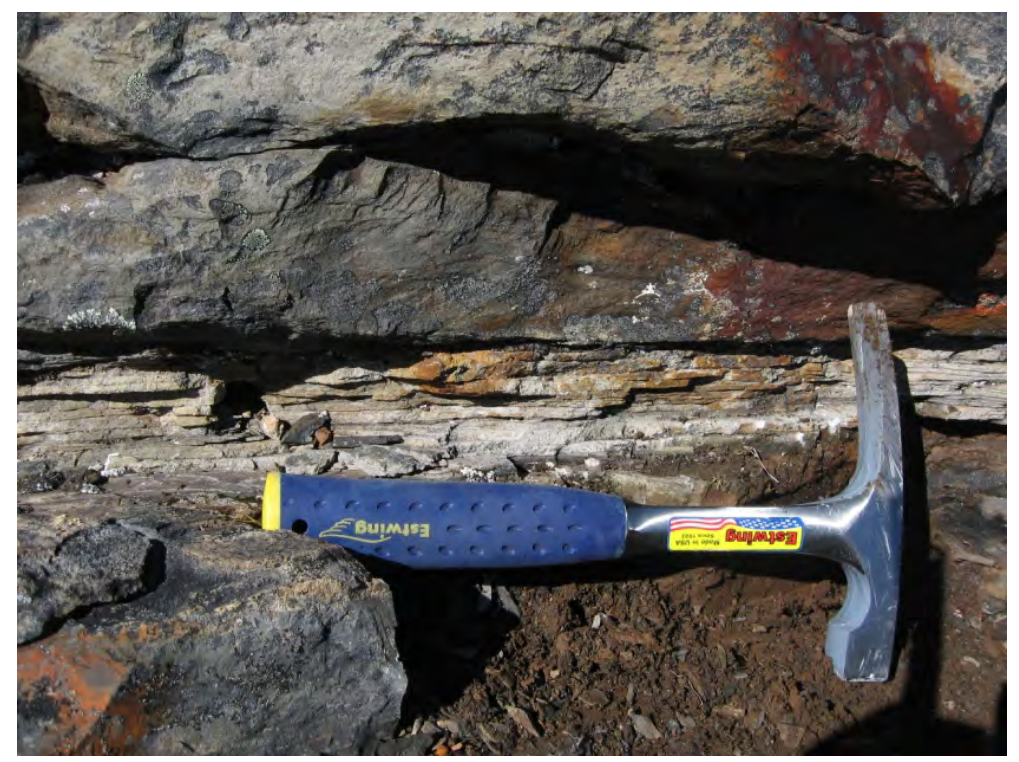

Figura 4.10- Areniscas laminada. Foto perfil EVP 1, Seccional Río Guanaco.

\section{1.4.3- Facies de Areniscas con estratificación entrecruzada planar (Ap)}

Areniscas medianas bien seleccionadas, de composición predominantemente cuarzosa y estratificación entrecruzada planar de ángulos entre15 y 25 grados (figura 4.11).

No se encontró material fósil asociado a esta facies.

Sólo está presente en el perfil EKA del Lago San Martín (4\%) y en el perfil PG de la Seccional Río Guanaco (1,5\%), dentro de la Formación Río Mayer. También se identificó esta facies en la Formación Cerro Toro (Lago Argentino) y en la Formación Springhill (Lago San Martín). 


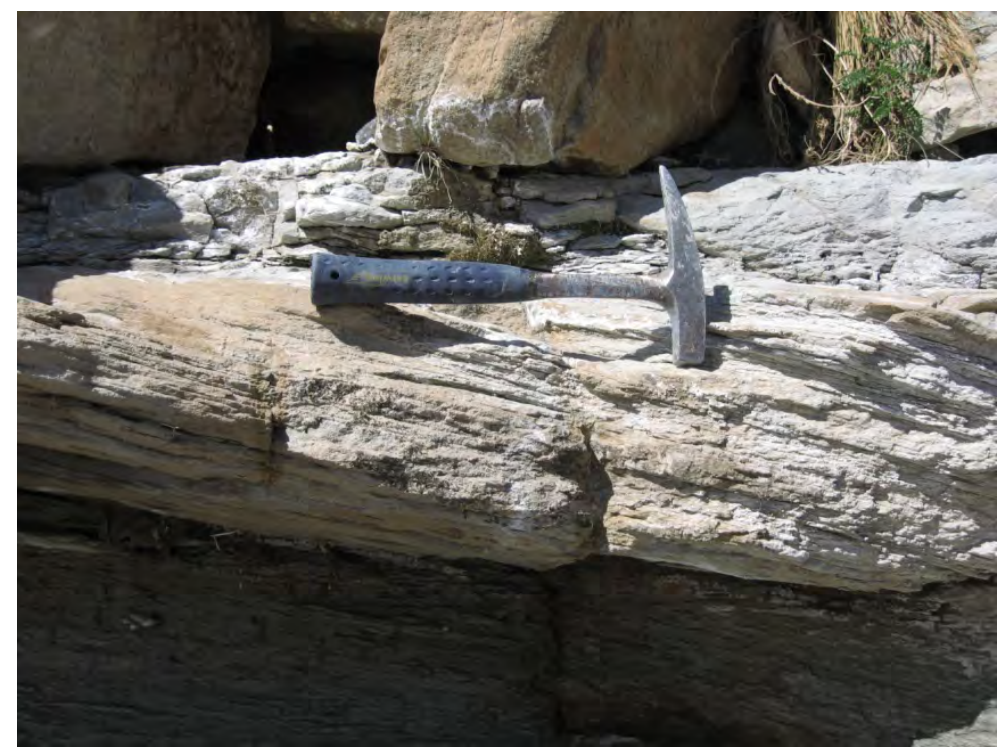

Figura 4.11- Areniscas con estructura entrecruzada planar. Foto perfil EKA, Lago San Martín.

\section{1.4.4- Facies de Areniscas con estratificación entrecruzada en artesa (Aa)}

Areniscas con tamaño de grano desde finas hasta gruesas con selección de moderada a buena, colores blanquecinos o grises y estratificación entrecruzada en artesa de pequeña escala. Dicha estructura suele a veces presentarse amalgamada y se torna difusa (figura 4.12). A igual que el resto de las areniscas en muestra de mano predomina la composición cuarzosa.

No se encontró material fósil asociado a esta facies.

Solo está presente en el perfil EKA (0,6\%) del Lago San Martín.

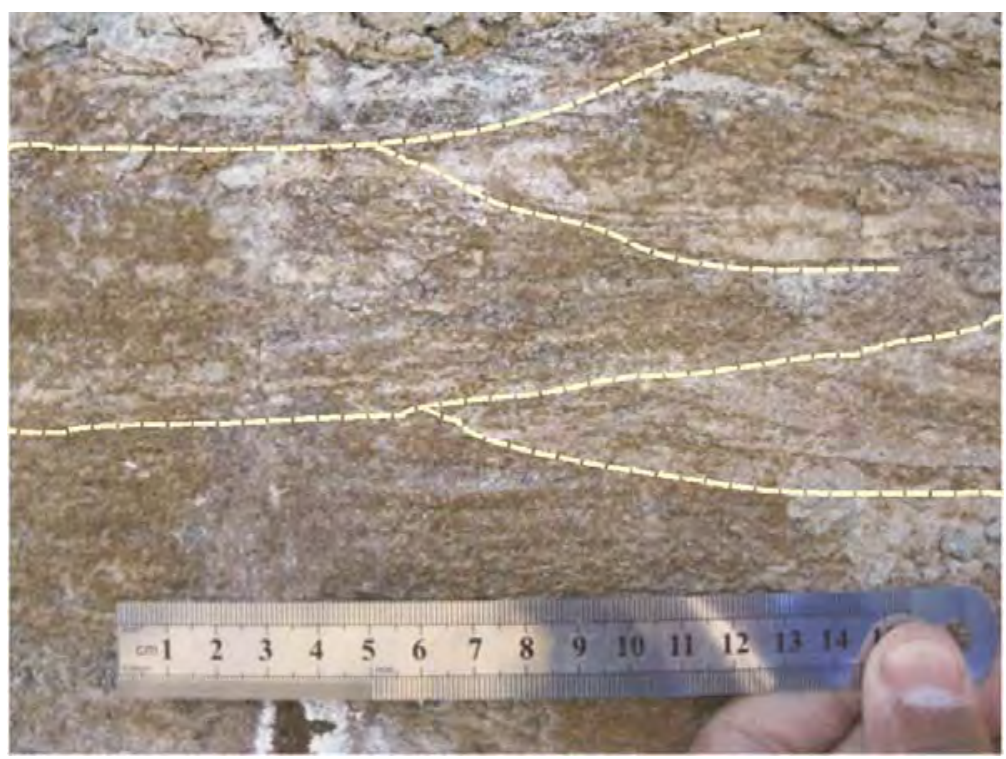

Figura 4.12- Areniscas con estructura entrecruzada en artesa. Foto perfil EKA, Lago San Martín. 


\section{1.4.5- Facies de Areniscas con deformación sin-sedimentaria (As)}

Areniscas finas a medianas de colores variables en donde dominan las grises y verdes, mal seleccionadas con abundante matriz pelítica e intercalaciones milimétricas de pelitas. Se evidencia deformación sin-sedimentaria como estructura dominante, en general se observan calcos de carga y laminación convoluta (figura 4.13).

Sólo se registraron briznas vegetales acompañando a esta facies.

Se encuentra en el perfil EKA del Lago San Martín (7,8\%) y en el perfil ECH del Lago Argentino, aunque en este último en depósitos de la Formación Cerro Toro.

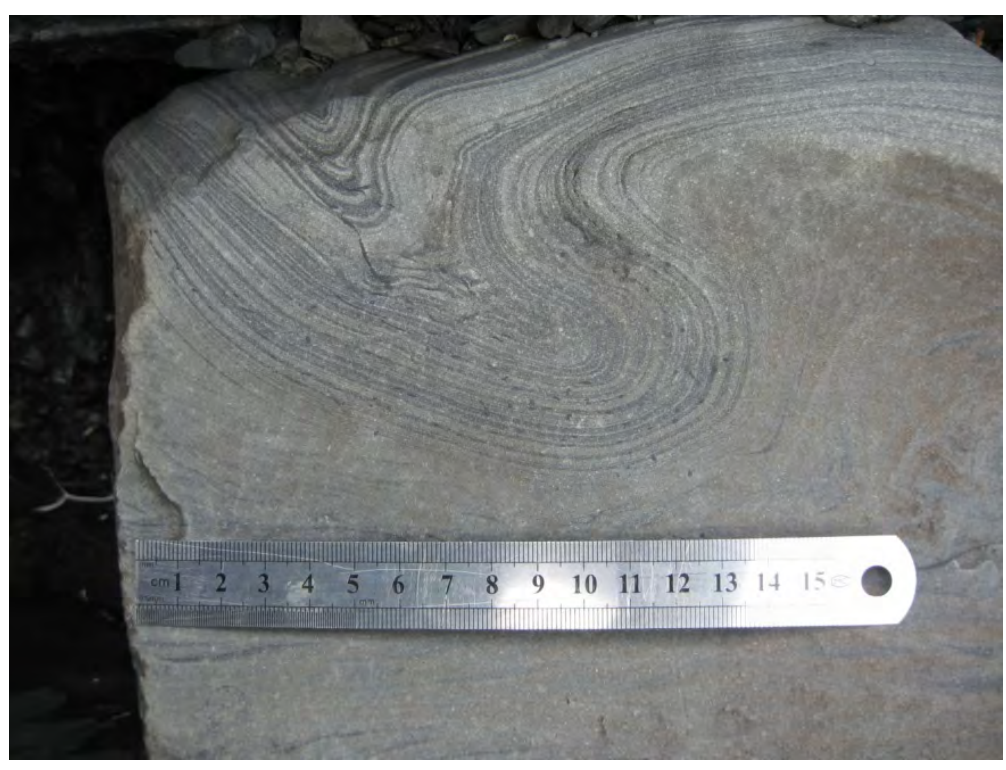

Figura 4.13- Areniscas con deformación sin-sedimentaria. Foto perfil ECH, Lago Argentino.

\section{1.4.6- Facies de Areniscas con intraclastos (Ai)}

Areniscas gruesas mal seleccionadas de colores grises, las cuales presentan un alto tenor de matriz pelítica. Poseen intraclastos pelíticos de colores negros subangulosos a subredondeados de tamaños entre 1 y 5 cm (figura 4.14).

No se registró material fósil acompañando a esta facies.

Es una facies muy aislada y se encuentra sólo en el perfil EKA del Lago San Martín $(2 \%)$. 


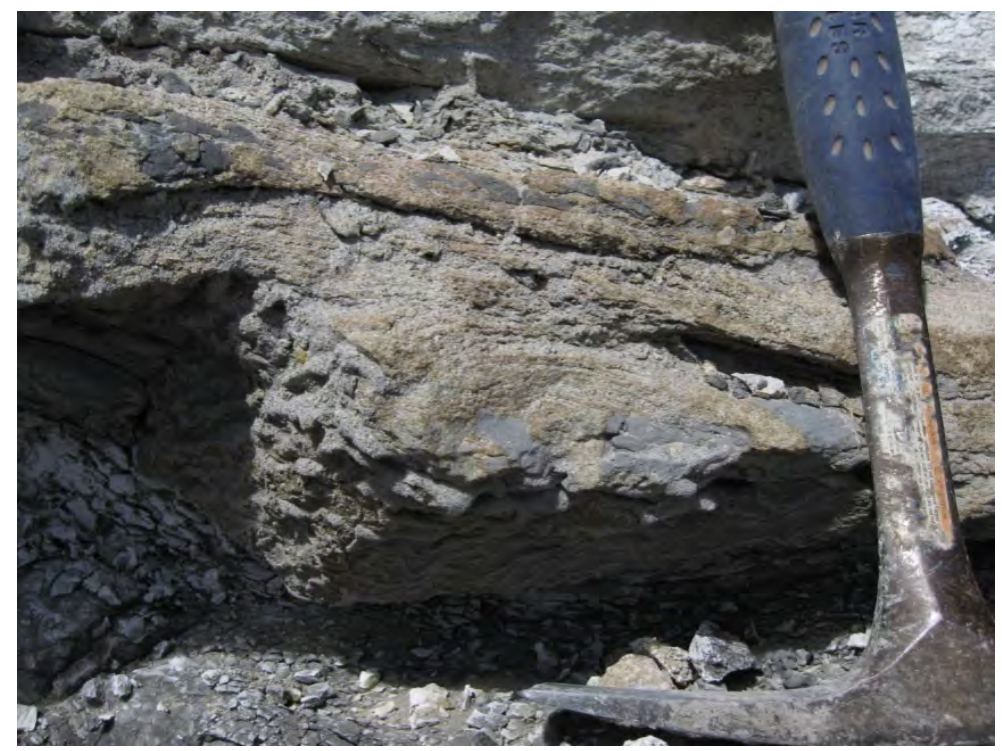

Figura 4.14- Areniscas con intraclastos. Foto perfil EKA, Lago San Martín.

\section{1.4.7- Facies de Areniscas sabulítica gradada (AGc)}

Arenisca mediana a gruesa de color verde-amarillento, mal seleccionada, que aflora en un estrato de 1,5 metros de espesor con estructura grano creciente. Presenta abundantes clastos de tamaño sábulo subangulosos, los cuales están diseminados en el tercio superior del estrato. Estos clastos sabulíticos son de composición lítica de origen volcánico y aparecen con coloraciones verdes por alteración. En sección delgada se reconoció que estos clastos son de origen volcánico y están en parte serpentinizados (figura 4.15).

Se reconocieron restos de troncos petrificados, gasterópodos y briznas vegetales.

Sólo se encuentra en el perfil ELV de la región entre los lagos San Martín y Viedma $(2 \%)$.

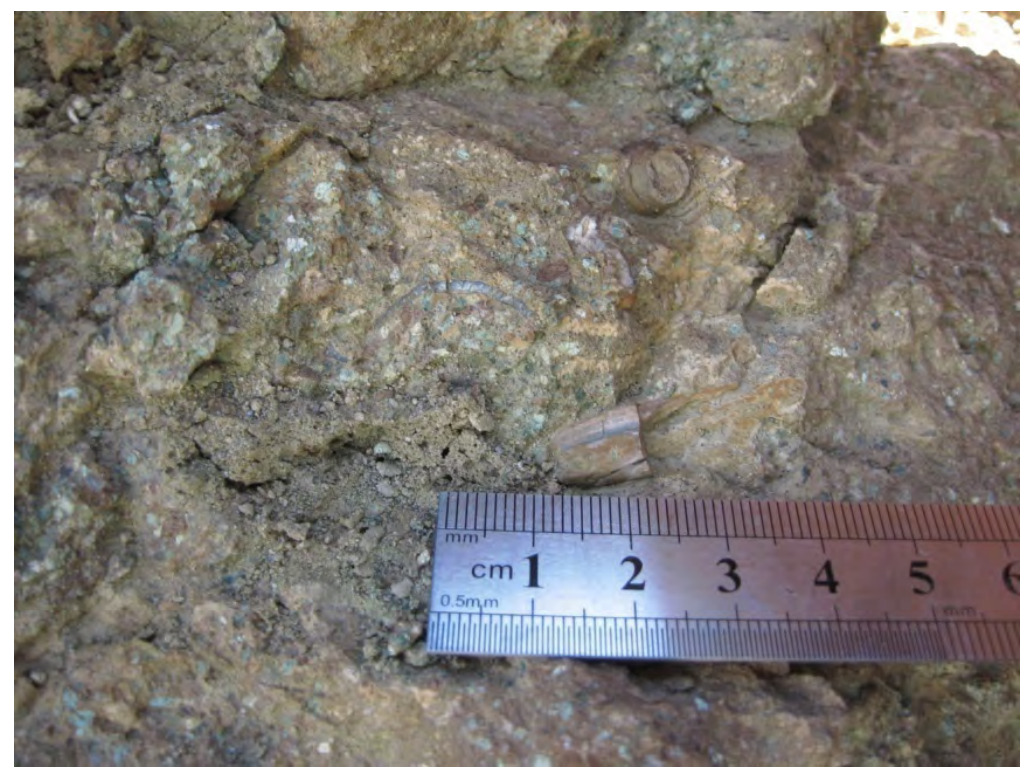

Figura 4.15- Areniscas sabulíticas. Foto perfil ELV, región entre los lagos Viedma y San Martín. 


\section{1.4.8- Facies de Arenisca glauconítica (Ag)}

Esta facies se presenta en dos regiones de manera diferente. En los perfiles PG y WVP de la Seccional Río Guanaco forma un nivel de 3 a $5 \mathrm{~cm}$ de espesor compuesto por clastos redondeados de glauconita de color verde y tamaño entre 0,5 y 2 mm (figura 4.16). La matriz es de arenisca fina. En la región del Lago San Martín se presenta como un estrato arenoso masivo de 1 metro de espesor en el cual los granos de glauconita son de tamaños considerablemente menores (aproximadamente 0,2 a 0,5 mm). Más detalle en el capítulo VI (petrografía).

Se encuentra en los perfiles PG y WVP de la Seccional Río Guanaco y en el perfil ELL del Lago San Martín.

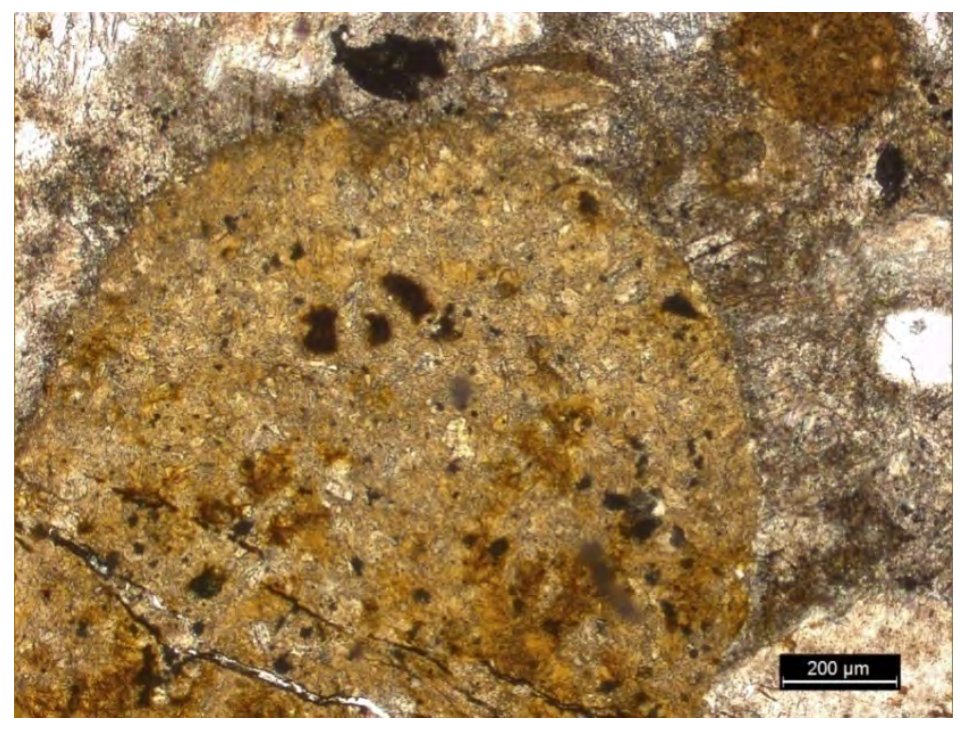

Figura 4.16- Arenisca

glauconítica. Foto perfil PG, Seccional Río Guanaco. 


\section{1.5- Facies Psefíticas}

\section{1.5.1- Facies de Paraconglomerado masivo con intraclastos (Fmi)}

Conglomerado masivo matriz-sostén de 0,3 metros de espesor con tamaño de grano entre grava fina y mediana (figura 4.17). Los clastos son de dos tipos, intraclastos pelíticos de color negro con formas subredondeadas y clastos de arenisca cuarzosa glauconítica de color verde y formas angulosas a subangulosas. Estos últimos provienen de la facies anteriormente descripta ya que el nivel de paraconglomerado se apoya directamente sobre la facies Ag. La matriz es sucia y se compone por una mezcla de arenisca cuarzosa mediana a gruesa y pelita negra.

No es posible observar con claridad la geometría externa del cuerpo por la poca continuidad lateral del afloramiento, aunque cabe destacar que pareciera acuñarse hacia los lados.

No hay material fósil asociado a esta facies.

Representa un nivel aislado dentro de la sedimentación de la Formación Río Mayer y sólo está presente en el perfil WVP de la Seccional Río Guanaco donde constituye el $0,43 \%$ del perfil.

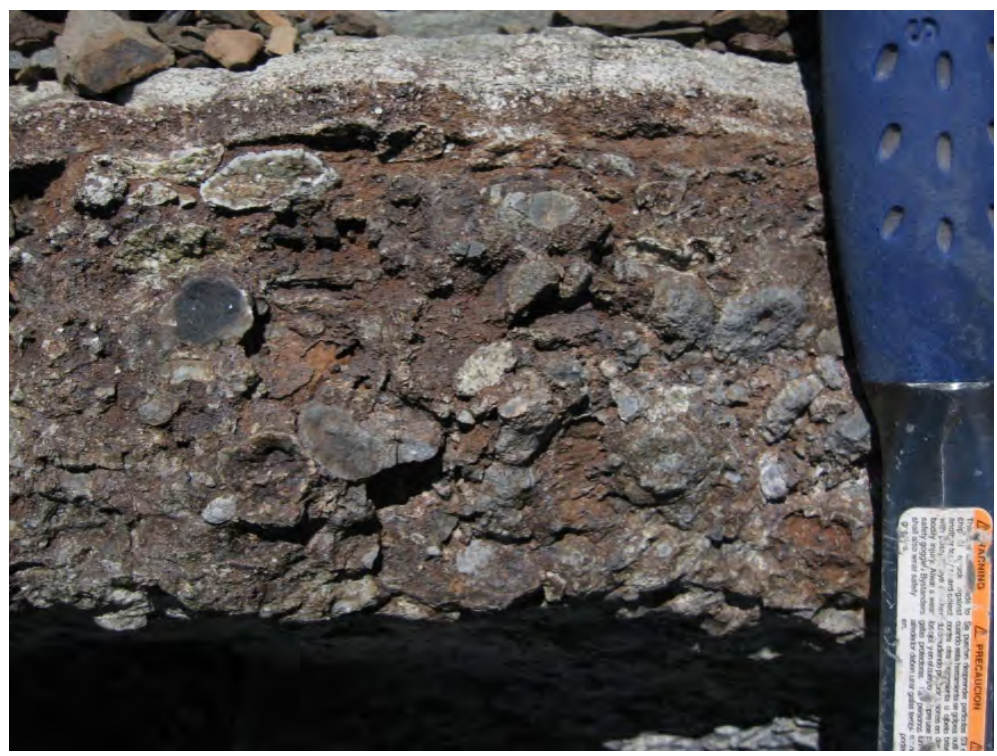

Figura 4.17- Conglomerado masivo con intraclastos. Foto perfil WVP, Seccional Río Guanaco. 


\section{1.7- Facies de Caliza}

\section{1.7.1- Facies de Wackestone masivo (Cm)}

Caliza masiva de color gris oscuro a negro que posee alta reacción al $\mathrm{HCl}$ y se presenta formando estratos entre 0,5 y 1 metro de espesor. Estas calizas son fosilíferas y suelen tener amonites, bivalvos, belemnites y troncos fósiles. La relación entre fango carbonático y los bioclastos (más de $10 \%$ de fósiles) permite clasificarlas como wackestone.

Asociado a esta facies se registraron trazas fósiles con mala preservación.

Se encuentra en el perfil de ELL y ELV de la región entre los lagos San Martín y Viedma. También en el perfil IG de la Seccional Río Guanaco pero dentro de la Formación Springhill.

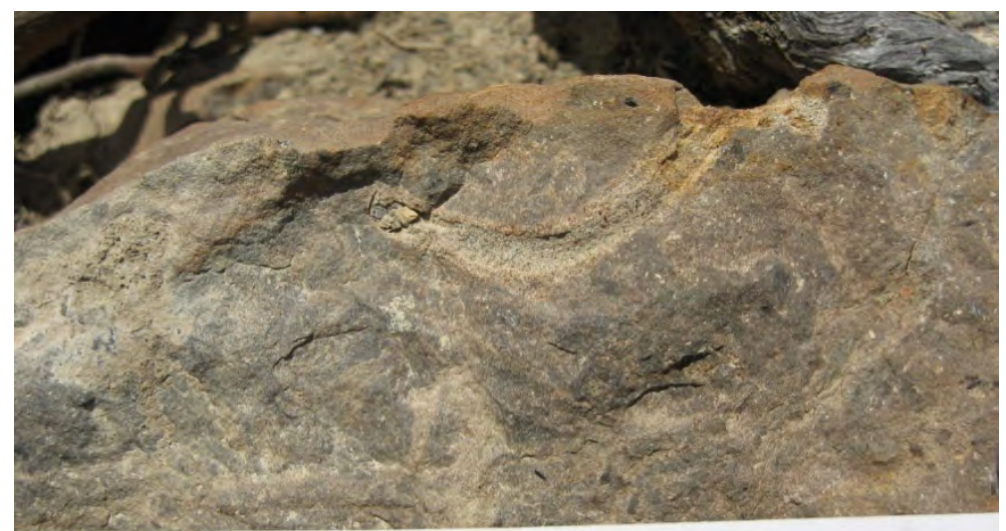

Figura 4.18- Caliza masiva. Foto perfil ELL, Lago San Martín.

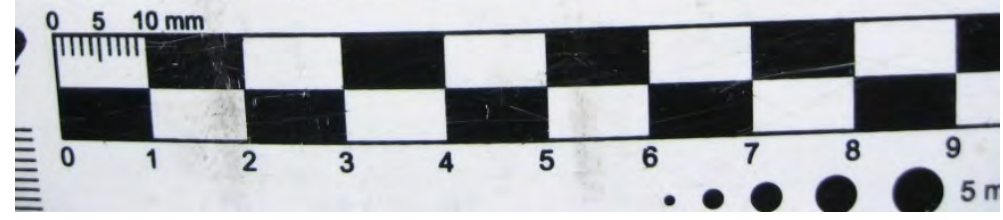




\section{2 - Interpretación de Facies}

Cada facies sedimentaria reconocida responde a un grupo de características depositacionales específicas, entre las que se incluyen la energía del agente, la tasa de sedimentación, la mayor o menor participación de carbonatos y la presencia de organismos bioturbadores, entre otros. A continuación se hará una interpretación elemental de las facies antes descriptas antes de agruparlas en asociaciones de facies.

\begin{tabular}{|c|c|}
\hline Facies & Interpretación \\
\hline Pelitas masivas (Pm) & $\begin{array}{l}\text { Depósitos de decantación silicoclástica. La estructura masiva puede } \\
\text { deberse a floculación de partículas y/o bioturbación. }\end{array}$ \\
\hline Pelitas laminadas (PI) & Depósitos de decantación silicoclástica en ausencia de bioturbación. \\
\hline $\begin{array}{l}\text { Pelitas con nódulos y/o } \\
\text { concreciones (Pn) }\end{array}$ & $\begin{array}{l}\text { Depósitos de decantación silicoclástica con formación de nódulos y/o } \\
\text { concreciones por precipitación de carbonatos de manera aislada. }\end{array}$ \\
\hline Margas masivas (Mm) & $\begin{array}{l}\text { Sedimentación mixta generada por un aumento en la productividad } \\
\text { carbonática y/o una disminución en el aporte clástico. }\end{array}$ \\
\hline $\begin{array}{l}\text { Margas bioturbadas } \\
\text { (Mb) }\end{array}$ & $\begin{array}{l}\text { Idem anterior pero con importante retrabajo de los sedimentos por } \\
\text { parte de los organismos. }\end{array}$ \\
\hline $\begin{array}{l}\text { Heterolítica pelítica con } \\
\text { estratificación lenticular } \\
(\mathrm{Htpw})\end{array}$ & $\begin{array}{l}\text { Depósitos dominados por decantación con breves períodos de eventos } \\
\text { tractivos. }\end{array}$ \\
\hline $\begin{array}{l}\text { Heterolíticas con estrat. } \\
\text { ondulosa (Hto) }\end{array}$ & $\begin{array}{l}\text { Intercalaciones de pelita y arenisca en igual proporción producto de la } \\
\text { alternancia de eventos de decantación y tracción. }\end{array}$ \\
\hline $\begin{array}{l}\text { Heterolítica arenosa con } \\
\text { estratificación flaser } \\
\text { (Htaf) }\end{array}$ & Depósitos dominados por tracción con breves pausas pelíticas. \\
\hline Areniscas masivas (Am) & $\begin{array}{l}\text { Rápida depositación de areniscas sin desarrollo de estructura ó pérdida } \\
\text { de la misma por bioturbación. }\end{array}$ \\
\hline Areniscas laminadas (Al) & Depósito de alto régimen de flujo. \\
\hline $\begin{array}{l}\text { Areniscas con } \\
\text { estratificación } \\
\text { entrecruzada planar (Ap) }\end{array}$ & $\begin{array}{l}\text { Depósito originado por la migración de dunas 2D en ambiente } \\
\text { subácueo. }\end{array}$ \\
\hline Arenisca c/ estratificación & Depósito originado por migración de dunas 3D en ambiente subácueo. \\
\hline
\end{tabular}




\begin{tabular}{|c|c|}
\hline $\begin{array}{l}\text { entrecruzada en artesa } \\
\text { (Aa) }\end{array}$ & \\
\hline $\begin{array}{l}\text { Arenisca c/ deformación } \\
\text { sin-sedimentaria (As) }\end{array}$ & $\begin{array}{l}\text { Depósito psamítico afectado por deformación sin-sedimentaria } \\
\text { producto de la saturación con agua y/o la carga de los sedimentos. }\end{array}$ \\
\hline $\begin{array}{l}\text { Arenisca con intraclastos } \\
\text { (Ai) }\end{array}$ & $\begin{array}{l}\text { Depósito de alta energía. Erosión del sustrato con arranque de clastos } \\
\text { pelíticos. }\end{array}$ \\
\hline $\begin{array}{l}\text { Arenisca sabulítica } \\
\text { gradada (AGc) }\end{array}$ & Depósito de alta energía producto de flujos densos. \\
\hline $\begin{array}{l}\text { Arenisca glauconítica } \\
\text { (Ag) }\end{array}$ & $\begin{array}{l}\text { Depósito con importante participación de material autigénico. Posible } \\
\text { mínimo aporte clástico a la cuenca. }\end{array}$ \\
\hline $\begin{array}{l}\text { Paraconglomerado } \\
\text { masivo con intraclastos } \\
\text { (Fmi) }\end{array}$ & $\begin{array}{l}\text { Depósito de alta energía producto de flujos densos. Erosión del sustrato } \\
\text { con arranque de clastos pelíticos y psamíticos. }\end{array}$ \\
\hline Wackestone masivo (Cm) & Máxima productividad carbonática en ambientes marinos someros. \\
\hline
\end{tabular}




\section{3 - Asociaciones de Facies}

Una asociación de facies es un conjunto de facies que se relacionan genéticamente entre sí, y que poseen un significado ambiental (Collinson, 1969). Con este principio como base, se definieron asociaciones de facies en la Formación Río Mayer (figura 4.18).

El primer paso fue distribuir las facies reconocidas en los perfiles de cada localidad. Para tal motivo, se realizaron secciones ideales a partir de los datos de campo, con especial atención de que en cada sección estén representadas todas las facies observadas. Así, por ejemplo, para la región del Lago San Martín la sección reconstruida se compone de los perfiles Ea. La Lila (parte inferior), Ea. La Federica (medio) y Ea. Kachaike (parte superior).

Para la definición de las asociaciones se tomó en cuenta una característica no usada para la enunciación de las facies anteriormente citadas que es el contenido fósil. Esta propiedad fue útil para separar aquellas asociaciones de neto carácter marino de las marinas con influencia continental (figura 4.19).

Cabe aclarar que las correlaciones aquí mostradas serán desarrolladas en capítulos siguientes, con lo cual ahora no se hará referencia a paralelismos paleoambientales con las formaciones supra e infrayacentes. La escasa información recuperada de los afloramientos de la región de la margen norte del Lago Argentino no permitió realizar correlaciones con el resto de los afloramientos.

De modo tal que se determinaron 3 asociaciones de facies en la Formación Río Mayer a saber: 


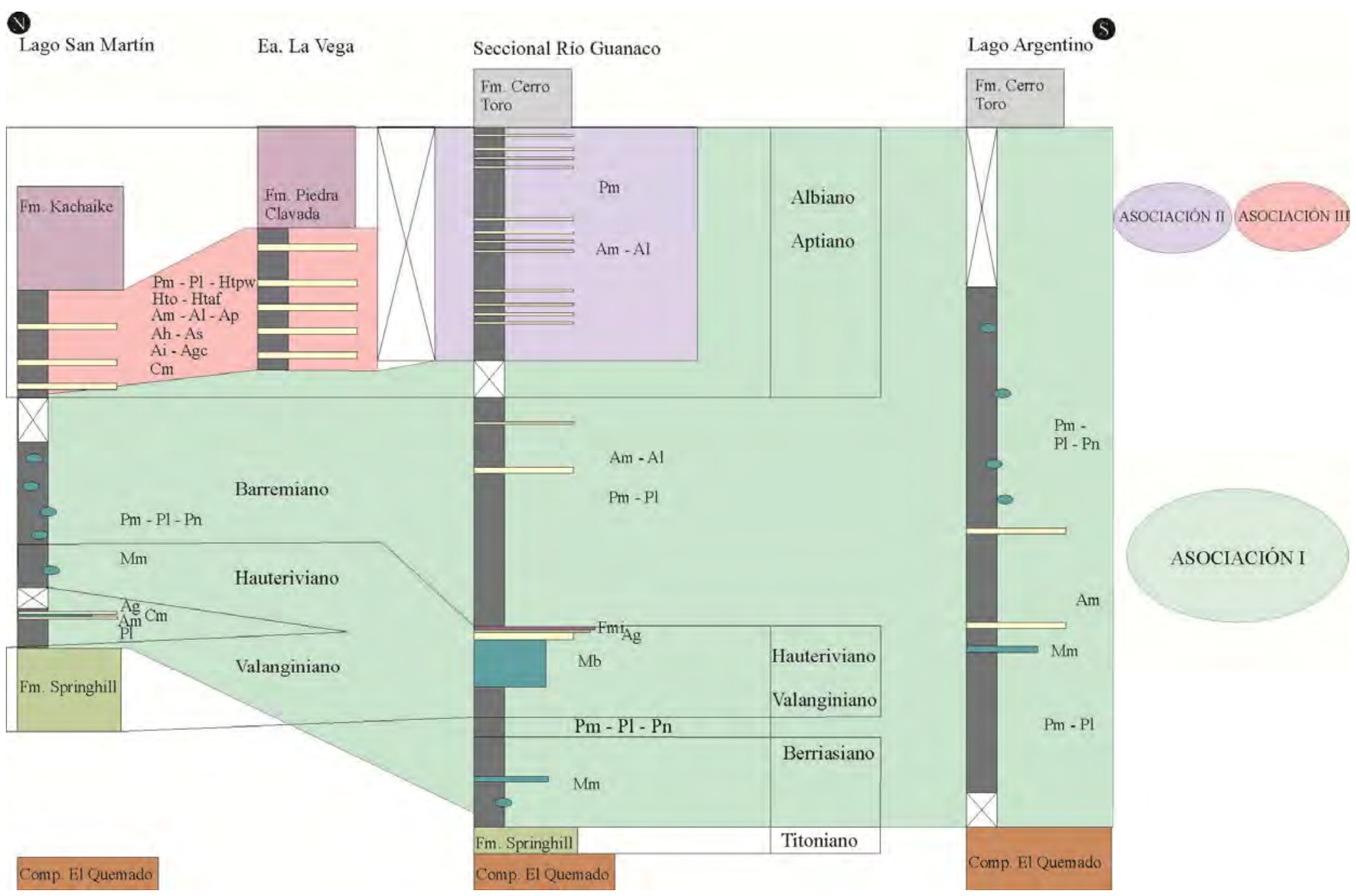

Figura 4.19- Distribución de facies en la Formación Río Mayer. Perfiles representativos de la sección completa de la unidad en cada localidad. 


\section{Facies}
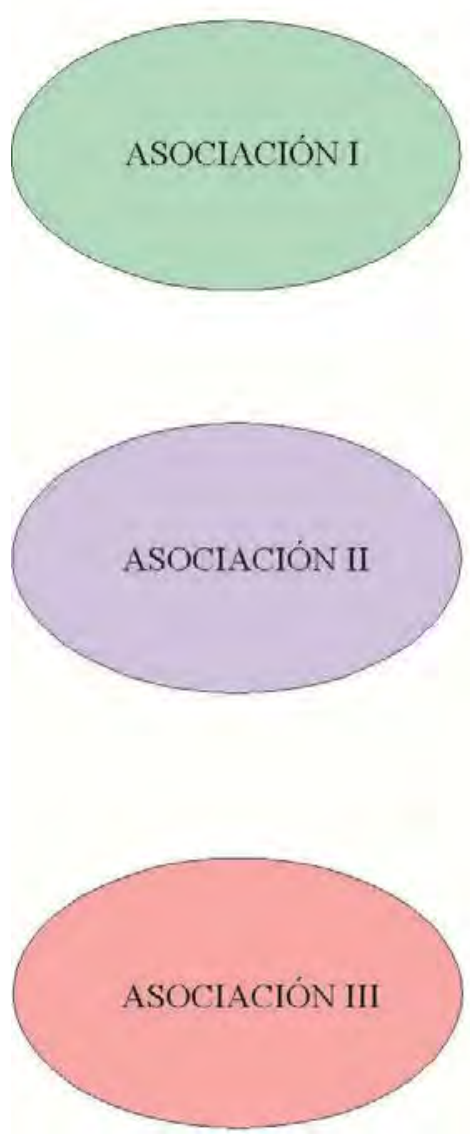

\section{Procesos}

\begin{tabular}{|l|l|l|}
\hline $\mathrm{Pm}-\mathrm{Pl}-\mathrm{Pn}-\mathrm{Mm}-\mathrm{Mb}$ & \multicolumn{2}{|c|}{ Depositación Hemipelágica } \\
\hline $\mathrm{Cm}$ & \multicolumn{2}{|c|}{ Precipitación carbonática } \\
\hline $\mathrm{Ag}$ & \multicolumn{2}{|c|}{ Depositación Autigénica } \\
\hline $\mathrm{Am}-\mathrm{Al}-\mathrm{Ap}$ & Corrientes de turbidez & $\begin{array}{l}\text { Depositación } \\
\text { Episódica }\end{array}$ \\
\hline $\mathrm{Fmi}$ & Flujos de detritos & . \\
\hline
\end{tabular}

\begin{tabular}{|l|l|l|}
\hline Pm & \multicolumn{2}{|c|}{ Depositación Hemipelágica } \\
\hline $\mathrm{Am}-\mathrm{Al}$ & Corrientes de turbidez & $\begin{array}{l}\text { Depositación } \\
\text { Episódica }\end{array}$ \\
\hline
\end{tabular}

\begin{tabular}{|l|c|c|}
\hline Pm - Pl- Htpw & \multicolumn{2}{|c|}{ Depositación Hemipelágica } \\
\hline $\mathrm{Cm}$ & \multicolumn{2}{|c|}{ Precipitación carbonática } \\
\hline $\mathrm{Am}-\mathrm{Al}-\mathrm{Ap}-\mathrm{Aa}-\mathrm{As}-\mathrm{Hto}-\mathrm{Htaf}$ & $\begin{array}{c}\text { Corrientes de turbidez/ } \\
\text { Flujos Hiperpícnicos }\end{array}$ & $\begin{array}{l}\text { Depositación } \\
\text { Episódica }\end{array}$ \\
\hline $\mathrm{Ai}-\mathrm{Agc}$ & & \\
\hline
\end{tabular}

\section{Paleoambiente}

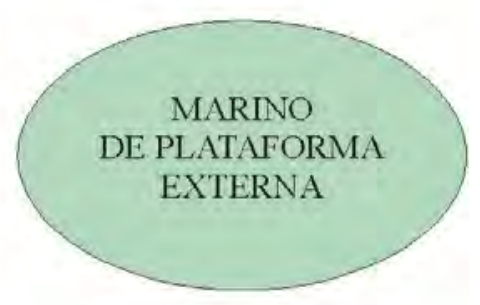

MARINO DE PLATAFORMA EXTERNACON INFLUENCIA DELTAICA DISTAI

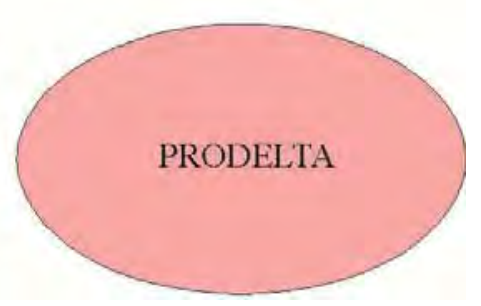

Figura 4.20- Asociaciones de facies presentes en la Formación Río Mayer. 
Asociación I: se compone de depósitos netamente marinos, en los que predominan los procesos suspensivos, y la presencia de pelitas ó margas se ve principalmente afectada por el mayor o menor aporte clástico. La fauna se compone de amonites, belemnites, bivalvos y trazas fósiles de ambientes de plataforma externa (desarrollo en capítulos VIII y IX). Este tipo de sedimentación se ve interrumpida eventualmente por flujos turbidíticos y/o de detritos. Esta asociación representa las típicas descripciones para esta unidad tradicionalmente manifestadas en la bibliografía.

Asociación II: es similar a la asociación I pero se diferencia principalmente en la evidencia de un mayor aporte de psamitas producto de la acción distal del sistema deltaico Kachaike-Piedra Clavada. Presenta impresiones de material vegetal (ramas, no briznas) y trazas fósiles que denotan conexión con ambientes litorales (ver capítulo VIII Ophiomorpha rudis, Teredolites isp.-).

Asociación III: en contraste con las dos asociaciones anteriores, en ésta hay una alta participación de eventos tractivos que suelen alternar con pausas de decantación. El material fósil está dominado por briznas vegetales restos de madera petrificada, con proporciones menores de bivalvos y gasterópodos. Sólo se registra un icnogénero el cual está vinculado a ambientes de mezcla salobres (ver capítulo VIII -Gyrolithes isp.-).

La participación de cada una de las facies sedimentarias dentro de cada asociación se expone en la tabla 4.a. De la mencionada tabla se desprende la notable participación de los depósitos relacionados a procesos hemipelágicos en las asociaciones 1 y 2, participando con más del 95\% de los depósitos. Por otro lado la asociación de facies 3 se caracteriza por un notorio incremento en la participación de areniscas que alcanzan el $35 \%$ de las sedimentitas de esta asociación. 


\begin{tabular}{|c|c|c|c|c|c|c|c|c|c|c|c|c|c|c|c|c|c|}
\hline & \multicolumn{17}{|c|}{ facies\% } \\
\hline & $\mathrm{Pm}$ & & $\mathrm{Pn}$ & $\mathrm{Mm}$ & $\mathbb{M b}$ & How & Hito & Hatat & $\mathrm{Am}$ & Al & $\mathrm{Ag}$ & Ap & $\mathrm{Ai}$ & As & $\mathrm{Ad}$ & AGC & $\mathrm{Fmi}$ C \\
\hline Asociación 1 & 58,12 & & 10,4 & 3,33 & 17,30 & & & & 1,44 & 0,69 & 0,35 & & & & & & $0,090,06$ \\
\hline Assciación & 96,9 & & & & & & & & 2,5 & 0,6 & & & & & & & | \\
\hline Assciación & 8,29 & 39,18 & & 0,36 & & 8,94 & 4,07 & 3,45 & 21,9 & 3,16 & & 2,64 & 1,33 & 4,67 & 0,36 & 1,2 & 0,48 \\
\hline
\end{tabular}

Tabla 4.a- Cantidades porcentuales de cada facies sedimentaria en las 3 asociaciones reconocidas en la Formación Río Mayer. 


\section{4 - Interpretación de los Procesos sedimentarios en la Formación Río} Mayer

A continuación se hará mención de las características principales de los procesos formadores de facies sedimentarias reconocidas. Sin embargo, el marco paleoambiental en el cual se desarrollan será discutido con mayor detalle en el capítulo IX.

Los procesos sedimentarios en ambientes de plataforma y marino profundo pueden ser de carácter erosivo o constructivo. Dentro de los erosivos el principal es la canalización generada en las inmediaciones del talud. Dicho tipo de rasgos no han sido identificados en la Formación Río Mayer. Entre los procesos de carácter constructivo se hallan una gran variedad de depósitos, entre ellos los autigénicos, hemipelágicos, y episódicos, que sí se encuentran representados en esta unidad. Una de las principales diferencias entre estos tres tipos de procesos es la tasa de sedimentación, que puede variar desde muy baja (dep. autigénicos) a muy alta (dep. de flujos de detritos).

Los procesos sedimentarios constructivos en plataforma interna afectada por influencia deltáica se componen de procesos que pueden asimilarse a los de plataforma externa, variando esencialmente en la periodicidad de los eventos episódicos, los cuales dejan de ser episódicos para ser ordinarios.

A continuación se detallarán brevemente las principales características de estos procesos a fin de comprender de una manera más acabada los paleoambientes en que se desarrollaron.

\section{4.1 - Características de los depósitos Autigénicos}

Este tipo de depósitos está constituido por un conjunto de minerales formados in situ. Las bajas tasas de sedimentación de los ambientes marinos profundos (por ejemplo 1 $\mathrm{mm} / \mathrm{ka}$ ) hacen posible la formación de minerales autigénicos o intracuencales. Uno de los más característicos es la glauconita, nombre dado a una asociación de minerales del grupo de las arcillas, entre las cuales las Cloritas y los Interestratificados I/S glauconíticos son los argilominerales más frecuentes.

La formación de glauconita se compone de dos etapas, primero se rellenan los poros

y fisuras en el sustrato con material arcilloso no glauconítico rico en potasio (K). El segundo paso es el enriquecimiento en K del material (Odin y Lamboy, 1988). 
Odin y Matter (1981), agrupan los posibles sustratos en 4 grupos:

$>\quad$ Pellets fecales: son el principal sustrato sobre el que se desarrolla el proceso de glauconitización y se generarían por la acción de diferentes tipos de organismos tanto suspensívoros como detritívoros. El proceso se iniciaría en poros generados en los pellets por disolución parcial de los agregados.

$>$ Bioclastos: Pueden ser tanto carbonáticos como silicoclásticos, en este sustrato el proceso se concentra en perforaciones realizadas por otros organismos.

Detritos minerales: se inicia en imperfecciones de los granos, en general microfracturas.

Microfaunal test infillings: en este caso el proceso de glauconitización de presenta en los microorganismos, pero a diferencia de los bioclastos, la arcillas glauconíticas rellenan las cámaras de foraminíferos y otros microorganismos.

Los depósitos glauconíticos poseen dos hábitos, granular y pelicular, dependiendo de la forma del sustrato sobre el que se desarrollan. Presentan tres componentes, restos del sustrato preliminar, minerales glauconíticos y minerales formados durante la diagénesis temprana. En regiones de latitudes bajas es común como relicto la presencia de Caolinita, mientras que a altas latitudes predominan asociaciones de illita, clorita y esmectita (Odin y Fullagar, 1988).

Como fuera mencionado antes, el proceso comienza con el relleno de poros y fisuras, esto da el color verde inicial al proceso (denominado “verdisement”). El sustrato original está en desequilibrio con el agua de mar, y poco a poco se va transformando. Mientras se van formando minerales autigénicos se van creando nuevos poros en el sustrato para rellenar. De esta manera el grano va evolucionando a medida que aumenta el contenido de $\mathrm{K}_{2} \mathrm{O}$ (figura 4.20). Odin y Fullagar (1988) indican que un contenido de $\mathrm{K}_{2} \mathrm{O}$ de $7 \%$ indica una pausa en la sedimentación de entre $10^{4}$ y $10^{5}$ años. La evolución continúa mientras las condiciones se mantienen, una regresión marina generaría ambientes más oxigenados y una transgresión que el depósito pase a ser una fosforita. También se puede cortar la evolución por un aumento en la tasa de sedimentación. 


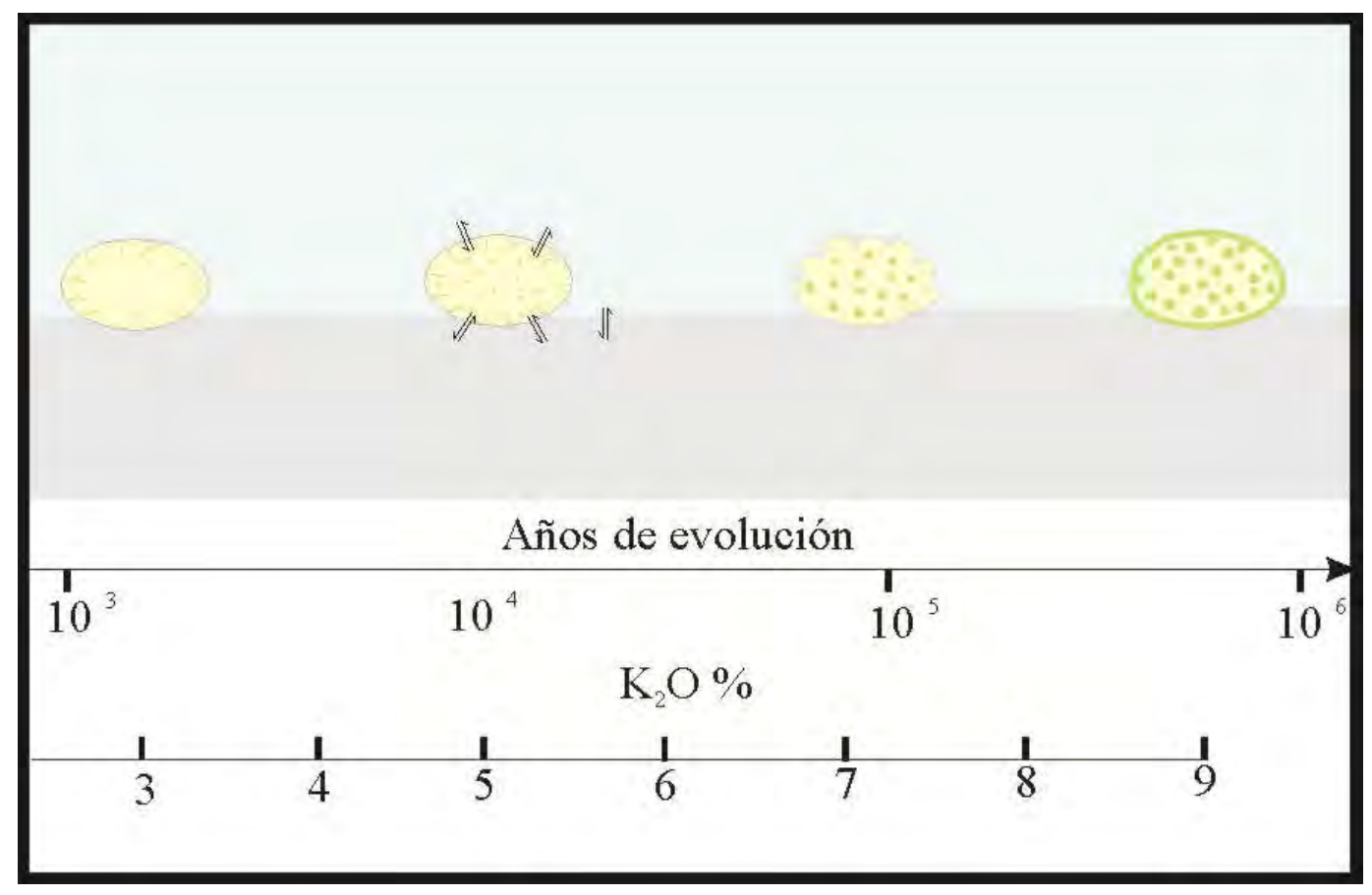

Figura 4.21- Glauconitización de un grano mineral ubicado en la interfase aguasedimento. Primero se rellenan los poros y fisuras, luego durante la evolución aumenta el contenido de $\mathrm{K}_{2} \mathrm{O}$ por intercambio catiónico. Cerca de los $10^{6}$ años no hay evolución. Modificado de Odin y Fullagar (1988).

Todo el proceso se desarrolla bajo un microambiente muy especial en la interfase agua-sedimento. Es fundamental la presencia de poros para la creación de dicho microambiente aislado parcialmente del agua de mar. El intercambio catiónico debe ser posible y ocurrir lentamente. Algunos estudios en ejemplos actuales demuestran que la glauconitización ocurre a pH 7,9- 8 (Boichard et al., 1985). A su vez, cerca de la interfase agua sedimento se encuentra el límite de la óxido-reducción, así tenemos agua con condiciones oxidantes y un microambiente desarrollado dentro de los sedimentos de características reductoras (Ireland et al., 1983). Las profundidades son variables, en el océano Atlántico se encuentra entre 65 y 550 m. b. n. m. Según Odin (1973), la profundidad óptima es de unos 200 m.b.n.m.

\section{4.2 - Características de los depósitos Hemipelágicos}

La depositación hemipelágica es un proceso complejo que se produce por la decantación de material en suspensión a través de la columna de agua. Dicho material no 
sólo se ve afectado por movimientos verticales, sino que puede ser movilizado por derivas laterales (Stow et al., 2001).

Se compone en más de 75\% de material terrígeno, con tasas de sedimentación típicas que rondan entre 5 y $15 \mathrm{~cm} / \mathrm{ka}$. Existen 5 posibles fuentes para el material terrígeno (Stow et al., 1996), que son:

$>\quad$ Fluvial: descarga de ríos.

$>\quad$ Costa: transporte por tormenta de sedimentos desde zonas costeras.

$>\quad$ Sedimentos glaciales: aportes relacionados a glaciares (ie: transporte en témpanos).

Sedimentos eólicos: El mayor aporte de sedimentos terrígenos al ambiente marino profundo es proveniente del continente por transporte eólico.

$>$ Sedimentos volcaniclásticos: se compone del aporte proveniente de erupciones volcánicas.

Un tipo particular de sedimentación hemipelágica es la producida durante las corrientes de turbidez la que denomina sedimentación hemiturbidítica (Stow y Wedsel, 1990). Se produce de dos maneras, (1) durante el estadio final de una corriente de turbidez diluida en la cual el material fino queda en suspensión o (2) por el "choque” de una corriente de turbidez (no necesariamente diluida) con un obstáculo de relieve positivo sobre el lecho marino (Stow et al., 2001).

Una característica importante de los depósitos tanto pelágicos como hemipelágicos es el contenido en proporciones variables de materia orgánica (MO). La preservación de MO depende de las siguientes variables (Stow et al., 2001):

Aporte vs. origen de la MO: En lugares dónde el aporte supera la degradación la MO será preservada. Por ejemplo son zonas favorables las regiones de up-welling o en cercanías a la desembocadura de ríos con gran aporte de detritos orgánicos.

Tipos de MO: cada clase de MO posee diferentes proporciones de biopolímeros con distintos comportamientos frente a la descomposición.

Anoxia de las aguas de fondo marino: la escasez de oxígeno limita el desarrollo de mega y mesofauna, además retarda el deterioro bacteriano de la MO. La anoxia puede ser resultado de varios factores, entre los principales se encuentran 
las restricciones a la circulación de corrientes por parte de una barrera topográfica. Este factor es fundamental para la preservación de MO.

$>$ Sepultamiento rápido: como consecuencia de una alta tasa de sedimentación la MO se aleja de manera rápida de la zona más oxigenada de la columna sedimentaria.

> Vulcanización natural: cuando se acumula gran cantidad de materiales metabolizables en el fondo marino, unos centímetros por debajo de la interfase agua-sedimento puede ocurrir la reducción del sulfato. Este proceso de carácter anaeróbico oxida la MO usando sulfato como oxidante. La liberación de H2S genera la unión de biomoléculas y la formación de geobiopolímeros resistentes que favorecen la preservación.

$>\quad$ Sedimentos finos: estos sedimentos limitan la permeabilidad y por lo tanto aíslan la MO atrapada en ellos de aguas oxigenadas.

Entre los modelos existentes para lutitas negras hay dos corrientes de ideas: los modelos en que prevalece el aporte y en los que domina la preservación (Stow et al., 1996).

Además de materia orgánica, asociados a depósitos hemipelágicos se pueden hallar sedimentos autigénicos. La asociación de hemipelagitas con fosfatos se asocia a muy bajo contenido de oxígeno en zonas marinas profundas (Burnett, 1977; Bentor, 1980); mientras que la asociación con glauconita se registra a menores profundidades (Odin y Matter, 1981).

\section{4.3 - Características de los depósitos de Sedimentación Episódica}

\section{4.3.1- En Ambientes Marinos}

Incluye un grupo de procesos que son los principales responsables del transporte de grandes volúmenes de material sedimentario desde los ambientes marinos someros hacia los profundos (Einsele, 1991).

El primer paso para analizar los depósitos es comprender las características de los flujos que los transportaron. Así, según Lowe (1979), podemos clasificar los flujos en dos tipos: plásticos y fluidos. Una diferencia importante es que los fluidos van depositando sedimento mientras van perdiendo energía, en cambio los plásticos no, sino que se congelan 
(“freezing”) al alcanzar un umbral mínimo de esfuerzo. Ambos son mezclas de proporciones variables de agua y sedimento (figura 4.21-A).

Los mecanismos de soporte de las partículas en el flujo son los siguientes (Middleton y Hampton, 1976):

I- empuje por una matriz cohesiva

II- colisión intergranular (dispersión de presión)

III- exceso de presión en el fluido poral (licuefacción)

IV- escapes de agua (fluidización)

V- turbulencia

Otra caracterización de los flujos se puede realizar sobre la base de relaciones entre velocidad, tiempo y espacio; así surgen las propiedades de estabilidad y uniformidad (figura 4.21-B). La estabilidad refiere a los cambios en la velocidad del flujo con respecto al tiempo en un punto fijo del espacio. En un flujo no estático si la velocidad aumenta se denomina “waxing” y si disminuye “waning”. En cambio, la uniformidad tiene en cuenta la variación de velocidad del flujo con respecto al espacio en el cual se mueve. Se usan los términos “accumulative” y “depletive” para referirse a variaciones positivas y negativas, respectivamente, de la uniformidad (Kneller y Branney, 1995).

Según Kneller y Branney (1995), por diferentes combinaciones de los parámetros de estabilidad y uniformidad existen 13 tipos de corrientes de turbidez (figura 4.21-B), sin embargo, los modelos clásicos de turbiditas se concentran en un solo tipo, un flujo muy inestable (waxing) y fuertemente uniforme (depletive). Siguiendo esta premisa, en la figura 4.21C, se muestra la posible coexistencia de un flujo de detrito originado por una inestabilidad en la pendiente del fondo marino con una corriente de turbidez. En su trayectoria hacia zonas más profundas el flujo pierde velocidad, deposita la carga más gruesa y paulatinamente puede incorporar agua hasta volverse turbulento. Esta evolución es la que refleja el modelo depositacional propuesto por Lowe (1982) para flujos de alta densidad que finalizan con la serie de Bouma (1962). 


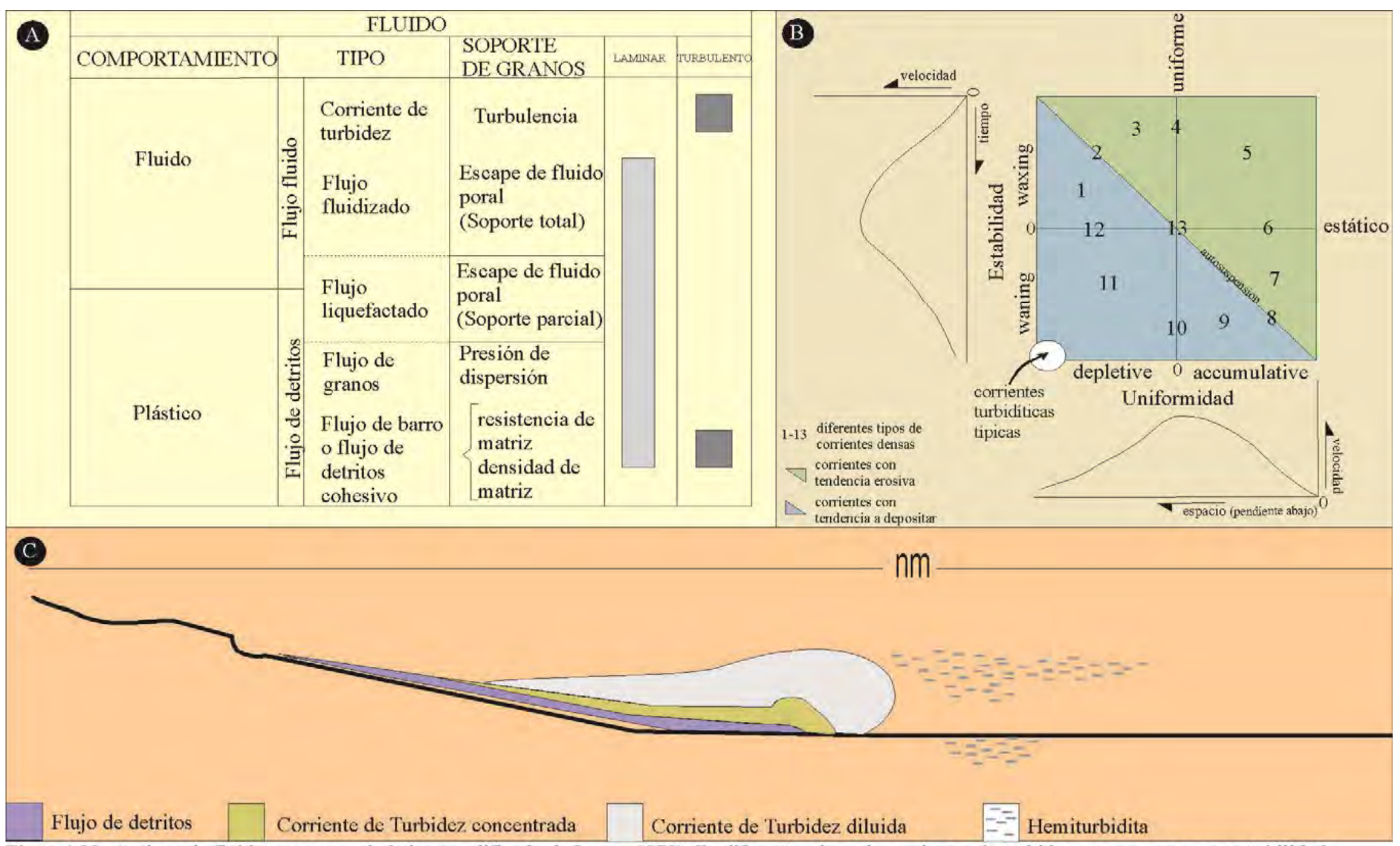

Figura4.22- A- tipos de fluidos y sus propiedades (modificado de Lowe, 1979). B- diferentes tipos de corrientes de turbidez con respecto a su estabilidad y uniformidad (modificado de Kneller y Branney, 1995). C- Evolución desde un flujo de detritos hacia una corriente de turbidez. 


\section{4.3.2- En Prodelta}

El prodelta es la región deltáica donde predomina la sedimentación de material fino, el cual en dirección hacia el mar se interdigita con los depósitos plataformales.

Cuando un río llega a la desembocadura pierde capacidad de carga y deposita la mayor parte del material que transporta. La distribución y morfología de las facies dependerá en gran medida de la relación de densidades entre la corriente fluvial entrante y el agua de mar (Bhattacharya, 2006). De esta manera tendremos 3 tipos de flujos para el transporte de sedimentos:

> Flujos Hiperpícnicos: la pluma fluvial es más densa que el agua de mar. Éstos actúan como bypass para los sedimentos desde las zonas someras a las profundas en forma de corrientes densas. Pueden constituir un aporte significativo a los depósitos turbidíticos profundos.

Flujos Homopícnicos: se dan cuando las densidades de la corriente fluvial y el agua de mar son equivalentes. Son muy raros, ya que una leve diferencia de densidades genera flujos hiper o hipopícnicos.

Flujos Hipopícnicos: aquí la corriente fluvial posee menor densidad que el agua de mar y genera una pluma de sedimentos en suspensión que se transporta mar adentro. Aporta gran cantidad de sedimentos al proceso hemipelágico. 


\section{5- Consideraciones preliminares}

En la Formación Río Mayer se identificaron un total de 18 facies sedimentarias las cuales se distribuyen en 6 grupos principales, Facies Pelíticas, de Margas, Heterolíticas, de Areniscas, Psefíticas y de Calizas.

Estas facies se agruparon en tres asociaciones de facies: I, II, y III las cuales se interpretaron como desarrolladas en ambiente marino de plataforma externa, marino con influencia deltáica distal y prodelta respectivamente.

Los distintos procesos formadores de facies sedimentarias fueron analizados por separado y en orden creciente de tasa de sedimentación. Los procesos hemipelágicos son los que predominan en la Formación Río Mayer y se los reconoce en las tres asociaciones, constituyendo casi la totalidad de las asociaciones de plataforma externa. Por otro lado los procesos que depositan las facies psamíticas (en menor medida psefíticas) tienen una participación muy importante en la asociación 3, que corresponde a los depósitos de prodelta. Finalmente, los procesos autigénicos actuaron en la formación de los niveles de glauconita y sólo fueron reconocidos en la asociación 1. 


\section{Capítulo V - Análisis por Difractometría de Rayos X}

\section{V.1 - Introducción}

Se analizó la composición mineral de la Formación Río Mayer por difractometría de rayos x (DRX) en un total de 119 muestras. Los detalles de la metodología empleada para la obtención de los difractogramas puede ser consultada en el capítulo I (ver capítulo I. 4.3.4). La cuantificación de los minerales intervinientes en cada muestra tiene dos pasos, primero la determinación de cada especie mineral a partir de la lectura de los picos producto de las refracciones de los rayos x. El segundo paso es la ponderación (semicuantitativa) de la participación de cada mineral.

Para la identificación mineral partir de los gráficos de roca total y fracción fina (figura 5.1) se empleó el valor de espaciado $2 \Theta$ (donde $\Theta$ es el ángulo de refracción), el cual mediante fórmulas matemáticas se convierte en espaciado (en $\AA$ ) de los planos generadores de las refracciones según la Ley de Bragg (Brindley, 1961; Brown, 1980). Luego se compara con patrones internacionales para cada mineral.

Con respecto a la semicuantificación se realizó por separado la roca total y la fracción arcilla. De este modo para la roca total se considera la altura del pico principal de cada mineral, que indica la intensidad de la refracción. Esta intensidad varia levemente cada vez que la misma muestra pasa por el difractómetro, por tal razón, la medición es semicuantitativa.

Para la cuantificación de las arcillas se tomó en cuenta la superficie generada entre el pico 001 de cada mineral en la muestra natural y el fondo de dicha muestra. Dado que los picos 001 de caolinita y 002 de clorita coinciden en $7 \AA$, se cuantificó este pico y se utilizaron para estimar las proporciones de estas dos especies minerales los picos 002 de

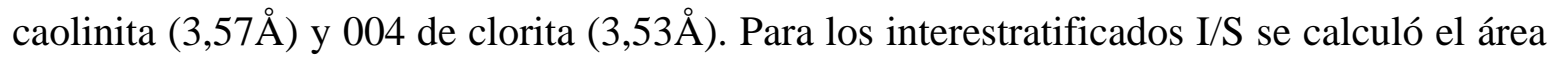
de los picos entre 10 y $14 \AA$.

Se calculó el índice de cristalinidad de illita (IC) ó de Kubler (1966) a partir del pico 001 de este mineral. Este índice expresa las condiciones aproximadas de soterramiento a las que estuvo expuesto el sedimento. Se calcula midiendo el ancho del pico a la mitad de su altura, expresado en 2Ө. Para este mineral, valores mayores a 0,42 son interpretados como 
diagenéticos, entre 0,42 y 0,25 como anquimetamorfismo y menores de 0,25 son metamórficos.
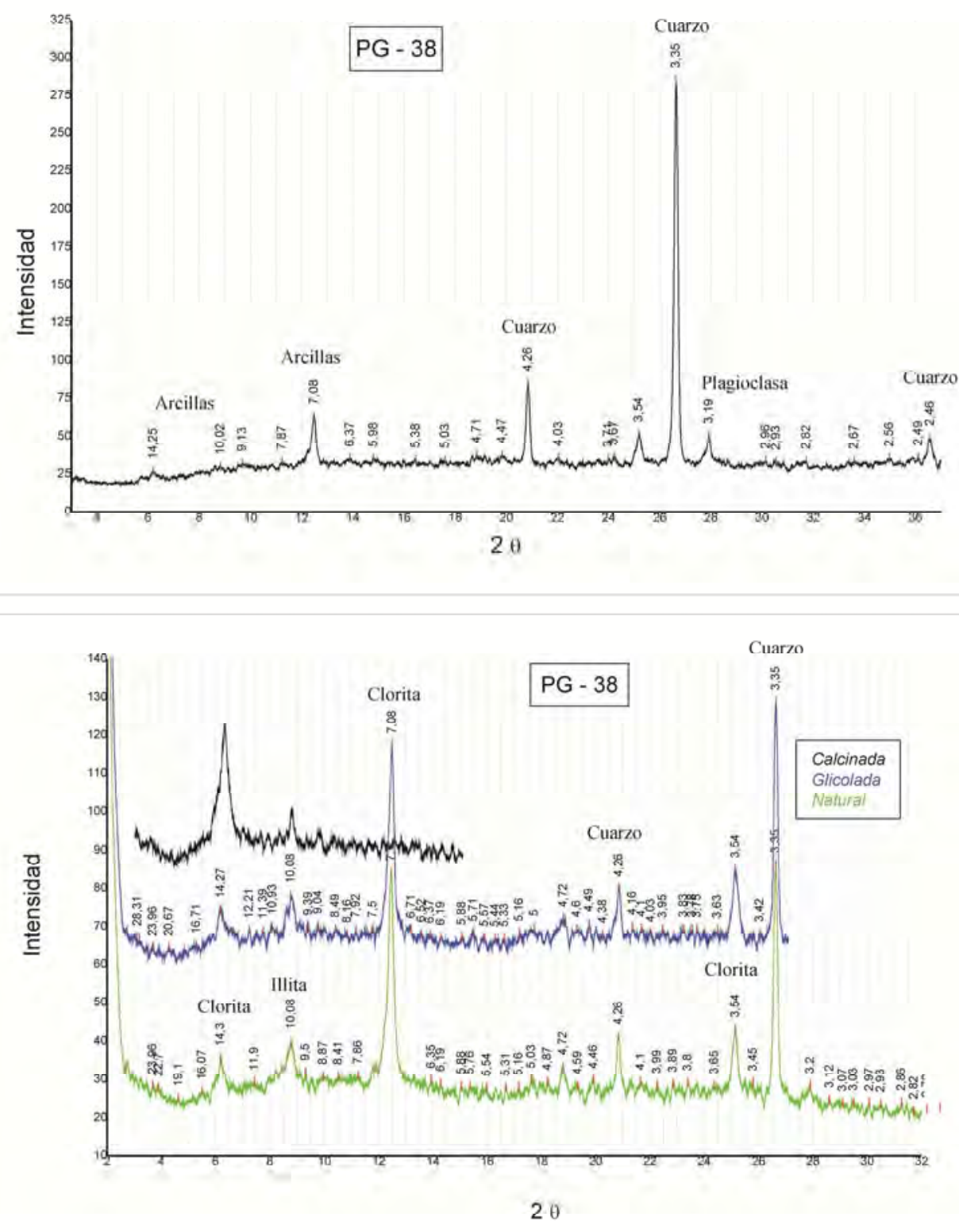

Figura 5.1- Ejemplos de diagramas de DRX, en este caso la muestra PG 38.Arriba la muestra total, donde se observa con claridad el predominio cuarzo acompañado por arcillas y plagioclasa. En el gráfico inferior la muestra de la fracción fina en la cual predomina la clorita acompañada principalmente por illita. 
Por otra parte se calculó el Índice de Esquevin (IE) (Esquevin, 1969), el cual mide la división entre el pico 002 y el 001 de la illita en la muestra natural, cuando los valores son mayores a 0,40 las muestras son aluminosas, y valores menores a 0,25 indican muestras ferromagnesianas.

También se procedió a la caracterización de los interestratificados I/S en las muestras en que el pico de ese grupo mineral estuviera bien desarrollado. Primero se cuantificó la cantidad de capas expansivas siguiendo dos metodologías, la de Powel et al., (1978) y la de Moore y Reynols (1989). Según los primeros autores el porcentaje de capas expansivas se puede calcular directamente utilizando el valor del pico 001 en la muestra natural. En cambio, la metodología empleada por Moore y Reynols (1989) se basa en el uso de los picos 002 y 003 del IS en la muestra glicolada. Los valores de las dos metodologías se muestran en la tabla 5.a.

\begin{tabular}{|c|c|}
\hline \multicolumn{2}{|c|}{ Powel et al ., 1978} \\
\hline Pico I/S (muestra natural) & $\%$ Capas expansivas \\
\hline $10,25-10,45$ & $20-30$ \\
\hline $10,45-10,90$ & $30-40$ \\
\hline $10,90-11,10$ & $40-50$ \\
\hline $11,10-11,40$ & $50-60$ \\
\hline $11,40-11,80$ & $60-70$ \\
\hline $11,80-12,26$ & $70-80$ \\
\hline
\end{tabular}

\begin{tabular}{|c|c|}
\hline \multicolumn{2}{|c|}{ Moore y Reynolds, 1989} \\
\hline$\Delta 2 \theta$ (muestra glicolada) & $\%$ Capas expansivas \\
\hline 5,68 & 80 \\
\hline 5,94 & 70 \\
\hline 6,16 & 60 \\
\hline 6,52 & 50 \\
\hline 7,01 & 40 \\
\hline 7,38 & 30 \\
\hline 7,88 & 20 \\
\hline
\end{tabular}

Tabla 5a- Cálculo de porcentaje de capas expansivas en los interestratificados IS según las metodologías de Powel et al. (1978) y Moore y Reynolds (1989).

Posteriormente, se clasificó cada muestra por su potencial en la producción de hidrocarburos según los criterios de Foscolos et al. (1976), los que se expresarán más adelante (apartado V.3.3).

El único registro comparativo de análisis de difractometría de rayos $\mathrm{X}$ en la Formación Río Mayer es un trabajo publicado por Iñiguez Rodríguez y Decastelli (1984) durante el $9^{\circ}$ Congreso Geológico Argentino. Estos autores analizan la composición mineralógica de las arcillas en 4 pozos que atraviesan el relleno sedimentario de la Cuenca Austral, en los cuales la Formación Río Mayer se correlaciona con parte inicial de la Formación Palermo Aike. 


\section{V.2 - Selección de las muestras}

Las mayor parte de las muestras analizadas (105) provienen de los perfiles IG, PG y EVP1 de la región de Río Guanaco (figura 3.8) y las restantes (14) de los perfiles PELL, PEF y PEKA del Lago San Martín (figura 3.2). Se eligieron estos perfiles porque entre ellos forman una columna representativa de la unidad, y en especial para la seccional Río Guanaco, las tres secciones observadas en el campo están presentes (figura 3.16).

Se decidió concentrar los datos en la región de Río Guanaco por poseer los mejores y más completos afloramientos del área de tesis. Esta iniciativa se hizo extensiva a los análisis geoquímicos y en menor medida a la petrografía (capítulos VII y VI respectivamente).

\section{V.3 - Seccional Río Guanaco}

\section{V.3.1- Análisis de la roca total y la fracción fina}

Perfil IG

Mediante difracción de rayos X se analizaron un total de 33 muestras de roca, las cuales arrojaron los siguientes resultados (figura 5.2; tabla 5.b):

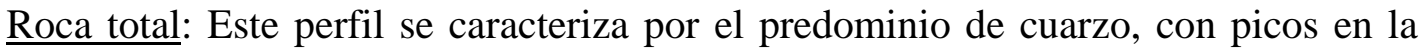
participación carbonática marcados por la presencia de calcita. Los contenidos de arcillas y feldespatos en general se encuentran entre muy escasos a escasos. Entre los feldespatos sólo se registró plagioclasa.

Fracción fina: Este perfil se caracteriza por poseer cantidades equivalentes de illita, clorita e interestratificados de illita/esmectita, con leve predominio de illita sobre las otras dos. La caolinita en general aparece acompañando en porcentajes menores al 5\%. 


\section{PERFIL INICIO DEL GRABEN}

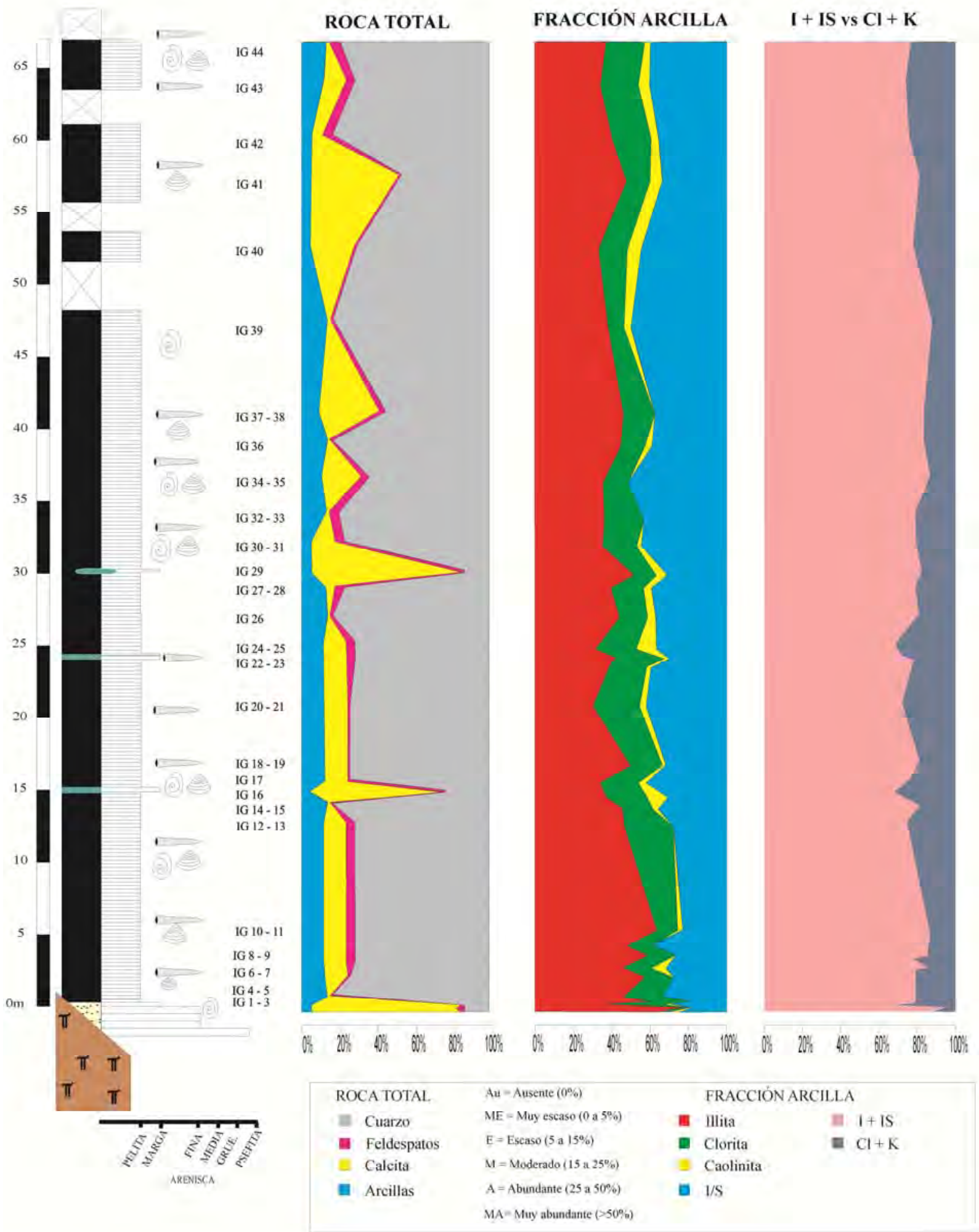

Figura 5.2 - Distribución y cantidades semicuantitativas de los minerales reconocidos a partir de la difracción de rayos $\mathrm{X}$ en el Perfil IG. 


\begin{tabular}{|c|c|c|c|c|c|c|c|c|c|c|}
\hline \multirow[b]{3}{*}{ MUESTRA } & \multicolumn{6}{|c|}{ Roca Total } & \multicolumn{4}{|c|}{ Arcillas } \\
\hline & \multirow[b]{2}{*}{ Cuarzo } & \multicolumn{2}{|c|}{ Feldespato } & \multirow[b]{2}{*}{ Calcita } & \multirow[b]{2}{*}{$\mathrm{Py}$} & \multirow[b]{2}{*}{ Arc } & \multirow[b]{2}{*}{$\mathrm{I}$} & \multirow[b]{2}{*}{ IS } & \multirow[b]{2}{*}{$\mathrm{Cl}$} & \multirow[b]{2}{*}{ K } \\
\hline & & $\mathrm{Pl}$ & FK & & & & & & & \\
\hline IG 1 & 10 & 1 & 0 & 60 & $\mathrm{x}$ & 4 & 64,38 & 24,03 & 5,79 & 5,79 \\
\hline IG 2 & 10 & 4 & 0 & 60 & 0 & 4 & 76,60 & 18,40 & 3,33 & 1,67 \\
\hline IG 3 & 10 & 1 & 0 & 60 & 0 & 4 & 37,47 & 28,78 & 29,35 & 4,40 \\
\hline IG 4 & 60 & 1 & 0 & 1 & 0 & 10 & 60,40 & 18,87 & 20,73 & 0,00 \\
\hline IG 5 & 60 & 1 & 0 & 1 & $\mathrm{x}$ & 10 & 46,35 & 32,96 & 20,68 & 0,00 \\
\hline IG 6 & 60 & 1 & 0 & 10 & $\mathrm{x}$ & 10 & 57,15 & 27,61 & 15,24 & 0,00 \\
\hline IG 7 & 60 & 1 & 0 & 10 & $\mathrm{x}$ & 10 & 46,17 & 31,62 & 14,80 & 7,40 \\
\hline IG 8 & 60 & 4 & 0 & 10 & $\mathrm{x}$ & 10 & 58,88 & 26,41 & 14,71 & 0,00 \\
\hline IG 9 & 60 & 4 & 0 & 10 & $x$ & 10 & 48,45 & 38,58 & 12,96 & 0,00 \\
\hline IG 10 - 11 & 60 & 4 & 0 & 10 & $\mathrm{x}$ & 10 & 63,57 & 22,78 & 10,92 & 2,73 \\
\hline IG $12-13$ & 60 & 4 & 0 & 10 & $\mathrm{x}$ & 10 & 46,92 & 27,80 & 25,28 & 0,00 \\
\hline IG14 - 15 & 60 & 1 & 0 & 1 & $x$ & 10 & 45,86 & 35,70 & 16,04 & 2,41 \\
\hline IG 16 & 20 & 1 & 0 & 60 & 0 & 4 & 37,78 & 30,47 & 21,16 & 10,58 \\
\hline IG 17 & 60 & 1 & 0 & 35 & $\mathrm{x}$ & 10 & 34,15 & 41,75 & 20,08 & 4,02 \\
\hline IG 18 - 19 & 60 & 1 & 0 & 10 & $\mathrm{x}$ & 10 & 49,92 & 31,53 & 16,86 & 1,69 \\
\hline IG 20 - 21 & 60 & 1 & 0 & 10 & $\mathrm{x}$ & 10 & 30,50 & 41,76 & 24,12 & 3,62 \\
\hline IG 22 & 60 & 4 & 0 & 10 & $\mathrm{x}$ & 10 & 39,05 & 39,26 & 19,72 & 1,97 \\
\hline IG 23 & 60 & 4 & 0 & 10 & 0 & 10 & 42,29 & 29,77 & 25,40 & 2,54 \\
\hline IG -24-25 & 60 & 4 & 0 & 10 & 0 & 10 & 31,83 & 36,70 & 20,98 & 10,49 \\
\hline IG 26 & 60 & 1 & 0 & 1 & 0 & 10 & 44,09 & 36,73 & 14,76 & 4,43 \\
\hline IG 27 - 28 & 60 & 4 & 0 & 4 & $\mathrm{x}$ & 10 & 39,94 & 39,09 & 16,78 & 4,19 \\
\hline IG 29 & 10 & 1 & 0 & 60 & $\mathrm{x}$ & 4 & 51,85 & 30,72 & 11,62 & 5,81 \\
\hline IG 30 - 31 & 60 & 4 & 0 & 10 & $\mathrm{x}$ & 4 & 35,35 & 44,32 & 17,68 & 2,65 \\
\hline IG 32 - 33 & 60 & 4 & 0 & 1 & 0 & 10 & 36,37 & 42,85 & 20,78 & 0,00 \\
\hline IG 34 - 35 & 60 & 4 & 0 & 20 & $\mathrm{x}$ & 10 & 35,56 & 51,36 & 13,09 & 0,00 \\
\hline IG 36 & 60 & 1 & 0 & 1 & $\mathrm{x}$ & 10 & 44,99 & 38,73 & 12,53 & 3,76 \\
\hline IG 37 - 38 & 60 & 4 & 0 & 35 & $\mathrm{x}$ & 10 & 46,20 & 37,43 & 16,37 & 0,00 \\
\hline IG 39 & 60 & 1 & 0 & 1 & $\mathrm{x}$ & 10 & 38,22 & 49,88 & 8,50 & 3,40 \\
\hline IG 40 & 60 & 1 & 0 & 20 & $\mathrm{x}$ & 4 & 33,66 & 44,31 & 14,69 & 7,35 \\
\hline IG 41 & 35 & 1 & 0 & 35 & $\mathrm{x}$ & 4 & 47,75 & 33,67 & 12,39 & 6,20 \\
\hline IG 42 & 60 & 4 & 0 & 4 & 0 & 4 & 40,50 & 35,38 & 20,10 & 4,02 \\
\hline IG 43 & 60 & 4 & 0 & 10 & $\mathrm{x}$ & 10 & 34,31 & 40,04 & 19,73 & 5,92 \\
\hline IG 44 & 60 & 4 & 0 & 1 & $\mathrm{x}$ & 10 & 36,91 & 39,52 & 20,49 & 3,07 \\
\hline
\end{tabular}

Tabla 5.b- Datos composicionales del perfil IG a partir de DRX. Para la Pirita (Py) solo se tuvo en cuenta la presencia (x) o la ausencia (0). Referencias: I- Illita; ISInterestratificados Illita-Esmectita; Cl- Clorita; K- Caolinita. Los valores de roca total son arbitrarios y representan un valor fijo tomado para graficar dentro de los intervalos desarrollados en la figura 5.2. El mismo procedimiento se tomará en cuenta en el resto de los perfiles del capítulo. 


\section{Perfil PG}

Mediante difracción de rayos $\mathrm{X}$ se analizaron un total de 60 muestras de roca, las cuales arrojaron los siguientes resultados (figura 5.3; tabla 5.cb):

Roca total: Este perfil se caracteriza por el predominio de cuarzo, con una importante participación carbonática en los primeros 40 m. A partir de allí se incrementan los contenidos de arcilla, pero principalmente el aporte de feldespatos (plagioclasas). La presencia de pirita es escasa, pero a partir de la muestra PG 42 se incrementa su participación.

Fracción fina: Este perfil se caracteriza por poseer predominio de illita. Pasados los 38 a 40 m de perfil, hacia arriba se observa un incremento en la proporción de clorita. 

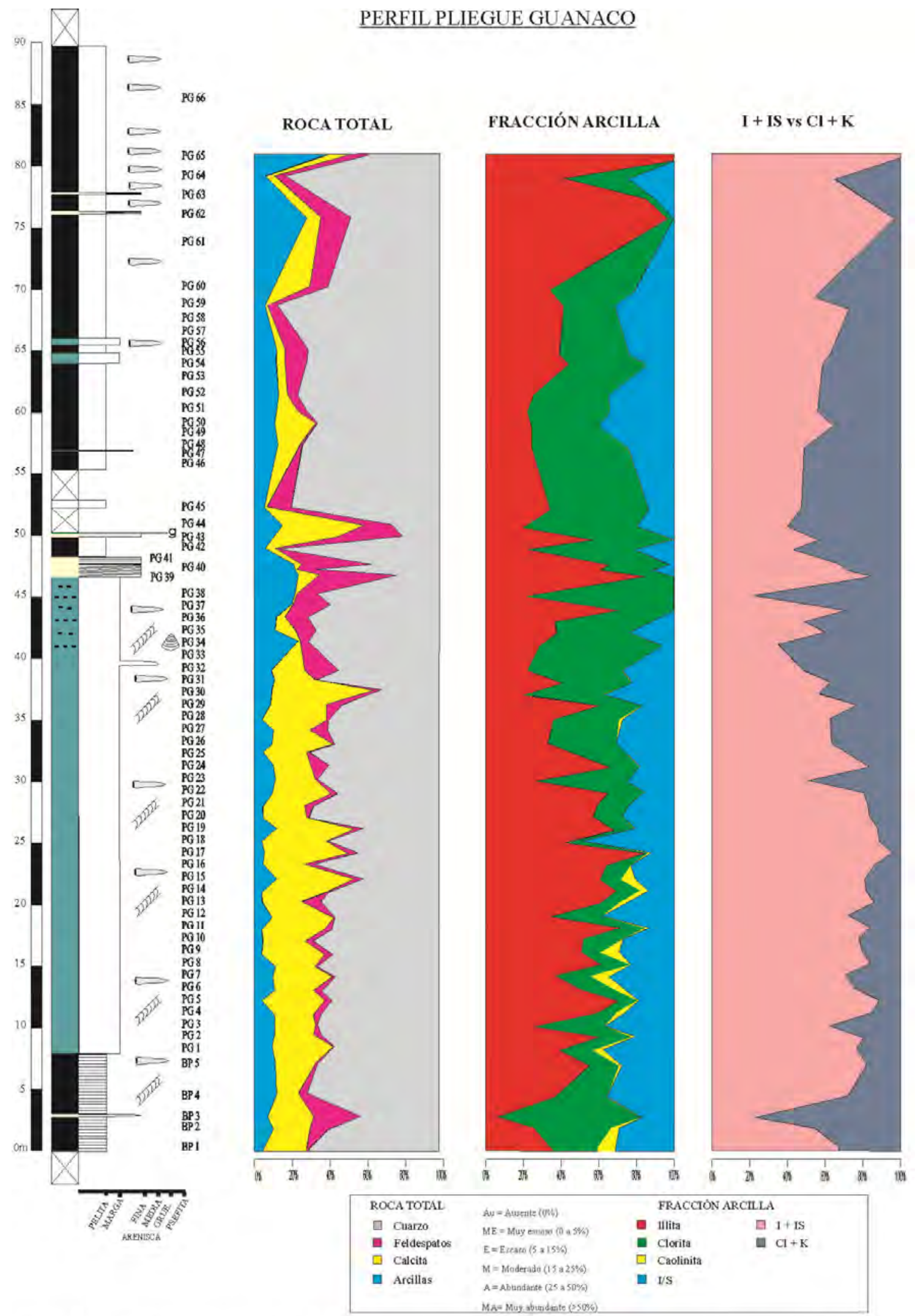

Figura 5.3 - Distribución y cantidades semicuantitativas de los minerales reconocidos a partir de la difracción de rayos $\mathrm{X}$ en el Perfil PG. 


\begin{tabular}{|c|c|c|c|c|c|c|c|c|c|c|}
\hline \multirow[b]{3}{*}{ MUESTRA } & \multicolumn{6}{|c|}{ Roca Total } & \multicolumn{4}{|c|}{ Arcillas } \\
\hline & \multirow[b]{2}{*}{ Cuarzo } & \multicolumn{2}{|c|}{ Feldespato } & \multirow[b]{2}{*}{ Calcita } & \multirow[b]{2}{*}{ Py } & \multirow[b]{2}{*}{ Arc } & \multirow[b]{2}{*}{$\mathrm{I}$} & \multirow[b]{2}{*}{ IS } & \multirow[b]{2}{*}{$\mathrm{Cl}$} & \multirow[b]{2}{*}{$\mathrm{K}$} \\
\hline & & $\mathrm{Pl}$ & FK & & & & & & & \\
\hline BP 1 & 60 & 1 & 0 & 20 & $\mathrm{x}$ & 4 & 36,22 & 31,01 & 23,41 & 9,36 \\
\hline BP 2 & 60 & 10 & 0 & 20 & $x$ & 10 & 25,76 & 28,89 & 41,22 & 4,12 \\
\hline BP 3 & 60 & 35 & 0 & 35 & $x$ & 10 & 6,42 & 17,15 & 76,43 & 0,00 \\
\hline BP 4 & 60 & 4 & 0 & 10 & $x$ & 10 & 36,85 & 35,24 & 27,92 & 0,00 \\
\hline BP 5 & 60 & 1 & 0 & 20 & $x$ & 10 & 55,22 & 27,49 & 15,72 & 1,57 \\
\hline PG 1 & 60 & 1 & 0 & 35 & 0 & 10 & 39,48 & 37,43 & 17,76 & 5,33 \\
\hline PG 2 & 60 & 4 & 0 & 20 & 0 & 10 & 60,34 & 20,52 & 17,40 & 1,74 \\
\hline PG 3 & 60 & 1 & 0 & 20 & 0 & 10 & 26,23 & 36,57 & 37,20 & 0,00 \\
\hline PG 4 & 60 & 4 & 0 & 20 & 0 & 10 & 59,03 & 26,24 & 11,33 & 3,40 \\
\hline PG 5 & 60 & 4 & 0 & 35 & $x$ & 4 & 70,59 & 18,82 & 10,59 & 0,00 \\
\hline PG 6 & 60 & 4 & 0 & 20 & 0 & 10 & 50,27 & 25,83 & 18,39 & 5,52 \\
\hline PG 7 & 60 & 1 & 0 & 35 & 0 & 10 & 36,92 & 34,46 & 19,08 & 9,54 \\
\hline PG 8 & 60 & 1 & 0 & 20 & 0 & 10 & 61,79 & 22,98 & 15,24 & 0,00 \\
\hline PG 9 & 60 & 4 & 0 & 35 & 0 & 4 & 51,27 & 28,86 & 9,93 & 9,93 \\
\hline PG 10 & 60 & 4 & 0 & 20 & 0 & 4 & 51,82 & 26,69 & 21,49 & 0,00 \\
\hline PG 11 & 60 & 4 & 0 & 35 & $x$ & 4 & 71,73 & 12,81 & 13,45 & 2,02 \\
\hline PG 12 & 60 & 1 & 0 & 35 & $x$ & 10 & 34,58 & 37,86 & 27,56 & 0,00 \\
\hline PG 13 & 60 & 10 & 0 & 20 & 0 & 4 & 60,95 & 25,61 & 9,60 & 3,84 \\
\hline PG 14 & 60 & 1 & 0 & 35 & 0 & 4 & 69,09 & 13,33 & 13,52 & 4,06 \\
\hline PG 15 & 35 & 4 & 0 & 35 & $x$ & 10 & 60,95 & 20,32 & 11,02 & 7,71 \\
\hline PG 16 & 60 & 4 & 0 & 20 & 0 & 4 & 64,08 & 22,63 & 13,29 & 0,00 \\
\hline PG 17 & 35 & 4 & 0 & 35 & $x$ & 4 & 84,51 & 11,74 & 2,50 & 1,25 \\
\hline PG 18 & 60 & 1 & 0 & 35 & 0 & 4 & 42,54 & 47,11 & 9,00 & 1,35 \\
\hline PG 19 & 35 & 4 & 0 & 35 & $x$ & 10 & 68,13 & 20,44 & 11,43 & 0,00 \\
\hline PG 20 & 60 & 1 & 0 & 20 & 0 & 4 & 57,02 & 26,90 & 16,08 & 0,00 \\
\hline PG 21 & 60 & 4 & 0 & 20 & 0 & 4 & 59,41 & 23,71 & 16,88 & 0,00 \\
\hline PG 22 & 60 & 4 & 0 & 35 & $x$ & 10 & 65,07 & 15,43 & 19,50 & 0,00 \\
\hline PG 23 & 60 & 1 & 0 & 20 & 0 & 10 & 27,01 & 24,51 & 48,48 & 0,00 \\
\hline PG 24 & 60 & 10 & 0 & 20 & $x$ & 10 & 66,29 & 18,13 & 15,58 & 0,00 \\
\hline PG 25 & 60 & 1 & 0 & 20 & 0 & 4 & & & & \\
\hline PG 26 & 60 & 1 & 0 & 35 & $x$ & 10 & 33,33 & 30,43 & 36,23 & 0,00 \\
\hline PG 27 & 60 & 10 & 0 & 20 & $x$ & 10 & & & & \\
\hline PG 28 & 60 & 1 & 0 & 35 & $x$ & 4 & 36,29 & 26,96 & 35,00 & 1,75 \\
\hline PG 29 & 60 & 10 & 0 & 35 & 0 & 10 & 60,64 & 16,62 & 22,74 & 0,00 \\
\hline PG 30 & 35 & 4 & 0 & 60 & 0 & 10 & 20,27 & 36,96 & 42,77 & 0,00 \\
\hline PG 31 & 60 & 1 & 0 & 20 & 0 & 10 & 40,91 & 22,38 & 36,71 & 0 \\
\hline PG 32 & 60 & 20 & 0 & 20 & 0 & 10 & 22,4 & 26,81 & 50,78 & 0 \\
\hline PG 34 & 60 & 4 & 0 & 1 & $x$ & 20 & 29,12 & 6,16 & 64,71 & 0 \\
\hline PG 35 & 60 & 10 & 0 & 10 & $x$ & 10 & 37,73 & 23,34 & 38,93 & 0 \\
\hline PG 36 & 60 & 10 & 0 & 4 & 0 & 10 & 36,84 & 12,44 & 50,72 & 0 \\
\hline PG 37 & 60 & 20 & 0 & 1 & $x$ & 20 & 71,26 & 0 & 28,74 & 0 \\
\hline
\end{tabular}

Tabla 5.c- Datos composicionales del perfil PG a partir de DRX. Para la Pirita (Py) solo se tuvo en cuenta la presencia (x) o la ausencia (0). Referencias: I- Illita; ISInterestratificados Illita-Esmectita; Cl- Clorita; K- Caolinita. 


\begin{tabular}{|c|c|c|c|c|c|c|c|c|c|c|}
\hline \multirow[b]{3}{*}{ MUESTRA } & \multicolumn{6}{|c|}{ Roca Total } & \multicolumn{4}{|c|}{ Arcillas } \\
\hline & \multirow[b]{2}{*}{ Cuarzo } & \multicolumn{2}{|c|}{ Feldespato } & \multirow[b]{2}{*}{ Calcita } & \multirow[b]{2}{*}{ Py } & \multirow[b]{2}{*}{ Arc } & \multirow[b]{2}{*}{$\mathrm{I}$} & \multirow[b]{2}{*}{ IS } & \multirow[b]{2}{*}{$\mathrm{Cl}$} & \multirow[b]{2}{*}{$\mathrm{K}$} \\
\hline & & $\mathrm{Pl}$ & FK & & & & & & & \\
\hline PG 38 & 60 & 10 & 0 & 1 & 0 & 20 & 21,69 & 0 & 78,31 & 0 \\
\hline PG 39 & 20 & 35 & 0 & 10 & 0 & 20 & 85,08 & 0 & 14,92 & 0 \\
\hline PG 40 & 60 & 10 & 0 & 1 & 0 & 20 & 60,93 & 10,71 & 28,36 & 0 \\
\hline PG 41 & 35 & 35 & 0 & 4 & 0 & 20 & 65,5 & 2,16 & 32,35 & 0 \\
\hline PG 42 & 60 & 1 & 0 & 4 & $x$ & 4 & 22,24 & 21 & 56,76 & 0 \\
\hline PG 43 & 20 & 35 & 0 & 35 & $x$ & 10 & 56,45 & 0 & 43,55 & 0 \\
\hline PG 44 & 35 & 20 & 0 & 60 & 0 & 20 & 20,37 & 19,55 & 60,08 & 0 \\
\hline PG 45 & 60 & 10 & 0 & 1 & $x$ & 4 & 34,35 & 13,18 & 52,47 & 0 \\
\hline PG 48 & 60 & 1 & 0 & 10 & $x$ & 10 & 24,81 & 24,06 & 51,13 & 0 \\
\hline PG 50 & 60 & 1 & 0 & 20 & $x$ & 10 & 24,32 & 40 & 35,68 & 0 \\
\hline PG 51 & 60 & 4 & 0 & 10 & $x$ & 10 & 22,03 & 33,92 & 44,06 & 0 \\
\hline PG 52 & 60 & 2 & 2 & 4 & $x$ & 10 & 25,53 & 34,21 & 40,25 & 0 \\
\hline PG 54 & 60 & 10 & 0 & 4 & $x$ & 10 & 44,91 & 13,85 & 41,24 & 0 \\
\hline PG 55 & 60 & 10 & 0 & 4 & $x$ & 10 & 39,24 & 23,26 & 37,5 & 0 \\
\hline PG 59 & 60 & 4 & 0 & 1 & $x$ & 4 & 41,28 & 31,45 & 27,27 & 0 \\
\hline PG 60 & 60 & 10 & 0 & 20 & $x$ & 10 & 34,18 & 20,77 & 45,06 & 0 \\
\hline PG 62 & 60 & 20 & 0 & 10 & $x$ & 35 & 96,66 & 0 & 3,34 & 0 \\
\hline PG 64 & 60 & 4 & 0 & 4 & $x$ & 4 & 41,43 & 24,04 & 34,53 & 0 \\
\hline PG 65 & 35 & 10 & 0 & 10 & $x$ & 35 & 100 & 0 & 0 & 0 \\
\hline
\end{tabular}

Tabla 5.c (continuación)- Datos composicionales del perfil PG a partir de DRX. Para la

Pirita (Py) solo se tuvo en cuenta la presencia (x) o la ausencia (0). Referencias: I- Illita; ISInterestratificados Illita-Esmectita; Cl- Clorita; K- Caolinita.

\section{Perfil EVP 1}

Mediante difracción de rayos x se analizaron un total de 12 muestras de roca, provenientes del perfil EVP 1, las cuales arrojaron los siguientes resultados (figura 5.4; tabla 5.d):

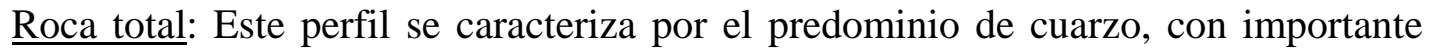
participación feldespatos y arcillas. La presencia de calcita es menor que en los otros perfiles analizados. La proporción de pirita es muy baja.

Fracción fina: Este perfil se caracteriza por el predominio de la clorita en comparación con la illita y los interestratificados de illita/esmectita. 


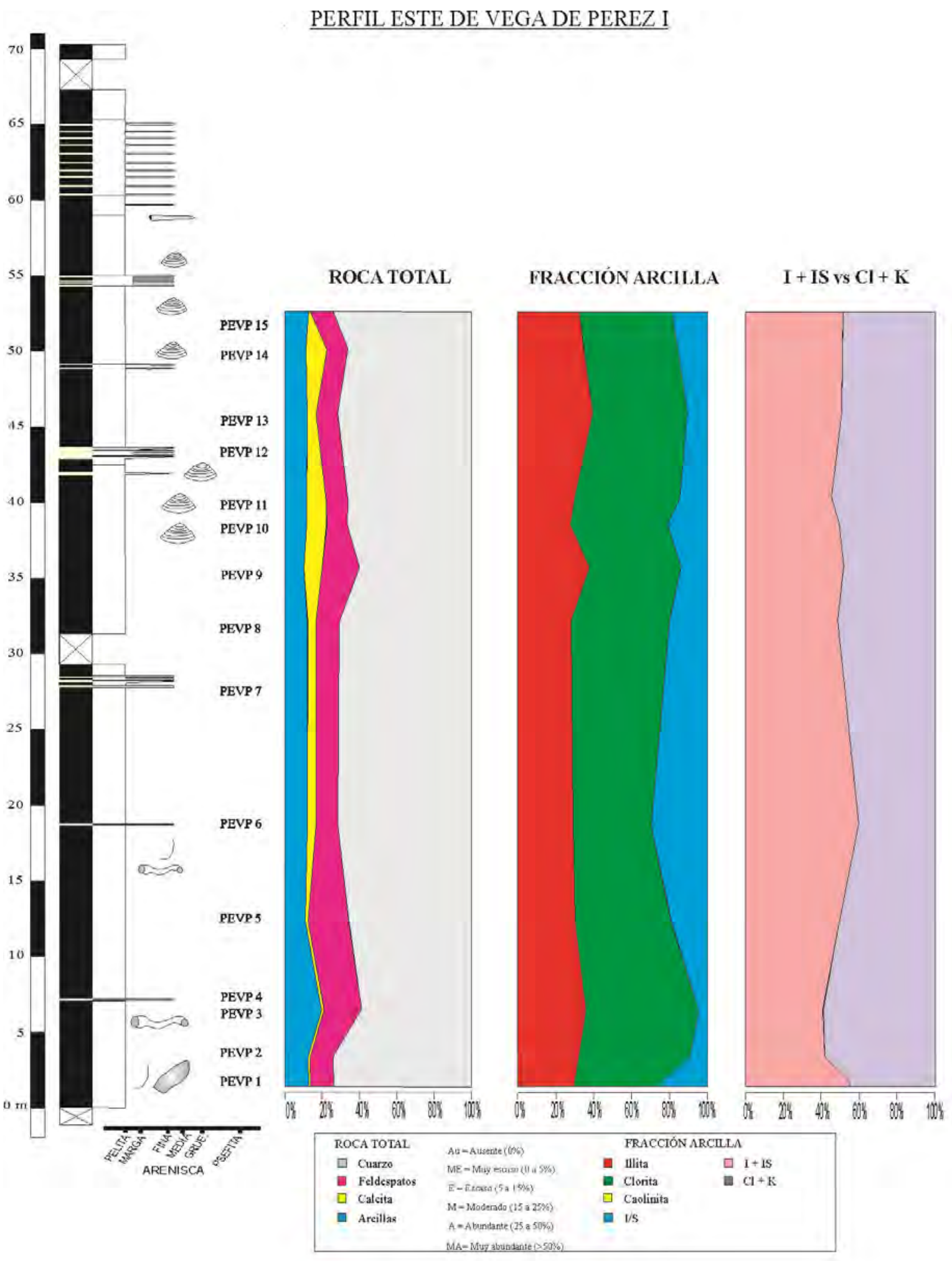

Figura 5.4 - Distribución y cantidades semicuantitativas de los minerales reconocidos a partir de la difracción de rayos $\mathrm{X}$ en el Perfil EVP 1. 


\begin{tabular}{|c|c|c|c|c|c|c|c|c|c|c|}
\hline \multirow[b]{3}{*}{ MUESTRA } & \multicolumn{6}{|c|}{ Roca Total } & \multicolumn{4}{|c|}{ Arcillas } \\
\hline & \multirow[b]{2}{*}{ Cuarzo } & \multicolumn{2}{|c|}{ Feldespato } & \multirow[b]{2}{*}{ Calcita } & \multirow[b]{2}{*}{$\mathrm{Py}$} & \multirow[b]{2}{*}{ Arc } & \multirow[b]{2}{*}{ I } & \multirow[b]{2}{*}{ IS } & \multirow[b]{2}{*}{$\mathrm{Cl}$} & \multirow[b]{2}{*}{$\mathrm{K}$} \\
\hline & & $\mathrm{Pl}$ & FK & & & & & & & \\
\hline PEVP 1-1 & 60 & 10 & 0 & 1 & 0 & 10 & 30,09 & 24,32 & 45,59 & 0,00 \\
\hline PEVP 1-2 & 60 & 10 & 0 & 1 & 0 & 10 & 32,28 & 9,39 & 58,33 & 0,00 \\
\hline PEVP 1-3 & 60 & 20 & 0 & 1 & 0 & 20 & 35,87 & 4,69 & 59,44 & 0,00 \\
\hline PEVP 1-5 & 60 & 20 & 0 & 1 & 0 & 10 & 30,22 & 19,09 & 50,70 & 0,00 \\
\hline PEVP 1-6 & 60 & 10 & 0 & 4 & 0 & 10 & 29,35 & 29,79 & 40,86 & 0,00 \\
\hline PEVP 1-8 & 60 & 10 & 0 & 4 & 0 & 10 & 28,42 & 20,42 & 51,16 & 0,00 \\
\hline PEVP 1-9 & 60 & 20 & 0 & 10 & $x$ & 10 & 37,50 & 14,29 & 48,21 & 0,00 \\
\hline PEVP 1-10 & 60 & 10 & 0 & 10 & $x$ & 10 & 27,81 & 21,19 & 50,99 & 0,00 \\
\hline PEVP 1-11 & 60 & 10 & 0 & 10 & 0 & 10 & 30,27 & 14,72 & 55,01 & 0,00 \\
\hline PEVP 1-13 & 60 & 10 & 0 & 4 & 0 & 10 & 39,39 & 11,11 & 49,49 & 0,00 \\
\hline PEVP 1-14 & 60 & 10 & 0 & 10 & 0 & 10 & 35,10 & 15,60 & 49,30 & 0,00 \\
\hline PEVP 1-15 & 60 & 10 & 0 & 1 & 0 & 10 & 31,83 & 19,38 & 48,79 & 0,00 \\
\hline
\end{tabular}

Tabla 5.d- Datos composicionales del perfil EVP 1 a partir de DRX. Para la Pirita (Py) solo se tuvo en cuenta la presencia (x) o la ausencia (0). Referencias: I- Illita; ISInterestratificados Illita-Esmectita; Cl- Clorita; K- Caolinita.

\section{V.3.2 - Índice de cristalinidad de Illita e Î́ndice de Esquevin}

Aquellas muestras que presentaron picos de illita en el difractograma lo suficientemente claros como para medir su cristalinidad y la relación entre sus picos 001 y 002 fueron medidas con estos parámetros. Cabe aclarar que dicha medición es estimativa, ya que se realizó sobre el difractograma de la muestra natural de rutina, un análisis más detallado para estas rocas puede realizarse obteniendo un concentrado de arcilla a partir de un volumen mayor de roca. Este proceso no fue realizado para las muestras de la Formación Río Mayer, sin embargo los resultados obtenidos son útiles para interpretaciones posteriores.

En la figura 5.5 se muestra la distribución de los valores del índice de cristalinidad de Illita en los perfiles de la Seccional Río Guanaco y en la figura 5.6 se puede observar la distribución de éstos valores versus índice de Esquevin. 


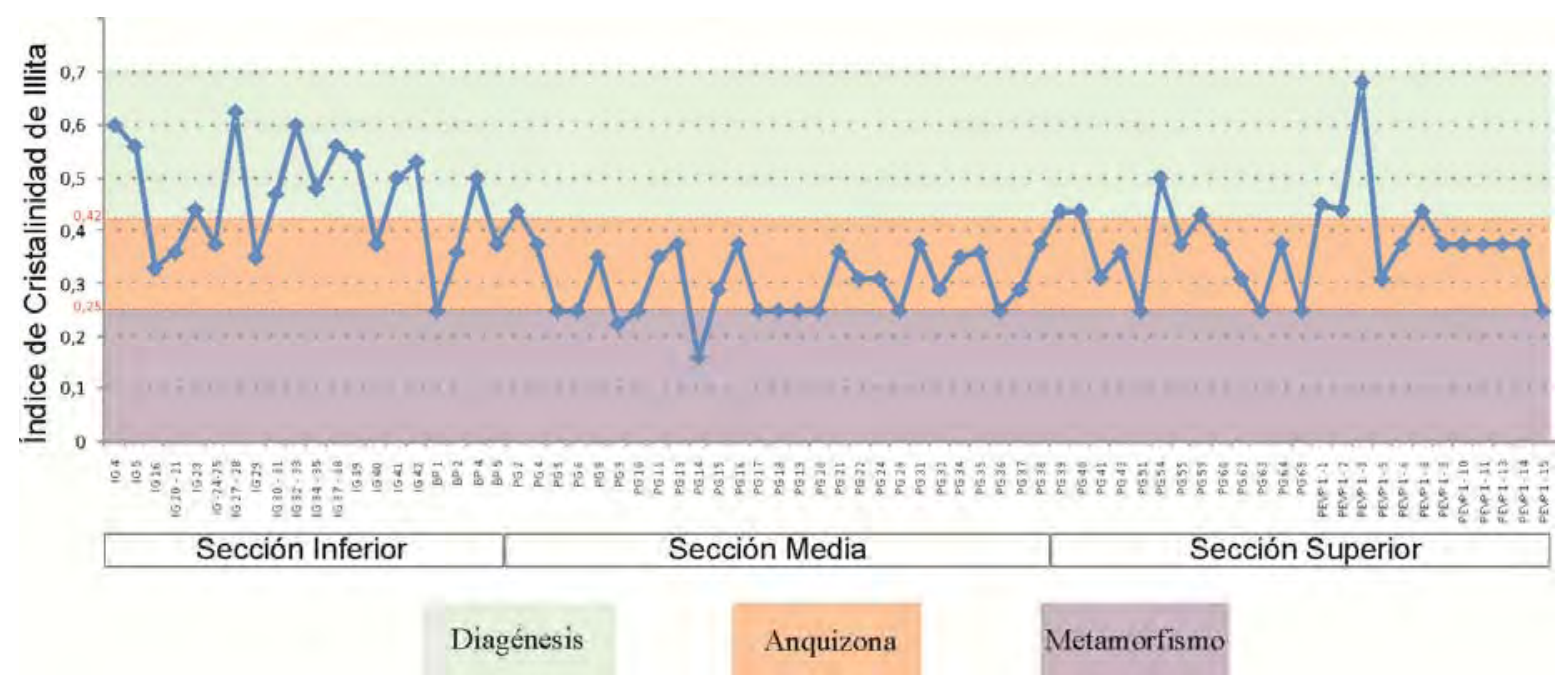

Figura 5.5- Distribución de los valores de Índice de cristalinidad de illita (IC) en los tres perfiles analizados en la región de las nacientes de Río Guanaco.
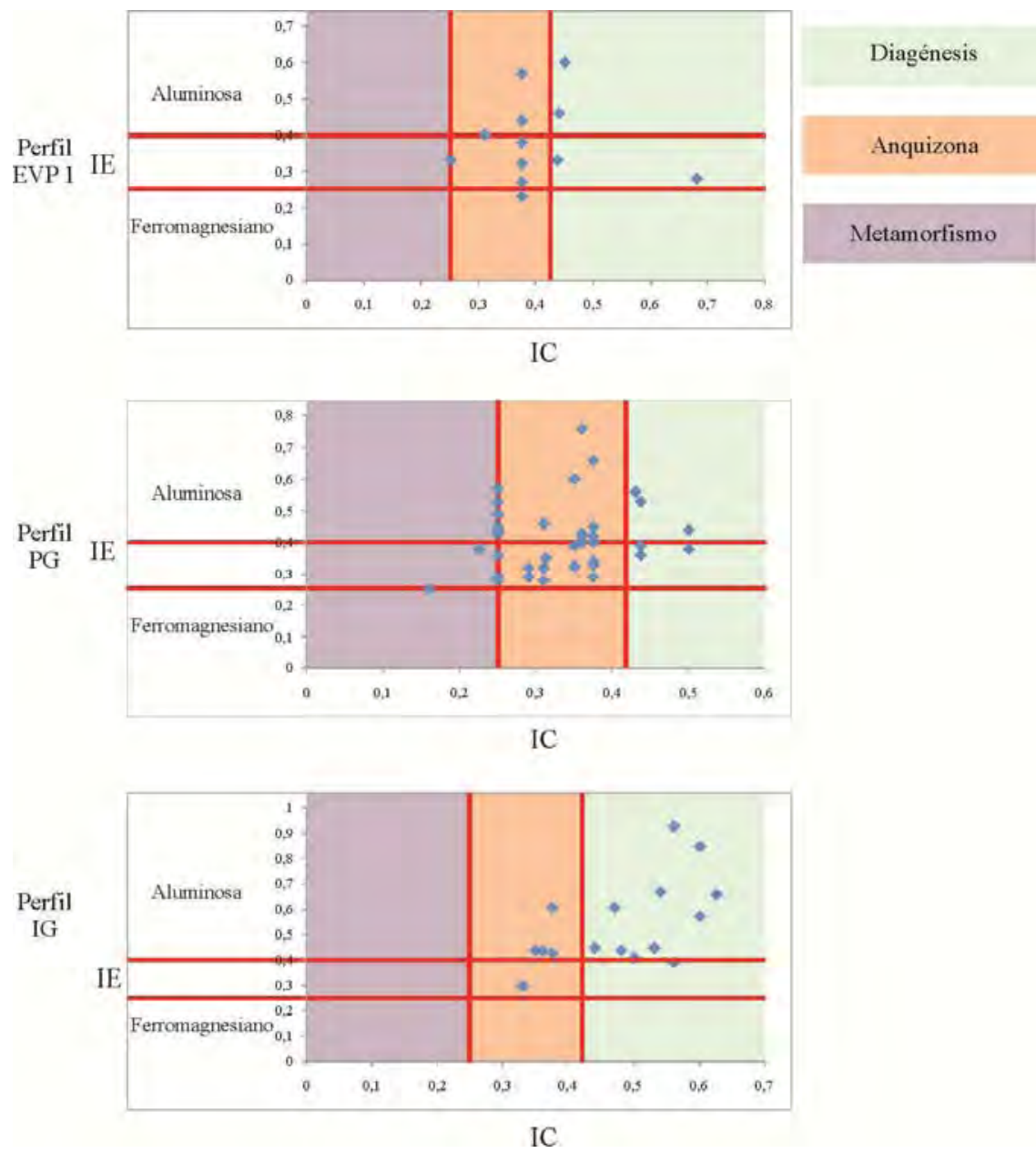

Figura 5.6- Gráficos de Índice de cristalinidad de illita (IC) versus Índice de Esquevin (IE). 


\section{V.3.3 - Interestratificados Illita / Esmectita (IS)}

En las muestras en que el pico correspondiente al interestratificados I/S tenía buena cristalinidad se cuantificó de forma estimativa el porcentaje de capas expansivas según los criterios de Powel et al., 1978 y Moore y Reynolds, 1989. Los picos de interestratificados IS de las muestras de la Formación Río Mayer para la región de Río Guanaco varían entre valores de 10,30 y 11,90 en la muestra natural, de este modo según los criterios de Powel et al. (1978) los contenidos de capas expansivas se encuentran entre $20-30 \%$ hasta $70-80 \%$. Por otro lado, la diferencia medida en $2 \Theta$ entre los picos 002 y 003 de la muestra glicolada de los interestratificados IS varían entre 7,8 y 5,6 lo que indica valores de capas expansivas en los IS entre 20 y 80\% (Moore y Reynolds, 1989).

En particular para el perfil IG las capas expansivas en los IS se concentran en valores de 30 a 60 \%; para el perfil PG entre 40 y 70\%; y para el perfil EVP1 entre 50 y 70\% (figura 5.7).

Con los valores mencionados y teniendo en cuenta los criterios de Foscolos et al. (1976), las muestras del perfil IG se encuentran casi todas en mesodiagénesis tardía; las provenientes del perfil PG están divididas entre mesodiagénesis tardía y temprana; mientras que las del perfil EVP1 en mesodiagénesis temprana (figura 5.7).

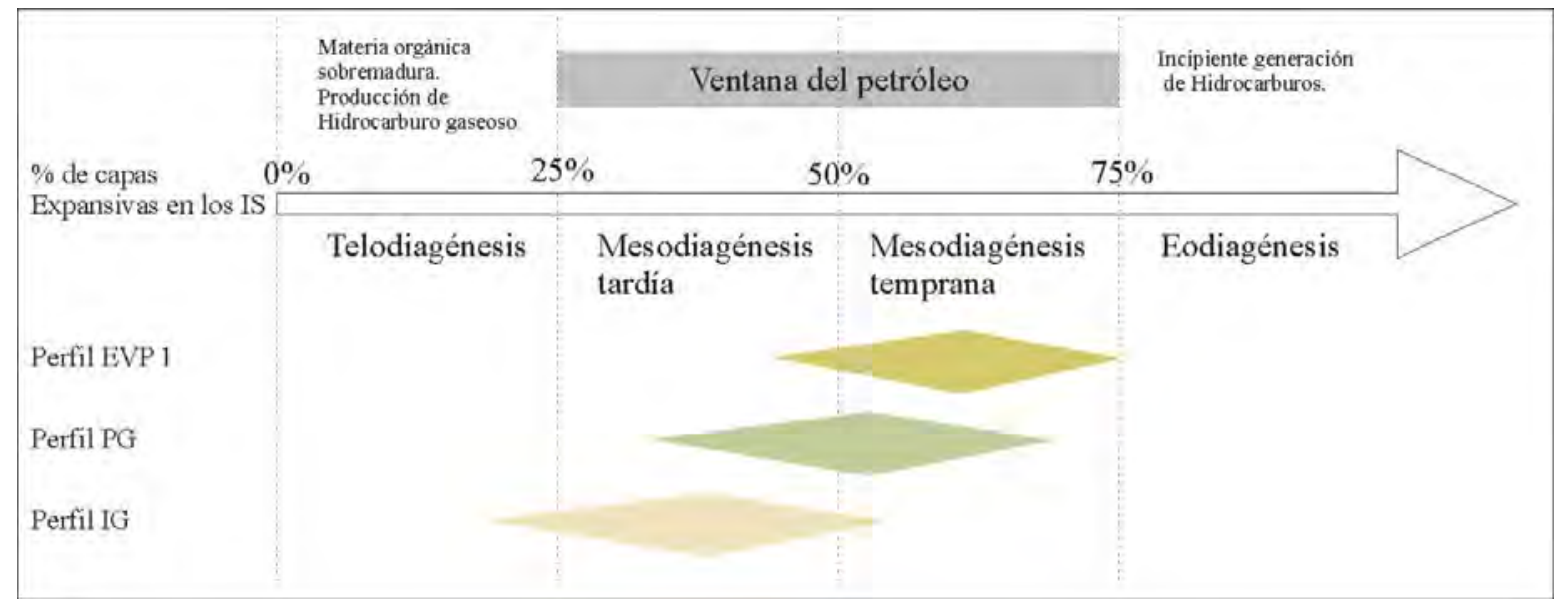

Figura 5.7- Distribución general de los valores obtenidos para el porcentaje de capas expansivas en los tres perfiles analizados en la Seccional Río Guanaco y su significado según Foscolos et al. (1976). 


\section{V.3.4 - Consideraciones preliminares para la difracción de rayos $X$ en la} Seccional Río Guanaco

En esta región del área de estudio la Formación Río Mayer se compone casi en su totalidad por proporciones variables de cuarzo, feldespato, calcita, illita, clorita, caolinita e interestratificados IS. De la distribución de esos minerales se pueden observar en la figura 5.8 diferentes regiones del perfil en las cuales, si bien los minerales son los mismos, las proporciones de cada uno varía.

En la asociación A predomina el cuarzo en la roca total con poco feldespato y arcillas en general rondando el 10\%. El comportamiento de la calcita está concentrado en niveles en la parte inferior (A1), mientras que en la parte superior pareciera ser más constante (A2). Dentro de la fracción fina domina la illita junto a los interestratificados IS, entre ambos sumando cerca del $90 \%$ de las arcillas presentes.

La asociación B se caracteriza por un aumento en la participación de calcita, un leve descenso en la cantidad de arcillas y cuarzo, mientras que el patrón de arcillas se mantiene como la asociación anterior.

La asociación C posee dominio de cuarzo con aumento de arcillas y feldespatos en detrimento de calcita, la cual vuelve a concentrarse en niveles. En cuanto a la fracción fina se registra un aumento de clorita.

Finalmente, la asociación D posee gran cantidad de cuarzo con un notable incremento de feldespato. El porcentaje de arcillas es constante y el de calcita disminuye respecto de las asociaciones previas. Para las arcillas se confirma el dominio de clorita que se marcaba incipientemente en la asociación C.

En cuanto al índice de cristalinidad de Illita y a los interestratificados IS se pueden observar comportamientos diferentes. Mientras que la cristalinidad da valores más allá de la diagénesis (anquimetamorfismo y hasta metamorfismo) los interestratificados IS se desarrollaron dentro de los campos de la eodiagénesis y mesodiagénesis. Si se considera el índice de Esquevin la mayor parte de las muestras se ubican en el campo de las illitas aluminosas, algunas en el campo indiferenciado y solo 1 es ferromagnesiana.

El cambio de esmectita a illita ocurre a valores de temperatura correspondientes a la diagénesis (Boggs, 1992; Surdam et al., 1989), por esta razón se asume que algunos valores 
de cristalinidad son heredados, pudiendo tener la illita un origen detrítico y provenir de las rocas metamórficas de la Formación Bahía de la Lancha.

Difracción de Ravos X - Río Guanaco

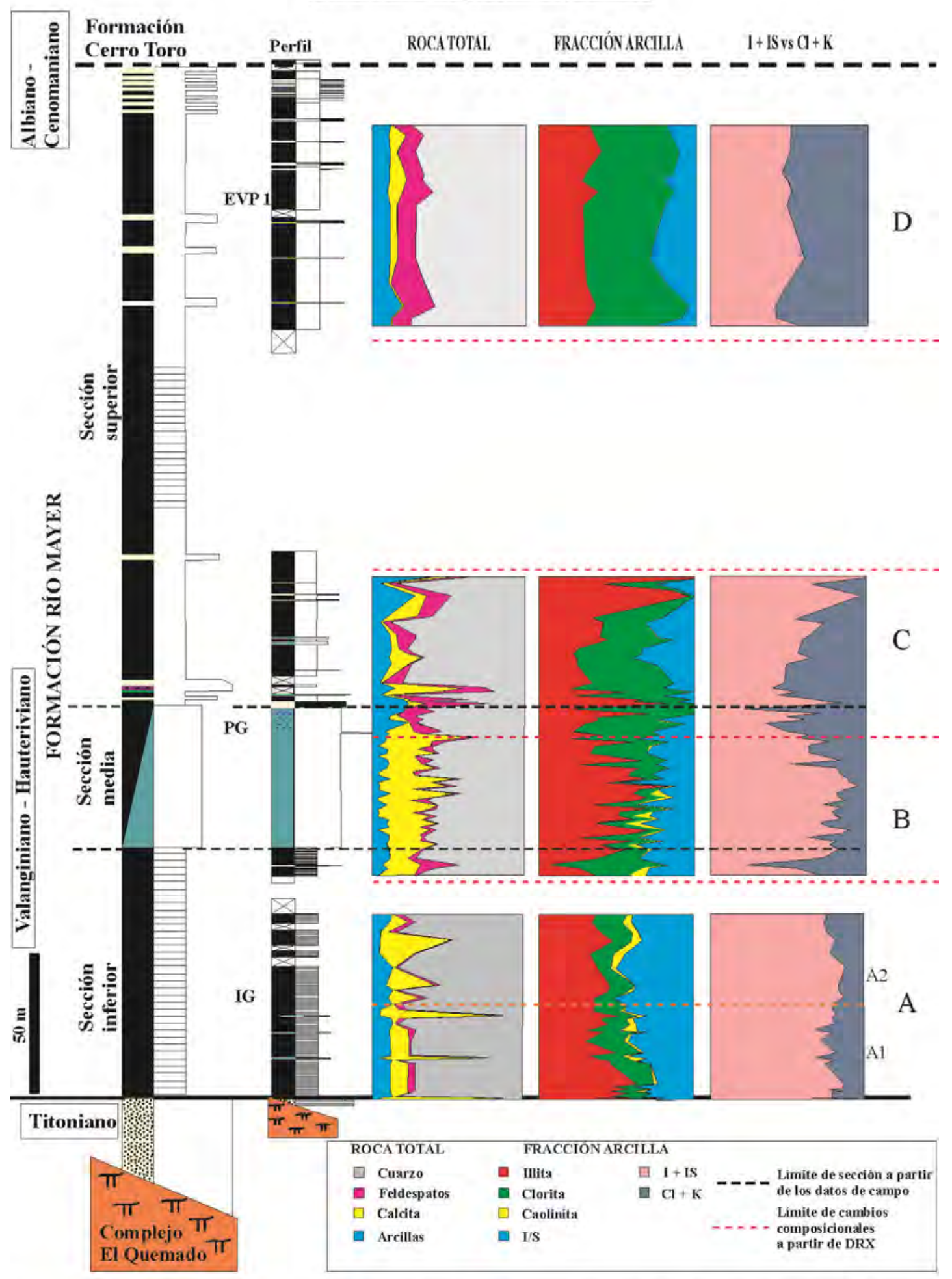

Figura 5.8-Distribución de los análisis mineralógicos por DRX para los tres perfiles seleccionados en la Seccional Río Guanaco. Se pueden observar tanto los cambios reconocidos en el campo (linea negra) como los identificados por la composición (linea roja). Las letras (A-D) indican asociaciones minerales con diferentes proporciones de los componentes. 
El paso desde composiciones ricas en Illita a composiciones ricas en Clorita queda bien expuesto en la figura 5.9, donde se muestran los contenidos de arcillas en cada sección y en la figura 5.10 donde se observan las tres secciones en el mismo gráfico.

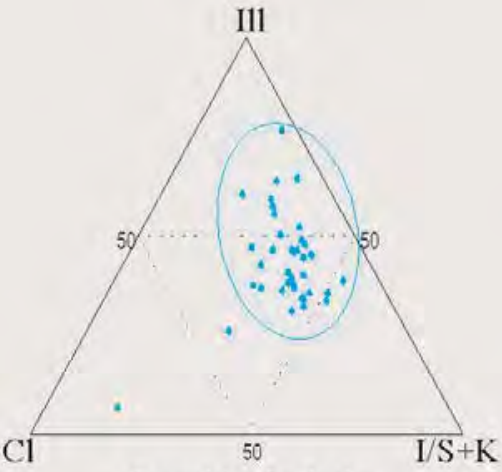

Sección Inferior

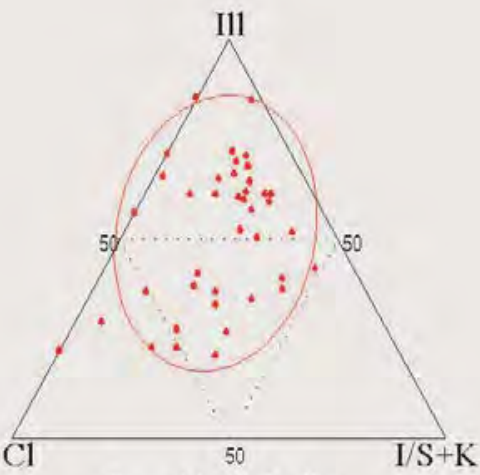

Sección Media

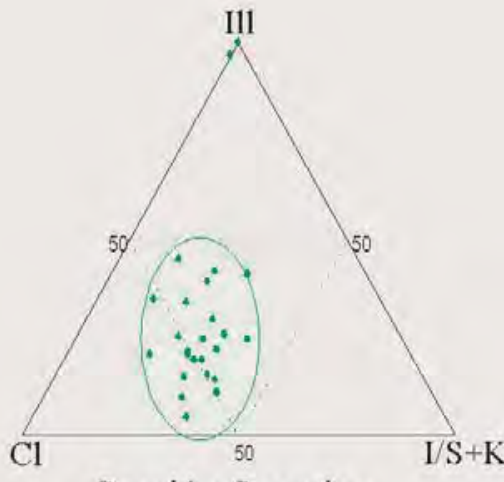

Sección Superior

Figura 5.9- Distribución general de los contenidos de arcillas en la fracción fina para las tres secciones analizadas en la Seccional Río Guanaco. Ill: Illita; Cl: Clorita; I/S+K: Interestratificados I/S más Caolinita.

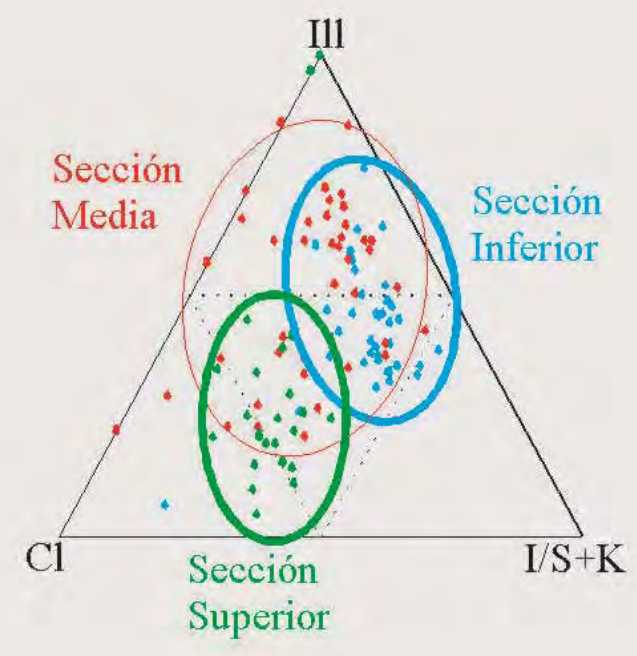

Figura 5.10- Contraste en la distribución de las muestras de las secciones inferior y superior en cuanto a los contenidos de arcillas en la fracción fina. Ill: Illita; Cl: Clorita; I/S+K: Interestratificados I/S más Caolinita. 


\section{V.4 - Lago San Martín}

Para esta región se reconstruyó un perfil a partir de muestras de los tres perfiles realizados en Estancia La Lila (ELL), Estancia la Federica (EF) y Estancia Kachaike (EKA). Como fuera antes mencionado, el volumen de datos es menor que para Río Guanaco. Para el perfil ELL se analizó una muestra de pelitas proveniente de la parte continental de la Fm. Springhill. Del perfil EF se realizaron análisis tanto de pelitas como de margas de la Fm Río Mayer, mientras que del perfil EKA las muestras pelíticas provienen de la transición a la Fm. Kachaike.

\section{V.4.1- Análisis de la roca total y la fracción arcilla}

Perfiles de ELL, EF y EKA (figura 5.9; tabla 5.e)

Roca total: La muestra de Fm. Springhill se caracteriza por la abundancia de cuarzo con arcillas y feldespatos acompañantes.

Para la Fm. Río Mayer en el perfil EF se reconocen dos composiciones. Una se desarrolla en la mitad inferior del perfil y posee una importante participación de calcita teniendo cuarzo, feldespatos y arcillas en menor proporción. La parte superior de este perfil es dominada por cuarzo primero y cuarzo y feldespatos luego, en detrimento de la proporción de calcita. Hacia el final de este perfil se incrementa la participación de arcillas.

Las muestras del perfil EKA están compuestas principalmente por cuarzo con proporciones menores de feldespatos y arcillas, con casi nula participación de calcita.

Fracción fina: es en esta fracción en la que más difieren las muestras de los tres perfiles. Primero, en el perfil ELL domina altamente la caolinita, con mínimos porcentajes de illita e interestratificados de illita/esmectita. Luego en el perfil EF domina la clorita asociada a interestratificados y en menor proporción illita. Finalmente las muestras de la transición hacia la Fm. Kachaike muestran un predominio de esmectita con mínimos valores de caolinita asociados. 


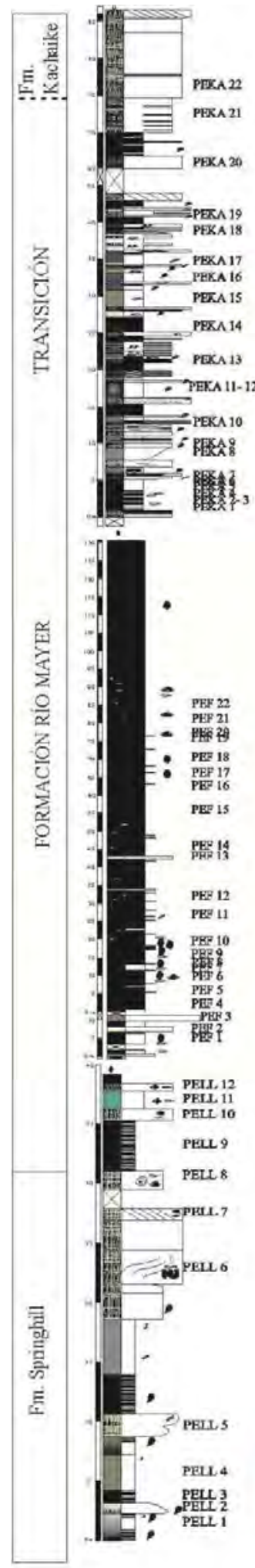

\section{PERFIL GENERAL PARA LAGO SAN MARTINN}

ROCATOTAL
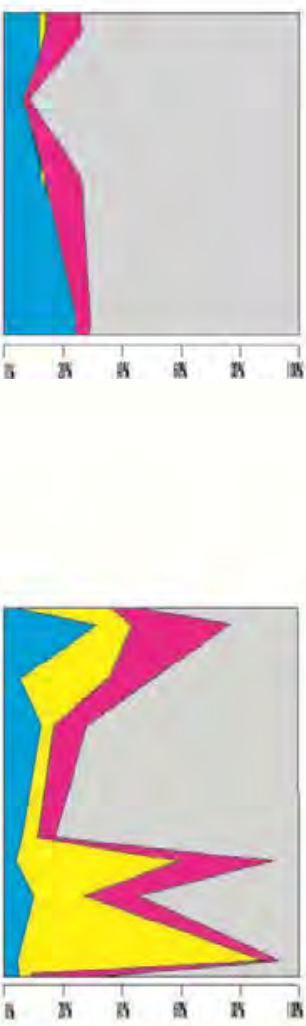

FRACCIONARCILLA
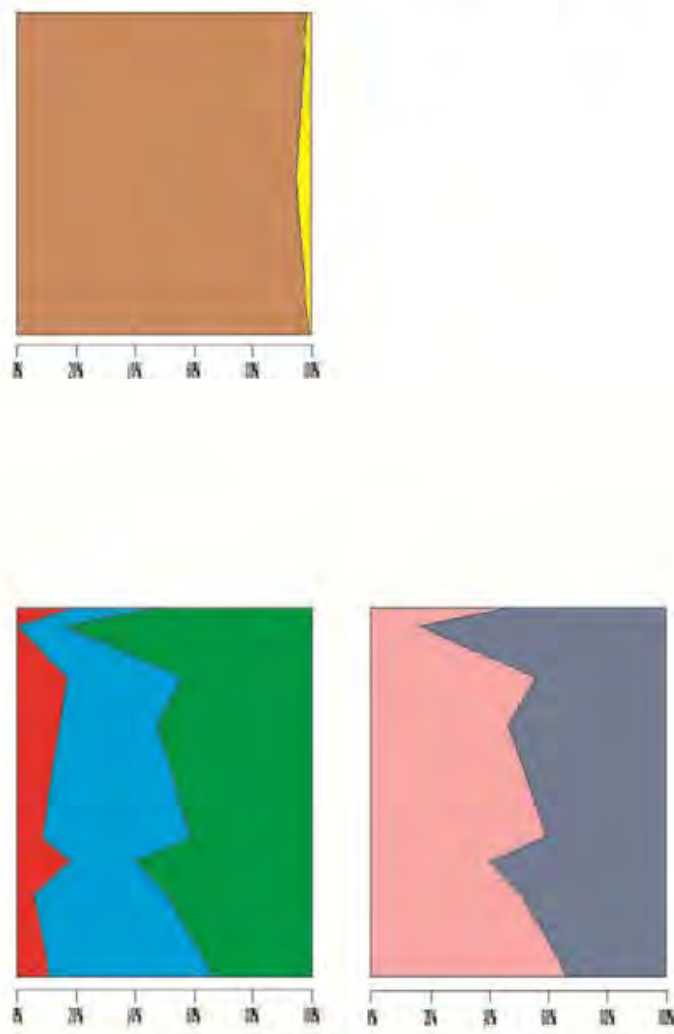

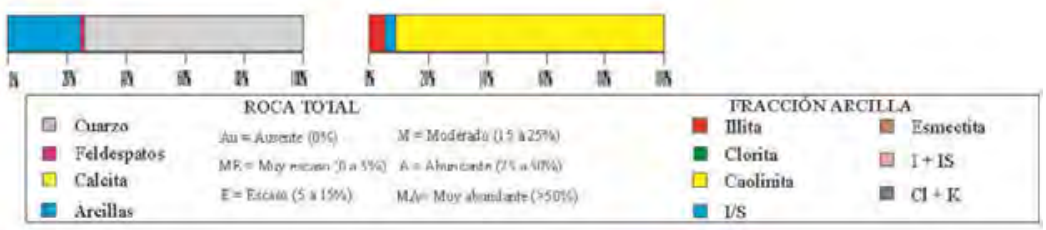

Figura 5.11- Distribución de los análisis mineralógicos por DRX para los tres perfiles realizados en el Lago San Martín. 


\begin{tabular}{|c|c|c|c|c|c|c|c|c|c|c|c|}
\hline \multirow[b]{3}{*}{ MUESTRA } & \multicolumn{6}{|c|}{ Roca Total } & \multicolumn{5}{|c|}{ Arcillas } \\
\hline & \multirow[b]{2}{*}{ Cuarzo } & \multicolumn{2}{|c|}{ Feldespato } & \multirow[b]{2}{*}{ Calcita } & \multirow[b]{2}{*}{ Py } & \multirow[b]{2}{*}{ Arc } & \multirow[b]{2}{*}{ I } & \multirow[b]{2}{*}{ Sm } & \multirow[b]{2}{*}{ IS } & \multirow[b]{2}{*}{$\mathrm{Cl}$} & \multirow[b]{2}{*}{$\mathrm{K}$} \\
\hline & & $\mathrm{Pl}$ & FK & & & & & & & & \\
\hline $\mathrm{PSCH} 4$ & 60 & 1 & 0 & 0 & 0 & 20 & 5,24 & 0,00 & 3,88 & 0,00 & 90,87 \\
\hline PEF 4 & 60 & 20 & 0 & 4 & $x$ & 4 & 10,94 & 0,00 & 55,63 & 33,43 & 0,00 \\
\hline PEF 5 & 4 & 4 & 0 & 60 & 0 & 1 & 0,00 & 0,00 & 0,00 & 0,00 & 0,00 \\
\hline PEF 10 & 60 & 20 & 0 & 20 & $x$ & 10 & 5,84 & 0,00 & 45,45 & 48,70 & 0,00 \\
\hline PEF 11 & 10 & 35 & 0 & 60 & $x$ & 4 & 18,32 & 0,00 & 22,14 & 59,54 & 0,00 \\
\hline PEF 12 & 60 & 4 & 0 & 4 & $x$ & 4 & 8,81 & 0,00 & 50,31 & 40,88 & 0,00 \\
\hline PEF 15 & 60 & 10 & 0 & 4 & $x$ & 10 & 14,62 & 0,00 & 32,49 & 52,88 & 0,00 \\
\hline PEF 17 & 60 & 10 & 0 & 35 & $x$ & 4 & 17,32 & 0,00 & 38,80 & 43,90 & 0,00 \\
\hline PEF 20 & 20 & 35 & 0 & 10 & $x$ & 20 & 0,00 & 0,00 & 16,47 & 83,53 & 0,00 \\
\hline PEF 21 & 60 & 10 & 0 & 35 & $x$ & 4 & 19,21 & 0,00 & 27,59 & 53,20 & 0,00 \\
\hline PEKA 1 & 60 & 3 & 1 & 0 & $x$ & 20 & 0,00 & 99,00 & 0,00 & 0,00 & 0,99 \\
\hline PEKA 11 & 60 & 7 & 3 & 1 & $x$ & 10 & 0,00 & 94,34 & 0,00 & 0,00 & 5,66 \\
\hline PEKA 14 & 60 & 1 & 0 & 0 & $x$ & 4 & 0,00 & 96,21 & 0,00 & 0,00 & 3,79 \\
\hline PEKA 17 & 60 & 1 & 9 & 1 & 0 & 10 & 0,00 & 98,43 & 0,00 & 0,00 & 1,57 \\
\hline
\end{tabular}

Tabla 5.e- Datos composicionales de los perfiles de la región del Lago San Martín a partir de DRX. Para la Pirita (Py) solo se tuvo en cuenta la presencia (x) o la ausencia (0). Referencias: I- Illita; Sm- Esmectita; IS- Interestratificados Illita-Esmectita; Cl- Clorita; KCaolinita.

\section{V.4.2 - Índice de cristalinidad de Illita e Índice de Esquevin}

Los porcentajes de illita en las muestras realizadas para la región del lago San Martín son en general bajos y los picos de este mineral no siempre están bien desarrollados. Por tal razón la estimación del IC solo se pudo realizar en tres muestras, y la disparidad de los valores $(0,25 ; 0,375,0,5)$ no permite hacer inferencias. Para el IE la situación es la misma (valores: $0,68,0,86,1)$.

\section{V.4.3 - Interestratificados Illita / Esmectita}

Los interestratificados IS son prácticamente nulos en las muestras de la Fm. Springhill y de la transición hacia la Fm Kachaike, por tal motivo sólo se identificaron picos de IS en las muestras del perfil EF, los cuales se caracterizan por una mala cristalinidad, lo que dificulta la interpretación. Los valores de los picos varían entre 10,9 y 11,9 , mientras que los valores de $\Delta 2 \Theta$ se encuentran entre 5,6 y 7 . Con estos resultados se 
pueden estimar altos porcentajes de capas expansivas en los interestratificados (entre $40 \mathrm{y}$ 80 \%), ubicándose según Foscolos et al. (1976) en los campos de la eodiagénesis y la mesodiagénesis temprana.

Cabe aclarar que los resultados que se desprenden de los apartados 4.2 y 4.3 se basan en un número significativamente menor que los realizados para la Seccional Río Guanaco. Por otro lado, tanto la cristalinidad de la illita como de los interestratificados IS en la región del Lago San Martín es muy baja lo que disminuye la calidad de la información.

\section{V.4.4 - Consideraciones preliminares para la difracción de rayos X en el Lago}

\section{San Martín}

Al igual que para la región de Río Guanaco, la composición de la Formación Río Mayer se constituye de proporciones variables de cuarzo, feldespato, calcita, illita, clorita, caolinita e interestratificados IS, además de esmectita (sólo en la transición hacia Fm. Kachaike). Debido al menor detalle realizado para esta región no han diferenciado asociaciones, aunque es evidente la presencia de 4 comportamientos. Primero la muestra proveniente de la Fm. Springhill posee grandes cantidades de caolinita, prácticamente ausente en el resto de las muestras. En el perfil EF, todo correspondiente a los depósitos típicamente citados para la Fm. Río Mayer, se divisan 2 tramos. Primero, una alta participación de calcita, con cuarzo variable y moderada cantidad de feldespatos y arcillas. Luego, el segundo tramo de la unidad estudiada posee un aumento considerable del contenido de cuarzo y feldespatos. Todo el conjunto del Perfil EF posee similar composición de las arcillas, dominando la clorita. Finalmente, la transición a la Fm. Kachaike posee altas cantidades de cuarzo y predomina la esmectita entre las arcillas.

Con respecto a la cristalinidad de illita y el índice de Esquevin poco aportan a la caracterización de las muestras. 


\section{V.5 - Consideraciones finales para la Formación Río Mayer a partir de la DRX}

La Formación Río Mayer en el área de estudio se compone principalmente de cuarzo y calcita, con porcentajes variables de feldespatos y arcillas (siempre subordinados a los dos anteriores), con frecuentes apariciones de pirita diseminada.

La fracción fina es variable, las muestras desarrolladas netamente en ambiente marino se dividen en sectores dominados por illita y sectores dominados por clorita. En general el acompañante mayoritario es el interestratificado IS con eventuales registros de proporciones menores de caolinita. En las muestras provenientes del prodelta domina la esmectita con más del $90 \%$.

La disparidad de información proveniente de la cristalinidad de illita y la participación de capas expansivas en los interestratificados IS sugieren un origen mixto de la illita, siendo en parte heredado y en parte diagenético. A su vez, todas las muestras se encontrarían mayoritariamente en etapa de mesodiagénesis y en segundo término en eodiagénesis.

Los resultados obtenidos en las arcillas de esta unidad se correlacionan con la argilozona C definida por Iñiguez Rodríguez y Decastelli (1984), en la cual los autores citan la mayor abundancia de interestratificados de illita y esmectita junto a clorita. Por su parte, en la Formación Río Mayer de afloramiento se registraron mayores contenidos de illita respecto de los documentados en subsuelo. A su vez, en ambos estudios se observó el mismo grado de diagénesis para la unidad sobre la base del estudio de las capas expansivas en los interestratificados.

Por último, Iñiguez Rodríguez y Decastelli (1984) citan la presencia de caolinita en la Formación Springhill y el predomino de esmectita en las argilozonas B y A que corresponden a las unidades ubicadas por sobre la Formación Río Mayer. Estos resultados están en concordancia con lo observado en la región del Lago San Martín. 


\section{Capítulo VI - Análisis Petrográfico}

\section{VI.1 - Introducción}

El estudio petrográfico de rocas sedimentarias es uno de los pilares en los que se fundamenta la clasificación y procedencia de este tipo de rocas, en especial para las areniscas. En cambio su utilización en depósitos predominantemente pelíticos se ve relegado frente a otros métodos de observación (difracción de rayos $\mathrm{X}$, geoquímica). Para las unidades comprendidas en el área de estudio, se realizó el análisis petrográfico de 59 cortes delgados provenientes de las formaciones Springhill (5), Río Mayer (51) y Kachaike/Piedra Clavada (3). Este estudio incluyó 21 cortes de areniscas, 25 de margas y pelitas, 4 de areniscas glauconíticas, 6 de calizas y 3 de trazas fósiles.

\section{2 -Petrografía de areniscas}

Las areniscas, según quedó evidenciado en los capítulos previos, son componentes menores en esta unidad y sólo constituyen cerca de un 5\% de los afloramientos de la Formación Río Mayer. Sin embargo, se efectuaron análisis petrográficos en algunos de los niveles psamíticos provenientes principalmente de la seccional Río Guanaco y en menor medida del Lago San Martín. Las muestras pertenecen a los perfiles PG, EVP 1 y 2, WVP, PELL, PEKA. Como complemento se analizaron 4 muestras de la Fm. Springhill y 3 de la Fm. Kachaike/Piedra Clavada.

Se caracterizaron los componentes detríticos participantes en cada muestra, además de identificar tipo de matriz y cemento. En segunda instancia, se seleccionaron un total de 13 muestras para realizar el conteo de clastos siguiendo la metodología de Gazzi-Dickinson (Ingersoll et al., 1984). Esto incluye el recuento de 400 puntos por sección delgada con el espaciamiento mayor igual al tamaño de grano máximo de la muestra. El objeto de esta metodología es que cada conteo pueda ser utilizado tanto para clasificar las rocas como para analizar su posible procedencia.

Las muestras de la Formación Río Mayer poseen en promedio 31,7\% de matriz, con lo cual, a excepción de una muestra el resto son vaques. A continuación se describirán los componentes detríticos principales observados en secciones delgadas de esta unidad. 


\section{2.1 - Componentes detríticos}

Se han reconocido un total de 9 componentes detríticos principales en las areniscas y vaques analizados, estos son: cuarzo monocristalino, cuarzo policristalino, plagioclasas, feldespato potásico, biotita, opacos, líticos volcánicos varios, bioclastos y líticos glauconíticos. A continuación se describirán las principales características observadas en estos componentes a excepción de los líticos glauconíticos que serán tratados aparte.

\section{2.1.1 - Cuarzo monocristalino}

Los clastos de cuarzo monocristalino son el componente mayoritario en las areniscas de la Formación Río Mayer, encontrándose en porcentajes entre 2,5 y 41\% (22\% de promedio). En general poseen extinción límpida, en ocasiones presentan engolfamientos y/o inclusiones negativas de vidrio volcánico. La forma suele ser subredondeada a subangulosa y en algunos casos se observan granos subhedrales (Figura 6.1).

Estos clastos de cuarzo se interpretan como de origen volcánico, por otra parte, algunos granos de cuarzo poseen extinción ondulosa, y su origen se considera metamórfico (Pettijohn et al., 1972).

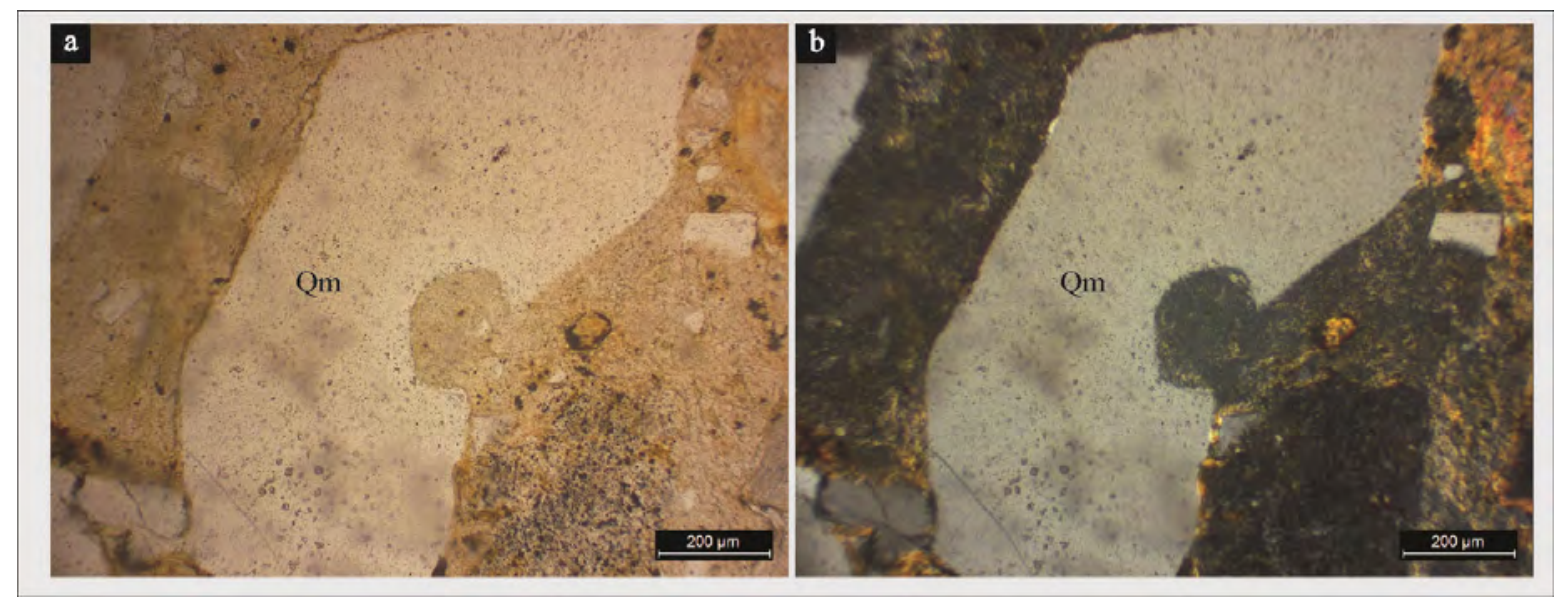

Figura 6.1- Microfotografía de un grano de Cuarzo monocristalino con engolfamiento (origen volcánico) proveniente de la muestra WVP 11 de la Seccional Río Guanaco. En a sin nicoles cruzados, en b con nicoles cruzados. (Escala 200 micrones) 


\section{2.1.2 - Cuarzo policristalino}

Este componente se encuentra menos representado que el anterior y participa con un $4 \%$ en promedio (valores entre 0 y 20\%). En general posee formas subangulosas a subredondeadas y se compone de varios cristales de cuarzo frecuentemente anhedrales con extinción ondulosa (figura 6.2).

El origen de estos clastos se considera metamórfico, aunque algunos litoclastos de cuarzo policristalino poseen cristales euhedrales equidimensionales y su origen podría ser tanto sedimentario como metamórfico.

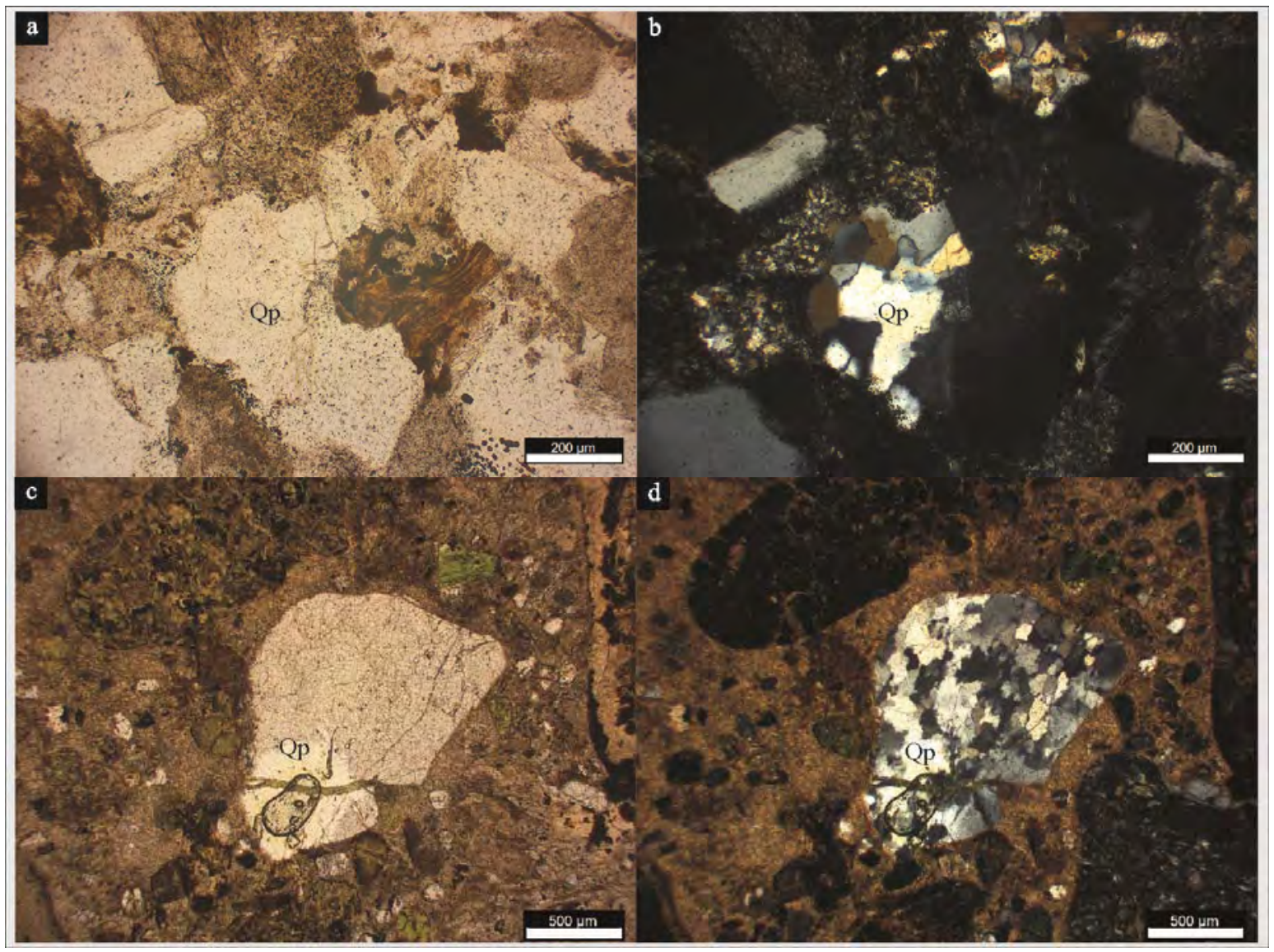

Figura 6.2- Microfotografía de granos de Cuarzo policristalino. Pertenece a la muestra LV 29 (a, b) y a la muestra LV 22 (c, d) de la Estancia La Vega. En a y c sin nicoles cruzados, en b y d con nicoles cruzados. Escala en fotos a y b 200 micrones, en fotos c y d 500 micrones. 


\section{2.1.3 - Plagioclasa}

Las plagioclasas son los feldespatos más frecuentes en esta unidad tal cual lo confirman los estudios de difracción de rayos $\mathrm{X}$ y son, después del cuarzo, el grupo más abundante en las areniscas. Están presentes entre un 0.2 y un $47 \%$, con un promedio cercano al $10 \%$. En general con formas subangulosas y en menor frecuencia subredondeadas, poseen macla polisintética de Albita (figura 6.3), aunque también se ha observado en este componente la macla de Carlsbad. Utilizando el método de Michel-Levy se determinaron composiciones que varían entre oligoclasa y andesina. Suelen presentarse alterados y pasan formar arcillas en especial por los planos de macla y/o en las fracturas.

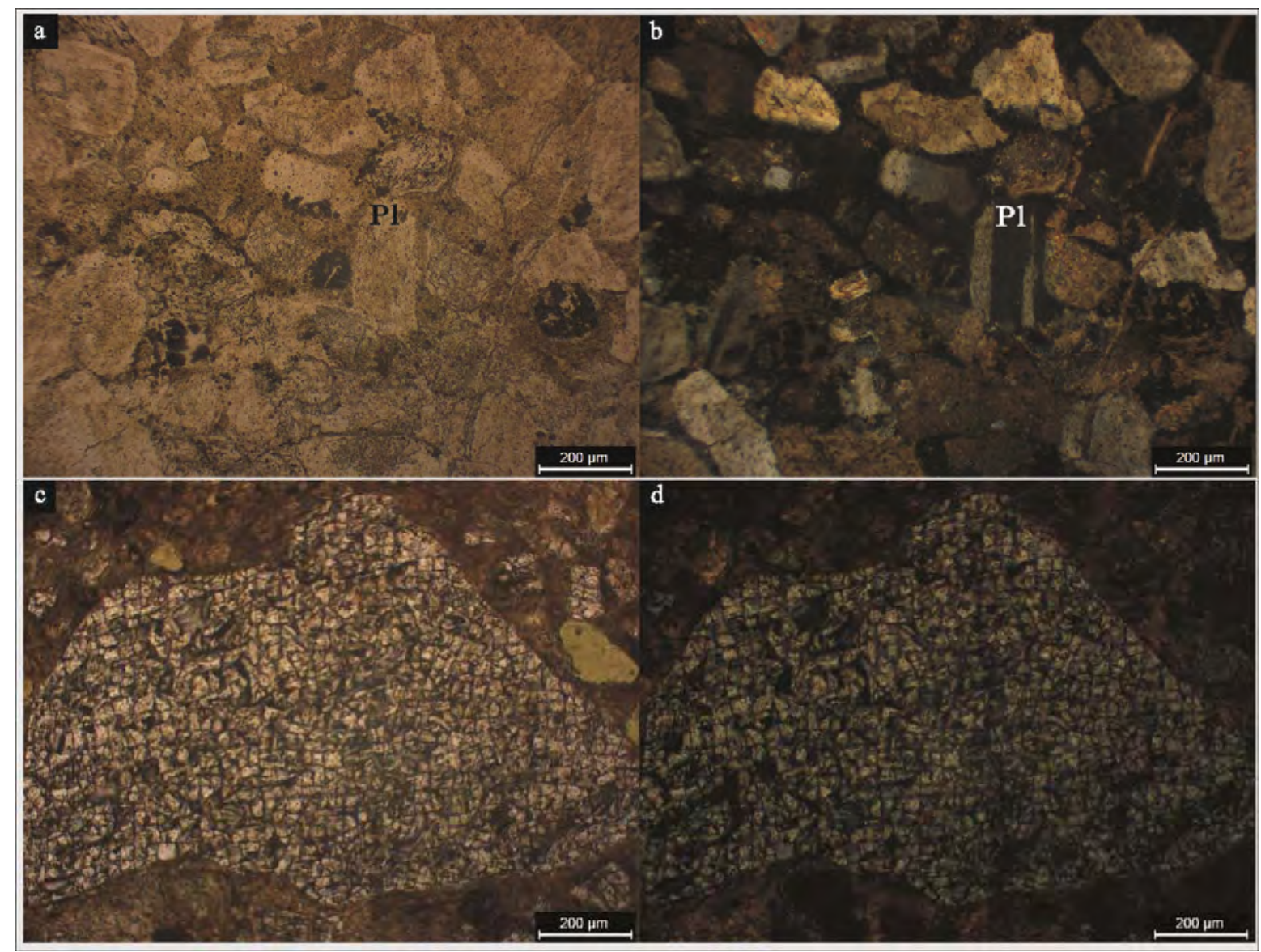

Figura 6.3- Microfotografía de grano de Plagioclasa en la muestra PEVP1-7 de la Seccional Río Guanaco (fotos a, b). En las fotos c-d un feldespato de la muestra LV 22 de la Estancia La Vega. En a y c sin nicoles cruzados, en b y d con nicoles cruzados. (Escala de todas las fotos 200 micrones). 


\section{2.1.4 - Feldespato potásico}

Se presenta en proporciones variables, entre 0,2 y $4 \%$ con promedio de $2 \%$, esta representación es similar a la obtenida por difracción de rayos x en la que se observa que este componente es mucho menos frecuente que las plagioclasas. Son cristaloclastos equidimensionales, poseen macla de Carlsbad, en ocasiones están zonados y se encuentran en la mayor parte de los casos, alterados y/o corroídos (figura 6.4).

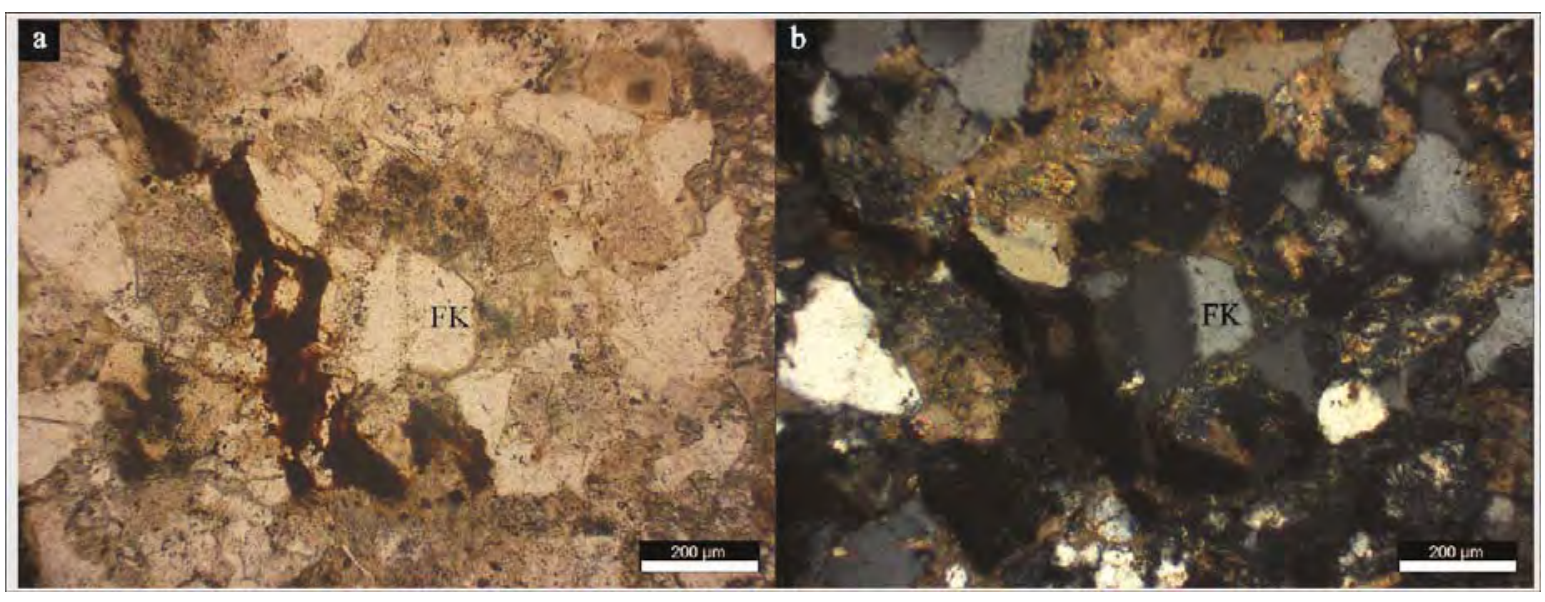

Figura 6.4- Microfotografía de un grano de Feldespato potásico. Pertenece a la muestra PEKA 20 del lago San Martín. En a sin nicoles cruzados, en b con nicoles cruzados. (Escala 200 micrones).

\section{2.1.5 - Biotita}

Se presenta en proporciones bajas, en general menores a 3\%, excepto en una muestra perteneciente al relleno inicial de un hemigraben en la seccional Río Guanaco (muestra WVP3), en la que posee 16\%. Son granos de color verde con pleocroísmo y clivaje perfecto que al cruzar nicoles generan colores de interferencia altos y extinción paralela (figura 6.5).

Predominan formas alargadas angulosas a subangulosas, algunos granos pueden evidenciar deformación por compactación (figura 6.5 a-b) aunque no es lo más frecuente. En general estos componentes se encuentran en los planos de laminación de algunas areniscas (figura 6.5 c-d) aunque en otras ocasiones están de manera diseminada en toda la sedimentita. 

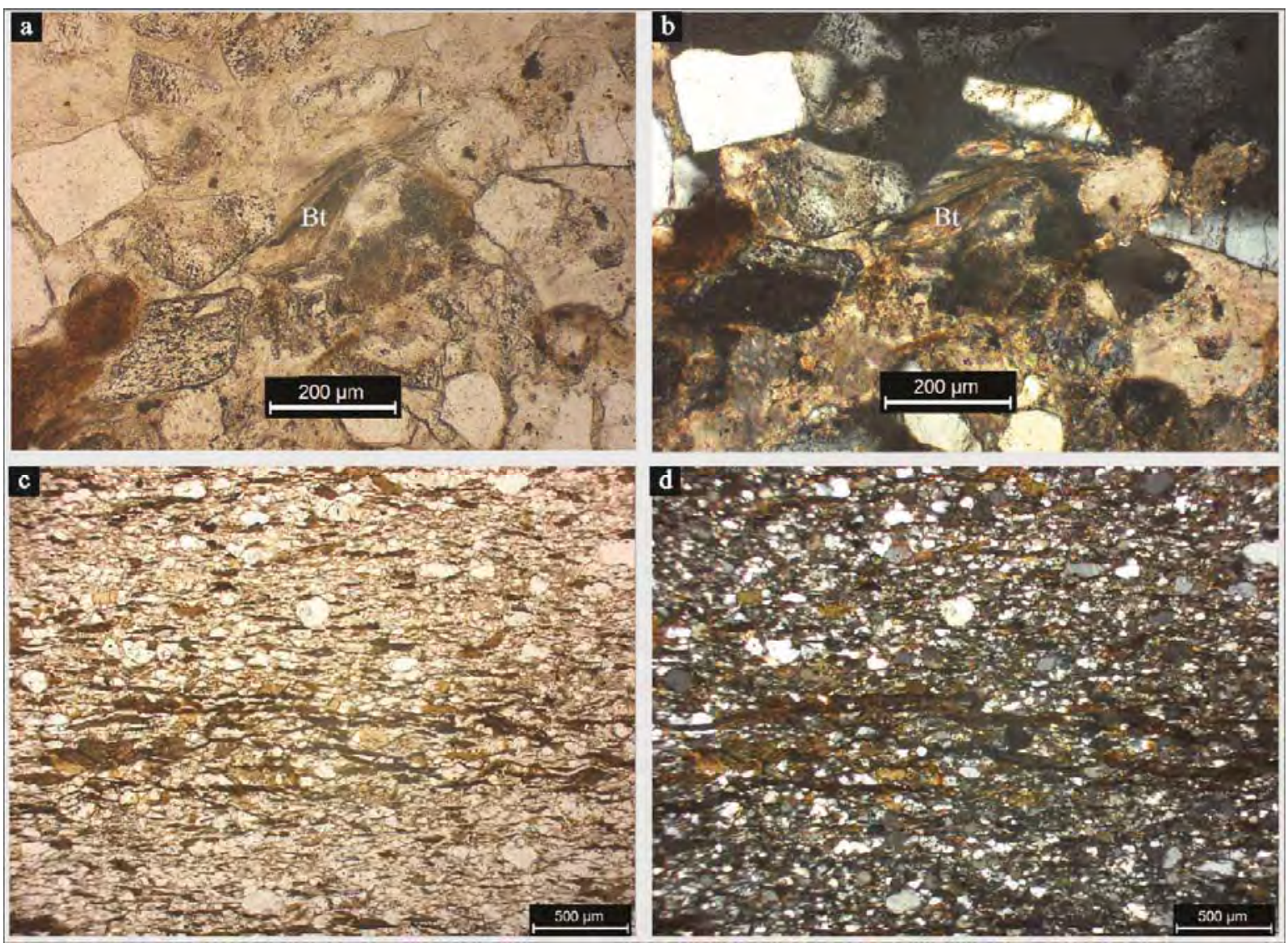

Figura 6.5- Microfotografías de granos de Biotita. Fotos a-b muestran un grano de biotita deformado por presión en la muestra PG 39 de la Seccional Río Guanaco. En las fotos c-d se observa el ordenamiento paralelo de los granos de biotita en los planos de laminación de las areniscas de la muestra BP3. Fotos a y c sin nicoles, b y d con nicoles cruzados. Escala en fotos a-b 200 micrones, en fotos c-d 500 micrones.

\section{2.1.6 - Opacos}

Los componentes opacos se presentan en proporciones entre 1 - 5\%. En general poseen formas subredondeadas a redondeadas y por definición son opacos a la luz polarizada (figura 6.6).

Un componente común observado en muestra de mano es la Pirita. 


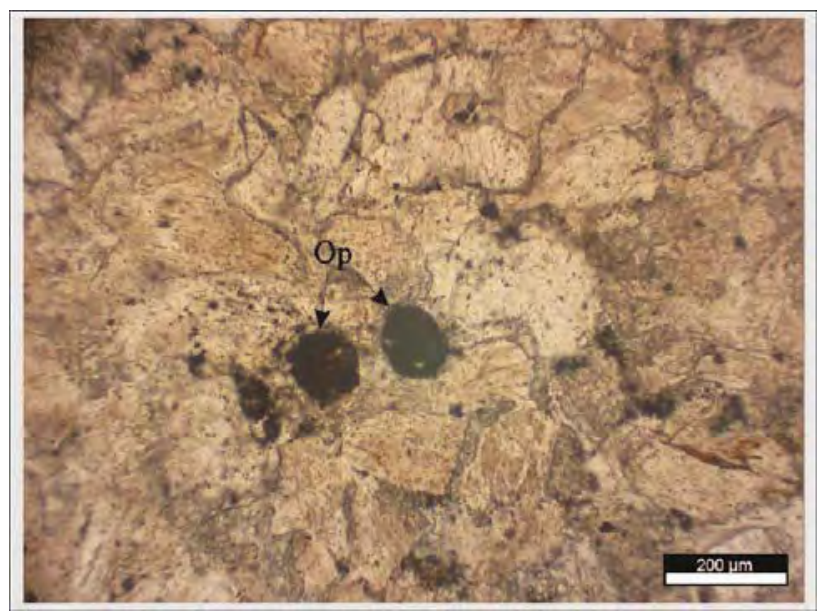

Figura 6.6- Microfotografía de los opacos. Pertenece a la muestra PEVP 7 de la Seccional Río Guanaco. Foto sin nicoles cruzados. (Escala 200 micrones).

\section{2.1.7 - Otros componentes detríticos}

Otros componentes detríticos frecuentes en las areniscas de esta formación son los líticos volcánicos, los bioclastos y los líticos glauconíticos. De estos tres componentes los bioclastos son muy escasos, y sólo se registran fragmentos de conchillas en algunas areniscas del perfil ELV y dentro de la Formación Springhill en el perfil ELL (figura 6.5 ab). Los líticos volcánicos son frecuentes y se concentran en los depósitos de prodelta en la región del Lago San Martín y Estancia La Vega (figura 6.7 c- j), donde participan con un porcentaje que puede alcanzar hasta un $8 \%$. Por su parte los litoclastos glauconíticos son abundantes en dos niveles de areniscas glauconíticas que serán tratados a continuación en un apartado diferente, con porcentajes que varían entre 25 y 35 \%.

Los líticos volcánicos se presentan de cuatro maneras: con textura pilotáxica (Lvp), con textura esferulítica (Lve), con textura traquítica (Lvt) y los líticos riolíticos (Lvr). Los primeros se caracterizan por la presencia de pequeños cristales o tablillas de plagioclasas euhedrales a subhedrales que se ubican dentro de una pasta afanítica de vidrio volcánico sin una distribución definida (figura 6.7 c-d). Esta textura es conocida como textura pilotáxica o afieltrada, y caracteriza a las pastas volcánicas de composiciones intermedias (Best y Christiansen, 2001). 


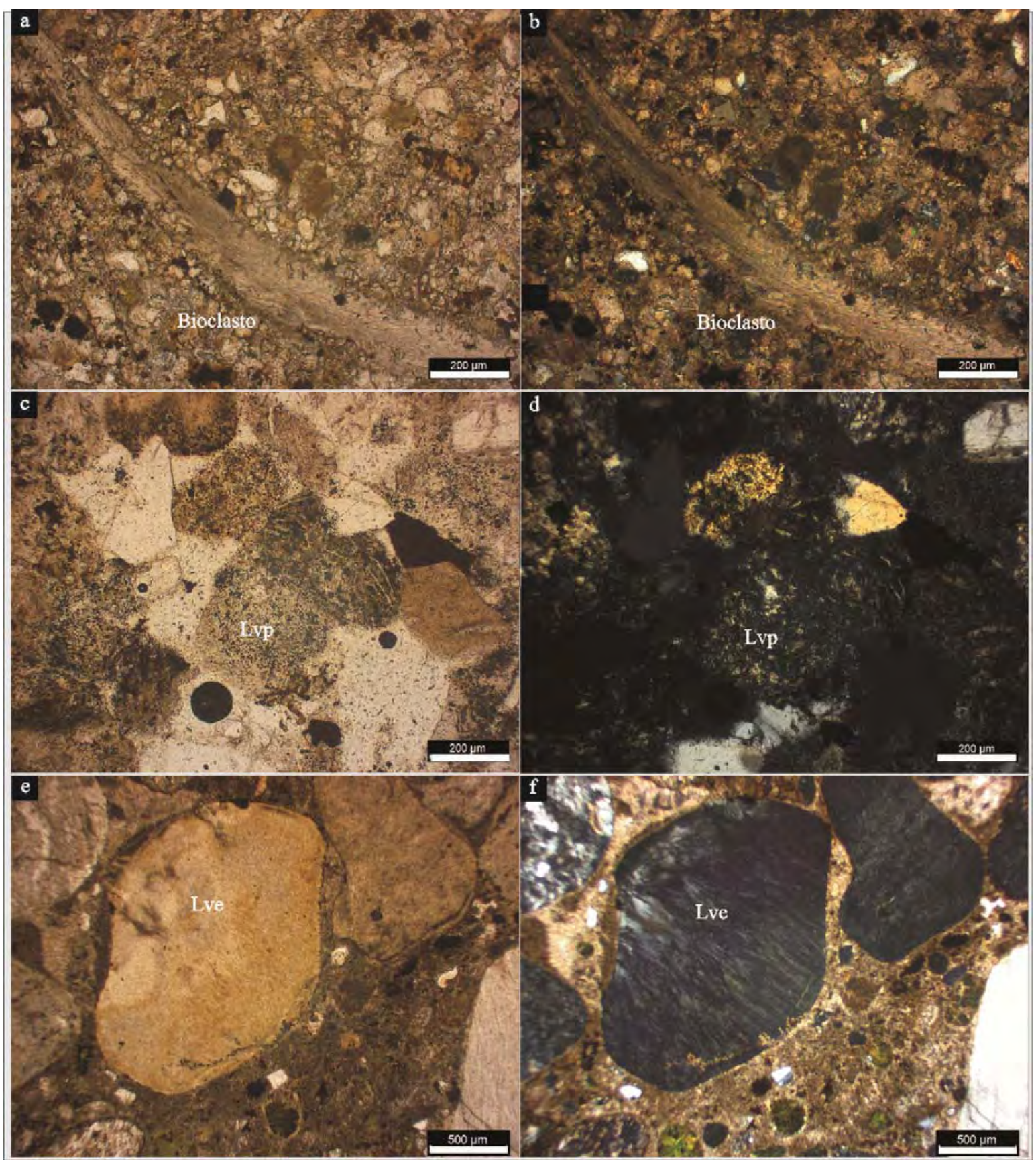

Figura 6.7- Microfotografía de los principales componentes detríticos acompañantes de los previamente descriptos. Bioclastos (a-b) de la muestra PELL 8 de Lago San Martín. Lítico volcánico con textura pilotáxica (c,d) de la muestra LV 29 de la Estancia La Vega. En las fotos e y f se observan un lítico formado por vidrio volcánico recristalizado con textura esferulítica proveniente de la muestra LV 22. En a, c, e, sin nicoles cruzados, en b, d, f, con nicoles cruzados. Escala en fotos a-d 200 micrones, en fotos e-f 500 micrones. 
El segundo tipo de líticos volcánicos, tiene formas subredondeadas y colores pálidos entre amarillo y pardo, y se caracteriza por la presencia de vidrio volcánico recristalizado que en ocasiones genera una típica textura esferulítica (figura 6.7 e-f). Su origen podría ser piroclástico, aunque no se han registrado trizas vítreas que confirmen esta hipótesis. Otro posible origen sería volcánico a partir de la recristalización de pastas vítreas.

Los líticos volcánicos con textura traquítica están caracterizados por la presencia de pequeñas tablillas de plagioclasas orientadas en forma paralela a sus ejes mayores e inmersas en una pasta afanítica (figura 6.7 g-h). Esta textura es característica de las rocas volcánicas mesosilícicas a ácidas, especialmente de las traquitas, aunque también está presente en andesitas y dacitas (Best y Christiansen, 2001).

Finalmente se reconocieron en los depósitos de la Formación Río Mayer líticos volcánicos de composición riolítica (figura 6.7 i-j), los cuales se componen de cristales de cuarzo y feldespato rodeados por una pasta afanítica.

Los 4 tipos de líticos volcánicos se caracterizan por tener formas subredondeadas y tamaños que varían desde arenisca fina a sábulo. Todos los líticos de este origen se concentran en las muestras de la región comprendida entre los lagos Viedma y San Martín, tanto en el tramo final de la Formación Río Mayer como en las formaciones Kachaike y Piedra Clavada. 


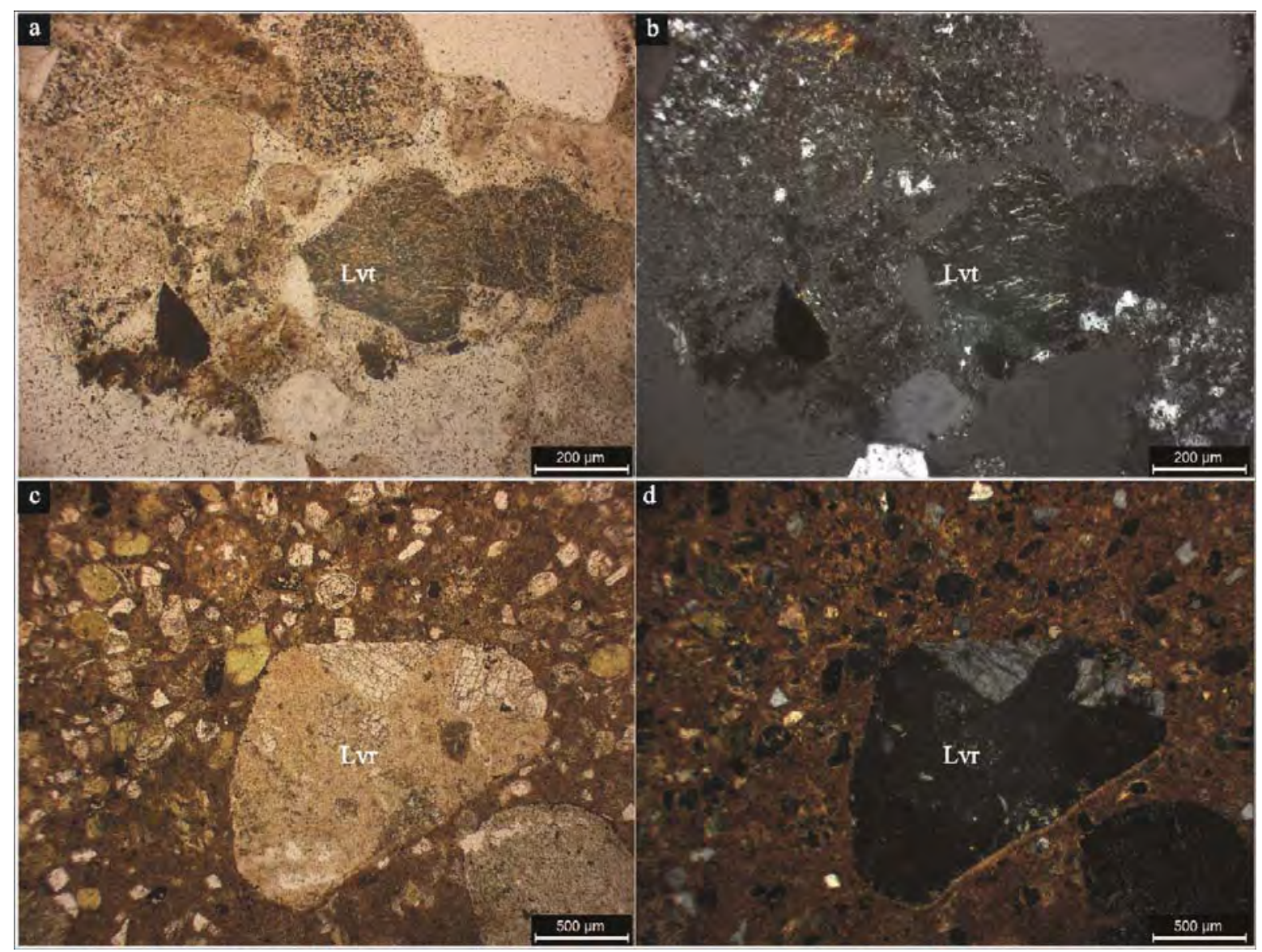

Figura 6.7 continuación- Microfotografía de los principales componentes detríticos acompañantes de los previamente descriptos. Lítico volcánico con textura traquítica (a,b) de la muestra LV 29 de la Estancia La Vega. En las fotos c y d se observan un lítico volcánico riolítico de la muestra LV 22. En a, c, sin nicoles cruzados, en b, d, con nicoles cruzados. Escala en fotos a-b 200 micrones, en fotos c-d 500 micrones.

\section{2.2 - Cementos}

El tipo de cemento que predomina en las areniscas de la Formación Río Mayer es el carbonático de tipo blocky, totalmente obliterante (figura 6.8 a, b). En general este cemento se presenta formando grandes cristales de calcita de color rosa pálido a la luz polarizada con un desarrollo excelente de clivaje en dos direcciones. Predomina el tamaño macroesparítico, con frecuencia en textura poiquilotópica.

En menor proporción suele aparecer en algunas muestras un cemento ferruginoso subordinado, el cual puede presentarse rodeando los clastos en forma de pátina o rellenar poros y verse como parches (figura 6.8c). En areniscas de la Formación Springhill es 
común el cemento silíceo creciendo en continuidad óptica con los granos de arena (figura 6.8d).

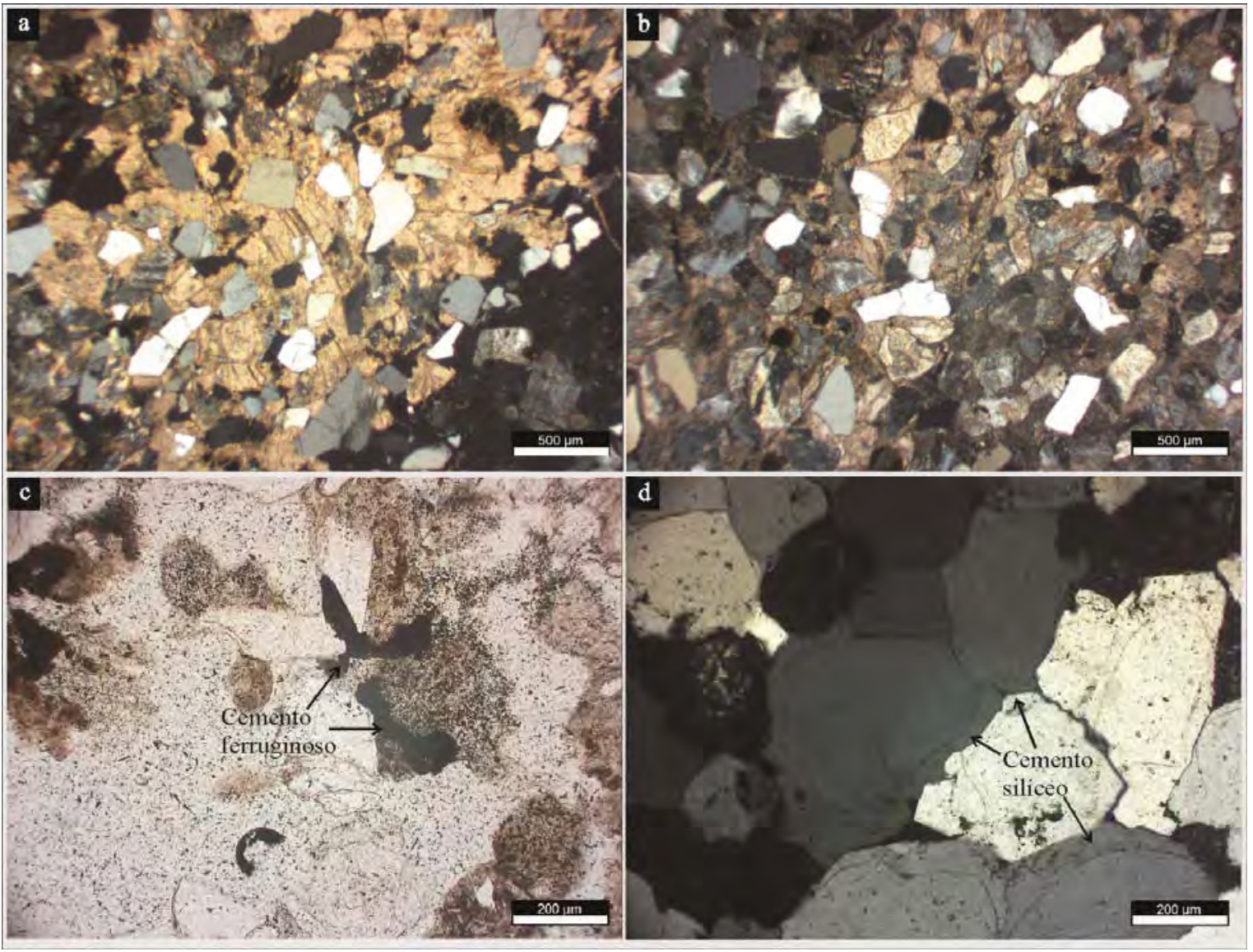

Figura 6.8- Microfotografía de los cementos reconocidos en las areniscas estudiadas. En a y b, cemento de calcita macroesparítica con textura poiquilotópica. Foto a muestra BP 3 y foto b muestra PG 39, ambos de la Seccional Río Guanaco. En c cemento ferruginoso, muestra LV 29 (Ea. La Vega, región entre los lagos Viedma y San Martín). En la foto d se observa el cemento silíceo en continuidad óptica con los granos de cuarzo. Muestra PELL 7 (formación Springhill), Lago San Martín. En c sin nicoles cruzados, en a, b, d con nicoles cruzados. (Escala en a y b, 500 micrones; en c y d, 200 micrones). 


\section{2.3 - Clasificación de Psamitas}

Se seleccionaron 13 muestras de las formaciones Springhill, Río Mayer y Kachaike/Piedra Clavada de areniscas y vaques de tamaño fino a medio (125 a 300 micrones) para la cuantificación de sus componentes. Las muestras de tamaños mayores ó menores no fueron cuantificadas pero sí formaron parte de la descripción inicial de los componentes detríticos.

A partir de los datos obtenidos del recuento de 400 puntos en las areniscas (Tabla 6.a) se catalogaron las muestras de estas formaciones según las clasificaciones de Folk et al. (1970) y Dott (1964, modificada por Pettijohn et al., 1972) (figura 6.9). Cabe aclarar que las muestras PG44, WVP11 y PELL11 corresponden a la facies de areniscas glauconíticas, y que los granos de glauconita no fueron tenidos en cuenta para la discriminación de áreas fuente por ser considerados componentes autigénicos.

\begin{tabular}{|c|c|c|c|c|c|c|c|c|}
\hline Región & Unidad & muestras & Qm & Qp & $\mathrm{F}$ & LV & LG & Matriz \\
\hline \multirow{7}{*}{ Río Guanaco } & \multirow{2}{*}{ F. Sp } & WVP2 & 62,28 & 3,51 & 12,28 & 21,93 & 0,00 & 68,75 \\
\hline & & WVP3 & 74,22 & 1,74 & 1,74 & 22,30 & 0,00 & 28,25 \\
\hline & \multirow{5}{*}{ F. R M } & BP3 & 90,61 & 3,87 & 4,42 & 1,10 & 0,00 & 28,75 \\
\hline & & PG39 & 69,53 & 3,00 & 18,88 & 8,58 & 0,00 & 7,25 \\
\hline & & PG44 & 12,85 & 1,12 & 7,82 & 3,35 & 74,86 & 30,25 \\
\hline & & WVP11 & 24,57 & 0,00 & 9,00 & 2,08 & 64,36 & 27,50 \\
\hline & & PEVP1 7 & 4,81 & 1,92 & 91,83 & 1,44 & 0,00 & 33,25 \\
\hline \multirow{6}{*}{ Lo San Martín } & \multirow{2}{*}{ F. Sp } & PELL7 & 78,14 & 21,86 & 0,00 & 0,00 & 0,00 & 0,00 \\
\hline & & PELL8 & 73,47 & 12,24 & 0,00 & 14,29 & 0,00 & 56,25 \\
\hline & \multirow{2}{*}{ F. R M } & PELL11 & 17,87 & 6,76 & 8,21 & 4,83 & 62,32 & 47,00 \\
\hline & & PEKA20 & 39,01 & 34,98 & 12,11 & 13,90 & 0,00 & 25,00 \\
\hline & \multirow{2}{*}{ F. K/PC } & PEKA22 & 25,32 & 12,03 & 16,46 & 46,20 & 0,00 & 43,00 \\
\hline & & LV29 & 15,82 & 8,54 & 4,43 & 71,20 & 0,00 & 14,50 \\
\hline
\end{tabular}

Tabla 6.a- Resultados del conteo de clastos (recalculados a 100\%) para plotear los diagramas de clasificación y proveniencia de areniscas de las Formaciones Springhill (F. Sp), Río Mayer (F. RM) y Kachaike/Piedra Clavada (F. K/PC). Qm= cuarzo monocristalino; $\mathrm{Qp}=$ cuarzo policristalino; $\mathrm{F}=$ feldespatos; $\mathrm{LV}=$ líticos volcánicos; LG: líticos glauconíticos. 


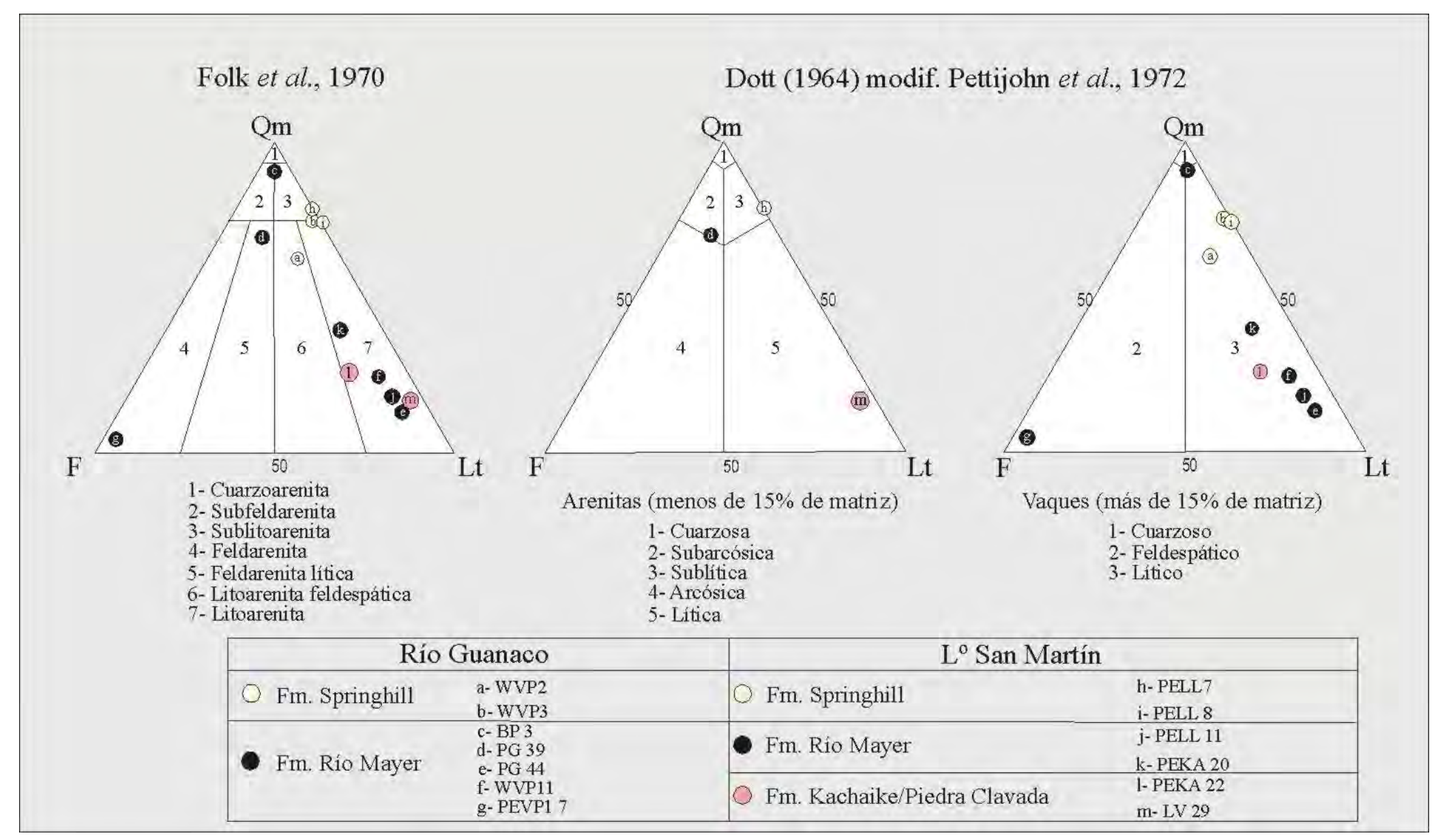

Figura 6.9- Clasificación de las muestras de areniscas y vaques analizados para las formaciones Springhill, Río Mayer y Kachaike/Piedra Clavada según las clasificaciones de Folk et al., 1970 y Dott, 1964 (modificada Pettijohn et al., 1992). 
Como se observa en la figura 6.9, las muestras de la Formación Río Mayer son en general vaques líticos/ feldespáticos (6 muestras) y una arenita subarcósica según Dott (1964). Según Folk et al. (1970), éstas muestras se ubican en los campos de Sublitoarenita (1), Feldarenita (1), Feldarenita lítica (1) y Litoarenita (4).

Las muestras analizadas de la Formación Springhill son 4, dos provenientes del Oeste de la Vega de Pérez (perfil WVP- Río Guanaco) y dos del Lago San Martín (perfil Ea. La Lila -PELL-).Tres de las muestras son vaques líticos y una arenita sublítica según Dott (1964). Según Folk et al. (1970), éstas muestras se ubican en los campos de Sublitoarenita (2), Litoarenita feldespática (1) y Litoarenita (1).

Las muestras estudiadas de la Formación Kachaike/Piedra Clavada son 2, una del perfil Ea. Kachaike (PEKA) del Lago San Martín y una del perfil de Ea. La Vega (LV). Corresponden a un vaque lítico y una arenita lítica según Dott (1964). Según Folk et al. (1970), éstas muestras se ubican en el campo de las Litoarenitas.

\section{2.3.1- Areniscas de la Formación Río Mayer}

Las muestras de psamitas de la Formación Río Mayer son en general vaques líticos o feldespáticos con aproximadamente un 30\% de matriz en promedio. Dentro de los componentes detríticos, no teniendo en cuenta los granos de glauconita, el constituyente mayor es el cuarzo (mono y policristalino), en general acompañado en proporciones variables de plagioclasa y líticos. Hacia el tercio final de la unidad estudiada se observa un incremento en la participación de líticos volcánicos, los cuales son más abundantes en la región del lago San Martín que en la seccional Río Guanaco. En esta última localidad es notoria la participación de plagioclasa (muestra PEVP 1-7), hecho que fue corroborado por difractometría de rayos X. El cemento dominante es carbonático de tipo macroesparítico.

\section{2.4 - Procedencia de Psamitas}

Con los datos de la tabla 6.a se graficaron los diagramas de Dickinson et al. (1983) para determinar el ambiente tectónico de las áreas de aporte de los sedimentos formadores de la Formación Río Mayer y su comparación con las formaciones Springhill y Kachaike/Piedra Clavada (figura 6.10). 


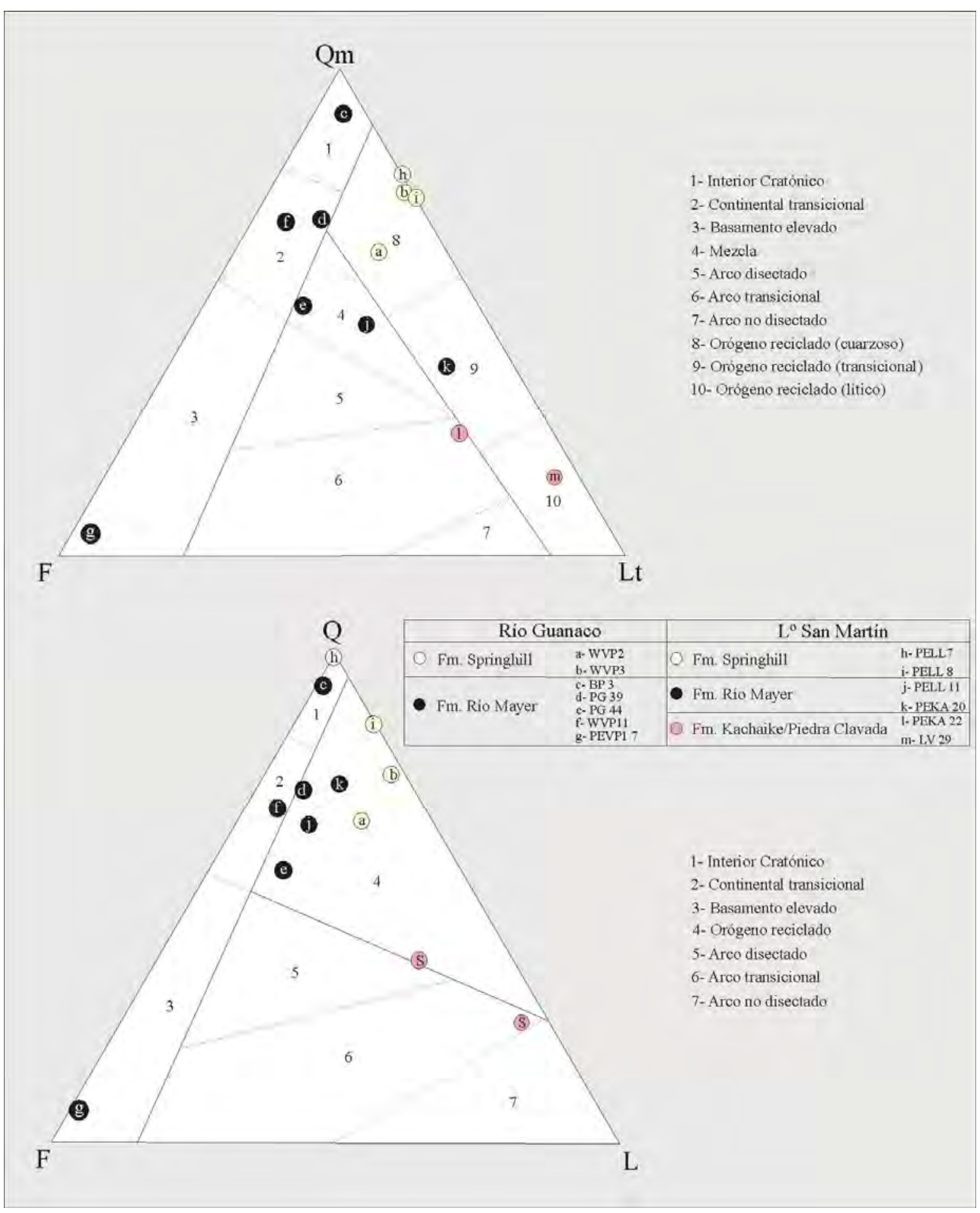

Figura 6.10 - Distribución de las muestras de areniscas y vaques analizados para las formaciones Springhill, Río Mayer y Kachaike/Piedra Clavada según la clasificación de Dickinson et al., 1983, para la discriminación tectónica de áreas de aporte. 
En el diagrama Qm-F-Lt las muestras de la Formación Springhill se ubican en los campos de orógeno reciclado cuarzoso. Las muestras de la Formación Río Mayer presentan una distribución más variada, para la Seccional Río Guanaco las muestras se encuentran cercanas a la línea que une el Qm y el F, generando ambientes de interior cratónico, continental transicional y basamento elevado. Por otro lado, las muestras de esta unidad en el Lago San Martín se ubican en los campos de mezcla y orógeno reciclado transicional. Para la Formación Kachaike/Piedra Clavada los ambientes son orógeno reciclado lítico y arco transicional.

En el diagrama Q- F- L las muestras de la Formación Springhill se ubican en los campos de orógeno reciclado e interior cratónico. Para la Formación Río Mayer domina el orógeno reciclado (4 muestras), en menor proporción interior cratónico, continental transicional y basamento elevado con una muestra en cada campo. En último lugar para la Formación Kachaike/Piedra Clavada una muestra se ubica en orógeno reciclado y una en arco transicional.

Con esta distribución de las muestras se definieron 4 poblaciones en el diagrama Qm-F-Lt y 3 poblaciones en el diagrama Q-F-L que se grafican en la figura 6.11.

En lo que respecta al diagrama Qm-F-Lt hay una gran división de las muestras en dos grupos principales, que son el pre-Aptiano y el Aptiano-Albiano. En el grupo de las muestras pre-Aptianas hay 2 poblaciones, la primer población (A) incluye a las muestra de areniscas y vaques de la unidad aquí estudiada en la Seccional Río Guanaco dentro de la sección media y el inicio de la sección superior. La segunda población (B) corresponde a las 4 muestras de la Formación Springhill más las areniscas glauconíticas de la base de la Formación Río Mayer en el Lago San Martín. Ambas asociaciones se caracterizan por tener más del 60 \% de cuarzo monocristalino (Qm), y se diferencian en la participación de feldespatos (F) y líticos (Lt), éstos últimos predominan en la población B.

Un cambio importante en la proveniencia de los sedimentos se observa a partir del Aptiano, que en base a los datos cuantificados de la petrografía genera dos poblaciones (C y D) que denota un notable decrecimiento del contenido de Qm, por ende un aumento en los porcentajes de F y Lt. La primera de las poblaciones (C) incluye a una muestras del prodelta de la Formación Río Mayer y a dos muestras de las formaciones Kachaike y Piedra Clavada. Por último, la muestra proveniente de la Seccional Río Guanaco en el final de la 
unidad estudiada se separa considerablemente de todas las analizadas con anterioridad y se considerará como una población pese a tener sólo una muestra.

Las relaciones entre estas 4 poblaciones se pueden explicar si se tienen en cuenta dos aspectos fundamentales que son: la participación de los líticos volcánicos y el paleoambiente de sedimentación en que se desarrollan. El primero de los factores divide en dos grandes grupos las muestras, las poblaciones pre-Aptianas y las Aptiano- Albianas. Esta diferenciación entre la sección inferior y la sección superior de la Formación Río Mayer ya fue observada a partir de los datos de DRX y será nuevamente tratada en el capítulo siguiente (Análisis geoquímico). La mayor participación de líticos volcánicos en el norte del área de estudio dentro de las muestras de la parte superior de la Formación Río Mayer y en las formaciones Kachaike y Piedra Clavada se relaciona con un importante aumento en la presencia de feldespatos observados en corte delgado y corroborados por DRX. Estas relaciones serán explayadas en los capítulos siguientes y discutidas en el capítulo IX.

El segundo factor a tener en cuenta es el paleoambiente de sedimentación, y podría ser el determinante para la división final entre las 2 poblaciones de cada grupo. En el grupo de las muestras pre-Aptianas se distinguen una población correspondiente a los ambientes cercanos a la línea de costa (Formación Springhill más areniscas glauconíticas del inicio de la Formación Río Mayer), y otra población correspondiente a las muestras depositadas por flujos turbidíticos en la plataforma externa. Similar situación se observa en las muestras del Aptiano-Albiano, ya que la población C corresponde a los ambientes de delta y prodelta, mientras que la población $\mathrm{D}$ está incluida en los depósitos turbidíticos de plataforma externa. 


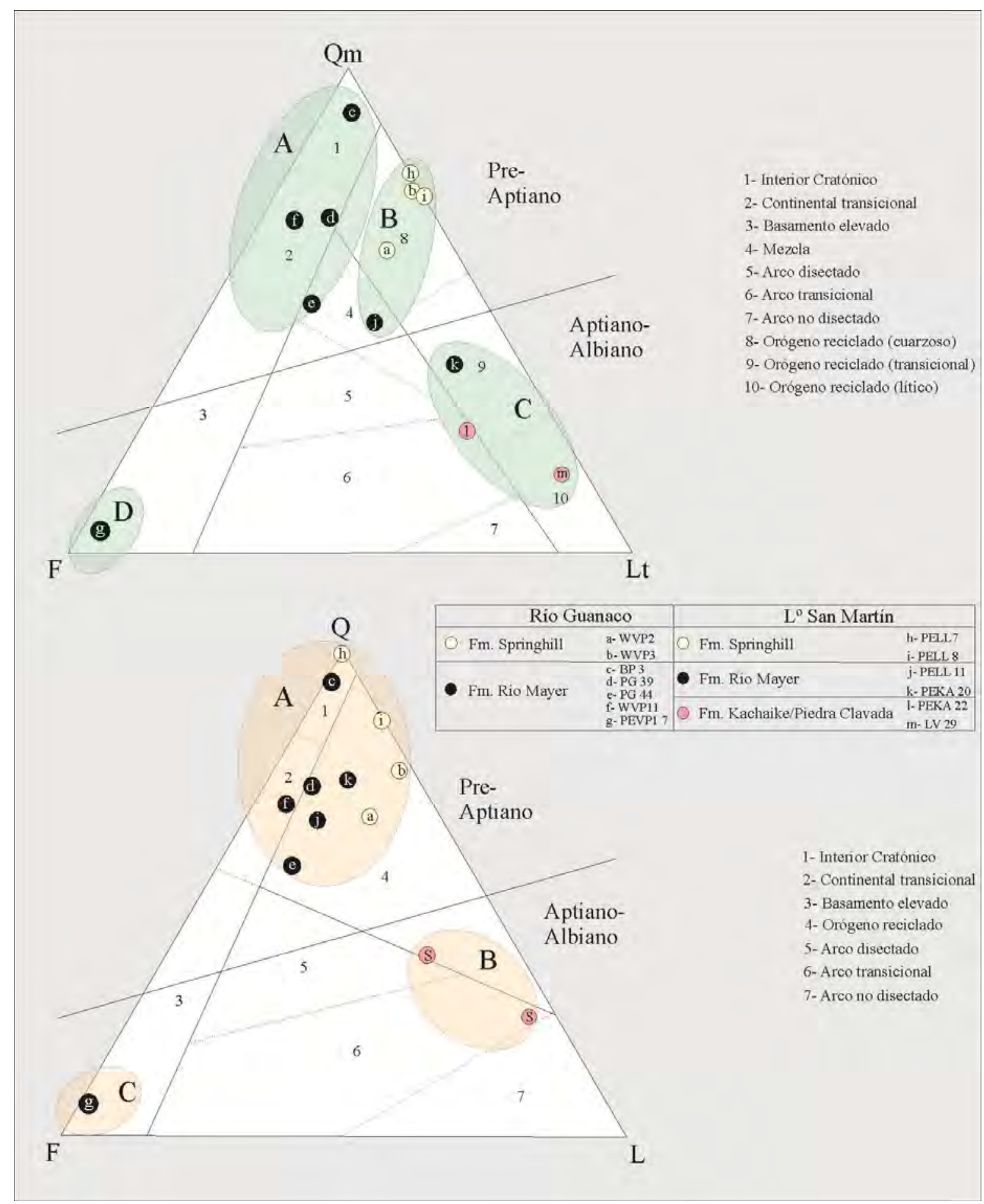

Figura 6.11 - Distribución de las muestras de las formaciones Springhill, Río Mayer y Kachaike/Piedra Clavada según la clasificación de Dickinson et al., 1983, agrupadas en asociaciones por afinidad. 
Una situación parecida fue observada por Walker et al. (1994) en los Apalaches, donde los autores identificaron una variación composicional de las areniscas provenientes de una misma roca fuente producto de la diferente posición paleogeográfica de las unidades analizadas. En este estudio Walker et al., trabajaron tanto con ambientes continentales como marinos, registrados en la transición de una etapa de rift a una etapa de margen pasivo, y el resultado demostró el paso desde composiciones que se encuadran en los campos del orógeno reciclado y arco volcánico hacia la región del bloque continental para unidades temporalmente coetáneas. Esta transición registra el movimiento de composiciones con abundantes líticos a composiciones cuarzo-feldespáticas producto del efecto del transporte de los sedimentos.

De lo dicho anteriormente se desprende que las poblaciones A y D podrían haber evolucionado desde las poblaciones B y C respectivamente, si se considera que el largo transporte al que habrían estado afectadas generó una concentración de los componentes cristaloclásticos en detrimento de los líticos. Esta situación genera que las muestras de arenisca de la plataforma externa tengan una impronta de bloque continental que contrasta con las características de orógeno reciclado y arco volcánico que se registran en la plataforma interna.

Por otro lado, el diagrama Q-F-L (figura 6.11) resultó menos discriminativo y se registraron 3 poblaciones que están parcialmente dividas por edad como en el diagrama anterior. La única muestra que se ubica en un grupo diferente respecto del mencionado diagrama es la muestra k (PEKA 20, prodelta), que se posiciona entre las muestras preAptianas dentro de la población A. Esta población se desarrolla entre ambientes del bloque continental y el orógeno reciclado, pero no se observa una división clara entre sus muestras.

Finalmente las poblaciones $\mathrm{B}$ y $\mathrm{C}$ son equivalentes a las poblaciones $\mathrm{C}$ y $\mathrm{D}$ respectivamente del diagrama Qm-F-Lt. 


\section{3 - Petrografía de pelitas y margas}

Las rocas pelíticas y las margas son los componentes principales de los perfiles sedimentológicos relevados en la Formación Río Mayer. Se realizaron cortes delgados de estas dos litologías para identificar sus componentes. En general se reconoció que ambos tipos de roca poseen similar composición desde el punto de vista cualitativo, y se diferencian en los porcentajes de los componentes. Es habitual que estén integradas por abundante material arcilloso, entre el cual suele reconocerse granos de cuarzo de tamaño limo fino. En las muestras de margas se registra la participación de micrita acompañando al material arcilloso. Es común en estas rocas la presencia de material biogénico (microfósiles), que suele estar recristalizado en calcita. Estos componentes que acompañan son más abundantes en las margas que en las pelitas.

En la figura 6.12 se puede observar la abundante participación de materia orgánica, tanto diseminada (imagen a, c, d) como en los planos de laminación de la pelita (foto b). Como complemento del material arcilloso aparecen principalmente cristaloclastos de cuarzo de tamaño limo grueso (30 a 62 micrones).

En la figura 6.13 se muestran varios cortes delgados de margas en los que se puede observar la abundante participación de material biogénico, con cristaloclastos de cuarzo tamaño limo como complemento. Ambos componentes diseminados en una mezcla de material pelítico-micrítico.

El material biogénico reconocido incluye una gran variedad de organismos, entre los que se destacan foraminíferos, calciesferas y briozoos. Algunos ejemplos de foraminíferos se muestran en la figura 6.14.

Tanto las muestras de pelitas como las de margas poseen abundante cantidad de materia orgánica, de manera diseminada o concentrada en los planos de laminación de la roca. Un caso extremo se observa en la figura 6.15, donde el material orgánico es muy abundante (2,87 \% COT; ver capítulo VII). Las fracturas se encuentran rellenadas por calcita macroesparítica. 


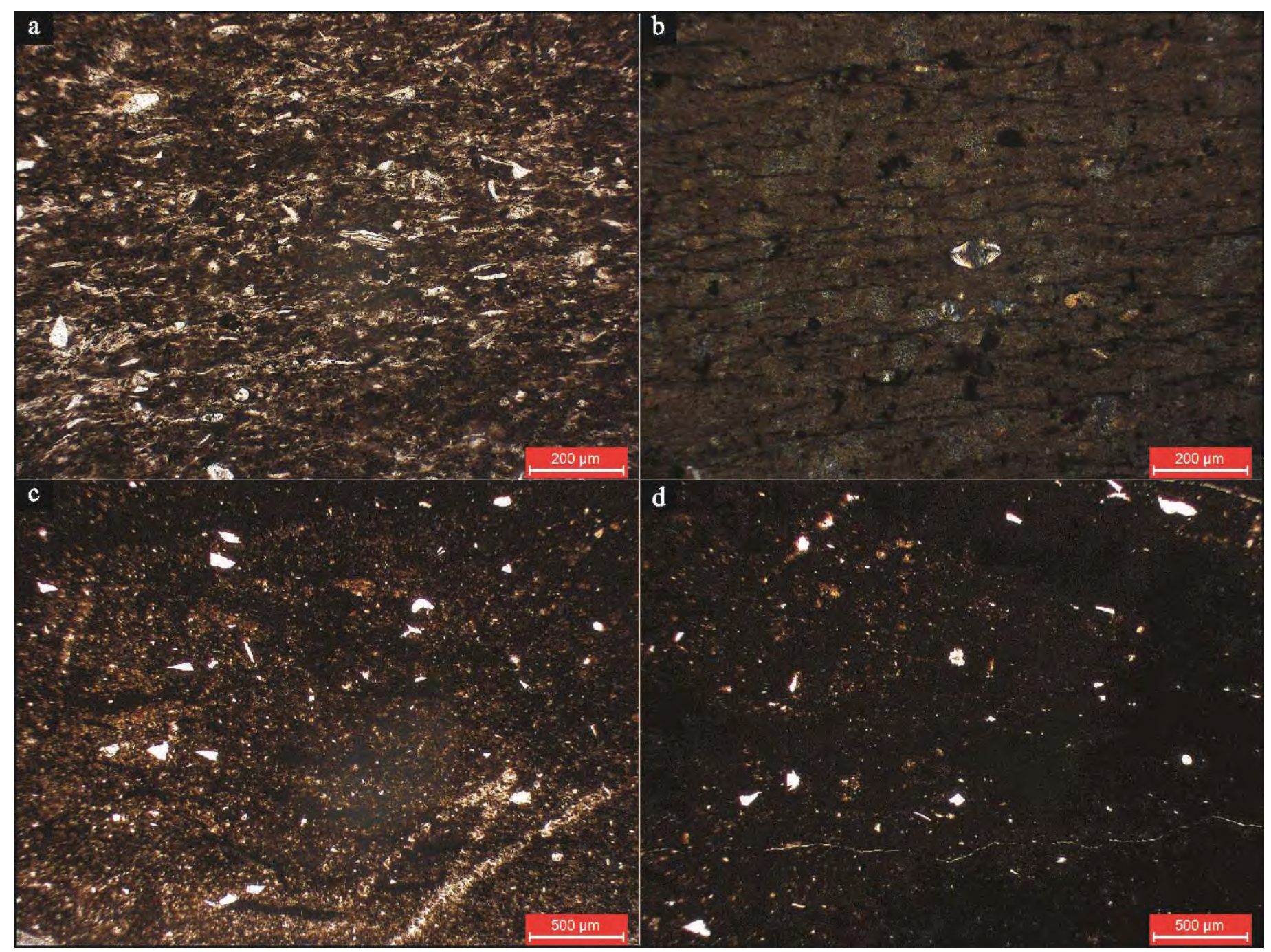

Figura 6.12- Microfotografía de pelitas. Las muestras provienen de los perfiles IG 12 (a) y BP 5 (b) de la Seccional Río Guanaco y del perfil PELL 12 (c-d) del Lago San Martín. Todas las imágenes sin nicoles cruzados. Escala en fotos a-b, 200 micrones; en fotos c-d, 500 micrones. 


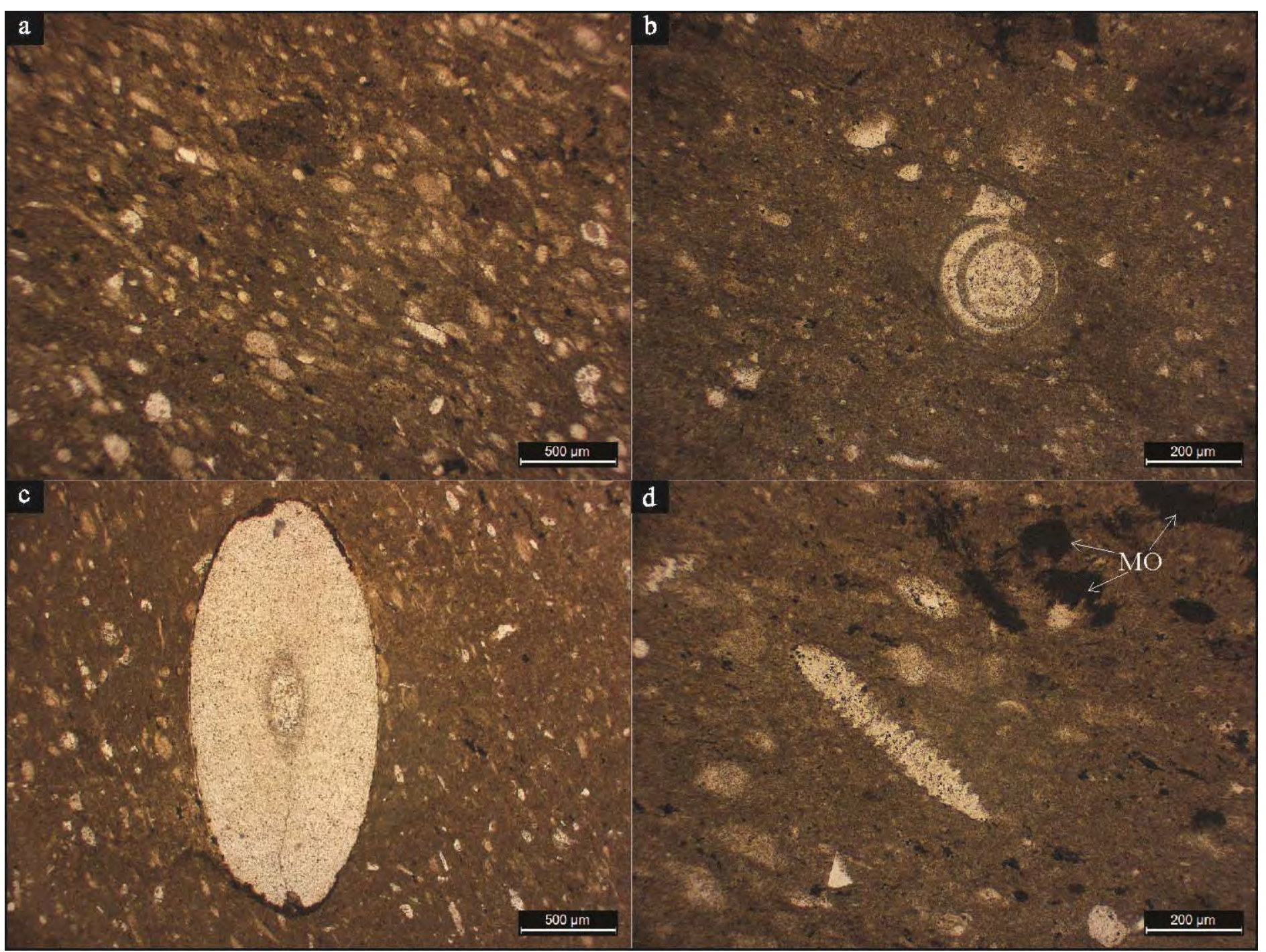

Figura 6.13- Microfotografía de margas. Las muestras provienen del perfil PG de la Seccional Río Guanaco. Foto a, muestra PG 20; b, PG 15; c, PG 19; d, PG 20. Todas las imágenes sin nicoles cruzados. Escala en fotos a-c, 500 micrones; en fotos b-d, 200 micrones. 


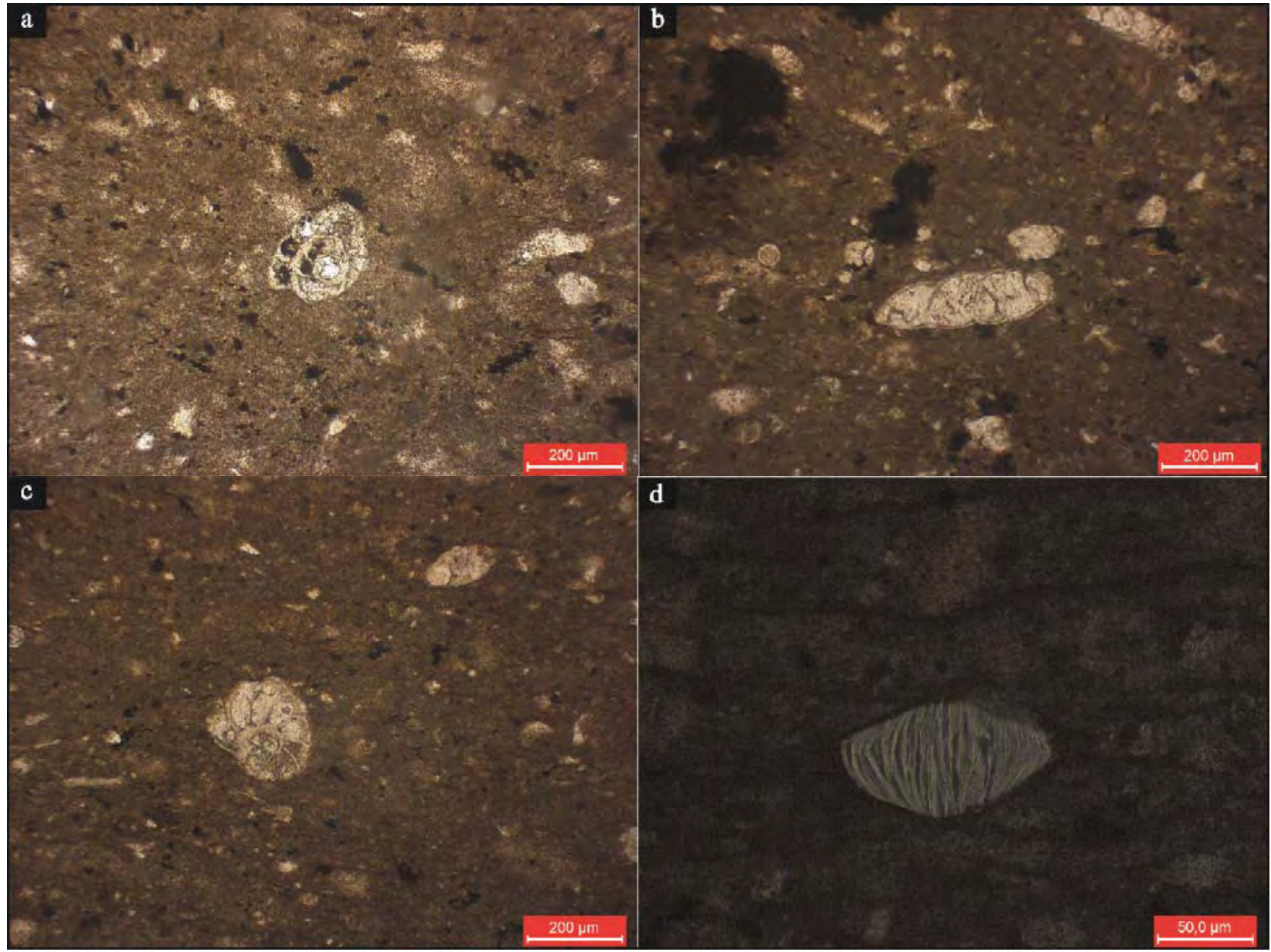

Figura 6.14- Microfotografía de foraminíferos acompañantes de pelitas y margas. Las muestras provienen del perfil PG de la Seccional Río Guanaco. Foto a, muestra PG 20; b - c, PG 15; d, BP 5. Todas las imágenes sin nicoles cruzados. Escala en fotos a, b, c, 200 micrones; en la foto d, 50 micrones. 


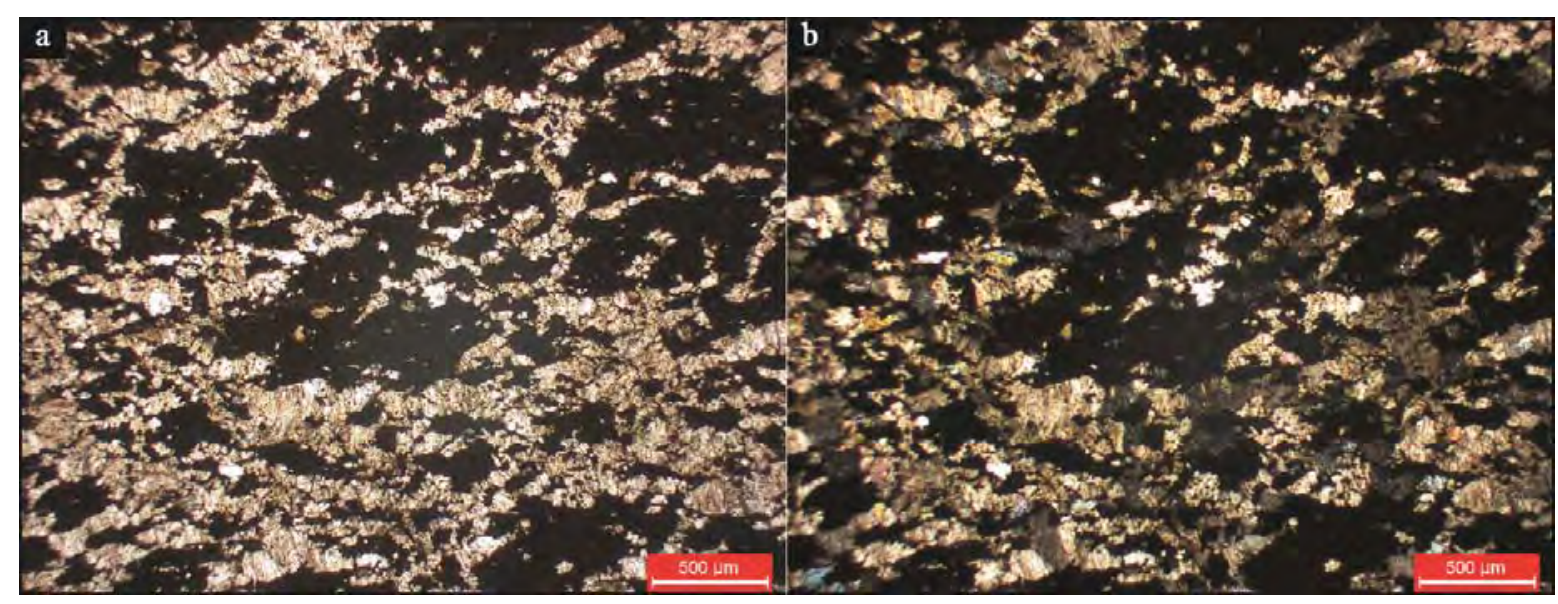

Figura 6.15 - Microfotografía de un nivel pelítico con abundante materia orgánica y fracturación. Las fracturas se encuentran rellenas de calcita macroesparítica. Muestra IG 17, perfil IG de la Seccional Río Guanaco. Foto a sin nicoles cruzados, b con nicoles cruzados. Escala 500 micrones. 


\section{4 - Petrografía de Calizas}

Se reconocieron dos niveles de caliza en la Formación Río Mayer, uno en el perfil PELL del Lago San Martín y otro en el perfil PELV en la Estancia La Vega. Por otro lado, dentro del relleno de los hemigrábenes de la Seccional Río Guanaco hay niveles de carbonatos en los metros previos al inicio de la Formación Río Mayer (Perfil IG).

VI. 4.1 - Nivel carbonático en el perfil PELL, Lago San Martín

Se desarrolla en los primeros metros de la unidad estudiada, posee aproximadamente 1 metro de espesor y se encuentra entre dos paquetes arenosos. Basado en las observaciones de campo el nivel corresponde a un wackestone, aunque en sección delgada todo está muy recristalizado. Contiene abundante material bioclástico, el cual se encuentra también recristalizado. Predominan los fragmentos de bivalvos y en menor proporción posee braquiópodos, placas de equinodermos, briozoos y serpúlidos (figura 6.16). Esta asociación es típica de carbonatos de aguas frías, compuestos por calcita con bajo contenido de magnesio. Es por esta razón que en las secciones delgadas no se observa dolomita.

La característica más sobresaliente es la abundante recristalización del material carbonático. Por el grado de recristalización se trataría de una mesogénesis temprana (Tucker y Wright, 1990).

VI. 4.2 - Nivel carbonático en el perfil PELV, Ea. La Vega

En el perfil de la Estancia La Vega se reconoció un nivel carbonático del cual poco puede decirse desde el punto de vista sedimentológico (figura 6.17). El alto grado de recristalización y la compresión a la que estas rocas estuvieron expuestas no permiten hacer otras inferencias que las diagenéticas, la cual se asume habría alcanzado la mesogénesis tardía (Tucker y Wright, 1990).

Un aspecto reconocible en la figura 6.17 es el alto contenido de materia orgánica presente en este nivel. 


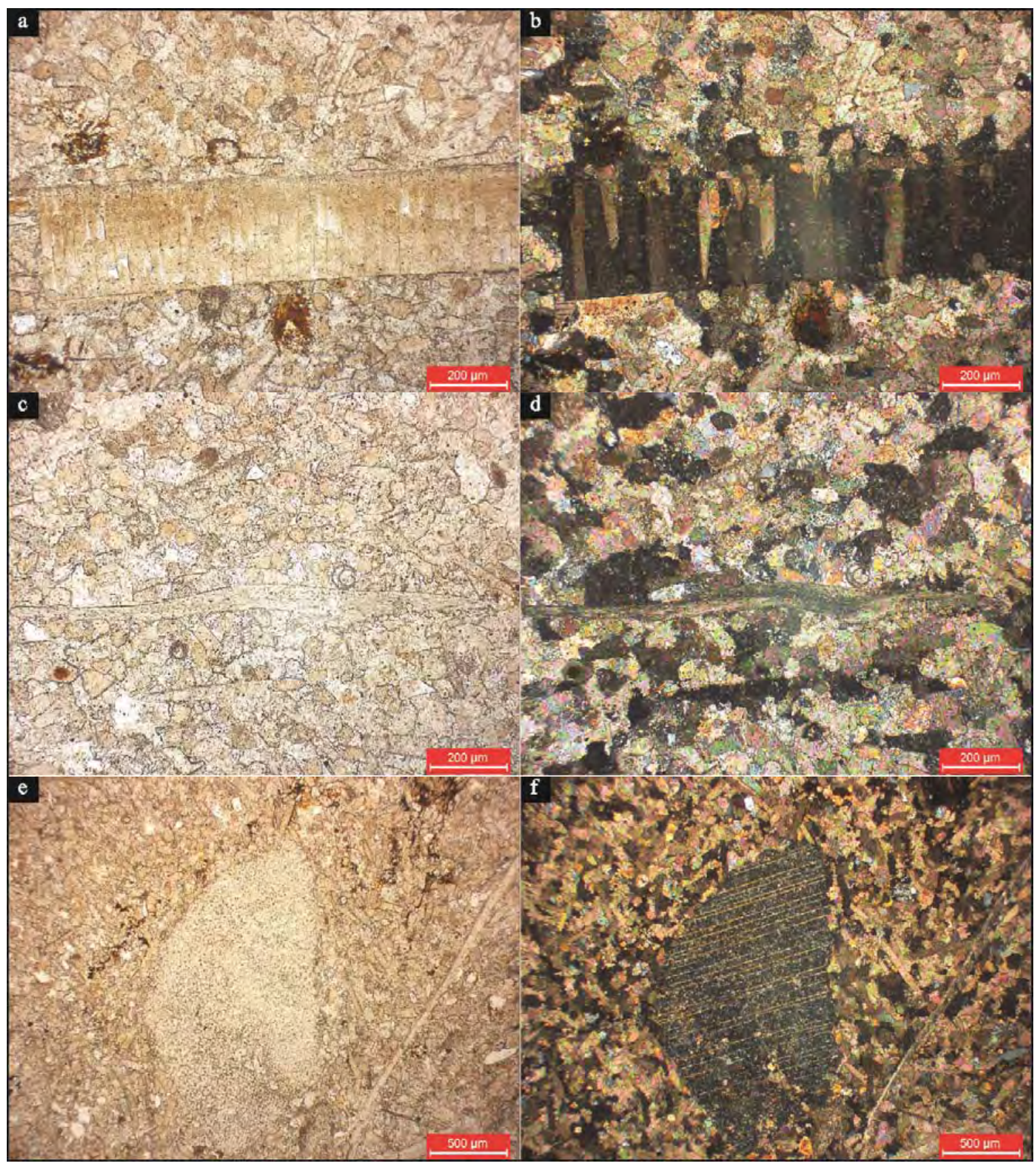

Figura 6.16 - Vistas generales del nivel carbonático de la Estancia La Lila (PELL) donde se puede observar el alto grado de recristalización. Fotos a-d, bioclastos recristalizados; fotos e-f, placa de equinodermo recristalizada. Imágenes a, c, e sin nicoles cruzados; imágenes b, d, f con nicoles cruzados. Escala en imágenes a-d, 200 micrones; en imágenes e-f, 500 micrones. El corte delgado proviene de la muestra PELL 10. 


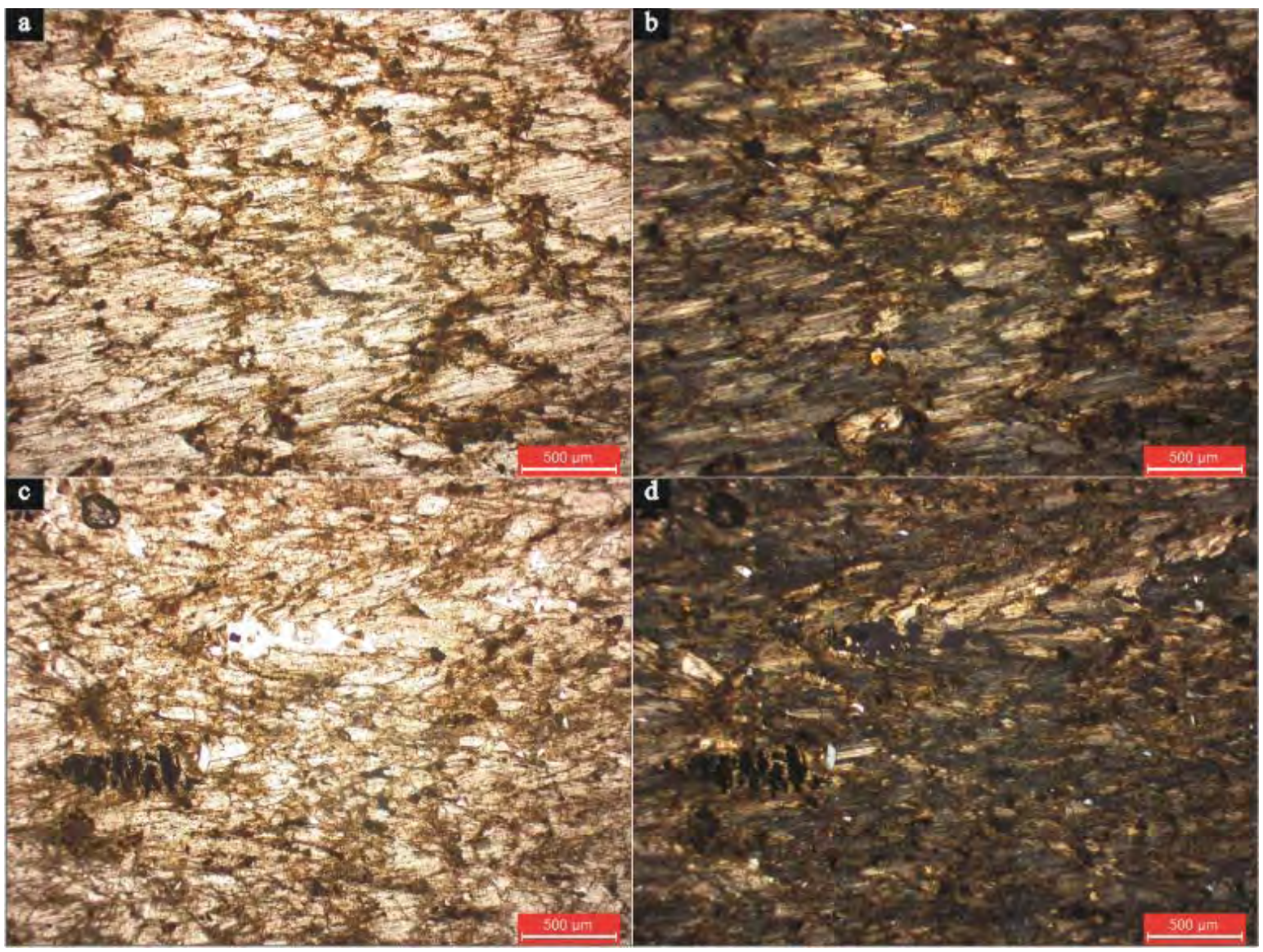

Figura 6.17- Vistas generales del nivel carbonático de la Estancia La Vega (PELV) donde se puede observar el alto grado de recristalización y compresión a la que las rocas estuvieron expuestas. Nótese la abundante cantidad de materia orgánica presente en la muestra. Imágenes a y c sin nicoles cruzados; imágenes b y d con nicoles cruzados. Escala en imágenes a-d, 500 micrones. El corte delgado proviene de la muestra PELV 16.

VI. 4.3 - Nivel carbonático en el perfil IG, Seccional Río Guanaco

Previo al inicio de la Formación Río Mayer en el área de la Seccional Río Guanaco se depositó el relleno de los hemigrábenes desarrollados en el Complejo El Quemado con sedimentos asignados a la Formación Springhill (Kraemer y Riccardi, 1997). La parte final de este relleno se compone niveles carbonáticos, los que al igual que los anteriormente nombrados posee elevada recristalización, aunque a diferencia de éstos la participación de material silicoclástico es evidente (figura 6.18). 


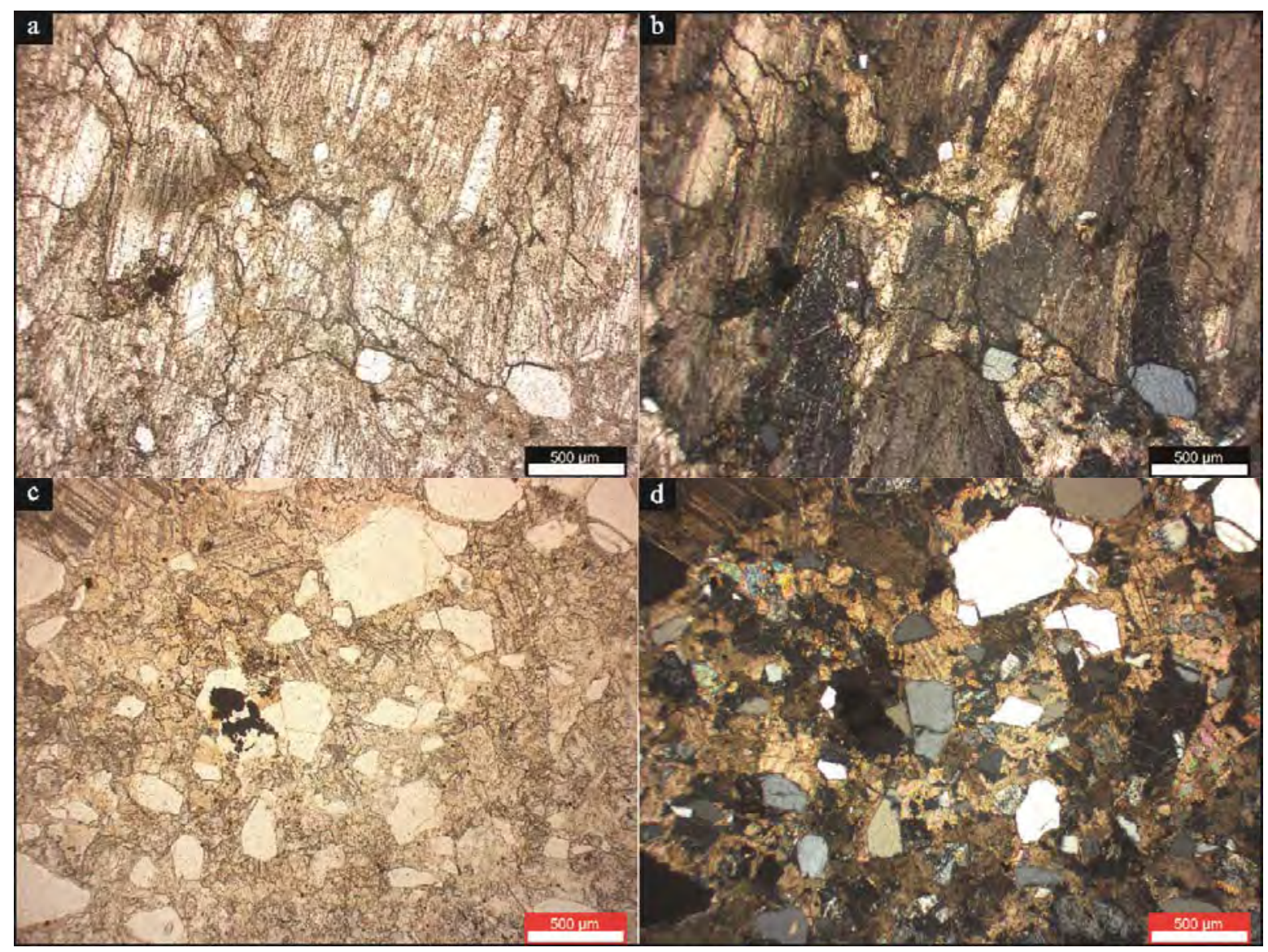

Figura 6.18 - Vistas generales del nivel carbonático del Perfil IG en la Seccional Río Guanaco. Se puede observar el alto grado de recristalización y la abundante cantidad de material silicoclástico acompañante. Imágenes a y c sin nicoles cruzados; imágenes b y d con nicoles cruzados. Escala en imágenes a-d, 500 micrones. El corte delgado proviene de las muestras IG 2 e IG 3. 


\section{5 - Petrografía de Glauconitas}

En la formación Río Mayer se han reconocido dos niveles portadores de glauconita, uno en los perfiles PG y WVP en la Seccional Río Guanaco y otro en el perfil PELL en el Lago San Martín. En general se presenta como glauconita granular, de tamaños entre 0,1 a 2 mm de diámetro, presenta coloraciones verdes que varían desde tonos claros y levemente amarillentos a verde oscuro. Los granos tienen formas subredondeadas a muy redondeadas (figura 6.19).

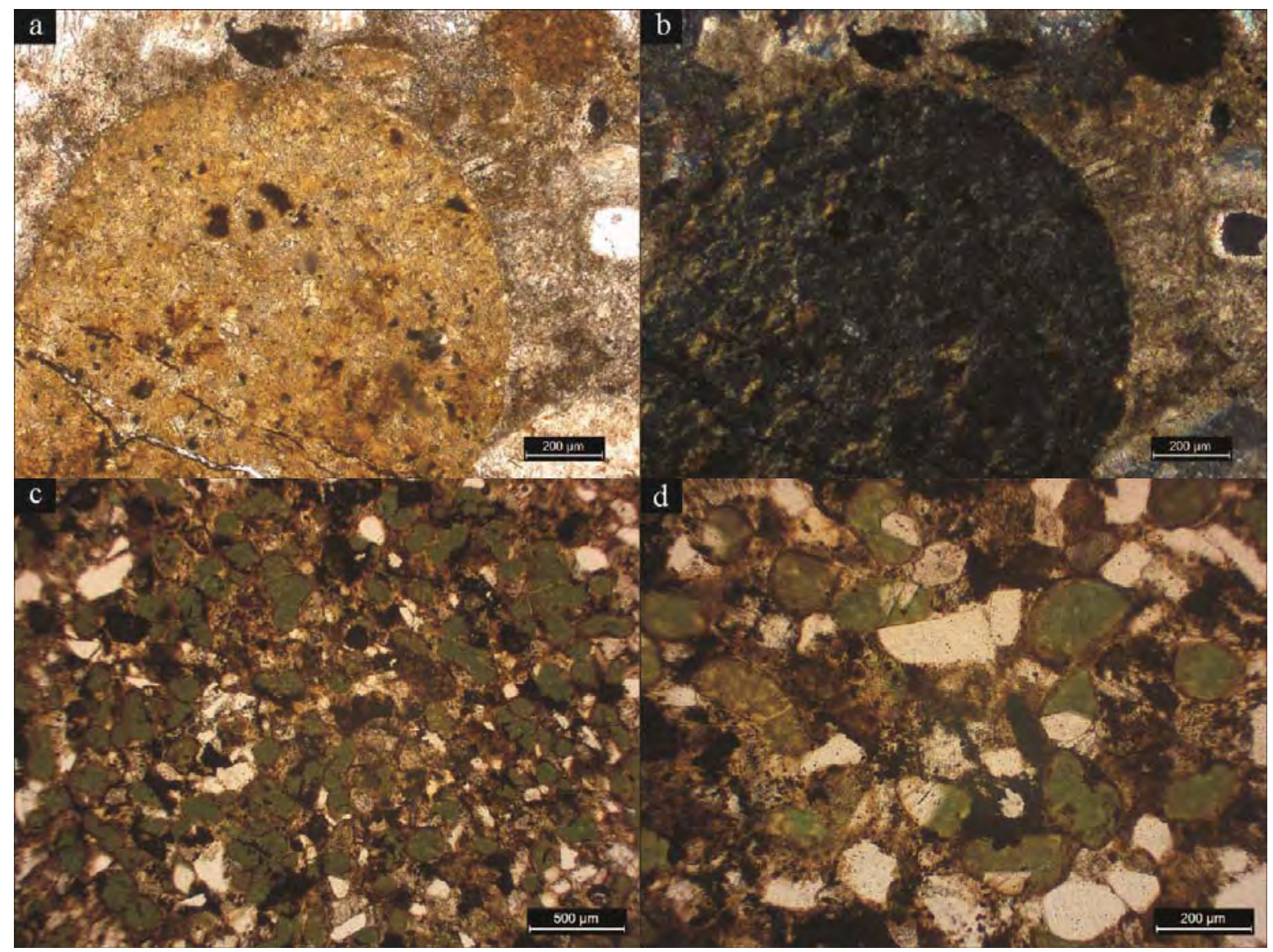

Figura 6.19- Granos de glauconita en la Formación Río Mayer. En a ejemplo del perfil PG en la Seccional Río Guanaco; foto sin nicoles cruzados, escala 200 micrones. Foto b, ídem a con nicoles cruzados. En la foto c ejemplares del perfil PELL del Lago San Martín; foto sin nicoles cruzados, escala 500 micrones. En d, detalle de la foto c, sin nicoles cruzados, escala 200 micrones. 
En las muestras de los perfiles PG y WVP los granos de glauconita poseen mayor tamaño (1 a 2 mm) y están rodeados por abundante cemento carbonático de tipo macroesparítico (figura 6.19 a, b). Por otro lado, en el Lago San Martín, los granos de glauconita poseen diámetros menores $(0,2 \mathrm{~mm})$, y están rodeados por una matriz principalmente pelítica con gran participación de granos de cuarzo monocristalino (figura 6.19 c, d).

Dentro de las muestras del perfil PELL se observa material relíctico sin glauconitizar. Cabe recordar, tal cual fuera desarrollado en el capítulo IV, que el proceso de glauconitización incluye el reemplazo de una material preexistente por arcillas muy ricas en potasio. Casos en los que el mineral previo es conservado como relicto se observan en la figura 6.20.
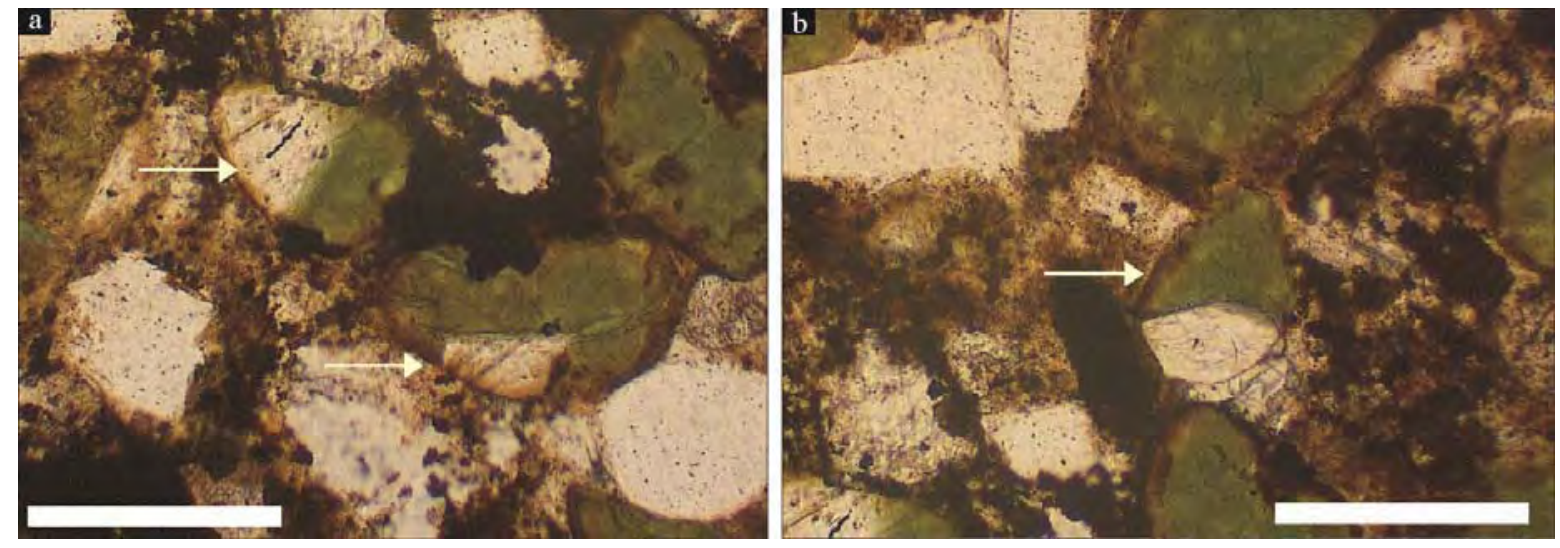

Figura 6.20- Ejemplos de granos de feldespato no enteramente glauconitizados (indicados con flechas) provenientes del perfil PELL del Lago San Martín. Escala 200 micrones. 


\section{6 - Petrografía de trazas fósiles}

Se realizó la observación petrográfica de algunos ejemplares de estructuras sedimentarias orgánicas (tres icnogéneros) de muestras provenientes de la Seccional Río Guanaco.

En la figura 6.21 (a-d) se observan los moteados generados por la acción de los organismos productores de Chondrites en las muestras de pelitas de la sección superior de la Formación Río Mayer (perfil WVP). En estas imágenes se puede ver que los moteados son producto de la concentración de óxidos en la región afectada por el organismo productor. Etológicamente, este icnogénero se considera fodinichnia, o sea, que el productor genera la traza por alimentación (más detalles en capítulo VIII), con lo cual los óxidos registrados en los moteados representarían los desechos dejados por el gusano.
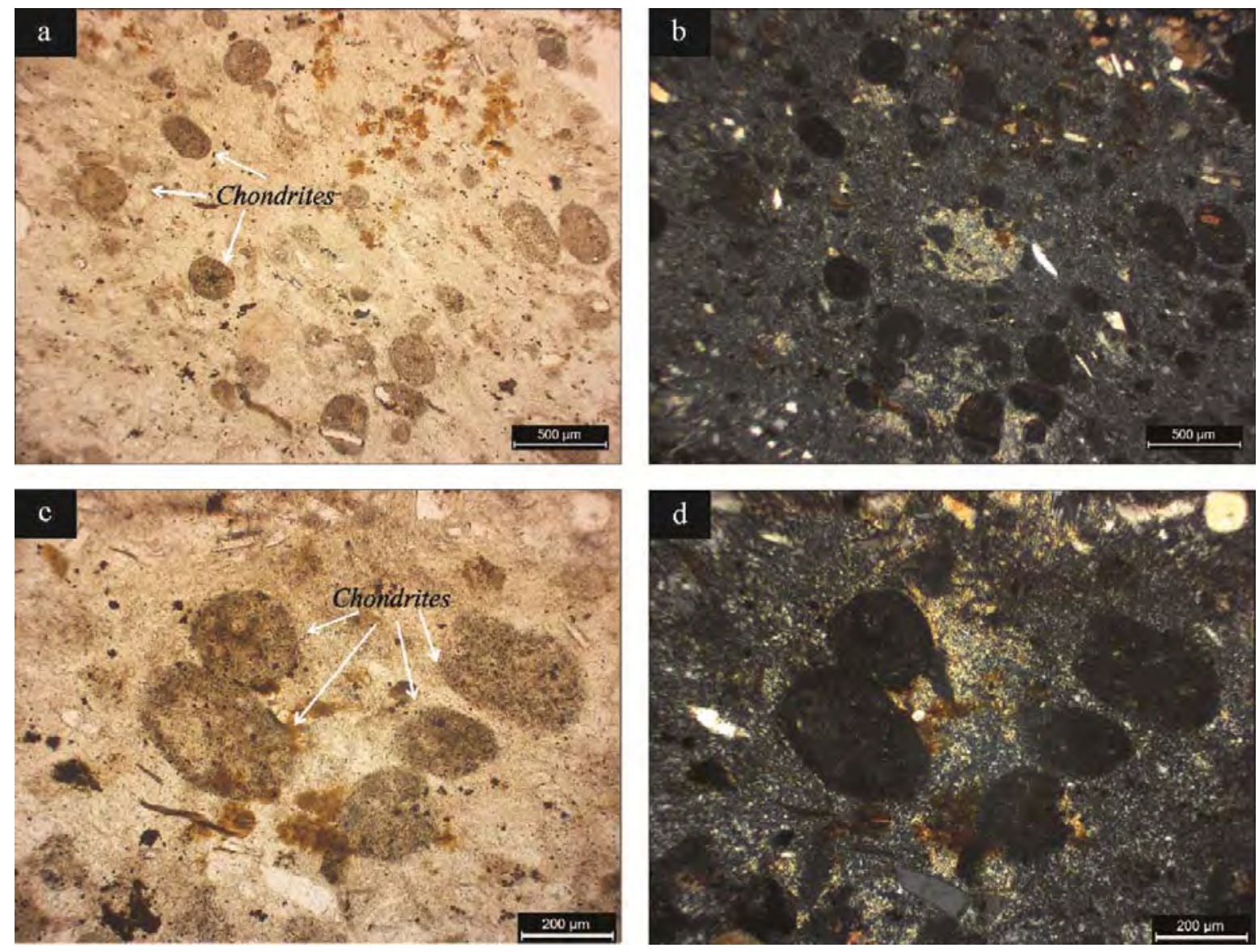

Figura 6.21- Microfotografía de secciones delgadas de estructuras sedimentarias orgánicas en la Seccional Río Guanaco. Fotos a-d icnogénero Chondrites en el perfil WVP; a-c sin nicoles cruzados, b-d con nicoles cruzados. En las imágenes a-b la escala son 500 micrones, en las imágenes c-d son 200 micrones. 
Vale la pena destacar que el pequeño tamaño de estos ejemplares de Chondrites, que se asemejan a los citados por Uchman (2007) con tamaños entre 0,2 y 0,6 mm. Esto genera que sean difíciles de reconocer en la muestra de tamaño mesoscópico si no se encuentran con una distribución en planta, sin embargo algunos ejemplares de mayor tamaño son tratados en el capítulo VIII. La presencia de trazas fósiles en pelitas que aparentaban ser masivas no ocurrió sólo con ejemplares de Chondrites sino también con el icnogénero Zoophycos, de este modo se realizaron cortes de pelitas masivas y resultó que en algunas se observaron estas estructuras, aunque en la mayoría no se registró perturbación alguna.

En la figura 6.22 (a-b) se presenta el contacto entre un tubo de Ophiomorpha que está relleno de modo pasivo por sedimento tamaño arenisca fina y la pelita que lo rodea. En la foto con nicoles cruzados (6.22b) se ve claramente la alta participación de cemento carbonático en el relleno del tubo.

En las imágenes c-d de la misma figura se presenta un detalle del spreiten del icnogénero Zoophycos, en el cual se divisan dos sectores bien diferenciados, una capa de material sedimentario relíctico de coloraciones oscuras (lamela sedimentaria) y una capa de material fecal producto de la actividad del organismo (lamela fecal) de tonalidades claras (más detalle en capítulo VIII). 

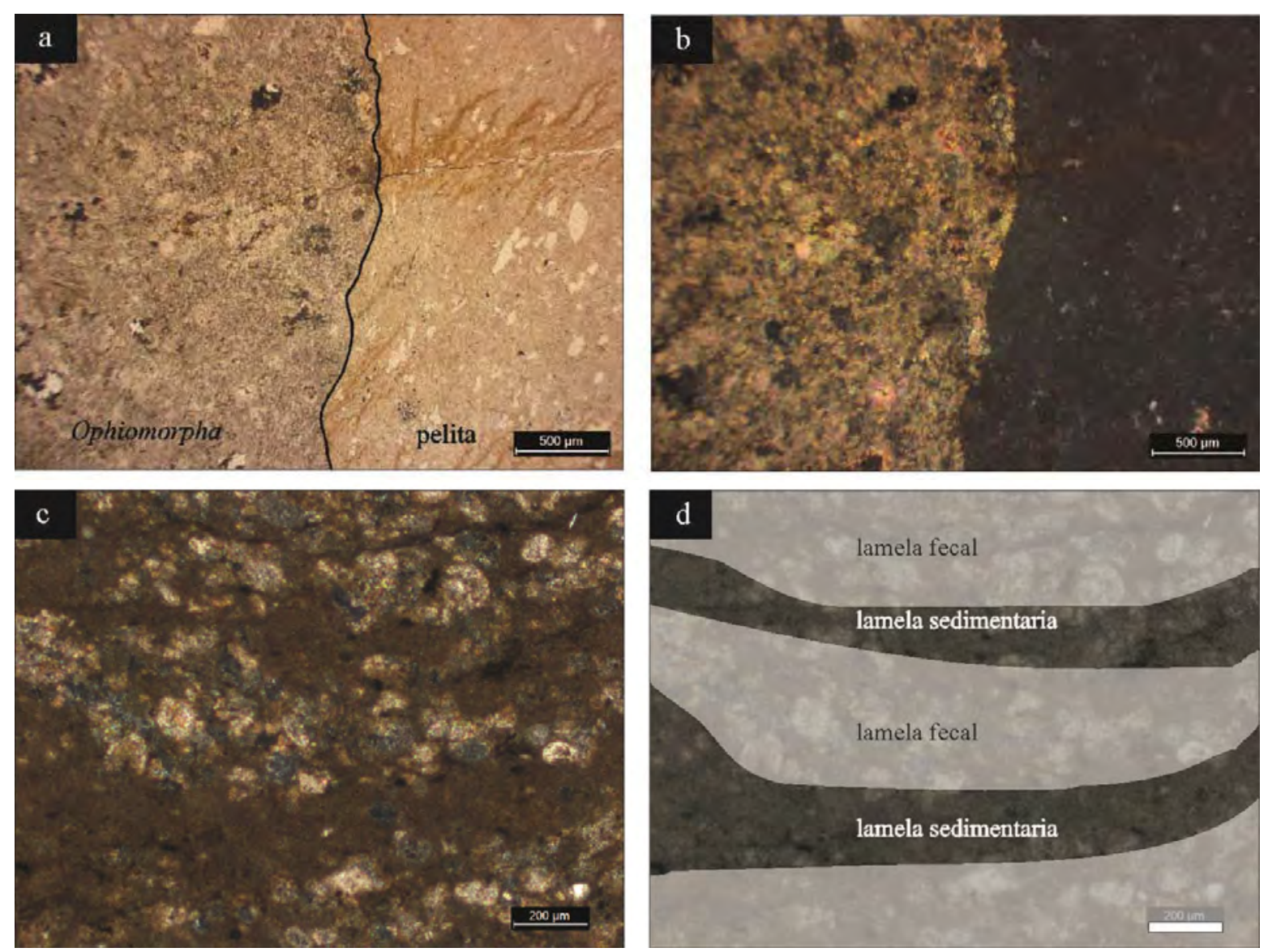

Figura 6.22- Microfotografía de secciones delgadas de estructuras sedimentarias orgánicas en la Seccional Río Guanaco. Fotos a-b icnogénero Ophiomorpha en el perfil CE; a sin nicoles cruzados, b con nicoles cruzados. Foto c icnogénero Zoophycos en el perfil PG. En c foto con nicoles cruzados, en d se muestra la interpretación donde se observa la alternancia de capas de material sedimentario (pelita) sin retrabajo por parte del organismo productor (lamela sedimentaria) y capas claras formadas por material fecal (lamela fecal). 


\section{7 - Consideraciones preliminares sobre los aspectos petrográficos}

A partir del estudio petrográfico de 59 cortes delgados provenientes de las formaciones Springhill, Río Mayer y Kachaike/Piedra Clavada se pueden realizar las siguientes consideraciones:

1- $\quad$ Los componentes principales de las areniscas de la Formación Río Mayer son el cuarzo monocristalino, líticos (sedimentarios o volcánicos), cuarzo policristalino y los feldespatos. Entre estos tres componentes y la matriz pelítica, siempre presente en las muestras, totalizan cerca del 90\% de las rocas.

2- $\quad$ Los componentes acompañantes son biotita, opacos y bioclastos.

3- El cemento predominante es el carbonático macroesparítico, con muy poca participación de cemento ferruginoso.

4- Según la clasificación de Dott (1964, modificada por Pettijhon et al., 1972) las muestras de la Formación Río Mayer son vaques líticos ó feldespáticos, a excepción de una arenisca subarcósica.

5- $\quad$ Según la clasificación de Folk et al. (1970), las muestras de las Formación Río Mayer se encuadran entre los campos de feldarenita a litoarenita, excepto una muestra que se clasifica como sublitoarenita.

6- $\quad$ Desde el punto de vista de la procedencia, tomando en cuenta el diagrama Qm-F-Lt (Dickinson et al., 1983) se definieron 4 poblaciones, dos correspondientes a los depósitos pre-Aptiano y dos a los depósitos del Aptiano-Albiano.

7- Dentro de cada grupo temporal se observaron diferencias que pueden estar relacionadas con los paleoambientes en que se encuentran, de este modo las muestras desarrolladas en la plataforma interna poseen afinidades con los campos de orógeno reciclado y arco volcánico, mientras que las muestras de las areniscas 
depositadas por flujos turbidíticos en la plataforma externa se ubican en el bloque continental.

8- $\quad$ Para el diagrama Qt-F-L (Dickinson et al., 1983), las diferenciaciones entre unidades son similares al diagrama Qm-F-Lt.

9- Se deduce de este tratamiento que la Formación Río Mayer en el área de la Seccional Río Guanaco está formada por materiales más estables que los formadores de las muestras provenientes del Lago San Martín. Esa estabilidad podría relacionarse con la concentración de clastos cristalinos producto de un transporte selectivo desde las zonas someras a las profundas.

10- Las pelitas y margas de la Formación Río Mayer están constituidas por abundante cantidad de material no distinguible en secciones delgadas, a excepción de dos componentes, los cristaloclastos de cuarzo tamaño limo y el material biogénico acompañante. Es de destacar la abundante cantidad de materia orgánica asociada a estas dos litologías, aunque la participación en las pelitas es considerablemente mayor que en las margas.

11- Dentro de las margas se reconocieron foraminíferos, briozoos, calciesferas, placas de equinodermos, fragmentos de bivalvos y braquiópodos. Esta asociación se corresponde con un Foramol, típica de aguas templado-frías. Esta observación se condice con lo esperado para asociaciones de organismos del Cretácico inferior, el cual tuvo características frías (Scotese et al., 1999; Scotese, 2001). Por ejemplo, Pirrie et al. (2004) estiman temperaturas alrededor 9,5 $\mathrm{C}$ en el agua de mar durante el Albiano para la región de Lago San Martín dentro de la Formación Río Mayer a partir de análisis isotópicos en rostros de belemnites.

12- Los dos niveles de calizas dentro de la Formación Río Mayer estuvieron afectados por un alto grado de recristalización, y en uno de los casos también por compactación. Esta característica aporta información diagenética de la unidad. De 
este modo se puede decir que el grado de diagénesis alcanzado por estas muestras estaría entre mesogénesis temprana y tardía. Sin embargo, cabe aclarar que un estudio diagenético de mayor detalle aportaría datos más precisos a cerca de la diagénesis alcanzada por la Formación Río Mayer.

13- Se reconocieron dos niveles portadores de glauconita, uno en la seccional Río Guanaco y otro en el Lago San Martín. El primero posee granos de glauconita de mayor tamaño (entre 1 y 2 mm) y alta participación de cemento carbonático, mientras que el segundo se halla formado por granos de tamaño arena fina, acompañados por cristaloclastos de cuarzo y una matriz pelítica.

14- Los granos de glauconita poseen diferentes grados de evolución, entre parcialmente glauconitizado hasta enteramente convertido en minerales autigénicos, en los que no se reconoce un núcleo de material original.

15- Petrográficamente se observaron algunas características de 3 icnogéneros, primero los moteados originados por la actividad de los organismos formadores de Chondrites. Luego se observó el contacto entre la arenisca fina que rellena un tubo de Ophiomorpha con la pelita que lo rodea. Por último se describió la alternancia entre el material sedimentario relíctico y el material fecal que resulta de la migración del tubo de un Zoophycos (spreiten). 


\section{Capítulo VII - Análisis Geoquímico}

\section{VII.1 - Introducción}

El análisis geoquímico es una herramienta fundamental para el estudio de secuencias pelíticas, ya que brinda información que no se observa con los estudios tradicionales aplicables a depósitos psefíticos y psamíticos (petrografía principalmente). Numerosos autores señalan la importancia de la geoquímica de rocas sedimentarias para determinar la proveniencia del material clástico que forma las sedimentitas, la meteorización o diagénesis a la que el depósito estuvo sometido y los ámbitos tectónicos en los cuales evolucionaron dichas secuencias (Bhatia y Taylor, 1981; Bhatia, 1983, 1985; Taylor y McLennan, 1985; Roser y Korsch, 1986; Spalletti et al., 2008; Zimmermann et al., 2011).

Si bien, el empleo de métodos geoquímicos en el estudio de secuencias sedimentarias se ha realizado en diversos tipos de rocas silicoclásticas, algunos autores asumen que el tamaño pelítico es el más apto para su realización (Cullers, 1995). La movilidad de algunos elementos químicos presentes en las arcillas durante la diagénesis hace que se deba tener cautela con este tipo de análisis para la determinación de proveniencia y ambiente tectónico (Spalletti et al., 2008). Por este motivo, para dichas interpretaciones es conveniente hacer énfasis en algunos elementos traza y de las tierras raras que poseen una movilidad reducida durante los procesos sedimentarios (Taylor y McLennan, 1985; Bhatia y Crook, 1986; McLennan, 1989; Condie, 1993; Asiedu et al., 2004; Spalletti et al., 2008; Zimmermann et al., 2011).

En el caso particular de pelitas negras un estudio que aporta valiosa información es el análisis del contenido de Carbono Orgánico Total (COT). Como fuera mencionado en el capítulo IV, son varios los factores causantes de la preservación de la materia orgánica en los sedimentos marinos, y la cuantificación del COT provee una estimación del contenido de materia orgánica que además de haber sido preservada en el sedimento permaneció con posterioridad a los factores diagenéticos. Este análisis permite realizar interpretaciones paleoambientales relacionadas con el aporte y degradación de materia orgánica, definir la potencialidad de la unidad como roca madre y hacer interpretaciones de tipo estratigráficosecuencial (Creany y Passey, 1993; Stein, 2007; Mutterlose et al., 2009; Negri et al., 2009). 
Otro importante enfoque desde el punto de vista de la geoquímica es el análisis de los isótopos estables del Carbono $\left(\mathrm{C}^{13}\right)$ y del Oxígeno $\left(\mathrm{O}^{18}\right)$. Esta herramienta permite hacer inferencias con respecto a los paleoclimas, la diagénesis y con frecuencia es utilizada para correlaciones tanto locales como regionales (Brand y Veizer, 1981; Veizer, 1983; Jacobsen y Kaufman, 1999; Anadon, et al., 2002). Las rocas constituyentes de la Formación Río Mayer poseen bajos contenidos de carbonatos en sus muestras, y en general son margas o pelitas margosas. Por otro lado, los niveles que están formados por altos contenidos de calcita muestran una elevada recristalización, y en algunos casos evidencias de disolución, lo que podría indicar modificaciones diagenéticas importantes. Por tal razón, en este caso en particular, los análisis isotópicos de C-O serán considerados al momento de indicar el grado alteración diagenética alcanzado por estas sucesiones.

El estudio geoquímico de la Formación Río Mayer resulta sumamente interesante, dado el activo panorama de la región sudoccidental de Gondwana durante su depositación. Las edades de esta unidad ocupan casi enteramente el Cretácico inferior, coexistiendo con el desarrollo del Batolito Patagónico y el comienzo de la ruptura de Gondwana para dar lugar a la apertura del océano Atlántico sur (Hervé et al., 2007; Calderón et al., 2007). Paralelamente, las cuencas marinas cretácicas se vieron afectadas por importantes momentos de anoxia generalizada a nivel mundial, conocidos como "Ocean Anoxic Events (OAE)” (Schlanger y Jenkyns, 1976; Negri et al., 2009). El clima del inicio Cretácico inferior (Neocomiano) era más frío que el del Cretácico superior (Scotese et al., 1999; Scotese, 2001), lo que podría verse reflejado en la composición isotópica de las rocas carbonáticas. En este sentido, algunos autores postulan que el escenario climático de algunos períodos del Cretácico inferior, en especial el Valanginiano, podrían actuar como modelo de los cambios climáticos actuales (Westermann et al., 2010; Duchamp-Alphonse, et al., 2011).

Por todas estas razones, la caracterización geoquímica de la Formación Río Mayer, enfocada desde distintos puntos de vista y aplicando diferentes metodologías, aporta una valiosa información para realizar interpretaciones de escala local y regional. 


\section{VII.1.1 - Selección de las muestras}

Del mismo modo que para los análisis por difractometría de rayos $\mathrm{X}$, las muestras analizadas se concentraron en la región de las nacientes del Río Guanaco, por poseer los afloramientos más completos y mejor preservados.

En el caso del análisis de roca total se examinaron 17 muestras de pelitas con mínimas cantidades de carbonatos (discriminadas por DRX con porcentajes menores a 5\%), ya que este es un requisito fundamental para el estudio de la proveniencia del sedimento. Para el COT se utilizaron 29 muestras tanto de pelitas como de margas, mientras que para los isótopos estables se analizaron 19 muestras ricas en calcita (en su mayor parte margas con 20 a $60 \% \mathrm{CaCO}_{3}$ ).

Para los tres estudios se tuvieron en cuenta las tres secciones discriminadas a partir del trabajo de campo realizado en la Seccional Río Guanaco (figura 3.16; 7.1), con la intención de que cada sección fuera bien caracterizada con un número similar de análisis. Debido a la naturaleza carbonática de la sección media, sólo pudieron ser efectuados 2 análisis de roca total para estudios de proveniencia para la mencionada sección.

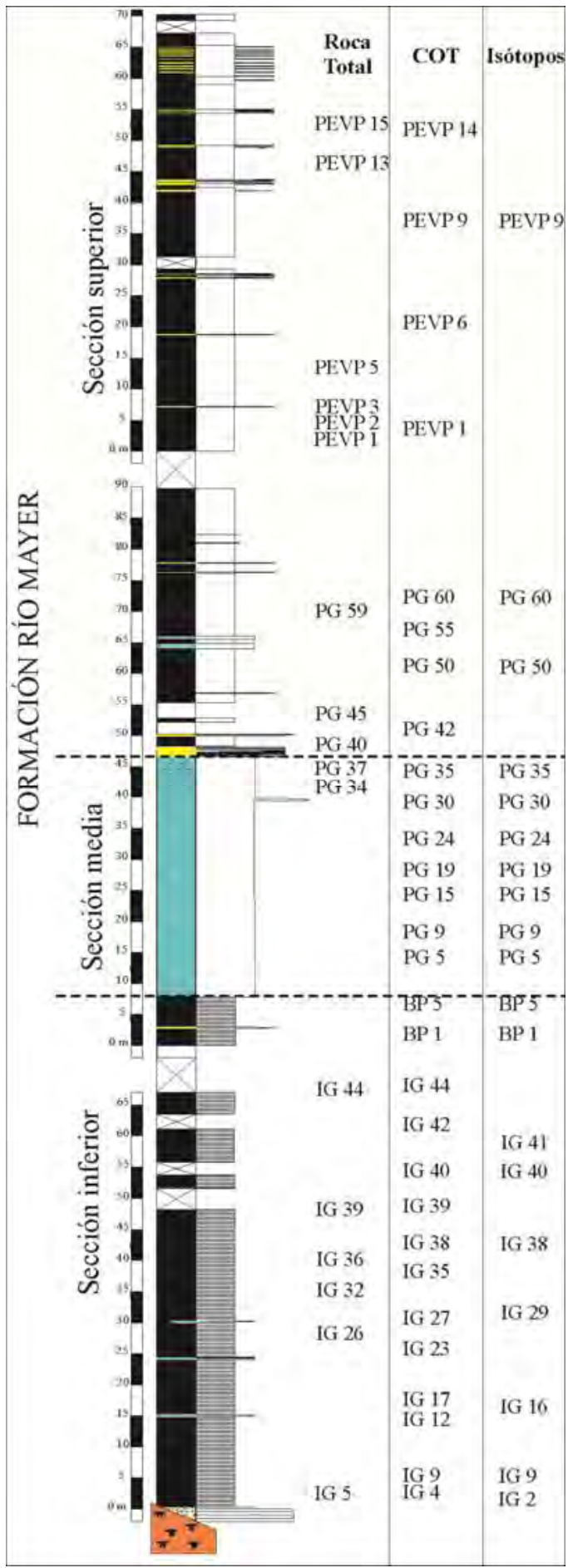

Figura 7.1- Distribución de las muestras analizadas de la Formación Río Mayer en la Seccional Río Guanaco (perfiles IG, PG, EVP1). 


\section{2 - Roca Total}

Las 17 muestras de pelitas seleccionadas de la Formación Río Mayer provenientes de la Seccional Río Guanaco fueron analizadas por sus elementos mayoritarios, minoritarios, trazas y tierras raras en los laboratorios de ALS Laboratory Group, con sede en la provincia de Mendoza y casa central en Canadá. El método empleado para las determinaciones fue ICP-MS (espectrometría de masas con plasma acoplado por inducción). Los resultados obtenidos se presentan en las tablas 7.a y 7.b.

\section{2.1 - Elementos mayoritarios y minoritarios}

De los resultados obtenidos que el comportamiento general de las muestras de las tres secciones es similar, con muy leves diferencias (figura 7.2). Los contenidos de sílice oscilan entre 58 y 75 \% y los de alúmina entre 9,5 y 19 \%. Las principales discrepancias se observan en el contenido de $\mathrm{Fe}_{2} \mathrm{O}_{3}, \mathrm{Na}_{2} \mathrm{O}$ y $\mathrm{MnO}$. En el caso del $\mathrm{Fe}_{2} \mathrm{O}_{3}$ en la sección inferior su promedio es 2,6 mientras que en las secciones media y superior asciende a 6,3\%. Para el $\mathrm{Na}_{2} \mathrm{O}$, el promedio en la sección inferior es de 0,57\%, en la sección media 1,36\% y en la superior 1,99. En el caso del $\mathrm{MnO}$, los valores de la sección inferior son menores a $0,02 \%$, mientras que en las secciones media y superior es de $0,31 \%$.

Dos de estos tres casos $\left(\mathrm{Fe}_{2} \mathrm{O}_{3} ; \mathrm{Na}_{2} \mathrm{O}\right)$ tienen un correlato con la composición mineralógica obtenida a partir de la difractometría de rayos X. El notorio aumento en los contenidos de clorita y de plagioclasas desde la sección inferior a las secciones media y superior, trae aparejado un incremento en los contenidos de Fe (presente en las cloritas) y de $\mathrm{Na}$ (plagioclasas). Este punto será desarrollado con mayor detalle a continuación en el presente capítulo. El caso del Mn será tratado con posterioridad al tratar el contenido de Carbono Orgánico Total. 


\begin{tabular}{|c|c|c|c|c|c|c|c|c|c|c|c|c|c|c|c|c|}
\hline \multirow{2}{*}{\multicolumn{2}{|c|}{ Muestra }} & $\mathrm{SiO} 2$ & Al2O3 & Fe2O3 & $\mathrm{CaO}$ & MgO & $\mathrm{Na} 2 \mathrm{O}$ & K2O & Cr2O3 & $\mathrm{TiO} 2$ & $\mathrm{MnO}$ & P2O5 & $\mathrm{SrO}$ & $\mathrm{BaO}$ & LOI & Total \\
\hline & & $\%$ & $\%$ & $\%$ & $\%$ & $\%$ & $\%$ & $\%$ & $\%$ & $\%$ & $\%$ & $\%$ & $\%$ & $\%$ & $\%$ & $\%$ \\
\hline \multirow{9}{*}{$\begin{array}{ll}\mathrm{s} & \mathrm{s} \\
\mathrm{e} & \mathrm{u} \\
\mathrm{c} & \mathrm{p} \\
\mathrm{c} & \mathrm{e} \\
\mathrm{i} & \mathrm{r} \\
\mathrm{c} & \mathrm{i} \\
\mathrm{n} & \mathrm{o} \\
\mathrm{n} & \mathrm{r}\end{array}$} & PA 15 & 67,6 & 12,85 & 5,94 & 1,18 & 1,75 & 2,24 & 1,53 & $<0.01$ & 0,49 & 0,28 & 0,09 & 0,02 & 0,07 & 4,2 & 98,2 \\
\hline & PA 13 & 66,5 & 13,95 & 5,74 & 2,19 & 1,81 & 2,35 & 1,76 & 0,01 & 0,51 & 0,28 & 0,06 & 0,02 & 0,07 & 5,01 & 100,5 \\
\hline & PA 5 & 65,5 & 15,05 & 6,33 & 1,12 & 1,78 & 3,12 & 1,56 & 0,01 & 0,66 & 0,36 & 0,06 & 0,02 & 0,06 & 3,97 & 99,6 \\
\hline & PA 3 & 65 & 14,25 & 7,43 & 1,4 & 2,19 & 2,45 & 1,59 & 0,01 & 0,56 & 0,5 & 0,07 & 0,02 & 0,07 & 4,49 & 100 \\
\hline & PA 2 & 62,6 & 15,9 & 7,28 & 0,93 & 2,07 & 2,17 & 2,19 & 0,01 & 0,61 & 0,44 & 0,06 & 0,02 & 0,11 & 4,89 & 99,3 \\
\hline & PA 1 & 63,5 & 16,3 & 7,62 & 0,86 & 2,18 & 2,18 & 2,27 & 0,01 & 0,6 & 0,46 & 0,07 & 0,02 & 0,11 & 4,5 & 100,5 \\
\hline & PG 59 & 68 & 13 & 5,64 & 0,88 & 1,29 & 1,25 & 1,96 & 0,01 & 0,44 & 0,14 & 0,38 & 0,01 & 0,09 & 7,64 & 100,5 \\
\hline & PG 45 & 75,2 & 10,55 & 4,81 & 0,75 & 1,13 & 1,35 & 1,24 & $<0.01$ & 0,41 & 0,18 & 0,04 & 0,01 & 0,07 & 3,55 & 99,3 \\
\hline & PG 40 & 58,3 & 19,55 & 5,56 & 1,8 & 1,86 & 0,84 & 3,12 & $<0.01$ & 0,74 & 0,35 & 0,11 & 0,01 & 0,17 & 6,74 & 99,2 \\
\hline \multirow{2}{*}{ Sección media } & PG 37 & 59 & 19,35 & 6,46 & 0,96 & 2,01 & 2,02 & 2,61 & 0,01 & 1,23 & 0,21 & 0,15 & 0,02 & 0,15 & 5,33 & 99,5 \\
\hline & PG 34 & 75,4 & 9,54 & 6,58 & 1,46 & 1,88 & 0,72 & 0,99 & $<0.01$ & 0,35 & 0,22 & 0,05 & 0,01 & 0,06 & 4,11 & 101,5 \\
\hline \multirow{6}{*}{$\begin{array}{ll}\mathrm{S} & \mathrm{i} \\
\mathrm{e} & \mathrm{n} \\
\mathrm{c} & \mathrm{f} \\
\mathrm{c} & \mathrm{e} \\
\mathrm{i} & \mathrm{r} \\
\text { o } & \mathrm{i} \\
\mathrm{n} & \mathrm{o} \\
& \mathrm{r}\end{array}$} & IG 44 & 70,9 & 11,4 & 2,96 & 1,89 & 1,13 & 0,61 & 1,44 & 0,01 & 0,26 & 0,01 & 1,28 & 0,02 & 0,06 & 6,15 & 98,1 \\
\hline & IG 39 & 65,2 & 19,25 & 1,97 & 0,59 & 1,26 & 0,43 & 3,17 & 0,01 & 0,28 & $<0.01$ & 0,13 & 0,01 & 0,1 & 8,91 & 101,5 \\
\hline & IG 36 & 68,8 & 15,75 & 2,39 & 0,75 & 1,2 & 0,61 & 2,28 & 0,01 & 0,26 & 0,01 & 0,14 & 0,02 & 0,09 & 7,31 & 99,6 \\
\hline & IG 32 & 67,2 & 15,35 & 3,27 & 1,05 & 1,56 & 0,84 & 1,99 & 0,01 & 0,35 & 0,02 & 0,22 & 0,02 & 0,08 & 8,2 & 100 \\
\hline & IG 26 & 70,3 & 15,65 & 2,58 & 0,66 & 1,8 & 0,6 & 1,99 & 0,01 & 0,28 & 0,01 & 0,13 & 0,02 & 0,09 & 7,33 & 101,5 \\
\hline & IG 5 & 69,1 & 15,85 & 2,58 & 0,69 & 1,87 & 0,36 & 2,37 & $<0.01$ & 0,27 & 0,02 & 0,03 & 0,01 & 0,14 & 6,5 & 99,8 \\
\hline
\end{tabular}

Tabla 7.a- Resultados de los elementos mayoritarios y minoritarios para las 17 muestras de pelitas de la Formación Río Mayer en la Seccional Río Guanaco. 

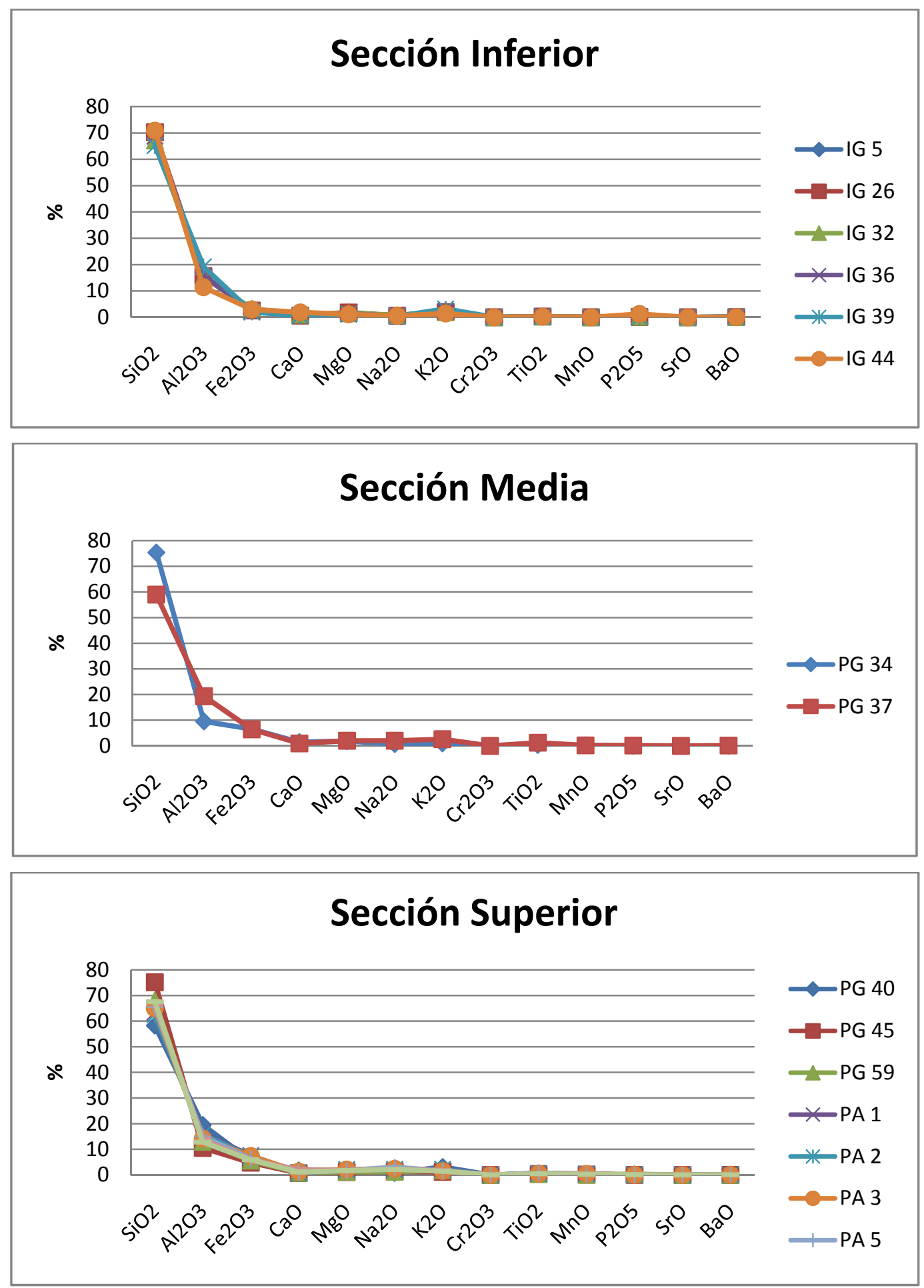

Figura 7.2- Distribución de los elementos mayoritarios y minoritarios en las muestras de la secciones inferior, media y superior de la Formación Río Mayer en la Seccional Río Guanaco. 
Para observar las variaciones de los elementos mayoritarios respecto a la sílice (figura 7.3) se utilizaron los diagramas de Harker (Alonso, 2011). Del mismo modo se realizaron diagramas bi-variantes de algunos elementos mayoritarios seleccionados $(\mathrm{K}, \mathrm{Na}$, $\mathrm{Fe}, \mathrm{Mg}$ ) versus $\mathrm{Al}_{2} \mathrm{O}_{3}$ y/o versus minerales determinados por DRX para observar como sus concentraciones varían con la mineralogía determinada en los capítulos previos (figura 7.4; 7.5).

Se puede observar en la figura 7.3 que las correlaciones entre $\mathrm{SiO}_{2}$ y la mayor parte de los elementos mayoritarios graficados están pobremente definidas, a excepción de las correlaciones negativas entre la $\mathrm{SiO}_{2}$ con el $\mathrm{Al}_{2} \mathrm{O}_{3}$ y el $\mathrm{K}_{2} \mathrm{O}$. En cuanto a la figura 7.4, quedan evidenciadas claramente las correlaciones positivas entre $\mathrm{Al}_{2} \mathrm{O}_{3}$ con $\mathrm{K}_{2} \mathrm{O}$ y $\mathrm{MgO}$, y en menor medida con $\mathrm{Fe}_{2} \mathrm{O}_{3}$ y $\mathrm{Na}_{2} \mathrm{O}$.

Las relaciones antes expuestas quedan debidamente justificadas con el desarrollo de la figura 7.5, en la cual se relacionan algunos elementos mayoritarios con los minerales determinados por difracción de rayos X. De estos diagramas se desprende que el principal aporte de $\mathrm{Al}_{2} \mathrm{O}_{3}$ y $\mathrm{K}_{2} \mathrm{O}$ es por parte de la illita, el $\mathrm{Fe}_{2} \mathrm{O}_{3}$ es aportado por las cloritas, mientras que el $\mathrm{Na}_{2} \mathrm{O}$ es por las plagioclasas. 

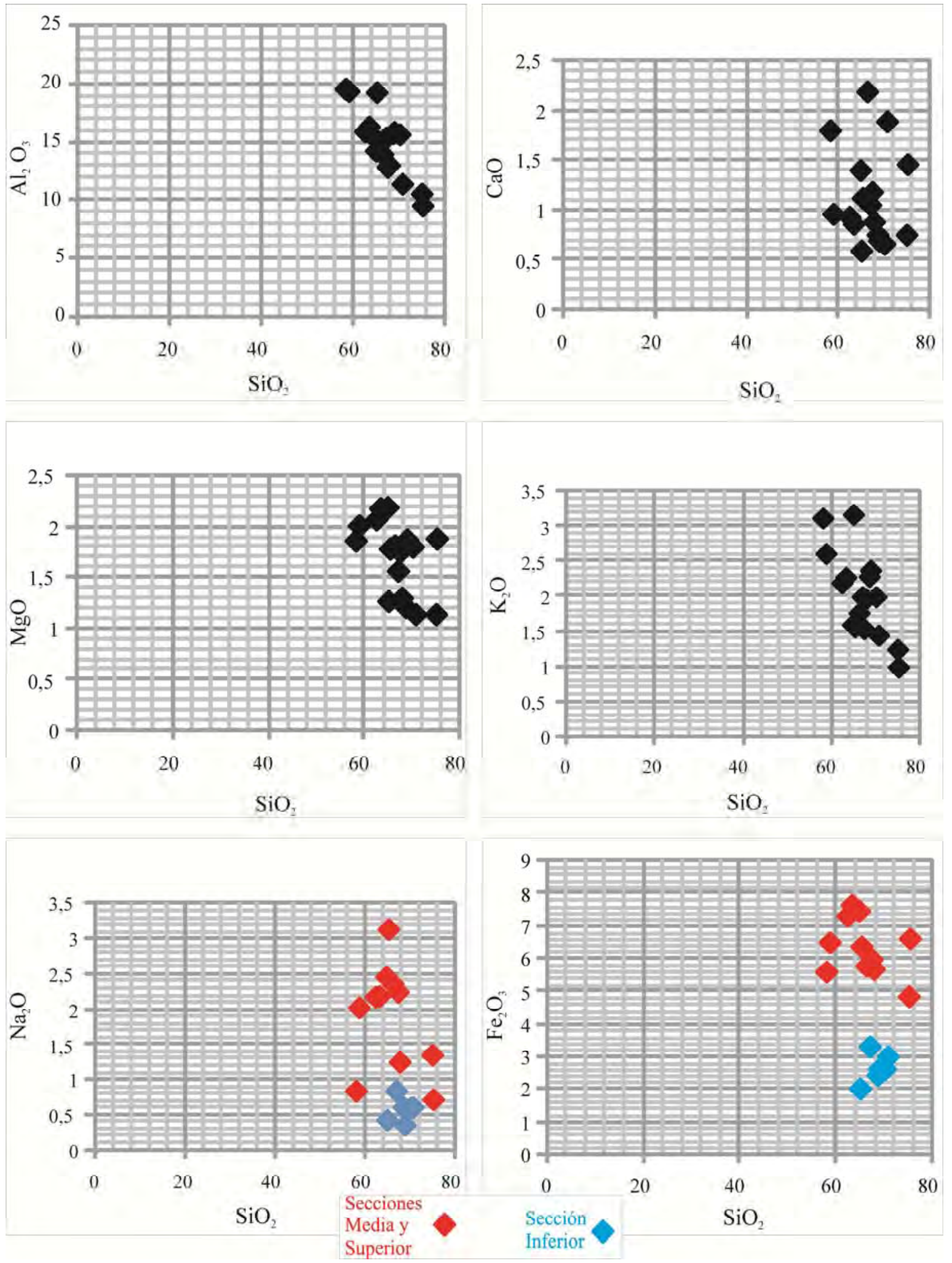

Figura 7.3 Diagramas bi-variantes de elementos mayoritarios seleccionados versus $\mathrm{SiO}_{2}$ (Alonso, 2011). En los diagramas de $\mathrm{Na} 2 \mathrm{O}$ y Fe2O3 se puede observar una diferenciación entre la sección inferior y media-superior indicada con distintos colores. 

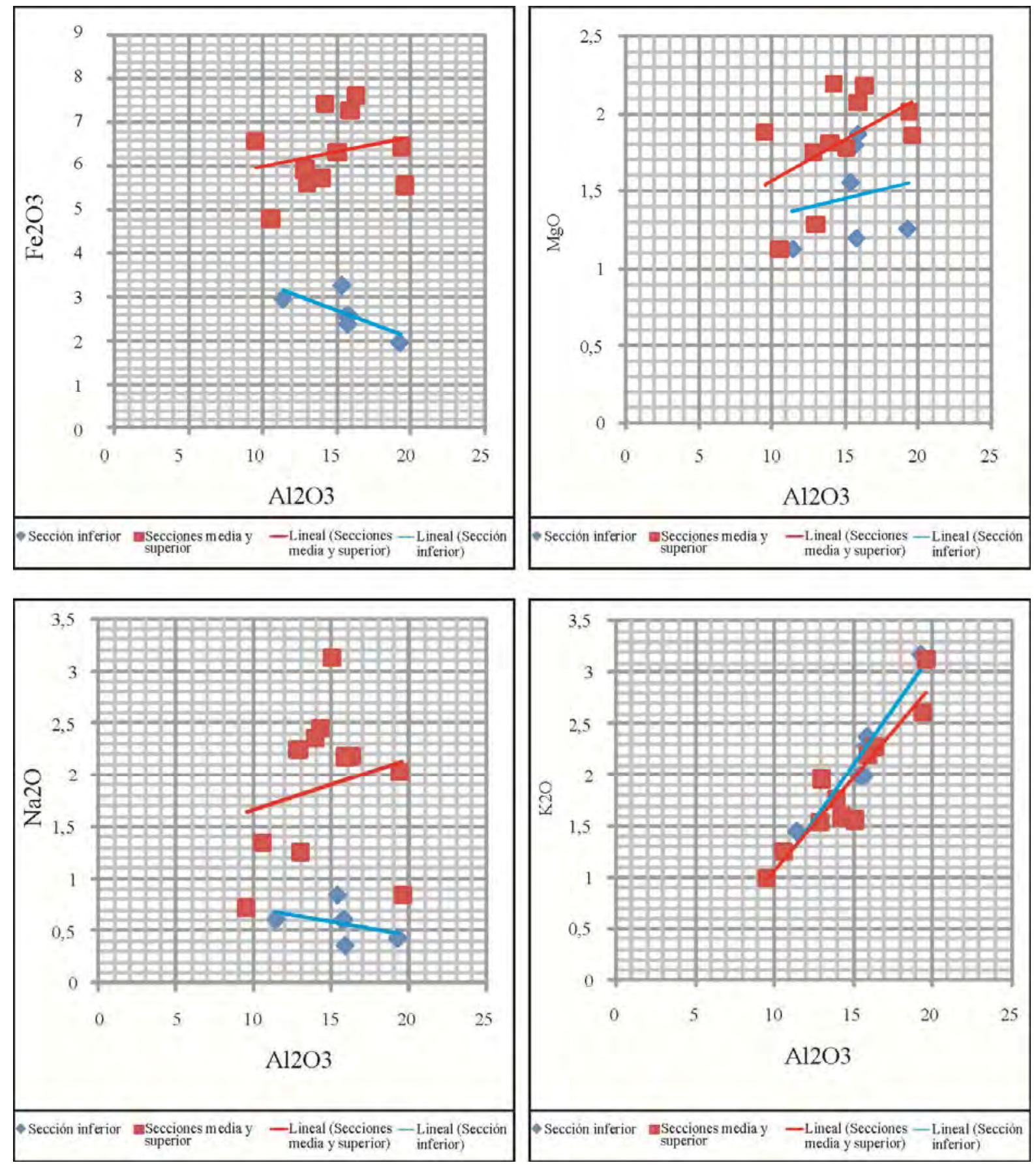

Figura 7.4- Diagramas bi-variantes de elementos mayoritarios seleccionados versus $\mathrm{Al}_{2} \mathrm{O}_{3}$. 

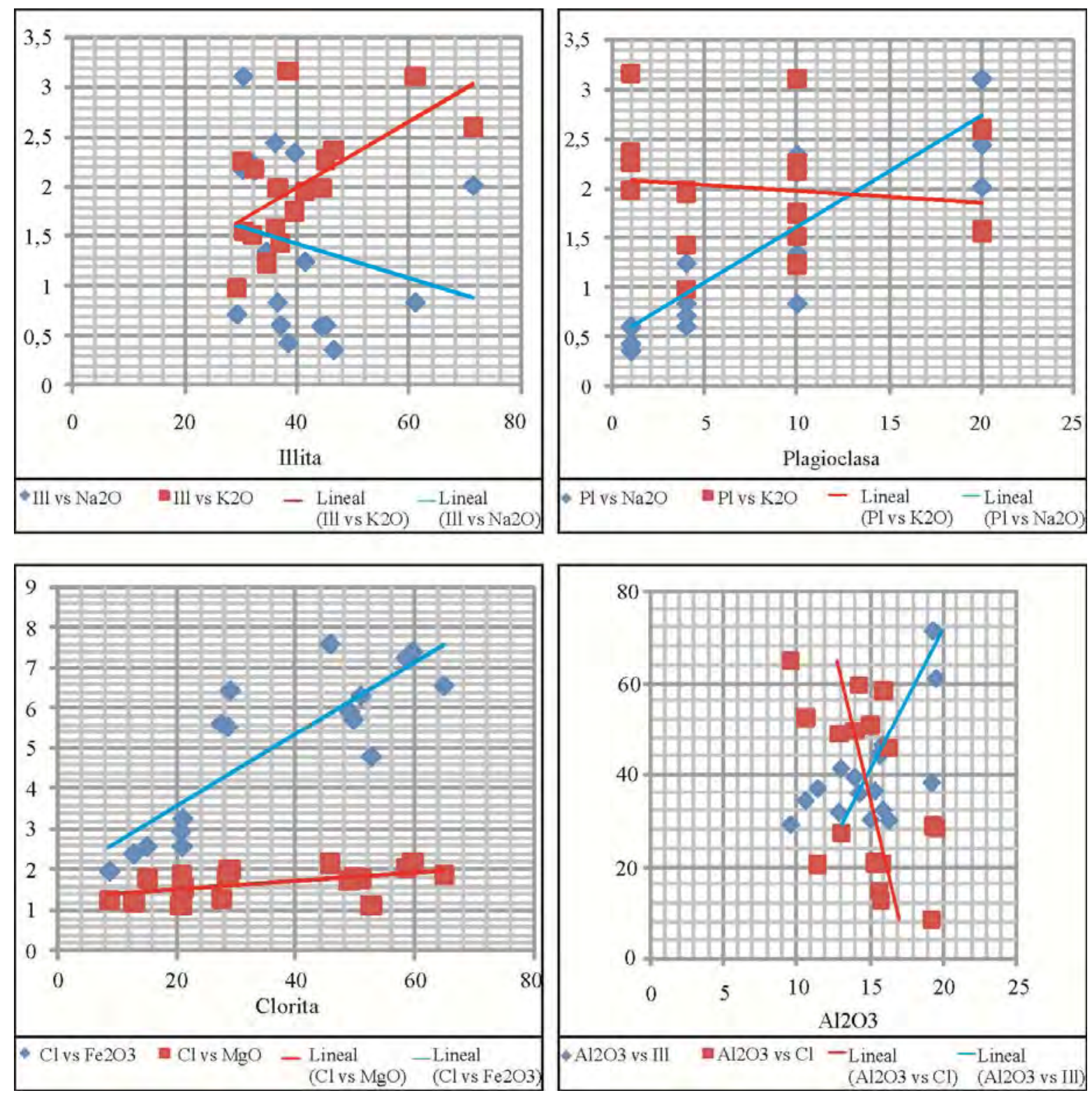

Figura 7.5- Diagramas bi-variantes de elementos mayoritarios seleccionados versus porcentajes de minerales determinados por difractometría de rayos X (Ill: illita; Pl: plagioclasa; Cl: clorita). 
Finalmente, se normalizaron los valores de elementos mayoritarios con respecto a la composición promedio de la Corteza Continental Superior (CCS) según los valores propuestos por Taylor y McLennan (1985). En la figura7.6 se graficaron estas relaciones a manera de curvas. Se observa que los contenidos de $\mathrm{SiO}_{2}$ y $\mathrm{Al}_{2} \mathrm{O}_{3}$ difieren poco respecto a la CCS, mientras que los óxidos de $\mathrm{Ca}, \mathrm{Mg}$, $\mathrm{Na}$ y $\mathrm{K}$ se encuentran con valores siempre inferiores a 1 en la relación. En cuanto al $\mathrm{Fe}_{2} \mathrm{O}_{3}$ y $\mathrm{TiO}_{2}$ se encuentran por debajo de los valores de CCS para la sección inferior y por encima de ese valor para las secciones media y superior. Como fuera mencionado antes, el aumento del contenido de hierro está relacionado con la presencia de clorita, en cambio el titanio estaría relacionado al diferente aporte de la sección superior. Esto será discutido más adelante.
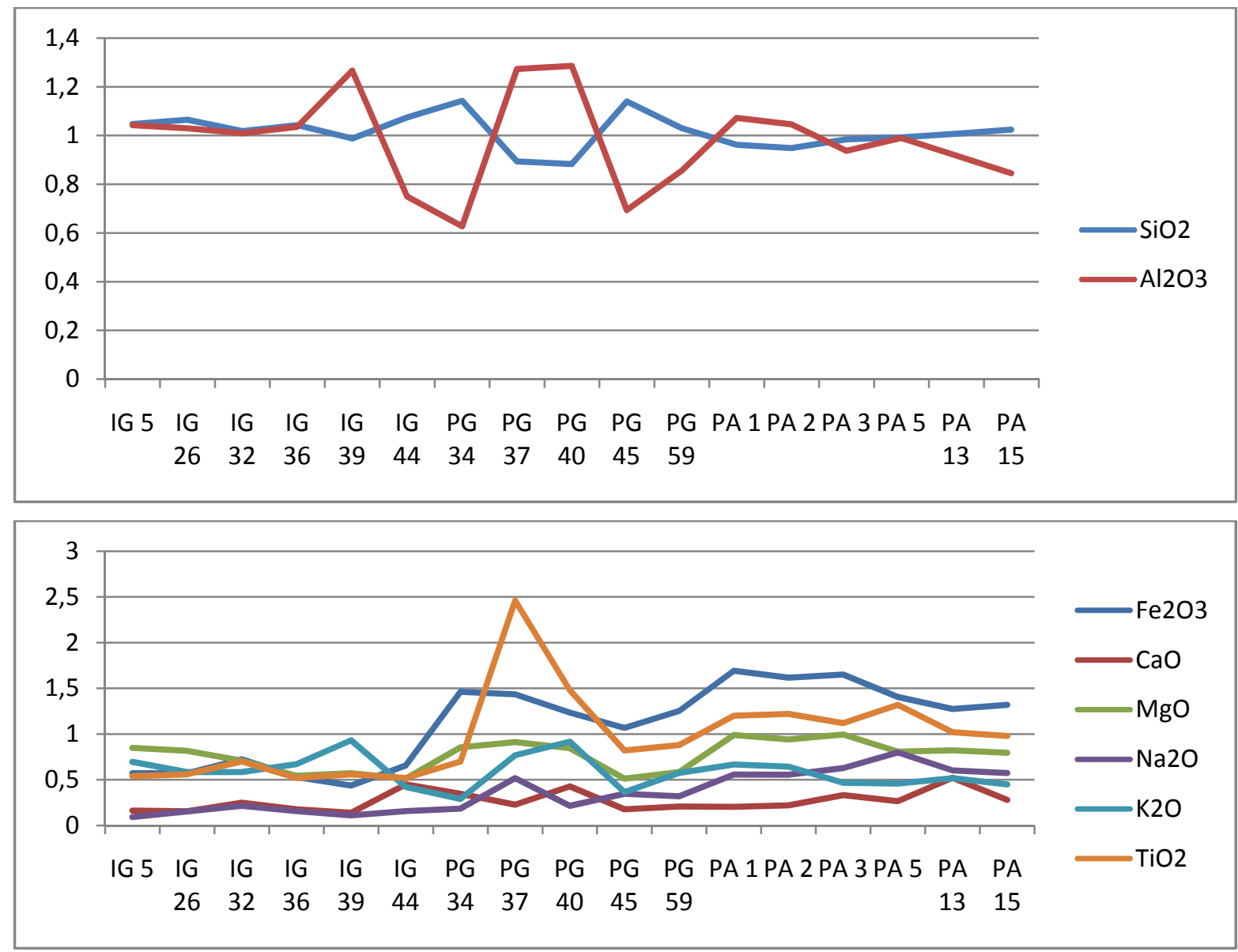

Figura 7.6- Diagramas de elementos mayoritarios seleccionados normalizados a la composición promedio de la Corteza Continental Superior (Taylor y McLennan, 1985). 


\section{2.2- Elementos traza y tierras raras}

Estos elementos químicos poseen una presencia poco homogénea en las muestras analizadas en la Formación Río Mayer. Se encuentran de muy diversas maneras frente a la composición promedio de la Corteza Continental Superior (CCS; Taylor y McLennan, 1985). Solo 4 elementos de los considerados en la tabla 7.c están siempre en proporciones menores a las de la CCS, éstos son: estroncio (Sr), niobio (Nb), estaño (Sn) y uranio (U). El resto de los elementos se encuentran tanto por debajo como por encima del valor promedio de la CCS.

A diferencia de lo observado para los elementos mayoritarios, el comportamiento de los elementos traza y tierras raras no es claramente relacionable con la composición mineralógica determinada por difractometría de rayos X. La razón principal sería la baja movilidad geoquímica de estos elementos, característica muy importante para la posterior identificación de áreas fuente y ambiente tectónico de las pelitas de la unidad estudiada. 


\begin{tabular}{|c|c|c|c|c|c|c|c|c|c|c|c|c|c|c|c|c|c|c|c|c|}
\hline \multirow{2}{*}{\multicolumn{2}{|c|}{ Muestra }} & $\mathrm{Ag}$ & $\mathrm{Ba}$ & $\mathrm{Ce}$ & Co & $\mathrm{Cr}$ & Cs & $\mathrm{Cu}$ & Dy & Er & $\mathrm{Eu}$ & $\mathrm{Ga}$ & $\mathrm{Gd}$ & $\mathrm{Hf}$ & Ho & $\mathrm{La}$ & $\mathrm{Lu}$ & Mo & $\mathrm{Nb}$ & $\mathrm{Nd}$ \\
\hline & & ppm & $\mathrm{ppm}$ & $\mathrm{ppm}$ & $\mathrm{ppm}$ & ppm & $\mathrm{ppm}$ & ppm & ppm & ppm & ppm & ppm & $\mathrm{ppm}$ & $\mathrm{ppm}$ & ppm & ppm & $\mathrm{ppm}$ & $\mathrm{ppm}$ & $\mathrm{ppm}$ & $\mathrm{ppm}$ \\
\hline & PA 15 & $<1$ & 583 & 51,2 & 14,9 & 40 & 3,3 & 28 & 4,05 & 2,18 & 1,06 & 16,5 & 4,42 & 2,8 & 0,8 & 21 & 0,34 & $<2$ & 5,9 & 21,2 \\
\hline & PA 13 & $<1$ & 642 & 51,5 & 18,3 & 40 & 4,38 & 30 & 3,47 & 2,12 & 0,87 & 17,4 & 3,5 & 2,9 & 0,7 & 20,1 & 0,34 & $<2$ & 5,6 & 18,3 \\
\hline & PA 5 & $<1$ & 574 & 58,4 & 22,4 & 50 & 4,67 & 38 & 3,6 & 2,05 & 0,95 & 16,7 & 4,02 & 3 & 0,7 & 21,8 & 0,32 & $<2$ & 6,8 & 20,5 \\
\hline & PA 3 & $<1$ & 598 & 58 & 21,9 & 50 & 4,58 & 41 & 3,37 & 2,03 & 0,89 & 17,6 & 3,56 & 2,8 & 0,68 & 22,2 & 0,33 & $<2$ & 6,9 & 19,2 \\
\hline & PA 2 & $<1$ & 909 & 50,7 & 30,6 & 50 & 6,98 & 33 & 3,75 & 2,31 & 0,94 & 20,4 & 3,82 & 3,1 & 0,75 & 19,2 & 0,37 & $<2$ & 6,5 & 17,5 \\
\hline & PA 1 & $<1$ & 891 & 49,6 & 30,6 & 40 & 7,13 & 29 & 3,74 & 2,31 & 0,93 & 21,1 & 3,67 & 3,2 & 0,75 & 18,4 & 0,39 & $<2$ & 6,7 & 17,2 \\
\hline & PG 59 & $<1$ & 865 & 98,5 & 13,2 & 60 & 10,85 & 36 & 7,8 & 4,83 & 1,66 & 16,6 & 8,36 & 3,9 & 1,57 & 41 & 0,71 & 4 & 6 & 41,4 \\
\hline & PG 45 & $<1$ & 664 & 38,1 & 15,7 & 30 & 7,23 & 36 & 3,98 & 2,31 & 1,17 & 12,2 & 3,95 & 2,1 & 0,77 & 13,9 & 0,3 & 2 & 3,1 & 17 \\
\hline & PG 40 & $<1$ & 1495 & 67,3 & 5,5 & 10 & 12,05 & 8 & 4,36 & 5,54 & 0,61 & 23,6 & 3,55 & 12,4 & 1,38 & 32,9 & 1,31 & $<2$ & 12,3 & 20,6 \\
\hline \multirow{2}{*}{$\begin{array}{c}\text { Sección } \\
\text { media }\end{array}$} & PG 37 & $<1$ & 1345 & 92,5 & 49,8 & 50 & 15,75 & 71 & 10,45 & 6,46 & 1,88 & 25,5 & 9,7 & 6,3 & 2,18 & 29,7 & 0,96 & $<2$ & 8,2 & 40,2 \\
\hline & PG 34 & $<1$ & 497 & 15,8 & 32,6 & 30 & 5,94 & 45 & 3,36 & 2,29 & 0,61 & 12,5 & 2,76 & 2,3 & 0,74 & 4,9 & 0,38 & $<2$ & 4,2 & 9,6 \\
\hline \multirow{6}{*}{$\begin{array}{ll}\mathrm{S} & \mathrm{i} \\
\mathrm{e} & \mathrm{n} \\
\mathrm{c} & \mathrm{f} \\
\mathrm{c} & \mathrm{e} \\
\mathrm{i} & \mathrm{r} \\
\mathrm{o} & \mathrm{i} \\
\mathrm{n} & \mathrm{o} \\
& \mathrm{r}\end{array}$} & IG 44 & $<1$ & 497 & 70,6 & 1,9 & 60 & 11,25 & 13 & 15,6 & 9,09 & 2,04 & 14,9 & 14,9 & 4,4 & 3,13 & 41,8 & 1,01 & 2 & 6,6 & 55,5 \\
\hline & IG 39 & $<1$ & 948 & 49,6 & 1,8 & 70 & 33,6 & 18 & 3,81 & 2,68 & 0,57 & 24,8 & 3,56 & 4,6 & 0,87 & 28,4 & 0,45 & 2 & 9,9 & 23,3 \\
\hline & IG 36 & $<1$ & 767 & 71,1 & 2,5 & 40 & 18 & 14 & 4,72 & 2,88 & 0,66 & 19,1 & 5,57 & 4,5 & 0,94 & 36,9 & 0,45 & 3 & 8,7 & 33,2 \\
\hline & IG 32 & $<1$ & 738 & 71,2 & 3 & 50 & 18,5 & 28 & 6,31 & 3,77 & 0,89 & 19,4 & 6,57 & 4,3 & 1,24 & 38 & 0,54 & 2 & 8,8 & 36 \\
\hline & IG 26 & $<1$ & 730 & 65,6 & 1,9 & 40 & 16,5 & 12 & 6,28 & 4,02 & 0,74 & 20,4 & 6,21 & 4,3 & 1,31 & 32,8 & 0,58 & 2 & 10 & 31,1 \\
\hline & IG 5 & $<1$ & 1170 & 58,9 & 3 & 20 & 17,4 & 11 & 6,86 & 4,46 & 0,51 & 20,4 & 5,77 & 6,3 & 1,42 & 26,1 & 0,65 & 2 & 12,4 & 26,1 \\
\hline
\end{tabular}

Tabla 7.b- Resultados de los elementos traza y tierras raras para las 17 muestras de pelitas de la Formación Río Mayer en la Seccional Río Guanaco. 


\begin{tabular}{|c|c|c|c|c|c|c|c|c|c|c|c|c|c|c|c|c|c|c|c|c|}
\hline \multirow{2}{*}{\multicolumn{2}{|c|}{ Muestra }} & $\mathrm{Ni}$ & $\mathrm{Pb}$ & $\operatorname{Pr}$ & $\mathrm{Rb}$ & $\mathrm{Sm}$ & Sn & $\mathrm{Sr}$ & $\mathrm{Ta}$ & $\mathrm{Tb}$ & Th & $\mathrm{Tl}$ & $\mathrm{Tm}$ & $\mathrm{U}$ & $\mathrm{V}$ & $\mathrm{W}$ & $\mathrm{Y}$ & $\mathrm{Yb}$ & $\mathrm{Zn}$ & $\mathrm{Zr}$ \\
\hline & & ppm & ppm & $\mathrm{ppm}$ & ppm & $\mathrm{ppm}$ & $\mathrm{ppm}$ & $\mathrm{ppm}$ & $\mathrm{ppm}$ & $\mathrm{ppm}$ & $\mathrm{ppm}$ & $\mathrm{ppm}$ & $\mathrm{ppm}$ & $\mathrm{ppm}$ & $\mathrm{ppm}$ & ppm & $\mathrm{ppm}$ & ppm & $\mathrm{ppm}$ & $\mathrm{ppm}$ \\
\hline \multirow{9}{*}{$\begin{array}{ll}\mathrm{s} & \mathrm{s} \\
\mathrm{e} & \mathrm{u} \\
\mathrm{c} & \mathrm{p} \\
\mathrm{c} & \mathrm{e} \\
\mathrm{c} & \mathrm{r} \\
\mathrm{i} & \mathrm{i} \\
\mathrm{o} & \mathrm{o} \\
\mathrm{n} & \mathrm{o} \\
& \mathrm{r}\end{array}$} & PA 15 & 35 & 16 & 5,49 & 62 & 4,67 & 2 & 172,5 & 0,5 & 0,74 & 6,59 & $<0.5$ & 0,35 & 1,28 & 93 & 2 & 21 & 2,44 & 106 & 98 \\
\hline & PA 13 & 43 & 16 & 4,92 & 70,5 & 3,95 & 2 & 160,5 & 0,4 & 0,61 & 7,73 & $<0.5$ & 0,32 & 1,33 & 118 & 1 & 18 & 2,08 & 93 & 83 \\
\hline & PA 5 & 48 & 25 & 5,48 & 63,3 & 4,34 & 2 & 186 & 0,4 & 0,68 & 7,44 & $<0.5$ & 0,3 & 1,54 & 111 & 1 & 17,9 & 2,06 & 159 & 89 \\
\hline & PA 3 & 43 & 40 & 5,1 & 62,8 & 3,61 & 2 & 158,5 & 0,5 & 0,61 & 7,35 & $<0.5$ & 0,32 & 1,3 & 106 & 2 & 17,7 & 2,17 & 127 & 94 \\
\hline & PA 2 & 56 & 13 & 4,74 & 87,3 & 3,91 & 2 & 157 & 0,5 & 0,64 & 7,68 & 0,5 & 0,36 & 1,36 & 125 & 2 & 20,1 & 2,57 & 125 & 110 \\
\hline & PA 1 & 58 & 13 & 4,59 & 89,9 & 3,8 & 2 & 152,5 & 0,6 & 0,65 & 7,83 & $<0.5$ & 0,38 & 1,38 & 126 & 2 & 20,4 & 2,61 & 109 & 110 \\
\hline & PG 59 & 59 & 16 & 10,3 & 74,5 & 8,66 & 2 & 102,5 & 0,4 & 1,38 & 9 & $<0.5$ & 0,7 & 4,16 & 123 & 1 & 41,9 & 4,49 & 141 & 102 \\
\hline & PG 45 & 41 & 13 & 4,25 & 46,4 & 4,08 & 1 & 121 & 0,2 & 0,7 & 3,73 & $<0.5$ & 0,32 & 1,57 & 108 & 1 & 19,3 & 2,11 & 102 & 59 \\
\hline & PG 40 & 22 & $<5$ & 6,27 & 100 & 3,32 & 2 & 127,5 & 1,4 & 0,58 & 26,1 & 0,5 & 1 & 5,93 & 112 & 3 & 37,4 & 7,48 & 117 & 335 \\
\hline \multirow{2}{*}{$\begin{array}{c}\text { Sección } \\
\text { media }\end{array}$} & PG 37 & 134 & 29 & 9,56 & 106,5 & 9,96 & 3 & 169 & 0,6 & 1,74 & 10,85 & 0,5 & 0,95 & 5,11 & 307 & 3 & 52,1 & 6,25 & 199 & 192 \\
\hline & PG 34 & 188 & 15 & 2,06 & 43,4 & 2,75 & 2 & 65 & 0,3 & 0,56 & 5,37 & $<0.5$ & 0,35 & 1,07 & 107 & 1 & 18,9 & 2,32 & 166 & 62 \\
\hline \multirow{6}{*}{$\begin{array}{ll}\mathrm{S} & \mathrm{i} \\
\mathrm{e} & \mathrm{n} \\
\mathrm{c} & \mathrm{f} \\
\mathrm{c} & \mathrm{e} \\
\mathrm{i} & \mathrm{r} \\
\mathrm{o} & \mathrm{i} \\
\mathrm{n} & \mathrm{o} \\
& \mathrm{r}\end{array}$} & IG 44 & 16 & 10 & 12,65 & 65 & 13,85 & 4 & 145 & 0,5 & 2,65 & 13,55 & $<0.5$ & 1,19 & 4,39 & 46 & 2 & 92,4 & 6,88 & 21 & 117 \\
\hline & IG 39 & 15 & 8 & 6,43 & 151,5 & 4,03 & 4 & 141 & 1 & 0,6 & 18,45 & 0,6 & 0,42 & 3,55 & 69 & 2 & 23,8 & 2,8 & 23 & 97 \\
\hline & IG 36 & 20 & 12 & 9,08 & 106 & 6,52 & 3 & 174,5 & 0,9 & 0,86 & 14,75 & $<0.5$ & 0,42 & 4,46 & 34 & 2 & 25,2 & 2,94 & 63 & 100 \\
\hline & IG 32 & 24 & 12 & 9,55 & 97,6 & 7,32 & 4 & 186 & 0,8 & 1,09 & 16,6 & $<0.5$ & 0,53 & 4,19 & 46 & 2 & 35,3 & 3,56 & 61 & 104 \\
\hline & IG 26 & 17 & 13 & 8,57 & 94,7 & 6,69 & 4 & 162,5 & 0,9 & 1,09 & 18,1 & 0,7 & 0,57 & 4,49 & 64 & 1 & 35 & 3,85 & 58 & 101 \\
\hline & IG 5 & 12 & 16 & 6,95 & 112 & 5,75 & 5 & 123,5 & 1,1 & 1,11 & 18,95 & 1,2 & 0,66 & 5,24 & 24 & 2 & 36,6 & 4,37 & 62 & 163 \\
\hline
\end{tabular}

Tabla 7.b (continuación)- Resultados de los elementos traza y tierras raras para las 17 muestras de pelitas de la Formación Río Mayer en la Seccional Río Guanaco. 


\begin{tabular}{|c|c|c|c|c|c|c|c|c|c|c|c|c|c|c|c|c|c|c|c|c|c|}
\hline \multirow{2}{*}{\multicolumn{2}{|c|}{ Muestra }} & V & $\mathrm{Cr}$ & Co & $\mathrm{Ni}$ & $\mathrm{Cu}$ & $\mathrm{Zn}$ & $\mathrm{Ga}$ & $\mathrm{Rb}$ & $\mathrm{Sr}$ & Y & $\mathrm{Zr}$ & $\mathrm{Nb}$ & Mo & Sn & Ва & La & $\mathrm{Ce}$ & $\mathrm{Pb}$ & Th & $\mathrm{U}$ \\
\hline & & ppm & $\mathrm{ppm}$ & ppm & ppm & ppm & $\mathrm{ppm}$ & ppm & $\mathrm{ppm}$ & ppm & $\mathrm{ppm}$ & ppm & ppm & ppm & ppm & ppm & ppm & ppm & ppm & ppm & ppm \\
\hline \multirow{9}{*}{$\begin{array}{ll}\mathrm{S} & \mathrm{s} \\
\mathrm{e} & \mathrm{u} \\
\mathrm{c} & \mathrm{p} \\
\mathrm{c} & \mathrm{e} \\
\mathrm{c} & \mathrm{e} \\
\mathrm{i} & \mathrm{r} \\
\mathrm{o}^{0} & \mathrm{i} \\
\mathrm{n} & 0 \\
\mathrm{r}\end{array}$} & PA 15 & 1,55 & 1,14 & 1,49 & 1,75 & 1,12 & 1,49 & 0,97 & 0,55 & 0,49 & 0,95 & 0,52 & 0,24 & & 0,33 & 1,06 & 0,70 & 0,80 & 0,76 & 0,55 & 0,21 \\
\hline & PA 13 & 1,97 & 1,14 & 1,83 & 2,15 & 1,20 & 1,31 & 1,02 & 0,63 & 0,46 & 0,82 & 0,44 & 0,22 & & 0,33 & 1,17 & 0,67 & 0,80 & 0,76 & 0,64 & 0,22 \\
\hline & PA 5 & 1,85 & 1,43 & 2,24 & 2,40 & 1,52 & 2,24 & 0,98 & 0,57 & 0,53 & 0,81 & 0,47 & 0,27 & & 0,33 & 1,04 & 0,73 & 0,91 & 1,19 & 0,62 & 0,26 \\
\hline & PA 3 & 1,77 & 1,43 & 2,19 & 2,15 & 1,64 & 1,79 & 1,04 & 0,56 & 0,45 & 0,80 & 0,49 & 0,28 & & 0,33 & 1,09 & 0,74 & 0,91 & 1,90 & 0,61 & 0,22 \\
\hline & PA 2 & 2,08 & 1,43 & 3,06 & 2,80 & 1,32 & 1,76 & 1,20 & 0,78 & 0,45 & 0,91 & 0,58 & 0,26 & & 0,33 & 1,65 & 0,64 & 0,79 & 0,62 & 0,64 & 0,23 \\
\hline & PA 1 & 2,10 & 1,14 & 3,06 & 2,90 & 1,16 & 1,54 & 1,24 & 0,80 & 0,44 & 0,93 & 0,58 & 0,27 & & 0,33 & 1,62 & 0,61 & 0,78 & 0,62 & 0,65 & 0,23 \\
\hline & PG 59 & 2,05 & 1,71 & 1,32 & 2,95 & 1,44 & 1,99 & 0,98 & 0,67 & 0,29 & 1,90 & 0,54 & 0,24 & 2,00 & 0,33 & 1,57 & 1,37 & 1,54 & 0,76 & 0,75 & 0,69 \\
\hline & PG 45 & 1,80 & 0,86 & 1,57 & 2,05 & 1,44 & 1,44 & 0,72 & 0,41 & 0,35 & 0,88 & 0,31 & 0,12 & 1,00 & 0,17 & 1,21 & 0,46 & 0,60 & 0,62 & 0,31 & 0,26 \\
\hline & PG 40 & 1,87 & 0,29 & 0,55 & 1,10 & 0,32 & 1,65 & 1,39 & 0,89 & 0,36 & 1,70 & 1,76 & 0,49 & & 0,33 & 2,72 & 1,10 & 1,05 & & 2,18 & 0,99 \\
\hline \multirow{2}{*}{$\begin{array}{l}\text { Sección } \\
\text { media }\end{array}$} & PG 37 & 5,12 & 1,43 & 4,98 & 6,70 & 2,84 & 2,80 & 1,50 & 0,95 & 0,48 & 2,37 & 1,01 & 0,33 & & 0,50 & 2,45 & 0,99 & 1,45 & 1,38 & 0,90 & 0,85 \\
\hline & PG 34 & 1,78 & 0,86 & 3,26 & 9,40 & 1,80 & 2,34 & 0,74 & 0,39 & 0,19 & 0,86 & 0,33 & 0,17 & & 0,33 & 0,90 & 0,16 & 0,25 & 0,71 & 0,45 & 0,18 \\
\hline \multirow{6}{*}{$\begin{array}{ll}\mathrm{S} & \mathrm{i} \\
\mathrm{e} & \mathrm{n} \\
\mathrm{c} & \mathrm{f} \\
\mathrm{c} & \mathrm{e} \\
\mathrm{i} & \mathrm{r} \\
\mathrm{i} & \mathrm{r} \\
\mathrm{o} & \mathrm{i} \\
\mathrm{n} & 0 \\
& \\
& \mathrm{r}\end{array}$} & IG 44 & 0,77 & 1,71 & 0,19 & 0,80 & 0,52 & 0,30 & 0,88 & 0,58 & 0,41 & 4,20 & 0,62 & 0,26 & 1,00 & 0,67 & 0,90 & 1,39 & 1,10 & 0,48 & 1,13 & 0,73 \\
\hline & IG 39 & 1,15 & 2,00 & 0,18 & 0,75 & 0,72 & 0,32 & 1,46 & 1,35 & 0,40 & 1,08 & 0,51 & 0,40 & 1,00 & 0,67 & 1,72 & 0,95 & 0,78 & 0,38 & 1,54 & 0,59 \\
\hline & IG 36 & 0,57 & 1,14 & 0,25 & 1,00 & 0,56 & 0,89 & 1,12 & 0,95 & 0,50 & 1,15 & 0,53 & 0,35 & 1,50 & 0,50 & 1,39 & 1,23 & 1,11 & 0,57 & 1,23 & 0,74 \\
\hline & IG 32 & 0,77 & 1,43 & 0,30 & 1,20 & 1,12 & 0,86 & 1,14 & 0,87 & 0,53 & 1,60 & 0,55 & 0,35 & 1,00 & 0,67 & 1,34 & 1,27 & 1,11 & 0,57 & 1,38 & 0,70 \\
\hline & IG 26 & 1,07 & 1,14 & 0,19 & 0,85 & 0,48 & 0,82 & 1,20 & 0,85 & 0,46 & 1,59 & 0,53 & 0,40 & 1,00 & 0,67 & 1,33 & 1,09 & 1,03 & 0,62 & 1,51 & 0,75 \\
\hline & IG 5 & 0,40 & 0,57 & 0,30 & 0,60 & 0,44 & 0,87 & 1,20 & 1,00 & 0,35 & 1,66 & 0,86 & 0,50 & 1,00 & 0,83 & 2,13 & 0,87 & 0,92 & 0,76 & 1,58 & 0,87 \\
\hline
\end{tabular}

Tabla 7. c- Valores de elementos traza y tierras raras seleccionados para las 17 muestras de pelitas de la Formación Río Mayer en la Seccional Río Guanaco normalizados con respecto a la composición promedio de la Corteza Continental Superior (Taylor y

McLennan, 1985). En verde se resaltan los valores mayores a 1. 


\section{2.3 - Clasificación geoquímica de las muestras}

Se catalogaron las muestras de pelitas de la Formación Río Mayer según la clasificación desarrollada en 1988 por Herron (figura 7.7), en la cual gran parte de las muestras (13) se encuadran en el campo de los vaques, dos muestras en el campo de las lutitas, mientras que sólo dos están enriquecidas en Fe y entran en el campo de las areniscas férricas.

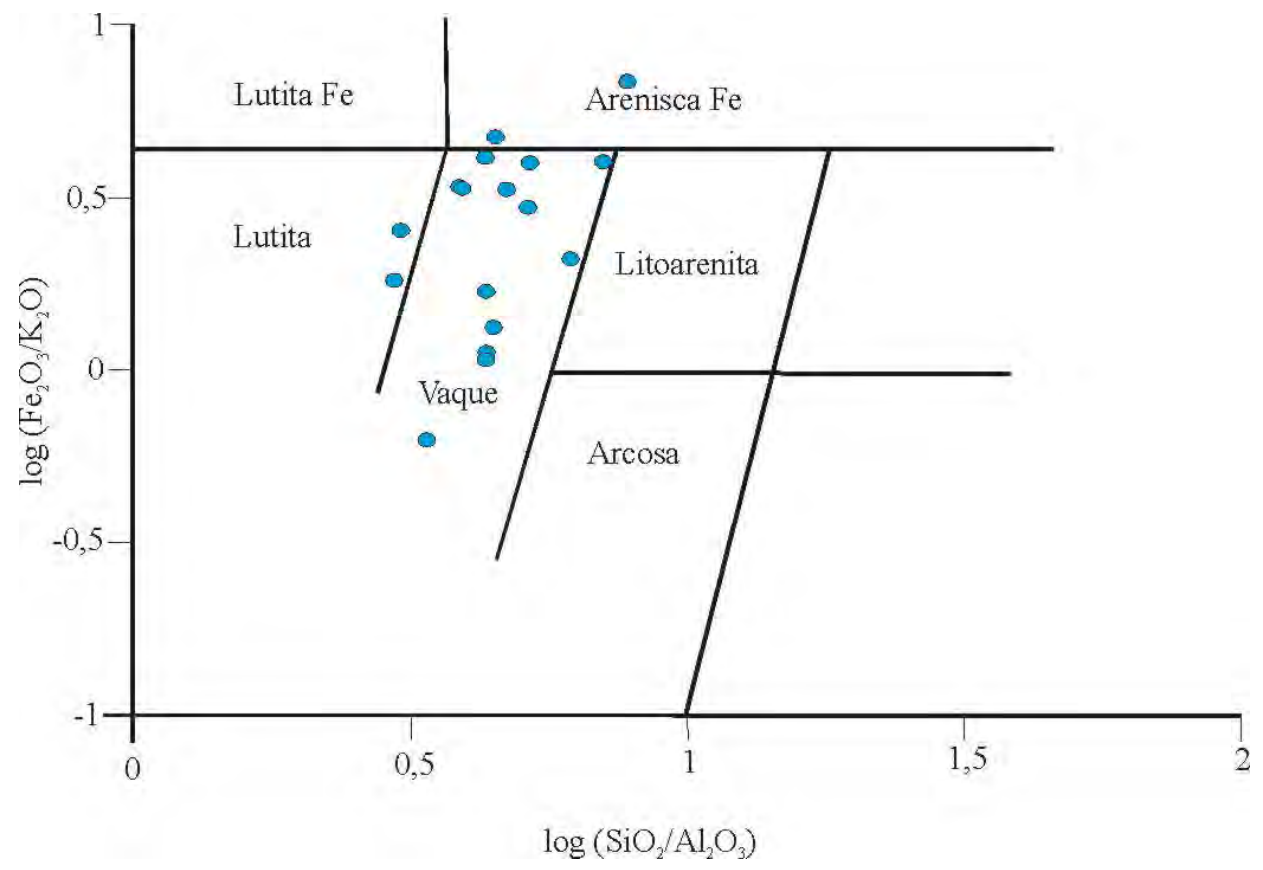

Figura 7.7- Clasificación geoquímica de las muestras de pelitas provenientes de la Formación Río Mayer en el diagrama log $\left(\mathrm{SiO}_{2} / \mathrm{Al}_{2} \mathrm{O}_{3}\right)$ vs $\log \left(\mathrm{Fe}_{2} \mathrm{O}_{3} / \mathrm{K}_{2} \mathrm{O}\right)$ (Herron, 1988).

Este tipo de clasificaciones pondera la relación entre los contenidos de sílice y alúmina para separar pelitas de areniscas, sin embargo las muestras de pelitas de la Formación Río Mayer poseen como componente mayoritario determinado pos DRX al cuarzo, con lo cual, pese a ser de granulometría fina caen en el campo de los vaques y no de las lutitas. 


\section{2.4 - Meteorización de las muestras analizadas}

Como se mencionaba anteriormente, una importante característica de los datos analíticos obtenidos por geoquímica, es que permiten hacer inferencias sobre el grado de meteorización y diagénesis al cual estuvieron sometidas las muestras analizadas (Boles y Franks, 1979; Nesbitt et al., 1996; McLennan, 2001). Con respecto a este tópico se consideraron los siguientes indicadores (tabla 7.d; figuras 7.8, 7.9):

Índice de alteración Química (CIA, Chemical index of alteration): éste indicador fue propuesto por Nesbitt y Young (1982) y utiliza la siguiente fórmula:

$$
\mathrm{CIA}=\left(\mathrm{Al}_{2} \mathrm{O}_{3} /\left(\mathrm{Al}_{2} \mathrm{O}_{3}+\mathrm{K}_{2} \mathrm{O}+\mathrm{Na}_{2} \mathrm{O}+\mathrm{CaO}\right)\right) \times 100
$$

Índice de Meteorización (CIW, Chemical index of weathering): es una variación del CIA propuesta por Harnois (1988), con la siguiente fórmula:

$$
\mathrm{CIW}=\left(\mathrm{Al}_{2} \mathrm{O}_{3} /\left(\mathrm{Al}_{2} \mathrm{O}_{3}+\mathrm{Na}_{2} \mathrm{O}+\mathrm{CaO}\right)\right) \times 100
$$

Índice CIW”: una variación del anterior indicador fue propuesta por Cullers (2000) y se basa en la fórmula:

$$
C I W "=\left(\mathrm{Al}_{2} \mathrm{O}_{3} /\left(\mathrm{Al}_{2} \mathrm{O}_{3}+\mathrm{Na}_{2} \mathrm{O}\right)\right) \times 100
$$

Índice de Variabilidad Composicional (ICV, Index of Compositional Variability): expresa el grado de meteorización y reciclado de los constituyentes de las pelitas (Cox et al., 1995). La formula es:

$$
\mathrm{ICV}=\left(\mathrm{Fe}_{2} \mathrm{O}_{3}+\mathrm{K}_{2} \mathrm{O}+\mathrm{Na}_{2} \mathrm{O}+\mathrm{CaO}+\mathrm{MgO}+\mathrm{MnO}+\mathrm{TiO}_{2}\right) / \mathrm{Al}_{2} \mathrm{O}_{3}
$$

$\underline{\text { Relación } \mathrm{SiO}_{2}} \underline{\mathrm{Al}}_{2} \underline{\mathrm{O}}_{3}$ expresa la maduración de las rocas analizadas (Asiedu et al., 2004; Spalletti et al., 2008).

En lo que respecta a los índices CIA, CIW y CIW”, los valores obtenidos para las tres secciones analizadas de la Formación Río Mayer muestran valores normales a moderados de meteorización, excediendo en ocasiones los valores típicos para muestras pelíticas. El CIA es el indicador mejor considerado entre los índices para determinar la 
meteorización de una roca (Bahlburg y Dobrzinski, 2009). Se asume que para este índice las rocas de la corteza superior inalteradas poseen un valor de 50, mientras que, un valor de 100 representa suelos residuales. Rangos de CIA para lutitas de diferentes partes del mundo se encuentran entre 70 y 75\% (Visser y Young, 1990). Para las muestras estudiadas los valores se encuentran entre 70 y 83 \%, que significa una meteorización desde moderada a levemente intensa. Además se observa una tendencia decreciente de los valores obtenidos de los índices desde la sección inferior a la superior, dicha tendencia se tratará a continuación. Cabe destacar que el tamaño de grano es importante en el resultado final del CIA si se comparan muestras de pelitas y areniscas, ya que los feldespatos y otros minerales lábiles tienden a concentrarse en la fracción pelítica, aumentado el valor del índice mencionado (Nesbitt et al., 1996), aunque esta observación no influye en el presente trabajo por tratarse exclusivamente de pelitas.

\begin{tabular}{|c|c|c|c|c|c|}
\hline Muestra & CIA & CIW & CIW" & ICV & SiO2/A12O3 \\
\hline IG 5 & 82,25 & 93,79 & 97,78 & 0,51 & 4,36 \\
\hline IG 26 & 82,80 & 92,55 & 96,31 & 0,51 & 4,49 \\
\hline IG 32 & 79,82 & 89,04 & 94,81 & 0,59 & 4,38 \\
\hline IG 36 & 81,23 & 92,05 & 96,27 & 0,48 & 4,37 \\
\hline IG 39 & 82,12 & 94,97 & 97,82 & 0,4 & 3,39 \\
\hline IG 44 & 74,32 & 82,01 & 94,92 & 0,73 & 6,22 \\
\hline PG 34 & 75,06 & 81,40 & 92,98 & 1,28 & 7,90 \\
\hline PG 37 & 77,59 & 86,65 & 90,55 & 0,8 & 3,05 \\
\hline PG 40 & 77,24 & 88,10 & 95,88 & 0,73 & 2,98 \\
\hline PG 45 & 75,95 & 83,40 & 88,66 & 0,94 & 7,13 \\
\hline PG 59 & 76,07 & 85,92 & 91,23 & 0,89 & 5,23 \\
\hline PA 1 & 75,43 & 84,28 & 88,20 & 0,99 & 3,90 \\
\hline PA 2 & 75,04 & 83,68 & 87,99 & 0,99 & 3,94 \\
\hline PA3 & 72,37 & 78,73 & 85,33 & 1,13 & 4,56 \\
\hline PA 5 & 72,18 & 78,02 & 82,83 & 0,99 & 4,35 \\
\hline PA 13 & 68,89 & 75,45 & 85,58 & 1,05 & 4,77 \\
\hline PA 15 & 72,19 & 78,98 & 85,16 & 1,04 & 5,26 \\
\hline
\end{tabular}

Tabla 7.d- Indicadores utilizados para realizar interpretaciones sobre el grado de meteorización y diagénesis alcanzado por las muestras de la Formación Río Mayer. 
El índice ICV permite diferenciar pelitas inmaduras de pelitas maduras (Cox et al., 1995). Las pelitas inmaduras se caracterizan por poseer elevadas cantidades de minerales silíceos no arcillosos (de primer ciclo), y se relacionan a zonas tectónicamente activas. Las pelitas maduras en cambio, se encuentran en zonas relativamente calmas o cratónicas, donde el reciclado de los sedimentos en muy activo. Éstas últimas se caracterizan por estar compuestas de mayor cantidad de arcillas respecto de las inmaduras (Cox et al., 1995). Los valores de ICV para la Formación Río Mayer se dividen en 2 grupos, uno que se compone de las muestras provenientes de la sección inferior en el cual el valor de este índice se halla cercano a 0,50. Este valor entra en el campo de ICV de las arcillas $(0,03-0,78)$ y cercano al de los feldespatos (0,54-0,87). El segundo grupo incluye a las secciones media y superior, con valores de ICV cercanos a 1, similares a los obtenidos para basamento y cobertura sedimentaria primaria por Cox et al. (1995). De este análisis se desprende que las pelitas de la sección inferior poseen mayor evolución, o sea, estuvieron más expuestas a la meteorización que las pelitas de las secciones media y superior. Esta observación se puede correlacionar con los valores de CIA, que disminuyen a medida que se asciende estratigráficamente dentro de la unidad estudiada.

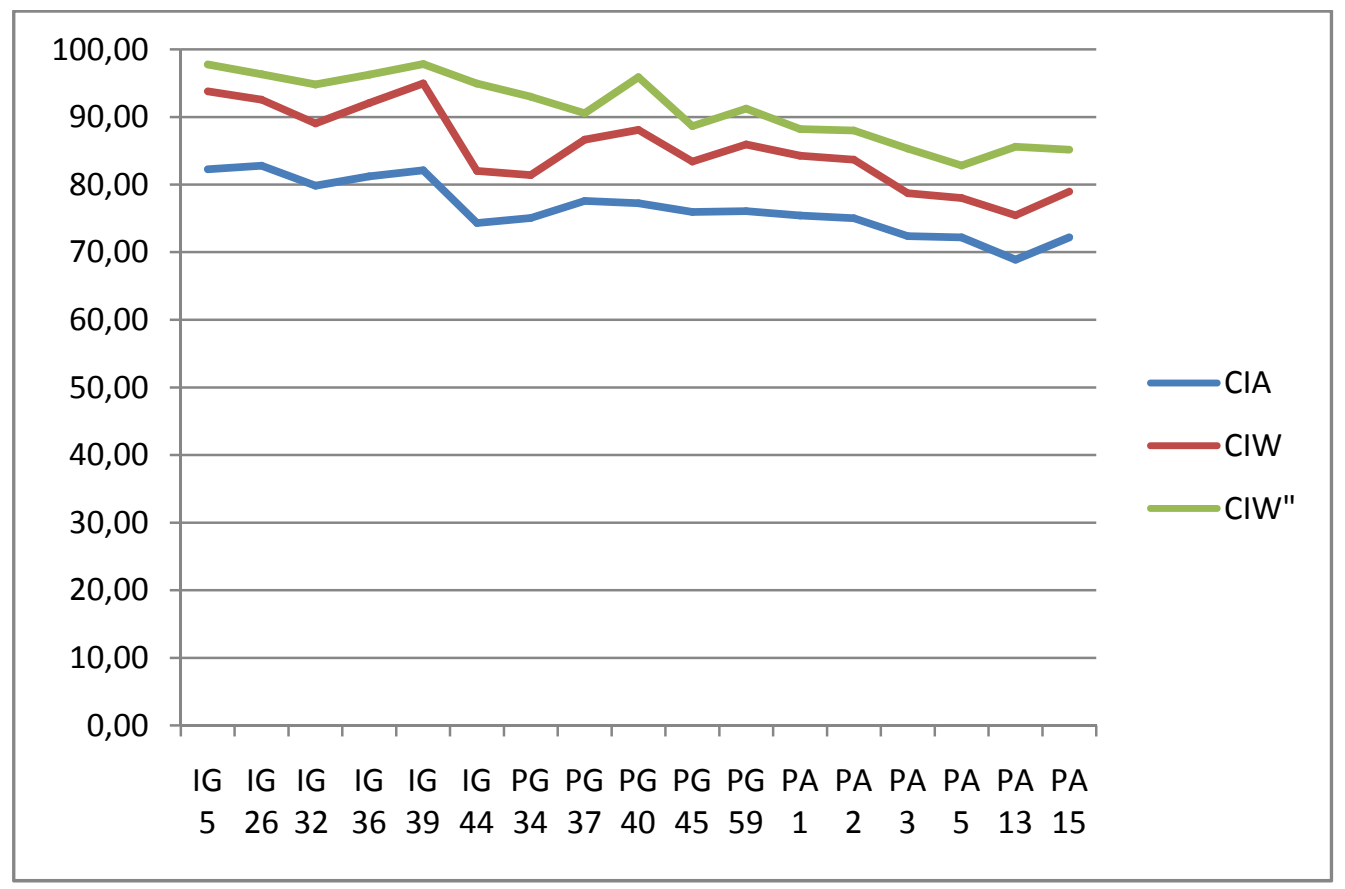

Figura 7.8- Distribución de los índices CIA, CIW, CIW” en las muestras provenientes de la Formación Río Mayer. 
Finalmente, en lo que respecta a meteorización, la relación $\mathrm{SiO}_{2} / \mathrm{Al}_{2} \mathrm{O}_{3}$ expresa la maduración de las pelitas analizadas. Las muestras de la Formación Río Mayer presentan un bajo grado de maduración (Asiedu et al., 2004). Sin embargo, el amplio rango de valores obtenidos $(2,98-7,9)$ no permite realizar mayores consideraciones.

En la figura 7.9 se observan varias evoluciones posibles para la meteorización de muestras provenientes de la Corteza Continental Superior (CCS). Las muestras de la Formación Río Mayer parecen alinearse con el último tramo de las trayectorias definidas por Nesbitt y Young (1984) y von Eynatten (2004) para la alteración de una muestra de la CCS, pero con mayores contenidos de $\mathrm{CaO}+\mathrm{Na}_{2} \mathrm{O}$. 

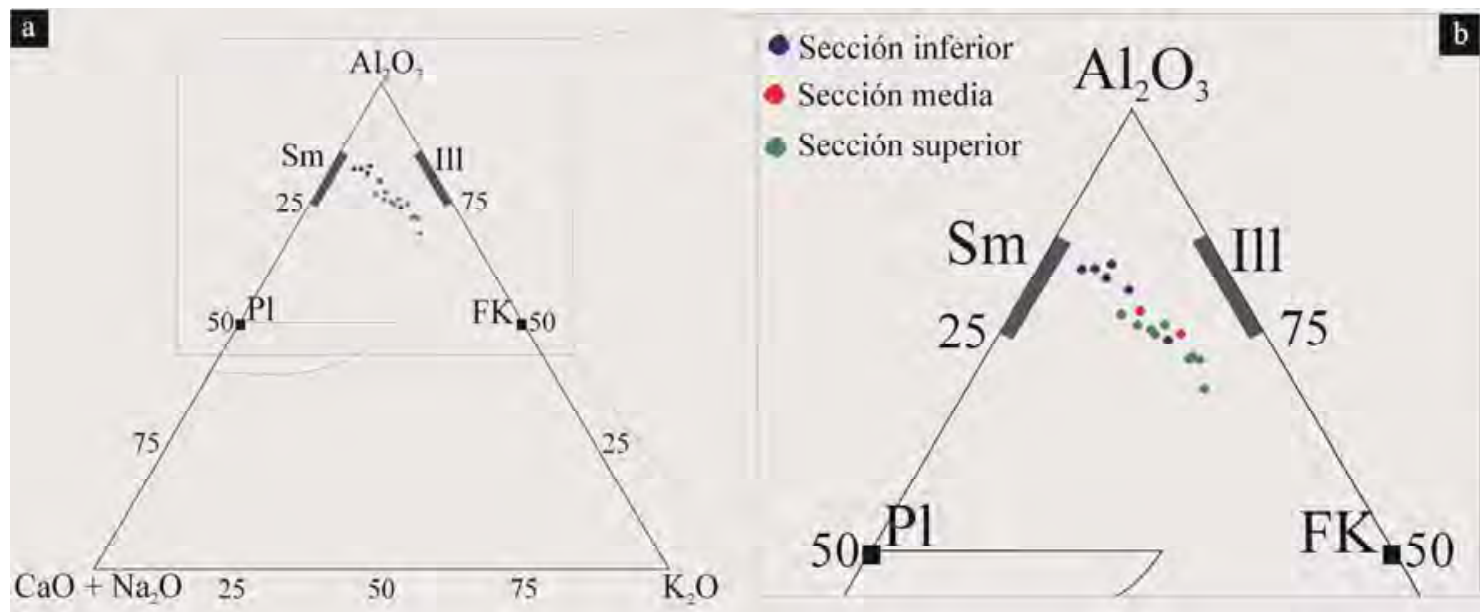

c

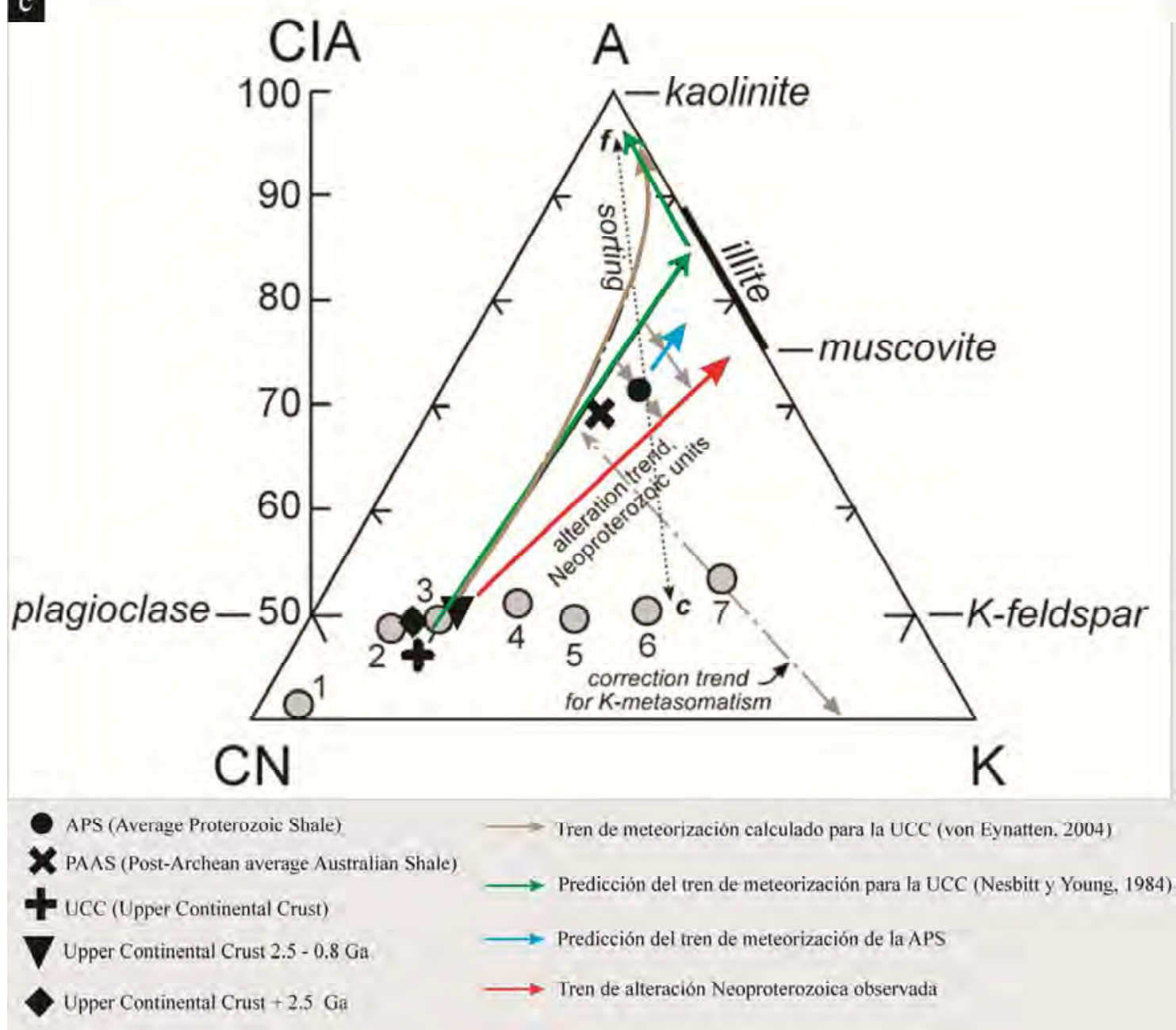

Figura 7.9- a- Distribución de las muestras de la Formación Río Mayer en el diagrama $\mathrm{CaO}+\mathrm{Na}_{2} \mathrm{O} /$ $\mathrm{Al}_{2} \mathrm{O}_{3} / \mathrm{K}_{2} \mathrm{O}$ (CIA). En b, detalle de a. En c, varias evoluciones posibles calculadas por diferentes autores a partir de la muestra CCS (UCC). 1, gabro; 2, tonalita; 3, granodiorita; 4, granita; 5, granito tipo A; 6, charnokita; 7, granito potásico (Tomado y modificado de Bahlburg y Dobrzinski, 2009). 


\section{2.5 - Proveniencia}

El uso de los análisis geoquímicos en la determinación del área fuente de los componentes formadores de una roca sedimentaria está ampliamente difundido (Taylor y McLennan, 1985; Roser y Korsh, 1988; Floyd et al., 1989, 1990; Zimmermann y Bahlburg, 2003; Spalletti et al., 2008; Zimmermann et al., 2011; entre otros).

En general, el empleo de los elementos mayoritarios en la determinación tanto de áreas fuente como del ambiente tectónico ha perdido su utilización con el transcurso de los años. La razón principal es la gran movilidad que tienen estos elementos durante la diagénesis. Sin embargo, su aplicación sigue vigente, aunque como complemento y debe tomarse recaudos y comparar con otros diagramas que utilicen elementos menos móviles.

En la figura 7.10a se observa el diagrama ternario $\mathrm{SiO}_{2} / 10, \mathrm{CaO}+\mathrm{MgO}, \mathrm{Na}_{2} \mathrm{O}+\mathrm{K}_{2} \mathrm{O}$ propuesto por Taylor y McLennan (1985). Las muestras de la Formación Río Mayer dentro de este esquema tienen una afinidad con el campo de las rocas graníticas, aunque empobrecidas en Na y K. En la figura 7.10b, las muestras arrojan bajos valores de $\mathrm{TiO}_{2} \mathrm{y}$ Ni\% y se disponen en el campo de la composición ácida (Floyd et al., 1989). Cabe destacar, que como señalaron Spalletti et al. (2008), los valores de andesitas y andesitas basálticas presentados por Taylor y McLennan (1985) también son afines a las composiciones ácidas a pesar de ser intermedias. En el diagrama $\mathrm{K}_{2} \mathrm{O}$ vs $\mathrm{Rb}$ (Floyd et al., 1990; figura 7.10c) también los resultados indican una composición ácida a intermedia. La correlación observada entre los valores de $\mathrm{K}_{2} \mathrm{O}$ y $\mathrm{Rb} \%$ tiene una significación muy importante, dada por un típico tren de diferenciación de una suite magmática ó tren principal, cuya relación de $\mathrm{K}_{2} \mathrm{O} / \mathrm{Rb}$ es 230 (Shaw, 1968). En este sentido, la relación entre estos elementos para la Formación Río Mayer es en promedio de 240. Por lo tanto, se desprende que los materiales formadores de las pelitas estudiadas provendrían de rocas intermedias y/o ácidas genéticamente relacionadas entre sí, como proponen otros autores (Rahman y Shigeyuki, 2007; Alonso, 2011). La relación entre los diferentes aspectos composicionales de la Formación Río Mayer y las posibles rocas fuente presentes en el área de estudio será tratado a continuación y ampliamente discutido en el capítulo IX. 


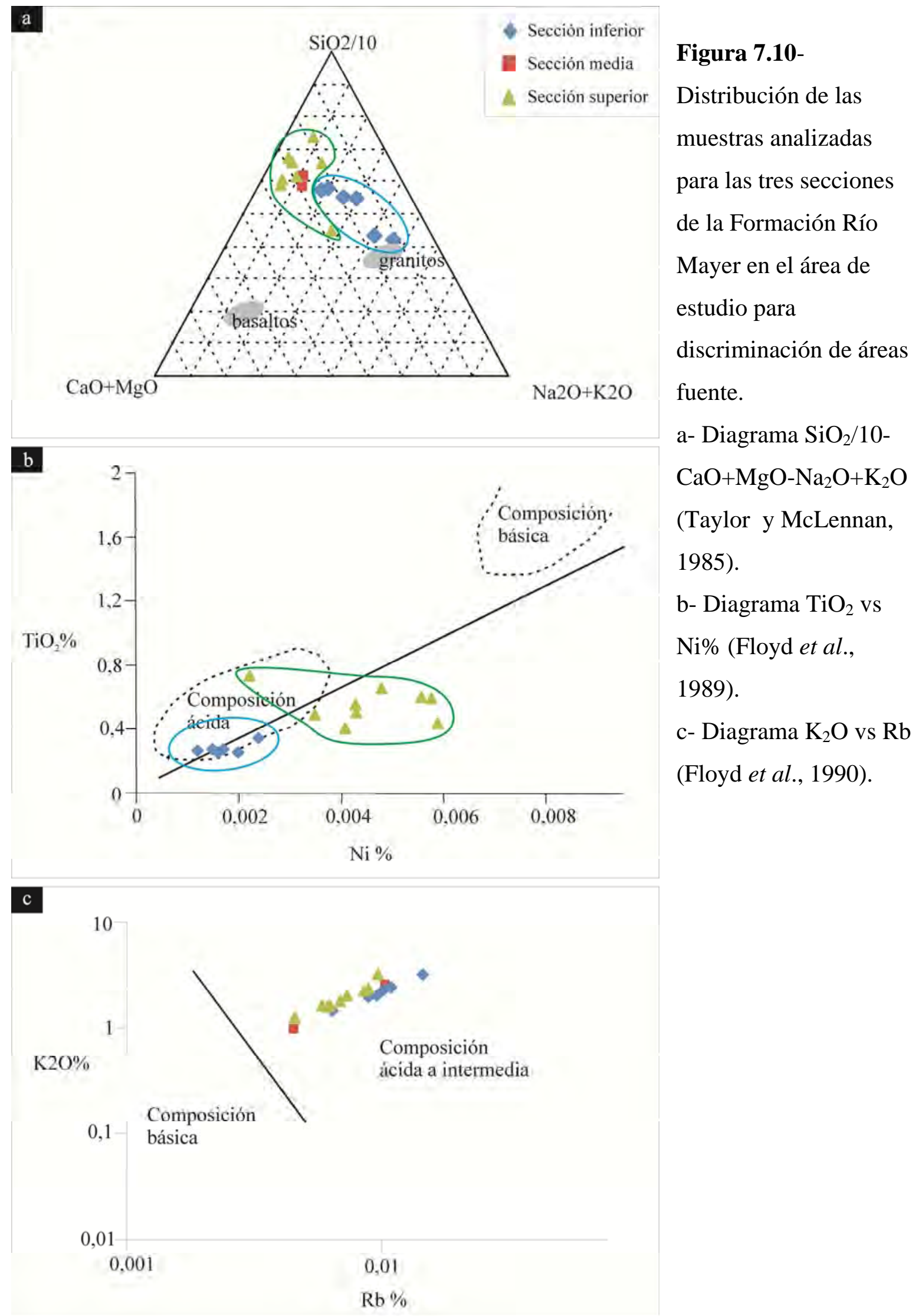


Gu et al. (2002) señalan que el valor Co/Th de 1,27 separa las afinidades ácidas de las intermedias a básicas. Valores inferiores a 1,27 de relación señalan una composición ácida del área fuente, mientras que valores superiores indican procedencia intermedia a básica. Una roca andesítica posee relación entre 7 y 10, mientras que en un basalto la relación es cercana a 20 (Gu et al., 2002). La relación Co/Th (figura 7.11a) indica que para la sección inferior las muestras proceden de un área fuente de características netamente ácidas, mientras que para las secciones media y superior hay participación de material de composición intermedia. En la figura 7.11b se muestra el diagrama La/Th vs Hf (ppm) del cual se desprende que la roca fuente de las pelitas de la Formación Río Mayer es de naturaleza ácida a intermedia. En ambos diagramas (7.11 a y b) se observa una tendencia desde una procedencia ácida en la sección inferior hacia una signatura intermedia de las secciones media y superior. Las posibles implicancias de esta tendencia serán tratadas más adelante. 

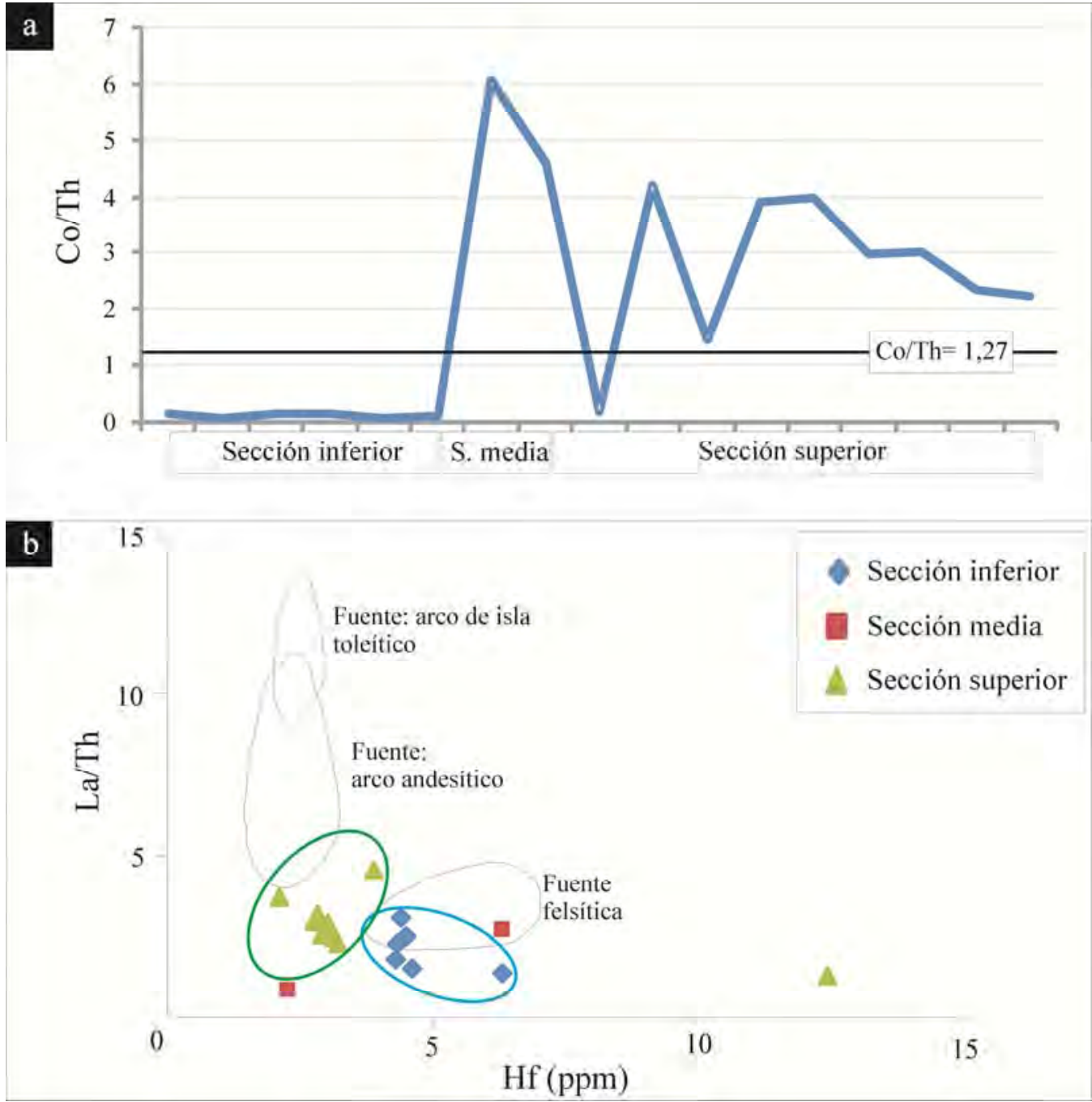

Figura 7.11- Distribución de las muestras analizadas para las tres secciones de la Formación Río Mayer en el área de estudio para discriminación de áreas fuente. aRelación Co/Th de las muestras estudiadas comparadas con el valor Co/Th= 1,27 (Gu et al., 2002). b- Diagrama La/Th vs Hf (ppm) (Floyd y Leveridge, 1987; Gu et al., 2002).

Los contenidos de algunos elementos traza como el Cr, V y Ni son empleados para discriminar la posible influencia de un área de aporte de naturaleza básica a ultrabásica (Spalletti et al., 2008). Los promedios de estos tres elementos en la Formación Río Mayer corresponden a Cr: 42,9 ppm, V: 101,1 ppm y Ni: 48,9 ppm, y son superiores a los valores promedio de la Corteza Continental Superior (CCS) propuestos por Taylor y McLennan (1985) $(\mathrm{Cr}=35$ ppm, V= 60 ppm, Ni=20ppm). A su vez, el comportamiento del V y Ni dentro de las tres secciones es coincidente con lo observado en la figura 7.11, ambos tienen 
valores cercanos a la CCS en la sección inferior, y se enriquecen en las secciones media y superior (Tabla 7.2). A su vez los promedios de estos tres elementos aumentan en las secciones media y superior, esto también evidencia el paso de proveniencias ácidas hacia composiciones más cercanas a las intermedias.

\section{2.6 - Ambiente tectónico}

El empleo de diagramas para discriminación de ambientes tectónicos es muy frecuente en la literatura geológica (entre otros, Maynard et al., 1982; Bhatia, 1983; Roser y Korsch, 1985, 1986, 1988; Bhatia y Crook, 1986; Merodio y Spalletti, 1990; Gu et al., 2002; Spalletti et al., 2008).

En el clásico diagrama de Roser y Korsch (1986), las muestras de la sección inferior se ubican en el campo de margen pasivo, mientras que las correspondientes a las secciones media y superior se encuentran en el campo del margen continental activo (figura 7.12 a). En el diagrama de la figura 7.12b los resultados son similares, las muestras de la sección inferior se sitúan cercanas al campo de margen pasivo, mientras que el resto se encuentran en condiciones de margen continental activo y arco. Cabe aclarar con respecto a estos dos diagramas que el contenido de $\mathrm{K}$ está en función del contenido de Illita, como fuera demostrado con anterioridad (figura 7.5). 

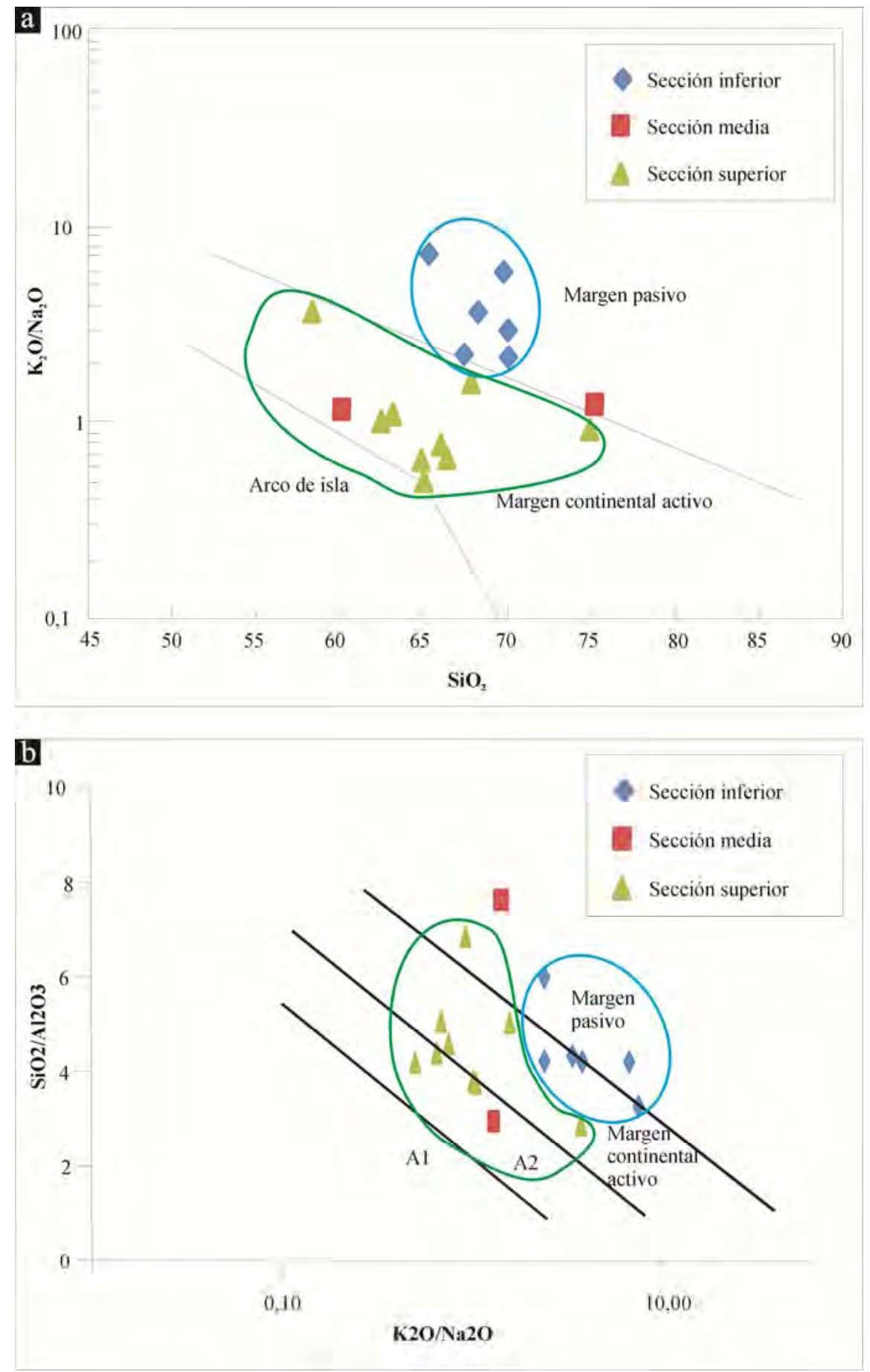

Figura 7.12- Distribución de las muestras analizadas para las tres secciones de la Formación Río Mayer en el área de estudio para discriminación de ambiente tectónico. En a se muestra el diagrama $\mathrm{K}_{2} \mathrm{O} / \mathrm{Na}_{2} \mathrm{O}$ vs $\mathrm{SiO}_{2}$ (Roser y Korsch, 1986). En b el diagrama $\mathrm{Si}_{2} \mathrm{O} / \mathrm{Al}_{2} \mathrm{O}_{3}$ vs $\mathrm{K}_{2} \mathrm{O} / \mathrm{Na}_{2} \mathrm{O}$ (Maynard et al., 1982; Roser y Korsch, 1986). Campos A1: 
Características de arco, detritos basálticos y andesíticos; A2: Arco evolucionado, detritos félsicos y plutónicos (Spalletti et al., 2008).

En la Figura 7.13 se observan dos diagramas (a y b) propuestos por Bhatia (1983). Para ambos diagramas las muestras de la Formación Río Mayer en su sección inferior indican el desarrollo de un margen continental activo. Con posterioridad, dicho margen evoluciona a un arco de isla de característica principalmente continental en la sección superior. Del mismo modo que para los diagramas de la figura 7.12, la mineralogía presente en cada una de las secciones tiene una influencia importante en el contenido de ciertos elementos químicos. En el caso de estos diagramas presentados en la figura 7.13 el contenido de $\mathrm{Fe}_{2} \mathrm{O}_{3}$ está condicionado por la presencia de Clorita (figura 7.5).

Una situación similar a la descripta en el párrafo anterior se puede observar en el diagrama Co-Th-Zr/10 (Bhatia y Crook, 1986; figura 7.14a). Las muestras de la sección inferior se encuentran cercanas al campo de margen continental activo, mientras que las secciones media y superior poseen afinidad de arco de isla, pero en contraste con los diagramas de Bhatia (1983; figura 7.13), el arco de isla es oceánico.

En la figura 7.14b se presenta el diagrama Hf- Rb/10- Ta*3 (Pearce et al., 1984), el cual es menos discriminativo de ambientes con respecto a los anteriores. En este, todas las muestras analizadas para esta unidad se ubican en el campo de arco volcánico.

El uso de elementos traza en los esquemas representados en la figura 7.14 mejoraría la discriminación del ambiente tectónico, hecho que fuera mencionado con anterioridad por otros autores (entre ellos Spalletti et al., 2008; Alonso, 2011). Esta observación queda evidenciada en la figura 7.14b, en la cual uno de los vértices del triángulo es el Rb, elemento afín al K. El mayor contenido de illita (principal aporte de K a la sedimentita) en la sección inferior haría suponer que las muestras provenientes de dicha sección deberían estar enriquecidas y por ende cerca del vértice del Rb. Sin embargo esto no se observa, y las muestras de las tres secciones presentan una distribución similar en el diagrama. 
a

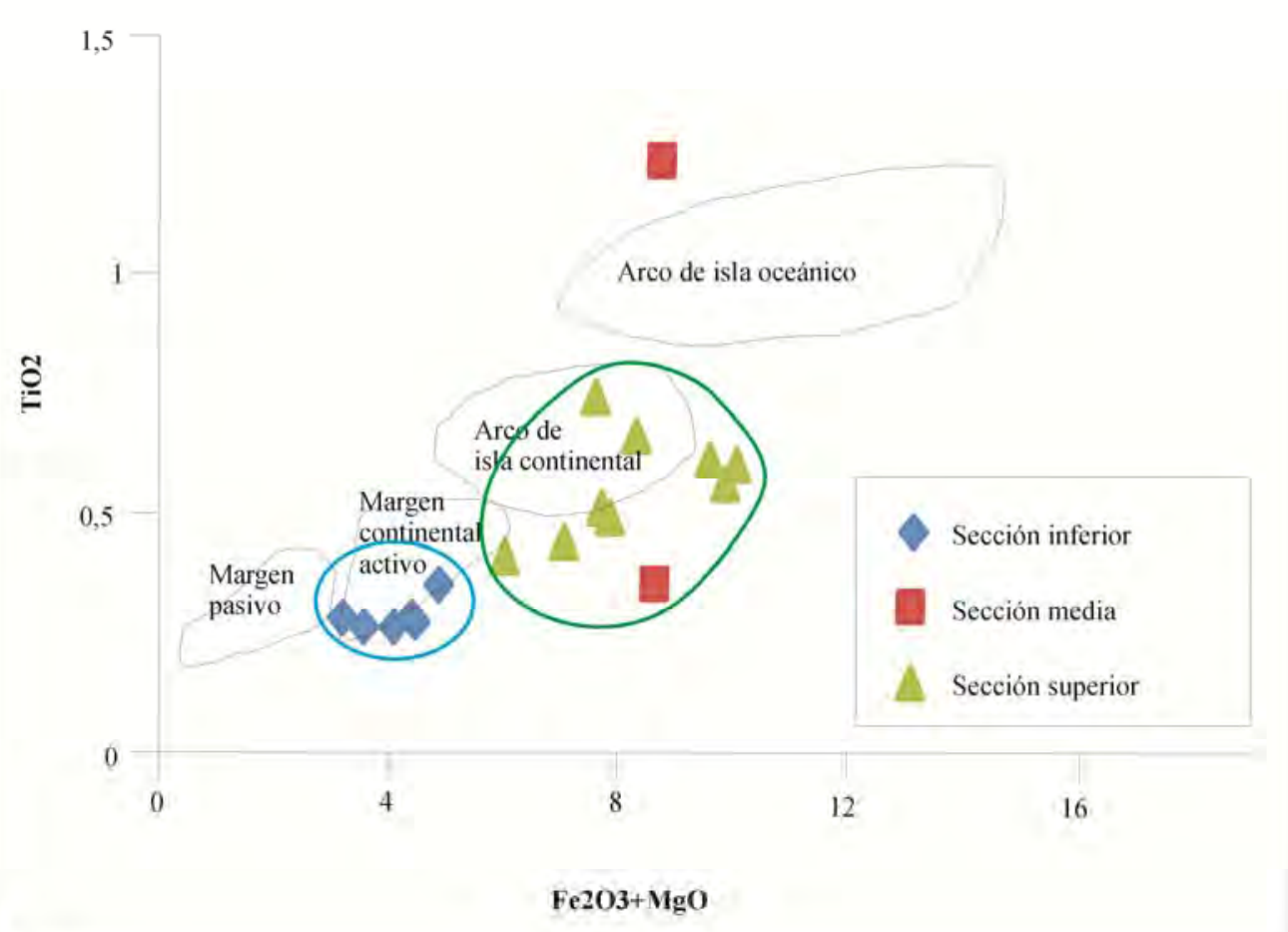

Б

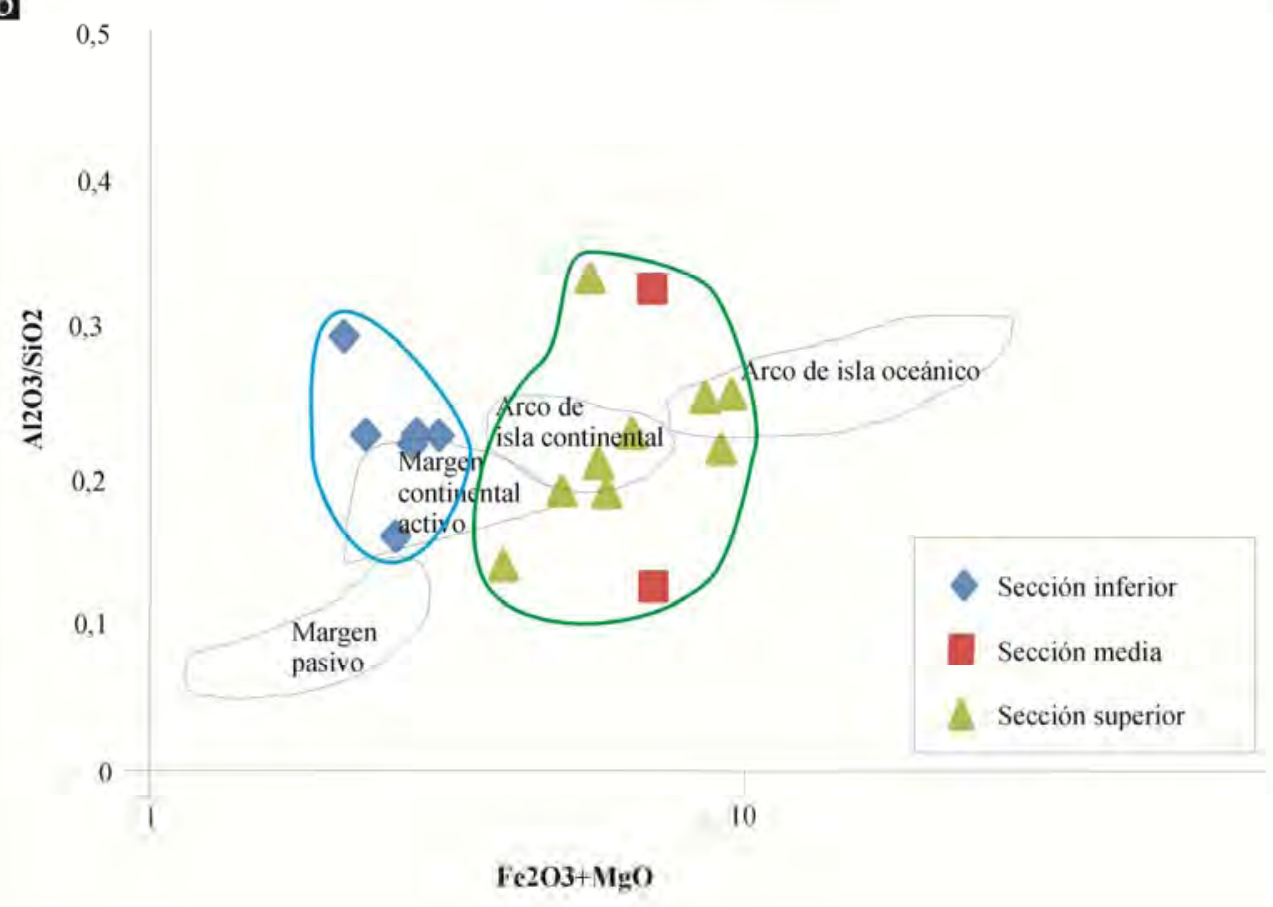

Figura 7.13- Distribución de las muestras analizadas para las tres secciones de la Formación Río Mayer en el área de estudio para discriminación de ambiente tectónico. En a se muestra el diagrama $\mathrm{TiO}_{2}$ vs $\mathrm{Fe}_{2} \mathrm{O}_{3}+\mathrm{MgO}$ (Bhatia, 1983). En b el diagrama $\mathrm{Al}_{2} \mathrm{O}_{3} /$ $\mathrm{Si}_{2} \mathrm{O}$ vs $\mathrm{Fe}_{2} \mathrm{O}_{3}+\mathrm{MgO}$ (Bhatia, 1983). 


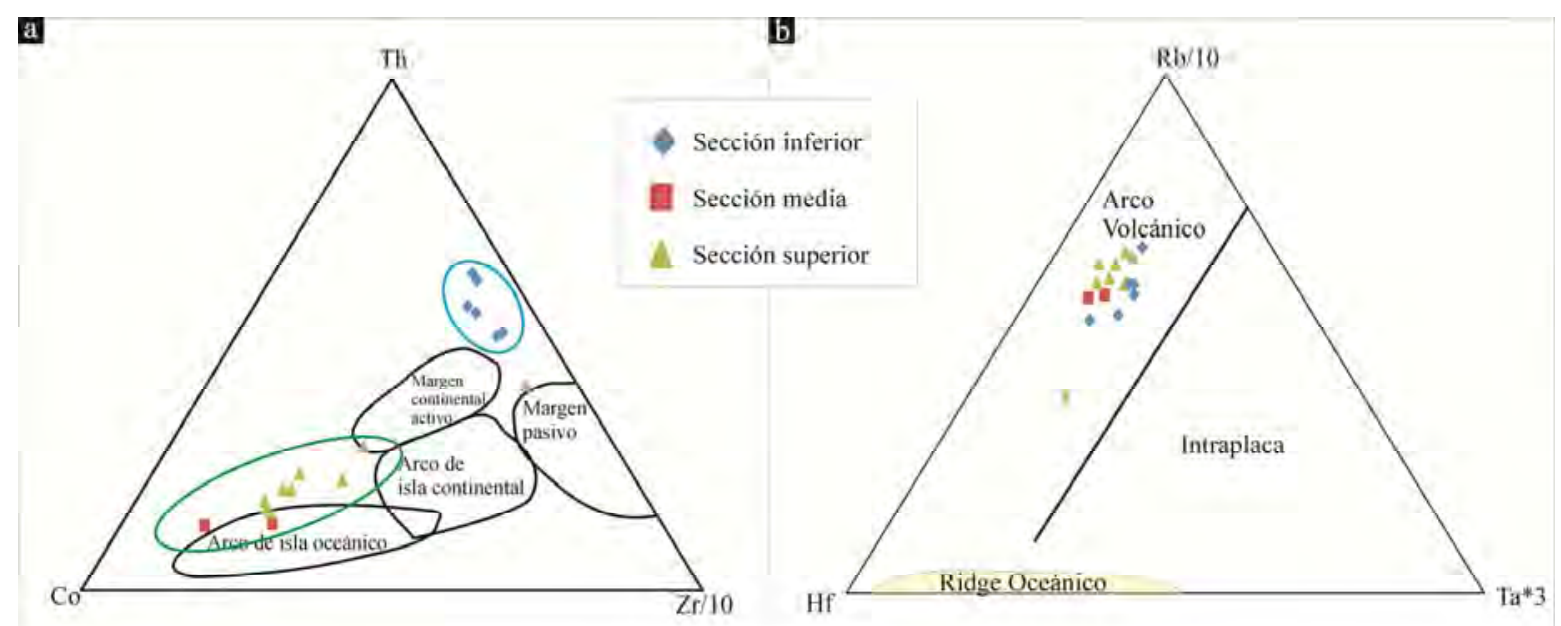

Figura 7.14- Distribución de las muestras analizadas para las tres secciones de la Formación Río Mayer en el área de estudio para discriminación de ambiente tectónico. En a se muestra el diagrama Co-Th-Zr/10 (Bhatia y Crook, 1986). En b el diagrama HfRb/10- Ta*3 (Pearce et al., 1984).

\section{2.7 - Tierras raras}

Los elementos de las Tierras Raras (conocidos como REE, sigla que se desprende de su nombre en inglés “Rare Earth Elements”) se consideran altamente confiables para la determinación de la proveniencia de rocas sedimentarias debido a que se transfieren desde la roca fuente a los sedimentos de la cuenca sin que exista un fraccionamiento (Taylor y McLennan, 1985; Alonso, 2011).

Se compararon los valores promedio de REE de las tres secciones de la unidad estudiada con los valores de pelitas promedio a nivel mundial, que son:

1- NASC: North American Shale Composite (Gromet et al., 1984).

2- ES: Average European Shale (Haskin y Haskin, 1966).

3- PAAS: Post-Archaean average Australian sedimentary rock (McLennan, 1989).

Para tal fin se procedió a la normalización de los valores de los elementos REE de las muestras de la Formación Río Mayer y de las tres pelitas mencionadas utilizando los valores condrito propuestos por Boynton (1984). Estos resultados se observan en la Figura 7.15 a, b, c. 

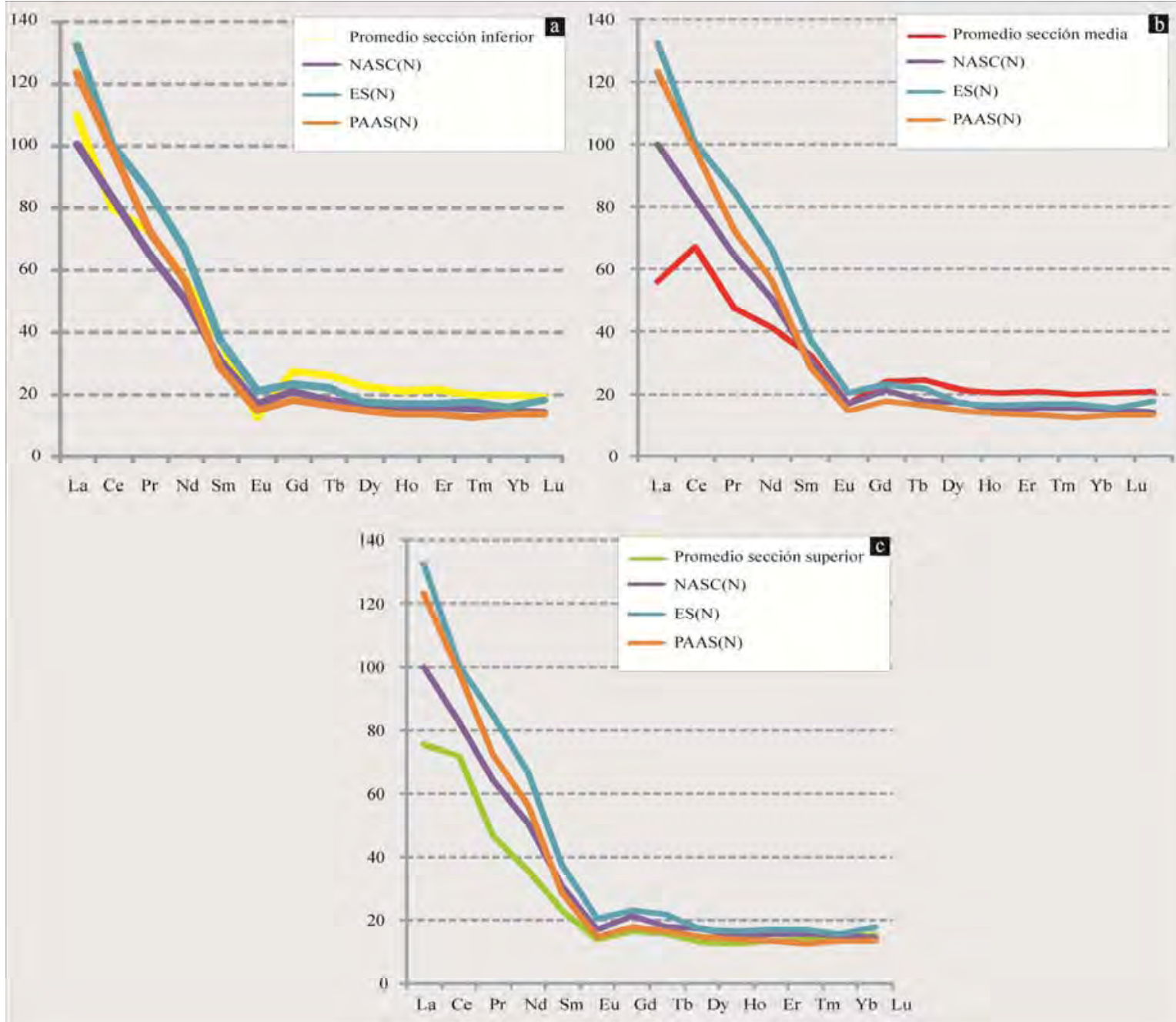

Figura 7.15- Distribución de los valores REE normalizados (condrito -según Boynton, 1984- ), analizados para las tres secciones de la Formación Río Mayer en el área de estudio (diagramas a, b, c) comparados con los patrones NASC, ES y PAAS también normalizados $(\mathrm{N})$.

En la sección inferior (figura 7.15a), los valores de tierras raras son parcialmente similares a los de la NASC y a los de PAAS para los elementos de las tierras raras livianas ó LREE (light rare earths elements; La, Ce, Pr, Nd, Sm, Eu), mientras que está enriquecida en elementos de las tierras raras pesadas ó HREE (heavy rare earths elements; Gd, Tb, Dy, Ho, Er, Tm, Yb, Lu). Por otro lado, la sección media de la Formación Río Mayer (figura 7.15b) está empobrecida en LREE con respecto a los tres patrones de comparación y posee valores levemente mayores en cuanto a HREE. Finalmente, la sección superior se encuentra 
siempre por debajo de los valores promedio de las pelitas NASC, ES y PAAS, tanto para LREE como para HREE (figura 7.15c).

En la figura 7.15d se graficaron los contenidos normalizados (condrito) de algunos elementos de las REE seleccionados para las tres secciones de la unidad estudiada a fin de compararlas con las probables rocas fuente de los sedimentos de la Formación Río Mayer y con las formaciones Zapata, Punta Barrosa y Cerro Toro de la cuenca de Rocas Verdes/Magallanes (Fildani y Hessler, 2005). Además en la misma figura se comparó estos mismos patrones de REE con los obtenidos por Pankhurst y Rapela (1995) y Páez et al. (2010) para rocas volcánicas jurásicas provenientes del Macizo del Deseado.

De la mencionada figura se desprende que la sección inferior tiene afinidad con la serie Tobífera (Complejo El Quemado) de composiciones félsicas y con las rocas principalmente riolíticas inalteradas del Macizo del Deseado (Complejo Volcánico Bahía Laura). En cuanto a las secciones media y superior, éstas se encuentran entre las composiciones ácidas a intermedias (figura 7.15d arriba) y se asemejan al patrón observado por Páez et al. (2010) para las rocas riolíticas alteradas por metasomatismo potásico en el Macizo del Deseado. Además, ambas secciones siguen un patrón similar al observado por Fildani y Hessler (2005) para las formaciones Punta Barrosa y Cerro Toro. Por otro lado, la Formación Zapata que posee afinidad con las ofiolitas del Complejo Sarmiento se diferencia mucho de la Formación Río Mayer.

Las comparaciones de la Formación Río Mayer con las diferentes unidades de la Cuenca de Rocas Verdes/Magallanes serán tratadas con mayor detalle en el capítulo IX. 


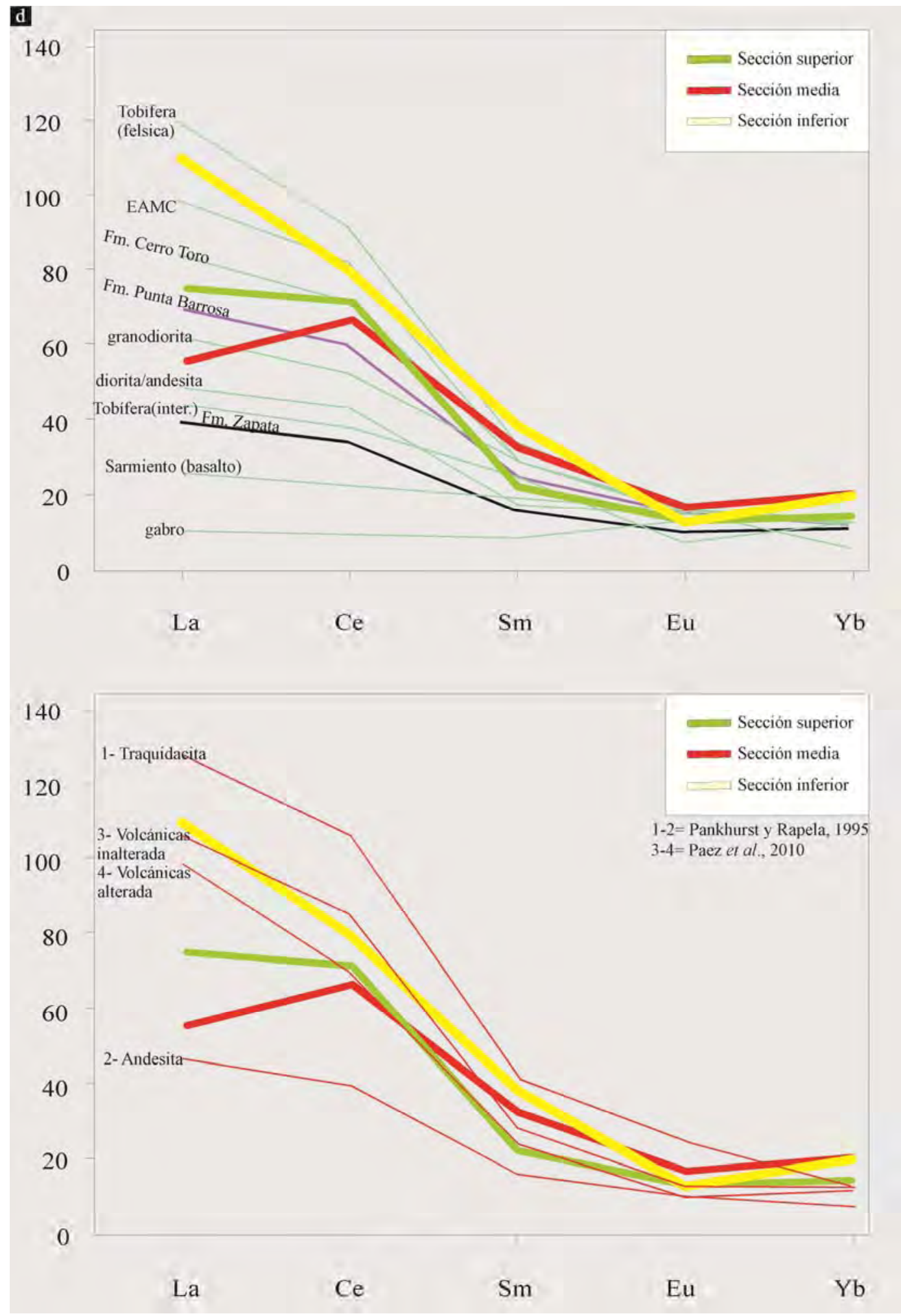

Figura 7.15 continuación- Distribución de los valores REE normalizados para las tres secciones de la Formación Río Mayer. Arriba se compara la distribución de algunos elementos REE seleccionados para cada una de las secciones estudiadas en la Formación 
Río Mayer con las Formaciones Zapata, Punta Barrosa y Cerro Toro de la Cuenca de Rocas Verdes (Chile). Además se comparan con las posibles rocas fuente de los sedimentos en esta región Patagónica: Formación Tobífera (composiciones félsica e intermedia); EAMC: Complejo metamórfico del este de los Andes; Batolito Patagónico (granodiorita, diorita/andesita, gabro); Basaltos de la Ofiolita Sarmiento (tomado y modificado de Fildani y Hessler, 2005). En la figura de abajo la comparación es realizada con las rocas volcánicas del Macizo del Deseado obtenidas por Pankhurst y Rapela (1995) y Páez et al. (2010).

Finalmente, para la determinación de proveniencia se compararon los valores de $\mathrm{Nb}$ y Zr de la Formación Río Mayer con los publicados para la Provincia Volcánica del ChonAike por Pankhurst et al. (1998). Estos autores concluyen que las unidades volcánicas del Jurásico ubicadas entre el Macizo del Deseado y el Macizo Norpatagónico (Formaciones Chon-Aike y Marifil) poseen más de 20 ppm de Nb y más de 350 ppm de Zr, mientras que las vulcanitas del Complejo El Quemado (junto con las Formaciones Tobífera e Ibáñez) se caracterizan por valores bajos de ambos elementos, siempre menores a 20 ppm de Nb y 350 ppm de Zr. Esta característica respondería a la afinidad diferente que poseen estas unidades, las formaciones Marifil y Chon-Aike se corresponden con un vulcanismo de interior continental mientras que el Complejo El Quemado y la Formación Tobífera corresponderían a un arco volcánico (Pankhurst et al., 1998).

En la figura 7.16 se observa claramente que la afinidad de las pelitas de la Formación Río Mayer es con las rocas volcánicas del Complejo El Quemado y en menor medida con la Formación Tobífera. Con lo cual se descartaría un aporte significativo desde el borde este de la cuenca durante la depositación de la unidad estudiada. 


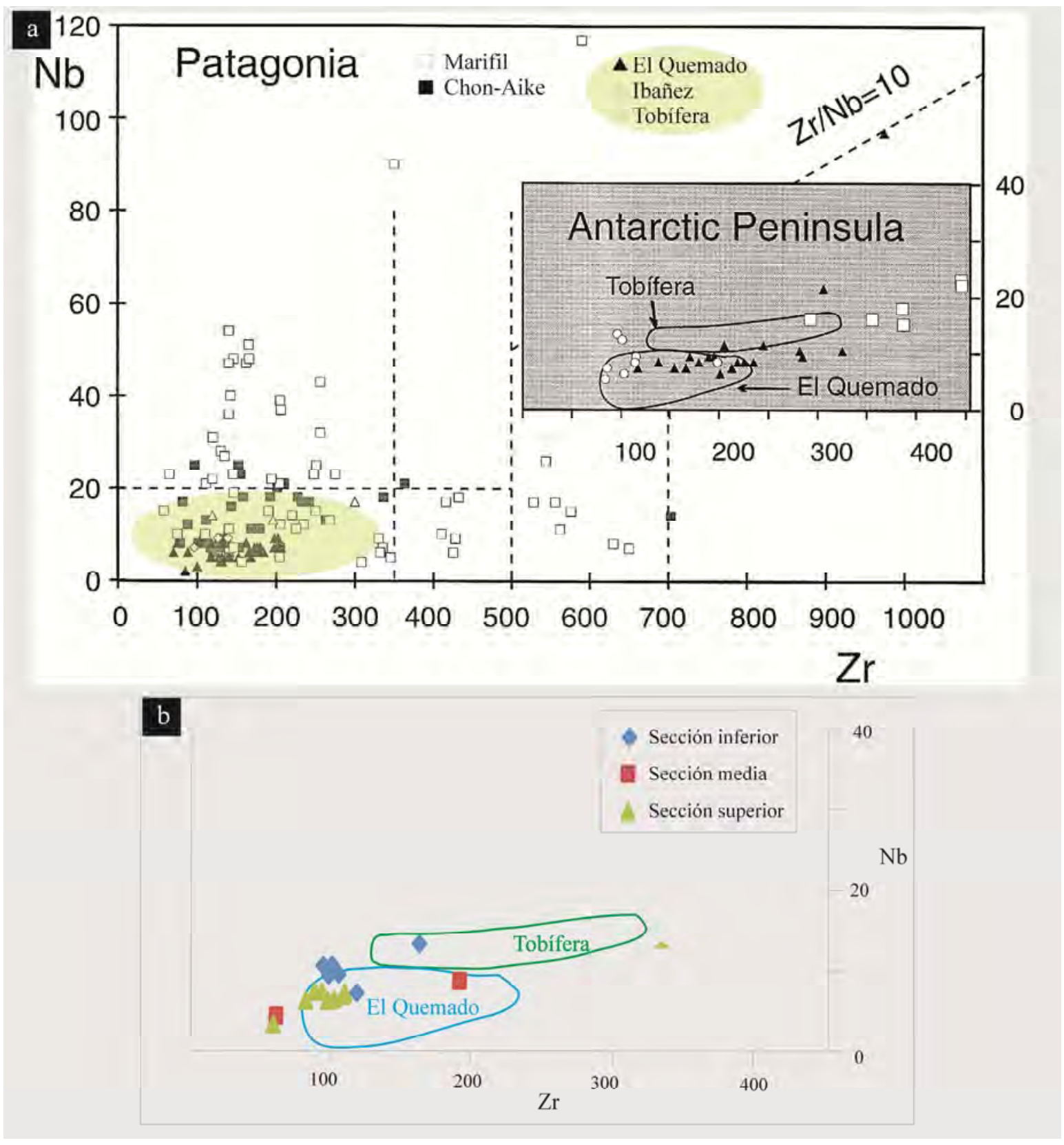

Figura 7.16- En a el gráfico publicado por Pankhurst et al. (1998) en el que se observa una clara distinción entre las composiciones del Complejo El Quemado (más Formaciones Ibáñez y Tobífera) y las de las vulcanitas jurásicas de la región oriental de Patagonia (Formaciones Marifil y Chon-Aike). En el gráfico b se observa la distribución de las muestras de la Formación Río Mayer, las cuales poseen una fuerte tendencia a las composiciones del Complejo El Quemado y en menor proporción con la Formación Tobífera. 
Las anomalías de Ce han sido utilizadas para estimar condiciones reductoras u oxidantes en los paleoambientes sedimentarios (Wright et al., 1987; Bertram et al., 1992; Jarvis et al., 1994; Yang et al., 1999; Mazumdar et al., 1999; Shields y Stille, 2001; Gómez Peral et al., 2010). Esta idea se basa en el estado de oxidación del Ce, ya que este elemento se comporta con valencias +3 y +4 dependiendo de las condiciones del medio en el que se encuentra. Para calcular la anomalía de Ce se utilizó la fórmula propuesta por Elderfield y Graves (1982) que utiliza los valores normalizados (condrito) de Ce, La y Nd y que se expresa por:

$$
\text { Anomalía Ce }=\mathrm{Ce} / \mathrm{Ce}^{*}=\left(3 \mathrm{Ce}_{\mathrm{N}} / 2 \mathrm{La}_{\mathrm{N}}+\mathrm{Nd}_{\mathrm{N}}\right)
$$

Según Shields y Stille (2001), valores de Ce/Ce* mayores a 1,05 describen anomalías positivas, mientras que valores inferiores a 0,95 representan anomalías negativas. Los valores entre 0,95 y 1,05 no son anomalías. Se observaron anomalías de Ce en algunas muestras analizadas, las cuales se grafican en la figura 7.16 en el apartado siguiente (VII.3). Las mismas arrojan anomalías levemente negativas en la sección inferior (0,925 a 0,724) vinculadas a paleoambientes reductores (Zimmermann et al., 2011). En cambio en las secciones media y superior las anomalías de Ce resultaron levemente positivas (1,09 a 1,32), hecho que indica condiciones depositacionales oxidantes en el paleoambiente (Zimmermann et al., 2011). 


\section{3 - Análisis de la Materia Orgánica}

El contenido de Carbono Orgánico Total (COT) es un parámetro muy utilizado en el análisis de secuencias marinas constituidas por pelitas negras. El mismo permite arribar a interpretaciones de diversa índole, como el reconocimiento de potenciales rocas generadoras de hidrocarburos, como así también es un buen indicador de eventos marinos anóxicos, tanto de escala local como regional y hasta global, también se lo ha empleado en estudios de estratigrafía secuencial (Creany y Passey, 1993; Stein, 2007; Mutterlose et al., 2009; Negri et al., 2009).

En la formación Río Mayer se realizaron 29 análisis de COT en perfiles de la Seccional Río Guanaco (figura 7.1; tabla 7.e). Se obtuvieron valores de este parámetro con un intervalo de 5 metros de perfil en los afloramientos que así lo permitieron. De esta manera, se generó una curva de variación de COT con buena continuidad (figura 7.17).

En la curva de COT se pueden observar cuatro sectores bien marcados, el primer tramo incluye a la sección inferior de la unidad (muestras IG 9 a IG 44), y en ella se registran los mayores valores de COT, con un máximo de 2,81\%. El segundo tramo se extiende entre las muestras BP1 y PG 30, abarcando casi la totalidad de la sección media de la Formación Río Mayer, con valores de COT que no superan el 0,31\%. Entre las muestras del tope de la sección media y la parte inferior de la sección superior (PG 35 a PG 60) se desarrolla el tercer tramo con un rango de valores de COT que varían entre 0,6 y 1,8\%. Finalmente, la parte superior de la tercera sección poseen los valores más bajos ya que no superan el $0,1 \%$ de COT.

La distribución de los contenidos de COT en los sedimentos de la Formación Río Mayer (figura 7.17) responde en forma coherente con lo observado en las variaciones de la anomalía de Ce. Los mismos señalan que en la sección inferior se registran condiciones reductoras, que posibilitaron la buena preservación de la materia orgánica. Desde la sección media hasta el final de la formación el ambiente se torna oxidante, generando una pérdida del contenido de materia orgánica retenida por el sedimento. Una excepción a este comportamiento se observa en algunas muestras del sector inferior de la sección superior, las cuales poseen valores de COT considerablemente mayores en comparación con los que se encuentran inmediatamente por abajo y por arriba. 


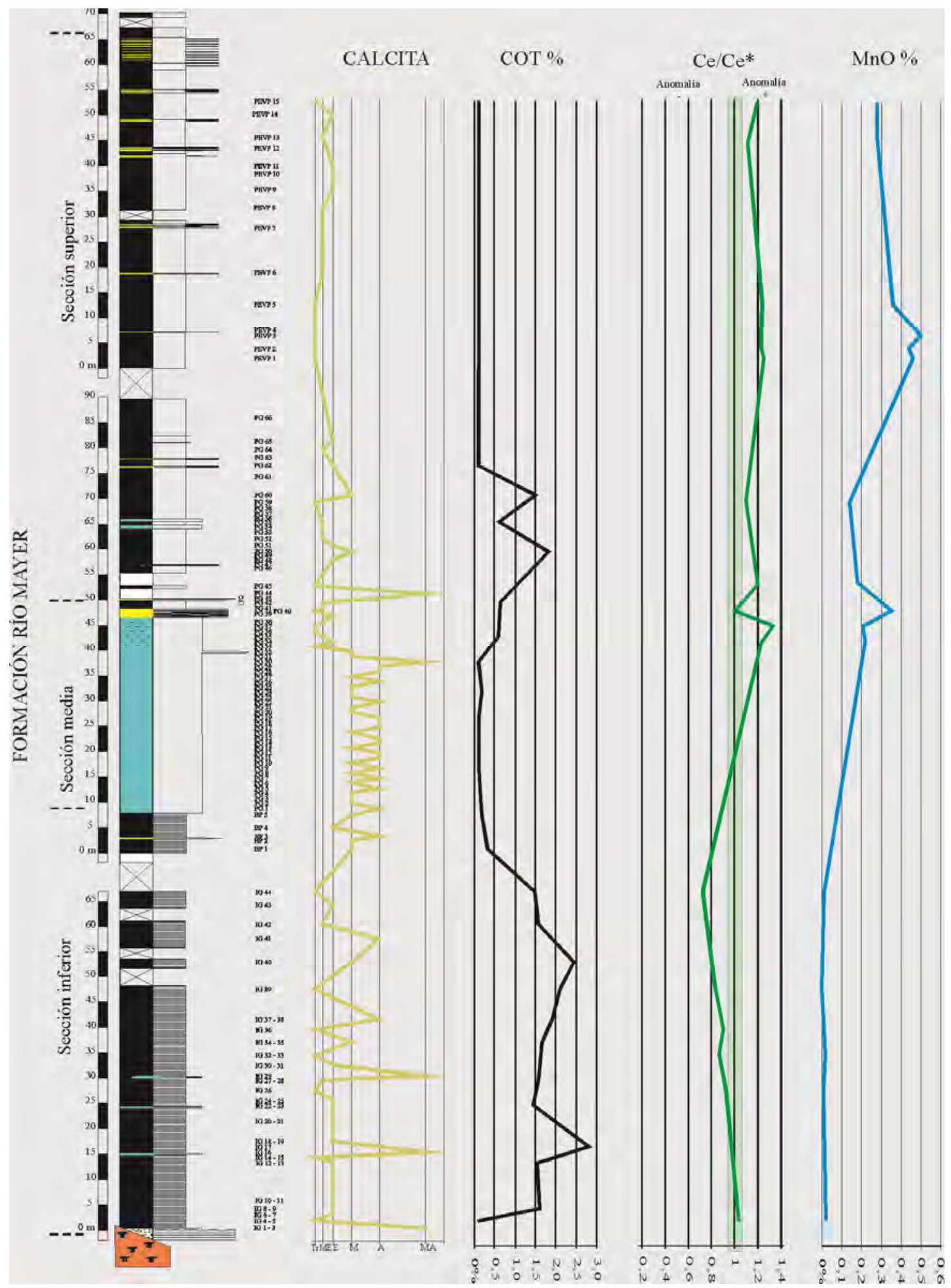

Figura 7.17- Distribución de los valores de COT obtenidos para las muestras de la Formación Río Mayer en la Seccional Río Guanaco. Comparación con los contenidos de Calcita (por DRX- ver capítulo V), la anomalía de Ce (sombreado el rango sin anomalía) y el porcentaje de MnO (análisis geoquímicos). 
Por otro lado, el contenido de $\mathrm{Mn}$ en el sedimento de los fondos marinos está directamente relacionado con la oxigenación del medio (Sagasti, 2001). Cuando las aguas son deficientes de oxígeno el $\mathrm{Mn}^{+2}$ permanece disuelto (Jarvis et al., 2001), mientras que este elemento participa en la composición de los carbonatos en condiciones de mayor oxigenación (Calvert y Pedersen, 1996). En la figura 7.17 quedan bien expuestos los comportamientos de la curva de COT, Ce/Ce* y MnO.

La distribución de las curvas representadas en la figura 7.17 (a excepción de la calcita) será nuevamente tratada en el capítulo VIII, en el cual se discutirán con mayor detalle las condiciones de oxigenación presentes en el paleoambiente de depositación de la Formación Río Mayer (Capítulo VIII.4). 


\section{4 - Isótopos Estables}

Como fuera mencionado en la introducción al presente capítulo, las rocas constituyentes de la Formación Río Mayer se caracterizan por bajos contenidos de carbonatos. A su vez, cuando éstos aparecen suelen estar recristalizados (ver capítulo VI), lo que sugiere que estos niveles fueron afectados por procesos diagenéticos. Para corroborar esta hipótesis se realizaron análisis isotópicos de $\mathrm{C}$ - O (tabla 7.e).

Los efectos de la diagénesis pueden ser descifrados por la variación en los isótopos estables de C-O de las rocas carbonáticas, en el caso particular del isótopo de O las tendencias del mismo suelen ser diagnósticas para entender la interacción con los fluidos diagenéticos (Veizer, 1983; Jacobsen y Kaufman, 1999; Gómez Peral et al., 2007; Knauth y Kennedy, 2009). Las calizas inalteradas poseen valores de $\delta 180$ que se ubican por encima de $-10 \%$. Cuando los valores de este isótopo se encuentran entre -10 y $-14 \%$ son interpretados como levemente modificados por efectos de la diagénesis, mientras que si los valores de $\delta 180$ son menores a $-14 \%$ se consideran muy alteradas (Fölling y Frimmel, 2002).

En la figura 7.18 se observa la distribución a modo de curva de los isótopos estables considerados y el contenido de calcita determinado en las muestras por difracción de rayos X. La curva de $\delta 13 C$ permanece casi invariable, a excepción de un valor muy negativo en la muestra IG2 (Formación Springhill) y un valor positivo en la muestra PG9. El comportamiento de la curva de $\delta 180$ es más irregular, con máximos y mínimos siempre en valores negativos menores a $-13 \%$.

En la figura 7.19 se muestra el diagrama $\delta 13 \mathrm{C}$ vs $\delta 180$. De esta figura se desprende que no existe una tendencia clara ni agrupamiento de muestras en poblaciones que permitan hacer discriminaciones. La unidad analizada posee un rango de valores de $\delta 180$ que van desde -13 a $-16 \%$, con mayoría entre -14 y $-15 \%$. Por otro lado, el $\delta 13 \mathrm{C}$ se ubica en general entre -2 y $-4 \%$. 


\begin{tabular}{|c|c|c|c|}
\hline MUESTRA & СОT \% & $\delta C_{\mathrm{PDB}} \%$ & $\delta O_{\mathrm{PDB}} \%$ \\
\hline IG 2 & & $-14,43$ & $-15,57$ \\
\hline IG 4 & 0,07 & & \\
\hline IG 9 & 1,59 & $-3,24$ & $-13,53$ \\
\hline IG 12 & 1,52 & & \\
\hline IG 16 & & $-7,32$ & $-15,16$ \\
\hline IG 17 & 2,81 & & \\
\hline IG 23 & 1,43 & & \\
\hline IG 27 & 1,56 & & \\
\hline IG 29 & & $-4,4$ & $-15,91$ \\
\hline IG 35 & 1,65 & - & - \\
\hline IG 38 & 1,88 & $-4,35$ & $-15,04$ \\
\hline IG 39 & 2,09 & & \\
\hline IG 40 & 2,44 & $-2,86$ & $-14,15$ \\
\hline IG 41 & & $-3,95$ & $-15,18$ \\
\hline IG 42 & 1,59 & & \\
\hline IG 44 & 1,49 & & \\
\hline BP 1 & 0,31 & $-3,61$ & $-14,44$ \\
\hline BP 5 & 0,17 & $-3,26$ & $-14,36$ \\
\hline PG 5 & 0,13 & $-1,74$ & $-14,44$ \\
\hline PG 9 & 0,09 & 2,06 & $-14,58$ \\
\hline PG 15 & 0,07 & $-2,43$ & $-15,31$ \\
\hline PG 19 & 0,09 & $-1,58$ & $-14,61$ \\
\hline PG 24 & 0,17 & $-1,75$ & $-14,56$ \\
\hline PG 30 & 0,09 & $-3,46$ & $-14,22$ \\
\hline PG 35 & 0,58 & $-3,74$ & $-14,7$ \\
\hline PG 42 & 0,62 & & \\
\hline PG 50 & 1,81 & $-3,75$ & $-14,08$ \\
\hline PG 55 & 0,6 & & \\
\hline PG 60 & 1,48 & $-2,63$ & $-13,27$ \\
\hline \multicolumn{4}{|l|}{ PG 65} \\
\hline PA 1 & 0,09 & & \\
\hline PA 6 & 0,09 & & \\
\hline PA 9 & 0,09 & $-3,41$ & $-14,96$ \\
\hline PA 14 & 0,09 & & \\
\hline
\end{tabular}

Tabla 7.e- Tabla de resultados para los análisis de COT e isótopos estables de C y O en la Formación Río Mayer. La muestra IG2 pertenece a las calizas de la Formación Springhill en los hemigrábenes de Río Guanaco. 


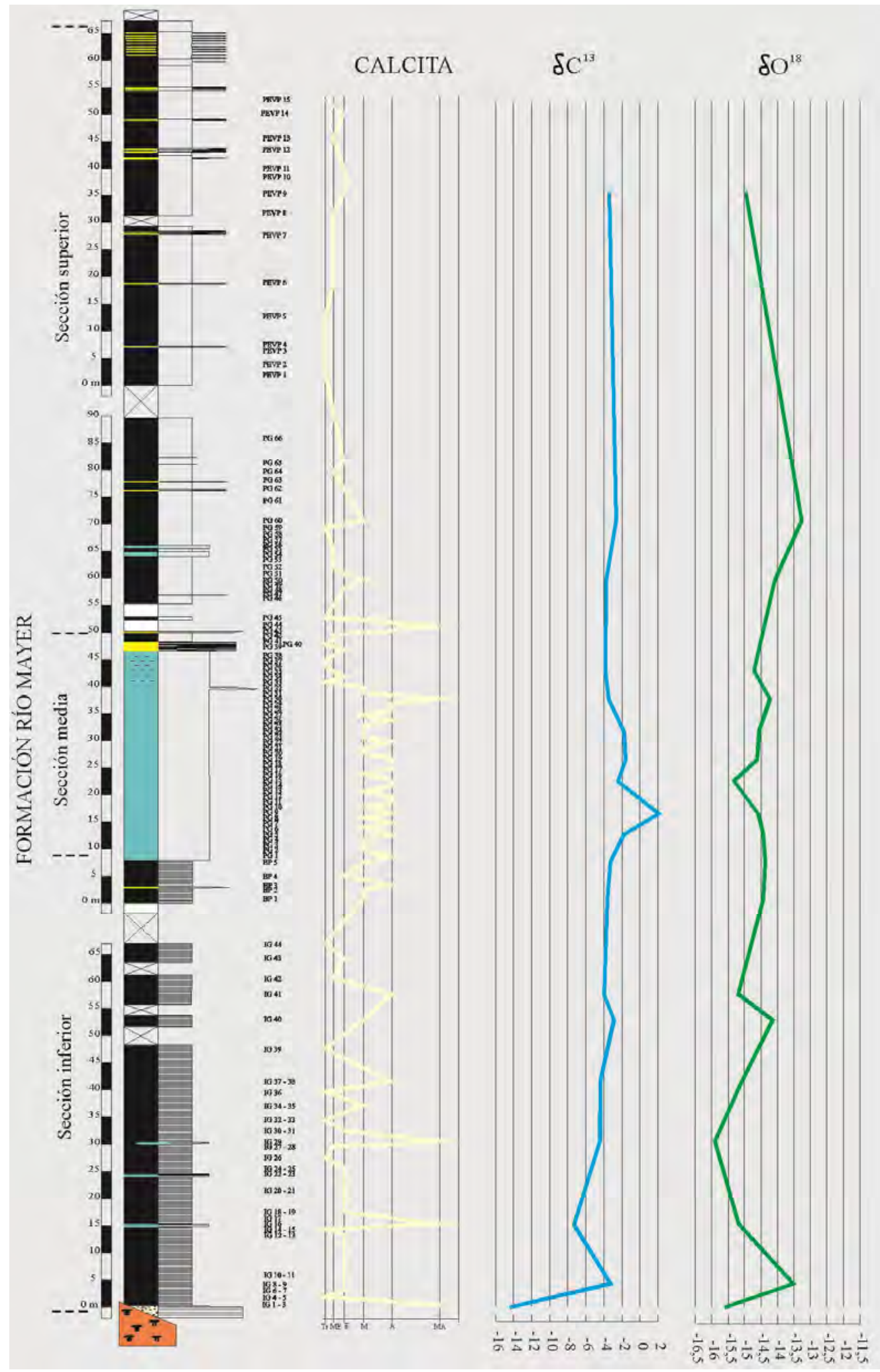

Figura 7.18- Distribución de los valores de isótopos estables de $\mathrm{C}$ y O obtenidos para las muestras de la Formación Río Mayer en la Seccional Río Guanaco. Comparación 
con los contenidos de Calcita (por DRX). La muestra IG2 pertenece a las calizas de la Formación Springhill en los hemigrábenes del complejo El Quemado.

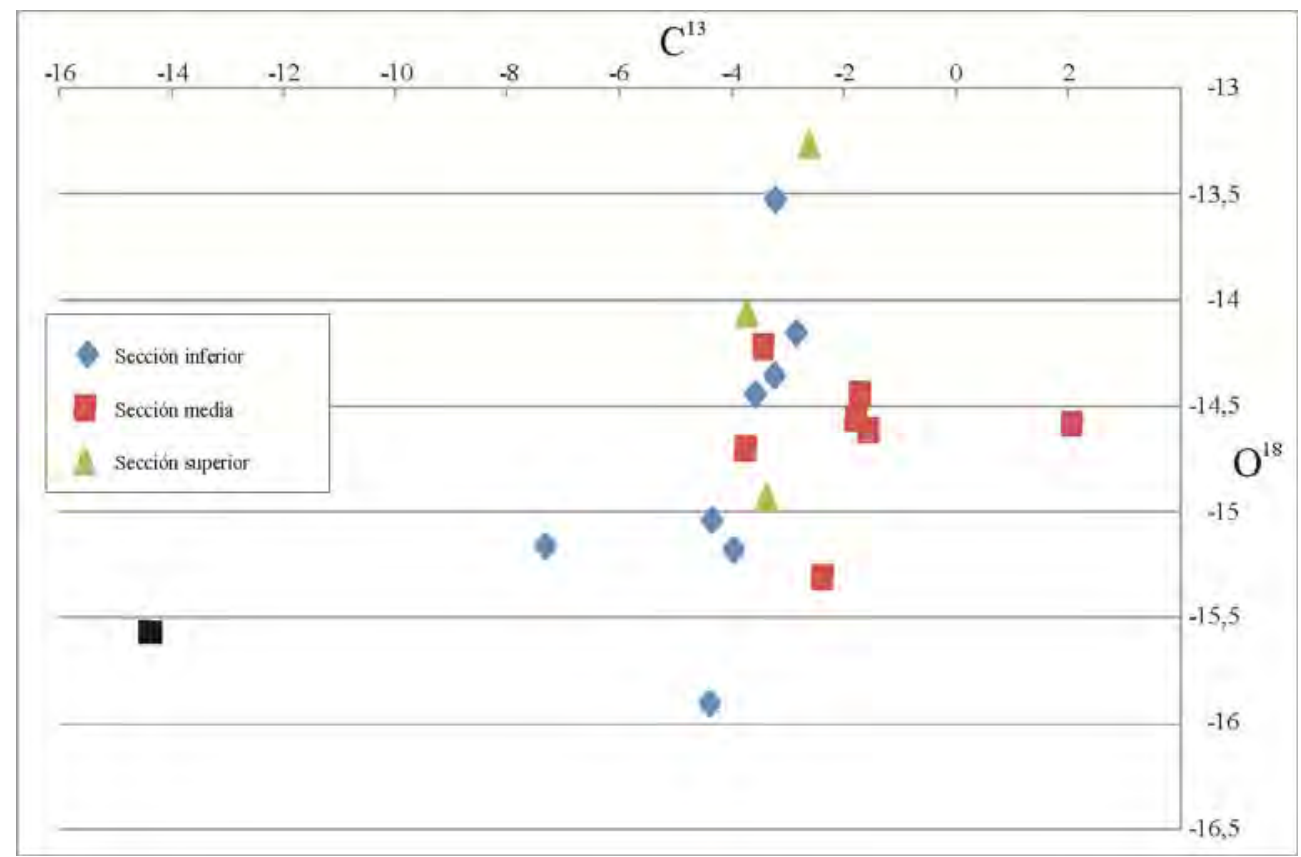

Figura 7.19- Gráfico de distribución de los valores de isótopos estables de $\delta 13 \mathrm{C}$ versus $\delta 180$ obtenidos para las muestras de la Formación Río Mayer en la Seccional Río Guanaco. La muestra IG2 (Formación Springhill) se representa con un cuadrado negro.

El análisis de los isótopos estables permitió confirmar la hipótesis de que los depósitos de la Formación Río Mayer se vieron afectados por modificaciones diagenéticas de índole variable durante el soterramiento. Los valores obtenidos para el $\delta 180$ indican alteraciones desde moderadas a importantes en las muestras (Fölling y Frimmel, 2002), aunque sin una clara tendencia en las secciones reconocidas.

Por otra parte, se puede observar que los valores tanto del isótopo del O como del C varían de manera irregular sin un patrón que los distinga en las tres secciones estudiadas, por lo que se podría asumir que las alteraciones producidas durante los procesos diagenéticos se distribuyeron de manera uniforme en toda la unidad, o dicho en otras palabras afectaron a la misma en su totalidad.

A excepción de una muestra con valor normal esperable del isótopo del C (muestra PG 9 de la sección media), se considera que los valores del isótopo del C también fueron alterados durante el soterramiento. 
Sin embargo, si se considera que toda la unidad estuvo expuesta a condiciones diagenéticas similares, que generaron un cambio en los valores isotópicos en todas las muestras, el valor positivo de la muestra PG 9 toma una dimensión importante. Las muestras provenientes de los perfiles IG y PG se desarrollan en el lapso BerriasianoHauteriviano, y especialmente la sección media de la unidad ocuparía el intervalo entre el Valanginiano y el Hauteriviano inferior. Es justamente en esa edad dónde se registra a nivel mundial una excursión positiva del Carbono (C), que en muchos casos coincide con el OAE (“Ocean Anoxic Event”) denominado “Weissert” (Erba et al., 2004). Esta excursión positiva del C se registra en ambientes marinos y continentales (e.g. Lini et al., 1992; Weissert et al., 1998; Gröcke et al., 2005; Duchamp-Alphonse et al., 2007) y en diferentes lugares del mundo (Fozy et al., 2010). En Argentina este suceso fue documentado en la Cuenca Neuquina por Aguirre-Urreta et al. (2008). La razón por la que este evento se produjo es aún tema de debate y contrastan dos modelos climáticos, uno que estima un aumento en las temperaturas globales y otros modelos que ponderan ciertas evidencias que indicarían climas más fríos durante este evento valanginiano (Fozy et al., 2010). Uno de los factores más citados como razón de este aumento en el contenido de carbono, y de un cambio significativo en el “Sistema Tierra”, es el desarrollo de la provincia volcánica de ParanáEtendeka (Erba et al., 2004; Fozy et al., 2010).

En la figura 7.20 se observa una tentativa correlación entre la curva desarrollada por Weissert et al. (1998) para la región del Tethys y la curva generada en este trabajo. Cabe aclarar que el marco bioestratigráfico con el cual se trabaja actualmente en la Cuenca Austral es muy pobre en comparación con otras cuencas (por ejemplo Cuenca Neuquina), por tal razón, esta hipótesis debe ser probada con un mayor muestreo de material fósil y un mayor número de análisis isotópicos. 


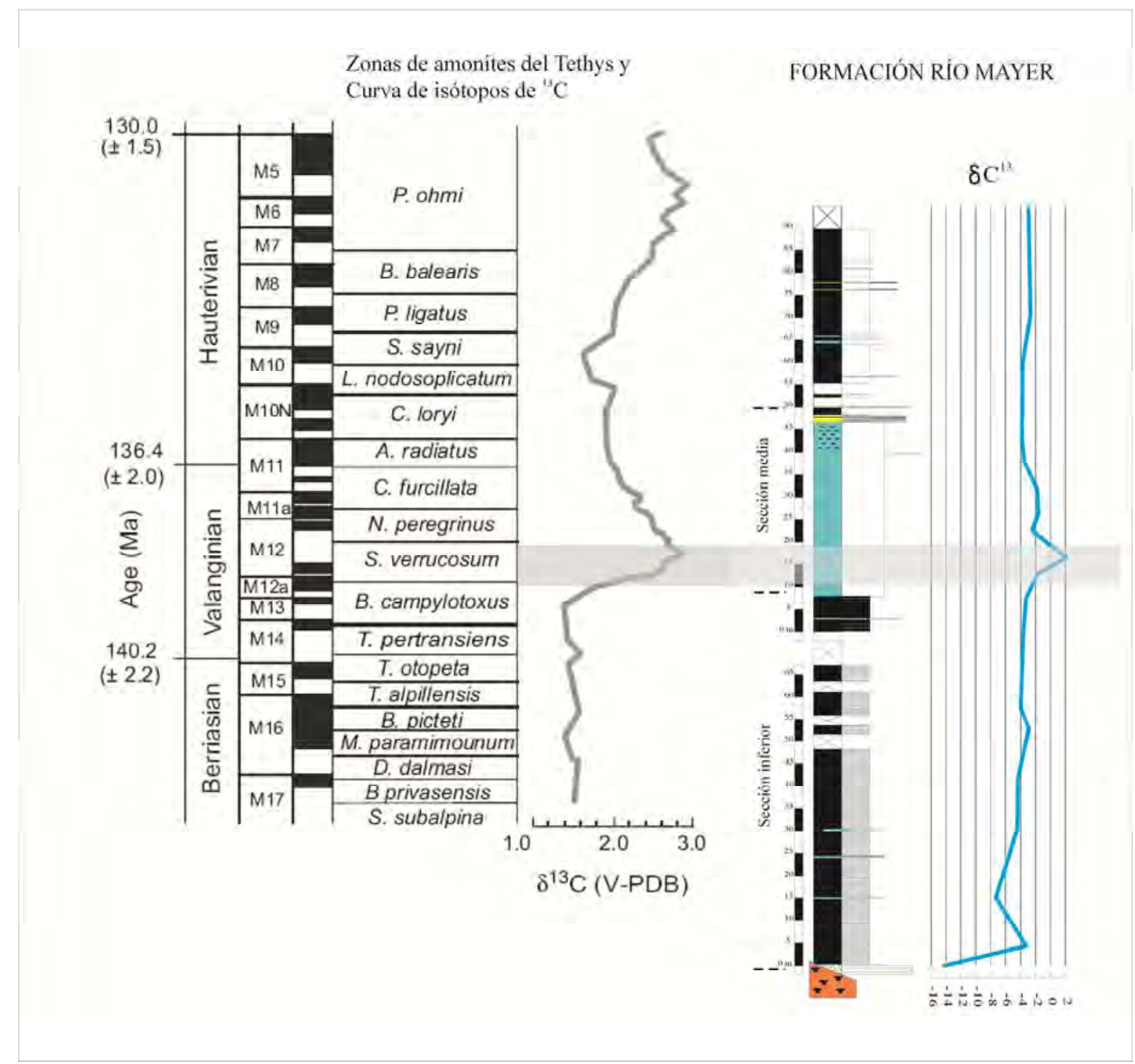

Figura 7.20- Comparación de las curvas de isótopos estables de $\delta 13 \mathrm{C}$ obtenidos para las muestras de la Formación Río Mayer en la Seccional Río Guanaco y los expresados por Weissert et al. (1998) para la región del Tethys. La posible correlación de la excursión positiva del Carbono durante el Valanginiano se presenta con un sombreado gris. (Tomado y modificado de Aguirre Urreta et al., 2008). 


\section{5 - Consideraciones finales sobre los aspectos geoquímicos}

Del tratamiento geoquímico de las muestras de la Formación Río Mayer se desprenden algunas interpretaciones a tener en cuenta:

Las tres secciones determinadas a partir del trabajo de campo poseen similar signatura geoquímica, respecto de los elementos mayoritarios y minoritarios, con algunas discrepancias. Estas diferencias reconocidas pueden ser explicadas por los cambios en la mineralogía de la roca, en especial los contenidos de arcillas.

La presencia de illita en las muestras enriquece los contenidos de $\mathrm{Al}_{2} \mathrm{O}_{3}$ y $\mathrm{K}_{2} \mathrm{O}$, mientras que la participación de clorita aporta importantes cantidades de $\mathrm{Fe}_{2} \mathrm{O}_{3}$.

De las 17 muestras analizadas en la unidad estudiada trece se ubican en el campo de los vaques de la clasificación geoquímica de Herron (1988) y apenas dos en el campo de las lutitas y otras dos están enriquecidas en Fe y son areniscas férricas.

El grado de meteorización es en general moderado, reconocido mediante el cálculo de varios indicadores y no se aleja del comportamiento esperado para rocas pelíticas.

Desde el punto de vista de la proveniencia los diagramas utilizados, basados tanto en elementos mayoritarios, minoritarios como elementos traza y tierras raras, muestran en general una tendencia evolutiva desde composiciones ácidas en la sección inferior a ácidaintermedia en las secciones media y superior. De igual modo las tierras raras avalan esta observación. Todas las muestras analizadas poseen afinidad con las rocas volcánicas del Complejo El Quemado y con la Formación Tobífera, con lo cual el aporte desde la Dorsal de Río Chico (borde nororiental de la Cuenca Austral) habría sido mínimo durante la depositación de la Formación Río Mayer.

El ambiente tectónico en el cual se depositaron las muestras estaría representado entre el margen continental activo y arco volcánico de diferentes características. En general la mayor parte de los diagramas dan resultados similares, sin embargo en algunos el ambiente es de margen pasivo y la razón es la participación de ciertos elementos mayoritarios (K, Fe) que están condicionados por la presencia de arcillas (illita y clorita).

La mayor parte de la sección inferior y media de la Formación Río Mayer se habrían desarrollado durante el Valanginiano. Cabe considerar que las sucesiones de pelitas negras representadas en este período son intensamente estudiadas debido a que algunos autores han postulado que las condiciones ambientales de este período serían similares a las 
actuales, con lo cual podría aplicarse como un análogo para estudiar los actuales cambios climáticos (Westermann et al., 2010; Duchamp-Alphonse, et al., 2011). De este modo el potencial futuro para estudiar con mayor detalle los aspectos geoquímicos de esta unidad resulta importante.

El análisis de los isótopos estables de O y C permitió corroborar las observaciones realizadas por petrografía, y confirmar que las rocas de la Formación Río Mayer están en mayor o menor medida alteradas diagenéticamente. Estas modificaciones se observan en los valores anormalmente bajos (muy negativos) de $\delta 180$, que posee un comportamiento similar en toda la unidad, lo que significaría que toda la formación se vio homogéneamente afectada por los efectos diagenéticos. El $\delta 13 \mathrm{C}$ indicaría que la diagénesis afecto a este isótopo de la misma manera, sin embargo se pudo registrar una tendencia positiva en la sección media de la unidad que podría correlacionarse con el evento Weissert. 


\section{Capítulo VIII - Estudio de las Estructuras Sedimentarias Orgánicas}

\section{VIII.1 - Introducción}

Las estructuras sedimentarias orgánicas representan evidencias de la interacción entre los organismos vivientes y el sustrato en el que habitan. La disciplina que estudia estas estructuras se denomina icnología, y se basa en el reconocimiento de las perturbaciones realizadas por los organismos en el sustrato. El análisis icnológico permite el reconocimiento de aspectos paleoambientales que complementan la información recuperada de las tareas sedimentológicas.

Se identificó en la Formación Río Mayer una importante icnofauna, sobre la cual muy poco se conocía previamente. Si bien el contenido fósil de esta unidad es ampliamente descripto en la bibliografía, las estructuras sedimentarias orgánicas que en ella se desarrollan son sólo eventualmente citadas en los trabajos realizados en esta formación. Entre las contribuciones previas que hacen mención a estas estructuras en la Formación Río Mayer cabe citar a Aguirre Urreta (1981) y a Medina et al. (2008). En el primer caso la autora cita la presencia de troncos con Teredolites en la Formación Río Mayer en la localidad de estancia La Vega. En el segundo trabajo los autores citan la presencia de Chondrites, Planolites, Thalassinoides y Zoophycos en la Formación Río Mayer en la región del Lago Cardiel (60 km al este del Lago San Martín). En ambos trabajos la edad de los depósitos es Aptiano-Albiano, y se encuentran en la transición hacia la Formación Piedra Clavada.

Se describieron un total de ocho icnogéneros para esta unidad: Bergaueria, Chondrites, Gyrolithes, Ophiomorpha, Palaeophycus, Teredolites, Thalassinoides y Zoophycos. Posteriormente, se agruparon estos icnogéneros en icnofacies e icnoasociaciones que caracterizan distintos momentos en la evolución paleoambiental de la Formación Río Mayer. A continuación se hará mención de las principales características de estos icnotaxones. 


\section{2 - Icnogéneros reconocidos}

Icnogénero Bergaueria Prantl, 1945

\section{Aspectos generales del icnogénero}

Los ejemplares de Bergaueria suelen aparecer como un semirelieve convexo de forma hemisférica, con paredes lisas, y que puede presentar además una depresión central (B. perata) ó una serie de pequeños tubérculos (B. radiata). Una revisión de este icnogénero fue realizada por Pemberton et al. (1988).

Este icnogénero se halla representado desde el Precámbrico hasta el Eoceno, con una mayor participación durante el Paleozoico inferior (Pemberton et al., 1988; Seilacher et al., 2005), tanto en ambientes marinos someros como profundos (Hofmann et al., 1994; Buatois et al., 2009, entre otros). Se lo ha interpretado dentro de la clasificación etológica de Seilacher como Cubichnia (descanso) y Domichnia (habitación) (Pickerill, 1989; Aceñolaza y Nieva, 2003).

\section{Bergaueria perata Prantl, 1945.}

Material recuperado: Observación de campo más 1 ejemplar (figura 8.1).

Descripción: Se presenta como un semirelieve convexo de paredes lisas, con forma hemisférica de unos 2,1 a 2,3 centímetros de diámetro. Levemente desplazada del centro posee una depresión subcircular de 0,7 a 0,9 centímetros de diámetro, que en uno de los ejemplares tiene en su interior una pequeña elevación cilíndrica de 0,3 centímetros de diámetro. Se asignó el nombre icnoespecífico siguiendo la descripción de Pemberton et al., 1988.

Observaciones: Los ejemplares provienen del cerro Pintado (figura 3.8) en la seccional Río Guanaco, en cercanías del perfil PG. Uno de los ejemplares presenta marcas reticuladas y radiales a la traza, de una extensión entre 1,5 y 6 centímetros. Dichas marcas no se continúan en el interior del estrato y poseen, en ocasiones, sección subcircular. El origen de dichas marcas es dudoso. Si bien la forma y distribución se asemejan a la potencial impresión del cuerpo de una anémona, su posible origen inorgánico es también considerado. 


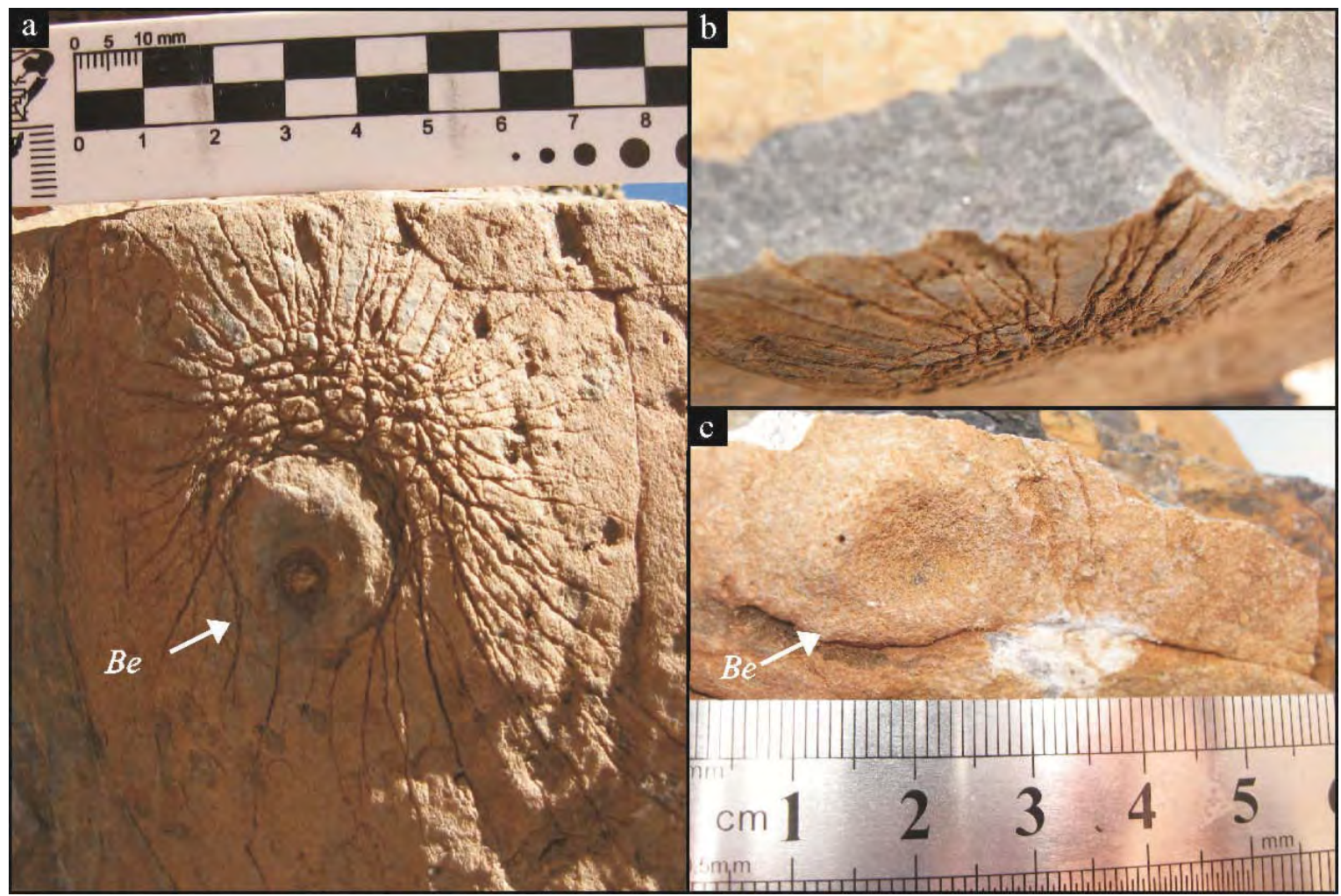

Figura 8.1- Ejemplares de Bergaueria perata Prantl, 1945. Material recuperado en el Cerro Pintado de la Seccional Río Guanaco, en cercanías del perfil PG (ver figura 3.8). En a ejemplar de $B$. perata con marcas asociadas y en b el corte transversal de la roca donde se observa que las marcas son superficiales y no se continúan hacia adentro del estrato. Otro ejemplar de Bergaueria en la foto c.

\section{Icnogénero Chondrites von Sternberg, 1833}

\section{Aspectos generales del icnogénero}

Este icnogénero es uno de los más frecuentemente citados en literatura icnológica (Uchman y Wetzel, 1999) y se caracteriza por presentar un patrón dendrítico de túneles que no se cortan entre si y se ramifican en ángulos variables. El tamaño en general de los túneles oscila entre 0,5 a $5 \mathrm{~mm}$. Se asume que el organismo productor es algún tipo de gusano, el cual suele cavar hasta niveles profundos desde la interfase agua-sedimento. Si bien es un componente frecuente en ambientes marinos de variadas características, se considera que este icnogénero representa bajo determinadas circunstancias anoxia en el paleoambiente (Bromley y Ekdale, 1984). En general, dicha interpretación se realiza cuando los Chondrites aparecen como único icnogénero en la roca. 
La mayor parte de los especímenes pueden ser catalogados dentro de una de las cuatro especies definidas por Fu (1991) quién realizó una revisión del icnogénero. Sin embargo, algunos ejemplares se alejan de las típicas descripciones y su identificación taxonómica es compleja (Uchman y Wetzel, 1999). Otro aspecto interesante de este taxón es que suele reutilizar trazas previas, ya que en estas estructuras suele haber mayor cantidad de alimento o puede encontrarse con una mayor facilidad para penetrar hasta zonas más profundas. Estas interacciones se conocen como formas compuestas (Chamberlain, 1975; Pickerill y Narbone, 1995). Es común la combinación de Chondrites desarrollados con Planolites y Thalassinoides (Krejci-Graf, 1936; Ehrenberg, 1942; Kennedy, 1967; Ekdale y Bromley, 1984; Fu, 1991; Wetzel, 1991). Otra combinación también citada pero muy poco registrada es con Gyrolithes (Uchman y Wetzel, 1999).

\section{Chondrites isp}

Material recuperado: Una muestra con varios ejemplares más observaciones de campo (figura 8.2).

Descripción: Se presenta como sistemas de pequeños túneles con ramificaciones generalmente en ángulos agudos. Se reconocieron dos morfologías diferentes, un grupo de ejemplares está formado por túneles que miden aproximadamente entre 0,5 y 1,5 milímetros y se distribuyen en un patrón dendrítico. Los túneles de primer orden alcanzan una longitud de unos 2 cm máximos, mientras que los de segundo orden pocas veces superan el centímetro de largo. El segundo tipo morfológico está dominado por túneles de segundo orden que miden aproximadamente entre 1 y 4 milímetros, son rectos a ligeramente curvos en planta y de corto desarrollo (no superan los 2 centímetros).

Observaciones: Se presenta en el perfil PG y Cerro Establo de la seccional Río Guanaco. Los ejemplares recuperados de la Formación Río Mayer podrían corresponder a las icnoespecies C. cf. intricatus (Brongniart, 1823) y C. cf. targinoii (Brongniart, 1828). 


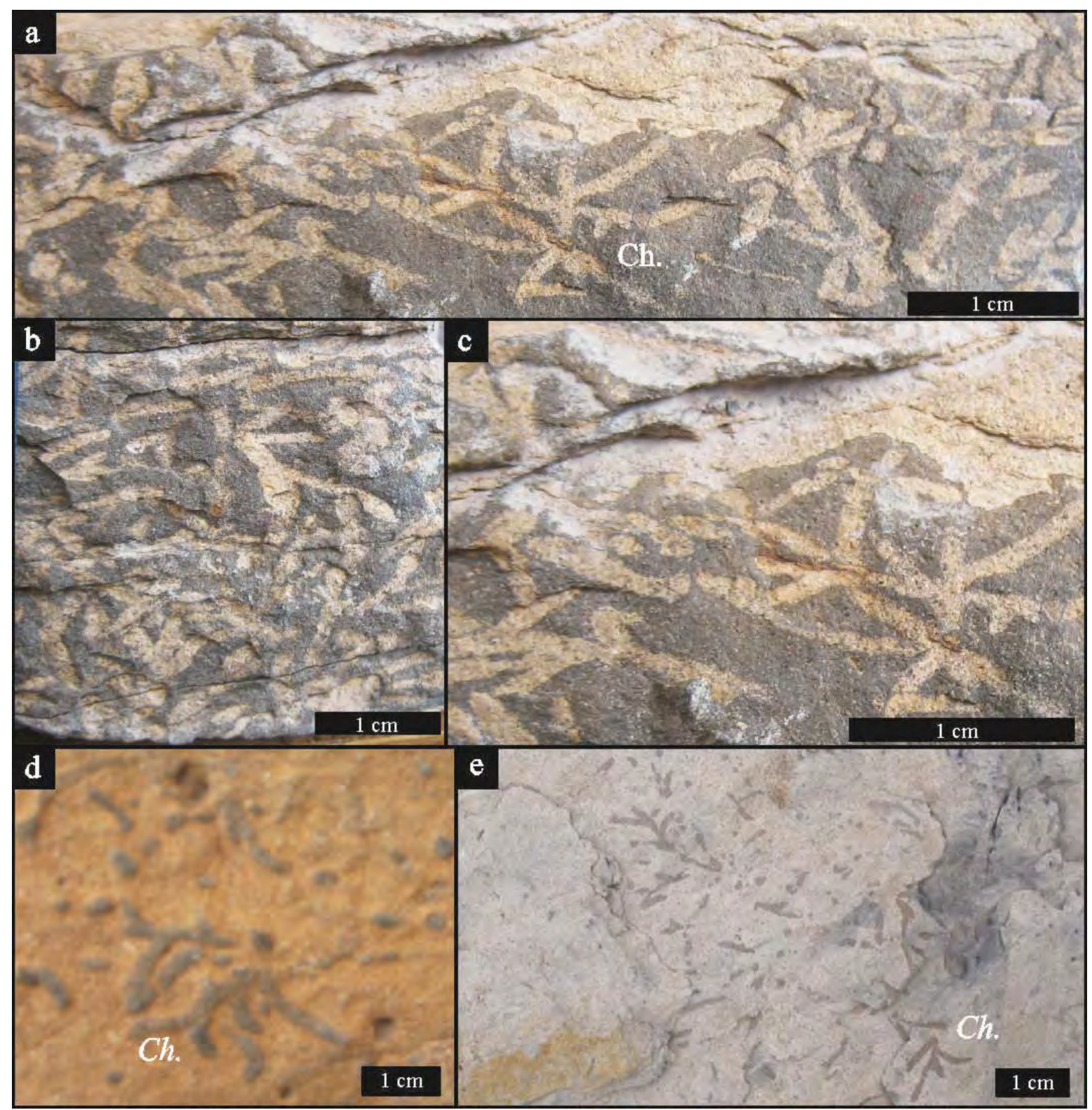

Figura 8.2- Ejemplares de Chondrites isp. Fotos a-d pertenecen al perfil PG y la foto e al perfil CE, ambos perfiles de la Seccional Río Guanaco. 
Icnogénero Gyrolithes de Saporta, 1884

\section{Aspectos generales del icnogénero}

Perforaciones verticales espiraladas perpendiculares al estrato. Se asocia este icnogénero a ambientes marginales con estrés de salinidad (Keij, 1965; Gernant, 1972; Ranger y Pemberton, 1992, 1998; Mayoral y Muñiz, 1993, 1995, 1998; Netto et al., 2007). Es un taxón común en el Mesozoico y Cenozoico con pocas apariciones en el Paleozoico (Netto et al., 2007). Se ha asignado esta traza a la actividad de varios organismos productores entre los que se encuentran principalmente crustáceos decápodos (Gernant, 1972; Bromley y Frey, 1974) y gusanos (Fedonkin, 1980; Hein et al., 1991; Jensen, 1977; Mayoral y Muñis, 1998). La razón por la cual los organismos generan esta perforación posee actualmente dos interpretaciones, primero que sería para que el organismo se proteja de los cambios bruscos de salinidad de los ambientes que habita y segundo que se trate de una estrategia alimenticia (Netto et al., 2007).

\section{Gyrolithes isp.}

Material: Observaciones de campo (figura 8.3).

Descripción: Los ejemplares de Gyrolithes se preservan como endichnias dentro de un nivel arenoso de la unidad. Este icnogénero se presenta en la Formación Río Mayer como pares de muy pequeñas perforaciones de sección circular a subcircular, de diámetro cercano a 1-2 mm, que se disponen de manera alternada en un plano perpendicular a la estratificación. En general, dichas perforaciones se desarrollan de manera recta, aunque también se registraron formas curvas.

Observaciones: se encuentra en el perfil de la Ea. La Vega, de la región entre los lagos Viedma y San Martín en facies de prodelta. 


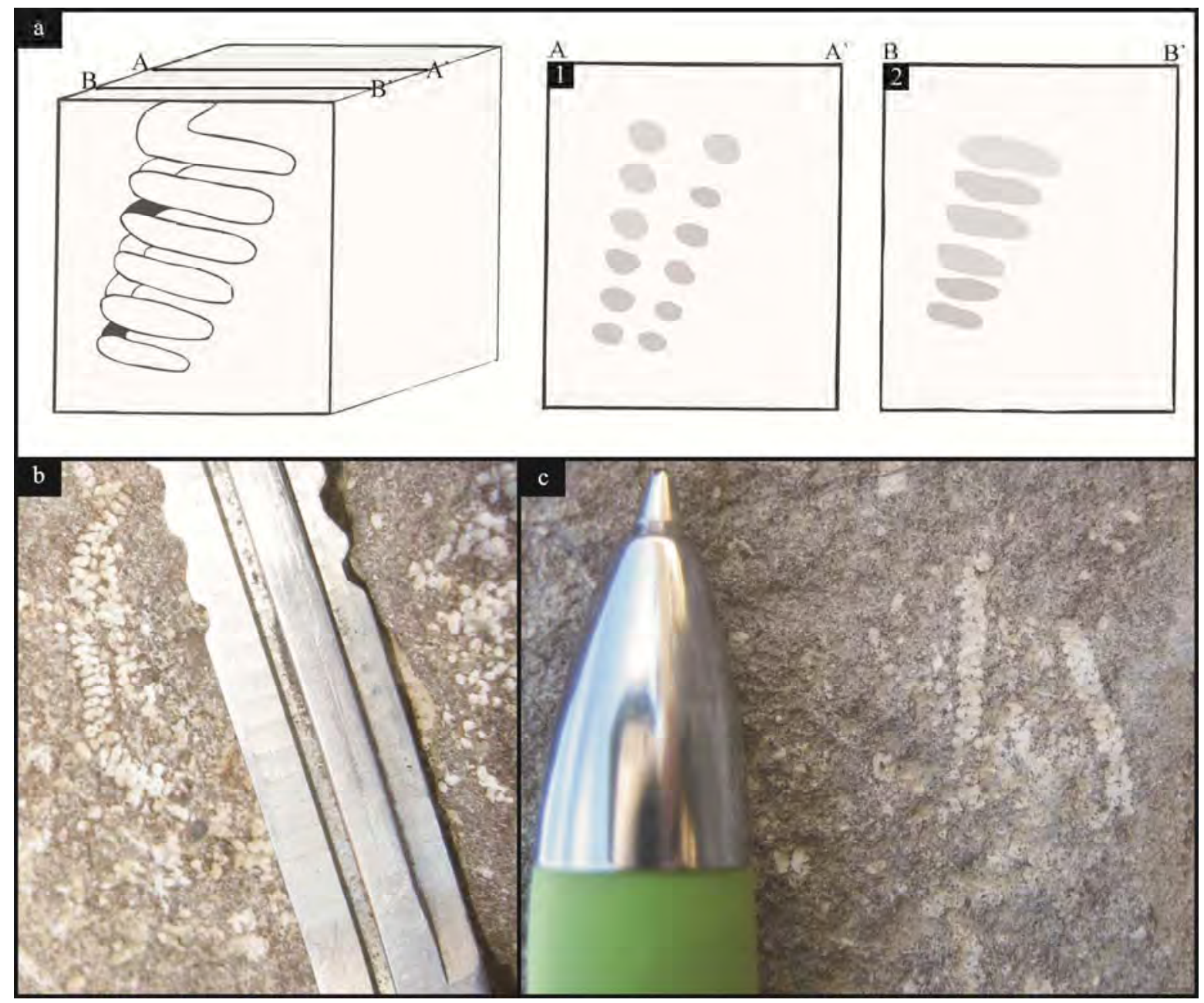

Figura 8.3- Ejemplares de Gyrolithes isp. En a una reconstrucción de las maneras posibles de encontrar este icnogénero (tomado y modificado de Netto et al., 2007), en la Formación Río Mayer se encontró la traza con las disposiciones 1 y 2. Las fotos b y c provienen del perfil ELV, en b se observa un ejemplar del icnogénero levemente curvo, mientras que en c las trazas son rectas (vertical e inclinada). 
Icnogénero Ophiomorpha Lundgren, 1891

\section{Aspectos generales del icnogénero}

Sistema tridimensional de túneles que varían entre 0.5 a $3 \mathrm{~cm}$ de diámetro, y que ocasionalmente pueden penetrar en el sustrato hasta $1 \mathrm{~m}$. Se caracteriza por una superficie interna suave, mientras que la superficie externa suele presentar elementos que refuerzan el tubo, en general pellets, aunque también pueden emplear fragmentos de conchillas o restos de madera entre otros elementos. Esta particularidad de poseer un tubo reforzado es la característica distintiva de este icnogénero.

El organismo productor se asume que es un crustáceo decápodo, más específicamente un callianásido (cf. Weimer y Hoyt, 1964; Frey et al., 1978), sin embargo otros artrópodos también fueron señalados como posibles productores de la traza (Frey et al., 1978).

\section{Ophiomorpha rudis (Ksiąžkiewicz, 1977)}

Material recuperado: Una muestra más observaciones de campo (figura 8.4).

Descripción: la traza corresponde a una exichnia, se presenta como tubos rectos desarrollados en estratos pelíticos rellenos de material más grueso (areniscas), el diámetro puede no ser constante y oscila entre 2 y 3 cm (figura 8.4a) y la extensión puede llegar a 0,5 $\mathrm{m}$ de longitud. El relleno es masivo y generalmente la superficie externa presenta desarrollo de pellets aunque en ocasiones puede presentar pequeños tramos sin reforzar. Posee coloración externa rojiza, lo que indica oxidación. Conforma sistemas de túneles que se comunican con los niveles arenosos por intermedio de chimeneas verticales (figura 8.4b). Las uniones entre los túneles son en general en forma de "Y" (figura 8.4c), en menor medida se observaron uniones en forma de “T”.

Observaciones: Uchman (2009) define la icnosubfacies de Ophiomorpha rudis, la cual se desarrolla tanto en la icnofacies de Zoophycos como en la de Nereites. La presencia de esta icnosubfacies está relacionada con la llegada de sistemas turbidíticos (Uchman, 2009). Sólo se reconoció este icnogénero en el Cerro Establo de la seccional Río Guanaco. 


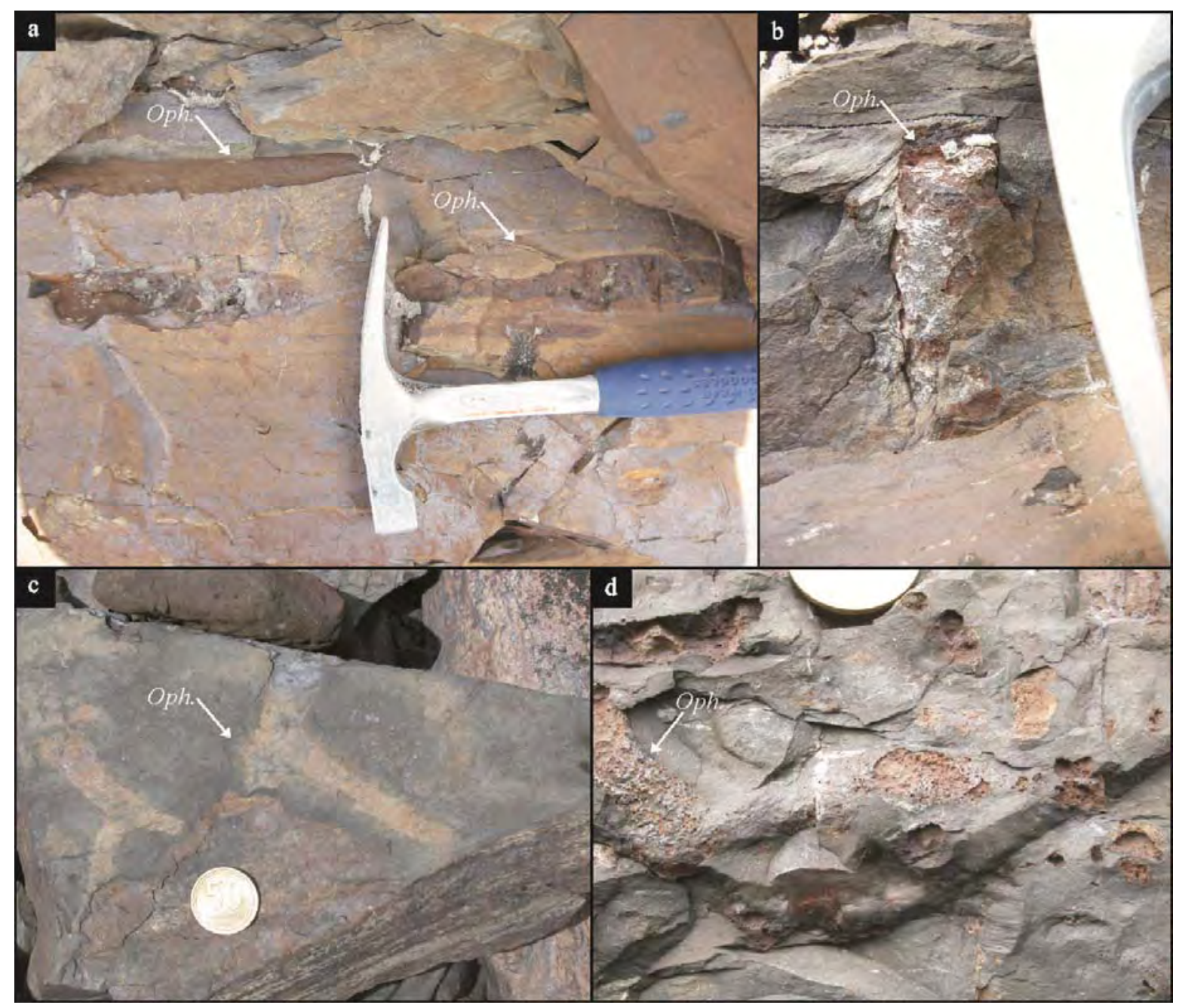

Figura 8.4-a- Corte en perfil de los estratos pelíticos mostrando los niveles de galerías. En la foto b se observa una chimenea vertical. En la imagen c se observan las típicas uniones en "Y”, mientras que en d se muestra un detalle de los tubos con pellets. En ambos caso las paredes externas presentan coloración rojiza por óxidos, aspecto común según Uchman (2009) en ejemplares de Ophiomorpha rudis en ambientes marinos profundos. Todas las fotos pertenecen al Cerro Establo. 
Icnogénero Palaeophycus Hall, 1847

\section{Aspectos generales del icnogénero}

Excavación cilíndrica horizontal a levemente inclinada, con relleno pasivo por el mismo sedimento que la rodea. En general la pared posee un recubrimiento suave del tubo (denominado lining), y puede presentar además estrías longitudinales o transversales. Se considera a este icnogénero como realizados por organismos similares a gusanos para morada.

\section{Palaeophycus isp.}

Material: Observaciones de campo (figura 8.5).

Descripción: excavaciones lisas de entre 0,5 y $1 \mathrm{~cm}$ de ancho que se desarrollan de manera recta a levemente curvada con un largo que puede alcanzar los $10 \mathrm{~cm}$, en general se presentan comprimidas, lo que le confiere una forma elipsoidal en corte transversal. Las trazas representas exichnias, ya que se desarrollan en sustrato pelítico, y a su vez son rellenas por pelita de forma pasiva. El escaso contraste litológico entre la roca que rellena la traza y el estrato pelítico genera que sólo sean distinguibles en los casos en que la pelita del relleno tenga una tonalidad levemente diferente de la roca hospedante.

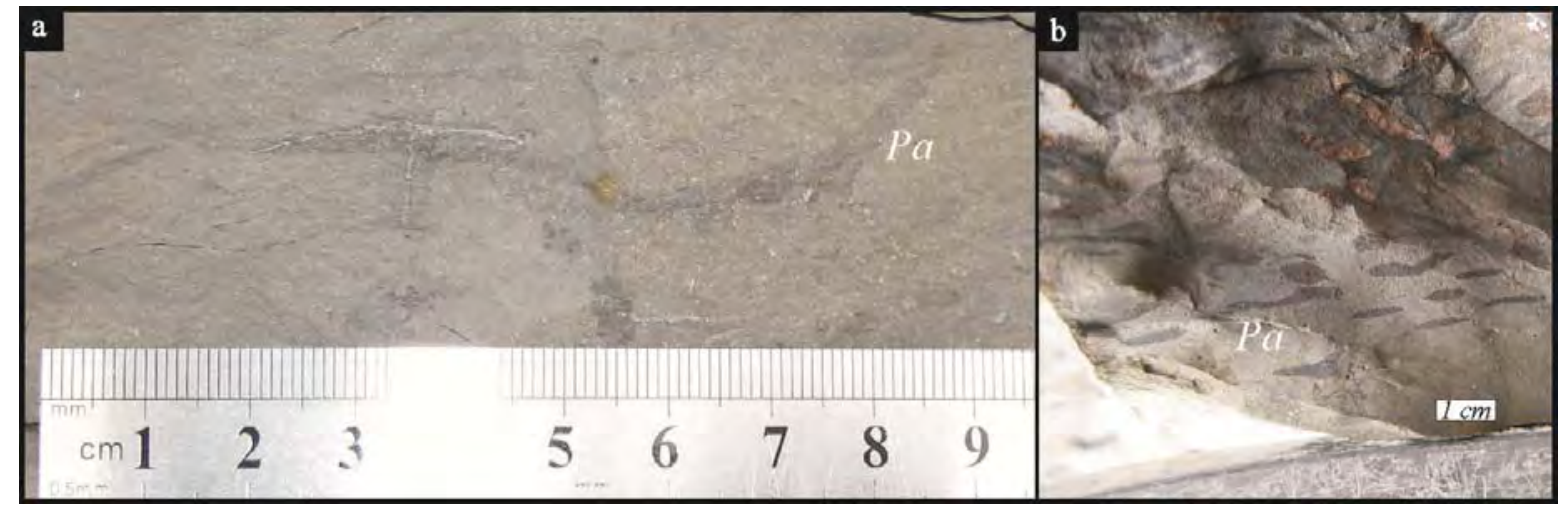

Figura 8.5- Ejemplares de Palaeophycus isp. Encontrados en el perfil EVP 1 de la Seccional Río Guanaco. En la imagen a se observa un corte longitudinal donde se aprecia un ejemplar de desarrollo subhorizontal curvo, mientras que en la imagen b el corte es aproximadamente transversal y se ven las secciones elipsoidales. 
Icnogénero Teredolites Leymerie, 1842

\section{Aspectos generales del icnogénero}

Este icnogénero se reconoce desde el Jurásico hasta el Reciente (Taylor y Wilson, 2003) y está constituido por perforaciones en sustrato leñoso. Se atribuye su presencia a la acción de bivalvos Teredos, los cuales perforan troncos para morar en ellos. Se considera icnofacies de Teredolites sólo cuando se encuentran las trazas in situ (MacEachern et al. 2007a, 2007b, 2007c), por tal razón, dicha icnofacies no se considera para la Formación Río Mayer, ya que los restos de madera que poseen este icnogénero son alóctonos.

\section{Teredolites isp.}

Material recuperado: dos muestras más observaciones de campo (figura 8.6).

Descripción: La traza se presenta como pequeñas “gotas” de 0,3 a 0,5 cm de diámetro y con largo variable que oscila entre 0,5 y $2 \mathrm{~cm}$. Pueden aparecer tanto de manera aplastada y sin deformación, esta característica depende exclusivamente de la preservación del material. En las muestras de Cerro Establo se encuentran asociadas a impresiones de madera desarrolladas en pelitas oscuras, aquí las trazas poseen formas deformadas (aplastadas), donde la morfología original de la estructura se ve distorsionada y luce de manera alargada. Por otro lado, en la Estancia La Vega la forma de la traza está mejor conservada ya que se asocia directamente a madera petrificada, con lo cual preserva la típica forma de "gota” ó “lágrima”, que en este caso son de un recorrido corto. La superficie externa de la traza es lisa en ambos casos. 


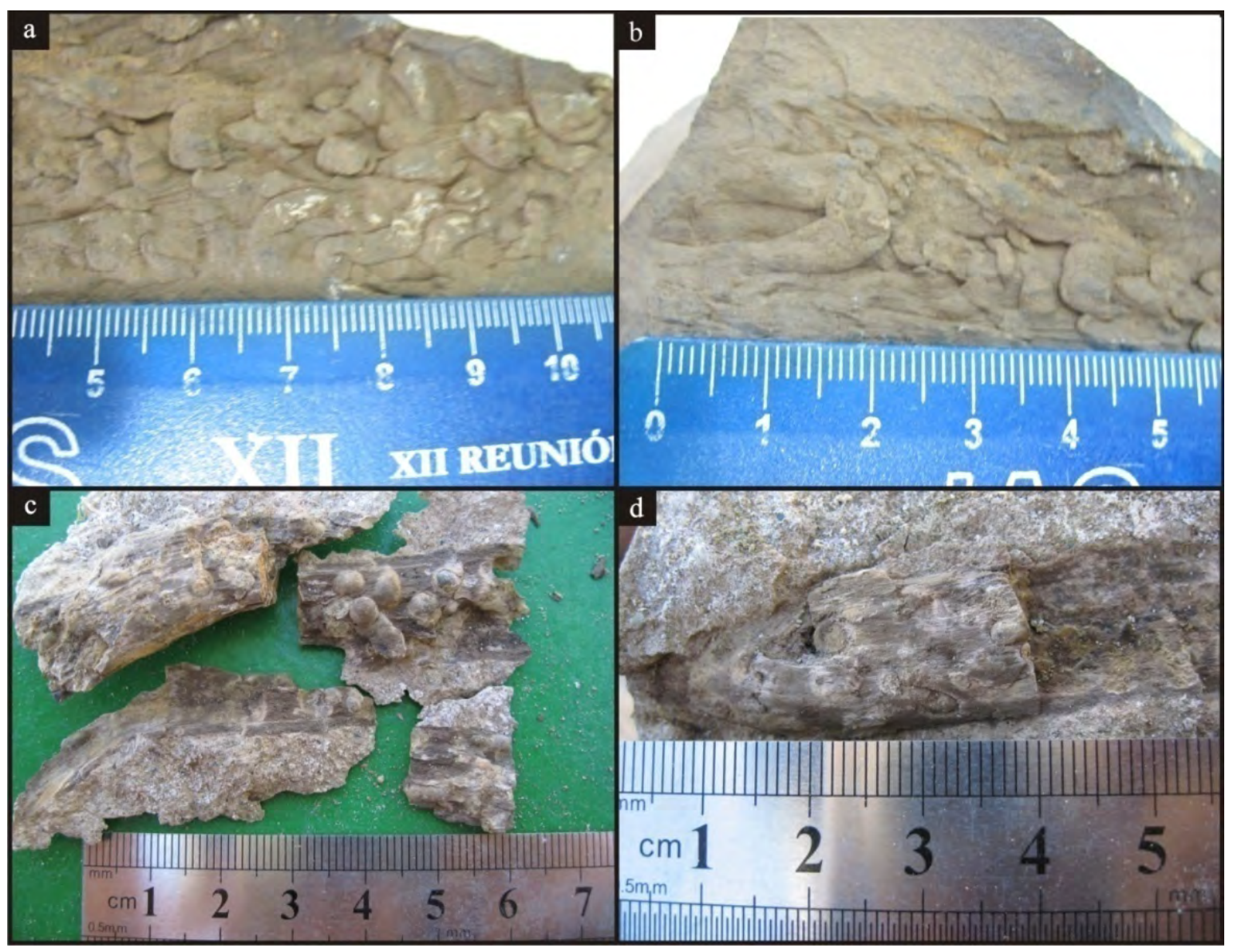

Figura 8.6- Ejemplares de Teredolites isp. Las muestras a y b pertenecen al Cerro Establo de la Seccional Río Guanaco y son pelitas que presentan impresiones de madera con Teredolites, mientras que las muestras c y d del perfil de la Ea. La Vega las trazas se encuentran directamente en restos de madera petrificada.

Icnogénero Thalassinoides Ehrenberg, 1944

\section{Aspectos generales del icnogénero}

Galerías cilíndricas horizontal a levemente inclinadas, que forman un sistema tridimensional de túneles que se cruzan con forma de "Y” y en menor medida de “T”. Presenta relleno pasivo por el mismo sedimento que la rodea. Se considera a este icnogénero como realizado por crustáceos thalassinoideos para utilizar como morada, aunque también otras interpretaciones incluyen a organismos detritívoros o, incluso a organismos cultivadores de bacterias (Ekdale y Bromley, 1984, 1991; Ekdale et al., 1984; Bromley, 1996; Savrda et al., 2001). 
Thalassinoides isp.

Material: Observaciones de campo (figura 8.7).

Descripción: Son excavaciones que se presentan de manera paralela a la estratificación y conforman galerías de entre 1 y $2 \mathrm{~cm}$ de ancho, las que se conectan entre sí en ángulos rectos (figura 8.7a) o formando una "Y” (figura 8.7b). Se desarrollan en sustrato pelítico y están rellenas de pelita, lo que genera al igual que el icnogénero Palaeophycus, que sean observables sólo en los casos en que la pelita del relleno tenga una tonalidad levemente diferente de la roca hospedante. Externamente poseen superficies lisas.

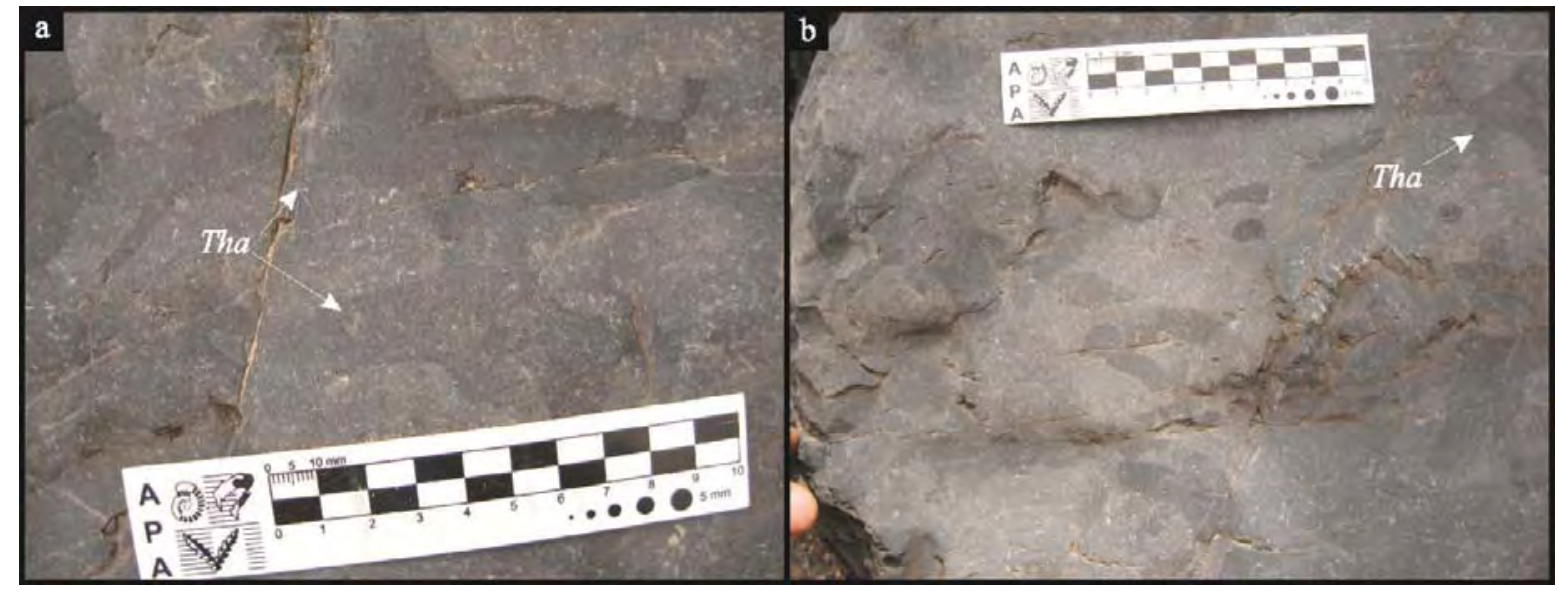

Figura 8.7- Ejemplares de Thalassinoides isp. Ambas fotos pertenecen al perfil PG de la Seccional Río Guanaco (en la parte inferior de la sección superior de la unidad). 
Icnogénero Zoophycos Massalongo, 1855

\section{Aspectos generales del icnogénero}

El nombre fue dado por Massalongo en 1855, quien definió el icnogénero al describir un espécimen de Macroalgae y no una traza fósil. Afortunadamente, describió varios ejemplares, y así definió cuatro icnoespecies que consideró plantas: Zoophycos caput-medusae, Z. villae, Z. brianteus y Z. scarabelli. Se consideró a Z. caput-medusae como especie tipo, pero su similitud con ejemplares de Postelsia palmaeformes (un alga) llevó a Olivero (2007) a definir una nueva especie tipo sobre la base a los ejemplares descriptos y dibujados por Massalongo en 1855. De esta manera Olivero redefine las especies originales sobre la base del material que se encuentra en el Museo de Toscana (Italia), proponiendo lectotipos y paralectotipos para 2 especies: Z. brianteus y Z. villae. (Olivero, 2007)

Evolutivamente son un componente común en las icnofaunas marinas costeras paleozoicas, sin embargo, durante el mesozoico experimenta un desplazamiento hacia facies profundas de plataforma distal, talud y planicie abisal. Finalmente en el cenozoico se considera de ambientes marinos profundos (Bottjer et al., 1988; Buatois et al., 2002).

Este icnogénero posee estructura variable, con spreiten complejo de gran variedad en cuanto a tamaño, inclinación y estructura, y se puede presentar de dos maneras: helicoidal y planar. Un estudio en ejemplares actuales muestra que los espesores de la traza varían entre 1 y $18 \mathrm{~mm}$, con una distribución de tamaños gaussiana y media en $6 \mathrm{~mm}$ (Löwemark y Schäfer, 2003).

Según Olivero y Gaillard (2007), el 95 \% de los ejemplares de Zoophycos se construyen hacia arriba ("upward”), tanto en sentido destral como sinistral.

Los ejemplares actuales se encuentran en profundidades que van desde los 1000 a los 5000 m, a esas profundidades los organismos están adaptados a bajas tasas de sedimentación y aporte de nutrientes, por lo cual suelen estar asociados a superficies de condensación (Ekdale y Lewis, 1991; Olivero y Gaillard, 1996; Gaillard et al., 1999; Löwemark y Schäfer, 2003; entre otros).

Morfológicamente presentan láminas que están bordeadas por un tubo marginal activo por el cual el organismo se desplaza en el sedimento, internamente cada lámina está formada por lamelas primarias y secundarias. Las lamelas secundarias suelen no ser 
visibles a escala mesoscópica por su pequeño tamaño y se disponen de manera perpendicular a las lamelas primarias. Hay dos tipos de lamelas secundarias, las sedimentarias (oscuras) y la fecales (claras). Por adición de sets de lamelas secundarias quedan delimitadas las lamelas primarias y a su vez el conjunto de éstas últimas dan forma a la lámina que puede ser de morfología simples (planar) o complejas (en espiral). Las láminas simples son poco comunes, mientras que las complejas son más frecuentes, poseen formas lobadas y se las puede considerar como evolucionadas a partir de las simples (Olivero y Gaillard, 2007). Dicha evolución habría tenido desarrollo desde el Devónico al Cretácico. Ambas formas pueden coexistir, por eso, Olivero y Gaillard (2007), interpretan que los lóbulos serían una adaptación a condiciones inestables en el ambiente o en el sedimento. De esta manera se generarían lóbulos angostos y largos para explorar nuevas zonas en busca de alimento y/o para esquivar obstáculos. Por otro lado, es de esperar que en ambientes estables se desarrollen formas no lobadas y grandes, lo que mostraría que los organismos productores del icnogénero poseen estrategias alimenticias (Olivero y Gaillard, 2007).

A partir de los resultados obtenidos por Löwemark y Schäfer (2003), estos autores postulan que este icnogénero no estaría formado por un organismo detritívoro, principalmente por la gran cantidad de material arrastrado hacia las galerías, el cual es muy rico en nutrientes ya que posee valores de COT mayores a la roca hospedante (Figura 8.8a). Así, durante periodos de incremento en el aporte de nutrientes el organismo acumularía comida en los túneles. Otra evidencia es que dichos autores encontraron la presencia de organismos excavando galerías ya hechas y de esta manera demuestran que en épocas de poco alimento podrían utilizar el material guardado en los spreiten.

Sin embargo, Olivero y Gaillard (2007), proponen un modelo de formación de la traza fósil basado en la estrategia alimenticia de un gusano sipuncúlido detritívoro, el cual posee boca y ano en un único orificio anterior (Figura 8.8b), siguiendo con modelo más ampliamente difundido. 

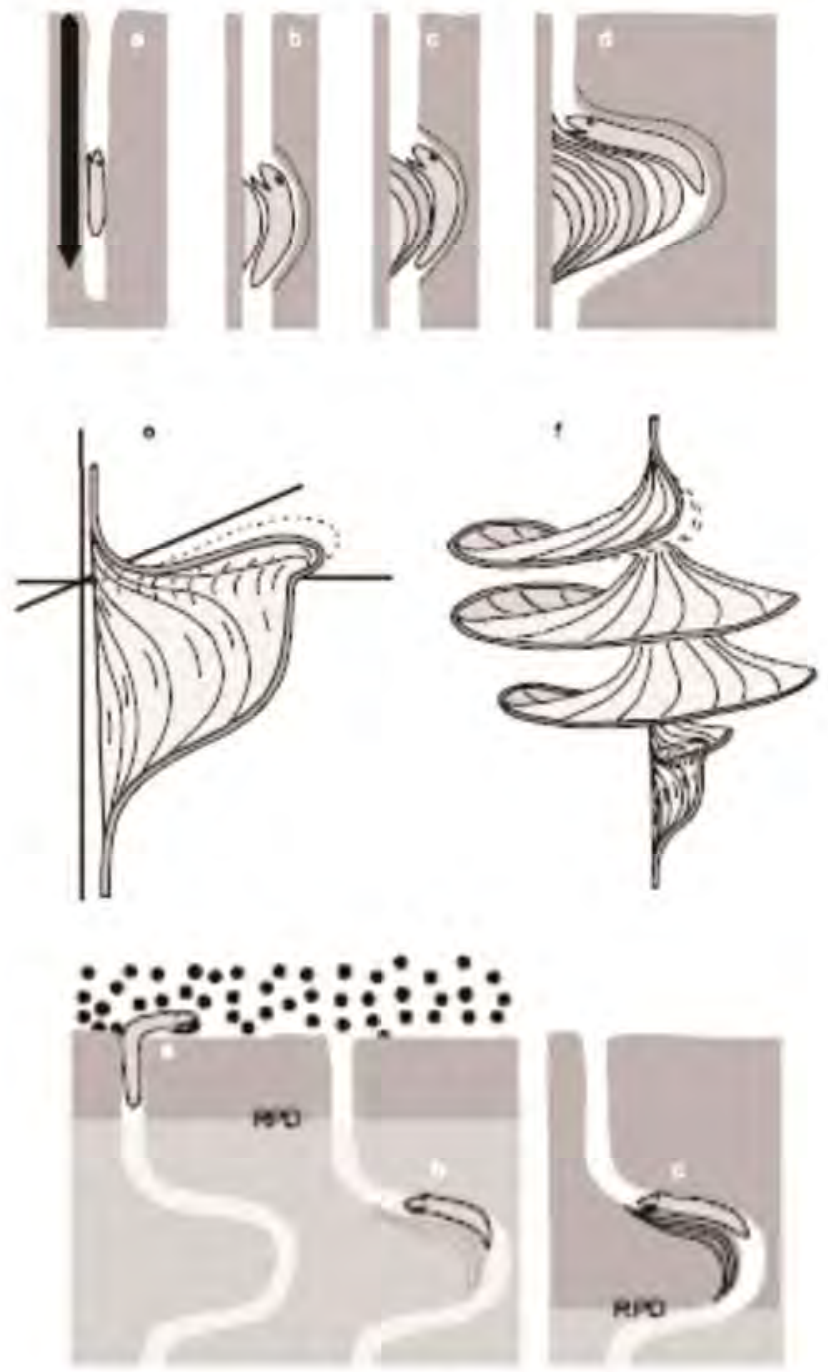

a
CONSTRUCTIC

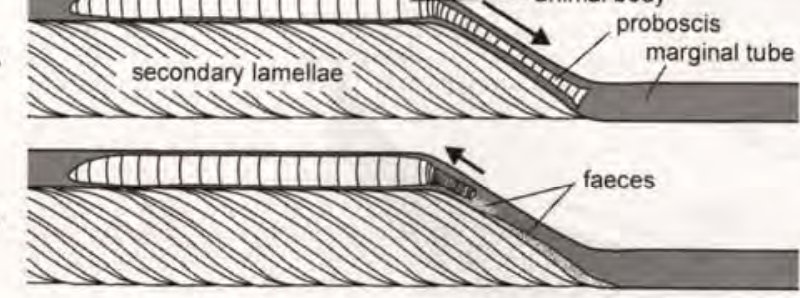

Figura 8.8-

Modelos de

formación de la

traza de

Zoophycos. En a

c

AIIIIIIIIIII empty tunnel partially
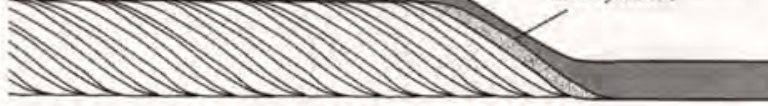

D

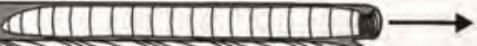

$\longrightarrow$

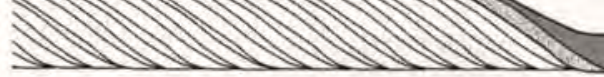

IIIIIIIIIIIIII coushing of the
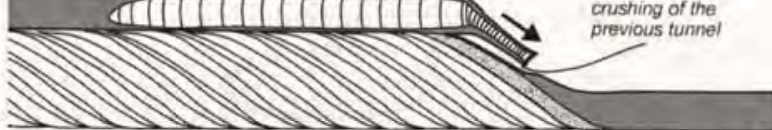

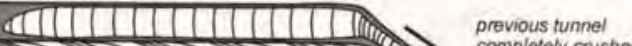

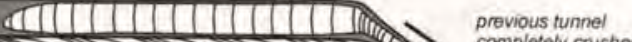

F

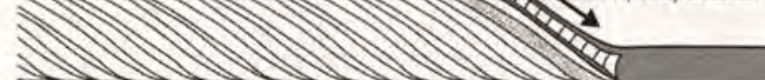

el modelo

presentado por

Löwemark y

Schäfer (2003);

en b el modelo

presentado por

Olivero y

Gaillard (2007).
IIIIIIIIIIIIIIIII

N.W. N

बIIIIIIIIIIIIII

H

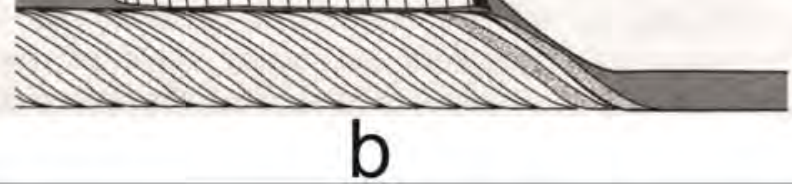


Zoophycos isp.

Material recuperado: una muestra y observaciones de campo (figuras 8.9; 8.10; 8.11)

Descripción: Este icnogénero posee morfologías diferentes dentro de la Formación Río Mayer, las que dependen de la relación de corte entre la traza y el afloramiento. Por tal motivo se categorizó a los ejemplares en grupos morfológicos, reconociéndose en la Fm. Río Mayer, tres tipos morfológicos:

Tipo 1- Se presenta como largos sistemas de túneles con spreiten que pueden extenderse por más de 1 metro, con anchos máximos de hasta 1 centímetro. En general se desarrollan paralelamente a los estratos, y en ocasiones, cuando aparecen en diagonal comunican dos niveles de túneles (Figura 8.10). Este tipo morfológico puede dividirse en dos subgrupos, denominados Zoophycos Tipo 1a y Tipo 1b. Se diferencian en el largo de los túneles, los Tipo 1a son largos (más de $50 \mathrm{~cm}$ ), mientras que los Tipo 1b son de corto desarrollo (10 a $40 \mathrm{~cm})$.

Tipo 2- Corresponde a una vista superior del icnogénero, mostrando el crecimiento radial desde un punto central o ápice. Posee un conjunto de lamellas que se curvan en sentido contrario a la dirección de construcción y en ocasiones bifurcan hacia el final (Figura 8.11).

Tipo 3- Al igual que el tipo 2 muestra un crecimiento desde un hipotético tubo central (no visible), pero esta vez en corte transversal, mostrando spreiten hacia ambos lados con direcciones de movimiento opuestas (Figura 8.12). 


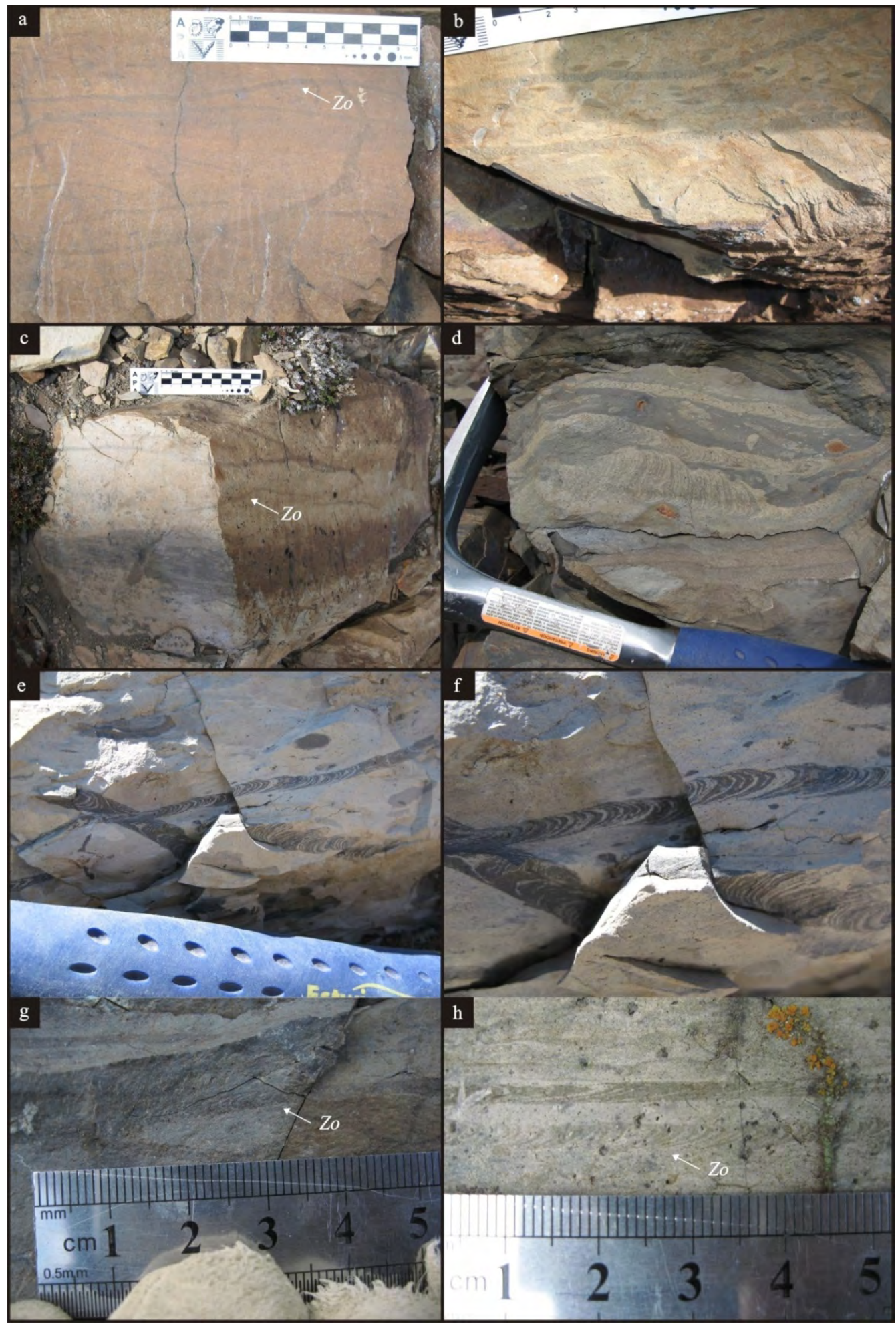

Figura 8.9- Ejemplares de Zoophycos tipo 1. Las fotos a-f provienen de la Seccional Río Guanaco, mientras que g-h son de la región del Lago Argentino. Fotos a, b y c pertenecen al perfil PG, la foto d al Cerro Establo y las fotos e y $\mathrm{f}$ al perfil WVP. Las correspondientes al Lago Argentino son del Cerro Horqueta. 


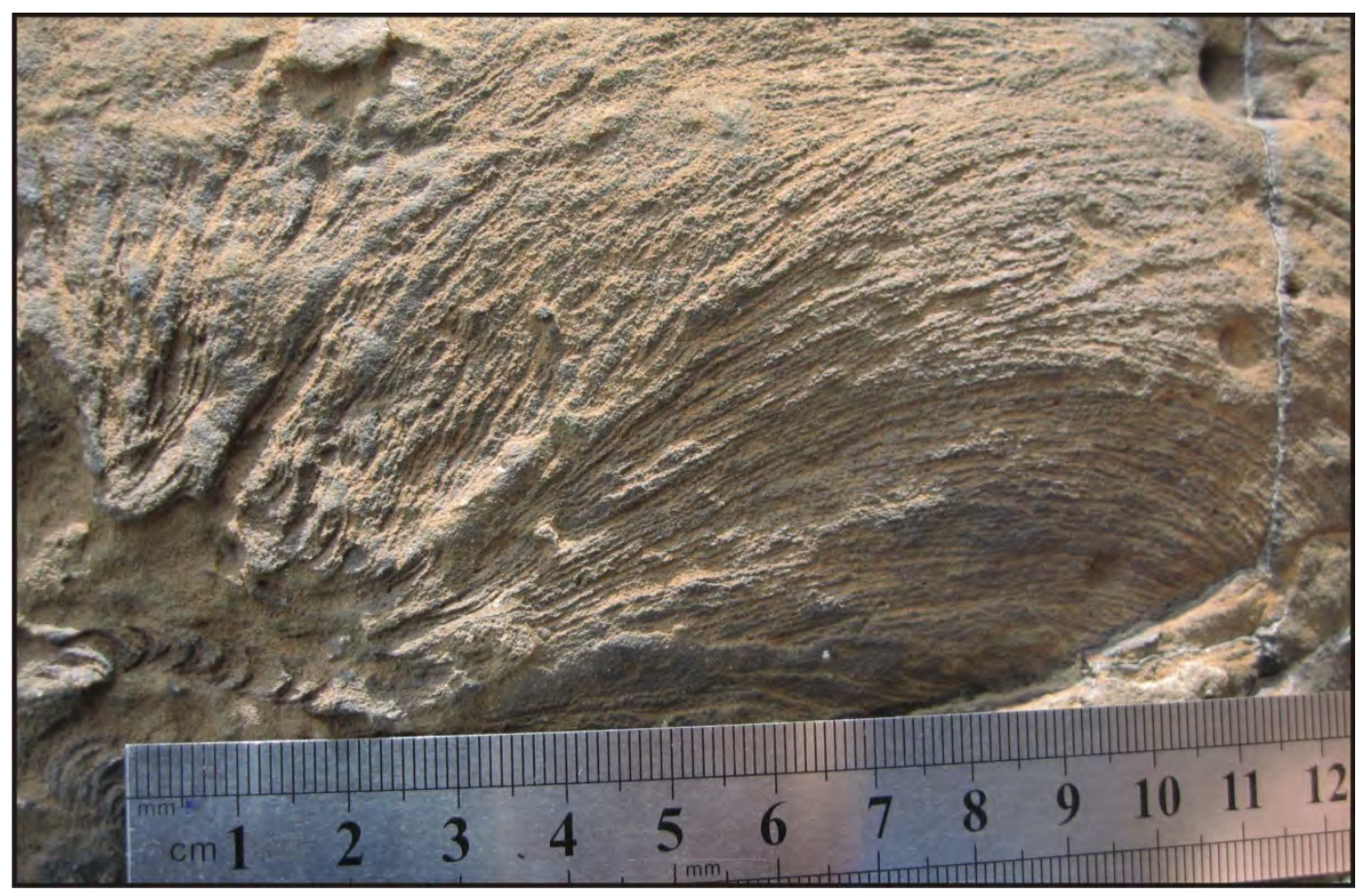

Figura 8.10-Ejemplar de Zoophycos tipo 2 del perfil PG de la Seccional Río Guanaco.

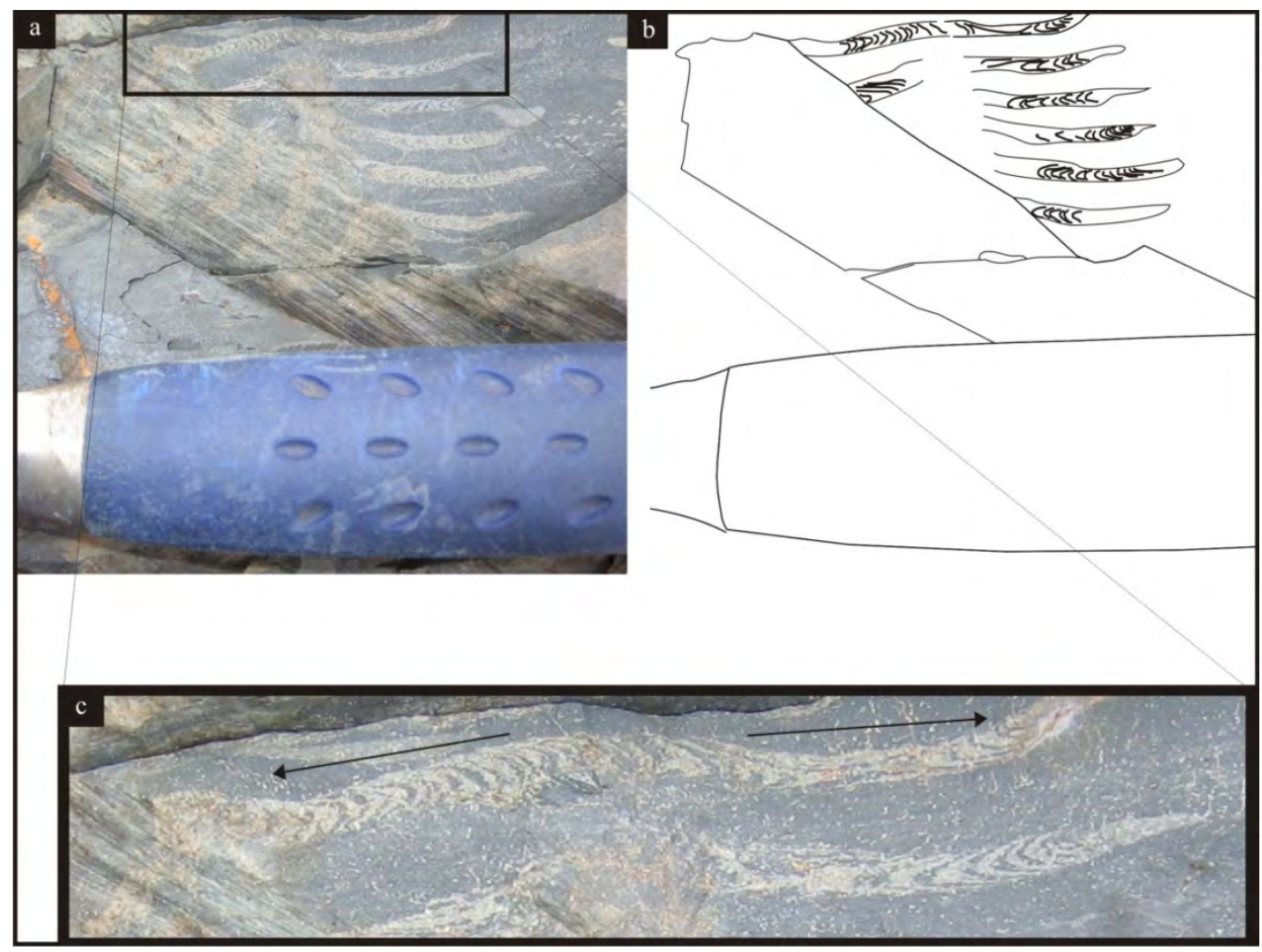

Figura 8.11- Ejemplar de Zoophycos tipo 3 en el Cerro Establo de la Seccional Río Guanaco. 


\section{3 - Icnofacies e Icnoasociaciones}

El conjunto de icnogéneros recuperados en la Formación Río Mayer permiten su agrupación en dos categorías, Icnofacies e Icnoasociaciones. Las primeras corresponden a las icnofacies arquetípicas definidas por Seilacher (1968) y luego ampliadas y modificadas por diversos autores (cf. MacEarchern et al., 2007a, 2007b). El segundo concepto es aún más inclusivo, ya que además de una icnofacies arquetípica contiene otros icnogéneros no habituales en esas icnofacies, o incluye icnotaxones que no definen icnofacies pero que aparecen asociados.

\section{3.1 - Icnofacies}

\section{3.1.1- Icnofacies de Zoophycos}

Esta icnofacies está dominada por estructuras de alimentación relativamente simples a complejas, las cuales suelen presentar spreiten. Tiene baja icnodiversidad y son comunes las asociaciones monoespecíficas de densidad variable (Buatois et al., 2002).

Es una icnofacies problemática en el esquema de Seilacher (1964, 1967), encontrándose entre las icnofacies de Cruziana y Nereites (cf. Buatois et al., 2002), por tal razón es la más discutida y la menos comprendida (MacEarchern et al., 2007 a, 2007b). Se desarrolla en condiciones de aguas tranquilas, en ambientes de plataforma externa a sectores batiales o sitios intracosteros protegidos, con sedimentos fangosos ricos en materia orgánica y deficientes de oxígeno (Frey y Pemberton, 1984, 1985). Del mismo modo que el icnogénero que le da nombre, esta icnofacies registra un desplazamiento batimétrico desde zonas someras en el Paleozoico a sectores profundos desde el Mesozoico (Bottjer et al., 1988; Buatois et al., 2002).

Los organismos productores de Zoophycos y Chondrites penetran considerablemente en el sustrato bajo condiciones de aguas intersticiales pobres en oxígeno, pero eso no necesariamente implica pobre oxigenación en la interfase aguasedimento (Bromley 1990, 1996).

Esta icnofacies se encuentra representada en los perfiles PG, WVP y CE de la Seccional Río Guanaco, donde domina el icnogénero Zoophycos. No se asignó esta icnofacies en la región del Lago Argentino debido a la presencia en solitario del icnogénero 
Zoophycos, el cual posee muy mala preservación y poca abundancia, además de la falta de afloramientos de calidad para buscar otros icnotaxónes.

La icnofacies de Zoophycos presente en los perfiles PG y WVP se compone principalmente de ejemplares de Zoophycos tipo 1a, tipo 2 y Chondrites. El gran desarrollo de esta icnofacies en estos perfiles indica gran estabilidad del ambiente, lo que permite un máximo aprovechamiento del sustrato por los organismos productores de estas trazas.

Por otro lado, los ejemplares de Zoophycos presentes en el Cerro Establo de la Seccional Río Guanaco son en general de pequeño desarrollo (tipos morfológicos 1b y 3) y los Chondrites son aislados, estas características distinguen esta icnofacies Zoophycos de la previamente definida. Este rasgo indica que el paleoambiente desarrollado sería de características inestables, posiblemente relacionado a los flujos turbidíticos que se encuentran en la sección superior de la Formación Río Mayer.

\section{3.1.2- Icnofacies transportadas}

En general, al describir una icnofacies, se describe una asociación de trazas fósiles encontradas en una capa sedimentaria. La relación de dichas trazas puede deberse a diferentes condicionantes, así se observan asociaciones de trazas que dependen del sustrato, icnofacies sustrato-controladas (sustratos duros y firmes) y otras icnofacies que se desarrollan en sustratos sueltos y se distribuyen según niveles de energía.

El reconocimiento de una de estas icnofacies permite caracterizar a las rocas portadoras con características paleoambientales deducidas de ejemplos icnológicos anteriormente registrados.

Una excepción a esta regla general es la icnofacies de Teredolites, la cual se produce por la acción de bivalvos teredos en troncos que se encuentran en ambientes litorales. La presencia de troncos petrificados con Teredolites en ambientes marinos desde someros hasta profundos evidencia la característica única de las icnofacies desarrollada en sustratos duros. Queda claro que la presencia de este icnogénero en ambientes turbidíticos no significa que en esos ambientes se esté produciendo la traza fósil, pero sí evidencia la presencia temporalmente coetánea (si no se tiene en cuenta la mezcla temporal, poco importante cuando se habla de decenas de millones años) de paleoambientes sedimentarios litorales con troncos. Esta característica fue observada por Savrda et al. (1993), y 
denominaron “log-ground” a la concentración de madera alóctona con Teredolites. Para reconocer la icnofacies se debe saber si la madera fue colonizada antes o después de su transporte. A pesar de la dificultad para tener seguridad sobre el origen y tiempo de formación de las perforaciones, se las ha empleado como un nivel de marcación a escala regional de fluctuaciones de nivel del mar (cf. MacEarchern et al., 2007c).

En el caso de la Fm. Río Mayer, la presencia de troncos con Teredolites se relaciona con el aporte desde zonas litorales de la deltaica Fm. Piedra Clavada.

\section{3.2 - Icnoasociaciones}

De la distribución de icnogéneros en la Formación Río Mayer se pueden reconocer tres asociaciones de icnofósiles (figura 8.12). El mayor desarrollo de icnofósiles se encuentra en la Seccional Río Guanaco (7 icnogéneros), en contraste con el resto de las localidades. No se hallaron trazas fósiles en los afloramientos de la Formación Río Mayer en el Lago San Martín, sí en la Fm. Springhill, aunque no serán aquí descriptas. En la estancia La Vega se reconocieron dos icnogéneros al igual que en el Lago Argentino (figura 8.12). 


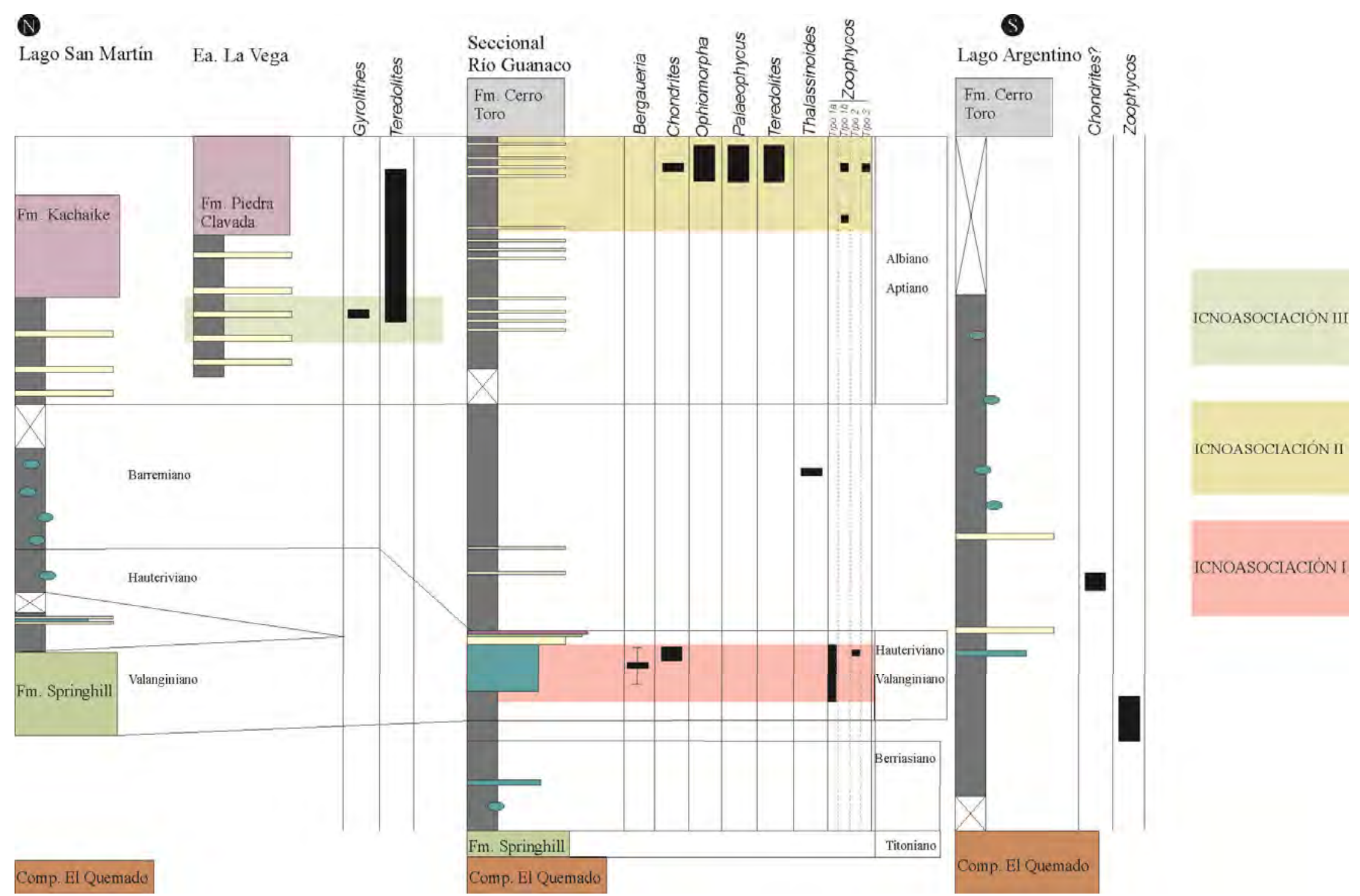

Figura 8.12- Distribución de los icnogéneros reconocidos en la Formación Río Mayer e Icnoasociaciones definidas en la unidad. 
Icnoasociación I: Incluye a los icnogéneros de Zoophycos y Chondrites los que señalan una icnofacies de Zoophycos desarrollada aproximadamente entre el Valanginiano y el Hauteriviano en la región de las nacientes del Río Guanaco. Asociada a esta icnofacies se hallan los ejemplares de Bergaueria (figura 8.13).

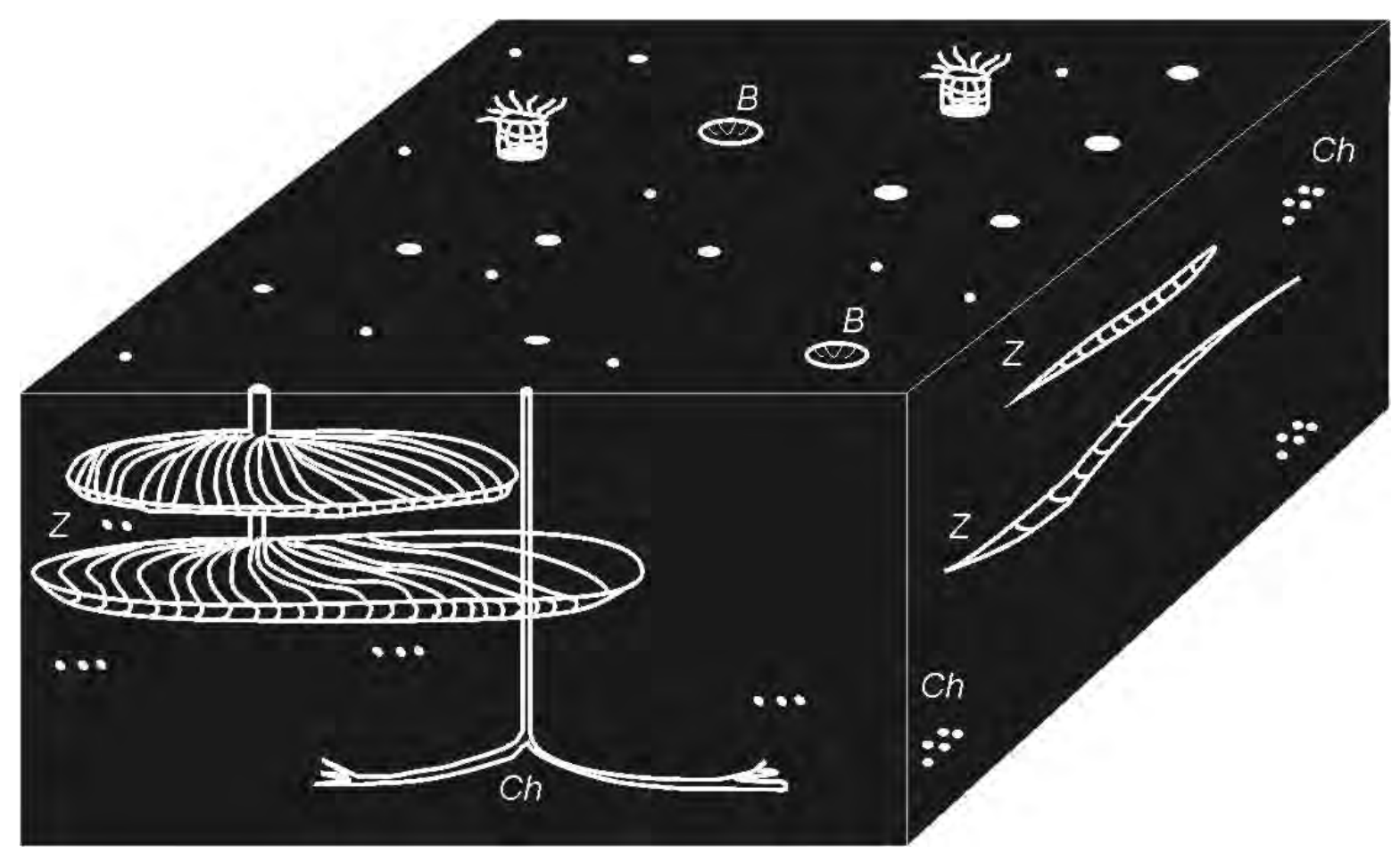

Figura 8.13- Icnoasociación I. Incluye un importante desarrollo de la icnofacies de Zoophycos con ejemplares de Bergaueria asociados. Se encuentra en la Seccional Río Guanaco en el perfil PG y WVP. 
Icnoasociación II: La segunda asociación de trazas fósiles aparece en el Albiano en las nacientes del Río Guanaco y se compone de los icnogéneros Chondrites, Ophiomorpha, Palaeophycus y Zoophycos (figura 8.14). Esta asociación define una icnofacies Zoophycos y una icnosubfacies de Ophiomorpha rudis (Uchman, 2009). Esta última, recibe también el nombre de “Colonizadores Condenados” (“Doomed Pioners” sensu Grimm y Föllmi, 1990), y está formada por trazas de organismos que viven en ambientes marinos someros y son transportados por tormentas a zonas profundas. El ejemplo clásico es el desarrollo de túneles o galerías de Thalassinoides y Ophiomorpha asociados a flujos turbidíticos en pelitas negras. Estos icnogéneros serían producidos por crustáceos, los cuales poseen un exoesqueleto que les permite ser transportados en flujos turbulentos. Una vez que se encuentran en ambientes profundos pueden vivir y alimentarse en sedimentos finos ricos en materia orgánica durante 5 a 7 días mínimo. (Föllmi y Grimm, 1990).

Se relaciona con esta segunda asociación el icnogénero Teredolites, el cual se presenta en madera transportada desde zonas litorales. 


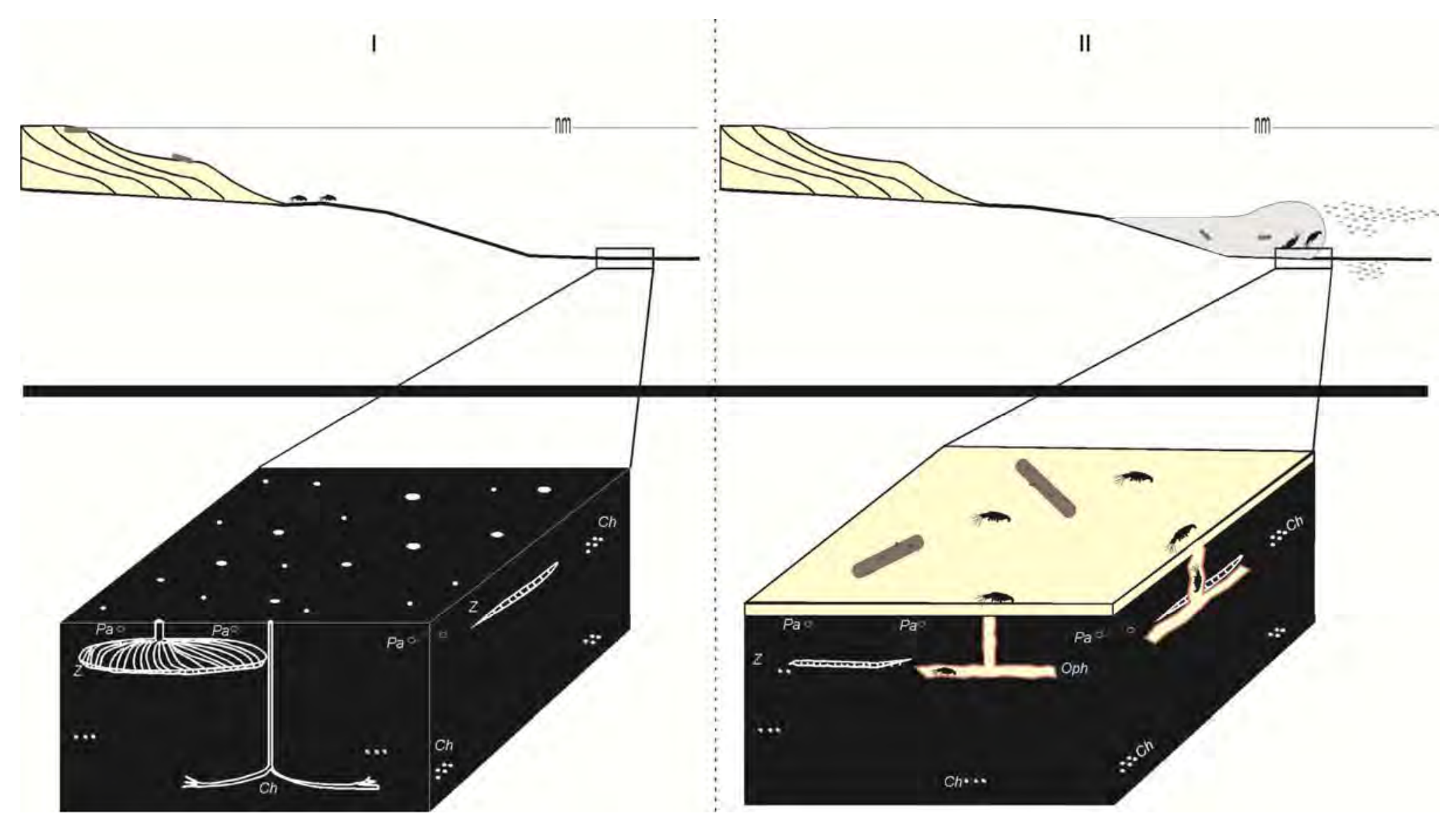

Figura 8.14- Icnoasociación II. Incluye a la icnofacies de Zoophycos (Chondrites: Ch; Palaeophycus: Pa; Zoophycos: Z) con ejemplares de Ophiomorpha (Oph) y Teredolites asociados. Se encuentra en la Seccional Río Guanaco en el perfil CE. En I se observa el desarrollo de la icnofacies de Zoophycos, alejada del frente deltaico. En II, las corrientes de turbidez generadas en el frente deltaico arrastran a los organismos productores de Ophiomorpha y a los restos de madera con Teredolites. 
Icnoasociación III: La tercera icnoasociación incluye a sólo dos icnogéneros, Teredolites y Gyrolithes (figura 8.15). Ambos son normalmente vinculados a ambientes litorales marinos y marinos marginales. En la Formación Río Mayer se encuentran en el perfil de Estancia La Vega, en la región entre los lagos Viedma y San Martín, dentro de la transición entre las formaciones Río Mayer y Piedra Clavada. Cabe aclarar que la representación de esta icnoasociación es muy escasa, si se compara con las anteriormente enunciadas.

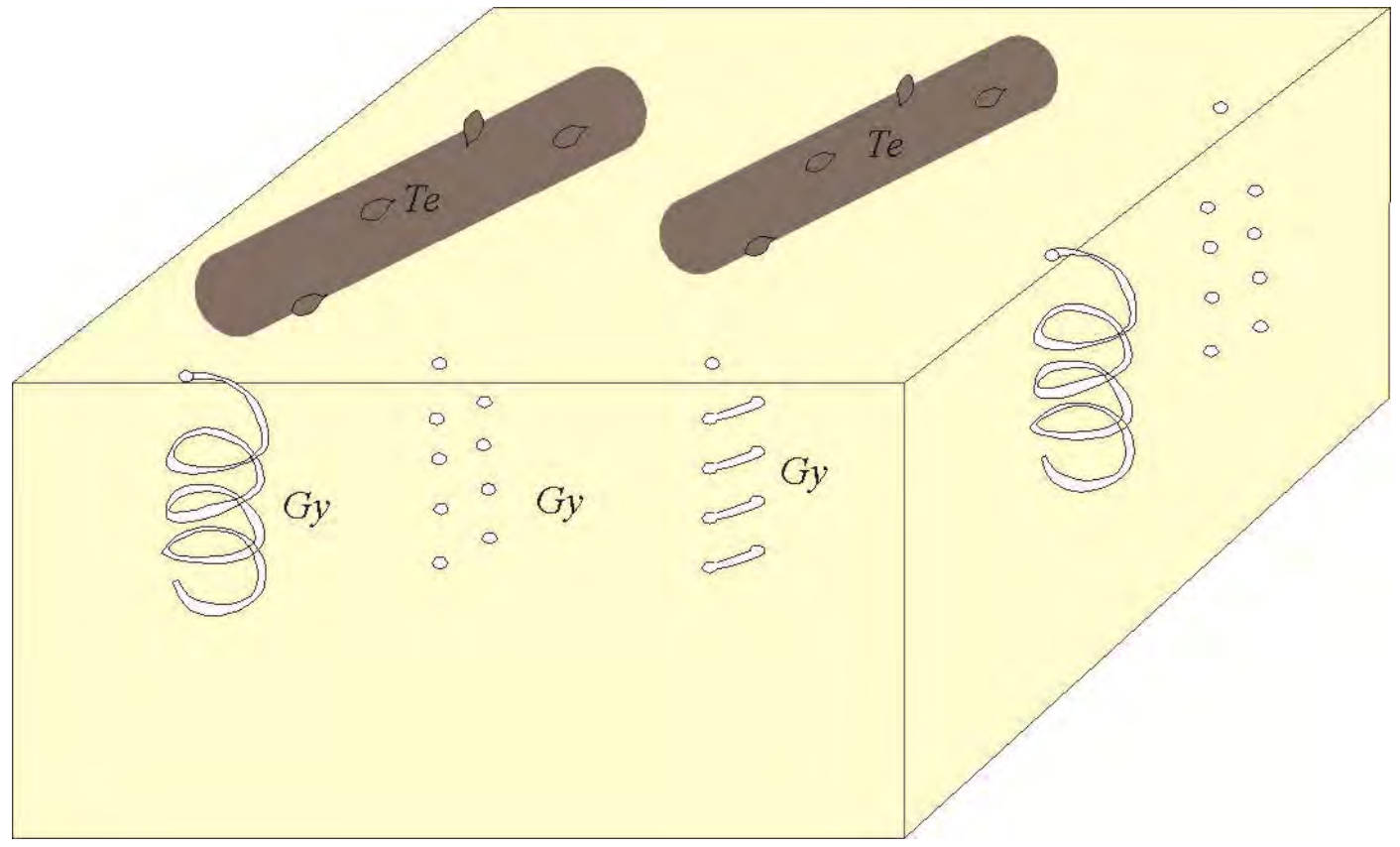

Figura 8.15- Icnoasociación III. Incluye a los icnogéneros Teredolites (Te) y Gyrolithes (Gy). Se encuentra en el perfil ELV de la región entre los lagos Viedma y San Martín. En la figura de muestran las tres maneras de encontrar Gyrolithes, en la Formación Río Mayer no se registraron ejemplares que describan la morfología completa de la traza (ejemplo del frente a la izquierda), solo los pares de perforaciones alineados y las perforaciones conectadas (ejemplos del frente a la derecha). 


\section{4 - Paleoniveles de oxigenación en la Formación Río Mayer}

El empleo de las estructuras sedimentarias orgánicas para la estimación de niveles relativos de oxigenación en cuencas sedimentarias está ampliamente difundido en la literatura icnológica (Rhoads y Morse, 1971; Sarvda y Bottjer, 1986, 1987; Ekdale y Mason, 1988; Buatois y Mángano, 1992; Allison et al., 1995; Savrda, 1995; Doyle et al., 2005). El principio básico es que al aumentar el contenido de oxígeno disuelto en el paleoambiente aumenta la icnodiversidad producto de una mayor y más diversa comunidad epi y endobentónica. Otro aspecto importante a considerar es el diámetro de las perforaciones, ya que su aumento indicaría condiciones de mayor oxigenación.

En general, la determinación de una curva de paleo-oxigenación relativa para un registro sedimentario no se basa solamente en las trazas fósiles, sino que se apoya en otras fuentes de evidencia. Dentro de sucesiones pelíticas se debe tener en cuenta el color de las rocas (mientras más oscuras menos oxígeno), la presencia o ausencia de laminación y otras características distintivas como poseer pirita diseminada. Un aspecto a considerar en pelitas de ambientes marinos de costa afuera es la participación de areniscas, las cuales indican la presencia de flujos que pueden provenir de zonas someras y transportan aguas oxigenadas. El tipo y abundancia de fósiles que acompañan los depósitos también suele considerarse, y se debe tener en cuenta si los organismos son epi o endobentónicos (los endobentónicos requieren mayor cantidad de oxígeno en el ambiente) como así también el tamaño de los mismos.

Además de estas características mencionadas, todas provenientes de la información obtenida en el trabajo de campo, otras fuentes de información pueden ser utilizadas para estimar la oxigenación relativa del paleoambiente. Uno de los principales es el contenido de carbono orgánico total (COT), el cual está fuertemente condicionado por los niveles de oxígeno (ver capítulos IV y VII). Desde la geoquímica hay otros dos indicadores que ayudan a este tópico; uno es la anomalía de Ce, la cual posee valores negativos en condiciones reductoras; otro es el contenido de $\mathrm{MnO}$, que aumenta su concentración con ambientes oxigenados (ver capítulo VII).

En la figura 8.16 se reconstruyó una curva estimativa de paleo-oxigenación para la Formación Río Mayer en la Seccional Río Guanaco. Se decidió realizarla en esta localidad por poseer una gran cantidad datos de diversa índole, entre ellos que cuenta con los mejores 
afloramientos del área de estudio y se realizaron los estudios geoquímicos de la unidad. Para diagramar la curva se tuvieron en cuenta:

1- Características de las rocas: color y laminación de las pelitas, presencia/ausencia de areniscas.

2- Icnología: diversidad y tamaño de las trazas fósiles.

3- Geoquímica: contenido de COT, anomalía de Ce y porcentaje de MnO.

A partir de la curva relativa de paleo-oxigenación se reconocieron cuatro sectores bien diferenciados en la Formación Río Mayer. La totalidad de la sección inferior de la unidad se desarrolló durante un período de muy baja oxigenación del ambiente, lo que otorgó a la formación una distintiva coloración negra con laminación bien preservada, altos contenidos de materia orgánica y ausencia de trazas fósiles. Posteriormente, la sección media de la formación posee condiciones con mayor oxigenación que la inferior. Esta característica permitió el progreso de una importante icnofacies de Zoophycos, la cual dejó una alta bioturbación en el intervalo. Si bien, la cantidad de oxígeno es mayor a la que previamente se disponía, la característica principal de esta icnofacies es que se genera típicamente en ambientes deficientes en oxígeno, pero no anóxicos. Por esta razón los depósitos aún conservan tonalidades grises oscuras, aunque tienen valores muy bajos de COT. La sección superior de la unidad posee un doble comportamiento, el tramo inferior es menos oxigenado que el tramo superior. Hacia el final de la mencionada sección el nivel de oxigenación es máximo, en gran medida por el aporte de flujos turbidíticos desde zonas someras, lo que deja un escaso contenido de materia orgánica preservada, coloraciones verdosas oscuras para las pelitas y la mayor icnodiversidad de la formación. A pesar de la mayor oxigenación, cabe aclarar que los valores promedios seguirían siendo moderados.

En conclusión, la Formación Río Mayer cuenta con tres sectores bien diferenciados desde el punto de vista de los contenidos de oxígeno disuelto en el paleoambiente, estos son: primero un paleoambiente anóxico en la sección inferior de la unidad, luego un paleoambiente en general disóxico con variaciones en el desarrollo de trazas fósiles y la preservación de materia orgánica, que se desarrolla entre la sección media y la parte inferior de la sección superior. Por último, presenta un sector con mejores condiciones de oxigenación para el desarrollo de organismos en el tramo final de la unidad. 


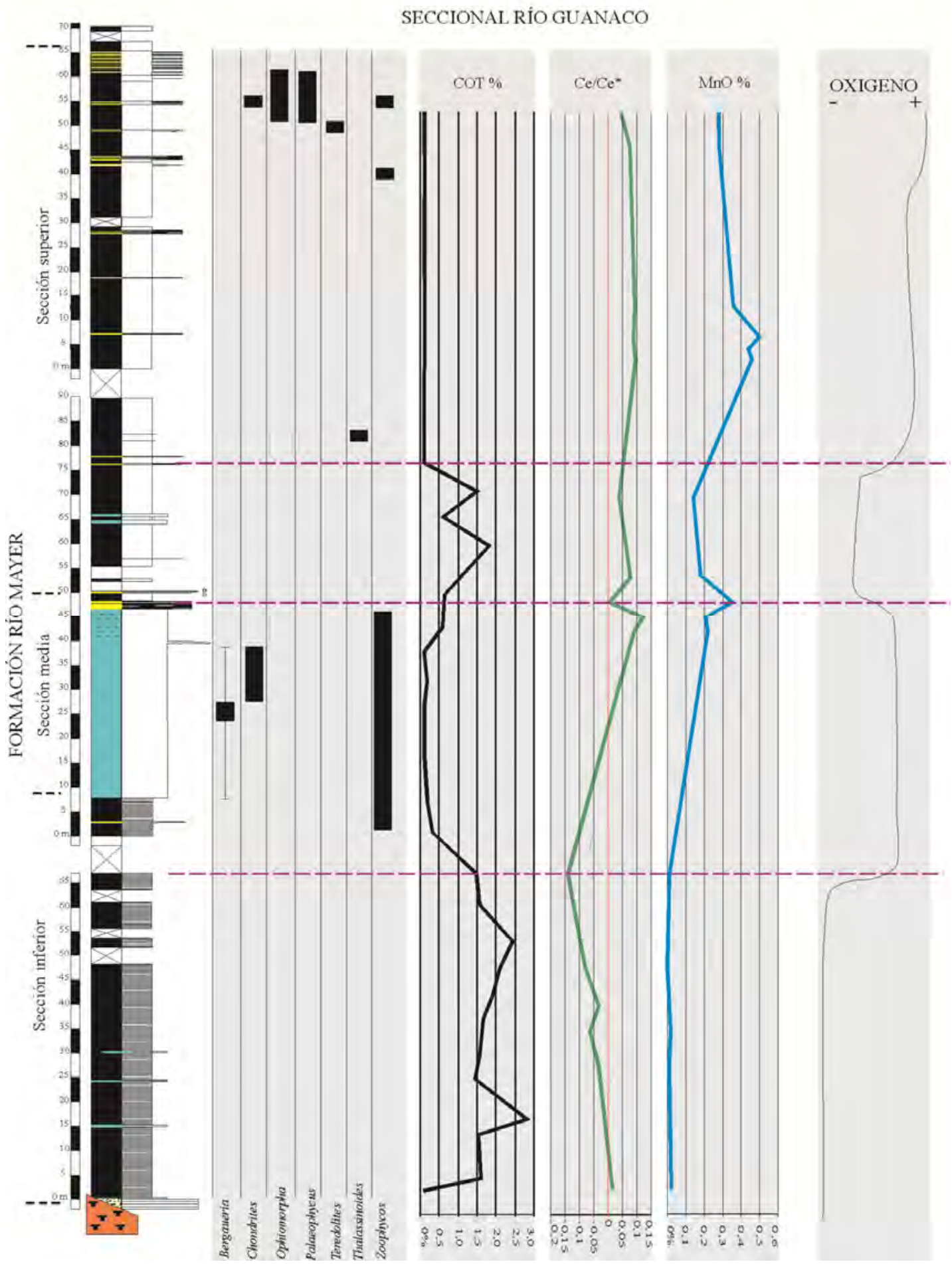

Figura 8.16- Reconstrucción de la curva de paleo-oxigenación en la Formación Río Mayer en la Seccional Río Guanaco (perfiles IG, PG, EVP1). Se utilizaron las características litológicas, la icnología y aspectos geoquímicos dependientes del nivel de oxígeno disuelto. 


\section{5 - Modelo Icnológico de la Formación Río Mayer}

Con el desarrollo icnológico realizado hasta el momento, sumado a información temporal aportada por el material fósil (principalmente amonites) recolectado en los perfiles sedimentológicos, se realizaron correlaciones que permitieron entender con mayor precisión la conexión entre los diferentes paleoambientes reconocidos en el capítulo IV y la relación con las formaciones litoestratigráficas que son coetáneas con la Formación Río Mayer en distintas edades.

\section{5.1 - Modelo Icnológico Valanginiano}

Con respecto a la Icnoasociación I, ésta posee un correlato con el desarrollo de trazas fósiles en otra localidad para la misma edad (Valanginiano) en la Formación Springhill (figura 8.17). En la región del Lago San Martín para esta unidad, Poiré y Franzese (2008) primero, y luego durante el presente trabajo de tesis, se reconocieron diversos icnogéneros que permiten definir una icnofacies de Cruziana. Durante este lapso temporal en la Seccional Río Guanaco, dentro de la Formación Río Mayer se registra la Icnoasociación I, compuesta por una icnofacies de Zoophycos con Bergaueria asociada. Esta es una distribución predecible para un ambiente de sustrato blando, donde la icnología estaría controlada por la energía del ambiente. Es probable que un estudio detallado en la Formación Springhill permita diferenciar una icnofacies de Skolithos de la de Cruziana. Del modelo icnológico original de Seilacher (1964, 1967), sólo falta la icnofacies de Nereites, pero la ausencia de sistemas turbidíticos de esta edad en el área de estudio no permite completar el panorama ideal. De existir esta última icnofacies en la Cuenca Austral habría que buscarla en los afloramientos al sur del Lago Argentino.

Figura 8.17- Modelo icnológico del Valanginiano de la Cuenca Austral. Este modelo involucra a las formaciones Springhill (Lago San Martín) y Río Mayer (Seccional Río Guanaco). En el norte del área de estudio se desarrolla una icnofacies de Cruziana (Fm. Springhill; Poiré y Franzese, 2008), mientras que unos 120 kilómetros al sur se encuentra una icnofacies de Zoophycos (Icnoasociación I, Fm. Río Mayer). Arenicolites (Ar); Bergaueria (B); Chondrites (Ch); Cylindrichnus (Cy); Ophiomorpha (Oph); Rosselia (Ro); Skolithos (Sk); Zoophycos (Z). 


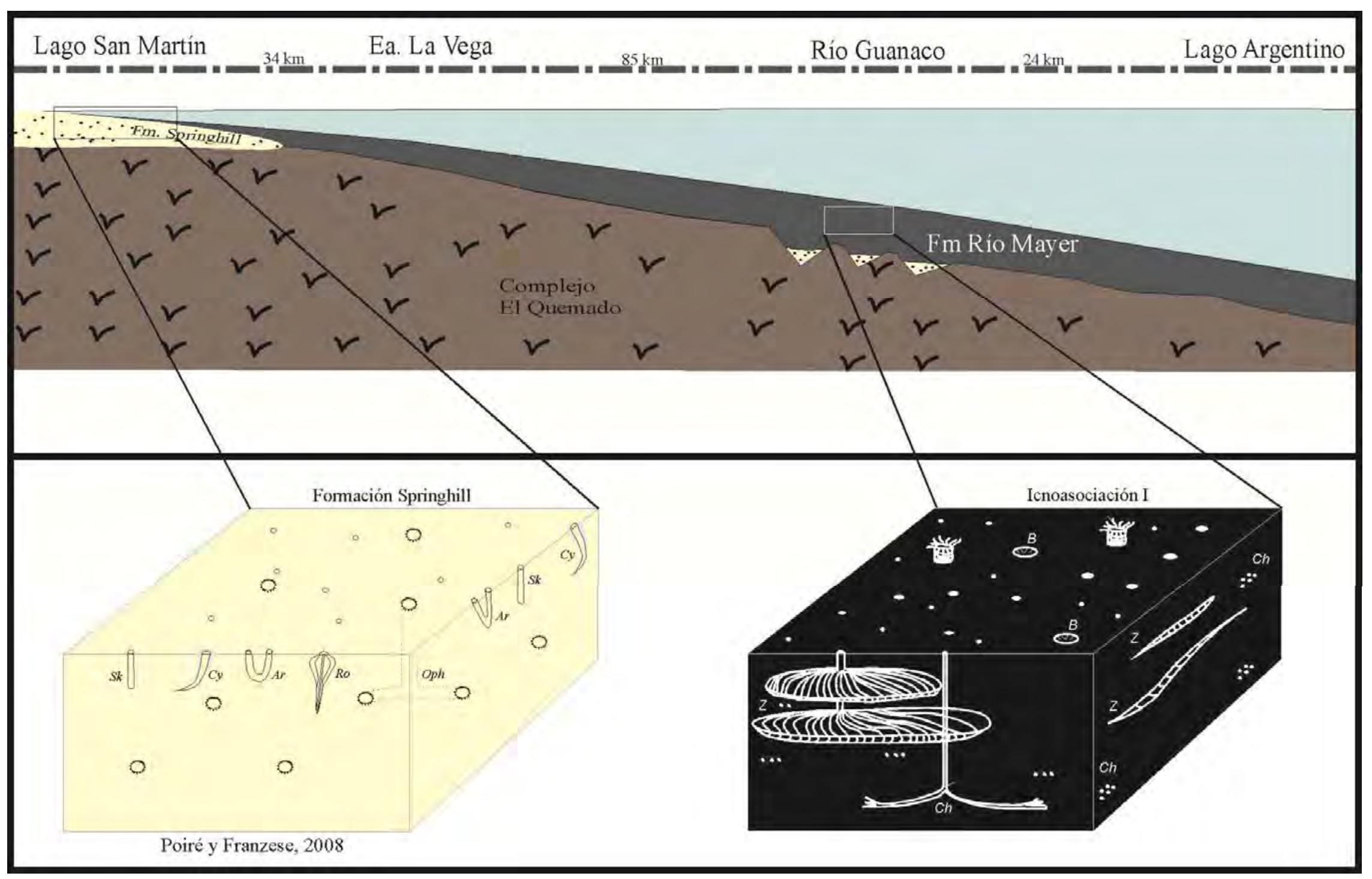

Figura 8.17 


\section{5.2 - Modelo Icnológico Albiano}

Otra correlación temporal puede ser realizada con las Icnoasociaciones II y III (figura 8.18). En la Icnoasociación II, ubicada en la Seccional Río Guanaco, la edad es Albiano- Cenomamiano inferior (ver Capítulo III). Para la región comprendida entre los lagos Viedma y San Martín (en la Estancia La Vega), se desarrolla la Icnoasociación III con una fauna de edad Albiano superior (Aguirre Urreta; 1987). Este paralelismo permite observar el pase desde ambientes litorales con estrés de salinidad en el norte de la región estudiada (Icnoasociación III) hacia ambientes marinos de plataforma distal. Estos últimos se ven afectados por flujos turbidíticos diluidos provenientes del frente deltaico que aportan oxígeno al sistema y componentes alóctonos como los fragmentos de madera con Teredolites y los Callianásidos formadores de Ophiomorpha (Icnoasociación II). También durante el Albiano, en la Formación Piedra Clavada en la localidad de Tres Lagos, ubicada a $40 \mathrm{~km}$ al sureste de la Estancia La Vega (figura 1.2) se registró una importante icnofauna con la cual se identificaron las Icnofacies de Trypanites, Glossifungites, Psilonichnus, Skolithos y Cruziana (Poiré et al., 2001, 2002; Archangelsky et al., 2008). Incorporando esta información al modelo icnológico desarrollado durante el Albiano queda claro que existe una correlación entre los modelos clásicos icnológicos basados en el reconocimiento de icnofacies (Seilacher, 1964, 1967; MacEarchern et al., 2007a, 2007b) y los paleoambientes de sedimentación registrados en el área de estudio. Las condiciones de salinidad y firmeza del sustrato habrían controlado la icnología de los depósitos que mayor relación poseen con los deltas de la Formación Piedra Clavada (paleoambientes de frente deltaico y prodelta). En condiciones de estrés salino, probablemente cercanos a la desembocadura de un canal, sólo se registran escasos ejemplares de Gyrolithes, mientras que en ambientes de salinidad normal las estructuras son muy variadas y estarían controladas principalmente por la firmeza del sustrato. Por otro lado, en los paleoambientes más alejados del frente deltaico, el principal condicionante parece ser el nivel de oxigenación del ambiente. Durante la sedimentación normal, con oxigenación moderada, se genera la presencia de los icnogéneros Chondrites, Palaeophycus y Zoophycos, todos de escaso desarrollo (icnofacies de Zoophycos). Al arribar flujos turbidíticos distales transportando madera y crustáceos, aumenta el contenido de oxígeno disuelto en el ambiente, y permite la formación de galerías de Ophiomorpha. 


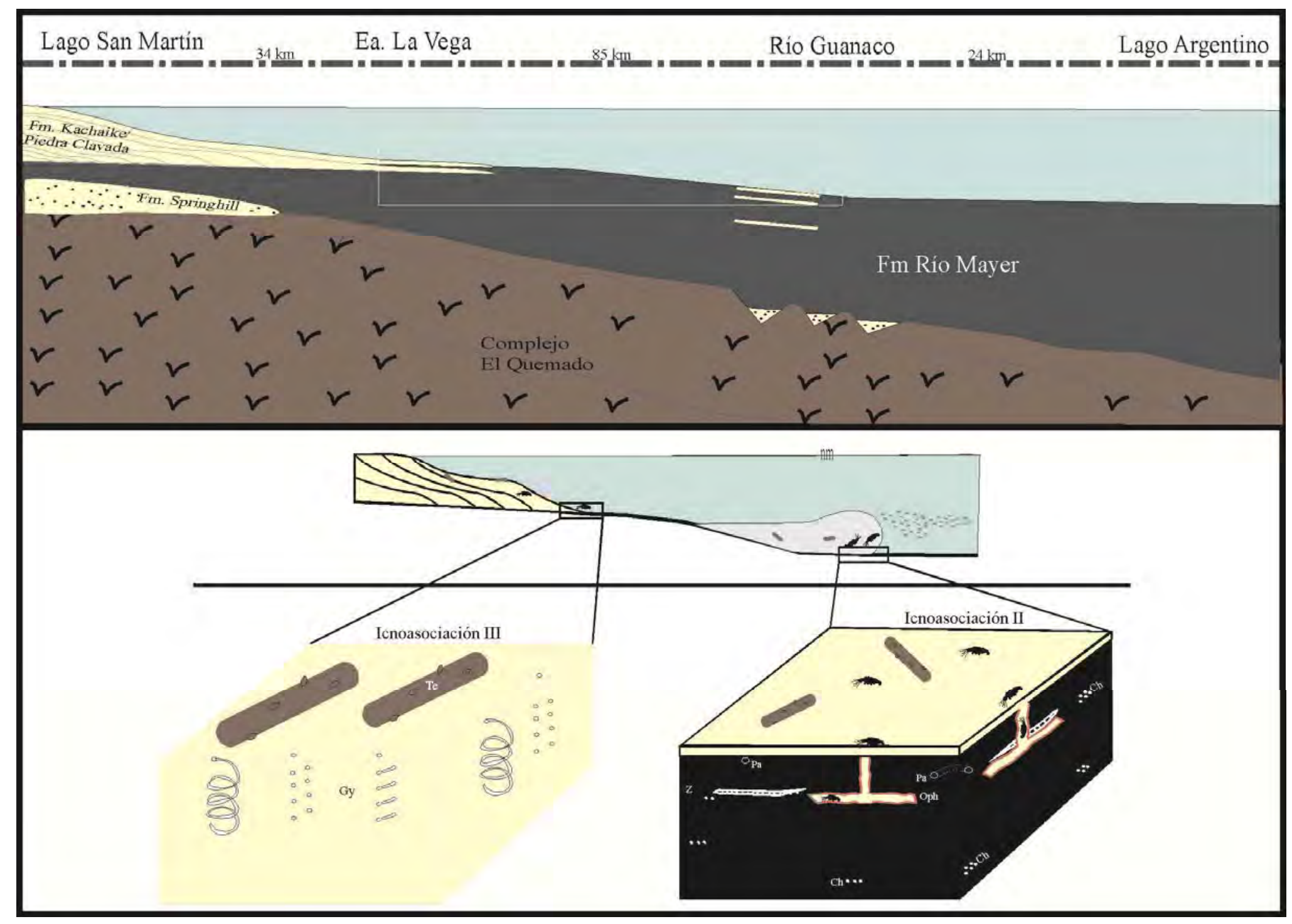

Figura 8.18 
Figura 8.18- Modelo icnológico del Albiano de la Cuenca Austral. Este modelo involucra a la Formación Río Mayer en dos localidades (Estancia La Vega y Seccional Río Guanaco), pero puede hacerse extensivo a los depósitos albianos de la Formación Piedra Clavada en la región de Tres Lagos (Poiré et al., 2001, 2002; Archangelsky et al., 2008). En el norte del área de estudio se desarrolla una asociación entre los icnogéneros Gyrolithes y Teredolites (Icnoasociación III, Fm. Río Mayer), mientras que unos 85 kilómetros al sur se encuentra una icnofacies de Zoophycos (Icnoasociación II, Fm. Río Mayer). Chondrites (Ch); Gyrolithes (Gy); Ophiomorpha (Oph); Palaeophycus (Pa); Teredolites (Te); Zoophycos (Z). 


\section{TERCERA PARTE}




\section{Capítulo IX - Discusión}

\section{1 - Límites temporales y físicos de la Formación Río Mayer en el área de} estudio

Como se ha observado en el desarrollo del presente trabajo de tesis doctoral, la Formación Río Mayer se comporta de manera diacrónica, y en el área de estudio se apoya tanto sobre la Formación Springhill (Titoniano - Valanginiano) cuando ésta está presente, como sobre el Complejo El Quemado (Jurásico medio-superior). Por otro lado, en su límite superior es cubierta por diferentes formaciones, de norte a sur formaciones Kachaike, Piedra Clavada, Lago Viedma y Cerro Toro.

En lo concerniente al límite inferior, éste es neto, lo que facilita su discriminación, dado el contraste existente entre las rocas volcánicas y volcaniclásticas del Complejo El Quemado (más allá de otros componentes reconocidos como pelitas negras y calizas Franzese et al., 2006; Poiré et al., 2006, 2007) o las areniscas con fósiles marinos de la Formación Springhill en comparación con las pelitas negras de la Formación Río Mayer. La Formación Springhill, cuando se desarrolla de manera completa, se presenta con facies de ambiente continental en su parte inferior y continúa con facies litorales y marinas. Así, cuando esta formación está presente, la transgresión se ubica dentro de sus rocas. De este modo el paso de la Formación Springhill a la Formación Río Mayer queda definido por la primera aparición de pelitas negras de ambiente marino. Esta situación, se observa en la región del Lago San Martín, en la cuesta conocida como "la Subida del Chancho" (corresponde al perfil de Estancia La Lila), donde dentro de la Formación Río Mayer se registran dos niveles de areniscas y una caliza en los primeros metros de la unidad. Estos tres niveles sumados a los aproximadamente 8 metros de pelitas negras que los dividen del último banco de areniscas, fueron incluidos por Riccardi (1968, 1971) dentro de la Formación Springhill. Finalmente para la región del Lago San Martín, se reconocieron edades valanginianas para los fósiles marinos asociados al inicio de la transgresión (Formación Springhill), en concordancia con lo enunciado por otros autores (Riccardi 1971; Kielbowicz, et al., 1983; Arbe 2002), aunque, como lo notaran Poiré y Franzese (2008, comunicación oral) no está claro si la fauna descripta por Riccardi se ubica en los últimos 
metros de la Formación Springhill o en las areniscas de los primeros metros de la Formación Río Mayer.

Una situación similar a la descripta en el norte del área de estudio se registra en la Seccional Río Guanaco dentro del Parque Nacional Los Glaciares. Los hemigrábenes desarrollados en el Complejo El Quemado son rellenados por materiales principalmente silicoclásticos y en menor medida carbonáticos. Estos sedimentos son dominados por la fracción arena, y corresponderían a la Formación Springhill (Kraemer y Riccardi, 1997). Esta idea es discutida por Poiré y Franzese (2008, comunicación oral), quienes no consideran adecuada esa denominación, ya que no se asemejarían estos afloramientos a la definición original de esa unidad. La principal diferencia observada entre los afloramientos de la Seccional Río Guanaco y la definición original de la Formación Springhill (Thomas, 1949a), es la ausencia de la denominada arenisca Springhill (Thomas, 1949b) en las nacientes del Río Guanaco. Por tal razón, se considera insuficiente la objeción a utilizar el nombre de Formación Springhill, dándole prioridad a Kraemer y Riccardi (1997). Sin embargo, es necesario la realización de un trabajo de definición más concreta de la Formación Springhill en el ámbito de la Cuenca Austral a partir de los afloramientos en la Provincia de Santa Cruz, ya que su definición original por parte de Thomas (1949a) se basa en el análisis de subsuelo en el campo petrolero de Magallanes (Provincia de Magallanes, Chile), y su correlato con las rocas que se encuentran en la Cordillera Patagónica Austral suele poseer falencias. Aclarado este punto, los depósitos de la Formación Río Mayer se ubican sobre las areniscas de la Formación Springhill. Del mismo modo que en el Lago San Martín, en la Seccional Río Guanaco, la primera evidencia de fósiles marinos se ubica dentro de la Formación Springhill, donde se reconocieron ejemplares de amonites de edad Titoniano. Esta observación se condice con lo descripto por Kraemer y Riccardi (1997).

En la margen norte del Lago Argentino no se registró la presencia de la Formación Springhill, a pesar de estar indicada por diversos autores (Blasco et al., 1979; Arbe, 2002), pero tampoco se encontró un buen afloramiento con el contacto entre el Complejo El Quemado y la Formación Río Mayer. Por esta razón no se puede aportar nada nuevo al límite inferior de la unidad en esta localidad. 
Con respecto al límite superior de la Formación Río Mayer, éste conlleva mayor dificultad en su definición, ya que es de carácter transicional. De norte a sur, esta unidad es cubierta por las formaciones Kachaike/Piedra Clavada, Lago Viedma y Cerro Toro.

En la región comprendida entre el lago San Martín y la localidad de Tres Lagos, la Formación Río Mayer es cubierta por las formaciones Kachaike y Piedra Clavada. Ambas formaciones se encuentran en sinonimia, discutida por diversos autores desde hace más de tres décadas ( $c f$. Riccardi y Rolleri, 1980), con la prioridad del nombre de Formación Piedra Clavada (Feruglio, 1938; Bianchi, 1967). Esta unidad está caracterizada por areniscas de finas a gruesas, de coloraciones amarillentas (Riccardi, 1971; Arbe, 1986, 2002). La transición entre las formaciones Río Mayer y Piedra Clavada se compone de intercalaciones de areniscas y pelitas, con alta participación de capas heterolíticas y material fósil de origen vegetal (perfiles de Estancia Kachaike y Estancia La Vega). Estos depósitos de la transición caracterizan las facies prodeltaicas del sistema deltaico de la Formación Piedra Clavada. La inclusión de los sedimentos prodeltaicos en la Formación Río Mayer ya había sido mencionada por Spalletti y Franzese (2007). En consecuencia, el final de la Formación Río Mayer (inicio de la Formación Piedra Clavada) está dado por la aparición de los primeros bancos de areniscas potentes de coloraciones amarillentas correspondientes al frente deltaico del sistema Kachaike-Piedra Clavada. En los perfiles relevados durante el presente trabajo no se recuperó material fósil que aporte edad a la transición entre las unidades aquí consideradas, con lo cual se tiene en cuenta el material bibliográfico. La edad de la Formación Piedra Clavada (y Kachaike) es albiana, con variaciones entre Aptiano superior y Albiano medio con dependencia de los autores y el material fósil considerado (Riccardi, 1971; Arbe, 2002; Archangelski et al., 2008; entre otros).

En el presente trabajo no se realizaron tareas de detalle en los afloramientos de la margen norte del Lago Viedma, con lo cual, el paso de la Formación Río Mayer a la Formación Lago Viedma no se documentó. La transición entre estas unidades fue caracterizada por Canessa et al. (2005), quienes citan la presencia de facies psamíticas de hasta 2 m de potencia intercaladas en los metros finales de Formación Río Mayer, cuya edad es albiana. Dichos niveles de arenisca fueron interpretados por los autores como barras plataformales. 
Desde la margen austral del Lago Viedma hacia el sur la Formación Río Mayer es cubierta por la Formación Cerro Toro, y el pasaje entre estas unidades también es transicional. En la Seccional Río Guanaco la transición se ubica en la sección superior de la unidad, abarcando principalmente los perfiles del este de la Vega de Pérez. Dicha transición se caracteriza por la participación de niveles psamíticos de escala decimétrica que se alternan con pelitas verde oliva a gris oscuras. Con frecuencia poseen restos vegetales (ramas) y fauna de invertebrados compuesta casi exclusivamente por diferentes grupos de bivalvos. La edad asignada al contenido fósil (Albiano - Cenomaniano inferior) junto con la participación de material fósil de origen vegetal, indican claramente un origen relacionado al sistema deltaico de la Formación Piedra Clavada. Por tal razón, se interpretaron los depósitos de la transición en la Seccional Río Guanaco como plataforma externa con influencia deltaica distal. Estos mismos depósitos fueron interpretados por Kraemer y Riccardi (1997) como el inicio de la Formación Cerro Toro (niveles con Birostrina cf. concentrica, véase perfil este de Vega de Pérez 1). Un criterio diferente se utilizó en este trabajo para marcar el final de la Formación Río Mayer y el inicio de la Formación Cerro Toro. El tramo final de la sedimentación de la unidad estudiada estuvo influenciado por el delta de la Formación Piedra Clavada durante el Albiano, esto generó la intercalación de niveles arenosos hacia el tope la Formación Río Mayer. El inicio de la Formación Cerro Toro, según el criterio aquí utilizado, estaría marcado por la desaparición de las areniscas en el tramo inferior de la Formación Cerro Toro, el que estaría compuesto por depósitos pelíticos. Esta idea de división de las unidades será tratada nuevamente en este capítulo en los temas de estratigrafía secuencial de la Formación Río Mayer y la correlación con las unidades de la Cuenca de Rocas Verdes. 


\section{2 - Aspectos Composicionales de la Formación Río Mayer}

Los aspectos composicionales de la Formación Río Mayer fueron analizados desde tres puntos de vista, la difracción de rayos X (capítulo V), la petrografía (capítulo VI) y la geoquímica (capítulo VII). Estos estudios se concentraron en los depósitos de la Seccional Río Guanaco, ya que en esta localidad se presentan los mejores y más completos afloramientos. Para esta región, a partir de los resultados del trabajo de campo (capítulo III), se distinguieron tres secciones en la Formación Río Mayer, cada una de las cuales fue caracterizada por las tres metodologías antes mencionadas. Un resumen de las características composicionales de cada sección se presenta en la tabla 9.a.

Por otro lado, se realizaron observaciones composicionales en el Lago San Martín, aunque en un número menor que en la Seccional Río Guanaco. En esta localidad del norte del área de estudio, a partir del análisis de difracción de rayos X, la Formación Río Mayer se divide en dos, un tramo inferior con mayores contenidos de calcita y un tramo superior con aumento en las proporciones de cuarzo y feldespatos. Entre las arcillas domina la clorita en la mayor parte de la unidad, excepto en la transición hacia la Formación Kachaike, donde el contenido de esmectita supera el 90 \% de la fracción fina. Petrográficamente, las areniscas son vaques líticos, y se destaca respecto de las muestras de la seccional Río Guanaco la mayor participación de líticos volcánicos. En esta localidad no se realizaron análisis geoquímicos. 


\begin{tabular}{|c|c|c|c|}
\hline & DRX & Petrografía & Geoquímica \\
\hline $\begin{array}{l}\text { Sección } \\
\text { Superior }\end{array}$ & $\begin{array}{l}\text { En roca total domina el } \\
\text { cuarzo, con moderados } \\
\text { contenidos de } \\
\text { feldespatos y escasa } \\
\text { participación de calcita. } \\
\text { Entre las arcillas domina } \\
\text { la clorita. }\end{array}$ & $\begin{array}{l}\text { Las muestras, en su } \\
\text { mayoría vaques, se } \\
\text { componen en un } 90 \text { \% de } \\
\text { cuarzo (monocristalino y } \\
\text { policristalino), feldespatos } \\
\text { y matriz pelítica. El } \\
\text { cemento predominante es } \\
\text { calcítico, de tipo } \\
\text { macroesparítico. }\end{array}$ & $\begin{array}{l}\text { El comportamiento de los elementos } \\
\text { mayoritarios y minoritarios es } \\
\text { similar en las tres secciones, a } \\
\text { excepción de los tres elementos } \\
\text { mencionados en la sección media } \\
\text { (Fe, Mn, Na). En el sector inferior } \\
\text { de esta sección hay un incremento } \\
\text { del contenido de COT, el cual se } \\
\text { vuelve casi cero en el tramo final de } \\
\text { la unidad estudiada. }\end{array}$ \\
\hline $\begin{array}{l}\text { Sección } \\
\text { Media }\end{array}$ & $\begin{array}{l}\text { Se destaca el alto } \\
\text { contenido de calcita, } \\
\text { siempre con cuarzo } \\
\text { abundante y escasos } \\
\text { feldespatos. Entre las } \\
\text { arcillas dominan la illita } \\
\text { y los Interestratificados } \\
\text { I/S. }\end{array}$ & $\begin{array}{l}\text { Sobresale de esta sección } \\
\text { de composición margosa } \\
\text { la abundancia de material } \\
\text { biogénico (microfósiles } \\
\text { calcáreos). }\end{array}$ & $\begin{array}{l}\text { En esta sección hay muy pocos } \\
\text { análisis de roca total, solo cabe } \\
\text { mencionar que desde el final de esta } \\
\text { sección aumentan los contenidos de } \\
\text { Fe, Mn y Na en la Formación Río } \\
\text { Mayer. El principal rasgo es la } \\
\text { presencia de una anomalía positiva } \\
\text { en los valores de }{ }^{13} \mathrm{C} \text { que se podría } \\
\text { correlacionar con el evento } \\
\text { Weissert. Los valores de COT } \\
\text { obtenidos son muy bajos. }\end{array}$ \\
\hline $\begin{array}{l}\text { Sección } \\
\text { Inferior }\end{array}$ & $\begin{array}{l}\text { En general predomina } \\
\text { cuarzo con picos de } \\
\text { participación de calcita y } \\
\text { escasos feldespatos. En } \\
\text { la fracción fina domina } \\
\text { la illita y los } \\
\text { Interestratificados I/S. }\end{array}$ & $\begin{array}{l}\text { Solo se encontraron rocas } \\
\text { pelíticas, las cuales son } \\
\text { ricas en componentes de } \\
\text { fracción arcilla y materia } \\
\text { orgánica. }\end{array}$ & $\begin{array}{l}\text { Esta sección posee los valores más } \\
\text { elevados de los índices que miden } \\
\text { meteorización, levemente por } \\
\text { encima de los esperados para } \\
\text { muestras pelíticas. Por otro lado } \\
\text { posee los mayores contenidos de } \\
\text { carbono orgánico total (COT) de la } \\
\text { unidad. }\end{array}$ \\
\hline
\end{tabular}

Tabla 9.a- Resumen de los aspectos composicionales (difracción de rayos X -DRX, Petrografía y Geoquímica) de las tres secciones identificadas en la Formación Río Mayer en la Seccional Río Guanaco. Más detalle en los capítulos V a VII. 


\section{2.1 -Procedencia y Ambiente tectónico}

De los datos composicionales obtenidos por las tres metodologías empleadas en la Formación Río Mayer surge una clara distinción de sectores que poseen diferente comportamiento dentro de la unidad.

Durante la primera etapa de sedimentación de la Formación Río Mayer en la región de las nacientes del Río Guanaco, la sección inferior de la unidad tiene una signatura geoquímica que indica una procedencia de rocas con afinidad ácida. La principal fuente de material a la unidad sería el Complejo El Quemado y equivalentes, que durante el inicio del Cretácico inferior (Berriasiano- Valanginiano) es la unidad que mayor superficie abarca en esta región de Gondwana, y sobre la cual se desarrolla el resto de las unidades del inicio de la cuenca Austral (formaciones Springhill y Río Mayer). Este complejo se caracteriza por la abundancia de riolitas e ignimbritas ácidas y en menor medida andesitas (Ramos et al., 1982). No se descarta para la unidad estudiada un aporte desde la Formación Bahía de la Lancha, ya que la incongruencia entre la información que brindan los valores de cristalinidad de illita y los interestratificados de illita-esmectita sugiere que, al menos parte de la illita es heredada y posee índices de cristalinidad indicativos de rocas metamórficas.

En las secciones media y superior de la formación el comportamiento de los componentes formadores de rocas sedimentarias es diferente. Los diagramas geoquímicos realizados en pelitas de estas secciones poseen una tendencia de acercamiento a los campos de rocas intermedias. Esto es observable tanto en los casos que se usan diagramas basados en elementos mayoritarios, como si se utilizan elementos traza y tierras raras. En los resultados de difracción de rayos $\mathrm{X}$ se observa un aumento en el porcentaje de feldespatos, mientras que por petrografía se incrementan los feldespatos y los líticos volcánicos. Todos estos cambios se observan desde aproximadamente el Valanginiano/Hauteriviano en la seccional Río Guanaco, con mayor desarrollo durante el Aptiano/Albiano de la sección superior.

Esta evolución desde composiciones predominantemente ácidas hacia intermedias se ajusta a los modelos de evolución del arco magmático que proponen Hervé et al. (2007). Dichos autores señalan diversas etapas de evolución del batolito patagónico austral durante los últimos 150 Ma, que incluyen cuatro etapas entre el Jurásico superior y el Cretácico superior. La primera etapa se compone de grandes volúmenes de granitos e ignimbritas 
riolíticas, de los cuales las últimas conforman el Complejo El Quemado, y se desarrolla en el Jurásico superior principalmente. Luego siguen tres etapas cretácicas, en las cuales, a partir de los 137 Ma (Valanginiano), aumenta la participación de materiales de composición intermedia, producto de la fusión de rocas provenientes de un manto deprimido o de menor participación cortical en la generación de magmas (Hervé et al., 2007). Durante los estadios 2 y 3 del Cretácico (136 -75 Ma), predominan rocas de composiciones entre tonalitas y granodioritas. Estas dos etapas se asocian a la apertura del Atlántico suroccidental y paralelamente al cierre de la cuenca marginal de Rocas Verdes (Hervé et al., 2007).

El desarrollo de la sedimentación de la Formación Río Mayer estuvo claramente influenciado, desde el punto de vista composicional, por la actividad volcánica en el arco asociado al Batolito Patagónico Austral. La evolución observada en el desarrollo plutónico/volcánico relacionada a este batolito dejó su sello en la signatura geoquímica de las pelitas de la unidad analizada.

Asimismo, si se comparan los resultados geoquímicos de las pelitas de la Formación Río Mayer con los valores de las vulcanitas de la Provincia Volcánica del Chon-Aike publicados por Pankhurst et al. (1998), queda muy clara la afinidad de las rocas aquí analizadas con las provenientes del Complejo El Quemado. Los bajos contenidos de Zr y Nb en la Formación Río Mayer y en las unidades volcánicas jurásicas de la Cuenca Austral contrastan con los altos contenidos de estos elementos en el Macizo del Deseado. Esta evidencia estaría indicando que durante la depositación de la Formación Río Mayer no se habría registrado aporte desde la Dorsal de Río Chico (Formación Chon-Aike).

En la región entre los lagos Viedma y San Martín, dentro de la transición entre las formaciones Río Mayer y Kachaike/Piedra Clavada, es notorio el incremento en la participación de los líticos de origen volcánico. Este comportamiento no se ve reflejado directamente en muestras de la misma edad de la seccional Río Guanaco (Aptiano/Albiano), pero en esta localidad lo que si se incrementa es la presencia de feldespatos, tanto en la pelitas (por difracción de rayos X) como en los vaques (petrografía). Los líticos volcánicos recuperados en la Estancia La Vega poseen gran cantidad de fenocristales de feldespato, muchos de los cuales están inalterados, con un muy buen estado de preservación y poseen hasta 10 veces el tamaño de los feldespatos hallados en los 
vaques de la Seccional Río Guanaco (figura 6.3). Esto se podría explicar por la meteorización y transporte a la que habrían sido expuestos estos sedimentos, que generaría el desprendimiento de dichos fenocristales, los que posteriormente se depositarían unos 85 km al sur en la sección superior de la Formación Río Mayer en la Seccional Río Guanaco.

Asimismo, la mayor participación de componentes de origen volcánico en las muestras de areniscas y vaques de la Formación Río Mayer en el Lago San Martín con respecto a muestras de la misma edad en las nacientes del Río Guanaco se condice con el desarrollo del arco volcánico del Neocomiano descripto por Ramos et al. (1982), que se habría desarrollado al norte de la latitud de $47^{\circ} \mathrm{S}$. Dichos autores citan la ausencia de vulcanismo para el Cretácico inferior entre los $47^{\circ}$ y $49^{\circ} \mathrm{LS}$.

En rasgos generales, las distintas fuentes de información utilizadas (principalmente petrografía y geoquímica, en menor medida difracción de rayos X), sugieren que la depositación de la Formación Río Mayer fue coetánea con el desarrollo de un arco volcánico al menos desde el Valanginiano. Dicho arco volcánico tuvo mayor influencia sobre la unidad en la región del Lago San Martín en comparación con la Seccional Río Guanaco. 


\section{3 - Paleoambientes de sedimentación}

Los depósitos de la Formación Río Mayer se desarrollan enteramente en ambientes marinos de plataforma. Esta plataforma no permaneció homogénea a través del Cretácico inferior, sino que se vio afectada por cambios principalmente eustáticos y de aporte terrígeno desde el continente. Las distintas variables que estos cambios introdujeron en la sedimentación de la formación se reflejan en la columna sedimentaria. A continuación se hará mención a las diferentes etapas reconocidas en la Formación Río Mayer con las correspondientes características paleoambientales que habrían puesto su impronta en la unidad. Luego de caracterizar las relaciones paleoambientales dentro de la unidad se hará una interpretación estratigráfico-secuencial a fin de comprender acabadamente los cambios antes mencionados.

\section{3.1 -Modelo sedimentario/icnológico}

Dentro del área de estudio, la depositación de la Formación Río Mayer se inicia en el Berriasiano en la Seccional Río Guanaco. En esta localidad dentro de los hemigrábenes del Complejo El Quemado se encuentra la Formación Springhill (figura 9.1a), de edad Titoniano, por sobre la cual se desarrolla la Formación Río Mayer. En parte de los hemigrábenes aún quedaba espacio de acomodación que fue rellenado por pelitas negras de la Formación Río Mayer, una vez relleno dicho espacio, la unidad cubrió toda la región aledaña (figura 9.1b, c). Esta primera etapa (Berriasiano- Valanginiano inferior) se caracteriza por la baja oxigenación del paleoambiente que genera la ausencia de bioturbación y las mayores concentraciones de Carbono Orgánico Total (COT) de la formación en el área de estudio. Los depósitos se componen de pelitas negras bien laminadas que alternan con margas a modo de niveles concrecionales o estratos mantiformes.

Figura 9.1- a, inicio de la sedimentación de la Cuenca Austral en el área de estudio, con la depositación de la Formación Springhill durante el Titoniano. En los diagramas b-c se deposita la Formación Río Mayer, primero rellena el espacio remanente en los hemigrábenes (b) luego cubre toda la región de las naciente del Río Guanaco. 


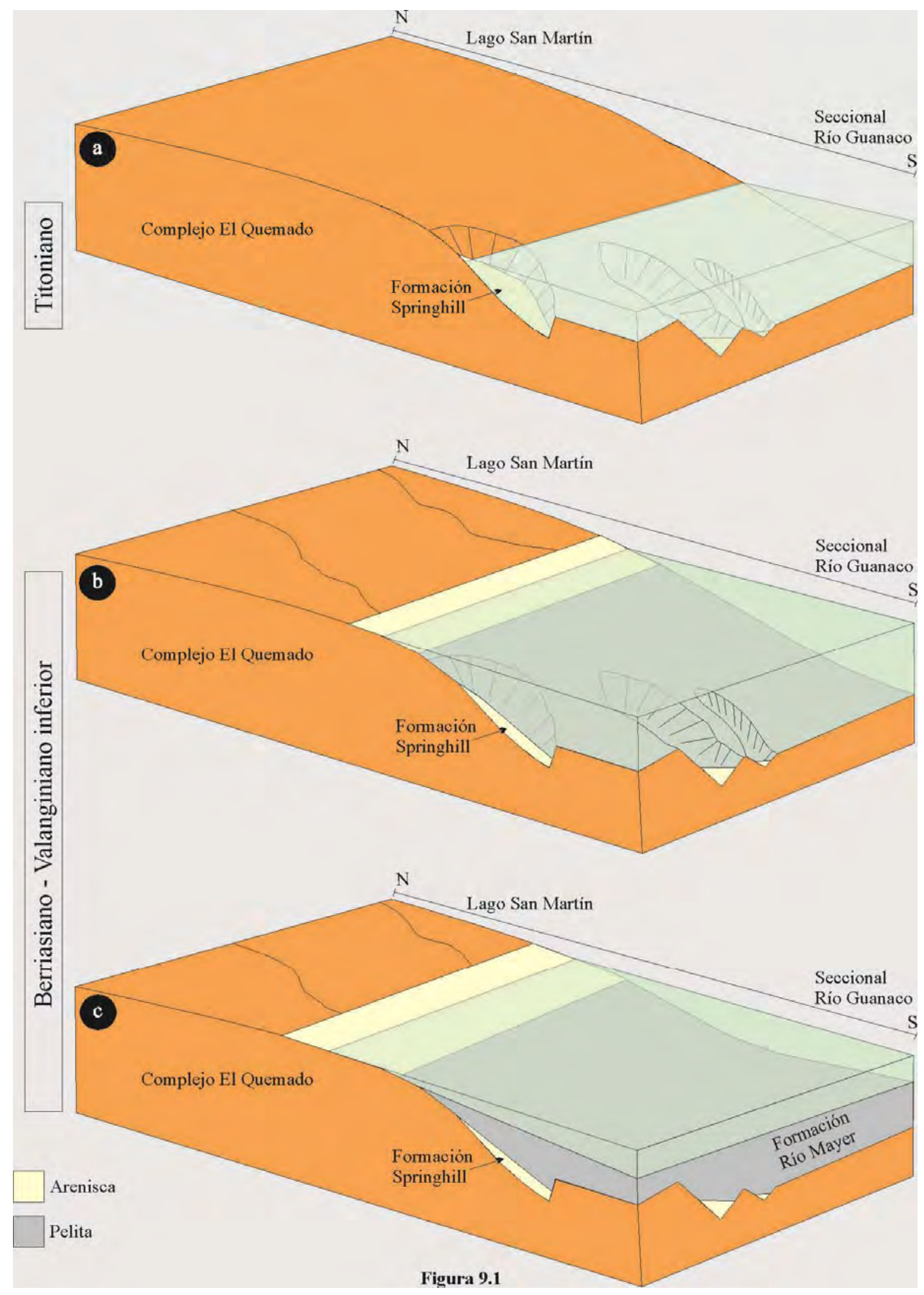


Durante el Valanginiano se habría producido una aceleración de la transgresión lo que genera la sedimentación de los depósitos marinos de la Formación Springhill en la región del Lago San Martín (figura 9.2). Es en este momento en que la cuenca se expande cuando en la Seccional Río Guanaco se comienzan a depositar las margas de la sección media. La razón principal de la sedimentación margosa sería la disminución del aporte clástico desde el continente producto de un prolongado proceso de transgresión que entramparía los sedimentos terrígenos en los bordes de cuenca.

En este lapso de tiempo se registra una gran participación de trazas fósiles con una importante icnofacies de Zoophycos en la Seccional Río Guanaco y paralelamente al norte del área de estudio una icnofacies de Cruziana en la Formación Springhill (capítulo VIII). La sección media de la Formación Río Mayer se caracteriza, composicionalmente, por un aumento en la presencia de calcita y una disminución importante del contenido de COT respecto de la sección inferior. El análisis de isótopos estables determinó que el material carbonático se encuentra modificado diagenéticamente, por tal motivo estos datos no se pueden utilizar para consideraciones paleoclimáticas, aunque se reconoció una asociación foramol que indica condiciones de aguas frías.

La sedimentación de la sección media de la unidad en las nacientes del Río Guanaco no fue homogénea, y se vio interrumpida por un nivel de erosión que marca una clara diferenciación del tercio superior de la sección (ver perfil PG, capítulo III). A partir de dicho nivel disminuye considerablemente la participación de calcita y aumentan principalmente feldespatos y arcillas, también aumenta el contenido de COT y disminuye la participación de trazas fósiles, aunque continúa el desarrollo de la icnofacies de Zoophycos (ver perfil PG, capítulos V, VII).

La importancia del reconocimiento de este nivel será tratado a la brevedad en el apartado de la discusión sobre estratigrafía secuencial en la Formación Río Mayer. 


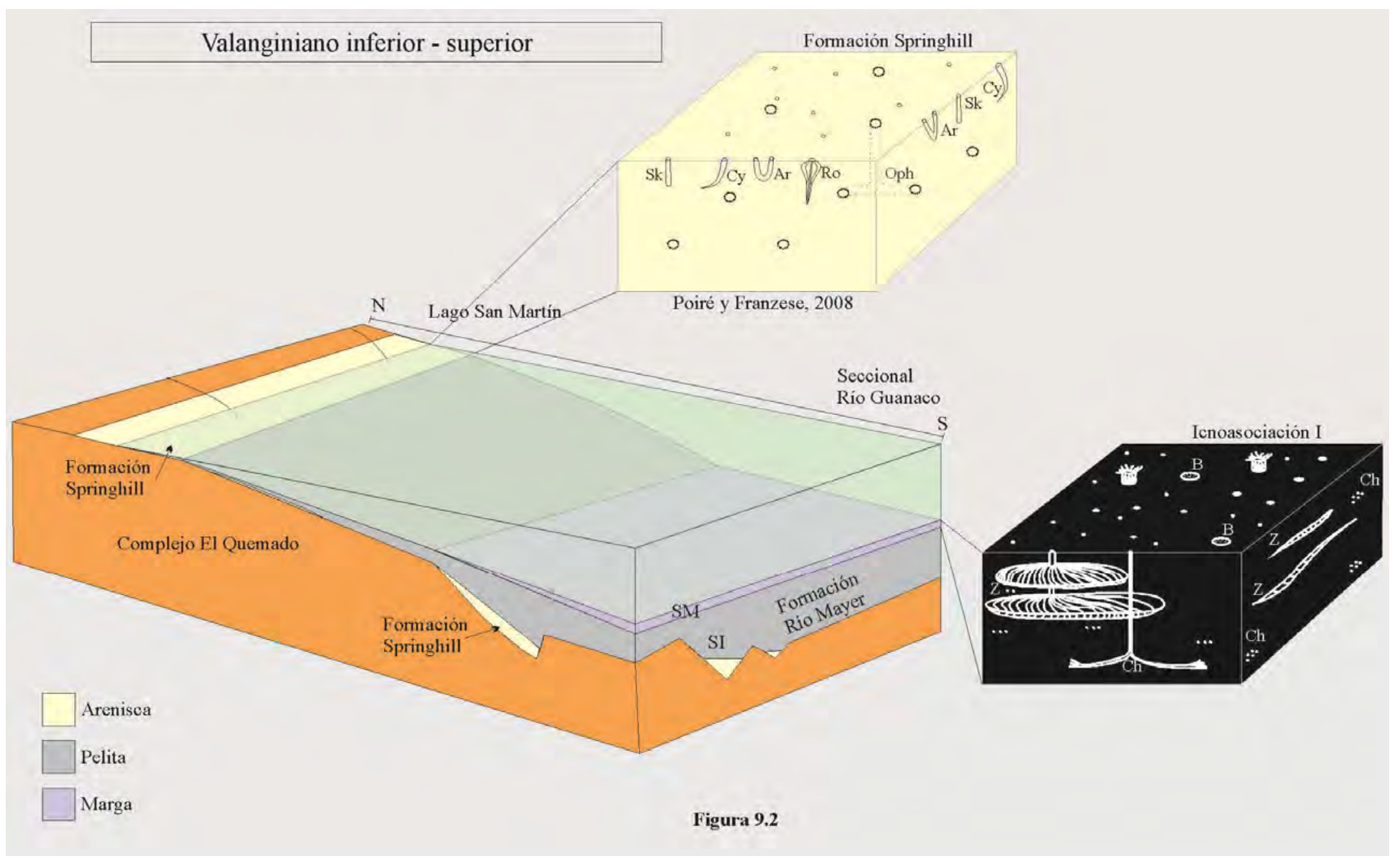

Figura 9.2- Modelo de depositación de la Formación Río Mayer durante el Valanginiano. En la Seccional Rio Guanaco se deposita la sección media de la unidad con un importante desarrollo de la icnofacies de Zoophycos, mientras que en Lago San Martín se inicia la Formación Springhill en facies marinas someras con icnofacies de Cruziana. Sección inferior: SI; Sección media: SM. 
Entre el final del Valanginiano y el inicio del Hauteriviano, sobre sedimentos pelíticos y margosos, se genera en la Seccional Río Guanaco la formación de un nivel de glauconita. Paralelamente, en el Lago San Martín se comienza a depositar la Formación Río Mayer con pelitas negras y luego con calizas y areniscas glauconíticas (figura 9.3a). A partir de este momento, en toda el área de estudio predomina la sedimentación pelítica (figura 9.3b).

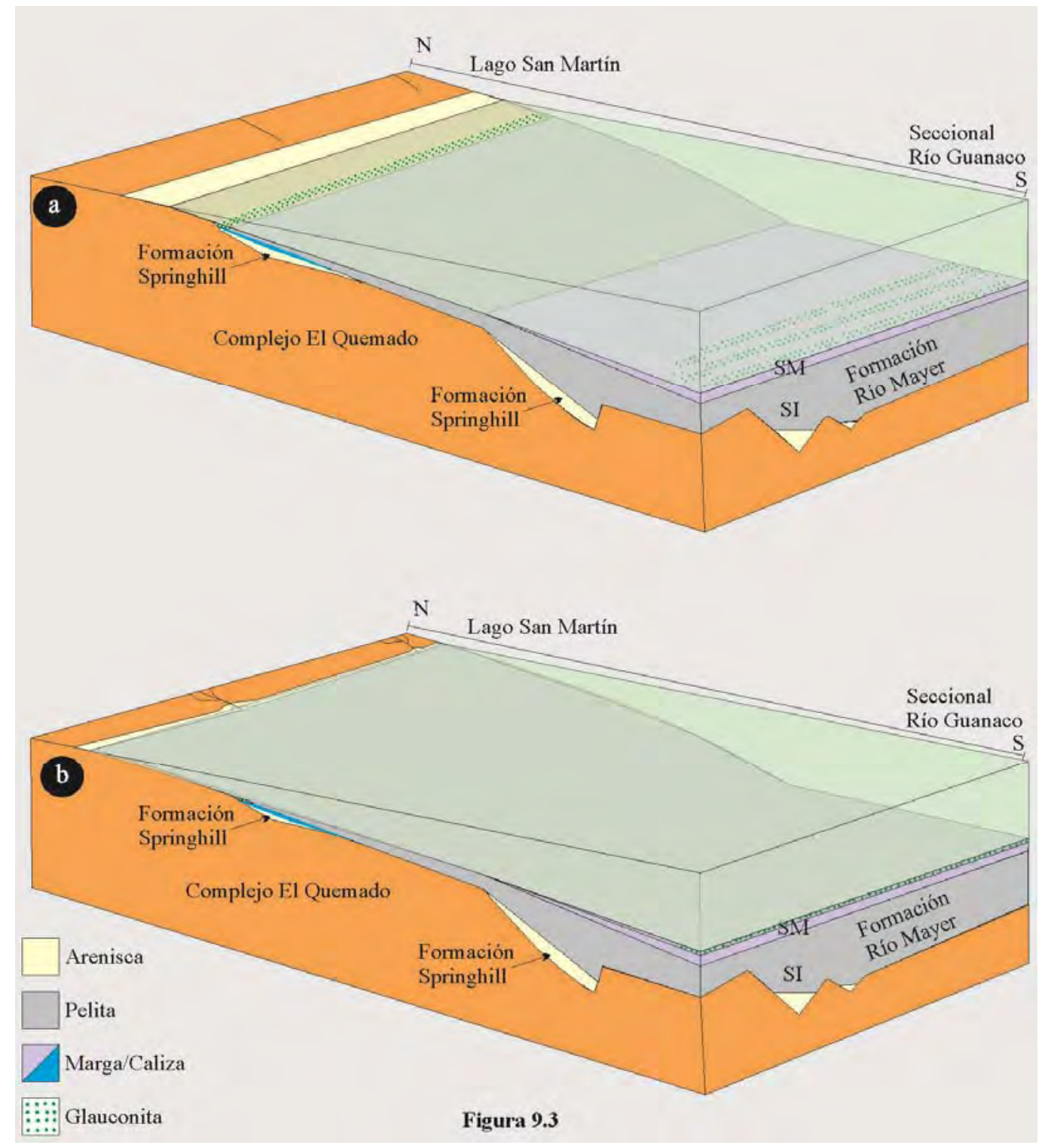

Figura 9.3- En a se observa el inicio de la Formación Río Mayer en el Lago San Martín y el final de la sección media en la Seccional Río Guanaco. Luego (b) predomina la sedimentación pelítica en toda el área de estudio. SI; Sección media: SM. 
A partir del Hauteriviano inferior y durante el Barremiano las condiciones se mantuvieron en mayor o menor medida estables. En toda la región predominó la decantación de pelitas, en general de color negro, con desarrollo de laminación y concreciones de margas. Eventuales niveles de areniscas se registraron en la región de la seccional Río Guanaco, no así la región del Lago San Martín. Estas características indican que el ambiente de plataforma externa en el cual se desarrolló la Formación Río Mayer estuvo afectado por flujos turbidíticos que transportaron sedimentos arenosos (menos frecuente psefíticos) hacia el offshore. La generación de esos flujos turbidíticos podría estar relacionada a eventos de tormenta en zonas someras de la plataforma (Gabaldon, 1991). La distribución espaciada de las capas de arenisca hace pensar que tormentas de magnitud necesaria para generar depósitos turbidíticos que lleguen hasta la seccional Río Guanaco, no fueron muy frecuentes.

En el Hauteriviano el aporte de la Formación Río Mayer empieza a estar influenciado por composiciones intermedias provenientes del Batolito Patagónico Austral con un arco que estaba en formación ubicado al norte del Lago San Martín.

En la figura 9.4 se observa este período de tiempo en el cual se depositó la parte basal de la sección superior de la unidad (SS), de características predominantemente pelíticas con algunas intercalaciones arenosas.

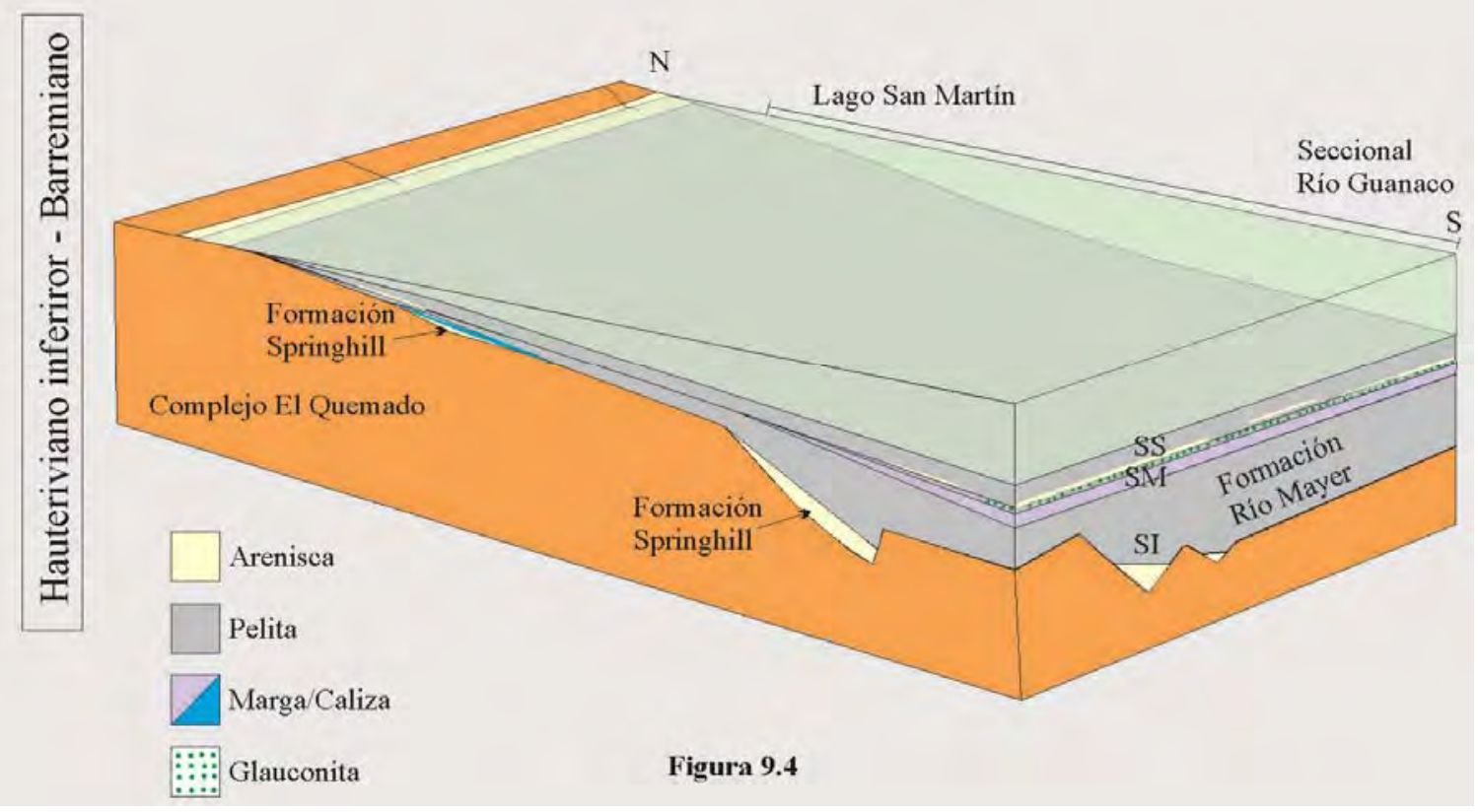


Figura 9.4- Desde el Hauteriviano inferior y durante el Barremiano predominó la decantación pelítica en toda el área de estudio (sección superior: SS), solo se vio afectada por flujos turbidíticos distales producidos por tormentas.

El cambio más importante en los ambientes sedimentarios del Cretácico inferior de la Cuenca Austral es la instalación del sistema deltaico Kachaike/Piedra Clavada (figura 9.5). La instauración de este sistema generó en la Formación Río Mayer la división en dos paleoambientes que se desarrollaron entre el Aptiano y el Albiano. En la región comprendida entre los lagos Viedma y San Martín la Formación Río Mayer corresponde a un paleoambiente de prodelta. Estos depósitos de la unidad se caracterizan por la abundancia de facies heterolíticas, el abundante contenido de materia orgánica vegetal diseminada en las rocas y la escasa presencia de trazas fósiles. Hacia el sur, en la Seccional Río Guanaco, el paleoambiente continúa con características de plataforma externa, pero a diferencia de la desarrollada desde el Berriasiano, la participación de areniscas es cada vez más frecuente hacia el tope de la formación. Estas areniscas provienen de flujos turbidíticos que se habrían generado en el frente deltaico. La presencia de la icnofacies de Zoophycos en esta localidad se ve interrumpida por los flujos turbulentos, que junto con las arenas transportan restos de madera con Teredolites y crustáceos que forman galerías de Ophiomorpha en las pelitas de la sección superior de la formación (figura 9.5).

Los contenidos de COT en este último intervalo son mínimos, producto de la mayor oxigenación del paleoambiente. Durante este lapso temporal la procedencia de las rocas posee un claro incremento en la participación de componentes de origen volcánico, dejando de manifiesto que el arco ya estaría actuando plenamente.

Figura 9.5- Desarrollo de la Formación Río Mayer durante el Aptiano-Albiano. Entre los lagos Viedma y San Martín la unidad corresponde a un paleoambiente de prodelta con escasa participación de trazas fósiles. En la Seccional Río Guanaco el paleoambiente continua siendo de plataforma externa, pero la influencia deltaica se observa en la frecuente aparición de areniscas con restos de plantas. Sección inferior: SI; Sección media: SM; Sección superior: SS. 


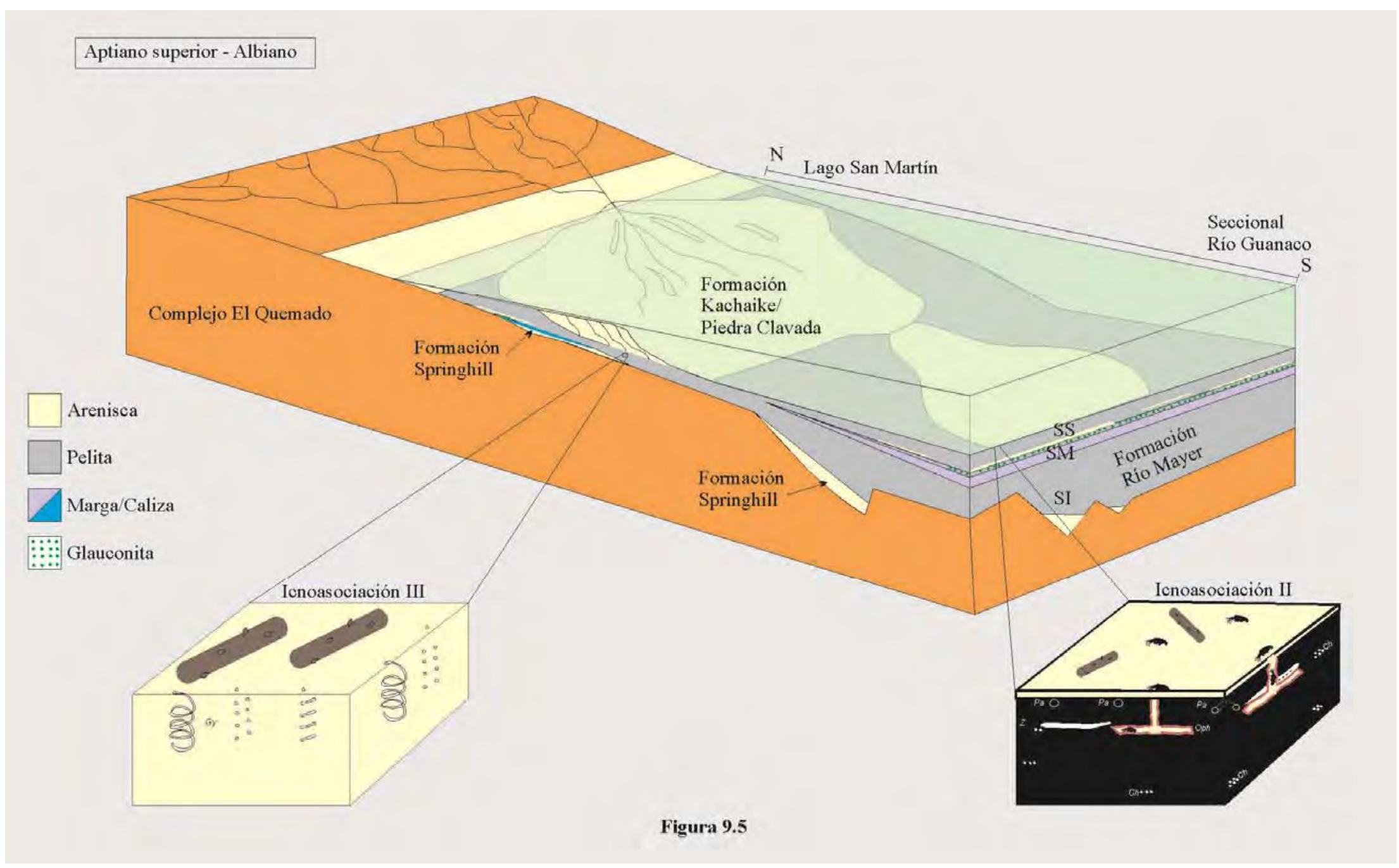

Figura 9.5 


\section{3.2 -Estratigrafía Secuencial en la Formación Río Mayer}

La estratigrafía secuencial es una importante herramienta para el análisis de cuenca y la exploración de hidrocarburos (Steckler et al., 1993). La metodología se basa en identificar estratos sedimentarios concordantes limitados por superficies de discontinuidad. Los modelos desarrollados asumen que los cambios en el nivel de base (fluctuaciones eustáticas), la tectónica y el volumen del aporte sedimentario son los responsables de la generación de las mencionadas discontinuidades (Vail et al., 1977; Pitman, 1978; Watts, 1982; Summerhayes, 1986; Galloway, 1989; Van Wagoner et al., 1988). De los tres factores posibles, las fluctuaciones en el nivel del mar son las más empleadas en secuencias marinas.

Se reconocen dos tipos de discontinuidades principales o límites de secuencia, el tipo 1 y el tipo 2 (Vail y Todd, 1981). Los límites de secuencia tipo 1 se generan cuando el descenso del nivel del mar es muy grande y se restringe la sedimentación a la región de la cuenca profunda, mientras que la plataforma queda totalmente expuesta. Por otro lado, durante el límite de secuencia tipo 2 parte de la plataforma queda sumergida y se registra sedimentación en ella (Steckler et al., 1993). Otras superficies importantes son la superficie transgresiva (ST) y la superficie de máxima inundación (SMI) (Posamentier y Vail, 1988). Entre los límites de secuencia y estas dos superficies quedan delimitados cuatro conjuntos de rocas denominados: cortejo de etapa de descenso ("falling stage systems tract"- FSST-), cortejo de mar bajo (CMB), cortejo transgresivo (CT) y cortejo de mar alto (CMA), todos controlados por la relación entre el espacio de acomodación y el aporte sedimentario (Coe y Church, 2003). El FSST solo ocurre en el caso de regresiones forzadas (límite de secuencia tipo 1) y el potencial de preservación de este cortejo en el registro geológico es muy bajo (Coe y Church, 2003).

En estratigrafía secuencial, una secuencia se encuentra formada por estos cortejos y está confinada entre dos límites de secuencia. La unidad fundamental para el desarrollo de una secuencia es la parasecuencia. Se define parasecuencia al conjunto de estratos concordantes, genéticamente relacionados entre sí, limitados por superficies de inundación o sus superficies correlativas que indican aumento de la profundidad del agua (Van Wagoner et al., 1988, 1990; Posamentier et al., 1988; Walker, 1990; Arnott, 1995; Spalletti et al., 2001a, 2001b; Coe y Church, 2003). La región cercana a la línea de costa es donde se 
registra el mayor desarrollo de parasecuencias, ya que es la zona donde en general el aporte sedimentario es mayor que la tasa de acomodación (Coe y Church, 2003). Según la línea de costa migre hacia el continente, permanezca estable o migre hacia el centro de cuenca el arreglo de las parasecuencias será retrogradante, agradante ó progradante (Coe y Church, 2003).

Los arreglos de parasecuencias retrogradantes caracterizan el CT, los arreglos progradantes se concentran en el final del CMA y el inicio del CMB, mientras que la agradación de parasecuencias se registra principalmente en el inicio del CMA y el final del CMB (Posamentier y James, 1993).

En la figura 9.6 se observa la evolución de un modelo estratigráfico secuencial típico (tomado y modificado de Haq, 1991; Coe y Church, 2003), el que se inicia con un límite de secuencia tipo 1. Entre los puntos máximo y mínimo en la curva teórica del nivel del mar se desarrolla el FSST (figura 9.6a, a la derecha). El desarrollo de este cortejo es complejo, su preservación, geometría y disposición lateral dependen del perfil de sedimentación, las tasas de sedimentación y espacio de acomodación principalmente (Coe y Church, 2003). Cuando el nivel del mar comienza nuevamente a ascender (figura 9.6b) se deposita el CMB hasta el punto en el cual la generación de espacio de acomodación en la cuenca se incrementa notoriamente (Coe y Church, 2003). A estos depósitos se los suele denominar también cuña de mar bajo. El nivel del mar continúa ascendiendo y genera que la relación entre el espacio de acomodación y el aporte sedimentario aumente de manera considerable. Esta situación hace migrar la depositación cada vez más hacia el continente, generando una transgresión, en consecuencia un cortejo transgresivo (CT) (figura 9.6c). La base de este CT es la superficie transgresiva (ST), la que suele estar bien representada en ambientes costeros (Coe y Church, 2003). Es frecuente que en la base del CT se generen niveles de calizas producto de la disminución del aporte clástico y un aumento en la productividad carbonática (Haq et al., 1988; Spalletti et al., 2001a, 2001b; Cattaneo y Steel, 2003). Cuando la transgresión consigue su punto máximo la cantidad de sedimentos que alcanzan las zonas profundas de la cuenca llega al mínimo, y favorece la formación de niveles condensados (Abbott, 1998) o la formación de minerales autigénicos (Coe y Church, 2003). Esta superficie se denomina “superficie de máxima inundación (SMI)” y marca el fin del CT y el inicio de la depositación del CMA (figura 9.6d). Finalmente, el 
CMA se desarrolla entre la superficie de máxima inundación y el próximo límite de secuencia desarrollado en la cuenca (figura 9.6e).

El ejemplo desarrollado en la figura 9.6 es el más citado en la bibliografía tradicional, sin embargo es común en el registro sedimentológico que no se preserven todos los cortejos (Coe y Church, 2003).

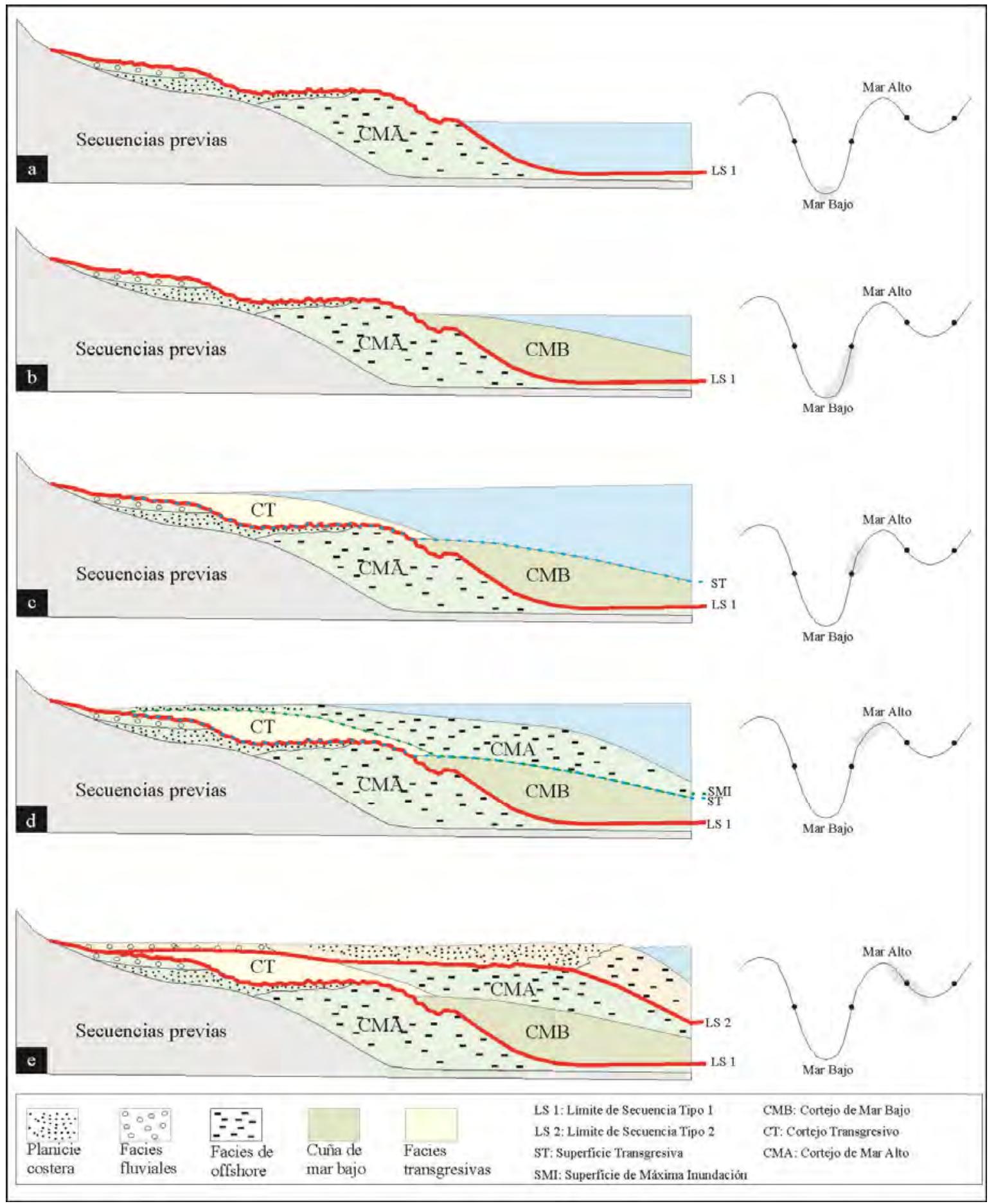


Figura 9.6- Modelo del progreso de una secuencia sedimentaria. Se inicia el modelo con el desarrollo un límite de secuencia tipo 1 (figura 9.6a). Posteriormente comienza el ascenso relativo del nivel del mar que genera primero la depositación del cortejo de mar bajo (figura 9.6b), luego los depósitos del cortejo transgresivo que se encuentran entre las superficies transgresiva y de máxima inundación (figuras 9.6 c y d). Sobre la SMI se deposita el cortejo de mar alto hasta la generación de un nuevo límite de secuencia (figuras 9.6 d y e). Modificado de Haq (1991) y Coe \& Church (2003).

\title{
IX. 3.2.1 -Superficies reconocidas
}

En los depósitos analizados en la Seccional Río Guanaco y en el Lago San Martín de la Formación Río Mayer se reconocieron diferentes tipos de superficies con edades variables. Una primera distinción de estas superficies fue agruparlas por edad y localidad, para posteriormente realizar correlaciones estimativas. Dichas correlaciones pueden tener un sesgo importante dado la distancia entre localidades (120 kilómetros) y la carencia de afloramientos intermedios que permitan afinar las interpretaciones, sin embargo representan un avance importante en la caracterización estratigráfica del Cretácico inferior de la Cuenca Austral.

Se reconocieron cuatro momentos con desarrollo de superficies:

\author{
a- Titoniano (Jurásico superior) \\ b- Neocomiano (Cretácico inferior- Berriasiano a Barremiano) \\ c- Aptiano/Albiano inferior \\ d- Albiano superior/Cenomaniano inferior (límite entre Cretácico inferior y superior)
}

En la seccional Río Guanaco fueron reconocidas las superficies desarrolladas en los momentos a, b y d, mientras que la superficie del Aptiano/Albiano inferior se infiere pero no se distingue con claridad su presencia. Por otro lado, en el Lago San Martín sólo se registraron en el presente trabajo las provenientes del Neocomiano y del Aptiano/Albiano inferior. Por esta razón la numeración de las superficies se basará en lo hallado en Río Guanaco mientras que para Lago San Martín se usaran letras.

A continuación se describirán las diferentes superficies, divididas en los cuatro grandes grupos. 


\section{3.2.1.1 Titoniano -Superficie Transgresiva 1 (ST1)-}

Se denominó ST1 a la superficie transgresiva que se desarrolló durante el Titoniano en los afloramientos de la Formación Springhill. Dicha superficie sólo se registró en la Seccional Río Guanaco. La expresión de esta superficie varía según la parte del depocentro que se considere, y posee características diferentes de norte a sur. En el Cerro Pintado (Perfil IG), que se encuentra en la región norte del hemigraben, la ST1 se reconoce por un notorio incremento en la productividad carbonática que genera la depositación de calizas. Unos 5 kilómetros hacia el sur, en el oeste de la Vega de Pérez (Perfil WVP), la ST1 se caracteriza por la primera aparición de sedimentos marinos (areniscas con amonites) que se depositan sobre vaques ricos en material carbonoso. En la figura 9.7 se muestra la superficie ST1 desarrollada dentro de la Formación Springhill en el perfil IG del Cerro Pintado.

En esta primera secuencia la zona de máxima inundación podría corresponderse con un nivel de condensación en la muestra IG 17 (unos 17 metros desde el inicio de la unidad), la cual presenta el máximo contenido de COT de la Formación Río Mayer (Wignall, 1991; Strohmenger y Strasser, 1993).

Figura 9.7- Desarrollo de la ST1 en la Seccional Río Guanaco. En la imagen a se observa la vista general del hemigraben del Complejo El Quemado en el Cerro Pintado. En b, detalle del hemigraben. En la figura c, arriba una foto de los depósitos la Formación Springhill, abajo la interpretación de la foto. En los últimos metros de la unidad aumenta la participación de carbonatos (color verde claro), en estos depósitos se recuperaron los fósiles de edad titoniana. La ST1 se encuentra en la base de los niveles carbonáticos. Nótese la presencia de una persona como escala $(1,90 \mathrm{~m})$. 


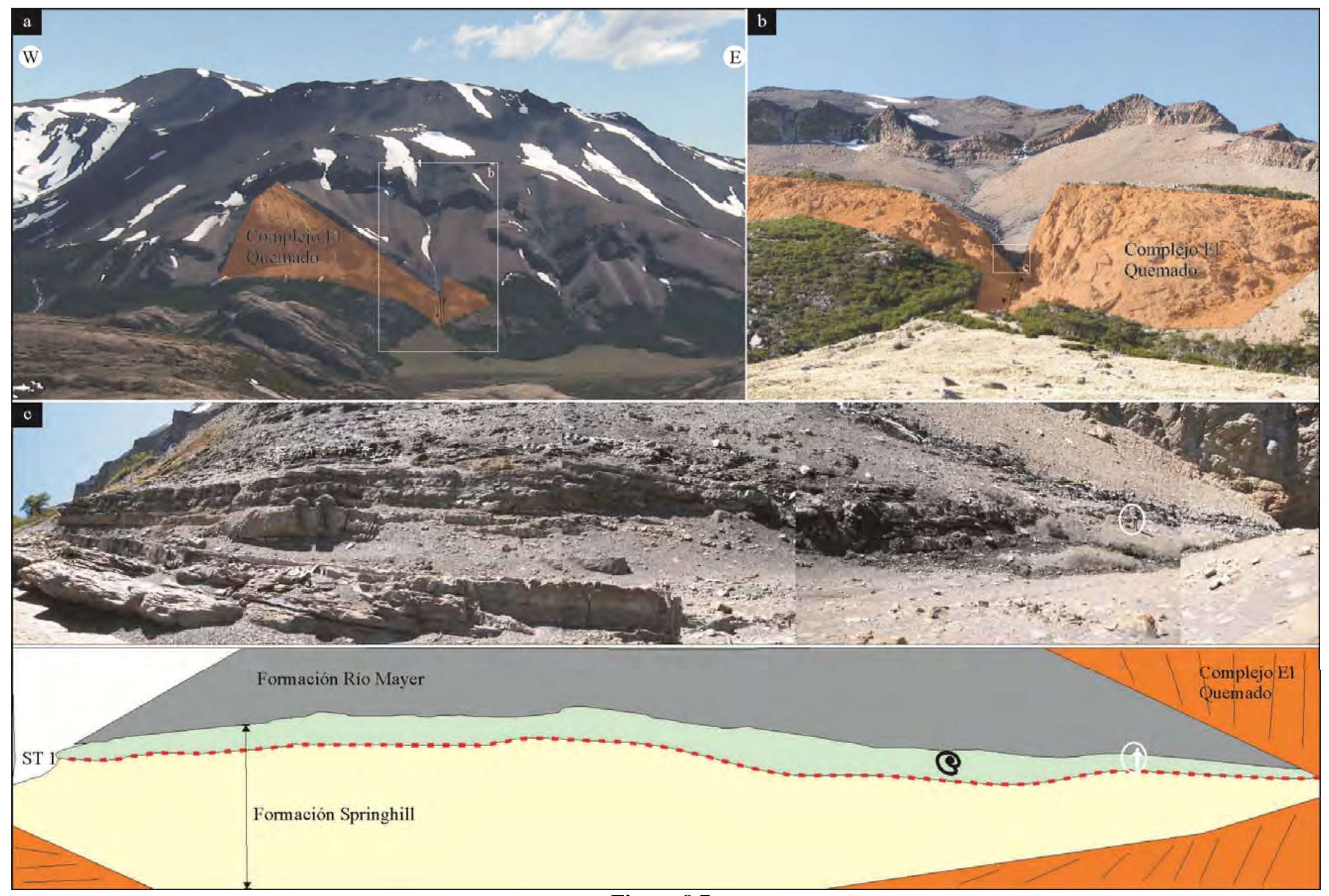

Figura 9.7- 


\section{3.2.1.2 -Superficies neocomianas}

En esta categoría se agrupan las superficies reconocidas en los depósitos tanto de la Seccional Río Guanaco como en el Lago San Martín, que se desarrollaron entre el Valanginiano y el Hauteriviano inferior.

\section{A) Seccional Río Guanaco}

Durante el Neocomiano en la Seccional Río Guanaco se registran las superficies ST2, SR1 y SMI. En la figura 9.8 se muestra la distribución de estas superficies en el perfil PG. La ST2 marca el inicio de la sección media de la unidad, se caracteriza por un incremento en la relación de productos carbonáticos/silicoclásticos evidenciada por el abrupto inicio de la sedimentación de margas sobre pelitas negras laminadas (figura 9.8 c). Este cambio estaría dado por un aumento en la superficie cubierta por la cuenca que generaría una importante disminución del aporte clástico, en consecuencia una menor dilución de los materiales carbonáticos. En el tramo final de la sección media hay un nivel de erosión muy marcado, constituido por una alta concentración de belemnites en una matriz de arena gruesa sabulítica, incluso rellenando pequeños canales (figura 9.8 d). Este nivel representa una superficie de erosión que constituye la SR1. A partir de esta superficie cambian los depósitos (aumenta el contenido de areniscas), aunque de manera muy rápida se restablecen las condiciones transgresivas que dejan nuevamente unos metros por encima de la SR1 pelitas negras laminas. Sin embargo no es posible señalar con seguridad una superficie transgresiva en este sector del perfil.

Entre las superficies ST2 y SR1 no se registra un nivel que pueda asumirse como superficie de máxima inundación, es probable que los depósitos de mar alto tuvieran poco desarrollo y la superficie regresiva los erosionó.

En cambio, entre los depósitos de carácter transgresivos post SR1, sí es evidente una superficie de máxima inundación (SMI), la cual está constituida por un nivel de glauconita (figura 9.8 f, g) muy constante en la región de las cabeceras del Río Guanaco, ya que se registró en los perfiles PG y WVP separados por 5 kilómetros de distancia. La edad tentativa de esta superficie estaría comprendida entre el Valanginiano superior y el Hauteriviano inferior. 


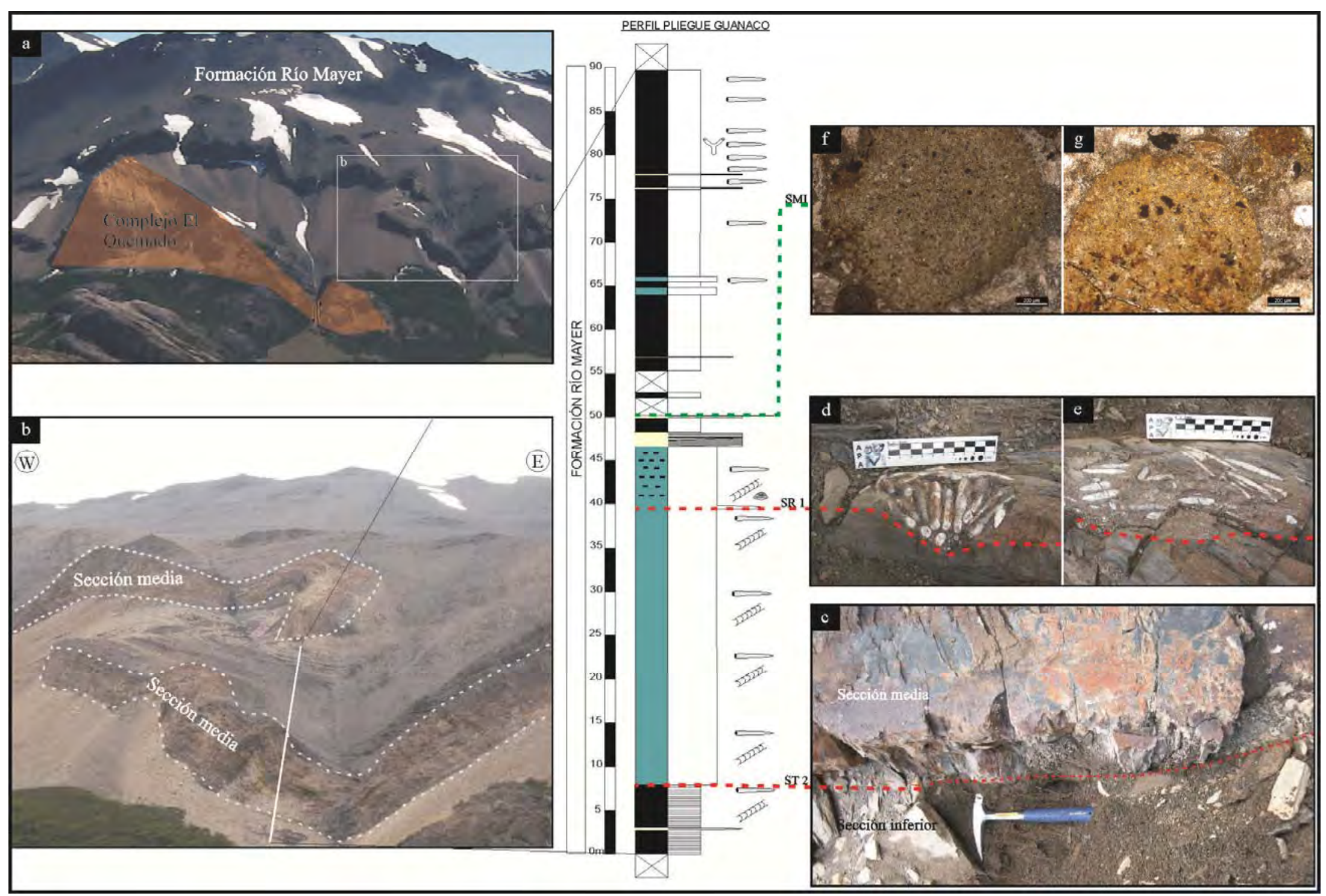

Figura 9.8- 
Figura 9.8- Ubicación del perfil PG en el Cerro Pintado (fotos a y b), dicho perfil abarca la sección media y el inicio de la sección superior de la Formación Río Mayer. En la foto c se observa la superficie ST2, marcada por el contacto neto entre las pelitas negras y las margas. En las imágenes d y e se muestra el nivel de erosión que representa la superficie regresiva (SR1). Las fotos $\mathrm{f}$ y g son microfotografías de los granos de glauconita que constituyen la superficie de máxima inundación (SMI).

\section{B) Lago San Martín}

Las superficies reconocidas en el Lago San Martín durante el Neocomiano se desarrollan en el perfil de Estancia La Lila, en la denominada Subida del Chancho (figura 9.9).

La primera superficie es transgresiva, denominada STa, y está marcada por un cambio neto desde ambientes continentales a marinos. Los afloramientos continentales de la Formación Springhill incluyen pelitas con desarrollo de paleosuelos (figura 9.9 c) y areniscas con troncos carbonizados (figura 9.9 d). Por arriba de estos niveles aparecen areniscas con fósiles marinos (figuras 9.9 e, f, g) y gran participación de trazas fósiles marinas. Al finalizar los niveles de areniscas se depositaron unos 5 a 10 metros de pelitas negras muy mal afloradas (inicio de la Formación Río Mayer), producto del aumento en la profundidad del agua en la región. Al tope de las pelitas hay un nivel de areniscas bioclásticas que marca una somerización importante del ambiente. Este nivel psamítico representa, en consecuencia, un evento regresivo limitado en su base por una superficie denominada SRa (figura 9.9 h). Inmediatamente por encima de las areniscas hay un nivel de caliza bioclástica (la roca está recristalizada y habría correspondido a un waquestone ver capítulo VI-) que señala un incremento en la productividad carbonática importante. Por sobre las calizas se depositó una arenisca glauconítica (figura 9.9 i, j). Estos dos últimos estratos marcarían una nueva tendencia transgresiva sobre los que se depositarían las pelitas que predominarán hasta finalizar la unidad estudiada. No se pudo determinar una zona de máxima inundación en este último tramo, aunque se registran varios niveles de condensación en el perfil de Estancia La Federica, la falta de datos complementarios como por ejemplo contenidos de carbono orgánico total, hace difícil la determinación de dicha zona. 


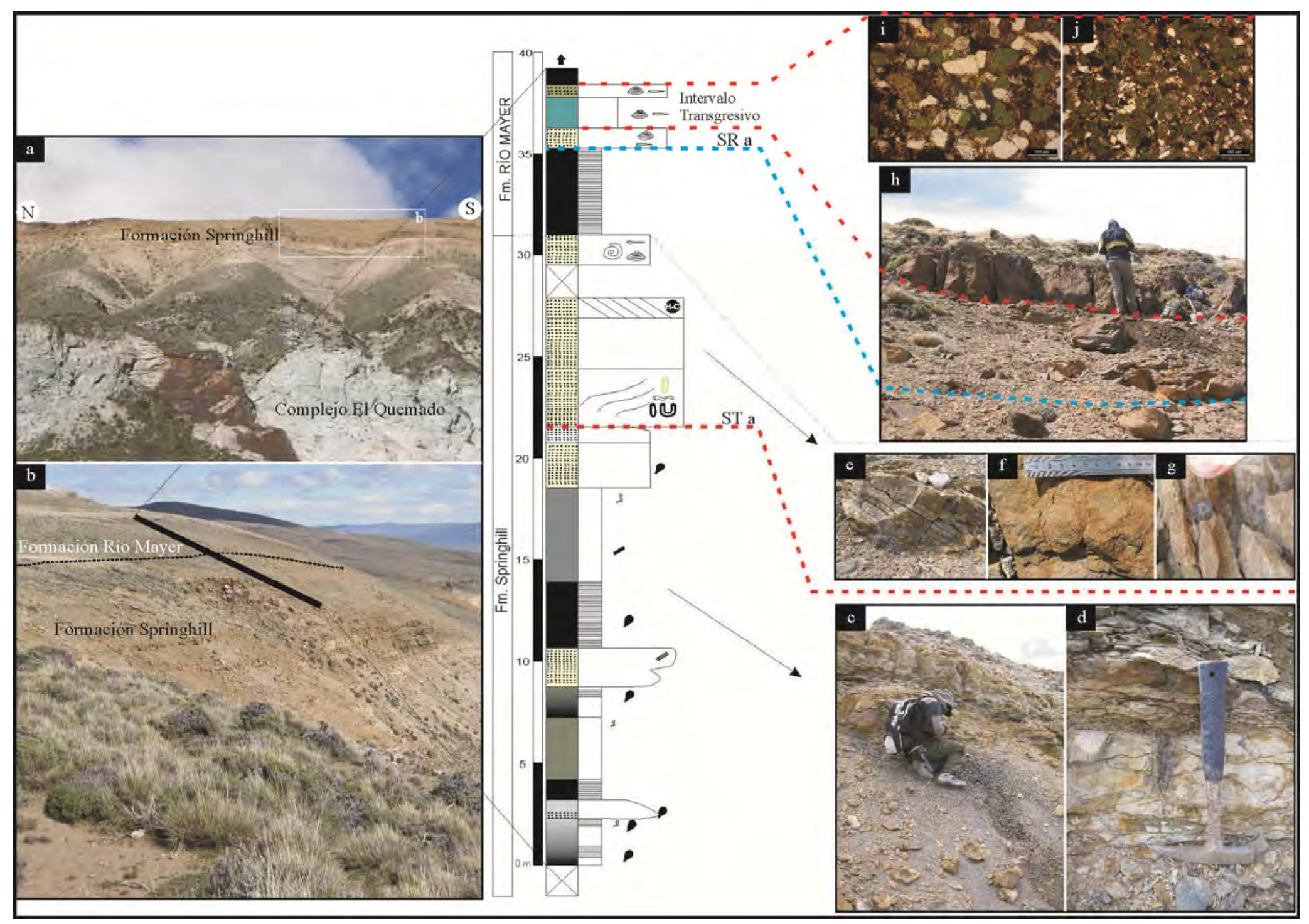

Figura 9.9- 
Figura 9.9- En a una vista de la Subida del Chancho (ver capítulo 3), y en b un detalle de los afloramientos de las formaciones Springhill y Río Mayer, con la traza del perfil de Estancia La Lila. La foto c son pelitas con desarrollo de paleosuelos y la foto d son areniscas con restos carbonosos que corresponden a los depósitos del Springhill continental. Las fotos e, f y g corresponden al Springhill marino y se desarrollan por arriba de la STa. En la imagen h se observa la SRa ubicada en la Formación Río Mayer entre las pelitas negras y las areniscas bioclásticas de ambientes someros. En las fotos i-j se ven microfotografías de la arenisca glauconítica que junto con las calizas representan la nueva etapa transgresiva de la cuenca.

\section{3.2.1.3 - Aptiano-Albiano inferior- Superficie Regresiva b (SRb)}

Esta superficie no puede ser caracterizada a partir de la información de un perfil como las anteriores, sino analizando la evolución paleoambiental de la Formación Río Mayer, razón por la cual más que una superficie regresiva es una zona regresiva. Dicha zona se caracteriza por un cambio paleoambiental muy importante, que involucra en mayor o menor medida, al sistema deltaico de la Formación Piedra Clavada. En la región del Lago San Martín es donde este cambio resulta más evidente, y se pasa de un ambiente marino de plataforma externa a un ambiente de prodelta. Esta situación no pudo registrarse en un perfil, y se ubicaría entre los perfiles de Ea. La Federica y Ea. Kachaike. En la región de la Seccional Río Guanaco el cambio es muy sutil, y sólo se puede asumir la presencia de esta zona regresiva por la llegada de flujos turbidíticos de una frecuencia cada vez mayor y con más cantidad de elementos que indican una proveniencia de la Formación Piedra Clavada.

La ubicación espacial de esta zona regresiva en el área de estudio se realizará en el apartado que sigue a continuación (3.2.2). 
IX. 3.2.1.4 -Superficie ST3 -Albiano superior-Cenomaniano inferior-

La última superficie reconocida tiene una importancia significativa en el marco estratigráfico de la Cuenca Austral. La ST3 se habría desarrollado entre el Albiano superior y el Cenomaniano inferior, y marca una profundización en los ambientes sedimentarios en varias zonas de la cuenca.

En la seccional Río Guanaco, hacia el final de la sección superior de la unidad estudiada hay un importante aumento de niveles de arenisca de espesores variables relacionados al sistema deltaico de la Formación Piedra Clavada. Por arriba de estos afloramientos y de manera abrupta desaparecen las areniscas y los depósitos se componen exclusivamente de pelitas negras. Este cambio notorio se debe a la profundización del ambiente producto de una nueva superficie transgresiva en la cuenca (ST3). Esta superficie marca el paso de la Formación Río Mayer a la Formación Cerro Toro (figura 9.10 b).

El desarrollo de una transgresión marina de esta edad fue previamente mencionada por Varela (2011) para la región de Tres Lagos. De este modo, hacia el este y noreste del área de estudio esta superficie divide la sedimentación deltaica de la Formación Piedra Clavada de los depósitos de planicie costera y estuario de la Formación Mata Amarilla (Varela, 2011) (figura 9.10 c). La transición de la Formación Piedra Clavada a la Formación Mata Amarilla no siempre lleva aparejada una profundización de los ambientes sedimentarios, y esto depende de la región de la cuenca que se esté analizando (Dr. Augusto Varela, comunicación personal). 


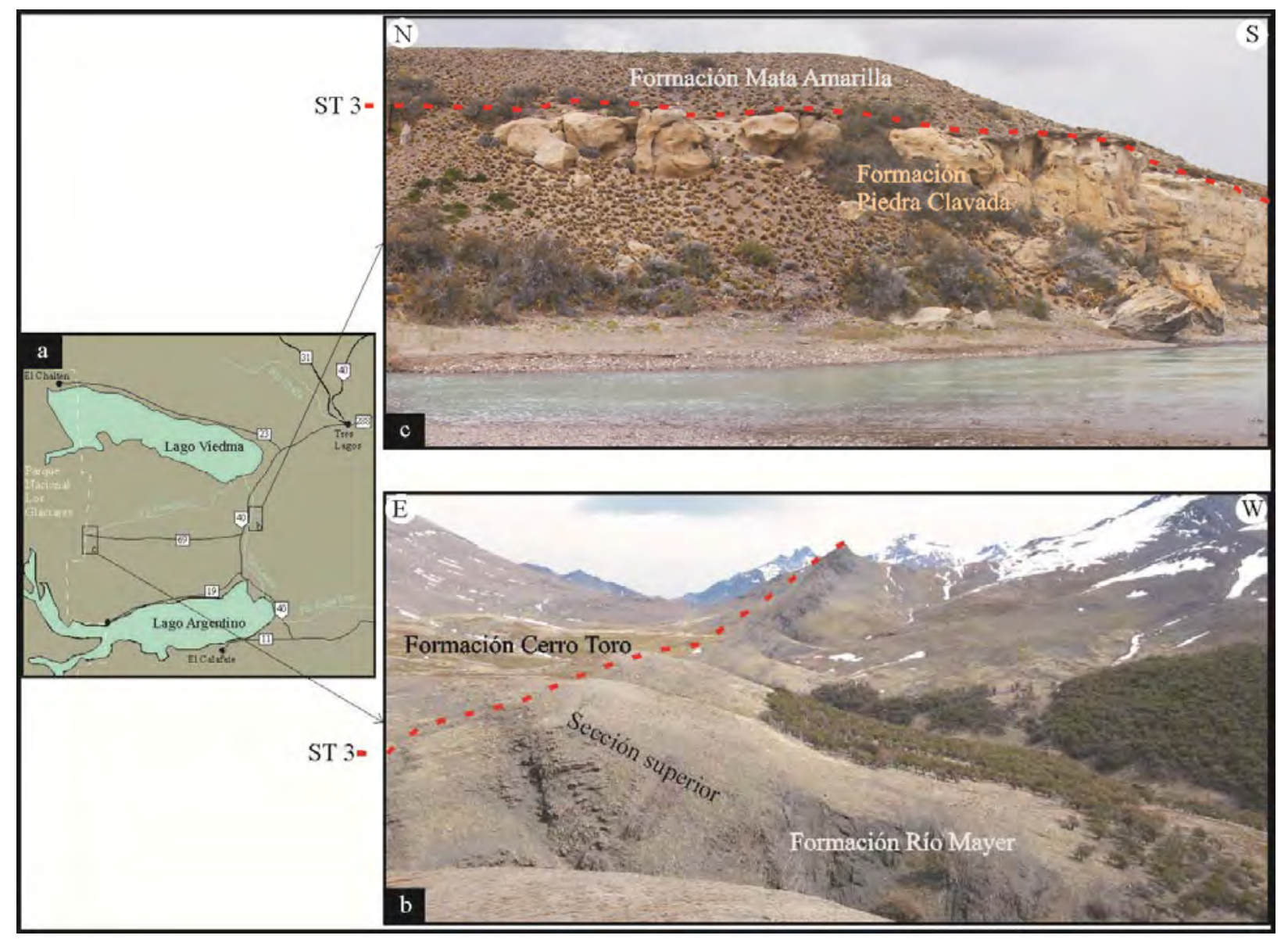

Figura 9.10- a- Mapa de ubicación de las fotos b y c. Foto b, expresión de la ST3 en la Seccional Río Guanaco (límite de las formaciones Río Mayer y Cerro Toro). Foto c, paso de la Formación Piedra Clavada a la Formación Mata Amarilla resultado de la transgresión al final del Cretácico inferior en la cuenca Austral (ST3). Foto c cortesía del Dr. Augusto Varela. 


\section{3.2.2- Modelo estratigráfico-secuencial para la depositación de la}

\section{Formación Río Mayer}

Una vez identificadas las superficies antes mencionadas y ubicadas en los perfiles se correlacionaron las áreas de trabajo (figura 9.11). Antes de hacer un desarrollo sobre la estratigrafía secuencial de la Formación Río Mayer cabe aclarar que, dado que esta unidad se depositó enteramente en ambientes marinos de plataforma externa, muchos de los posibles cambios relativos del nivel del mar son crípticos. Esto genera una pérdida de información que impide descifrar un panorama completo de los eventos ocurridos, sólo se registran los mayores que permiten generalizar el comportamiento de la unidad a través del Cretácico inferior. Una comprensión más acabada se podría alcanzar analizando los depósitos ubicados hacia el norte del lago San Martín, ya que en esa región se están los sedimentos de ambientes marinos someros que son susceptibles de registrar variaciones relativas del nivel del mar de menor escala que las que se reconocen en la plataforma externa.

De la figura 9.11 se desprende que en el área de estudio en la Formación Río Mayer se reconocieron tres secuencias, todas se presentan de manera incompleta, y exhiben el par de cortejos Transgresivo-Mar Alto. Por otro lado, el tramo final de la unidad estudiada junto con las Formaciones Kachaike y Piedra Clavada se agruparían en una jerarquía de orden superior a las anteriormente citadas. La división de este último tramo en secuencias de menor jerarquía se debería registrar en los depósitos del sistema deltaico, los que no forman parte de este trabajo de tesis doctoral.

La primera secuencia depositacional (S1) comprende el lapso Titoniano- Berriasiano (con duda podría llegar hasta el Valanginiano inferior). Esta secuencia solo se registró en la Seccional Río Guanaco y se compone de los cortejos Transgresivo y de Mar Alto. El límite entre ambos estaría marcado por una zona de máxima inundación que registra los mayores contenidos de COT de la unidad estudiada.

La segunda secuencia (S2) se desarrolla enteramente en el Valanginiano. La base está representada por las superficies ST1 (Río Guanaco) y STa (Lago San Martín). El cortejo Transgresivo incluye a los depósitos marinos de la Formación Springhill hacia el norte y a las margas de la sección media de la Formación Río Mayer hacia el sur. El cortejo de Mar Alto está

poco definido, no se registra en Río Guanaco (probablemente erosionado) y está poco representado en el Lago San Martín. 


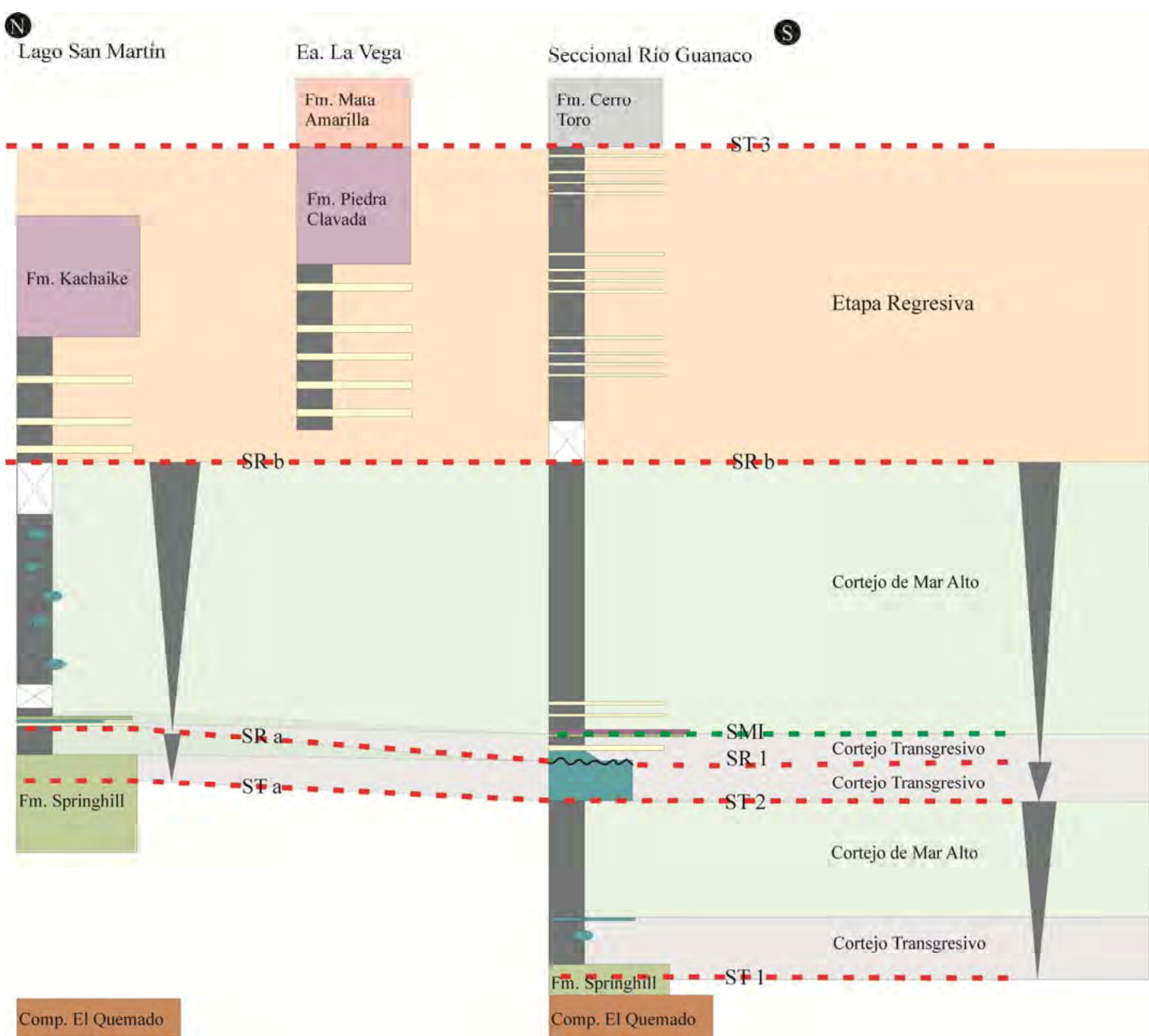

Figura 9.11- Correlación

tentativa de las superficies reconocidas en el

Cretácico inferior de la

Cuenca Austral. La superficie titoniana solo se registró en la Seccional Río Guanaco. La correlación se concentra desde las superficies neocomianas hasta el límite entre el Cretácico inferior y superior.

Las secuencias de depositación se indican con los triángulos grises. 
La tercera secuencia (S3) comienza con una superficie regresiva (SR 1 y SR a), que deja depósitos que denotan una somerización de los ambientes, aunque rápidamente de recuperan las condiciones transgresivas. En ambas regiones es difícil señalar una superficie transgresiva, con lo cual se definió una zona transgresiva que se caracteriza por una profundización de la cuenca, que produce nuevamente la depositación de pelitas negras en toda el área de estudio. Al tope del Cortejo Transgresivo se registra la SMI, que posee una clara definición en la Seccional Río Guanaco, no así en el Lago San Martín, y que da inicio al cortejo de Mar Alto, con un muy importante desarrollo que abarcaría el lapso Hauteriviano- Barremiano hasta la SRb.

Finalmente, desde la SRb hasta la ST 3 se registra un período de condiciones principalmente regresivas, que se extiende hasta el límite entre el Cretácico inferior y el superior, momento en que una nueva profundización de la cuenca (ST 3) genera un cambio en los ambientes de depositación y el inicio de otras unidades litoestratigráfica (Formaciones Cerro Toro y Mata Amarilla).

Este esquema difiere del propuesto por Arbe (2002), quien propone que la Formación Río Mayer participa en los Ciclos Río Mayer y Lago San Martín formando parte tanto de los subciclos transgresivos como de los regresivos en el lapso Berriasiano - Aptiano (figura 9.12). El subciclo transgresivo Springhill de Arbe se extiende entre el Berriasiano y el Hauteriviano inferior, con lo cual dentro de este subciclo se encuadran las S1 y S2 definidas en este trabajo más el cortejo transgresivo de la S3. Por otro lado, el cortejo de mar alto de la S3 corresponde al subciclo regresivo 1 (SR1) del mencionado autor.

Ambos modelos presentados no son excluyentes sino complementarios y se diferencian en la escala de trabajo, ya que Arbe durante su estudio abarcó los afloramientos de la cuenca en su conjunto y la estratigrafía de todo el Cretácico. Esta diferencia en la escala de trabajo genera que el ciclo Transgresivo-Regresivo Springhill de segundo orden definido por Arbe, aquí se desdobló en tres secuencias de tercer orden formadas por cortejos Transgresivo y de Mar Alto. Finalmente, durante el lapso Aptiano-Cenomaniano inferior no se pudieron definir secuencias de tercer orden, y la etapa regresiva aquí reconocida se encuadra en la secuencia de segundo orden de Arbe denominada Ciclo Lago San Martín. 


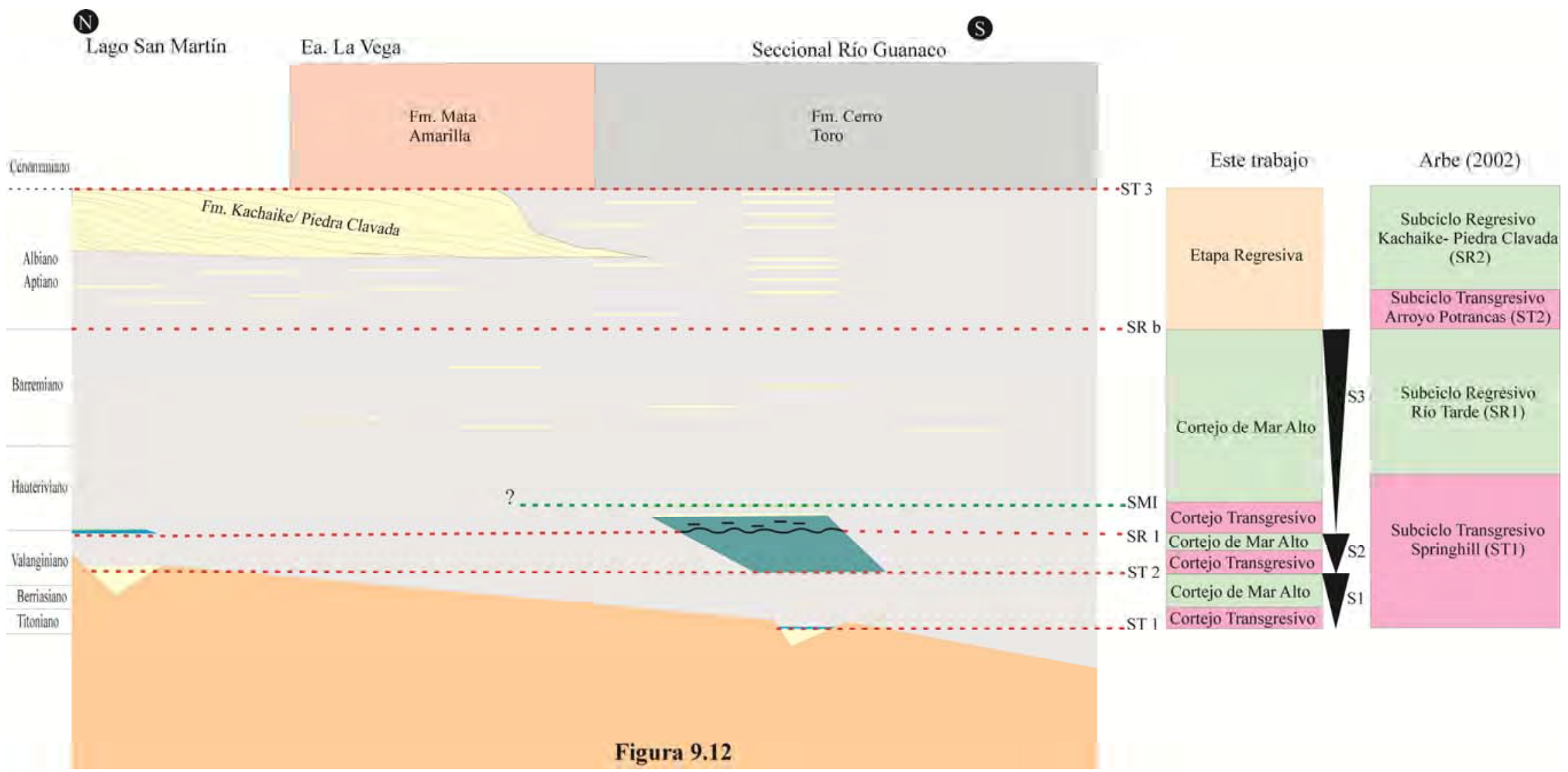

Figura 9.12- Comparación de los modelos estratigráfico- secuenciales presentados por Arbe (2002) y este trabajo de tesis doctoral para el Cretácico inferior de la Cuenca Austral. 
Las secuencias S1, S2, S3 se correlacionan con el grupo de secuencias definidas por Biddle et al. (1986) denominado “The Springhill and Lower Inoceramus Formations” que se extiende entre el Jurásico superior y Aptiano medio. Por otra parte, la etapa regresiva se corresponde con la secuencia “Margas Verdes and Middle Inoceramus Formations” que abarca desde el Aptiano medio hasta el Cenomaniano medio. Estos autores dividieron el relleno de la Cuenca Austral en secuencias basados en información de subsuelo.

En último término se compara el presente modelo estratigráfico secuencial del Cretácico inferior con el realizado por Kraemer y Riccardi (1997), previo estudio sísmico, en la región de la Seccional Río Guanaco. La principal dificultad para comparar los modelos son los diferentes límites entre unidades estratigráficas utilizados. En la figura 9.12 se observa una imagen del Cerro Pintado de la Seccional Río Guanaco, en a se presenta la interpretación realizada por Kraemer y Riccardi (1997) y en b la realizada en el este trabajo de tesis doctoral. De esta figura se desprende que según la interpretación de Kraemer y Riccardi (1997) el perfil IG quedaría enteramente dentro de la Formación Springhill, y que la Formación Río Mayer comenzaría con las margas de la sección media en el perfil PG. El criterio utilizado en este trabajo ya fue expuesto en el primer apartado de este capítulo. En su modelo Kraemer y Riccardi (1997) definen para el Cretácico Inferior tres secuencias sísmicas y tres discontinuidades (figura 9.12). La primera discontinuidad corresponde a la base de la Formación Springhill, la discontinuidad 2 se correlaciona con la ST2, ya que se ubican ambas en la base de las margas de la sección media, y la discontinuidad 3 se ubica dentro de la sección superior de la Formación Río Mayer. En este último tramo del Cretácico inferior también hay una no coincidencia de la definición del límite entre dos unidades, en este caso es el paso de la Formación Río Mayer a la Formación Cerro Toro, y este tema ya fue citado previamente.

En resumen, todas las discontinuidades observadas en información sísmica por Kraemer y Riccardi (1997) tienen un correlato con los depósitos analizados en la Seccional Río Guanaco, pero la información de campo presentada por estos autores difiere, al menos parcialmente, de la recolectada en el presente trabajo. 

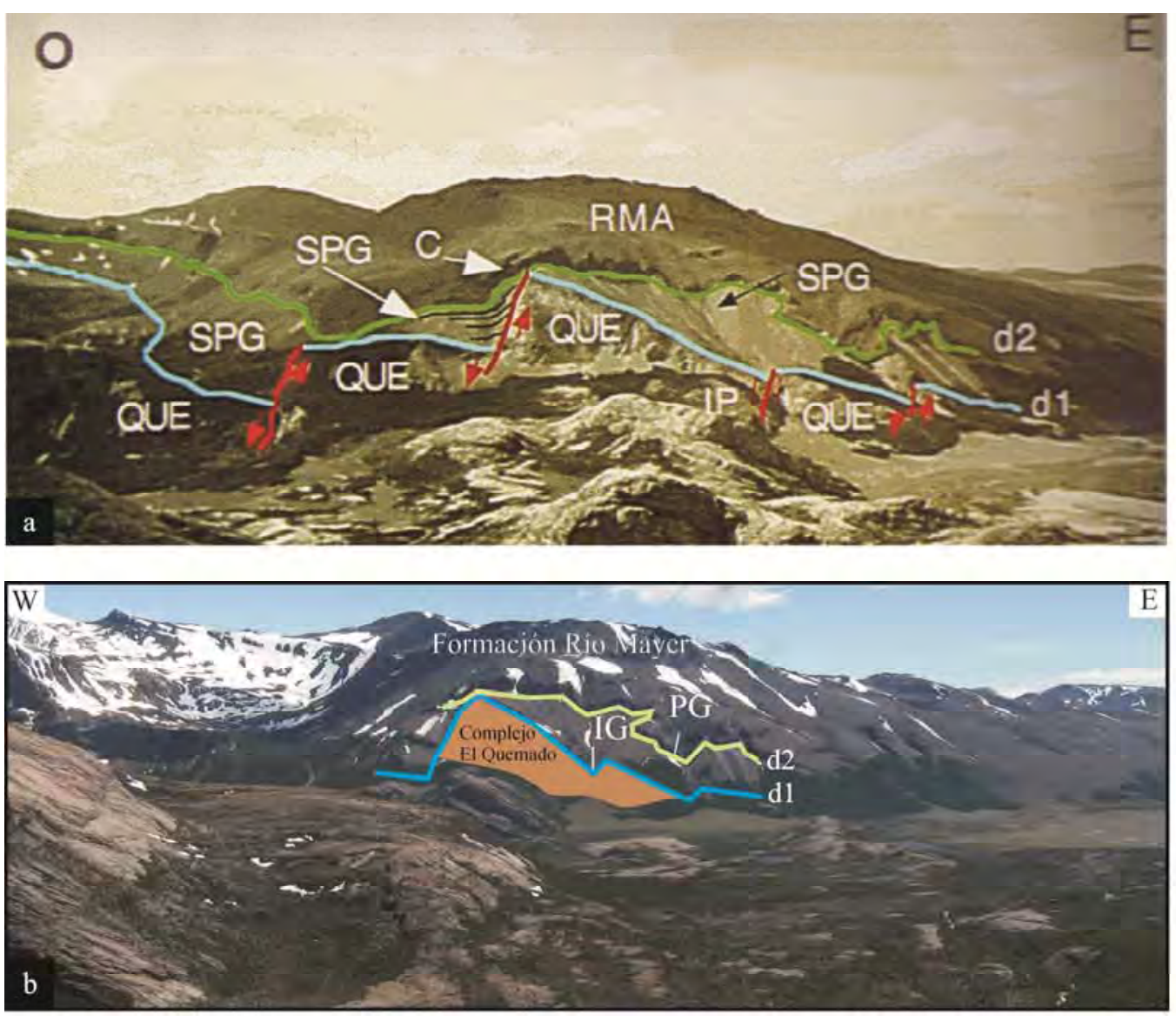

Hauteriviano

\section{Valanginian}

Berriasiano

Titoniano

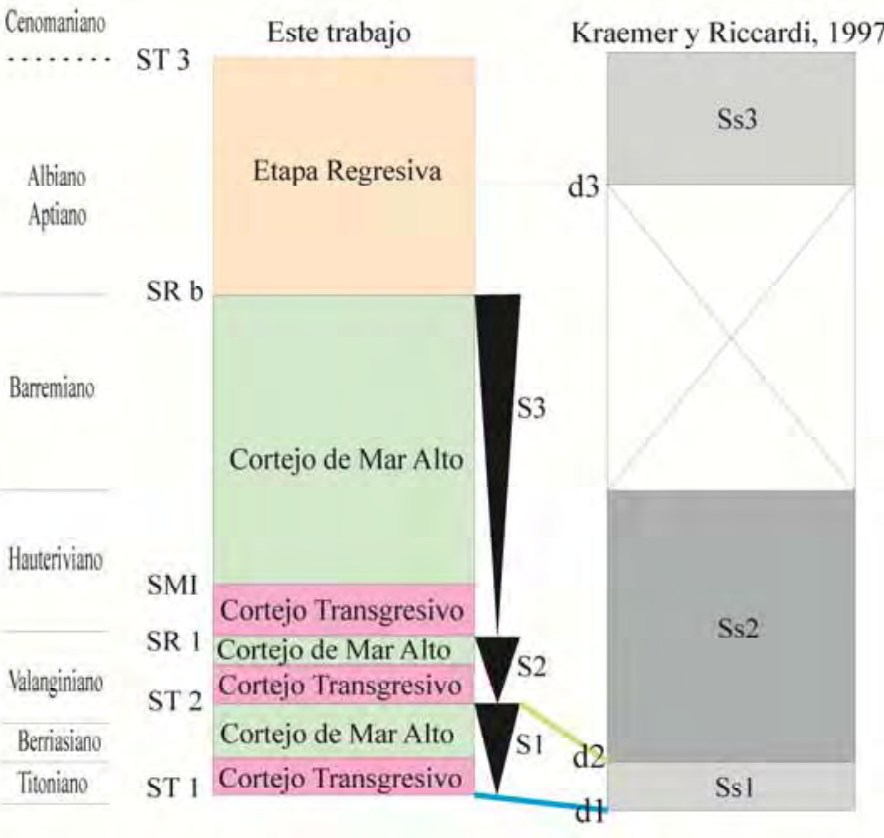

QUE: Complejo El Quemado

SPG: Formación Springhill

C: Margas del la Sección Media

RMA: Formación Río Mayer

d1-d2: Discontinuidades sísmicas

IG: Perfil IG

PG: Perfil PG

Figura 9.12- Comparación de las interpretaciones estratigráficas del Cerro Pintado y del modelo estratigráfico- secuencial presentado en este trabajo de tesis doctoral con las secuencias sísmicas definidas por Kraemer y Riccardi (1997) para el Cretácico inferior de la Cuenca Austral. Ss: Secuencia Sísmica; d: Discontinuidad. 


\section{4 -Correlación de la Formación Río Mayer con las unidades de la Cuenca}

\section{de Rocas Verdes}

La correlación de las unidades sedimentarias cretácicas de la Cuenca Austral (CA) y la Cuenca de Rocas Verdes/Magallanes (CRV/M) es frecuente en los trabajos científicos relacionados al margen sudoccidental de Gondwana (cf. Calderón et al., 2007). Sin embargo el desarrollo de ambas cuencas fue desigual principalmente por las diferencias en la configuración de sus etapas extensivas. Esta diferencia radica en la extensión cortical a la cual estuvieron afectadas durante el Jurásico, de esta manera en la CRV/M la extensión fue de una magnitud tal que generó la formación de corteza oceánica mientras que en la CA esto no sucedió. Este hecho se ve reflejado en una mayor subsidencia termal en la CRV/M, la cual determinó que durante un lapso temporal más largo se mantuvieran las condiciones de sedimentación marino profundas. De este modo, la CA representa los bordes de la cuenca marginal de RV/M que se desarrollaron con una corteza continental no adelgazada (cf. Calderón et al., 2007; Covault et al., 2009).

La Formación Río Mayer se correlaciona directamente con la Formación Zapata (1000 a 1200 m de pelitas negras con muy escasas areniscas intercaladas), ya que ambas representan los primeros depósitos marinos de plataforma externa y se ubican por sobre el Complejo El Quemado (Formación Tobífera) o la Formación Springhill. Si se hace un correlato entre estas dos unidades se acentúa el diacronismo registrado en el presente trabajo y que previamente fuera mencionado por otros autores ( $c f$. Arbe, 2002), ya que la formación Zapata se inicia en el Jurásico superior y se extiende hasta el inicio del Cretácico superior (Fildani y Hessler, 2005).

Pese a la continuidad reconocida entre estas unidades es posible que no estuvieran totalmente conectadas la una con la otra, ya que la distribución de los elementos REE de ambas indica diferentes tendencias en la procedencia. La Formación Zapata posee afinidad a las rocas máficas del Complejo Sarmiento (ofiolitas) mientras que la Formación Río Mayer es afín a las composiciones ácidas del Complejo El Quemado.

La correlación de las unidades descriptas en la CA de Argentina y en la CRV/M de Chile es un tema que requiere muchos análisis sedimentológicos de índole variable a fin de entender cómo funcionaron los sistemas depositacionales de una región gondwánica que estuvo formada por varios depocentros que podrían haber funcionado parcialmente 
conectados. En este sentido, dentro del territorio argentino hay una clara diferenciación entre los depósitos de la Formación Cerro Toro ubicados al norte y sur del Lago Argentino. En los afloramientos de esta unidad en la margen norte del mencionado lago los sedimentos poseen abundante cantidad de areniscas y hay deformación sedimentaria de pequeña escala mientras que al sur del Lago Argentino se registran importantes depósitos de slumps de una decena de metros. A su vez, la definición de Formación Cerro Toro en Argentina difiere de la realizada en Chile, principalmente en la ausencia de su carácter más importante y distintivo, el conglomerado Lago Sofía. Este conglomerado sólo se registra en Argentina en el límite con Chile y pareciera ser la continuidad hacia el norte de los depósitos presentes en la región chilena de Última Esperanza. Aunque la duda mayor es si todos los afloramientos mapeados y citados como Formación Cerro Toro en territorio argentino pertenecen a una única unidad, o son dos unidades que se correlacionan una con la Formación Punta Barrosa y otra con Cerro Toro de la CRV/M. El reciente inicio de una tesis doctoral en la Formación Cerro Toro de Argentina permitirá esclarecer este inconveniente estratigráfico, y develar la duda sí esta formación es la misma en los dos países y se presenta de manera diacrónica o son dos unidades diferentes nombradas de la misma forma.

En síntesis, los afloramientos de la Formación Río Mayer (FRM) son equivalentes a los de la Formación Zapata (FZ), aunque se ha registrado en la unidad aquí estudiada una mayor participación de areniscas que las mencionadas en la literatura para los depósitos marinos profundos de la CRV. Este hecho respondería a la disposición de ambas formaciones en el contexto de la cuenca en su conjunto. La FRM representa la sedimentación en plataforma externa mientras que la FZ corresponde a los ambientes de cuenca profunda, pero sin la formación de un sistema marino profundo constituido por canales y lóbulos submarinos. Por esta razón en la FZ no se observan niveles psamíticos en la mayor parte de su espesor, sólo aparecen en el techo. En cambio la existencia de tormentas en la plataforma podría generar el transporte de arenas y gravas en dirección al off-shore. Del mismo modo, la abundante participación de margas en la FRM, no registradas en la FZ, estaría en sintonía con esta disposición paleogeográfica. 


\section{5 -La Formación Río Mayer como roca generadora de Hidrocarburos: su} importancia en la Cuenca Austral y las perspectivas a futuro.

La importancia de la Formación Río Mayer (FRM) en el desarrollo hidrocarburífero de la Cuenca Austral ha sido reconocida tiempo atrás por diversos autores (Pittion y Gouadain, 1992; Pittion y Arbe, 1999). Esta unidad forma parte del sistema petrolero “Inoceramus inferior -Springhill”, que es el mejor documentado de la cuenca y el que ha aportado mayor cantidad de hidrocarburos. En dicho sistema petrolero la FRM (en subsuelo corresponde a la parte inferior de la Formación Palermo Aike) es considerada como roca sello y roca madre (Rodríguez y Miller, 2005; Argüello et al., 2005).

Las propiedades como roca madre de hidrocarburos de la FRM observadas en este trabajo de tesis doctoral son equiparables con consideraciones previas realizadas por Rodríguez y Cagnolatti (2008) en la Formación Palermo Aike inferior. Los espesores, la litología y el contenido de Carbono Orgánico Total documentados por estos autores se ajustan a los reconocidos para la sección inferior de la unidad estudiada en la Seccional Río Guanaco. Sin embargo el grado diagenético alcanzado por las rocas de la FRM en afloramiento no permitió que los análisis de pirólisis dieran resultados positivos (Héctor Villar, comunicación personal), con lo cual no se pudieron determinar los tipos de querógeno en afloramiento para su comparación con los de subsuelo.

Hasta el momento, todos los enfoques con respecto a la FRM desde el punto de vista petrolero han sido considerando a esta unidad como roca madre de hidrocarburos, sin embargo el gran desarrollo a nivel mundial de los yacimientos de "shale-oil" y "shale-gas" hacen mirar con otros ojos secuencias sedimentarias que antes pasaban desapercibidas como roca reservorio. Los yacimientos petroleros asociados a pelitas no representan un descubrimiento reciente, sino que dada la demanda de combustibles por el aumento del consumo, los crecientes precios internacionales de los hidrocarburos y el avance de los métodos de extracción permitieron difundirlos a regiones en donde no eran considerados. En los Estados Unidos de Norteamérica este tipo de yacimientos generó un aumento de las reservas de gas natural probadas cercano al 50\% en un año, pasando de 1.342 trillones de pies cúbicos (TPC) a 2.011 TCP entre 2007 y 2008 (Palacios, 2011). Se estima que para el año 2035 el shale gas aportará un 20 a 23 \% de la producción de gas natural de ese país (Palacios, 2011). 
Uno de los más importantes yacimientos de shale gas a nivel mundial es el que se registra en la Formación Barnett Shale en la Cuenca de Fort Worth en Texas (EEUU), con una producción acumulada en el año 2003 cercana a los 0,8 TPC de gas (Montgomery et al., 2005; Hill et al., 2007) y reservas probadas por más de 2,5 TCP de gas (Pollastro et al., 2004). Esta formación posee un espesor variable que va de los 3 a 9 metros en su parte menos espesa hasta los 300 metros, y se compone de lutitas silíceas y calcáreas que alternan con niveles de caliza (Montgomery et al., 2005; Rodríguez, 2011). Se habría depositado en ambientes de off-shore afectados por flujos turbidíticos distales en condiciones anóxicas a disóxicas (Ruppel y Loucks, 2006). Los valores de COT varían entre 3,3 y 4,5 \% y poseen la particularidad de estar concentrados en la lutitas ricas en arcillas y sílice, no en las calcáreas (Montgomery et al., 2005).

En comparación, la Formación Río Mayer posee todos los atributos necesarios para incorporarse a este nuevo (viejo) horizonte exploratorio, ya que está probada su capacidad como roca madre de hidrocarburos (Rodríguez y Cagnolatti, 2008). Por otro lado, posee elevados contenidos de COT (hasta 2,8\% en afloramiento) que de manera similar a otros yacimientos se registran en las pelitas, las condiciones diagenéticas a las estuvo expuesta la ubican en la ventana del petróleo y como complemento tiene espesores importantes en una gran superficie areal de la cuenca. Además, en la sección media de la unidad se registró la presencia de más de 30 metros continuos de margas que poseen un comportamiento frágil, lo que amplía la expectativa de búsqueda en estos depósitos, ya que el método de extracción de hidrocarburos no convencionales se basa en la fracturación de las rocas (Cartwright, 2011). En este sentido, estudios recientes se han enfocado en modelar "target Shales” a partir de datos de campo con análogos o modelos teóricos para evaluar la posibilidad de predecir la distribución de fracturas (Gale et al., 2007). 


\section{Capítulo X - Conclusiones}

A partir del estudio sedimentológico e icnológico de la Formación Río Mayer en la región comprendida entre los lagos San Martín y Argentino se pueden realizar las siguientes conclusiones:

1- La Formación Río Mayer en el área de estudio de apoya de manera neta sobre la Formación Springhill o sobre el Complejo El Quemado, mientras que el límite superior es transicional hacia las formaciones Kachaike, Piedra Clavada, Lago Viedma y Cerro Toro.

1a- En la Seccional Río Guanaco se encontraron los mejores y más completos afloramientos de la unidad, razón por la cual los análisis de laboratorio se concentraron en las muestras de esa localidad. A partir del trabajo de campo se dividió a la Formación Río Mayer en la Seccional Río Guanaco en 3 secciones, denominadas inferior, media y superior. La sección inferior se compone casi exclusivamente de pelitas negras con intercalaciones de margas, la sección media es mayormente de composición margosa y la sección superior está formada por pelitas negras a verde oliva oscuro con frecuentes intercalaciones de areniscas.

2- Se reconocieron un total de 18 facies sedimentarias en la Formación Río Mayer distribuidas en 6 grupos: Facies de Pelitas, de Margas, Heterolíticas, de Areniscas, Psefíticas y de Caliza. Las facies sedimentarias fueron reunidas en 3 asociaciones de facies, cada una asignada a un paleoambiente particular.

2a- La primera asociación de facies se corresponde con los ambientes marinos de plataforma externa, en los cuales los depósitos hemipelágicos predominan. Esta asociación representa la mayor parte de los afloramientos de la unidad estudiada y constituye los típicos afloramientos de la Formación Río Mayer citados en la bibliografía.

2b- La segunda asociación también se ubica en ambientes plataformales por debajo del nivel de olas de mal tiempo, pero se ve influenciada por flujos turbidíticos distales provenientes del sistema deltaico de la Formación Piedra Clavada. 
2c- Finalmente la tercera asociación corresponde a los depósitos de prodelta ubicados en la zona norte del área de estudio.

3- Se analizó la composición mineralógica de la Formación Río Mayer por difractometría de rayos $\mathrm{X}$ en un total de 119 muestras.

3a- En general las muestras en roca total se componen de proporciones variables de cuarzo, calcita, plagioclasas y arcillas. De los cuatro componentes el cuarzo es el dominante en casi todo el espesor de la unidad.

3b- La fracción fina se compone illita, interestratificados I/S y Clorita, con muy escasas participaciones de caolinita. En general hay dos comportamientos principales, la sección inferior de la unidad está dominada por illita y la sección superior por clorita. Sólo se registró esmectita en las muestras provenientes del prodelta en la región del Lago San Martín.

3c- A partir del análisis de los interestratificados I/S se determinó que todas las muestras se encuentran mayoritariamente en la mesodiagénesis y en menor medida en la eodiagénesis.

4- Se realizó el análisis petrográfico de 51 cortes delgados de la Formación Río Mayer, que abarcaron principalmente areniscas, pero también pelitas, margas, glauconitas, calizas y trazas fósiles.

4a- Los componentes principales de las areniscas de la Formación Río Mayer son el cuarzo monocristalino, los líticos y los feldespatos. Entre estos tres componentes y la matriz pelítica, siempre presente en las muestras, totalizan cerca del $90 \%$ de las rocas. El cemento predominante es el carbonático macroesparítico.

4b- Según la clasificación de Dott (1964, modificada por Pettijhon et al., 1972) las muestras de la Formación Río Mayer son vaques líticos ó feldespáticos, a excepción de una arenisca subarcósica. Según la clasificación de Folk et al. (1970), las muestras varían entre feldarenitas a litoarenitas, excepto una muestra que se clasifica como sublitoarenita.

4c- En cuanto a la procedencia de las areniscas, tomando en cuenta el diagrama Qm- F -Lt (Dickinson et al., 1983) se definieron 4 poblaciones, dos correspondientes a los 
depósitos pre-Aptiano y dos a los depósitos del Aptiano-Albiano. A su vez, dentro de cada grupo temporal se definieron dos poblaciones que respondería al transporte que sufrieron hasta depositarse en cada paleoambiente.

4d- Las pelitas y margas se componen de material no distinguible al microscopio a excepción de algunos componentes tamaño limo, abundantes microfósiles y materia orgánica. Las calizas muestran un alto grado de recristalización que indicaría un estadio de mesodiagénesis temprana.

4e- Se observaron algunas características de 3 icnogéneros al microscópio, Chondrites (moteados producto de la alimentación del organismo), Ophiomorpha (contacto entre el relleno del tubo y la pelita que lo rodea) y Zoophycos (migración del tubo spreiten-).

5- Se analizó la composición química de la Formación Río Mayer en la Seccional Río Guanaco desde diferentes puntos de vista: Roca Total (17 análisis), Carbono Orgánico Total (29 análisis) e Isótopos estables de C y O (19 análisis), los que arrojaron los siguientes resultados:

5a- Las tres secciones determinadas a partir del trabajo de campo poseen similar signatura geoquímica, respecto de los elementos mayoritarios y minoritarios. Las diferencias reconocidas pueden ser explicadas por los cambios en la mineralogía de la roca, la presencia de Illita en las muestras enriquece los contenidos de $\mathrm{Al}_{2} \mathrm{O}_{3}$ y $\mathrm{K}_{2} \mathrm{O}$, mientras que la participación de Clorita aporta importantes cantidades de $\mathrm{Fe}_{2} \mathrm{O}_{3}$.

5b- El grado de meteorización es en general moderado, reconocido mediante el cálculo de varios indicadores y no se aleja del comportamiento esperado para rocas pelíticas.

5c- Desde el punto de vista de la proveniencia en general hay una tendencia evolutiva desde composiciones ácidas en la sección inferior a ácida-intermedia en las secciones media y superior. Todas las muestras analizadas poseen afinidad con las rocas volcánicas del Complejo El Quemado y con la Formación Tobífera, con lo cual el aporte desde la Dorsal de Río Chico (borde nororiental de la Cuenca Austral) habría sido mínimo durante la depositación de la Formación Río Mayer. 
5d- El ambiente tectónico en el cual se depositaron las muestras estaría representado entre el margen continental activo y arco volcánico de diferentes características.

5e- Los valores de COT varían entre 0 y 2,8 \%, y se distribuyen en sectores ricos en materia orgánica y sectores pobres en materia orgánica. La sección inferior y en inicio de la sección superior de la unidad en la Seccional Río Guanaco poseen los valores más elevados, comparables con los necesarios para ser considerados roca madre de hidrocarburos.

5d- El análisis de los isótopos estables de O y C permitió corroborar las observaciones realizadas por petrografía, y confirmar que las rocas de la Formación Río Mayer están en mayor o menor medida alteradas diagenéticamente. Sin embargo se pudo registrar una tendencia positiva en la sección media de la unidad que podría correlacionarse con el evento Weissert (Valanginiano).

6- Se identificó en la Formación Río Mayer una importante icnofauna, sobre la cual muy poco se conocía previamente. Se describieron un total de 8 icnogéneros para esta unidad: Bergaueria, Chondrites, Gyrolithes, Ophiomorpha, Palaeophycus, Teredolites, Thalassinoides y Zoophycos.

6a- El conjunto de icnogéneros recuperados en la Formación Río Mayer permiten su agrupación en dos categorías, Icnofacies e Icnoasociaciones. Dentro de la primera categoría se reconoció una importante icnofacies de Zoophycos, que se presenta de dos maneras diferentes: muy desarrollada y dominante o de manera restringida e interrumpida. La primera se desarrolla en ambientes de plataforma externa dentro de los depósitos de la sección media. Por otro lado, en la parte final de la unidad, la frecuencia de flujos turbidíticos interrumpe el normal desarrollo de la icnofacies y genera la segunda forma de presentarse.

6b- De la distribución de icnogéneros en la Formación Río Mayer se pueden reconocer tres asociaciones de icnofósiles. El mayor desarrollo de icnofósiles se encuentra en la Seccional Río Guanaco con 7 icnogéneros, mientras que en la estancia La Vega y en el Lago Argentino se reconocieron 2 icnogéneros.

La icnoasociación I incluye a los icnogéneros de Zoophycos, Chondrites y Bergaueria. La icnoasociación II se compone de los icnogéneros Chondrites, 
Ophiomorpha, Palaeophycus y Zoophycos, y la icnoasociación III incluye a solo dos icnogéneros, Teredolites y Gyrolithes.

6c- Se realizaron correlaciones que permitieron entender con mayor precisión la conexión entre los diferentes paleoambientes reconocidos y la relación con las formaciones litoestratigráficas que son coetáneas con la Formación Río Mayer en distintas edades. De este modo se definieron dos modelos:

- Modelo Icnológico Valanginiano: Incluye la icnofacies de Zoophycos en la Seccional Río Guanaco y la icnofacies de Cruziana en el Lago San Martín.

- Modelo Icnológico Albiano: Se compone de la icnoasociación II de la Seccional Río Guanaco y la icnoasociación III de la Estancia la Vega. En este modelo podría incluirse las icnofacies de Skolithos, Cruziana, Psilonichnus, Glossifungites y Tripanites definidas por Poiré et al. (2001, 2002) en la localidad de Tres Lagos.

6d- Se reconstruyó la curva relativa de paleo-oxigenación a partir de la cual se reconocieron 4 sectores bien diferenciados en la Formación Río Mayer. La totalidad de la sección inferior de la unidad se desarrolló durante un período de muy baja oxigenación del ambiente (anóxico). La sección media y superior se desarrollaron un paleoambiente en general disóxico con variaciones en el desarrollo de trazas fósiles y la preservación de materia orgánica, que hacia el final presenta un sector con las mejores condiciones de oxigenación de la unidad.

7- A partir de las tres metodologías de laboratorio empleadas en la Formación Río Mayer (DRX, Petrografía y Geoquímica) surge una clara distinción de dos sectores que poseen diferente comportamiento dentro de la unidad. La sección inferior de la unidad se diferencia composicionalmente de la sección superior, mientras que la sección media posee un comportamiento dispar con mayor afinidad a la sección superior. La evolución geoquímica desde composiciones predominantemente ácidas hacia intermedias se ajusta a los modelos de evolución del arco magmático que proponen Hervé et al., 2007, de este modo la Formación Río Mayer estuvo claramente influenciada por la actividad volcánica del Batolito Patagónico Austral. Por otro lado, si se comparan los resultados geoquímicos de las pelitas de esta unidad con los valores de las vulcanitas de la Provincia Volcánica del Chon- Aike publicados 
por Pankhurst et al. (1998), queda muy clara la afinidad de las rocas aquí analizadas con las provenientes del Complejo El Quemado (y Formación Tobífera). En definitiva, las distintas fuentes de información utilizadas (principalmente petrografía y geoquímica, en menor medida difracción de rayos $\mathrm{X}$ ), sugieren que la depositación de la Formación Río Mayer fue coetánea con el desarrollo de un arco volcánico al menos desde el Valanginiano. Dicho arco volcánico tuvo mayor influencia sobre la unidad en la región del Lago San Martín en comparación con la Seccional Río Guanaco.

8- Se generó un modelo estratigráfico-secuencial para el Cretácico inferior de la Cuenca Austral. Se identificaron 3 secuencias de tercer orden compuestas por cortejos Transgresivo y de Mar Alto desarrolladas entre el Titoniano y el Aptiano. Posteriormente, desde el Aptiano hasta el Cenomaniano inferior se registran condiciones regresivas asociadas al sistema deltaico de la Formación Piedra Clavada.

8a- Comparado con el esquema de Arbe (2002) se observan diferencias, que se deben a la escala de trabajo. El ciclo Transgresivo-Regresivo Springhill de segundo orden definido por Arbe, se desdobló en tres secuencias de tercer orden formadas por cortejos Transgresivo y de Mar Alto. Durante el lapso Aptiano-Cenomaniano inferior no se pudieron definir secuencias de tercer orden, y la etapa regresiva aquí reconocida se encuadra en la secuencia de segundo orden de Arbe denominada Ciclo Lago San Martín.

8b- Las secuencias S1, S2, S3 se correlacionan con el grupo de secuencias definidas por Biddle et al. (1986) denominado “The Springhill and Lower Inoceramus Formations” que se extiende entre el Jurásico superior y Aptiano medio. Por otra parte, la etapa regresiva se corresponde con la secuencia "Margas Verdes and Middle Inoceramus Formations" que abarca desde el Aptiano medio hasta el Cenomaniano medio.

8c- Todas las discontinuidades observadas en información sísmica por Kraemer y Riccardi (1997) tienen un correlato con los depósitos analizados en la Seccional Río Guanaco, pero la información de campo presentada por estos autores difiere, al menos parcialmente, de la recolectada en el presente trabajo. 
9- Los afloramientos de la Formación Río Mayer son equivalentes a los de la Formación Zapata, aunque se han registrado en la unidad aquí estudiada una mayor participación de areniscas que las mencionadas en la literatura para los depósitos marinos profundos de la Cuenca de Rocas Verdes. Este hecho respondería a la disposición de ambas formaciones en el contexto de la cuenca en su conjunto, ya que la Formación Río Mayer representa la sedimentación en plataforma externa mientras que la Formación Zapata corresponde a los ambientes de cuenca profunda, pero sin la formación de un sistema marino profundo constituido por canales y lóbulos submarinos. Por otro lado, mayor cantidad de estudios de detalle deben realizarse para comprender con mayor seguridad como varió la transición desde los depósitos de la Cuenca Austral hacia los depósitos de la Cuenca de Rocas Verdes, y así correlacionar de una manera fiable las unidades litoestratigráficas de ambas cuencas.

10- La Formación Río Mayer posee todos los atributos necesarios para incorporarse al nuevo horizonte exploratorio: Yacimientos de Hidrocarburos no Convencionales. Los contenidos de COT, el estadio de diagénesis alcanzado, los importantes espesores y la gran distribución areal hacen que esta unidad sea muy propicia para la búsqueda de nuevas reservas hidrocarburíferas en la Cuenca Austral. 


\section{REFERENCIAS}

Abbott, S. T. 1998. Transgressive Systems Tracts and onlap shellbeds from midPleistocene Sequences, Wanganui Basin, New Zealand. Journal of Sedimentary Research (68) 2: 253 - 268.

Aceñolaza, G. F. y Nieva, S. M. 2003. Caracteres estratigráficos e icnológicos de la Formación Candelaria (Cambro-Ordovícico) aflorante en el NE de la Provincia de Tucumán. Revista de la Asociación Argentina de Geología, 58 (3): 434 - 446.

Aguirre Urreta, M.B. 1987. La icnofacies Teredolites en el Cretácico de la Cuenca Austral Argentina. $10^{\circ}$ Congreso Geológico Argentino, San Miguel de Tucumán, actas.

Aguirre Urreta, M. B. 2002. Invertebrados del cretácico inferior. En Haller, M. J. (Ed) Geología y Recursos Naturales de Santa Cruz. Relatorio del Decimoquinto Congreso Geológico Argentino, 925 pp.

Aguirre Urreta, M. B. y Doyle, P. 1989. A problematical belemnite from the lower Cretaceous of the Austral Basin, Patagonia, Argentina. Monatsciefe Neues Jahrbuch Geologie Palaontologia 6: 345 - 355.

Aguirre Urreta, M. B. y Riccardi, A. C. 1989. El Género Lithancylus Casey en el Aptiano superior de Patagonia. Notas del Museo de la Plata, Tomo XXI, Paleontología, $\mathrm{n}^{\circ} 107$.

Aguirre Urreta, M. B., Price, G. D., Ruffell, A. H., Lazo, D. G., Kalin, R. M., Ogle, N. y Rawson, P. F. 2008. Southern hemisphere early Cretaceous (ValanginianEarly Barremian) carbon and oxygen isotope curves from the Neuquén basin, Argentina. Cretaceous Research 29, 87-99.

Allison, P. A., Wignall, P. B y Brett, C. E. 1995. Palaeo-oxigenation: effects and recognition. Geological Society, London, Special Publication, 83. En: D.W Bisence, P.A Allison (Eds), Marine Palaeoenvironmental Analysis from Fossils, 97-112.

Alonso, M. S. 2011. Estratigrafía, sistemas depositacioneles y aspectos composicionales del relleno Neógeno de la Cuenac Rodeo-Iglesia, San Juan, Argentina. Tesis Doctoral inédita. Universidad de Buenos Aires, Facultad de Ciencias Exactas y Naturales. 312pp.

Ameghino, C. 1890. Exploraciones geológicas en Patagonia. Boletín del Instituto Geográfico Argentino, 11(1): 3-46. 
Ameghino, F. 1898. Sinopsis geológica-paleontológica. Segundo Censo de la República Argentina. 1. Buenos Aires.

Anadón, P., Ghetti, P. y Gliozzi, E. 2002. Sr/Ca, Mg/Ca ratios and $\mathrm{Sr}$ and stable isotopes of biogenic carbonates from the Late Miocene Velona Basin (central Apennines, Italy) provide evidence of unusual non-marine Messinian conditions. Chemical Geology 187, 213-230.

Arbe, H. A. 1986. El Cretácico de la Cuenca Austral: sus ciclos de Sedimentación. Tesis doctoral inédita. Universidad de Buenos Aires Facultad de Ciencias Exactas y Naturales, Buenos Aires.

Arbe, H. A. 1989. Estratigrafía, discontinuidades y evolución sedimentaria del Cretácico en la Cuenca Austral, provincia de Santa Cruz. En G. Chebli \& L.A. Spalletti (Eds.), Cuencas Sedimentarias Argentinas, Instituto Superior de Correlación Geológica, Universidad Nacional de Tucumán, Serie de Correlación Geológica 6:419-442.

Arbe, H. A. 2002. Análisis estratigráfico del Cretácico de la Cuenca Austral, 103-128. In Haller, m. j. (ed) Geología y Recursos Naturales de Santa Cruz. Relatorio del Decimoquinto Congreso Geológico Argentino, 925 pp.

Arbe, H. y Hechem J. 1984. Estratigrafía y facies de depósitos continentales, litorales y marinos del Cretácico superior, lago Argentino. Actas IX Congreso Geológico Argentino, 7: 124-158.

Archangelsky, A., Archangelsky, S., Poire, D. G. y Canessa, N. D. 2008. Registros palinológicos de la Fm. Piedra Clavada (Albiano) en su área tipo, Provincia de Santa Cruz, Argentina. Rev. Museo Argent. Cs. Ns., n.s. 10, 185-198.

Argüello, J., Trapiche, A., Berdini, O., Pedrazzini, M. y Benotti, S. 2005. Entrampamiento de petróleo y gas en la Formación Springhill, sector continental de la Cuenca Austral, República Argentina. En Trampas de Hidrocarburos en las Cuencas Productivas de Argentina, VI Congreso de Exploración y Desarrollo de Hidrocarburos.

Arnott, R. W. C. 1995. The parasequence definition - Are transgressive deposits inadequately addressed?. Journal of Sedimentary Research (65) 1: 1 - 6.

Asiedu, D. K., Dampare, S. B., Asmoah Sakyi, P., Banoeng-Yakubo, B., Osae, S., Nyarko, B. J. B. y Manu, J. 2004. Geochemistry of Paleoproterozoic metasedimentary rocks from the Birim diamontiferous field, southern Ghana: 
implications for provenance and cristal evolution at the Archean-Proterozoic boundary. Geochemical Journal 38: 215 - 228.

Bahlburg, H. y Dobrzinski, N. 2009. A review of the Chemical Index of Alteration (CIA) and its application to the study of Neoproterozoic glacial deposits and climate transitions. En: Arnaud, E., Halverson, G.P. \& Shields, G.A., (eds.), The Geological Record of Neoproterozoic Glaciations. Geological Society, London, Memoir.

Bentor, Y. K. 1980. Phosphorites, the unsolved problems. Society for Economic, Paleontologist and Mineralogist, Special Publication, 29: 3-18.

Berry, E. W. 1937. An Upper Cretaceous flora from Patagonia. Johns Hopkins University Studies Geology, Baltimore 12: 11 - 31.

Bertram, C. J., Elderfield, H., Aldridge, R. J. y Conway Morris, S. 1992. ${ }^{87} \mathrm{Sr} /{ }^{86} \mathrm{Sr}$, ${ }^{143} \mathrm{Nd} /{ }^{144} \mathrm{Nd}$ and REEs in Silurian phosphatic fossils. Earth and Planetary Science Letters113; 239- 249.

Best, M. G. y Christiansen, E. H. 2001. Igneous Petrology. Blackwell Science, Oxford, England, 460pp.

Bhatia, M. R. 1983. Plate tectonics and geochemical composition of sandstones. Journal of Geology 92, 181 - 193.

Bhatia, M. R. 1985. Rare earth element geochemistry of Australian Paleozoic graywackes and mudrocks: provenance and tectonic control. Sedimentary Geology 45: 97 - 113.

Bhatia, M. R. y Taylor S. R. 1981. Trace element geochemistry and sedimentary provinces: A study from the Tasman Geosyncline, Australia. Chemical Geology 33; 115- 125.

Bhatia, M. R. y Crook, K. A. W. 1986. Trace elements characteristics of graywackes and tectonic setting discrimination of sedimentary basins. Contrib Mineral Petrol 92:181-193.

Bhattacharya, J. P. 2006. Deltas. Facies Models Revisited, SEPM Special Publication No. 84: 237-292.

Bianchi, J. L. 1967. Informe preliminar acerca de los perfiles estratigráficos realizados en el sector occidental de la Cuenca Austral, durante las campañas 1964-65 y 1965-66. Informe Inédito, Yacimientos Petrolíferos Fiscales (Y.P.F.), Buenos Aires. 
Biddle, K., Uliana M., Mitchum R.Jr., Fitzgerald, M. y Wright R. 1986. The stratigraphic and structural evolution of central and eastern Magallanes Basin, Southern America. En: Foreland basins, P. Allen and P. Homewood (Eds.), International Association of Sedimentology Special Publication, 8: 41-61.

Blasco, G. B., Nullo, F. y Proserpio, C. 1979. Aspidoceras en Cuenca Austral, Lago Argentino, Provincia de Santa Cruz. Revista de la Asociación Geológica Argentina, 34 (4): 282 - 293.

Boggs, S. Jr. 1992. Petrology of sedimentary rocks. Maxwell Macmillan, 707 pp.

Boles, J. R. y Franks, S. G. 1979. Clay diagenesis in Wilcox Sandstones of southwest Texas: implications of smectite diagenesis on sandstone cementation. Journal of Sedimentary Petrology 49: 55 - 70.

Boichard, R., Burollet, P. F., Lambert, B. y Villain, J. M. 1985. La plate-forme carbonatée du Pater Noster (Indonésie). Mém. 20, Total Cie. Franç. Pétroles Publ., 103 pp.

Bonarelli, G. y Nágera J.J. 1921. Observaciones geológicas en las inmediaciones del lago San Martín (territorio de Santa Cruz). Dirección General de Minas, Buenos Aires, Boletín, 27b: 1-39.

Borrello, A. V. 1956. Combustibles sólidos minerales. Museo Argentino de Ciencias Naturales Bernardino Rivadavia, Ciencias Geológicas, Buenos Aires, 5: 26 - 66.

Borrello, A. V. 1967. Estado actual del conocimiento geológico del Flysch en la Argentina. Revista del Museo de La Plata, 6 (geología 44): 125 - 153.

Bottjer, D. J., Droser, M. L. y Jablonski, D. 1988. Palaeonvironmental trends in the history of trace fossils: Nature 333: $252-255$.

Bouma, A. H., 1962. Sedimentology of some Flysch Deposits: A Graphic Approach to Facies Interpretation. Elsevier, Amsterdam, 168 pp.

Boynton, W.V., 1984. Cosmochemistry of the rare earth elements: meteorite studies. In: Henderson, P. (Ed.), Rare Earth Element Geochemistry. Elsevier, Amsterdam, pp. 63-114.

Brand, U. y Veizer, J. 1981. Chemical diagenesis of multicomponent carbonate system: stable isotopes. Journal of Sedimentary Petrology 51, 987-997.

Brandmayr, J. 1945. Contribución al conocimiento geológico del extremo sud sudoeste del Territorio de Santa Cruz (Región Cerro Cazador - Alto Río Turbio). Boletin de Informaciones Petroleras, Buenos Aires, 256: 415 - 437. 
Brindley, G. W. 1961. Experimental Methods. En: G. Brown (Ed.), The X-Ray identification and crystal structure of Clay Minerals. Mineralogical Society: 1-50.

Bromley, R.G. 1990. Trace fossils. Biology and taphnomy. Special Topics in palaeontology. Unwin Hyman. Londres, 280 pp.

Bromley, R.G. 1996. Trace Fossils. Biology, Taphonomy and Applications, Second Edition. Chapman and Hall, London. 361 pp.

Bromley, R.G. y Frey, R.W. 1974. Redescription of the trace fossil Gyrolithes and taxonomic evaluation of Thalassinoides Ophiomorpha and Spongeliomorpha. Bull Geol. Soc. Den. 23: 311-335.

Bromley, R.G., Ekdale, A.A. y Asgaard, U. 1999. Zoophycos in the Upper Cretaceous Chalk of Denmark and Sweden. Greifswalder Geowissenschaftliche BeitraÈge 6, $133 \pm 142$.

Brongniart, A.T. 1823. Observations sur les Fucoïdes. Société d'HistorieNaturelle de Paris, Mémoire 1, 301-320.

Brongniart, A.T. 1828. Histoire des Végétaux Fossiles ou Recherches Botaniques et Géologiques sur les Végétaux Renfermés dans les Diverses Couches du Globe, vol. 1. G. Dufour \& E. d'Ocagne, Paris, pp. 1-136.

Brown, G. 1980. Tables for the determination of $d$ in $\AA$ from $2 \theta$ for the $K \alpha$ and $K \beta$ radiations of cooper, cobalt and iron. En Brindley, G. W. \& G. Brown (Eds.), Crystal Structures of Clay Minerals and their X-Ray identification. Mineralogical Society Monograph 5: 439-475.

Buatois, L. A. y Mangano, M. G. 1992. La oxigenación como factor de control en la distribución de asociaciones de trazas fósiles, Formación Kotick Point, Cretácico de Antártica. Ameghiniana 29 (1): 69 - 84.

Buatois, L. A., Mangano, M. G. y Aceñolaza, F. 2002. Trazas Fósiles, señales de comportamiento en el Registro Estratigráfico. Edición especial MEF n 2. 382 pág.

Buatois, L. A., Mángano, M. G., Brussa, E., Benedetto, J. y Pompei, J. 2009. The changing face of the deep: Colonization of the Early Ordovician deep-sea floor, Puna, northwest Argentina. Palaeogeography, Palaeoclimatology, Palaeoecology 280, 291-299.

Burnett, 1977 W.C. Burnett, Geochemistry and origin of phosphorite deposits from off Peru and Chile. Bulletin of the Geological Society of America, 88: 813-823. 
Caldenius, C. C. 1932. Las glaciaciones cuaternarias en la Patagonia y Tierra del Fuego. Dirección General de Minas y Geología, Buenos Aires, 95: 1 - 152.

Calderón, M., Fildani, A., Herve, F., Fanning, C. M., Weislogel, A. Y Cordani, U. 2007. Late Jurassic bimodal magmatism in the northern sea-floor remnant of the Rocas Verdes basin, southern Patagonian Andes. Journal of the Geological Society, London, Vol. 164, 2007: 1011-1022.

Calvert, S. E. y Pedersen, T. F. 1996. Sedimentary geochemistry of manganese: implications for the environment of formation of manganiferous black shales. Economic Geology 91: 36-47.

Caminos, R. 1980. Cordillera Fueguina. En: Simposio de Geología Regional Argentina, No. 2, p. 1463-1501. Córdoba.

Canessa, N. D. Poiré, D. G. y Doyle, P. 2005. Estratigrafía de las unidades cretácicas de la margen norte del Lago Viedma, entre el Cerro Pirámides y la Estancia Santa Margarita, Provincia de Santa Cruz, República Argentina. Actas del XVI Congreso Geológico Argentino. La Plata.

Canessa, N. D., Franzese, J. R., Poiré, D. G. y Doyle, P. 2006. Control tectónico en la sedimentación cretácica de la Cuenca Austral, margen noroeste del Lago Viedma, Provincia de Santa Cruz, República Argentina. Actas del IV Congreso Latinoamericano de Sedimentología - XI Reunión Argentina de Sedimentología, Bariloche, Argentina.

Cartwright, J. 2011. Diagenetically induced shear failure of fine-grained sediments and the development of polygonal fault systems. Marine and Petroleum Geology 28: $1593-1610$.

Cattaneo, A. y Steel, R. J. 2003. Transgressive deposits: a review of their variability. Earth-Science Reviews 62: 187-228.

Cecioni, G. 1955. Distribuzione verticale di alcune Kossmaticeratidae nella Patagonia Chilena. Societa Geologica Italiana, 74: 141-149.

Chamberlain, C. K. 1975. Trace fossils in DSDP cores from the Pacific. Journal of Paleontolology 49: 1074-1096.

Cichowolski, M. 2003. The nautiloid genus Cymatoceras from the Cretaceous of the Neuquén and Austral basins, Argentina. Cretaceous Research 24 (2003) 375 390. 
Coe, A. L. y Church, K. D. 2003. Sequence Stratigraphy and sea-level change. En: Coe (Ed.): The sedimentary record of sea-level change. Cambridge University Press, 287 pp.

Collinson, J. D. 1969. The sedimentology of the Grindslow Shales and the Kinderscout Grit: a deltaic complex in the Namurian of northern England: Journal of Sedimentary Petrology, v. 39: 194-221.

Conci, I. 1935. Estudios de algunas rocas magmáticas del Lago Argentino y del Cerro Fitz Roy (Lago Viedma) coleccionadas por el Dr. Egidio Feruglio y el Padre De Agostini. Revista Minera, Buenos Aires, 7: 76 - 89.

Condie, K. C. 1993. Chemical composition and evolution of the upper continental crust: Contrasting results from surface samples and shales. Chem. Geol. 104, 137.

Covault, J. A., Romans, B. W. y Graham, S. A. 2009. Outcrop expression of a continental-margin-scale shelf-edge delta from the Cretaceous Magallanes Basin, Chile. Journal of Sedimentary Research 79: 523-539.

Cox, R., Lowe, D. R. y Cullers, R. L. 1995. The influence of sediment recycling and basement composition on evolution of mudrock chemistry in the southwestern United States. Geochimica et Cosmochimica Acta, Vol. 59, No. 14. pp. 29192940.

Creany, S. y Passey, Q. R. 1993. Recurring Paterns of Total Organic Carbon and Source Rock Quality within a Sequence Stratigraphic Framework. The American Association of Petroleum Geologist Bulletin 77; 386-401.

Cullers, R. L. 1995. The controls on the major and trace-element evolution of shales, siltstones and sandstones of Ordovician to Tertiary age in the Wet Mountains region, Colorado, USA. Chemical Geology, 123; 107-131.

Cullers, R. L. 2000. The geochemistry of shales, siltstones and sandstones of Pennsylvanian-Permian age, Colorado, USA: implications for provenance and metamorphic studies. Lithos 51; 181-203.

Dalziel, I. W. D., de Wit, M. J. and Palmer, K. F. 1974. Fossil marginal basin in the southern Andes. Nature, v. 250, p. 291 - 294.

Darwin, C. 1842. On the distribution of the erratic boulders and on the contemporaneous unstratified deposits of South America. Geological Society of London, 6: 415 - 431. 
Darwin, C. 1846. Geological observations on the volcanic Island and parts of South America visited during to voyage of H. M. S. Beagle. Londres.

D’Erasmo, G. 1935. Sopra alcuni avanzi di vertebrate fossili della Patagonia raccolti dal Dott. E. Feruglio. Att. R. Acad. Sci. Fis. Mat. Nápoli, Nápoles 20: 1 - 26.

de Saporta, G. 1884. Les organismes problématiques des anciennes mers. Paris, Masson, $102 \mathrm{p}$.

Di Benedetto, H. J. 1972. Informe geológico entre meseta de las Vizcachas y Ea. La Primavera, Provincia de Santa Cruz, Cuenca Austral. YPF, Buenos Aires, informe inédito.

Di Benedetto, H. J. 1973. Informe geológico Zona sur Lago Argentino. YPF, Buenos Aires, informe inédito.

Dickinson, W.R., Beard, L.S., Brakenridge, G.R., Erjavec, J.L., Ferguson, R.C., Inman, K.F., Knepp, R.A., Lindberg, F.A. y Ryberg, P.T. 1983. Provenance of North American Phanerozoic sandstones in relation to tectonic setting. Geological Society of America Bulletin 94, 222-235.

D’Orbigny, A. 1842. Voyage dans l’Amérique Mériodionale. Paris, Geología 3: 7 289.

Doyle, P., Poiré, D. G., Spalletti, L. A., Pirrie, D., Brenchley, P. y Matheos, S. D. 2005. Relative oxygenation of the Tithonian - Valanginian Vaca Muerta Chachao formations of the Mendoza Shelf, Neuquén Basin, Argentina. En The Neuquén Basin, Argentina: a Case Study in Sequence Stratigraphy and Basin Dynamics (Eds. Veiga, G. D., Spalletti, L. A., Howell, J. A. \& Schwarz, E.), Geol. Soc. London Spec. Publ., 252, 185 - 206.

Duchamp-Alphonse, S., Gardin, S., Fiet, N., Bartolini, A., Blamart, D. y Pagel, M., 2007. Fertilization of the northwestern Tethys (Vocontian basin, SE France) during the Valanginian carbon isotope perturbation: evidence from calcareous nanofossils and trace element data. Palaeogeography Palaeoclimatology Palaeoecology 243: 132-151.

Duchamp-Alphonse, S., Fiet, N., Adatte, T. y Pagel, M. 2011. Climate and sea-level variations along the northwestern Tethyan margin during the Valanginian Cisotope excursion: Mineralogical evidence from the Vocontian Basin (SE France). Palaeogeography, Palaeoclimatology, Palaeoecology 302: 243-254.

Ehrenberg, K. 1942. Uber einige Lebensspuren aus dem Oberkreideflysch von Wien und Umgebung. Paleobiologica 7: 282-313. 
Ehrenberg, K. 1944. Ergänzende Bemerkungen zu den seinerzeit aus dem Miozän von Burgschleinitz beschrieben Gangkernen und Bauten dekapoder Krebse. Paläontologische Zeitschrift 23: 345-359.

Einsele, G. 1991. Submarine mass flow deposits and turbidites. En: Einsele, G., Ricken, W. y Seilacher, A. (Eds.), Cycles and events in stratigraphy. Springer-Verlag, Berlin: $79-93$.

Ekdale, A.A. y Bromley, R.G. 1984. Cretaceous chalk ichnofacies in northern Europe. Geobios, Memorial Special 8, 201-204.

Ekdale, A.A., Bromley, R.G. y Pemberton, S. G. 1984. Ichnology -Trace fossils in Sedimentology and stratigraphy. SEPM Short Course 15, 317.

Ekdale, A.A. y Mason, T. R. 1988. Characteristic trace-fossil associations in oxygenpoor sedimentary environments. Geology, 16, 720-723.

Ekdale, A.A. y Bromley, R.G. 1991. Analysis of composite ichnofabrics: an example in uppermost Cretaceous chalk of Denmark. Palaios 6: 232-249.

Ekdale, A.A. y Lewis, D.W. 1991. The New Zeeland Zoophycos revisited: morphology, ethology and paleoecology. Ichnos1, 183-194.

Elderfield, H. y Graves, M.J. 1982. The Rare earth elements in sea water. Nature, 296, 214-219.

Erba, E., Bartolini, A. y Larson, R.L. 2004. Valanginian Weissert oceanic anoxic event. Geology 32: 149 -152.

Esquevin, J. 1969. Influence de la composition chimique des illites sur leur cristallinité. Bulletin Centre Rech. Pau., S.N.P.A., 3: 147-154.

Falkner, T. 1774. A description of Patagonia and the Adjoining Parts of South America. Traducción al Castellano en Biblioteca Centenario Universidad Nacional de La Plata I: 17 - 126.

Favre, F. 1908. Die Ammoniten der unteren Kreide Patagoniens. Neues Jarhb. Min. Geol. Palaont., Stuttgart 25: $601-647$.

Fedonkin, M. A. 1980. Fossil traces of Precambrian Metazoa. Izvestiya Akademii Nauka SSSR, series geologie, 1:39-46.

Féraud, G., Alric, V., Fornari, M., Bertrand, H. y Haller, M. 1999. 40Ar/39Ar dating of the Jurassic volcanic province of Patagonia: migrating magmatism related to Gondwana break-up and subduction. Earth and Planetary Science Letters, 172, 83-98. 
Feruglio, E. 1936. Paleontographia Patagonica. Mem. Ist. Geol. Univ, Padova. 11: 1 384.

Feruglio, E. 1938. El Cretáceo superior del Lago San Martín y de las regiones adyacentes. Physis, 12: $293-342$.

Feruglio, E. 1944. Estudios geológicos y Glaciológicos en la región del Lago Argentino (Patagonia). Boletín de la Academia Nacional de Ciencias, Córdoba. 37: 3 - 255.

Feruglio, E. 1950. Descripción Geológica de la Patagonia. Y.P.F. Buenos Aires, Tomos I, II, III.

Fildani, A., Cope, T., Graham, S. y Wooden, J. 2003. Initiation of the Magallanes foreland basin: Timing of the southernmost Patagonian Andes orogeny revised by detrital circon provenance analysis. Geology v. 31 n 12, $1081-1084$.

Fildani, A. y Hessler, A. 2005. Stratigraphic record across a retroarc basin inversion: Rocas Verdes - Magalanes Basin, Patagonian Andes, Chile. GSA Bulletin, $117 \mathrm{n}^{\circ}$ 11/12: 1596 - 1614 .

Fildani, A., Romans, B.W., Fosdick, J.F., Crane, W.H., y Hubbard, S.M. 2008. Orogenesis of the Patagonian Andes as reflected by basin evolution in southernmost South America. Arizona Geological Society, Digest 22: 1- 10.

Flores, M. y Perrot, J. 1961. Sketch map of outcroops. Part I. Austral Basin (North Half). Escala 1:500.000. Pan American Argentina Oil CO., Exploration Department, Inédito.

Floyd, P. A., Leveridge B. E. 1987. Tectonic environment of the Devonian Gramscatho basin, south Cornwell: framework mode and geochemical evidence from turbidite sandstones. J Geol Soc London 144:531-542

Floyd, P. A., Winchester, J. A. y Park, R. G. 1989. Geochemistry and tectonic setting of Lewisian clastic metasediments from the Early Proterozoic Loch Maree Group of Gairloch, NW Scotland. Precambrian Research 45, 203-214.

Floyd, P.A., Franke, W., Shail, R. y Dörr, W. 1990. Provenance and depositional environment of Thenohercynian synorogenic greywacke from the Giessen nappe, Germany. Geologische Rundschau 79, 611-626.

Folk, R.L., Andrews, P.B. y Lewis, D.W. 1970. Detrital sedimentary rock classification and nomenclature for use in New Zealand. New Zealand Journal of Geology and Geophysics 13, 937-968. 
Fölling, P.G. y Frimmel, H.E. 2002. Chemostratigraphic correlation of carbonate succesions in the Gariep and Saldania Belts, Namibia and South Africa. Basin Res. 13, 1-37.

Föllmi, K. B. y Grimm, K. A. 1990. Doomed pioneers: gravity-flow deposition and bioturbation in marine oxygen-deficient environments. Geology 18: 1069-1072.

Foscolos, A. E., Powell, T. G. y Gunther, P. R. 1976. The use of clay minerals, inorganic and organic geochemical indicators for evaluating the degree of diagenesis and oil generating potential of shales. Geochimica et Cosmochimica Acta, 40: 953 - 960 .

Fossa Mancini, E., Feruglio, E. y Yussen de Campana, J.C. 1938. Una Reunión de geólogos de Y.P.F. y el problema de la Terminología Estratigráfica. Boletín de Informaciones Petroleras, Buenos Aires, 171: 31-95.

Fozy, I., Janssen, N. M. M., Price, G. D., Knauer, J. y Pálfy, J. 2010. Integrated isotope and biostratigraphy of a Lower Cretaceous section from the Bakony Mountains (Transdanubian Range, Hungary): A new Tethyan record of the Weissert event. Cretaceous Research 31; 525-545.

Franzese, J. R., Poiré, D. G. y Muravchik, M. 2006. Secuencias de sin-rift de la Cuenca Austral entre los Lagos Argentino y Viedma, Argentina. Actas del IV Congreso Latinoamericano de Sedimentología - XI Reunión Argentina de Sedimentología, Bariloche, Argentina.

Frenguelli, J. 1930. Nomenclatura estratigráfica Patagónica. Annales de la Sociedad Científica, Santa Fe, 3: $71-83$.

Frenguelli, J. 1935. "Ptilophyllum hislopi” (Oldham) en los “Mayer River Beds” del Lago San Martín. Notas del Museo de La Plata, Paleontología, 1 (Paleontología 3): $71-83$.

Frenguelli, J. 1941 a. Nuevos elementos florísticos del Magalliano de Patagonia austral. Notas del Museo de La Plata, Paleontología, 6 (Paleontología 30): 173 202.

Frenguelli, J. 1941 b. Las concreciones de los varves y su significado geológico. Notas del Museo de la Plata 6: 173 - 202.

Frenguelli, J. 1953 a. La flora de la región del alto Río Chalía en Santa Cruz (Patagonia). Notas del Museo de la Plata 16: 239 - 275. 
Frenguelli, J. 1953 b. Recientes progresos en el conocimiento de la Geología y la Paleogeografía de Patagonia basados en el estudio de sus plantas fósiles. Revista del Museo de la Plata 4: 321 - 341.

Frey, R.W., Howard, J.D. y Pryor, W.A. 1978. Ophiomorpha: ist morphologic, taxonomic and environmental significance. Palaeoclimatology, Palaeogeography, Paleoecology, 23: 199-229. Amsterdam.

Frey, R. W. y Pemberton, S. G. 1984. Trace fossils Facies Models. In : R. G. Walker (ed), Facies Models. Geoscience Canada Series. Pp. 189-207.

Frey, R. W. y Pemberton, S. G. 1985.Biogenic structures in outcrops and cores. I. Approaches to ichnology. Bulletin of Canadian Petroleum Geology. 33 :72 - 115.

Fu, S. 1991. Funktion, Verhaltenund Einteilung fucoider und lophoctenoider Lebensspuren. Courier Forschungs Institut Senckenberg 135, 1-79.

Furque, G. 1973. Hoja 58b, Lago Argentino, descripción de la hoja geológica a escala 1:200000.

Gabaldon, V. 1991. Plataformas siliciclásticas externas: Facies y su distribución areal. (Plataformas dominadas por tormentas). Publicación Especial del Boletín Geológico y Minero, Instituto Tecnológico GeoMinero de España. 93 pp.

Gaillard, C., Hennebert, M. y Olivero, D., 1999. Lower Carboniferous Zoophycos from the Tournai area (Belgium): environmental and ethologic signicance. Geobios 32, 513-524.

Gale, J.F., Reed, R.M. y Holder, J. 2007. Natural fractures in the Barnett Shale and their importance for hydraulic fracture treatments. AAPG Bulletin 91: 603 - 622.

Galloway, W. E. 1989. Genetic stratigraphic sequences in Basin Analysis: Architecture and Genesis of Flooding Surface Bounded Depositional Units. Bulletin of the American Association of Petroleum Geologist 73: 125 - 142.

Gernant, R.E. 1972. The paleoenvironmental significance of Gyrolithes (lebensspur). Journal of Paleontology, 46:735-741.

Gómez Peral, L. E., Poiré, D. G., Strauss, H. y Zimmermann, U. 2007. Chemostratigraphy and diagenetic constraints on Neoproterozoic carbonate successions from the Sierras Bayas Group, Tandilia System, Argentina. Chemical Geology 237:127-146

Gómez Peral, L.E., Poiré, D.G. y Kaufman, A.J. 2010. REE of Neoproterozoic- early Cambrian Phosphate concretions and their digenetic implications. Tandilia 
System, Argentina. 18th International Sedimentological Congress, 26th Sept. - 1st Oct., 2010, Mendoza, Argentina, Abstract volume, 397.

Grimm, K. A. y Fölmi, K. B. 1990. Doomed pioneers: Event deposition and bioturbation in anaerobic environments. American Association of Petroleum Geologists Bulletin, 74.

Gressly, A. 1838. Observations géologiques sur le Jura Soleurois: Neue Denksch. allg. schweiz., Ges. ges. Naturw., v. 2, p. 1-112.

Gröcke, D.R., Price, G.D., Robinson, S.A., Baraboshkin, E., Ruffell, A.H. y Mutterlose, J. 2005. The Valanginian (Early Cretaceous) positive carbon-isotope event recorded in terrestrial plants. Earth and Planetary Science Letters 240; 495509.

Gromet L. P., Dymek, R. F., Haskin, L. A. y Korovtev, R. L. 1984. The "North American Shale Composite”: its compilation, major and trace element characteristics. Geochimica et Cosmochimica Acta, 48; 2469-2482.

Gu, X.X., Liu, J.M., Zheng, M.H., Tang, I.X. y Qi, L. 2002. Provenance and tectonic setting of the Proterozoic turbidites in Hunan, south China: geochemical evidence. Journal of Sedimentary Research 72, 393-407.

Hall, J. 1847. Palaeontology of New York. Volume I. Containing descriptions of the organic remains of the Lower Division of the New York System (Equivalent to the Lower Silurian rocks of Europe). C. van Benthuysen, Albany, 338 pp.

Halle, T. G. 1913. Some Mesozoic plant-bearing deposits in Patagonia and Tierra del Fuego and their floras. Kungl. Sv. Vetenskapsakad. Handl., Stockholm, 51 (3): 3 $-58$.

Haq, B.U., Hardenbol, J. y Vail, P.R., 1988. Mesozoic and Cenozoic chronostratigraphy and cycles of sea-level change. En: Wilgus, C.K., Hastings, B.S., Kendall, C.G.St.C., Posamentier, H.W., Ross, C.A., Van Wagoner, J.C. (Eds.), Sea-Level Changes-An Integrated Approach. SEPM Special Publication 42: $72-108$.

Haq, B. U. 1991. Sequence stratigraphy, sea-level change, and significance for the deep sea. IAS Special publication 12: 3 - 39.

Harnois, L. 1988. The CIW index: A new chemical index of weathering. Sedimentary Geology 55, 319-322.

Haskin, M.A., y Haskin, L.A. 1966. Rare earths in European shales. A redetermination. Science 154:. 507-509. 
Hatcher, J. B. 1897. On the geology of Southern Patagonia. American Journal of Science, 4 (23): $327-354$.

Hein, F.J., Robb, G.A., Wolberg, A.C. y Longstaffe, F.J. 1991. Facies descriptions and associations in ancient reworked (?transgressive) shelf sandstones: Cambrian and Cretaceous examples. Sedimentology, 38:405-431.

Herron, M.M. 1988. Geochemical classification of terrigenous sands and shales from core or log data. Journal of Sedimentary Petrology 58, 820-829

Hervé, F. Demant, A. Ramos, V. A. Pankhrust, R. J. y Suárez, M. 2000. The Southern Andes, in Cordani, U. G., et al., eds., Tectonic evolution of South America: Río de Janeiro, 31 st International Geological Congress, p. 605 - 634.

Hervé, F., Pankhurst, R. J., Fanning, C. M., Calderón, M. y Yaxley, G. M. 2007. The South Patagonian batholith: 150 my of granite magmatism on a plate margin. Lithos

Hill, R.J., Zhang, E., Tang, Y., y Katz, B. 2007. Estimating shale gas potential from confined pyrolysis experiments (abstract): Rocky Mountain Natural Gas 2006, Program and Abstracts, p. 124, 126.

Hofmann, H.J., Cecile, M.P. y Lane, L.S. 1994. New occurrences of Oldhamia and other trace fossils in the Cambrian of the Yukon and Ellesmere Island, Arctic Canada. Canadian Journal of Earth Sciences 31, 767-782.

Huene, F. 1929. Los Saurisquios y Ornitisquios del Cretáceo Argentino. Anales del Museo de la Plata 3: 1 - 196.

Hunicken, M. 1955. Depósitos neocretácicos y terciarios del extreme SSw de Santa Cruz (Cuenca carbonífera de Río Turbio). Revista del Museo Argentino de Ciencias Naturales Bernardino Rivadavia, Buenos Aires. 4: 1 - 164.

Ingersoll, R.V., Bullard, T.F., Ford, R.L., Grimm, J.P., Picke, J.D. y Sares, S.W. 1984. The effect of grain size on detrital modes: a test of the Gazzi-Dickinson point-counting method. Journal of Sedimentary Petrology 54, 103-116.

Iñiguez Rodríguez, A. M. y Decastelli, O. O. 1984. Mineralogía y diagénesis de arcillas de las Formaciones Cretácico-Terciarias de la Cuenca Austral. Actas del IX Congreso Geológico Argentino. Bariloche. Tomo III, 402-414.

Ireland, B. J., Curtis, C. D. y Whiteman, J. A. 1983. Compositional variation within some glauconites and illites and implications for their stability and origins. Sedimentology, 30: 769-786. 
Jacobsen, S.B. y Kaufman, A.J. 1999. The Sr, C and O isotopic evolution of Neoproterozoic seawater. Chem. Geol. 161, 37-57.

Jarvis, I., Burnett, W., Nathan, Y., Almbaydin, F. S. M., Attia, A. K. M., Castro, L. N., Flicoteaux, R., Hilmy, M. E., Husain, V., Qutawnah, A. A., Serjani, A. y Zanin, Y. N. 1994. Phosphorite geochemistry: state-of-the-art and environemental concerns. Eclogae Geol. Helv. 87; 643- 700.

Jarvis, I., Murphy, A. M., y Gale A. 2001. Geochemistry of pelagic and hemipelagic carbonates: citreria for identifying systems tracts and sea-level change. Journal of the Geological Society, London 158: 685-696.

Jensen, S. 1997. Trace fossils from the Lower Cambrian Mickwitzia sandstone, southcentral Sweden. Fossils and Strata, 42:1-111.

Katz, H. R. 1963. Revision of Cretaceous stratigraphy in Patagonian Cordillera of Ultima Esperanza, Magallanes Province, Chile. American Association of Petroleum Geology Bulletin, v. 47, p. 506 - 524.

Kellner, A. W. A., Aguirre Urreta, M. B. y Ramos, V. A. 2003. On the Pterosaur Remins from the Río Belgrano Formation (Barremian), Patagonian Andes of Argentina. Anales de la academia de ciencias de Brazil.

Kennedy, W.J. 1967. Burrows and surface traces from Lower Chalk of Southern England. Bull. Br. Mus. Nat. Hist. Geol. 15: 12-187.

Keij, A. J. 1965. Miocene trace fossils from Borneo. Palaeontologische Zeitschrift, 39:220-228.

Kielbowicz, A. A., Ronchi, D. I. y Stach, N. H. 1983. Foraminíferos y ostrácodos Valanginianos de la Formación Springhill, Patagonia Austral. Revista de la Asociación Geológica Argentina 38: 313-339.

Knauth, L. P. y Kennedy, M. J. 2009. The late Precambrian greening of the Earth. Nature 460: 728-732.

Kneller, B. C. y Branney, M. J. 1995. Sustained high-density turbidity currents and the deposition of thick massive sands: Sedimentology, v. 42: 607-616.

Kraemer, P. E. y Riccardi, A. C. 1997. Estratigrafía de la región comprendida entre los lagos Argentino y Viedma (49 40’ $-50^{\circ} 10^{\prime}$ LS), Provincia de Santa Cruz. Revista de la Asociación Argentina de Geología, 52 (3): 333-360.

Kraemer, P. E., Ploszkiewicz, J. V. y Ramos, V. A. 2002. Estructura de la cordillera patagónica austral entre los $46^{\circ}$ y $52^{\circ}$ S. In Haller, m. j. (ed) Geología y Recursos 
Naturales de Santa Cruz. Relatorio del Decimoquinto Congreso Geológico Argentino, 925 pp.

Kraglievich, L. 1930. La formación Friaseana del Río Frías, Río Fénix, Laguna Blanca, etc. Y su fauna de mamíferos. Physis 10: 127 - 161.

Krejci-Graf, K. 1936. Zur Natur der Fucoiden. Senckenbergiana 18, 308-315.

Książkiewicz, M. 1977. Trace fossils in the flysch of the Polish Carpathians. Palaeontologia Polonica 36, 1-208.

Kubler, B. 1966. La cristallinité de l'illite et les zones tout-a-fait supéreures du metamorphisme. En “Colloque sur le étages tectoniques”. Nêuchatel: 105 - 122.

Leanza, A. F. 1970. Amonites nuevos o poco conocidos del Aptiano, Albiano y Cenomaniano de los Andes Australes con notas acerca de su posición estratigráfica. Revista de la Asociación Geológica Argentina 25(2): 197-261.

Leanza, A. F. 1972. Andes Patagónicos Australes. En: A:F. Leanza (Ed.) Geología Regional Argentina. Academia Nacional de Ciencias: 689-706. Córdoba.

Leymerie, M. A. 1842. Suite de mémoire sur le terraine Crétacé du département de l`Aube. Mem. Soc. Geol. France 5: 1-34.

Lini, A., Weissert, H. y Erba, E. 1992. The Valanginian carbon isotope event: a first episode of greenhouse climate condition during the Cretaceous. Terra Nova 4; 374-384.

Lista, R. 1880. Mis exploraciones y descubrimientos en la Patagonia, 1877 - 1880. Ediciones Marymar, Buenos Aires (1975).

Lowe, D. R. 1979. Sediment gravity flows: their classification, and some problems of application to natural flows and deposits. En: L. J. Doyle y O. H. Pilkey, Geology of Continental Slopes. Society of Economic Paleontologists and Mineralogists Special Publication 27, $75-82$.

Lowe, D. R. 1982. Sediment gravity flows II: depositional models with special reference to the deposits of high-density turbidity currents. Journal of Sedimentary Petrology, 52: 279- 297.

Löwemark, L. y Schäfer, P. 2003. Ethological implications from a detailed X-ray radiograph and 14C study of the modern deep-sea Zoophycos. Palaeogeography, Palaeoclimatology, Palaeoecology, 192, 101-121.

Lundgren, B. 1891. Studieröfver fossil förandelösa block. Geologiska Föreningen I Stockholm Förhandlinger 13, 111-121. 
MacEachern, J. A., Bann, K. L., Pemberton, S. G. y Gingras, M. K. 2007a. The Ichnofacies paradigm: High resolution palaeoenvironmental interpretation of the rock record. In: Applied Ichnology. Edited by Mac Eachern, Bann, Gingras and Pemberton. Society of Economic Paleontologists and Mineralogists Short Course Notes 52.380 pp.

MacEachern, J. A., Pemberton, S. G., Gingras, M. K. y Bann, K. L. 2007b. The Ichnofacies paradigm: A fifty-year retrospective. In: Trace Fossils: Concepts, Problems, Prospects. Edited by William Miller, III. ELSEVIER. 611 pp.

MacEachern, J. A., Pemberton, S. G., Gingras, M. K., Bann, K. L. y Dafoe, L. T. 2007c. Uses of Trace Fossils in Genetic Stratigraphy. In: Trace Fossils: Concepts, Problems, Prospects. Edited by William Miller, III. ELSEVIER. 611 pp.

Marinelli, R. V. 1998. Reservorios deltáicas de la Formación Piedra Clavada. Boletín de Informaciones Petroleras XV (54): 28 - 37.

Massalongo, A. 1855. Zoophycos, novumgenus Plantarum fossilum, Typis Antonellianis, Veronae, pp. 45 - 52.

Maynard, J.B., Valloni, R. y Yu, H. 1982. Composition of modern deep sea sands from arc-related basins. Geological Society of London, Special Publication, vol. 10, pp. 551-561.

Mayoral, E. y Muñiz, F. 1993. Consideraciones paleoetológicas acerca de Gyrolithes. En: Jornadas de Paleontología, 9, 1993. Comunicaciones, Barcelona, SPE, p. 1822.

Mayoral, E. y Muñiz, F. 1995. Nueva icnoespecie de Gyrolithes del Mioceno Superior de la cuenca de Guadalquivir (Lepe, Huelva). Revista Española de Paleontología, 10:190-201.

Mayoral, E. y Muñiz, F. 1998. Nuevos datos icnotaxonómicos sobre Gyrolithes del Plioceno Inferior de la cuenca del Guadalquivir (Lepe, Huelva, España). Revista Española de Paleontología, 13:61-69.

Mazumdar, A., Banerjee, D.M., Schidlowski, M., y Balaram, V. 1999. Rare-earth elements and Stable Isotope Geochemistry of early Cambrian chert-phosphorite assemblages from the Lower Tal Formation of the Krol Belt (lesser Himalaya, India). Chemical geology 156, 275-279.

McLennan, S.M. 1989. Rare earth elements in sedimentary rocks: Influence of provenance and sedimentary process. Mineralogical Society of America, Reviews in Mineralogy 21, 169-200. 
McLennan, S. M. 2001. Relationships between the trace element composition of sedimentary rocks and upper continental crust. Geochemistry, Geophysics, Geosystems (G3) 2(4), doi:10.1029/2000GC000109.

Medina F. A., Archangelsky, S., Guler, V., Archangelsky, A. y Cárdenas, O. 2008. Estudio bioestratigráfico integrado del perfil La Horqueta (límite AptianoAlbiano), lago Cardiel, Patagonia, Argentina. Revista del Museo Argentino de Ciencias Naturales, 10(2): 273-289.

Medina, F. A. y Riccardi, A. C. 2005. Desmoceratidae, Silicetidae and Kossmaticeratidae (Ammonitida) from the Upper Aptian-Albian of Patagonia (Argentina). Revue de Paléobiologie, Genéve, 24 (1): 251-286.

Mercerat, A. 1896. Coupes Geologiques de la Patagonie Australe. Anales del Museo Nacional Buenos Aires, V: 309 - 319.

Merodio, J.C. y Spalletti, L.A. 1990. Geoquímica de pelitas: su empleo en la definición de ambientes sedimentarios y tectónicos para el Ordovícico de la Precordillera Occidental. Asociación Geológica Argentina Revista 45 (3-4), 336345.

Middleton, G. V. y Hampton, M. A. 1976. Subaqueous sediment transport and deposition by sediment transport and deposition by sediment gravity flows. En Stanley, D. J. y Swift, D. J. P. (Eds.), Marine Sediment Transport and Environmental Management. New York, Wiley: 197 - 218.

Montgomery, S.L., Jarvie, D.M., Bowker, K.A., y Pollastro, R.M. 2005. Mississippian Barnett Shale, Fort Worth Basin, north-central Texas: Gas-shale play with multitrillion cubic foot potential: AAPG Bulletin, v. 89, p. 155-175.

Moore, D.M. y Reynolds Jr., R.C. 1989. X-ray Diffraction and the Identification and Analysis of Clay Minerals. Oxford University Press, Oxford, 332 pp.

Moreno, F. P. 1879. Viaje a la Patagonia Austral 1876 - 1877. Edición Solar S.A. Buenos Aires (1969).

Moyano, C. M. 1888. Exploración de los ríos Gallegos, Coile, Santa Cruz y canales del Pacífico. Boletín del Instituto Geográfico Argentino, Buenos Aires IX: 1-20; 2535; 89-107; 113-124.

Mutterlose, J., Pauly, S. y Steuber, T. 2009. Temperature controlled deposition of early Cretaceous (Barremian-early Aptian) black shales in an epicontinental sea. Palaeogeography, Palaeoclimatology, Palaeoecology 273: 330-345. 
Negri, A., Ferretti A., Wagner T. y Meyers, P.A. 2009. Phanerozoic organic-carbonrich marine sediments: Overview and future research challenges. Palaeogeography, Palaeoclimatology, Palaeoecology 273; 218-227.

Nesbitt, H. W. y Young, Y. M. 1982. Early Proterozoic climates and plate motions inferred from major element chemistry of lutites. Nature 299:715-717.

Nesbitt, H.W. y Young, G. M. 1984. Prediction of some weathering trends of plutonic and volcanic rocks based on thermodynamic and kinetic considerations. Geochimica Cosmochimica Acta 48; 1523-1534.

Nesbitt, H.W., Young, G.M., McLennan, S.M. y Keays, R.R. 1996. Effects of chemical weathering and sorting on the petrogenesis of siliciclastic sediments, with implications for provenance studies: Journal of Geology 104, 525-542.

Netto, R. G., Buatois, L. A., Mángano, M. G. y Balistieri, P. 2007. Gyrolithes As A Multipurpose Burrow: An Ethologic Approach. Revista Brasileira de Paleontologia 10 (3):157-168.

Nordenskjold, E. 1905. Die Krystallinen Gesteine der Magellanslander. Wiss. Ergebn. Schwed. Exp. N. d. Magellanslendern, Stockholm, 1: 175 - 240.

Nullo, F. E., Proserpio, C. y Ramos, V. A. 1978. Estratigrafía y tectónica de la vertiente este del Hielo Continental Patagónico, Argentina -Chile. $7^{\circ}$ Congreso Geológico Argentino, Neuquén. Actas.

Nullo, F. E., Proserpio, C. A. y Blasco de Nullo, G. 1981. El Cretácico de la Cuenca Austral entre el Lago San Martín y Río Turbio. In: Volkheimer, W., Mussachio, E. A. (Eds.) Cuencas Sedimentarías del Jurásico y Cretácico de América del Sur: 181-220. Buenos Aires.

Nullo, F. E., Panza, J. L. y Blasco, G. 1999. Jurásico y Cretácico de la Cuenca Austral. En R. Caminos (Ed.) Geología Argentina. Subsecretaría de Minería de la NaciónServicio Geológico Minero Argentino: 528-535, Buenos Aires.

Odin, G. S. 1973. Répartition, nature minéralogique et genèse des granules verts recueillis dans les sediments marins actuel. Sciences Terre, Nancy, 18: 79-94.

Odin, G. S. y Fullagar, P. D. 1988. Geological significance of the glaucony facies. En Odin (Ed.), Green Marine Clays, Developments in Sedimentology 45, 445 pp.

Odin, G. S. y Lamboy, M. 1988. Glaucony from the margin off northwestern Spain. En Odin (Ed.), Green Marine Clays, Developments in Sedimentology 45, 445 pp.

Odin, G. S. y Matter, A. 1981. De glaconiarum origine. Sedimentology, 28: 611-641. 
Olivero, D. 2007. Zoophycos and the Role of Type Specimens in Ichnotaxonomy. In: Trace Fossils: Concepts, Problems, Prospects. Edited by William Miller, III. ELSEVIER. 611 pp.

Olivero, D., y Gaillard, C. 1996. Palaeoecology of Jurassic Zoophycos from SouthEastern France. Ichnos, 4, 249-260.

Olivero, D., y Gaillard, C. 2007. A constructional Model for Zoophycos. In: Trace Fossils: Concepts, Problems, Prospects. Edited by William Miller, III. ELSEVIER. 611 pp.

Páez, G. N., Ruiz, R., Guido, D. M., Jovic, S. M. y Schalamuk, I. B. 2010. The effects of K- metasomatism in the Bahía Laura Volcanic Complex, Deseado Massif, Argentina: Petrologic and metallogenic consequences. Chemical Geology 273: 300-313.

Palacios, A. L. 2011. Shale gas transforma la matriz energética de Norteamérica. Revista Energía y Debate № 42, 6 - 9. México.

Paulcke, W. 1907. Die Cephalopoden der oberen Kreide Sudpatagoniens. Ber Naturf. Ges., Freiburg 15: 167 - 248.

Pankhurst, R. J. y Rapela, C. W. 1995. Production of Jurassic rhyolite by anatexis in the lower crust of Patagonia. Earth Planet. Sci. Lett. 134, 23-36.

Pankhurst, R. J., Leat, P. T., Sruoga P., Rapela C. W., Márquez M., Storey B. C. y Riley, T. R. 1998. The Chon Aike province of Patagonia and related rocks in West Antarctica: A silicic large igneous province. Journal of Volcanology and Geothermal Research 81: 113-136.

Pankhurst, R. J., Riley, T. R., Fanning, C. M. y Kelley, S. P. 2000. Episodic silicic volcanism in Patagonia and Antarctic Peninsula.: Chronology of magmatism associated with the break-up of Gondwana. Journal of Petrology, v. 41, 605 - 625.

Pearce, J.A., Harris, N.B.W. y Tindle, A.G. 1984. Trace element discrimination diagrams for the tectonic interpretation of granitic rocks. J. Petrol. 25, 953-956.

Pemberton, S. G., Frey, R.W. y Bromley, R.G. 1988. The ichnotaxonomy of Conostichus and other plug-shaped ichnofossils. Canadian Journal of Earth Science. 25, $866-892$.

Peroni, G., Cagnolatti, M. y Pedrazzini, M. 2002. Cuenca Austral: Marco Geológico y Reseña Histórica de la actividad petrolera. Rocas reservorio de las cuencas productivas de la República Argentina, V Congreso de Exploración y Desarrollo de Hidrocarburos, Mar Del Plata. 
Pettijohn, F.J., Potter, P.E. y Siever, R. 1972. Sand and Sandstone. Springer, New York, 553 pp.

Piatnitzky, A. 1938. Observaciones Geológicas en el Oeste de Santa Cruz (Patagonia). Boletín de Informaciones Petroleras 165: 45-85.

Pickerill, R. K. 1989. Bergaueria perata Prantl, 1945 from the Silurian of Cape George, Nova Scotia. Atlantic Geology, 25, 191-197.

Pickerill, R. K. y Narbonne, G.M. 1995. Composite and compound ichnotaxa, a case example from the Ordovician of Québec, eastern Canada. Ichnos 4, 53-69.

Pirrie, D., Marshall, J. D., Doyle, P. y Riccardi, A.C. 2004. Cool early Albian climates; new data from Argentina. Cretaceous Research, 25, 27 - 33.

Pitman, W. C. III. 1978. The relationship between eustasy and stratigraphic sequences of passive margins. Geological Society of America Bulletin 89: 1389 - 1403.

Pittion, J. L. y Gouadain, J.1992. Source-rock and oil generation in the Austral Basin. 13 World Petroleum Congress, Buenos Aires, Proceedings, 2: 113 - 120.

Pittion, J. L. y Arbe, H. A. 1999. Sistemas petroleros de la Cuenca Austral. IV Congreso de Exploración y Desarrollo de Hidrocarburos, Mar del Plata, 239 262.

Poiré, D. G., Carloni, A., Ferrer, O. y Canessa, N. D. 2001. Características icnológicas de la Formación Piedra Clavada (Cretácico), Tres Lagos, Cuenca Austral, Argentina. IV Reunión Argentina de Icnología y Segunda Reunión de Icnología del Mercosur (Tucumán, 2001), Resúmenes p. 65.

Poiré, D.G., Canessa, N. D., Carloni, A. y Ferrer, O. 2002. La Formación Piedra Clavada en el área de Tres Lagos, provincia de Santa Cruz, Argentina. XV Congreso Geológico Argentino (El Calafate, Santa Cruz), Actas: p. 6

Poiré, D.G., Franzese, J.R., Spalletti, L.A. y Matheos, S.D. 2007. Estratigrafía de las rocas reservorios de la Cuenca Austral en el sector cordillerano, provincia de Santa Cruz, Argentina. Guía de Campo Inédita: Centro de Investigaciones Geológicas, La Plata, 112 pp.

Poiré, D. G., Franzese, J. y Muravchic, M. 2007. Sedimentación carbonática asociada al vulcanismo jurásico del Complejo El Quemado, Cuenca Austral, Argentina. En: III Simposio Argentino del Jurásico, Mendoza.

Poiré, D.G. y Franzese, J.R. 2008. Trazas fósiles de ambientes litorales marinoparálicos de la Formación Springhill (Cretácico Inferior), Andes Patagónicos 
Australes, provincia de Santa Cruz, Argentina. XII Reunión Argentina de Sedimentología, Buenos Aires, Actas. 143 pp.

Pollastro, R.M., Hill, R.J., Ahlbrandt, T.A., Charpentier, R.R., Cook, T.A., Klett, T.R., Henry, M.E., y Schenk, C.J. 2004, Assessment of undiscovered oil and gas resources of the Bend Arch-Fort Worth Basin Province of North-Central Texas and southwestern Oklahoma: U.S. Geological Survey Fact Sheet 2004-3022, 2 p. (http://pubs.usgs.gov/fs/2004/3022/).

Posamentier, H.W. y Vail, P.R. 1988. Eustatic controls on clastic deposition: II. Sequences and systems tract model. En: Wilgus, C.K., Hastings, B.S., Kendall, C.G.St.C., Posamentier, H.W., Ross, C.A., Van Wagoner, J.C. (Eds.), Sea-Level Changes- An Integrated Approach. SEPM Special Publication 42: 125- 154.

Posamentier, H.W., Jervey, M. T. y Vail, P. R. 1988. Eustatic controls on clastic deposition. I. Conceptual framework. Society of Economic Paleontologists and Mineralogists, Special Publication, 42: 109-204.

Posamentier, H. W. y James, D. P. 1993. An overview of sequence-stratigraphic concepts: uses and abuses. IAS Special Publication 18: 3 - 18.

Potter, P. E., Maynard, J. B. y Depetris, P. J. 2005. Mud and Mudstones. Springer, New York, 297 pp.

Powel, T. G., Foscolos, A. E., Gunther, P. R. y Snowdon, L.R. 1978. Diagenesis of organic matter and fine clay minerals: a comparative study. Geochimica et Cosmochimica Acta, 42: 1187 - 1197.

Prantl, F. 1945. Two new problematic trails from the Ordovician of Bohemia. Académie Tchèque des Sciences, Bulletin International, Classe de Sciences Mathématiques, Naturelles et de la Médecine, 46, 49-59.

Quartino, B. J. 1952. Rasgos geológicos y litológicos de la Cuenca de los lagos Fontana y La Plata. Universidad de Buenos Aires, Facultad de Ciencias Exactas y Naturales, Tesis 717, Inédita.

Quensel, P. D. 1911. Geologisch - petrographische Studien en der patagonischen Cordillera. Bulletin Geological Institute Uppsala, 9: 1 - 113.

Quensel, P. D. 1913. Die Quarzporphyr und Porphyroid formation in Supatagonien und Feuerland. Bull. Geol. Inst. Uppsala 12: 9 - 40.

Rahman, M. y Shigeyuki, S. 2007. Geochemestry of sandstones from the Miocene Surma Group, Bengal Basin, Bangladesh: Implications for Provnance, tectonic setting and weathering. Geochemical Journal 41; 415-428. 
Ramos, V. A. 2002. Evolución tectónica. In Haller, m. j. (ed) Geología y Recursos Naturales de Santa Cruz. Relatorio del Decimoquinto Congreso Geológico Argentino, 925 pp.

Ramos, V. A., Niemeyer, H., Skarmeta, J. y Muñoz, J. 1982. Magmatic evolution of the Austral Patagonian Andes. Earth-Science Reviews 18: 411-443.

Ranger, M. J. y Pemberton, S. G. 1988. Marine influence in the McMurray Formation in the Primrose area, Alberta. En: D.P. James y D.A. Leckie (Eds.) Sequences, stratigraphy, sedimentology: surface and subsurface. Canadian Society of Petroleum Geologists, 439-450.

Ranger, M. J. y Pemberton, S. G. 1992. The sedimentology and ichnology of estuarine point bars in the McMurray Formation of the Athabasca Oil Sands Deposit, northeastern Alberta, Canada. En: S.G. Pemberton (Ed.) Applications of ichnology to petroleum exploration - a core workshop, Society of Economic, Paleontologists and Mineralogists, $401-421$.

Rhoads, D. C. y Morse, J. M. 1971. Evolutionary and ecologic significance of oxygendeficient marine basins. Lethaia, 4: 413 - 428.

Riccardi, A. C. 1968. Estratigrafía de la región oriental de la Bahía de la Lancha, Lago San Martín, Santa Cruz. Museo de la Plata, Tesis Doctoral n 274, 347pp.

Riccardi, A. C. 1970. Favrela R. Douvillé, 1909 (Ammonitina, Cretácico inferior): edad y distribución. Ameghiniana VII (2): 119-138.

Riccardi, A. C. 1971. Estratigrafía en el oriente de la Bahía de la Lancha, Lago San Martín, Santa Cruz, Argentina. Extracto de la Revista del Museo de la Plata, Sección Geológica, Tomo VII: 245-318.

Riccardi, A. C. 1986. Historia del estudio geológico de la Cordillera Patagónica Austral. Boletín de la Academia Nacional de Ciencias, Córdoba, Argentina. Tomo 57, 123-147.

Riccardi, A. C. 1988. The cretaceous system of southern South America. Geological Society of America, Memoir 168: 1-116.

Riccardi, A. C., Aguirre Urreta, M. B. y Medina, F. 1987. Aconeceratidae (Ammonitina) from the Hauterivian-Albian of southern Patagonia. Palaeontographica 196: 105-185.

Riccardi, A. C. y Rolleri. E. O. 1980. Cordillera Patagónica Austral. En: J:C:M: Turner (Ed.) Segundo Simposio de Geología Regional Argentina. Academia Nacional de Ciencias II: 1173- 1304. Córdoba. 
Riggi, J. C. 1957. Resumen geológico de la zona de los lagos Pueyrredón y Posadas, Provincia de Santa Cruz. Revista de la Asociación Geológica Argentina 12: 65 97.

Rodríguez, N. D. 2011. Estudio del origen y madurez de gases generados por el Barnett Shale, cuenca Fort Worth, Texas. Revista Energía y Debate $N^{\circ}$ 44: 46 -50. México.

Rodríguez, J. y Miller, M. 2005. Cuenca Austral. En Frontera Exploratoria de la Argentina, VI Congreso de Exploración y Desarrollo de Hidrocarburos.

Rodríguez, J. F. y Cagnolatti, M. J. 2008. Source Rocks and Paleogeography, Austral Basin, Argentina. AAPG Convention, San Antonio, TX.

Roll, A. 1937. Estudio geologic de la zona entre el Río Shehuen y el Río Santa Cruz. YPF Buenos Aires, informe inédito.

Roser, B.P. y Korsch, R.J. 1985. Plate tectonics and geochemical composition of sandstones: a discussion. Journal of Geology 93, 81-84.

Roser, B. P. y Korsch, R. J. 1986. Determination of tectonic setting sandstonemudstone suites using $\mathrm{SiO} 2$ content and K2O/Na2O ratio. Journal of Geology 94 (5), 635-650.

Roser, B. P. y Korsch, R. J. 1988. Provenance signatures of sandstone mudstone suites determined using discriminant function analysis of major-element data. Chemical Geology 67, 119-139.

Ruppel, S. C., y Loucks, R. G. 2006. Stratigraphy and depositional history of the Barnett Formation and equivalent Mississippian rocks in the Ft. Worth Basin (abs.): Geological Society of America, South-Central Section, Abstracts with Programs, v. 38, no. 1, p. 3.

Russo, A. y Flores, M. A. 1972. Patagonia Austral Extraandina. In: A. F. Leanza (Ed.) Geología Regional Argentina. Academia Nacional de Ciencias: 707-725. Córdoba.

Russo, A., Flores, M. A. y Di Benedetto, H. 1980. Patagonia Austral Extraandina. En: J. C. M. Turner (Ed.) Segundo Simposio de Geología Regional Argentina. Academia Nacional de Ciencias II: 1431-1462. Córdoba.

Sagasti, G. 2001. Estudio Sedimentológico y de Estratigrafía Secuencial de las sedimentitas carbonáticas de la Formación Agrio (Cretácico inferior), en el sector surmendocino de la Cuenca Neuquina, República Argentina. Tesis Doctoral 
inédita. Universidad Nacional de La Plata, Facultad de Ciencias Naturales y Museo. 280pp.

Savrda, C. E. 1995. Ichnological application in paleoceanographic, paleoclimatic and sea-level studies. Palaios, 10: 565 - 577.

Savrda, C. E. y Bottjer, D. J. 1986. Trace-fossil model for reconstruction of paleooxygenation in bottom waters. Geology, 14: 3 - 6.

Savrda, C. E. y Bottjer, D. J. 1987. The exaerobic zone, a new oxygen-related marine biofacies. Nature 327: $54-56$.

Savrda, C. E., Ozalas, K., Demko, T. H., Hutchinson, R. A. y Scheiwe, T. D. 1993. Log-grounds and the ichnofossil Teredolites in transgressive deposits of the Clayton Formation (Lower Palaeocene), western Alabama. Palaios, 8: 311 - 324.

Savrda, C. E., Krawinkel, H., McCarthy, F. M. G., McHugh, C. M. G., Olson, H.c. y Mountain, G. 2001. Ichnofabrics of a Pleistocene slope succession, New Jersey margin: relations to climate and sea-level dynamics. Palaeogeography, Palaeoclimatology, Palaeoecology 171: 41- 61.

Scasso, R.A. y Limarino, C.O. 1997. Petrología y Diagénesis de Rocas Clásticas. Asociación Argentina de Sedimentología, Buenos Aires, 1-259 pp.

Schlanger, S.O. y Jenkyns, H.C. 1976. Cretaceous oceanic anoxic events: causes and consequences. Geologie en Mijnbouw 55, 179-184.

Scotese, C. R. 2001. Atlas of earth history. Arlington, TX: PALEOMAP Project.

Scotese, C. R., Boucot, A. J. y McKerrow, M. S. 1999. Gondwanan palaeogeography and palaeoclimatology. Journal of African Earth Science 28, 99-114.

Seilacher, A. 1964. Sedimentological classification and nomenclature of trace fossils. Sedimentology, 3, 256-263.

Seilacher, A. 1967. Bathymetry of trace fossils. Marine Geology 5, 413-428.

Seilacher, A., Buatois, L. A. y Mángano, M. G. 2005. Trace fossils in the EdiacaranCambrian transition: Behavioral diversification, ecological turnover and environmental shift. Palaeogeography, Palaeoclimatology, Palaeoecology 227: 323- 356.

Shaw, D.M. 1968. A review of K-Rb fractionation trends by covariance analysis. Geochimica et Cosmochimica Acta, 32; 573-601.

Shields, G. y Stille, P. 2001. Diagenetic constraints on the use of cerium anomalies as palaeoseawater redox proxies: an isotopic and REE study of Cambrian phosphorites. Chemical geology, 175, 29-48. 
Shultz, M. R. y Hubbard, S. M. 2005. Sedimentology, stratigraphic architecture, and icnology of cravity-flow deposits partially ponded in grwth-fault-controlled slope minibasin, Tres Pasos Formation (Cretaceous), southern Chile. Journal of Sedimentary Research 75, 440-453.

Simpson, G. G. 1940. Review of mammal-bearing Tertiary of South America. Proc. Am. Phil. Soc. Philadelphia 83: 649 - 709.

Spalletti, L. A., Poiré, D. G., Schwarz, E. y Veiga, G. D. 2001a. Sedimentologic and sequence stratigraphic model of a Neocomian marine carbonate-siliciclastic ramp: Neuquén Basin, Argentina. Journal of South American Earth Sciences (14) 6: 609 $-624$.

Spalletti, L. A., Poiré, D. G., Pirrie, D., Matheos, S. y Doyle, P. 2001b. Respuesta sedimentológica a cambios en el nivel de base en una secuencia mixta clásticacarbonática del Cretácico de la Cuenca Neuquina, Argentina. Revista de la Sociedad Geológica de España 14: 57 - 74.

Spalletti, L.A. y Franzese, J.R. 2007 Mesozoic Paleogeography and Paleoenvironmental evolution of Patagonia (Southern South America). En: Patagonian Mesozoic Reptiles. Gasparini, Z., Salgado, L., y Coria, R.A. (Eds.) Indiana University Press, Bloomington \& Indianapolis, pp. 29-49.

Spalletti, L. A., Queralt, I., Matheos, S. D., Colombo, F. y Maggi, J. 2008. Sedimentary petrology and geochemistry of siliciclastic rocks from the upper Jurassic Tordillo Formation (Neuquén Basin, western Argentina): Implications for provenance and tectonic setting. Journal of South American Earth Sciences 25; 440-463.

Stanton, T. W. 1901. The Marine Cretaceous Invertebrates. Rep. Princeton University Expedition to Patagonia 1896 - 1899: 1-43.

Steckler, M. S., Reynolds, D. J., Coakley, B. J., Swift, B. A. y Jarrard, R. 1993. Modelling passive margin sequence stratigraphy. IAS Special Publication 18: 19 41.

Stein, R. 2007. Upper Cretaceous/lower Tertiary black shales near the North Pole: Organic-carbon origin and source-rock potential. Marine and Petroleum Geology 24, 67-73.

Steinmann, G. 1883. Reisenotizen aus Patagonien. Neues Jarhb Min. Geol. U Pal., Stuttgart, 2: $255-258$. 
Stolley, E. 1912. Uber einige Cephalopoden aus der Unteren Kreide Patagoniens. Ark, Zool. Sven. Vet., Stockholm 7: 12 - 18.

Stow, D. A. V. y Wedsel, A. 1990. Hemiturbidite: a new type of deep water sediment. En: Cochran, J. R. y Stow, D. A. V. (Eds), Proceedings ODP Scientific Results, 116: $25-34$.

Stow, D. A. V., Reading H. G. y Collison, J. D. 1996. Deep seas. En: Reading H. J. (Ed.), Sedimentary Environments: Processes, Facies and Stratigraphy. Third edition: 395-453.

Stow, D. A. V., Huc, A. Y. y Bertrand, P. 2001. Depositional process of black shales in deep water. Marine and Petroleum Geology 18: 491 -498.

Strohmenger, C. y Strasser, A. 1993. Eustatic controls on the depositional evolution of Upper Tithonian and Berriasian deep-water carbonates (Vocontian Trough, SE France). Bulletin du Centre de Recherches Exploration-Production Elf Aquitaine 17: 183-203

Summerhayes, C. P. 1986. Sealevel curves based on seismic stratigraphy: their chronostratigraphic significance. Palaeogeography, Palaeoclimatology, Palaeoecology 57: 27 - 42.

Surdam R. C., Crossey, L. J., Hagen E. S, y Heasler, H. P. 1989. Organic- inorganic interactions and sandstone diagenesis. American Association of Petroleum Geologists Bulletin 73: 1-23.

Taylor, S. R. y McLennan, S. M. 1985. The Continental Crust: its Composition and Evolution. Blackwell, Oxford, pp 1-312.

Taylor, P. D. y Wilson M. A. 2003. Palaeoecology and evolution of marine hard substrate communities. Earth-Science Reviews 62: 1-103.

Thomas, C. R. 1949a. Manantiales field, magallanes province, chile. AAPG, Bulletin, 33 (9): 1579-1589.

Thomas, C. R. 1949b. Geology and Petroleum Exploration in Magallanes Province, Chile. AAPG, Bulletin, 33 (9): 1553-1578.

Tucker, M. E. y Wright, V. P. 1990. Carbonate Sedimentology. Blackwell Sc. Public., London. 482 p.

Turic, M. 1967. Relevamiento Geológico del Valle del Río Leona, Santa Cruz. YPF Buenos Aires, informe inédito. 
Turic, M. 1971.Geología de la Comarca del Lago San Martín entre las estancias La Lila y Los Cerros (Departamento de Lago Argentino- Provincia de Santa Cruz): YPF Buenos Aires, informe inédito.

Turic, M., Amarado Flores, F., Gómez Omil, R., Pombo, R., Sciutto, J., Robles, D. y Cáseres, A. 1987. Geología de las cuencas petroleras de la Argentina. En Schlumberger (Ed) Evaluación de las Formaciones en la Argentina. 1-44, Buenos Aires.

Uchman, A. 2007. Deep-sea trace fossils from the mixed carbonate-siliciclastic flysch of the Monte Antola Formation (Late Campanian-Maastrichtian), North Apennines, Italy. Cretaceous Research 28: 980 - 1004.

Uchman, A. 2009. The Ophiomorpha rudis ichnosubfacies of the Nereites ichnofacies: Characteristics and constraints. Palaeogeography, Palaeoclimatology, Palaeoecology 276: 107-119.

Uchman, A. y Wetzel, A. 1999. An aberrant, helicoidal trace fossil Chondrites Sternberg. Palaeogeography, Palaeoclimatology, Palaeoecology 146: 165-169.

Vail, P. R., Mitchum, R. M., Tood, R. G., Widmer, J.M., Thompson, S. I., Sangree, J. B., Bubb, J. N. y Hatlelid, W. G. 1977. Seismic stratigraphy and global changes of sea-level. American Association Petrologist and Geologist, Memoir, 26: 49-212.

Vail, P. R. y Todd, R. G. 1981. Northern North Sea Jurassic unconformities, chronostratigraphy and sea level changes from seismic stratigraphy. En: Illing, L. V. y Hobson, G. D. (Eds.): Proceedings of the Petroleum Geology of the Continental Shelf of NW Europe Conference, London, 216 - 235.

Van Wagoner, J.C., Posamentier, H.W., Mitchum, R.M., Vail, P.R., Sarg, J.F., Loutit, T.S. y Hardenbol, J. 1988. An overview of the fundamentals of sequence stratigraphy and key definitions. En: Wilgus, C.K., Hastings, B.S., Kendall, C.G.St.C., Posamentier, H.W., Ross, C.A., Van Wagoner, J.C. (Eds.), Sea-Level Changes-An Integrated Approach. SEPM Special Publication, vol. 42: 39- 45.

Varela, A. N. 2011. Sedimentología y Modelos Deposicionales De La Formación Mata Amarilla, Cretácico De La Cuenca Austral, Argentina. Tesis Doctoral inédita. Universidad Nacional de La Plata, Facultad de Ciencias Naturales y Museo. 289pp.

Veizer, J. 1983. Chemical Diagenesis of carbonates: theory and application of trace element technique. In M.A. Arthur, T.F.Anderson, I.R. Kaplan, J. Veizer, L.S. 
Land Editors, Stable isotopes in Sedimentary Geology. S.E.P.M. Short Course, 10, pp. (3-1), 3-100.

Viedma, A. 1783. Diario de un viaje a la Costa Patagónica para reconocer puntos en donde establecer poblaciones. En P. De Angelis 1837, vol. VI, Buenos Aires, 1 81.

Visser, J.N.J. y Young, G.M. 1990. Major element geochemistry and paleoclimatology of the Permo-Carboniferous glacigene Dwyka Formation and post-glacial mudrocks in southern Africa. Palaeogeography, Palaeoclimatology, Palaeoecology, 81; 49-57.

von Eynatten, H. 2004. Statistical modelling of compositional trends in sediments. Sedimentary Geology 171, 79-89.

von Sternberg, G.K. 1833.Versucheiner geognostisch-botanischen Darstellung der Flora der Vorwelt. IV Heft. C.E. Brenck, Regensburg, 48 pp.

Walker, R. G. 1990. Facies models and sequence stratigraphy. Journal of Sedimentary Petrology, 60: 777-786.

Walker, R. G. 2006. Facies models revisited. Facies Models Revisited, SEPM Special Publication No. 84: 1-17.

Walker, D., Simpson, E. L. y Driese, S. G. 1994. Paleogeographic influences on sandstone composition along an evolving passive margin; an example from the basal Chilhowee Group (uppermost Proterozoic to Lower Cambrian) of the southcentral Appalachians. Journal of Sedimentary Research, 64: 807 - 814.

Westermann, S., Föllmi, K. B., Adatte, T., Matera, V., Schnyder, J., Fleitmann, D., Fiet N., Ploch, I. y Duchamp-Alphonse, S. 2010. The Valanginian $\delta 13 \mathrm{C}$ excursion may not be an expression of a global oceanic anoxic event. Earth and Planetary Science Letters 290: 118-131.

Weissert, H., Lini, A., Föllmi, K.B. y Kuhn, O. 1998. Correlation of Early Cretaceous carbon isotope stratigraphy and platform drowning events: a possible link? Palaeogeography, Palaeoclimatology, Palaeoecology 137: 189-203.

Weimer, R.J. y Hoyt, J.H. 1964. Burrows of Callianassa major Say, geologic indicators of littoral and shallow neritic environments. Journal of Paleontology 38: 761-767.

Wetzel, A. 1991. Ecologic interpretation of deep-sea trace fossil communities. Palaeogeography, Palaeoclimatology, Palaeoecology 85: 47-69.

Wignall, P. 1991. Model for transgressive black shales?. Geology 19: 167-170. 
Wilckens, O. 1907. Die Lamellibranchiaten, Gastropoden u.s.w. oberen Kreide Sudpatagoniens. Ber. Naturforsch, Ges. Freiburg, 15: 91 - 166.

Witte, L. 1917. La geología de la región del Lago Viedma. En: Patagonia, resultados de las expediciones realizadsa en 1910 - 1916. Sociedad Científica Alemana, Buenos Aires 2: 275 - 327.

Wright, J. Schrader, H. y Holser, W.T. 1987. Paleoredox variations in ancient oceans recorded by rare earth elements in fossil apatite. Geochimica Cosmochimica Acta, $51,613-644$.

Yang, J., Sun, W., Wang, Z., Xue, Y. y Tao, X. 1999. Variations in Sr and C isotopes and Ce anomalies in successions from China: evidence for the oxygenation of Neoproterozoic seawater. Precambrian Res. 93, 215-233.

Zambrano, J. J. y Urien, C. M. 1970. Geological outline of the Basins in Southern Argentina and their Continuation off the Atlantic shore. Journal of Geophysics Research. Washington 75 (8): 1363 - 1396.

Zimmermann, U. y Bahlburg, H. 2003. Provenance analysis and tectonic setting of the Ordovician clastic deposits in the southern Puna Basin, NW Argentina. Sedimentology 50:1079-1104.

Zimmermann, U., Poiré, D. G. y Gómez Peral, L. 2011. Neoproterozoic to Lower Palaeozoic successions of the Tandilia System in Argentina: implication for the palaeotectonic framework of southwest Gondwana. International Journal of Earth Sciences, 100:489-510.

Zuffardi, P. 1944. Descripción de algunas rocas de la región de los lagos Argentino y Viedma. Boletín de la Academia Nacional de Ciencias, Córdoba 37: 209 - 255. 


\section{Agradecimientos}

Quisiera agradecer enormemente a toda la gente que estuvo presente en estos cinco años de desarrollo de mi tesis doctoral. Muy especialmente a mi esposa Florencia, que me acompañó en cada momento. A mi familia, mis padres y hermanos, siempre presentes cuando los necesité.

Al Dr. Daniel Poiré, quien fiel a su estilo me dio una gran libertad para desarrollar este trabajo, siempre bajo su orientación, y en quien además de un director encontré un amigo.

A todas las personas que me acompañaron en las tareas de campo: Abril Cereceda, Mariana Olivo, Daniela Cúccaro y Joanna Kaufman en la primer campaña, Sergio Páez en la segunda y tercera, y a Augusto Varela en la última.

A todos los integrantes del Centro de Investigaciones Geológicas con quienes compartí este período.

A los compañeros de las cátedras de Sedimentología y Rocas Sedimentarias de la Facultad de Ciencias Naturales y Museo.

A mis amigos de aventuras geológicas, Augusto Varela, Andrés Bilmes y Leandro D’Elía, con quienes realizamos innumerables actividades en estos años.

Muy especialmente al Dr. Augusto Varela con quien hemos vivido muchas historias patagónicas durante estos 6 años compartidos de viajes y trabajo.

A los Dres. Luis Buatois, Murray Gingras y Alfred Uchman, por sus sugerencias en diferentes aspectos icnológicos de este trabajo. 
A la Dra. Lucía Gómez Peral por su gran ayuda y entusiasmo en los aspectos geoquímicos.

A los Dres. Ernesto Schwarz y Gonzalo Veiga, quienes ocuparon parte de su tiempo en ayudarme a comprender varios aspectos sedimentológicos aquí abordados.

Al Dr. Sergio Matheos por su colaboración en la petrografía de rocas carbonáticas.

A la Dra. Beatriz Aguirre Urreta quien realizó las identificaciones taxonómicas del material de amonoideos y al Dr. Juan Pablo Pérez Panera quien analizó el material de microfósiles.

A la Dra. Marina Aguirre de quien aprendí mucho en los diez años que llevamos trabajando juntos.

A Pablo García y Cecilia Genazzini del laboratorio de DRX quienes siempre estuvieron dispuestos a colaborar durante estos años.

A Daniel Mártire y Marcos Pousada por la realización de las secciones delgadas.

Estoy muy agradecido a la Dirección de Parque Nacionales, muy especialmente al director del Parque Nacional Los Glaciares, Carlos Corbalán (“Charly”) quien siempre colaboró con esta investigación. También a todos los guardaparques que me acompañaron durante los trabajos.

A los dueños de estancias La Lila, Kachaike, La Vega y San Ernesto que permitieron permanecer en sus campos durante las campañas para llegar a los afloramientos. También a todos los puesteros que fueron una linda compañía.

A Miguel Ferrari de la localidad de Tres Lagos por cuidar y mantener nuestra querida F 100 y tenerla siempre lista para nuestro trabajo. 
Al CONICET que financió este trabajo de tesis a partir de la Becas Tipo I y II y los PIP nº 6237 y 1016.

A la International Association of Sedimentologist por el subsidio otorgado para la asistencia a congresos. 


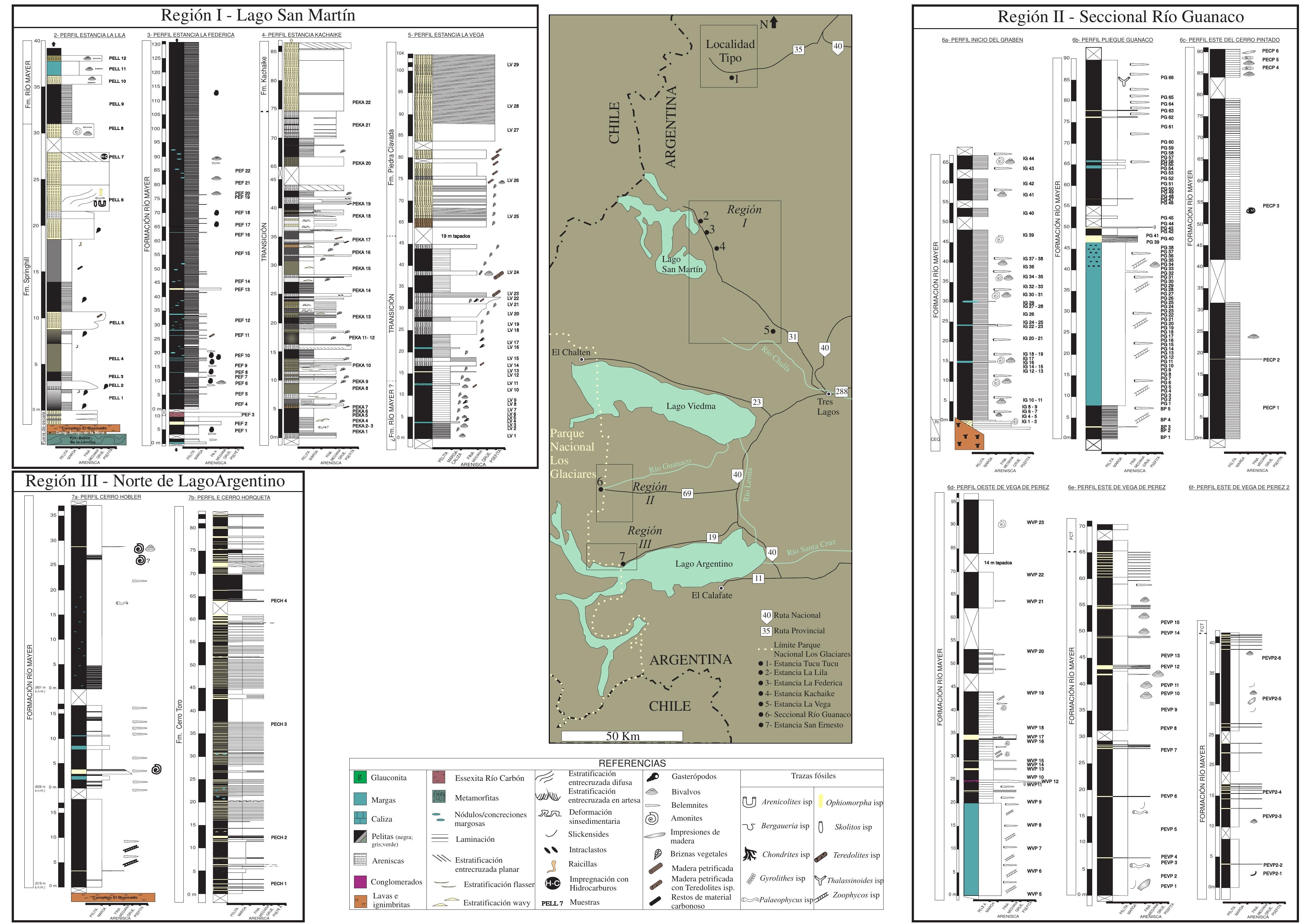


